\title{
Stream flow characterization over longwall coal mines in Pennsylvania, Ohio, and West Virginia
}

\author{
Scott A. Wade \\ West Virginia University
}

Follow this and additional works at: https://researchrepository.wvu.edu/etd

\section{Recommended Citation}

Wade, Scott A., "Stream flow characterization over longwall coal mines in Pennsylvania, Ohio, and West Virginia" (2008). Graduate Theses, Dissertations, and Problem Reports. 2644.

https://researchrepository.wvu.edu/etd/2644

This Thesis is protected by copyright and/or related rights. It has been brought to you by the The Research Repository @ WVU with permission from the rights-holder(s). You are free to use this Thesis in any way that is permitted by the copyright and related rights legislation that applies to your use. For other uses you must obtain permission from the rights-holder(s) directly, unless additional rights are indicated by a Creative Commons license in the record and/ or on the work itself. This Thesis has been accepted for inclusion in WVU Graduate Theses, Dissertations, and Problem Reports collection by an authorized administrator of The Research Repository @ WVU. For more information, please contact researchrepository@mail.wvu.edu. 


\title{
Stream Flow Characterization over Longwall Coal Mines in Pennsylvania, Ohio, and West Virginia
}

\author{
Scott A. Wade \\ Thesis submitted to the \\ Eberly College of Arts and Sciences \\ at West Virginia University \\ in partial fulfillment of the requirements \\ for the degree of
Master of Science
in
Geology \\ Henry W. Rauch, Ph.D., Chair \\ J. Steven Kite, Ph.D. \\ Terry E. Ackman \\ Jay W. Hawkins, R. P. G. \\ Department of Geology and Geography
}

\author{
Morgantown, West Virginia \\ 2008
}

Keywords: Mine Subsidence, Stream Flow Impact, Geophysics 


\title{
Abstract \\ Stream Flow Characterization over Longwall Coal Mines in Pennsylvania, Ohio, and West Virginia
}

\author{
Scott A. Wade
}

Six streams were studied in Ohio, Pennsylvania, and West Virginia to evaluate subsidence impacts from active and abandoned longwall coal mines on stream discharge. Mined longwall panels included in this study ranged in age from five months to fifteen years old and in depth from 100 to 600 feet (30.5 to $182.9 \mathrm{~m}$ ) beneath the studied streams.

Significant stream flow losses and gains were detected in each stream studied. Comparing longwall panel locations to stream flow measurements, geophysical surveys, and geomorphology surveys, it was concluded that longwall mine subsidence caused some of the detected stream flow losses and gains. Data collected suggests that longwall mine subsidence can impact stream flow and that the impact can be different for different baseflow conditions. The impact on a stream can vary across a longwall panel and the significance of an impact is related to many factors.

The greatest stream flow changes are across the upstream and downstream edges of the longwall subsidence basins, corresponding to zones of tension. Tension zones form fractures within the surface-rock fracture zone (soil zone). Naturally occurring fractures located within the tension zone may also dilate during longwall subsidence and enhance its hydraulic conductivity. Effects to stream discharge from mine subsidence depends on the baseflow conditions. In most cases, normalized stream discharges increase across the fractured tension zones during high baseflow conditions, and declined during low baseflow condition. These characteristics are caused by the increased permeability and storage capacity of dilated fractures within the tension zones.

All streams in the study had a normalized discharge decline across subsided longwall panels. This characteristic is caused by in increase in fractures throughout the panel increasing underfow rates and bank storage potential.

Sediment thickness and particle size distribution fluctuated at measuring stations spaced across the mined longwall panel. Erosion over the upstream tension zone thinned the sediment as the stream entered the subsidence basin. The coarsest and thickest sediment is over the upstream quarter-panel reach where the largest and greatest amount of sediment is deposited from the upstream erosion. A downstream fining trend is detected. This characteristic is caused by the slope of the subsidence basin and its impact on stream power causing it to decrease from the upstream quarter-panel to the downstream quarter-panel. 


\section{Acknowledgements}

I thank the Lord God Almighty; for without His empowerment, encouragement, guidance, and support, this research would never have been completed.

I thank my beautiful wife Christy, who was with me throughout this endeavor, who wanted to help with the hard work, who took extra turns watching babies, who consistently encouraged and lovingly prodded me onward. I will always be grateful and blessed with fond memories of good adventure.

I thank my oldest son Oliver for the memories of him creek-side and the enormous pool of patience that he exhibited during long trips and long days. I also apologize to my son Oliver for the pain that resulted from one these trips; a pain that he will never remember but my wife and I surely will.

I thank Dr. Henry Rauch for providing me the opportunity to finish my Masters with this project and for providing invaluable resources and discussion.

I thank Jay Hawkins and the Office of Surface Mining for the funding and the positive and thorough reviews of multiple drafts.

I thank Terry Ackman of the Department of Energy, National Energy Technology Laboratory, for loaning the geophysical equipment, the assistance and positive review of the data.

I thank Steven Kite for providing the opportunity to understand the importance of geomorphology. This knowledge was invaluable in understanding the changing substrate over longwall mining.

Thanks also to the Pennsylvania Department of Environmental Protection, Harrisburg Regional Office, for the initial information and equipment to get started with the field work. 


\section{$\underline{\text { Table of Contents }}$}

Pg.

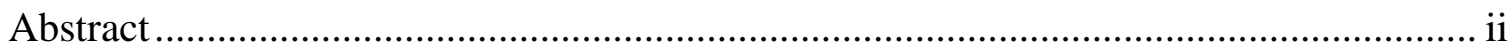

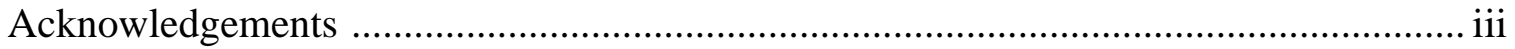

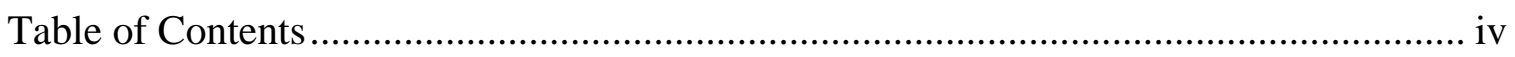

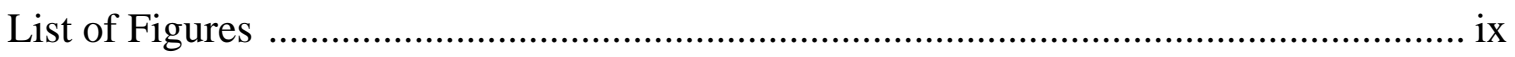

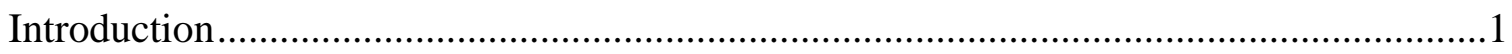

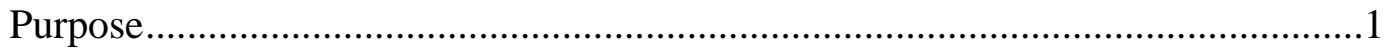

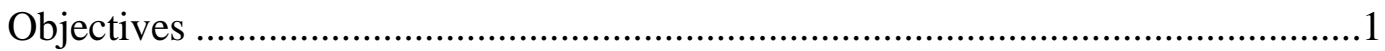

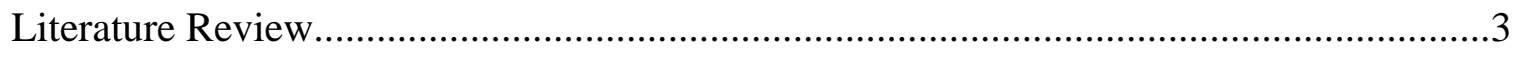

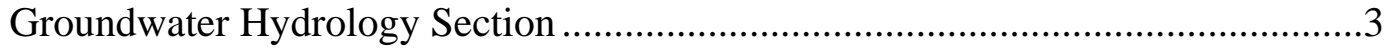

Mining Section ........................................................................................

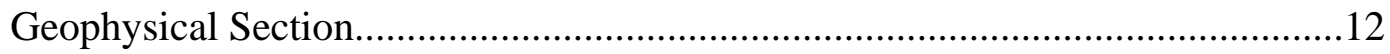

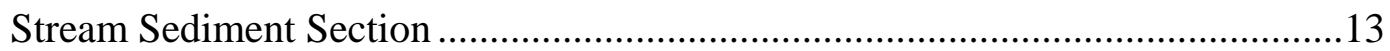

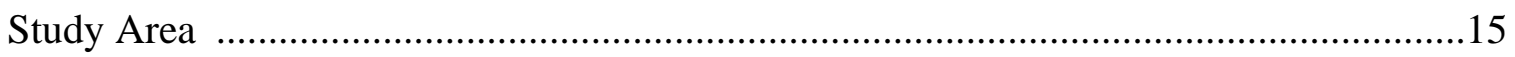

Descriptions of Study Areas ....................................................................15

Crabapple Creek, Ohio................................................................17

Williams Creek, Ohio ......................................................................21

Stream F, Pennsylvania..............................................................25

Templeton Fork, Pennsylvania .....................................................28

Island Creek, West Virginia..............................................................31

West Fork, West Virginia .................................................................35 


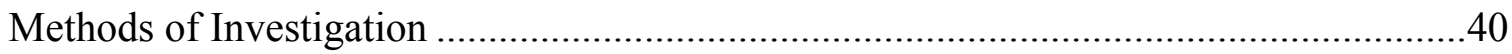

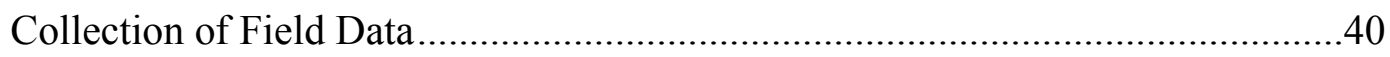

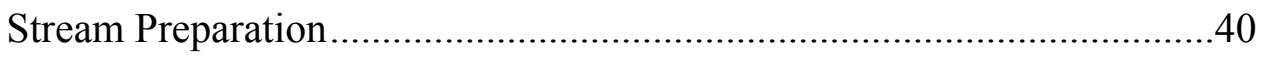

Stream Flow Measurements ……………………………........................

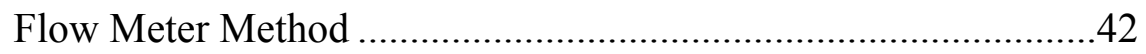

Surface Velocity Method ..............................................................

Geophysical Surveying Methods ..............................................................47

Electromagnetic Geophysics Overview ……………………..........4

Terrain Conductivity Survey Method ............................................49

Very Low Frequency Survey Method............................................51

Stream Alluvium Sampling Methods......................................................58

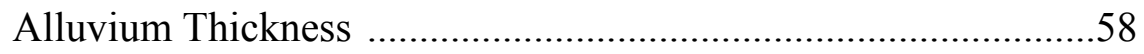

Alluvium Particle Size Distribution..............................................60

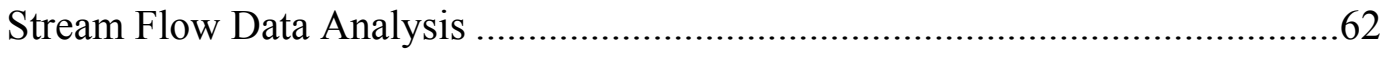

Timing of Stream Flow Measurements........................................................62

Time Corrections for Stream Flow Measurements .....................................64

Discharge to Area Ratio Calculation ........................................................66

Net Discharge Ration Change....................................................................67

Stream Discharge Change per $100 \mathrm{ft}$......................................................67

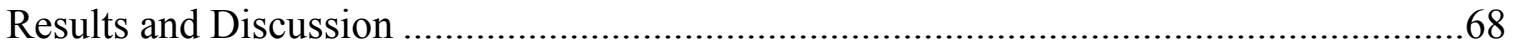

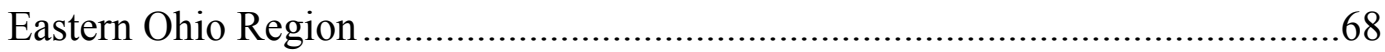

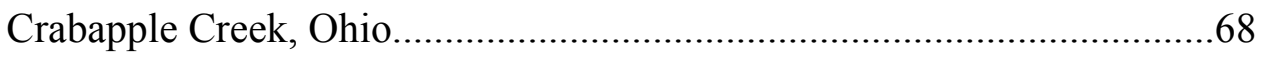

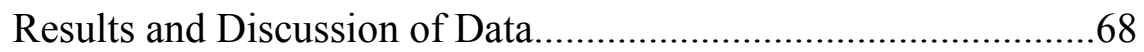


Stream Flow Measurements................................................68

Geophysical Measurements .................................................77

Alluvial Sediment Measurements .........................................86

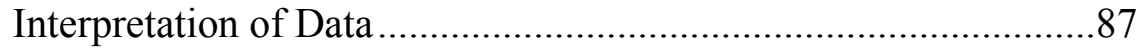

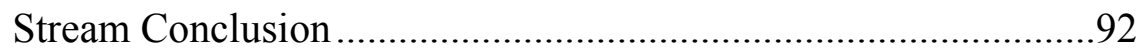

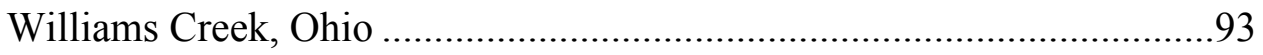

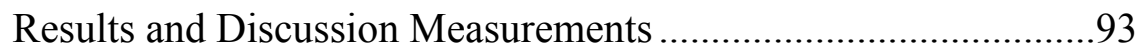

Stream Flow Measurements...............................................93

Geophysical Measurements ................................................99

Alluvial Sediment Measurements .......................................110

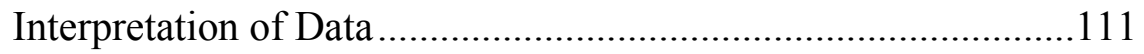

Stream Conclusion ...................................................................

Southwestern Pennsylvania Streams................................................................118

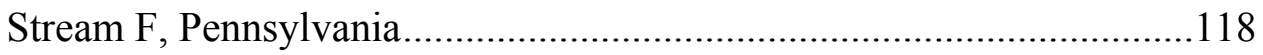

Results and Discussion Measurements .........................................118

Stream Flow Measurements.............................................118

Geophysical Measurements .............................................124

Stream Sediment Measurements.......................................131

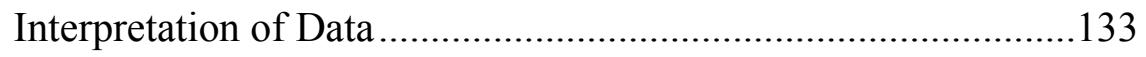

Stream Conclusion ...................................................................139

Templeton Fork, Pennsylvania ...............................................................141

Results and Discussion Measurements ........................................141

Stream Flow Measurements..............................................141 


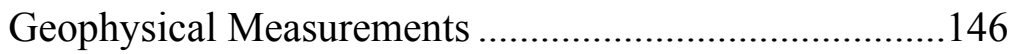

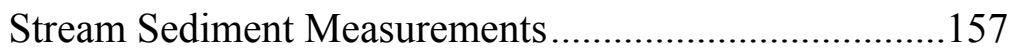

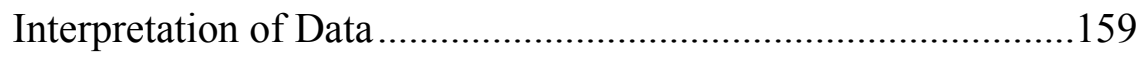

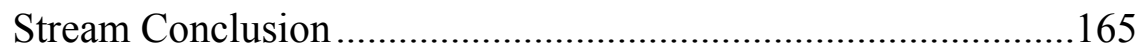

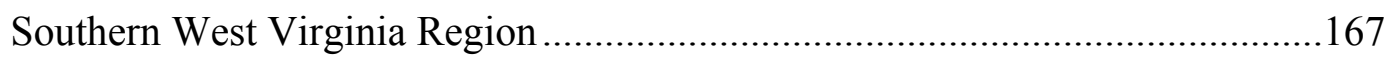

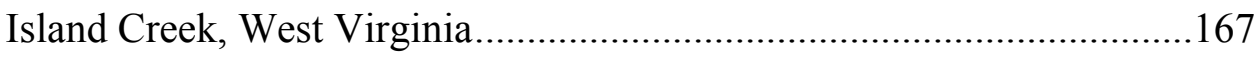

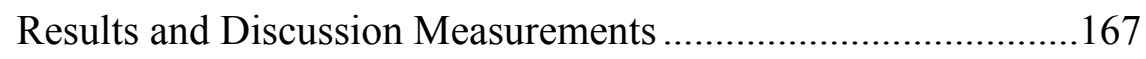

Stream Discharge Measurements.................................167

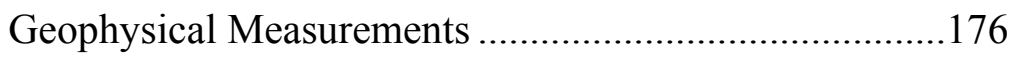

Stream Sediment Measurements.................................177

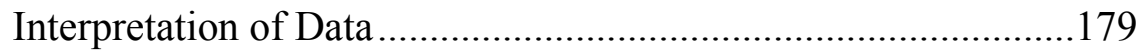

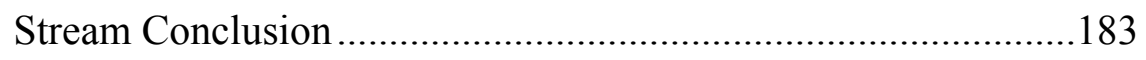

West Fork, West Virginia ............................................................ 184

Results and Discussion Measurements ....................................184

Stream Discharge Measurements................................ 184

Geophysical Measurements .........................................192

Stream Sediment Measurements...................................197

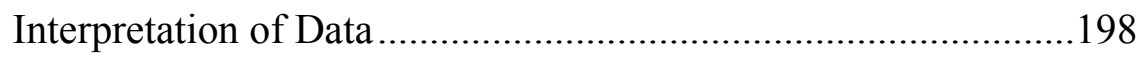

Stream Conclusion .......................................................204

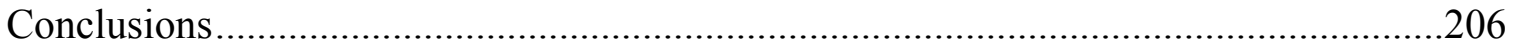

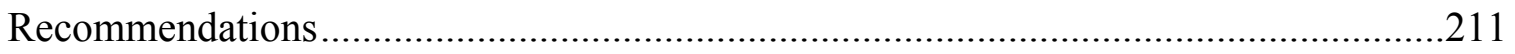

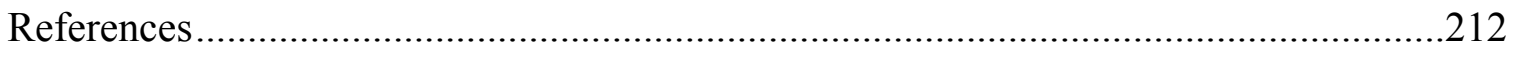


Appendices

Appendix I: Stream Flow Tables ........................................................218

Appendix II: Previously Reported Stream Discharge Data ....................233

Appendix III: Geophysical Anomaly Tables .......................................236

Appendix IV: Stream Sediment Table ................................................244

Appendix V: Survey and Mining Sequence Tables.............................247

Appendix VI: Stream and Mine Elevation Graphs .............................249

Appendix VII: Geomorphological Channel Classifications for Studied Stream Reaches ..............................................256

Appendix VIII: Particle Size Distribution Tables..................................260

Appendix IX: Particle Size Distribution Graphs ..................................278

Appendix X: Stream Discharge Summary Graphs ..............................295

Appendix XI: Stream Discharge-Terrain Conductivity Graphs .............302

Appendix XII: Stream Discharge-Very Low Frequency Graphs ...........309

Appendix XIII: Geologic Logs for Study Areas.................................316 


\section{List of Figures}

Figure 1. Effluent and Influent Stream Type Diagram ........................................4

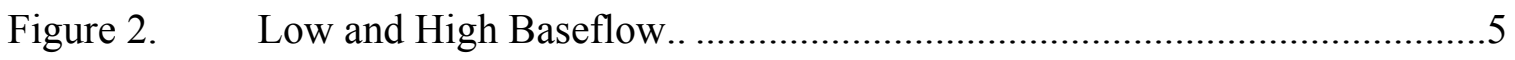

Figure 3. Relative Longwall Panel Designation...............................................

Figure 4. Longwall Subsidence Strain in Overburden ........................................

Figure 5. Longwall overburden Strata Movement and Angle of Draw.....................

Figure 6. Subsidence Zone Cross-Section......................................................

Figure 7. Northern Sites Location Map....................................................... 16

Figure 8. Crabapple Creek Topographic Map.................................................18

Figure 9. Photograph of Groundwater Discharge from Subsidence Fractures..........21

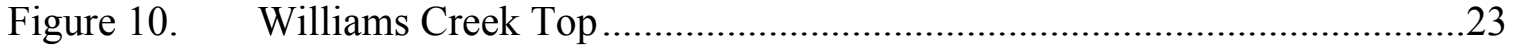

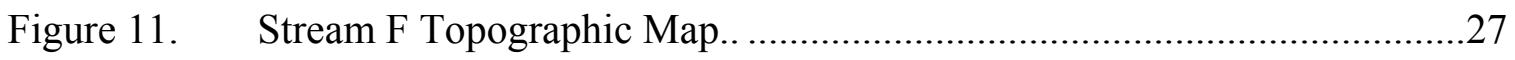

Figure 12. Templeton Fork Topographic Map....................................................30

Figure 13. Southern Sites Location Map........................................................ 32

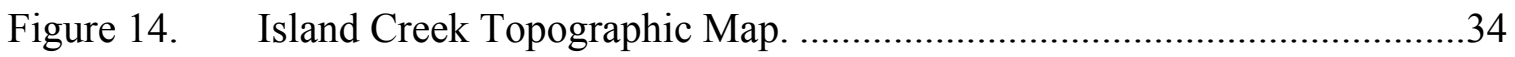

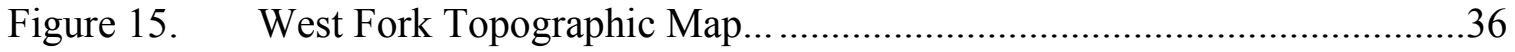

Figure 16. Stream Flow Measurement Method Diagram........................................43

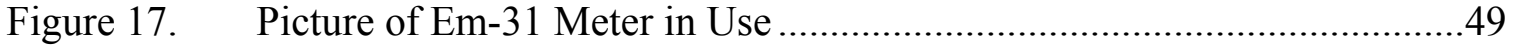

Figure 18 Schematic of Terrain Conductivity Principle. .....................................50

Figure 19. Map of VLF Transmitter Locations World-Wide..................................52

Figure 20. Picture of Abem-Wadi VLF Meter .....................................................53

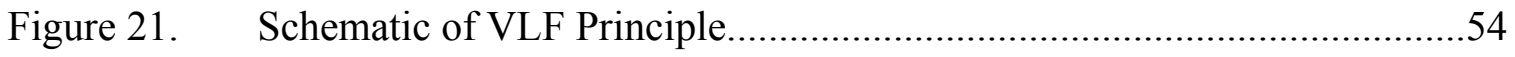

Figure 22. Example of Raw VLF Data over Anomaly $\quad$...........................................56 
Figure 23. Example of Filtered VLF Data over Anomaly .....................................57

Figure 24. Example Recession Curve Hydrograph................................................65

Figure 25. Crabapple Creek Station Location Map...............................................69

Figure 26. Crabapple Creek Extremely Low Baseflow Hydrograph ........................71

Figure 27. Crabapple Creek High Baseflow Hydrograph ....................................... 74

Figure 28. Crabapple Creek Low Baseflow Hydrograph.......................................76

Figure 29. Crabapple Creek Geophysical Survey Graph. ….................................78

Figure 30. Crabapple Creek Comparative Terrain Conductivity Surveys .................82

Figure 31. Crabapple Creek Comparative VLF Surveys. ........................................83

Figure 32. Williams Creek Station Location Map... .......................................... 94

Figure 33. Williams Creek Stream Discharge Summary. .......................................96

Figure 34. Williams Creek High Baseflow Hydrograph.......................................97

Figure 35. Williams Creek Low Baseflow Hydrograph.......................................98

Figure 36. Williams Creek Terrain Conductivity Graph.....................................100

Figure 37. Williams Creek Terrain Conductivity and VLF Data Graph..................105

Figure 38. Williams Creek Alluvial Sediment Thickness Graph.............................111

Figure 39. Stream F Station Location Map.....................................................119

Figure 40. Stream F High Baseflow Hydrograph............................................... 121

Figure 41. Stream F Low Baseflow Hydrograph ........................................... 123

Figure 42. Stream F Terrain Conductivity Graph........................................... 125

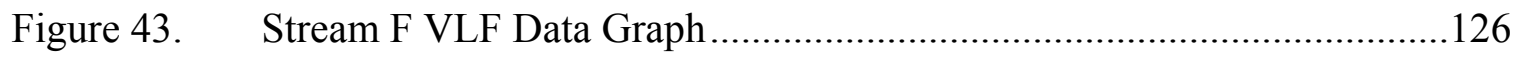

Figure 44. Stream F Photograph of Pot-Hole ................................................. 127

Figure 45. Stream F Terrain Conductivity and VLF Data over Downstream Gate-Entry Reach 130 
Figure 46. Stream F Alluvial Sediment Thickness Graph.................................... 132

Figure 47. Templeton Fork Station Location Map................................................ 142

Figure 48. Templeton Fork High Baseflow Hydrograph...................................... 143

Figure 49. Templeton Fork Low Baseflow Hydrograph ....................................... 145

Figure 50. Templeton Fork Terrain Conductivity and VLF Data Graph................149

Figure 51. Templeton Fork Sediment Thickness Graph. .....................................158

Figure 52. Island Creek Station Location Map............................................... 168

Figure 53. Island Creek High Baseflow Hydrograph........................................ 170

Figure 54. Island Creek Low Baseflow Hydrograph ..........................................171

Figure 55. Island Creek Extremely Low Baseflow Hydrograph............................ 173

Figure 56. Island Creek Permit Data Hydrograph.............................................. 175

Figure 57. Island Creek Alluvial Sediment Thickness Graph..............................178

Figure 58. Island Creek Pre-Mining and Post-Mining Stream

Discharge Comparison.................................................................180

Figure 59. West Fork Station Location Map.................................................. 185

Figure 60. West Fork Low Baseflow Hydrograph............................................ 186

Figure 61. West Fork High Baseflow Hydrograph (Stations 1 Through 9b) ............190

Figure 62. West Fork High Baseflow Hydrograph (Stations 1 Through 11)...........191

Figure 63. West Fork Terrain Conductivity and VLF Data Graph.........................193

Figure 64. West Fork Alluvial Sediment Thickness Graph .................................198

Figure 65. West Fork Photograph of Insurgence Point.........................................202 


\section{Introduction}

\section{$\underline{\text { Purpose }}$}

This study analyzed stream flow variations with respect to surface and subsurface subsidence impacts from active or abandoned longwall coal mines. Stream flow measurements, geophysical surveys, and alluvial surveys provide the data to interpret the conditions of the stream and the controlling factors affecting its discharge. The study sought to find stream-specific and regional trends of stream flow impacts and causes for them.

Six perennial stream reaches in three Mid-Atlantic states were selected to be studied. This group of sites provided a range of geologic settings, topographic regions, and mine ages for comparison. Using these data, we hope to improve the understanding and predictability of stream flow impacts from longwall mine subsidence.

\section{Objectives}

Objectives of this study were to determine the effects of longwall mine subsidence on stream flow, by completing and comparing the following:

1. Investigating the potentially different responses of stream discharge at high and low baseflow;

2. Comparing geologic setting, topographic settings, mine ages, mine depths, angle of draw and angle of dewatering influences of the sites to delineate impact trends;

3. Delineating rock fractures beneath the stream by geophysical surveys to assist in interpreting stream flow variability over the study reach; 
4. Characterizing alluvial thickness and sediment particle size to interpret the stream substrate conditions and changes in the stream substrate that may be occurring as a result of subsidence;

5. Analyzing short reaches of streams in order to collect data that may assist in interpreting basin-wide or region-wide trends in stream responses to longwall mining. 


\section{Literature Review}

\section{Ground water Hydrology Section}

Stream water, the focus of this study, is a surface expression of the ground water table. Effluent streams are those that receive groundwater from an aquifer. Ground water with a water table higher than the stream surface causes groundwater flow to the stream. Influent streams are those that contribute water to the underlying aquifer. Streams may be effluent in some reaches and influent in other reaches as the water table may change along the course of a stream. Streams may change from being effluent reaches during normal flow to influent during low water table periods of drought or influent during the rising limb of flooding conditions when the surface of the stream is elevated (Fetter, 2001; Figure 1).

Baseflow is ground water that flows to recharge streams. Ground water recharge to streams in a valley setting may have both confined and unconfined conditions present. Unconfined ground water flow to streams will occur in the shallow colluvial and shallow alluvial sediments on the stream's floodplain. The source for this ground water will be along the valley-walls.

Ground water, originating from the valley-walls, will also enter tensile vertical and horizontal fractures in the valley-walls and form a deeper unconfined aquifer system. The ground water entering into these fractures will then move through compressional slump fractures at the base of the valley-walls and into horizontal-bedding fractures present beneath the valley-bottom. Wyrick and Borchers classified this as the valley-bottom, horizontalbedding plane confined aquifer. In pumping tests at their study area in the Appalachian Plateau Province in southern West Virginia, Wyrick and Borchers (1981) found highly transmissive slump fractures between 30 to 40 feet deep below the base of valley-walls. Drill 
logs and pumping data show valley-bottom, confined, highly transmissive horizontal-bedding fractures 50 to 65 feet $(15.2$ to $19.8 \mathrm{~m}$ ) below the surface. Vertical valley-bottom fractures may also be present as stress relief arching occurs. Valley-bottom vertical fractures can intersect the confined aquifer formed by unequal bed separation. The vertical fractures may not be highly transmissive because a low permeable clay unit at the base of the alluvial wedge may often seal the fractures (Wyrick and Borchers, 1981). These fractures are associated with unequal stress distribution in accordance with the stress-relief fracture model proposed by Ferguson (1974) and modified by Wyrick and Borchers (1981).
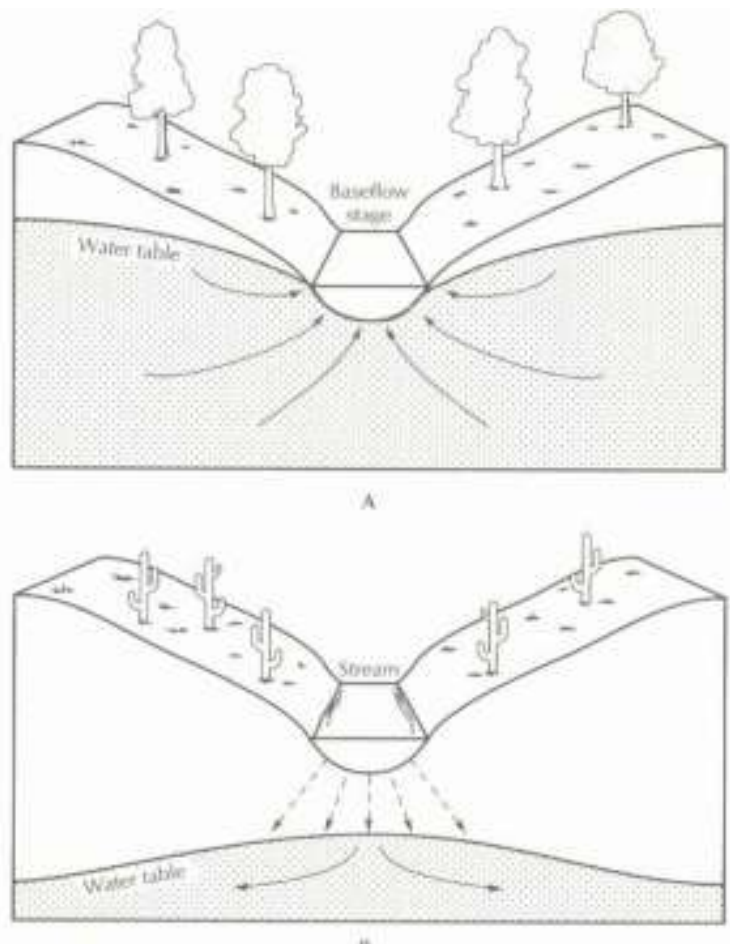

Figure 1. Effluent (top) and influent (bottom) stream types and their relationship with the water table. As the water table consistently slopes toward the stream, the stream discharge will increase in the downstream direction. If the water table slopes away from the stream, the stream will seep into the ground and lose flow in the downstream direction (Fetter, 2001). 
During baseflow conditions, the amount of ground water discharge to a stream is proportional to the hydraulic gradient of the water table (Fetter, 2001) and the potentiometric surface of the confined valley aquifer. During higher baseflow conditions, a ground water surplus causes a steepened hydraulic gradient toward the stream, resulting in higher stream flows. During lower baseflow conditions, there is less ground water surplus. This produces a shallower hydraulic gradient, or a potentiometric surface of a confined aquifer, resulting in lower stream flows (Figure 2).
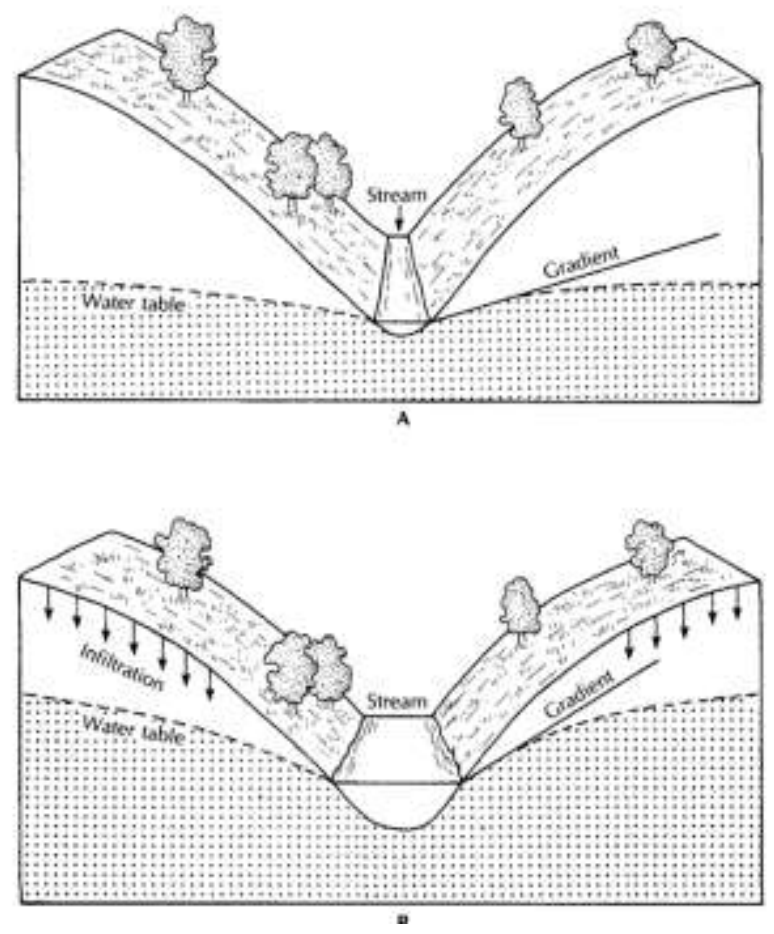

Figure 2. Diagrams depict low stream flow (top) and high stream flow (bottom) conditions during low and high baseflow conditions. Note the difference in water table gradient near the stream (Fetter, 2001).

\section{Mining Section}

Strata over coal mines are known as overburden. Overburden over mined longwall panels move and settle to fill the unsupported voids left after mining, causing mine induced subsidence. Mine subsidence may have a significant impact to the ground surface, the 
subsurface, stream water and ground water regimes (Cifelli and Rauch, 1986; Tieman and Rauch, 1987; Rauch, 1989; Leavitt and Gibbens, 1992 and Carver and Rauch, 1994).

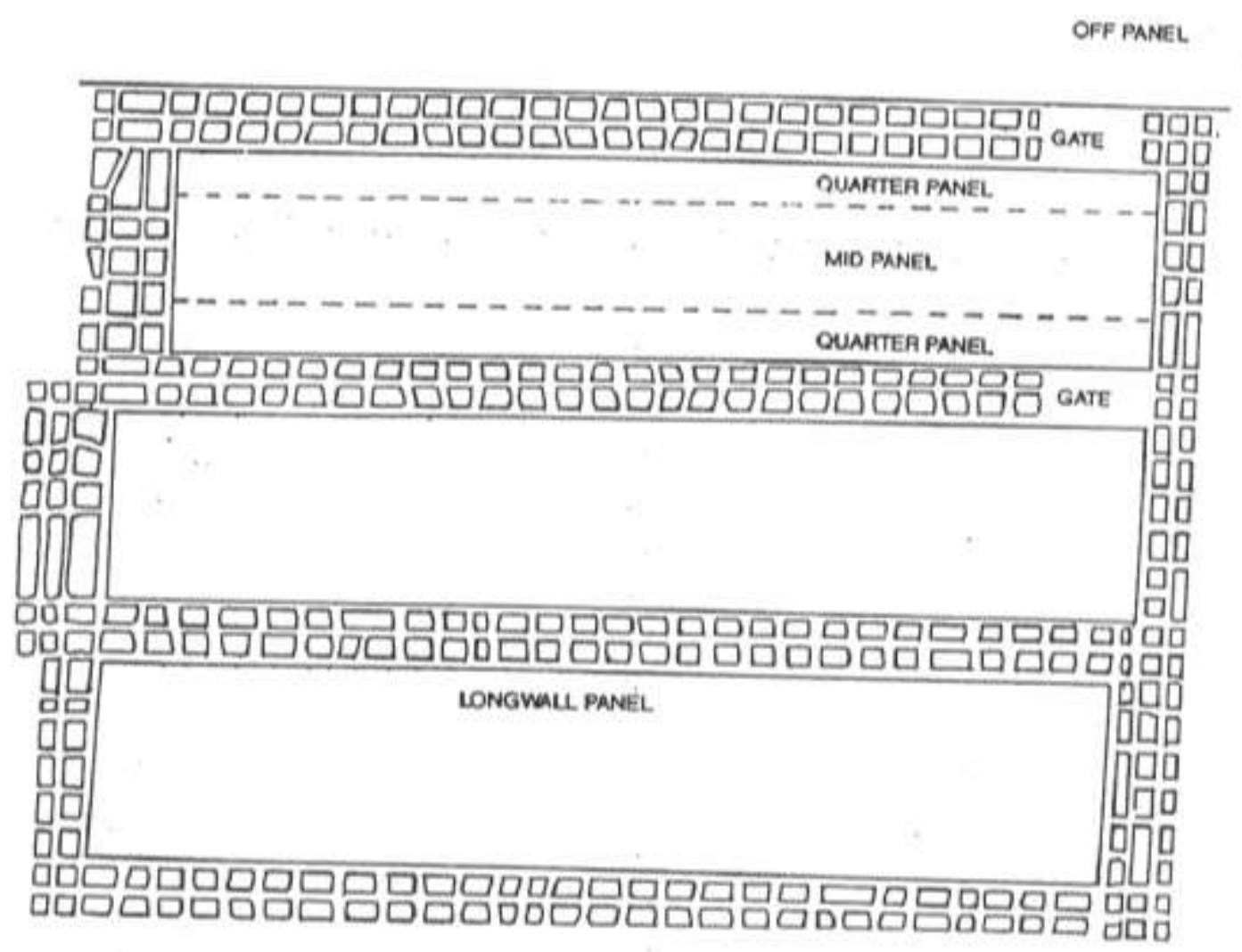

Figure 3. Planimetric longwall panel designation (Leavitt and Gibbens, 1992).

Mine subsidence may alter baseflow to streams by causing subsidence fracturing and dilating natural fractures (Parizek, 1995). Increasing fracture density and aperture can cause a change to ground water flow paths. Shallow mined longwall panels may create subsidence fracturing that causes catastrophic stream water losses. Ground water over shallow mines may also be lost to the mine voids beneath them through the same intense fracturing. 
Deeper mined longwall panels more routinely create partial stream flow losses and additional underflow impacts than catastrophic stream flow losses. Underflow is the movement of ground water beneath a stream in naturally occurring horizontal-bedding-plane aquifers. Mine-induced subsidence-fractures can enhance or increase underflow potential as well as increase the secondary permeability and storativity of aquifers over mined areas (Hobba, 1978; Tieman and Rauch, 1994).

There are two zones over a mined longwall panel; the mid-panel and the quarterpanel zones (Leavitt and Gibbens, 1992; Figure 3). These zones refer to areas of differing total subsidence. The mid-panel zone is located in the center of the longwall panel and experiences the greatest amount of surface subsidence. The quarter-panels are located nearer the edges of the mined panels and experience less surface subsidence. The mid-panel experiences compressional strain as the strata subsides into the mined longwall void.

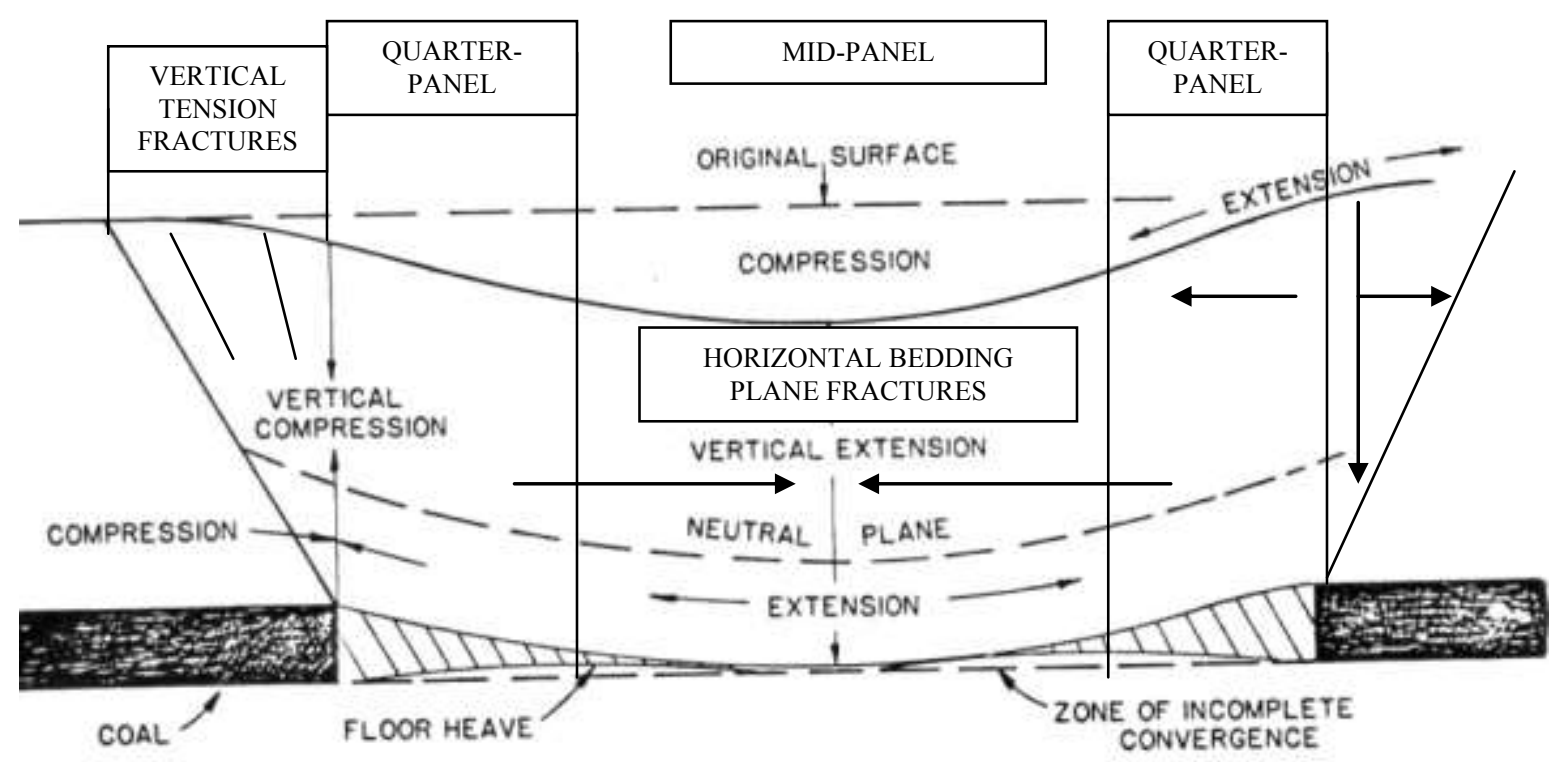

Figure 4. Schematic depiction of strain in overburden during subsidence, as a result of the longwall mining process (modified from Singh and Kendorski, 1978). 
A tension zone forms on all four sides of a mined longwall panel causing vertical tension fractures to form parallel to the edges of the panel (Singh and Kendorski, 1978, Peng, 2006; Figure 4). The tension zone extends from the edge of the mined longwall panel to the edge of the subsidence basin. The surface low of limited size located above the mined longwall panel forms subsidence basin. The angle of draw is measured from the vertical edge of the longwall panel to the edge of the subsidence basin (Peng, 2006).

Subsidence fractures are identified as causing large stream flow fluctuations over longwall coal mines (Dixon and Rauch, 1990; Leavitt and Gibbens,1992; Carver and Rauch, 1994; Ackman and Dilmore, 2002). Subsidence induced stream impacts are affected by the thickness of mine overburden beneath a stream. The greater the overburden thickness, the less likely that a stream will be severely impacted by longwall mining (Cifelli and Rauch, 1986; Rauch, 1989; Dixon and Rauch, 1990; Hutchinson and Barta, 2002; Peng, 2006).

Overburden lithology above a longwall panel can increase or decrease bedrock hydraulic conductivity beneath a stream, and ultimately determine whether a change in the local water table and/or stream flow is temporary or permanent (Peng, 2006).

Mine subsidence theory separates the overburden above longwall panels into four distinct vertical zones (Figure 6). The first zone above the coal is the caving zone. This zone extends upward two to eight times the height of the mined coal (Rauch, 1989). The bedrock in this zone becomes completely unsupported and ultimately collapses into the mine voids, forming gob, also known as rubble. This completely broken rock will accumulate on the floor of the mine void, filling up the void with rubble. 


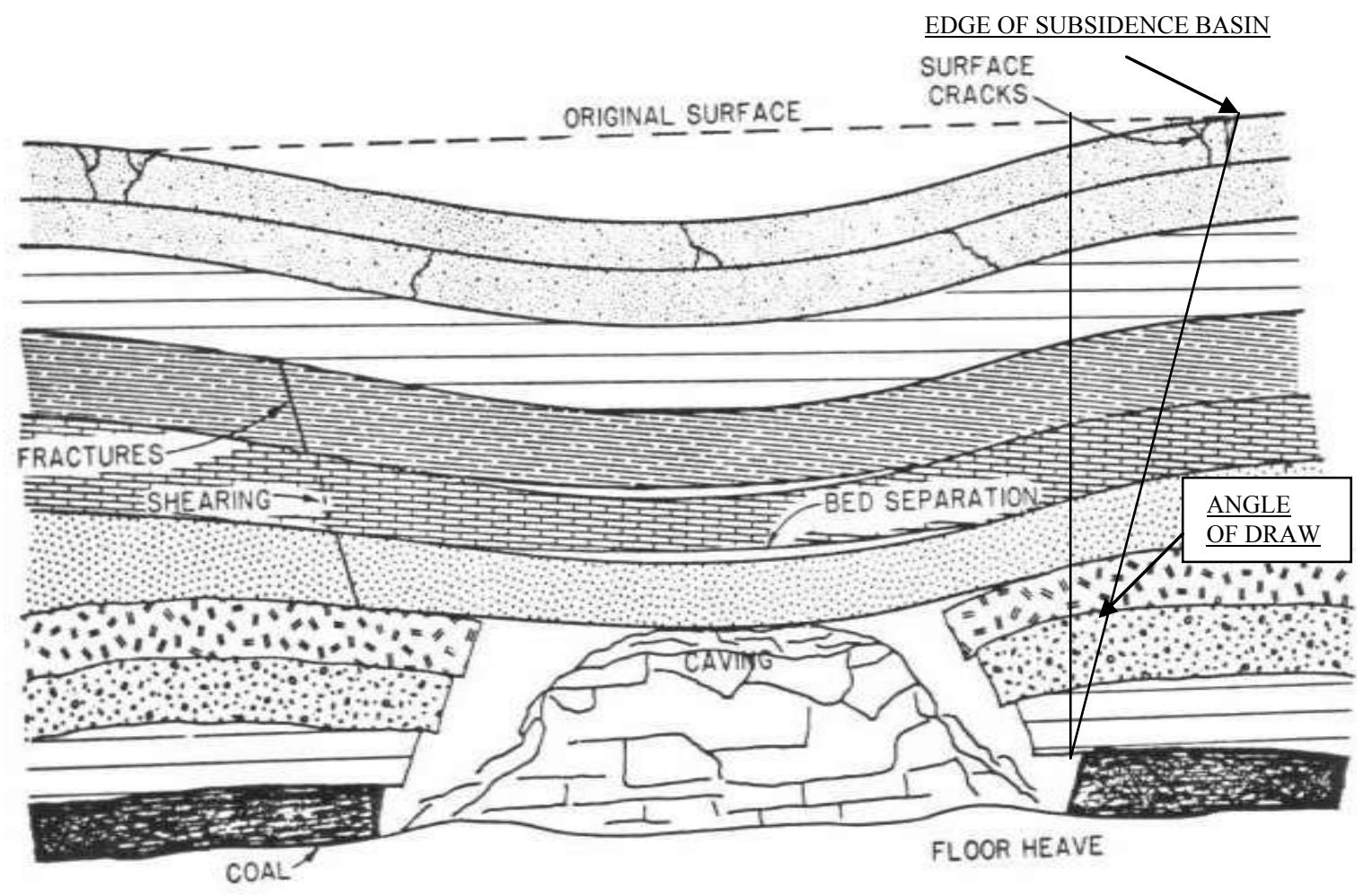

Figure 5. Overburden disturbance and subsidence development caused by underground mining. Dimension measured as the angle of draw, from the vertical edge of the longwall panel to the limit of the subsidence basin (modified from Singh and Kendorski, 1978)

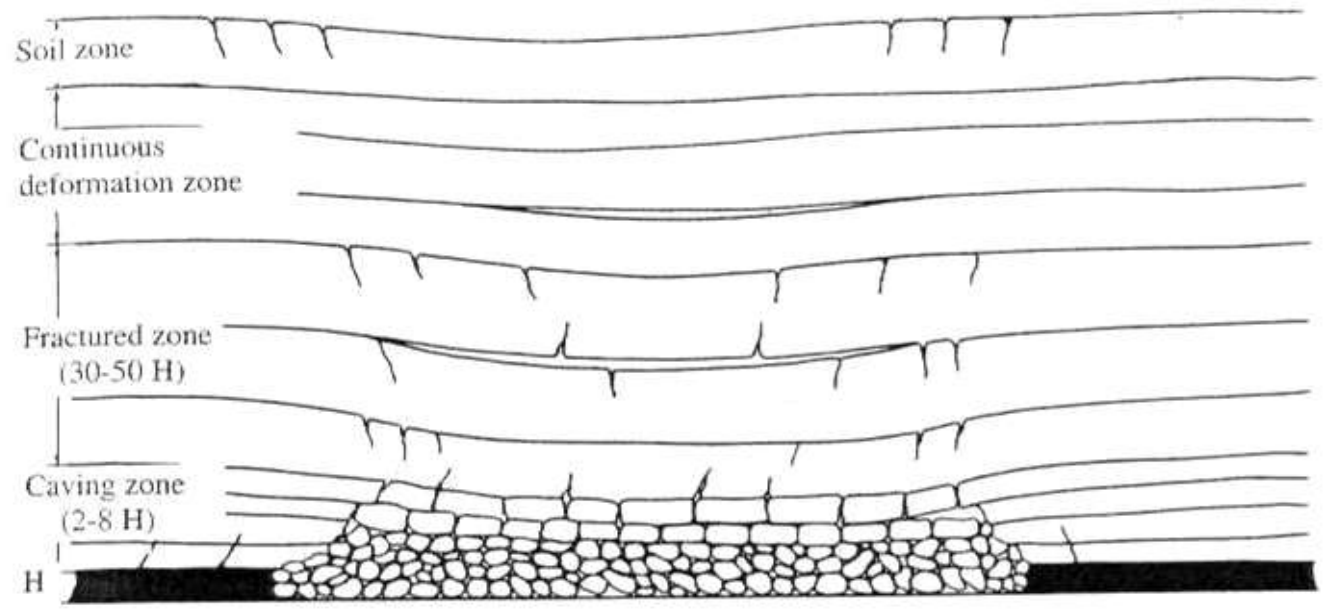

Figure 6. Mine subsidence theory pertaining to longwall extraction method. Variable $H$ represents the height of the mined coal seam (Peng, 2006). 
The fractured zone of the mine subsidence theory is above the caving zone. The bedrock within the fractured zone breaks and settles until its weight is resting on the caved bedrock that collapsed below. This zone can be a considerably thick, as much as 30 to 50 times the thickness of the mined coal seam (Peng, 2006). Subsidence fractures within this zone enhance the vertical hydraulic conductivity of the bedrock within this zone (Rauch, 1989). If the overburden is shallow enough that the fractured zone intersects the lands surface, complete dewatering of a stream may occur where stream water to flows directly into the mine voids (Dixon and Rauch, 1990). Fracturing may intersect the surface at overburden depths of less than 150 feet (45.7 m) (Peng, 2006).

The third zone has several different names. Some include the composite beam zone, continuous bending zone, deformation zone, confining layer zone, and dilated zone. Lateral compression within this zone prevents or restricts the strata from maintaining open vertical fractures. Vertical fractures may be present or have developed in this zone during mine subsidence, but the horizontal compressional strain reduces their aperture. The horizontal compressional strain of mine subsidence also causes vertical strata movement resulting in bed separation and vertical extension (Singh and Kendorski, 1978; Coe and Stowe, 1984). Bed separation enhances the horizontal hydraulic conductivity of the strata in this zone. This zone is present if the bedrock over the mining area is greater than 60 times the mining height, i.e. 480 feet $(146.3 \mathrm{~m})$ at mining height of 8 feet $(2.4 \mathrm{~m})$. The composite beam zone may prevent surface or ground water movement deeper into the fractured zone and ultimately to the caved zone.

The fourth zone is the "surface rock fracturing" or "soil zone". The shallow bedrock zone may experience fracturing that penetrates as deep as deep as 50 feet (Rauch, 1989; Peng, 
2006). Tension fractures form around the perimeter of the subsidence basin within the angle of draw, and are a common feature in this zone.

Different subsidence zones present at or near the surface will generally result in distinctly different impacts on stream flow (Cifelli and Rauch, 1986; Tieman and Rauch, 1987; Carver and Rauch, 1994). Stream flow may diminish over zones of tension due to open vertical fractures, whereas, stream flow may re-appear where compressional strain has sealed vertical fractures (Singh and Kendorski, 1978). Deeper longwall mines have a lesser impact on streams, and occasionally, there may be no stream flow impacts detected over longwall mine panels (Johnson, 1992).

Streams over deeper longwall mines may experience some of the following effects. Carver (1994) reported a 33\% reduction in baseflow recession constants for subsided and recovered Mine $\mathrm{Z}$ streams compared to un-subsided streams, indicating that baseflow is higher in the post-mine equilibrium phase. Gill (2000) concluded that stream reaches between adjacent mined longwall panels experienced dewatering effects from overlapping tension zones. He also reported temporary increases in stream discharges near the edges of mined longwall panels. The cumulative downstream effect of additional ground water contribution to stream flow was an increase in specific conductance and a decrease in water temperature (Gill, 2000).

Research has shown that stream reaches with less than 10 inches of total sediment and that lack well-sorted medium size particles may prolong stream dewatering. However, streams that have thick sediments with greater than $60 \%$ medium size particles and some fines, have less stream discharge impacts from mine subsidence (Gill, 2000). 
Owsiany (2001) measured shallow ground water levels in valley bottoms. Longwall mines with less than 300 feet of cover may impact that water-table in the short-term. It was detected that ground water may return to near pre-mining levels, ultimately exhibiting no permanent impacts to stream discharge in the long term.

The rate of evapotranspiration may be lower in recharge zones where longwall mines have increased the fracture density and aperture causing an increase in secondary permeability and storativity. This theory proposes that precipitation that typically evaporates or vegetation transpirates, is instead added to the ground water system. This increase in ground water volume also increases base flow to stream discharges over deep underground mines, or to mine pools of shallower underground mines (Hobba, 1981).

\section{Geophysical Section}

Mine subsidence can concentrate ground water into fractured strata. Water-filled fractures are identified by some geophysical surveying techniques. Electromagnetic (EM) techniques have been successful in locating water-filled fractures by using the relatively higher conductive properties of water in the fractures to differentiate them from the surrounding more resistive rock. The Very Low Frequency (VLF) technology detects and records the secondary electromagnetic fields created by VLF waves encountering sheet-like conductive bodies, such as water-filled fractures.

Distinct vertically conductive features near the edges of longwall panels have been identified as subsidence fractures using this technology. Identified locations can be mine induced subsidence fractures or dilated natural fractures, both of which can cause stream dewatering (Hutchinson and Barta, 2002). 
Terrain Conductivity (TC), an EM technique with a shallow penetration depth,, records the apparent conductivity of the subsurface and is used to target potential water loss zones in streams. Stream gaging above and below these targeted fracture zones verifies stream discharge losses or gains (Ackman and Dilmore, 2002; Geonics EM-31 Manual, 1975)

The angle of dewatering influence is similar to the angle of draw in that it defines the lateral extent of dewatering that occurs adjacent to the vertically projected mine panel sides or ends. The effective angle of dewatering influence depends on the lithologic and hydrogeologic setting, but mines with wider panels and fewer clay beds have the largest influence areas. Softer lithologic units, such as claystone, are able to seal subsidence fractures and reduce negative impacts to stream flow (Rauch, 1989). Carver and Rauch (1994) reported an angle of dewatering influence of $24^{\circ}$ to $31^{\circ}$ for low baseflow and $4^{\circ}$ to $16^{\circ}$ for high baseflow

\section{$\underline{\text { Stream Sediment Section }}$}

Jacobson, Femmer and McKenney (2001) discuss habitats and changes in habitats to disturbances. Jacobson etal, formulated a table that used the known factors of a channel condition and location and subjected it to a stressor, and predicted the response the response of the stream channel to the given factors. Although mine subsidence fracturing was not mentioned specifically, two factors in the table are applicable to the effects of underground mining.

The first factor is upland runoff changes. Mine subsidence typically decreases upland runoff by inducing infiltration (Hobba, 1978; Tieman and Rauch, 1994). The reduction of runoff can decrease the following variables: channel cross-sectional area, flood disturbance, 
woody debris recruitment, and connectivity with the floodplain. Runoff reduction may increase drought disturbance, embeddedness, vegetational cover, and woody debris retention (Jacobson, R., Femmer, S., and McKenney, R., 2001)

The second factor is riparian discharge changes. Mine subsidence may increase or decrease stream discharge, in part depending on the depth above the mine workings. When mine subsidence decreases discharge, the stream channel may decrease in the following: channel cross-sectional area, flood disturbance, woody debris recruitment, and connections with the floodplain. There may be a stream channel increase in the following: drought disturbance, embeddedness, cover, woody debris retention.

Mine subsidence may increase discharge, resulting in an increase in the following: channel cross-sectional area, flood disturbance, woody debris recruitment, and connections with the floodplain. This increase may result in a decrease in the following: drought disturbance, embeddedness, cover, woody debris retention (Jacobson, R., Femmer, S., and McKenney, R., 2001).

Some studies have shown that the proper amount of alluvium may assist the stream in sealing subsidence fractures and thereby, reducing the amount of water lost from the stream. Gill (2000) concluded that in streams with less than 10 inches of alluvium and a lack of medium sized stream sediment $(2 \mathrm{~mm}$ to $128 \mathrm{~mm}$ ) may have prolonged stream impacts, perhaps as long as 13 years after mining. Streams that have at least 60 percent medium sized particles with at least some finer sand sediment experienced a lesser degree of impact from mine subsidence.

Surface depressions can affect stream gradient, and thus stream bed characteristics. Pooling of the stream in these depressions disrupts the sediment in the channel by changing 
the gradient of a stream across a panel. It is considered feasible that in the case of increased retention time within these pools, fine clays in transport. Furthermore, bedrock stream channels can change to alluvium and alluvial channels to bedrock due to the change in gradient and pooling effects.

\section{Study Area}

Stream selection intended to fulfill the requirements set forth in a contract between the Office of Surface Mining and the author. The objective to stream selection was to choose streams that did not go dry after longwall mining in order to collect data on discharges at different baseflow levels. The contract required two streams studied in each of three physiographically different provinces. Partial flow loss streams were preferred to streams with complete flow loss. Furthermore, the drainage basin of a stream must be large enough to sustain flow in its main channel for the majority of the year. Therefore, intermittent and ephemeral streams were not included in this study. Streams with little electrical or metallic interference were also preferred to benefit from the planned geophysical surveys. Chosen streams have a contiguous control reach that provides a baseline for stream flows, geophysics and stream sediments.

\section{Description of Study Areas}

Six streams are studied, two in each of the three physiographic regions. The three regions are Eastern Ohio, Southwestern Pennsylvania (Figure 7) and Southern West Virginia (Figure 13). One study stream in Southwestern Pennsylvania, Stream F, was given an alias 
because stream flow data collected by the mine operator was shared with the author (Figure 7).

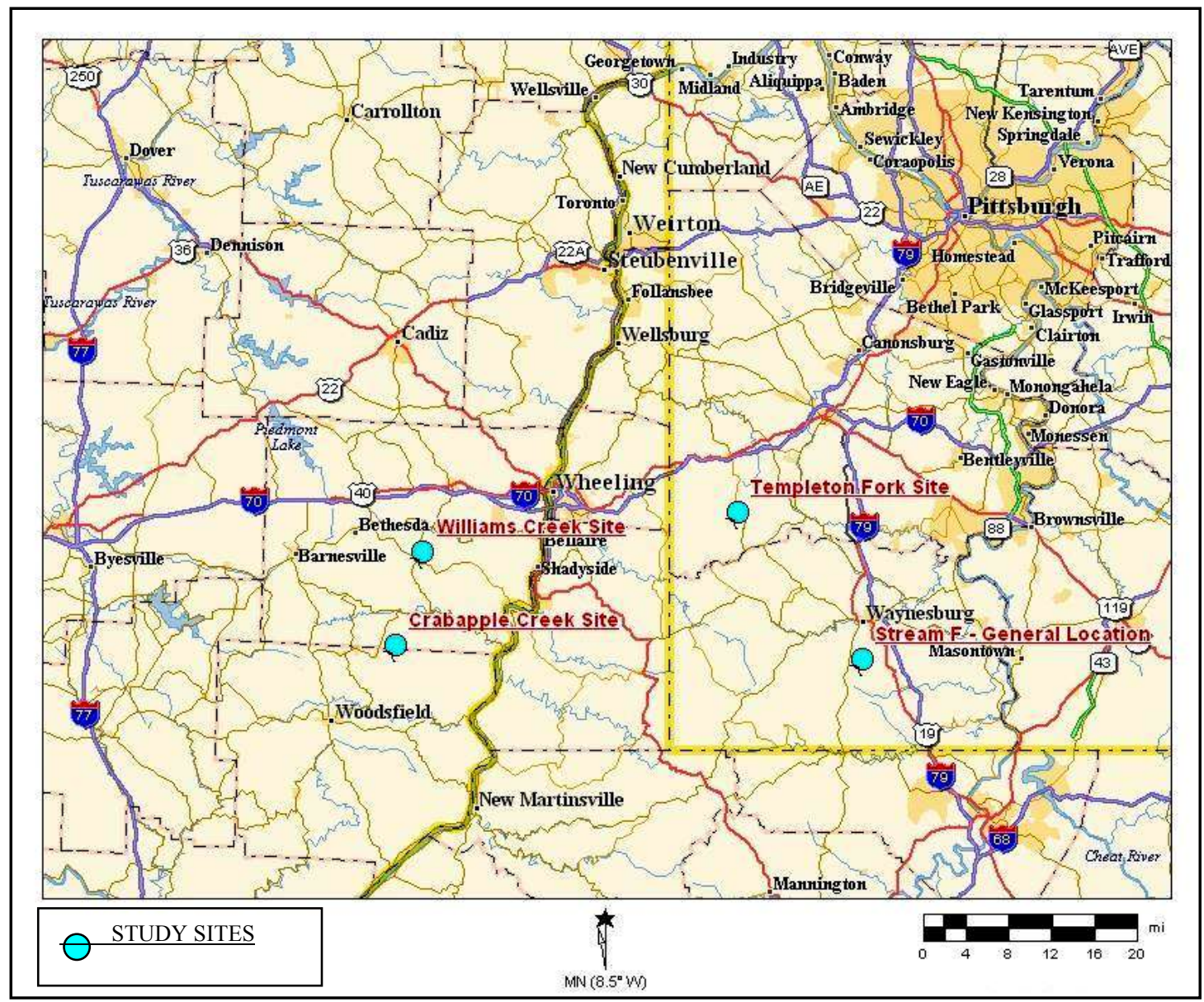

Figure 7. Location map for four study sites in Eastern Ohio and Southwestern Pennsylvania. The study reaches for Crabapple Creek and Williams Creek are located in Belmont County, Ohio. Templeton Fork is located in Washington County, Pennsylvania. Stream F is shown with an general location in Greene County, Pennsylvania. (Map prepared using DeLorme Topo 5.0). 


\section{Crabapple Creek, Ohio}

Crabapple Creek is a first and second order stream in Belmont County, Ohio. The study area is northeast of the village of Beallsville, near the Belmont and Monroe County lines, Ohio (Figure 7). It is a tributary of Captina Creek, which flows to the Ohio River. The study reach of Crabapple Creek is near its headwaters. This reach has an average slope of $1.1 \%$, an average wetted width of 9.3 feet and an average depth of 0.39 , at high baseflow. The study area drainage basin is mixed between forested and pastureland with the stream banks being well vegetated with established foliage.

The floodplain is primarily pastureland with some fields cut only for hay. The stream bottom is mostly bedrock and the banks are comprised of non-cohesive sandy loams. The study reach is found on the Armstrong Mills, Cameron and Woodsfield, U.S.G.S. 7.5' Quadrangle Maps (Figure 8).

The study reach of Crabapple Creek is 285 to 310 feet above the mined longwall panel (Appendix VI, Figure 1). The lithology of the rock beneath the stream and above the mined Pittsburgh Coal seam is a typical sequence of alternating clastic sandstone, shales and carbonates (Appendix XIII, Figure 1). The lithology by percentage, based on one drill hole, is sandstone at $8 \%$, shale at $17 \%$, limestone at $48 \%$, claystone at $24 \%$ and coal above the mined bed at $3 \%$.

Crabapple Creek is a first order stream until it intersects with Tributary A, another first order stream, where it forms a secondary stream. Tributary B enters Crabapple Creek two hundred feet downstream, and is a first order stream. Crabapple Creek remains a second order stream through the remaining measuring stations. 


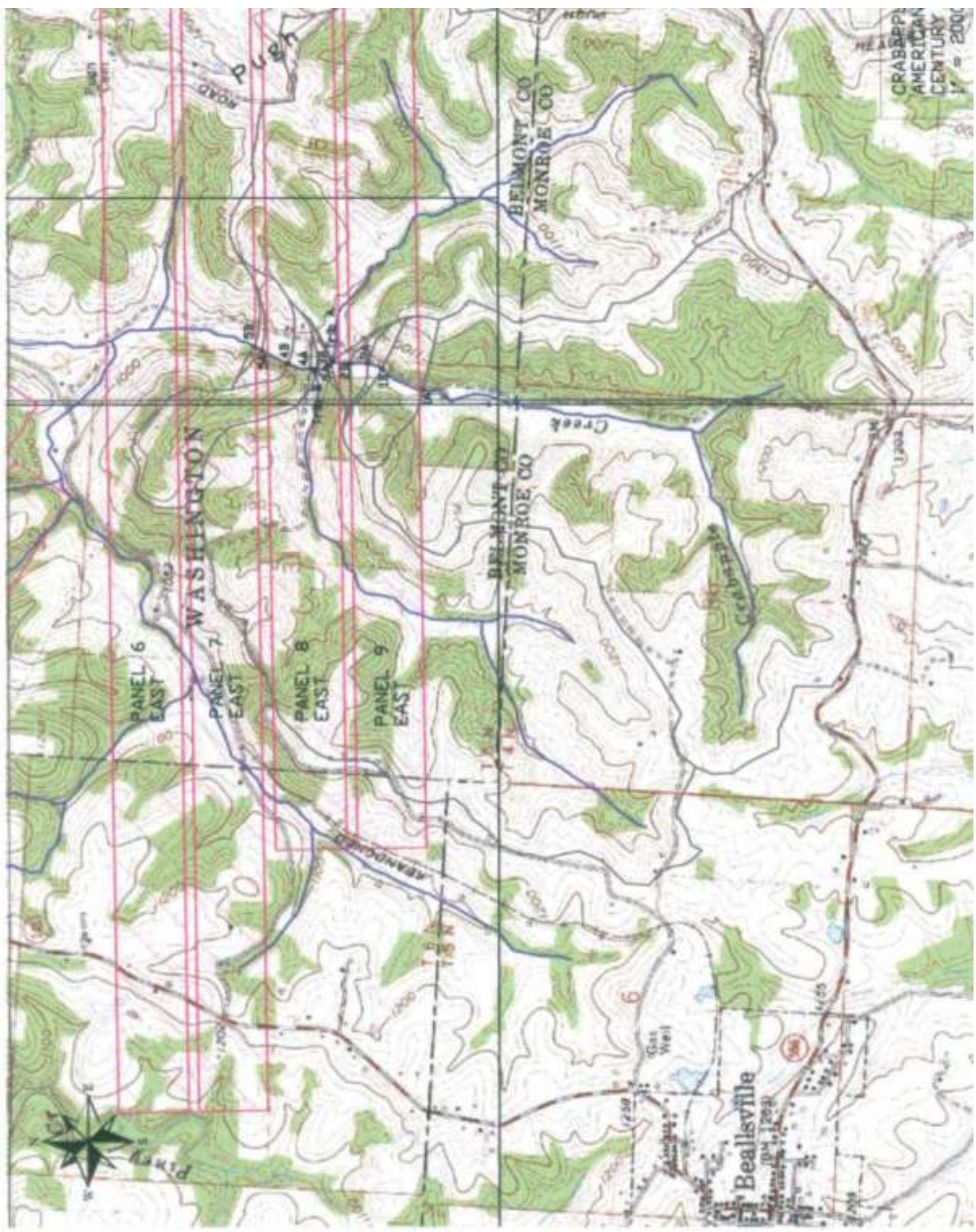

Figure 8. Crabapple Creek, Ohio, topographic map. Longwall panels of the American Energy Corporation's Century Mine are magenta. Panels 6 East through 9 East are labeled. Crabapple Creek and unnamed tributaries are blue. Drainage basins for measuring stations are black. Armstrong Mills, Cameron and Woodsfield, U.S.G.S. 7.5' Topographic Map. 
Three stream flow measurements were collected for Crabapple Creek. The first measurement was collected during extremely low baseflow, the second during high baseflow, and the third during low baseflow. The extremely low baseflow measurement was collected in June 2005, during a long period of near drought conditions. At the time of this measurement, panels 7 East and 8 East were mined, but panel 9 East had not yet mined beneath the stream. Panel 9 East was mined before high and low baseflow stream flow measurements could be collected.

This stream has many bedrock exposures. The bedrock consists of sandstone, coal and limestone. These lithologies dominate the upper third of the study reach. Massive sandstone bedrock is exposed in the lower two thirds of the study reach.

The stream was originally surveyed using the described geophysical methods on May 12, 2005, prior to longwall panel 9 East being mined (Appendix V, Table 1). Problems with the VLF source or data recorder required that stream be resurveyed on January 26, 2006. Some of the data from the first survey was salvaged and compared to the second set of data. This provided some information on geophysical changes in the shallow subsurface from pre-mining to post-mining.

The biggest change observed between pre-mining and post-mine subsidence conditions was the pooling of water over the downstream quarter of the panels 8 East and 9 East. The premining stream gradient over the proposed location of panel 9 East was very consistent, had positive drainage and never pooled for more than 5 feet. Prior to mining of panel 9 East, a two foot limestone bedrock waterfall was present at the 350 foot point downstream. This waterfall marks the upstream edge of the pooled reach that was discovered during the survey of January 26, 2006. The pooled reach over panel 9 East stretches from 350 to 550 feet (106.7 to $167.6 \mathrm{~m}$ ) downstream. Once the pooled formed, the geophysical surveys were conducted on the edge of the bank because the pool depth was greater than 4 feet. The pool over panel 9 East became shallower near 550 feet $(167.6 \mathrm{~m})$ downstream. Stream flow was detectable again near 570 feet 
downstream. The discharge was measured at Station 2B, at 590 feet $(179.8 \mathrm{~m})$ downstream, a high point in the channel bottom.

Prior to longwall mining of panel 9 East, the reach from 000 to 350 feet $(106.7 \mathrm{~m})$ had very little alluvium present (Appendix IV, Table 1; Appendix VII, Table 1). The majority of the stream bed consists of coal and limestone bedrock. However, alluvium was present from 350 feet $(106.7 \mathrm{~m})$ to 880 feet (268.3 m) downstream, preventing bedrock outcrops within this reach .

Fracturing of sandstone bedrock in the streambed between panels 8 East and 7 East was detected. Fracturing produced asymmetrical cobbles and boulders of sandstone approximately 6 inches $(0.15 \mathrm{~m})$ to 36 inches $(0.92 \mathrm{~m})$ in diameter. The fracturing of the sandstone reflects the tension strain exerted at the surface, over gate-entry entries. Downstream of the measured reach, the streambed has a local increase in gradient, ending in a plunge pool. At the tail of this pool was a large deposit, approximately 15 feet $(4.5 \mathrm{~m})$ diameter, of sandstone boulders that had fractured off of the immediate upstream reach.

The downstream edge of panel 8 East and the upstream edge of panel 7 East were noted to have some local disturbances. The downstream edge of panel 8 East exhibited a small landslide coming in from the 30-foot high south stream bank. Also from the south side of the stream, springs were observed during the geophysical surveys of May 12, 2005. Located just above stream level over the upstream edge of panel 7 East; the diffuse spring discharges entered the stream from the sandstone ledge through bedding partings during (Figure 9). 


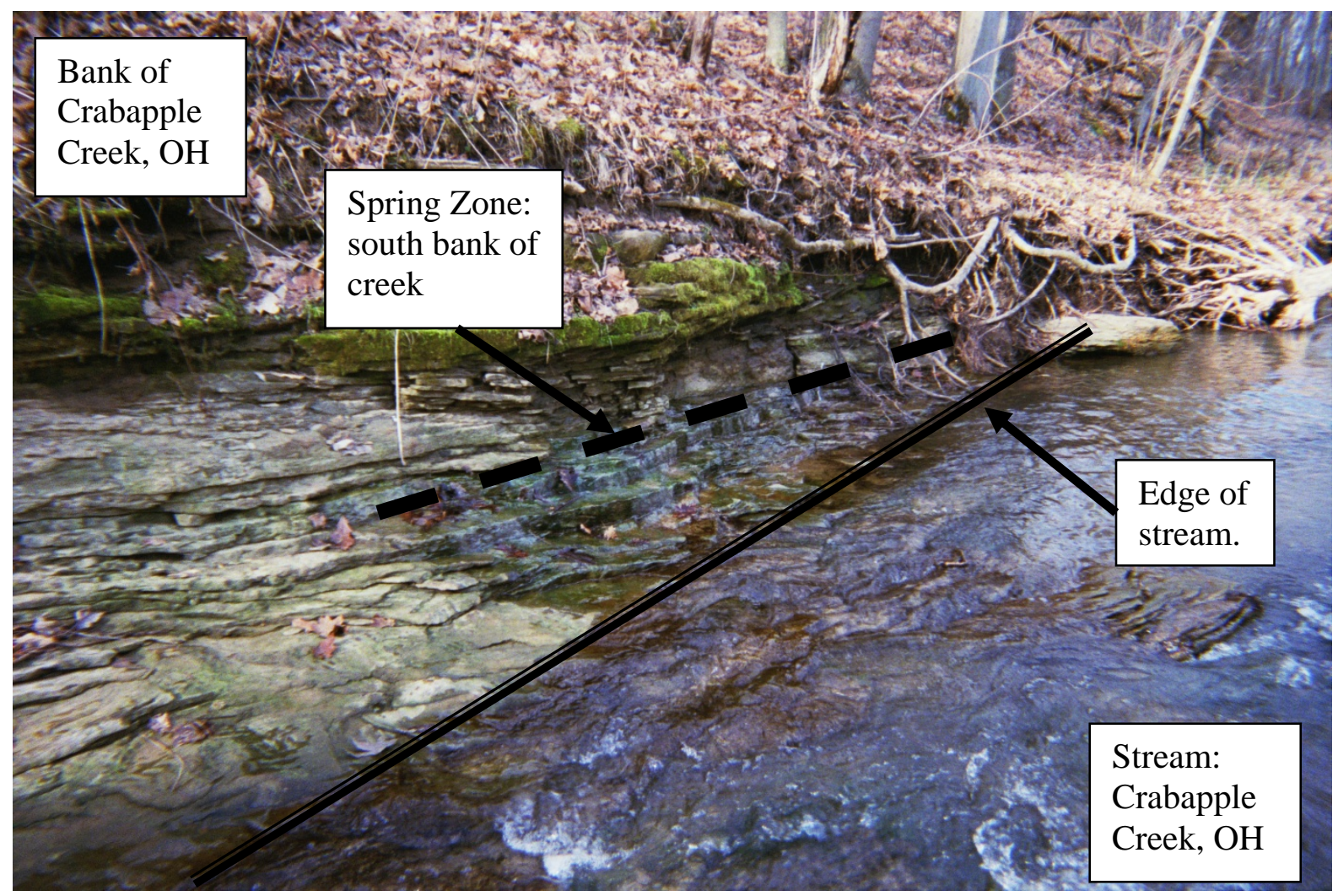

Figure 9. Diffuse spring discharges from a sandstone in Crabapple Creek, Ohio. The springs discharge from the southern bank of the stream, over the upstream edge of longwall panel 7 East of the American Energy Century Mine. Photograph taken by Scott Wade (WVU Graduate Student) during field work on May 12, 2005.

\section{Williams Creek, Ohio}

Williams Creek is a third order stream located in Belmont County, Ohio, north of the village of Centerville. The creek has an average slope of $0.5 \%$, an average wetted width of $12.5 \mathrm{ft}(3.8 \mathrm{~m})$ and an average depth of $0.58 \mathrm{ft}(0.18 \mathrm{~m})$, at high baseflow. Williams Creek enters McMahon Creek near Glencoe, Ohio, a tributary of the Ohio River. A 2,400-foot (731.7 m) reach of Williams Creeks was studied, beginning approximately 1,700 feet (518.3 m) downstream of SR-9. 
Williams Creek flows northeast across the main headings of the deep mine complex, and then east across the barrier coal. The stream crosses onto the end of panel 21 East at approximately 600 feet $(182.9 \mathrm{~m})$, turns and flows southeast across the southern edge of panel 21 East, then onto panel 20 East. The study reach is found on the Armstrong Mills and St. Clairsville, U.S.G.S. 7.5' Quadrangle Maps (Figure 10).

This reach of Williams Creek is 260 to 280 feet above the mined longwall panel (Appendix VI, Figure 2). The lithology of the rock beneath the stream and above the mined Pittsburgh Coal seam is a typical sequence of alternating clastic sandston, shales and carbonates (Appendix VIII, Figure 1). The lithology by percentage, based on one drill hole, is sandstone at $8 \%$, shale at $17 \%$, limestone at $48 \%$, claystone at $24 \%$ and coal above the mined bed at $3 \%$.

Williams Creek flows over the Ohio Valley Coal Company’s Powhatan No. 6 Mine, located in the Pittsburgh Coal seam. This mine contains the second oldest mined longwall panels included in this study (Appendix V, Table 2). Panel 21 East was mined in 1997, approximately 9 years prior to this study. Between the east side of SR-9 and the study reach, the stream flows across a property used by the mining company to ventilate the mine. The main headings of the Powhatan No. 6 Mine are aligned north-south, with most of the longwall panels lying east of SR-9. There are two shafts into the main headings on the property located upstream of the study reach. The study reach begins at the upstream property line of Mr. Robert Groves' farm. The studied reach is located entirely on this farm, providing an ideal setting for stream surveys. Downstream of the mine shafts there were no interferences from electric lines, debris in the stream, or piped crossings. 


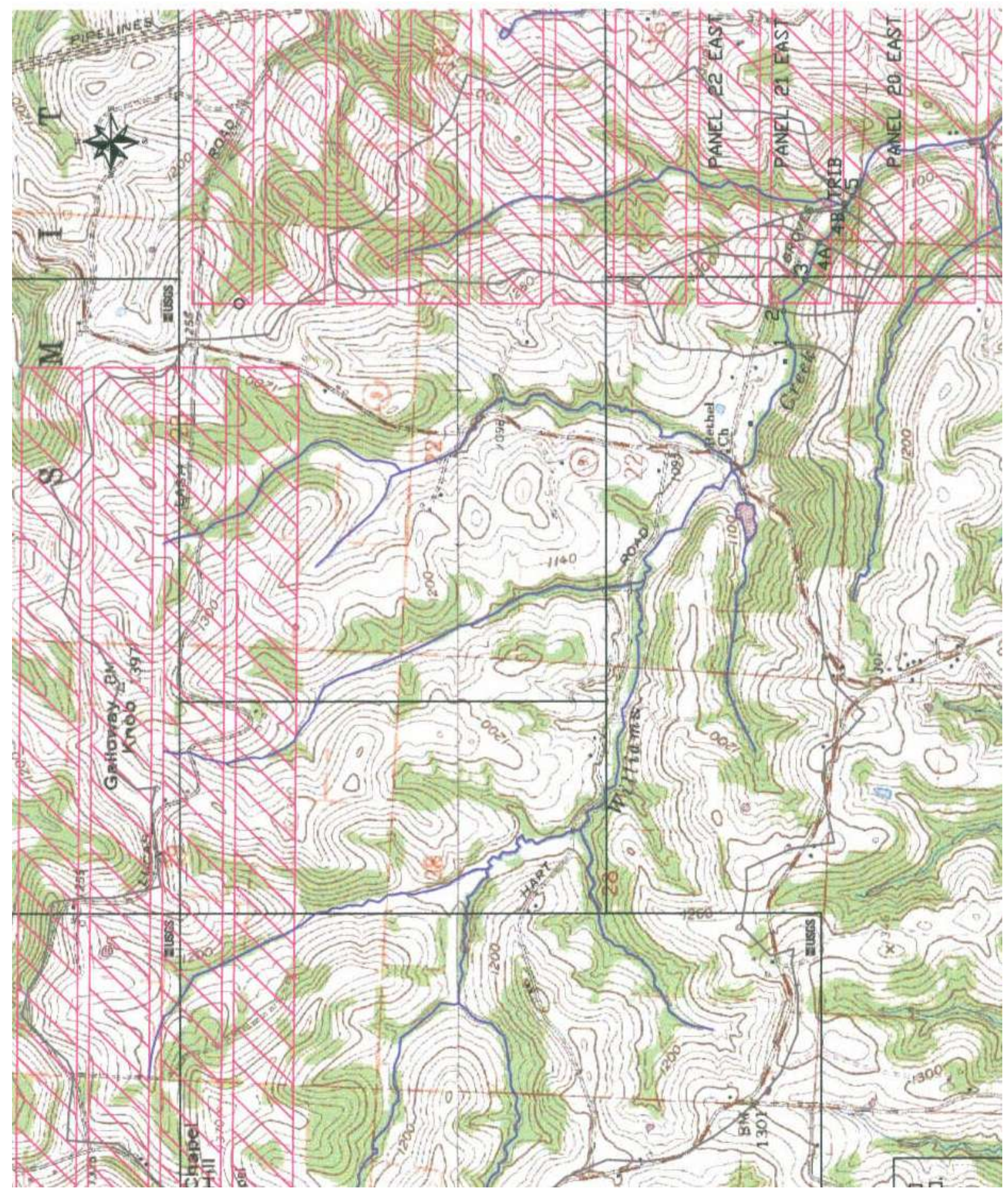

Figure 10. Williams Creek, Ohio, topographic map. Longwall panels of the Ohio Valley Coal Company's Powhatan No.6 Mine are magenta. Panels 20 East through 22 East are labeled in the southeast corner of the map. Williams Creek and unnamed tributaries are shown in blue and flow east-southeast. Drainage basins for measuring stations are black. Armstrong Mills and St. Clairsville,Ohio U.S.G.S. 7.5' Topographic Map. Scale: 1" = 2000'. 
Williams Creek becomes a third order stream, the largest order stream studied, approximately 1500 feet $(457.3 \mathrm{~m})$ upstream of the first measuring station, just before crossing SR-9. The first measuring station has 2300 acres of drainage area. Approximately $15 \%$ of the headwater drainage area for this upstream measuring station has been longwall mined, and the percentage of longwall mining increases in the downstream measuring stations.

Longwall panels have extracted coal under the Galloway Knob area, which is the northwestern portion of the drainage area for Station 1. Some of these longwall panels are within under the headwaters of several perennial streams, which is also the headwater recharge area for Williams Creek. The mining in the headwater area may have impacted the baseflow to Williams Creek upstream of the study reach, but the extent to which it has altered the baseflow is difficult to assess and is not evaluated in this research.

Most of Williams Creek has a substantial amount of alluvial sediment on the streambed. The upstream and downstream stations, however, are both located on bedrock (Appendix IV). The upstream station is located on sandstone bedrock and the downstream station is located on mudstone bedrock. Sandstone and coal bedrock are exposed approximately 300 feet upstream of the edge of longwall panel 21 East. The bedrock exposed in the stream bottom and bank appears to be fractured, possibly due to mine subsidence. This reach has a higher than average stream gradient and is located in the tension zone of the subsidence basin of panel 21 East (Appendix VII, Table 2). 


\section{Stream F, Pennsylvania}

Stream $\mathbf{F}$ is a second order stream located in Greene County Pennsylvania. The creek has an average slope of $0.3 \%$, an average wetted width of 5.0 feet $(1.5 \mathrm{~m})$ and an average depth of $0.65 \mathrm{ft}(0.20)$, at high baseflow. Stream F flows southeast over increasingly younger longwall panels of Mine $\mathrm{V}$. The study reach is 3,200 feet $(975.6 \mathrm{~m})$ and flows at approximately 45 degrees to the short axis of the longwall panels.

The Pittsburgh Coal seam was longwall mined $595(181.4 \mathrm{~m})$ feet below the stream elevation at panel 1, as determined from U.S.G.S. topographic mapping and coal structure contours produced by Dodge (1984). No other coal seams within the drainage area of Stream F are known to be mined (Dodge, 1984). This is an active mine that continues to extract coal to the south of the of the study area. Longwall mining is present north of the study area as well, however, when Stream F surveys were conducted, no longwall mining had yet been conducted within the drainage area of the study stream (Figure 11). Longwall panels 1 and 2 mined beneath the stream in July 2004 and April 2005, respectively. Geophysical surveys were conducted approximately 9 months after panel 1, and 1 month after panel 2 mined beneath the stream (Appendix V, Table 1 and 2).

The study reach of Stream F is 595 feet above the mined longwall panel (Appendix VI, Figure 3). The lithology of the rock beneath the stream and above the mined Pittsburgh Coal seam is a typical sequence of alternating clastic sandstone, shales and carbonates (Appendix VIII, Figure 2). The lithology by percentage, based on one drill hole, is sandstone at $22 \%$, shale at $40 \%$, limestone at $23 \%$, claystone at $10 \%$ and coal above the mined bed at $2 \%$. 
The unmined control section of the study reach of Stream $F$ is from 0 to 650 feet (198.2 m). The stream flows from the control reach, across a gate-entry, then across the study panels. The mined panels are approximately 1140 feet $(347.5 \mathrm{~m})$ wide and the room and pillar gate-entry width is approximately 220 feet $(67.0 \mathrm{~m})$ wide.

Stream gradient is impacted by mine subsidence. The stream slope increases across the upstream edge of the panel 1 , from 700 to 1100 feet (213.4 to $335.4 \mathrm{~m}$ ), the only cascade reach within the study area (Appendix VII, Table 3). Subsidence of panel 1 also causes pooling over the downstream quarter-panel. The gradient of the creek is inverted over this reach due to mine subsidence. Subsidence can cause the streambed over the panel to fall to a point below that of the streambed further downstream, causing the stream to pool and flood the lowest parts of the valley bottom.

The stream over the gate-entry was lowered between 2100 feet to 2440 feet (640.2 to $743.9 \mathrm{~m}$ ) downstream to create positive drainage, by excavating the stream bottom. The author was not present during excavation, but evidence of excavation includes a soil furrow at the stream bank that appeared after earlier inspections, graded banks and a different stream profile from earlier records. Stream banks were graded and seeded, and the stream bed consisted of silted over crushed gravel in the riffle reaches.

Four stream particle surveys were completed in the study reach. Nearly 50 percent of the stream sediment within the control reach is sand and silt size. The increased slope of the stream exposes larger particles over the cascade reach of panel 1, yet silt dominates the sediment particles in the pooled and gate-entry reaches. 


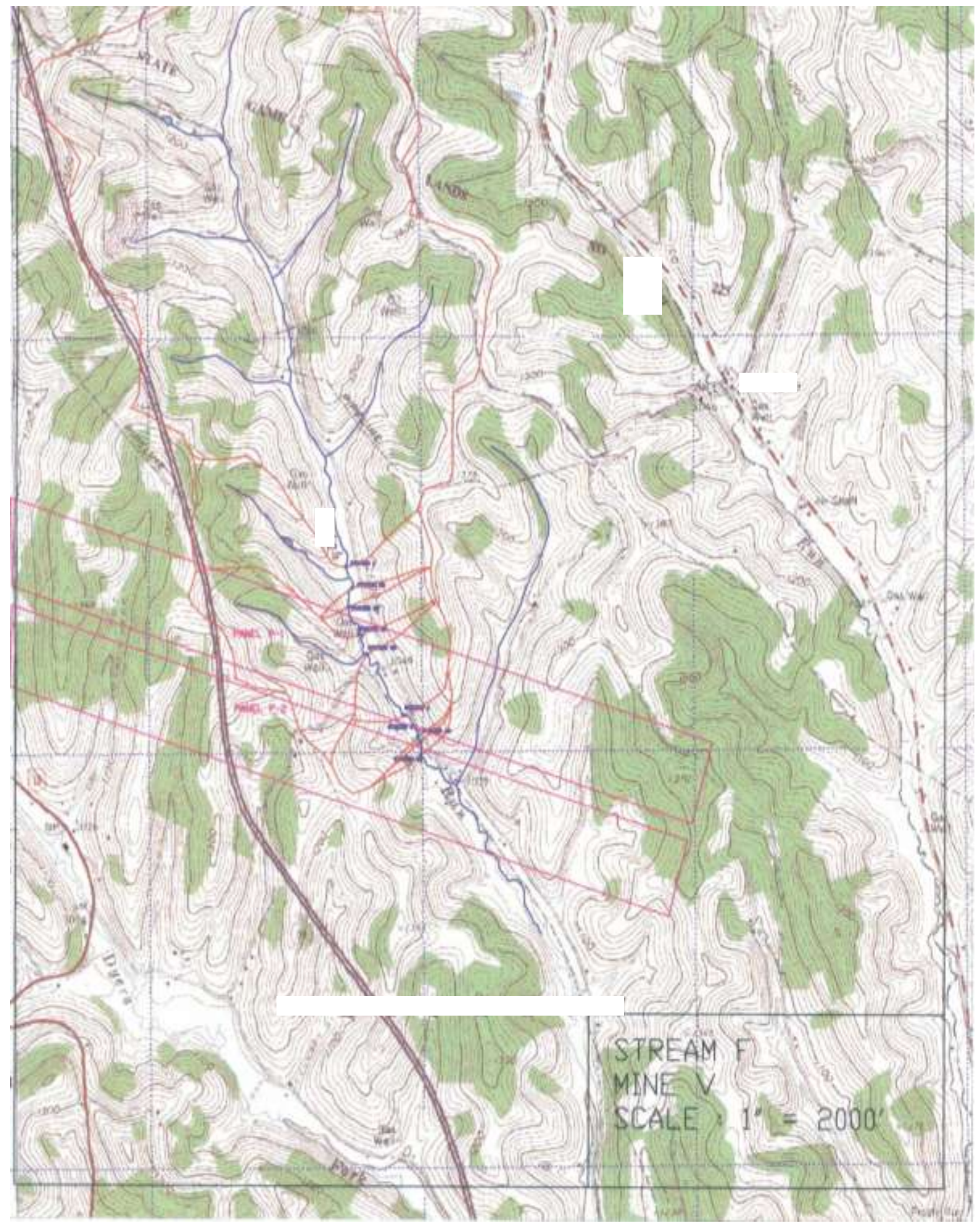

Figure 11. Stream F, Pennsylvania, topographic map. Panels 1 and 2 of Mine $V$ are magenta. Stream $F$ and unnamed tributaries are blue. Drainage basins for measuring stations are red. Stream $F$ was given an alias because stream flow data collected by the mine operator was shared with the author. U.S.G.S. 7.5' Topographic Map names are withheld and identifying names have been redacted to conceal the stream's exact location. 
Two stream measuring events were conducted. Geophysics and high flow measurements were conducted prior to the stream being regraded and the stream alluvium altered by excavation (Appendix V, Table 1). The low flow measurement, alluvial thickness measurement and particle analysis measurement was conducted after the stream over the gate-entry was regraded.

Mine $\mathrm{V}$ representatives stated the first couple of panels under Stream F did not produce water, and that this area was dry. Stream flow data was obtained from the coal company to assist in assessing mine subsidence impacts (Appendix II, Tables 1 to 4). In return, the stream location is genralized and the company and stream name are withheld at their request. Drainage areas are measured for each of the company stream flow stations using the same techniques as for all remaining stations, allowing the discharge data offered by the mine company to be converted to drainage area-adjusted discharge ratios. Time correction could not be employed because the discharge measurements were not time stamped.

\section{Templeton Fork, Pennsylvania}

Templeton Fork is a second order stream located in Washington County, Pennsylvania. The channel has an average slope of $0.1 \%$, an average wetted width of 7.5 feet and an average depth of $0.57 \mathrm{ft}$, at high baseflow. Templeton Fork is a tributary to Enlow Fork, which flows west to the Ohio River. A 2,700 foot reach of Templeton Fork was studied beginning just upstream of where SR-231 crosses the creek. The study area and drainage basin is found on the Claysville and Prosperity U.S.G.S. 7.5' Quadrangle Maps (Figure 12). 
Templeton Fork flows southwestward across longwall panels of the Enlow Fork Mine operated by Consolidation Coal Company in the Pittsburgh Coal seam. The stream crosses from solid unmined coal within the control reach onto panel F10 at 860 feet $(262.2 \mathrm{~m})$ downstream. The stream continues across the short axis of panel F10, over the gate-entry then onto panel F9. Panel F9 and F10 are the study panels. These panels, from the inside edge of the gates, are approximately 1,020 feet $(310.9 \mathrm{~m})$ wide. The gate-entry widths are 190 feet $(57.9 \mathrm{~m})$ wide. The mining progresses in a northerly direction, therefore, the younger panels are located upstream towards the headwaters.

The study reach of Templeton Fork is 535 feet above the mined longwall panel (Appendix VI, Figure 4). The lithology of the rock beneath the stream and above the mined Pittsburgh Coal seam is a typical sequence of alternating clastic sandstone, shales and carbonates (Appendix VIII, Figure 2). The lithology by percentage, based on one drill hole, is sandstone at $25 \%$, shale at $40 \%$, limestone at $23 \%$, claystone at $10 \%$ and coal above the mined bed at $2 \%$.

Templeton Fork is a second order stream from the beginning of the study reach to 1,900 feet $(579.2 \mathrm{~m})$ downstream. At that point, just above Station 8, another second order stream enters Templeton Fork, forming a third order stream over the remaining study reach. The first station, Station 1A, has a 2438 acre (986.6 hectare) drainage area. No mining was conducted within the headwaters of Station 1A prior to or during the study of this reach.

Most of the streambed has a substantial amount of alluvial sediment, yet at the upstream edge of the subsidence basin a claystone bedrock unit is exposed. This exposed bedrock forms a plunge pool immediately downstream in a reach of increased gradient. 


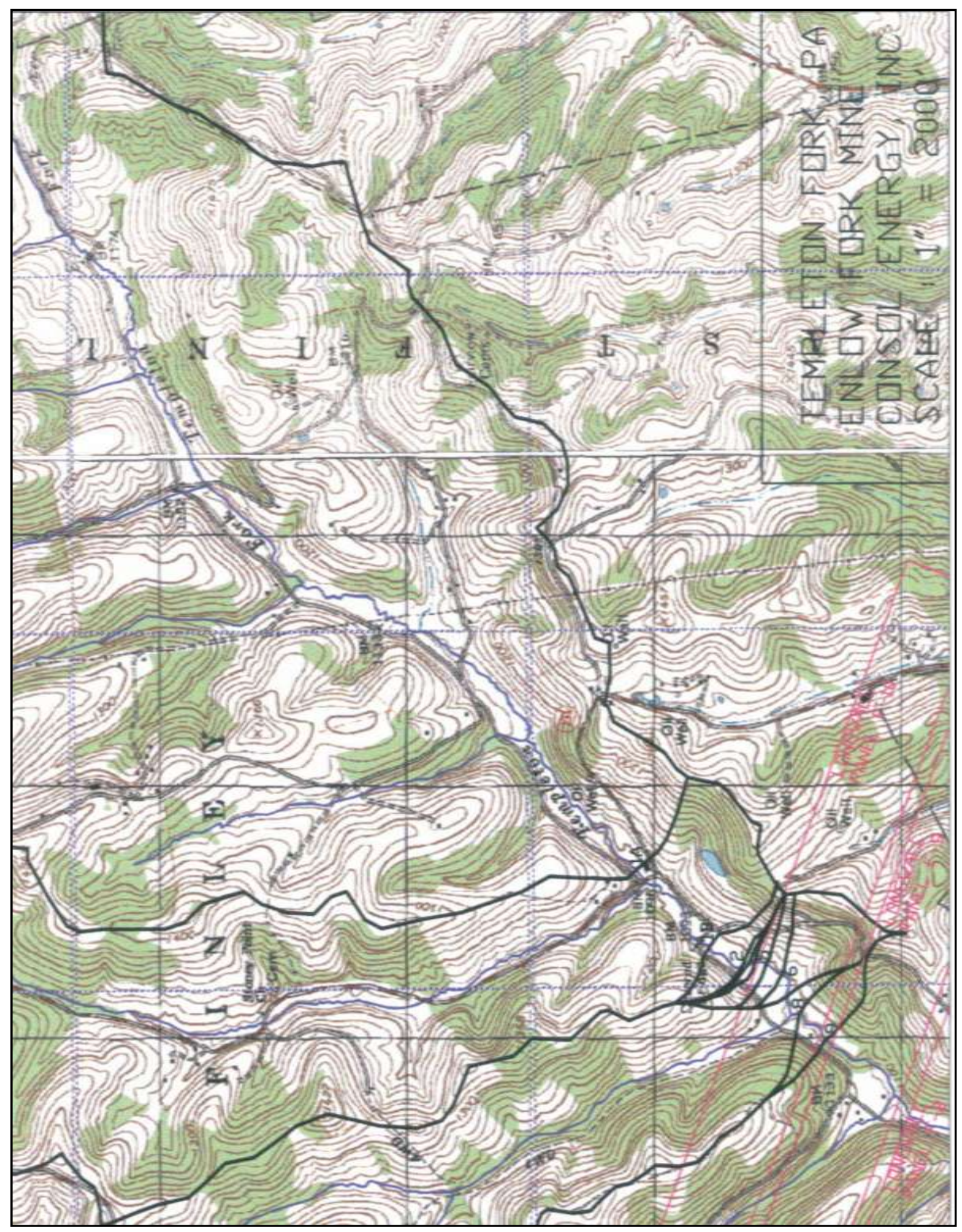

Figure 12. Templeton Fork, Pennsylvania, topographic map. Ouline of panels F-9 and F-10 of the Consol Energy, Inc. Enlow Fork Mine are magenta. Templeton Fork and unnamed tributaries are blue. Drainage basins for measuring stations are black. Templeton Fork is found on the Claysville and Prosperity,U.S.G.S. 7.5' Topographic Maps. Scale: 1" = 2000'. 
No stream-flow changes were observed during the stream flow, geophysical or sediment surveys. However, subsidence impacts of longwall panel F10 caused the stream to pool over the downstream quarter-panel of panel F10 and F9 (Appendix VII, Table 4). The gate-entry reach between panel F10 and panel F9 was excavated to alleviate pooling and create positive stream drainage.

Dates of mining were obtained from the Pennsylvania Department of Environmental Protection surface inspector. These dates are included for review in Appendix V, Table 2.

\section{Island Creek, West Virginia}

Island Creek is in Logan County, West Virginia. It is a second order stream over most of the study reach. Island Creek is a tributary to the Guyandotte River, joining it at the city of Logan (Figure 13). The study reach has an average channel slope of $4.5 \%$, an average wetted width of 4.1 feet $(1.2 \mathrm{~m})$, and an average water depth of 0.41 feet $(0.12 \mathrm{~m})$, at high baseflow. All of the monitoring stations established for this study are in the perennial reach of Island Creek, as delineated by U.S.G.S. topographic mapping. The drop in elevation from the upstream to the downstream extents of the study reach is 140 feet $(42.7 \mathrm{~m})$, ranging from 1460 feet $(445.1 \mathrm{~m})$ to 1300 feet $(405.5 \mathrm{~m})$ above mean sea level. The upper half of the study reach has a higher gradient than the lower half (Appendix VI, Graph 5). The regional structure in the study area has a northwest dip. The study reach is 2600 feet $(792.7 \mathrm{~m})$ long and begins just above a tributary named Deadman Branch (Figure 14).

The Lower Cedar Grove Coal seam is located beneath the study reach and was mined by the longwall method. Mining in this seam was completed prior to this study. The coal seam ranges from 4.6 to 5.6 feet ( 1.4 to $1.7 \mathrm{~m}$ ) thick and ranges from 100 to 170 feet (30.5 to 
$51.8 \mathrm{~m}$ ) beneath Island Creek (Appendix VI, Figure 5). The lithology of the rock beneath the stream and above the mined Lower Cedar Grove Coal seam is a typical sequence of alternating clastic sandstone and shales (Appendix VIII, Figure 3). The lithology by percentage, based on one drill hole, is sandstone at $38 \%$, shale at $60 \%$, limestone at $0 \%$, claystone at $0 \%$ and coal above the mined bed at $2 \%$.

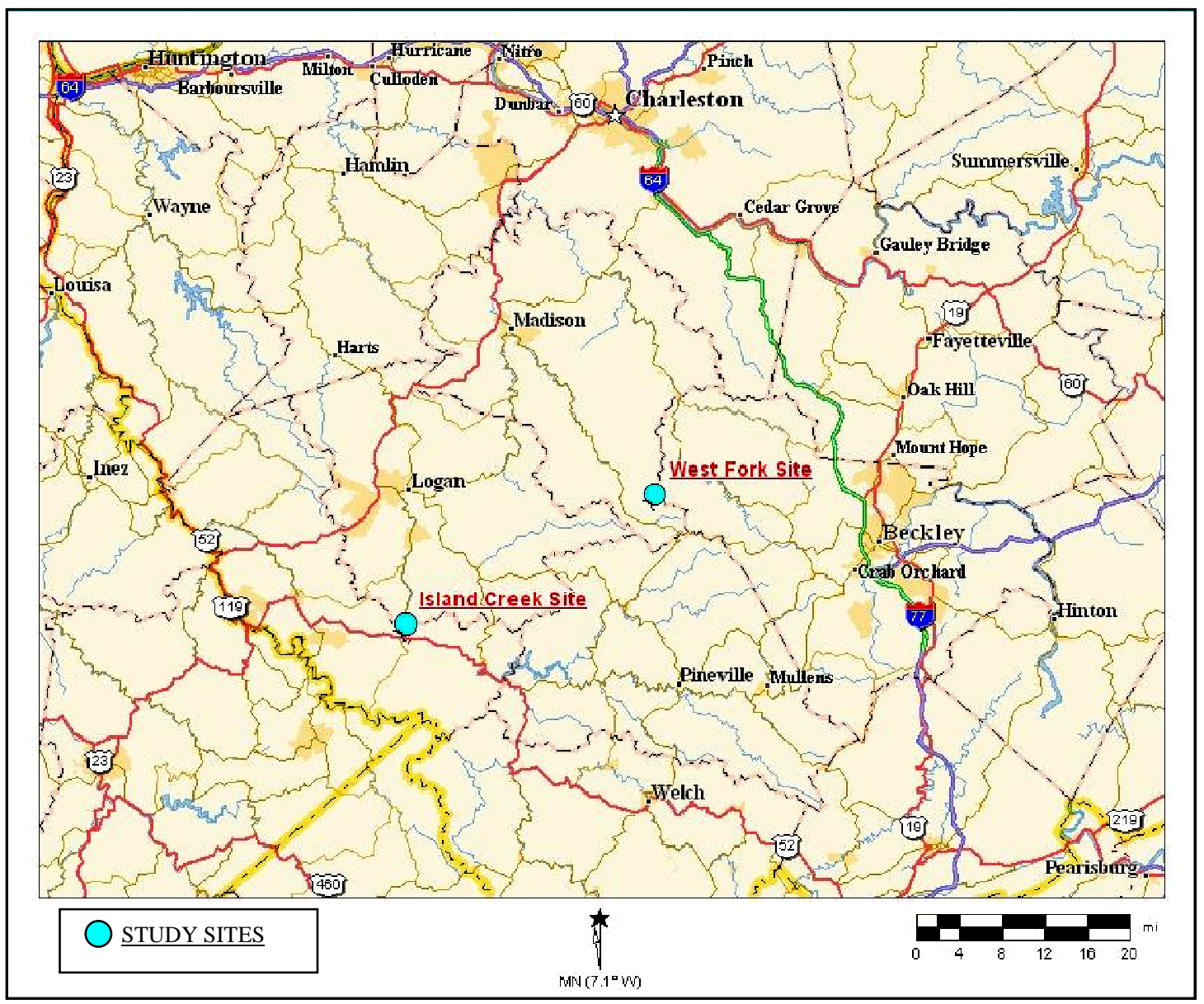

Figure 13. The two study sites in Southern West Virginia are in blue and their names underlined. Island Creek is located in southern Logan County, and West Fork is located in southeastern Boone County (Map prepared using DeLorme Topo 5.0). 
Deadman Branch is a first order stream and is the only first order stream entering the study reach of Island Creek. Island Creek becomes a second order stream where Deadman Branch joins it. A completed surface mine is located within the watershed of Deadman Branch. This is the only known surface mine within the drainage area of the study reach.

Island Creek flows across two consecutive panels within the study reach. It flows across the northeast corner of longwall panel 15 LT initially. Then it flows over the gateentry for several hundred feet before turning and flowing directly across longwall panel 16 LT. Longwall panel 16 LT mined under the stream first in May 1997, and longwall panel 15 LT mined under the stream in December 1997 (Appendix V, Table 2). Longwall panel 16 LT was 8 years and 9 months old and longwall panel 15 LT was 8 years and 2 months old when this stream was studied.

The Lower Cedar Grove Coal seam was the only mine beneath Island Creek in the study reach at the time of the surveys. After stream surveys were completed, mining commenced within the study reach in the Alma A coal seam. The Alma A Coal seam is approximately 67 feet beneath the Lower Cedar Grove Coal seam in this area. Stream surveys were collected prior to the mining of the Alma A Coal seam and therefore do not include impacts observed by the mining of this seam.

Stream flow measurements indicate that the Lower Cedar Grove Coal longwall mine continued to dewater Island Creek during the stream flow study. Other circumstances, such as the dewatering of the Lower Cedar Grove Coal in advance of mining the Alma A seam may be impacting the stream. Although water may have been pumped out of the Lower Cedar Grove mine, the water was not being discharged into the Island Creek watershed within the study area. There are no known unnatural recharges to Island Creek. 


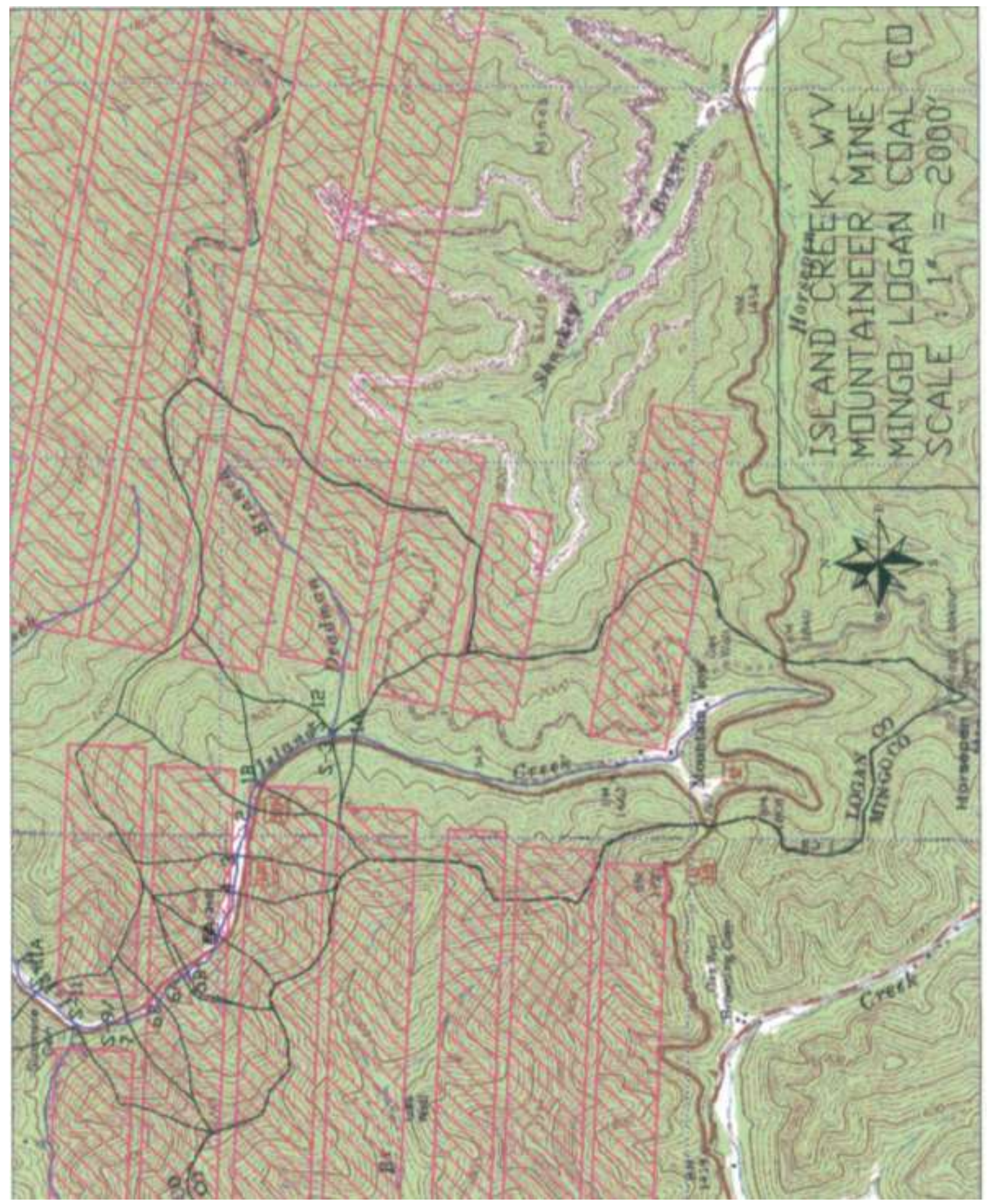

Figure 14. Island Creek, West Virginia, topographic map. Longwall panels of the MingoLogan Coal Company's Mountaineer Mine are magenta. Island Creek, and its tributary streams, are blue. Drainage basins for measuring stations are red. DEP measuring stations are red. The measured stream reach is on the Barnabus and Man, WV,U.S.G.S. 7.5' Quadrangle Maps. Scale: 1" = 2000'. 
Stream flows were measured three times, once in the winter of 2006 and twice in May 2006. Sampling events were conducted during high baseflow, low baseflow and extremely low baseflow conditions. The stream flowed throughout the measured reach during both the high and low baseflow dates, but went dry within the measured reach during the extremely low baseflow event.

\section{West Fork, West Virginia}

West Fork is a first order stream tributary in Boone County, West Virginia and a tributary to Pond Fork. The perennial reach of West Fork begins at the confluence of Tributary A to West Fork, approximately 100 feet (30.5 m) upstream of study reach (Figure 15). There are several more tributary streams that converge upstream of the study reach, consisting of West Fork's headwaters.

West Fork has an average slope of 1.9\%, an average wetted width of 6.5 feet $(1.9 \mathrm{~m})$ and an average depth of 0.50 feet $(0.15 \mathrm{~m})$, within the study reach at high baseflow. The eastern drainage divide of West Fork is also the Boone and Raleigh County line. West Fork flows into Pond Fork near the village of Van on State Route 85 in Boone County. The study reach of West Fork is on the Pilot Knob, WV 7.5' Quadrangle Map.

The Campbell Creek Coal, also known as the No. 2 Gas Coal, and the Eagle Coal seams were both longwall mined in the study area. Both longwall mines were completed prior to surveying the stream. The Harris No. 2 longwall mine, in the Campbell Creek / No. 2 Gas Coal seam, is the shallowest longwall mine in the drainage area at 150 feet $(45.7 \mathrm{~m})$ 


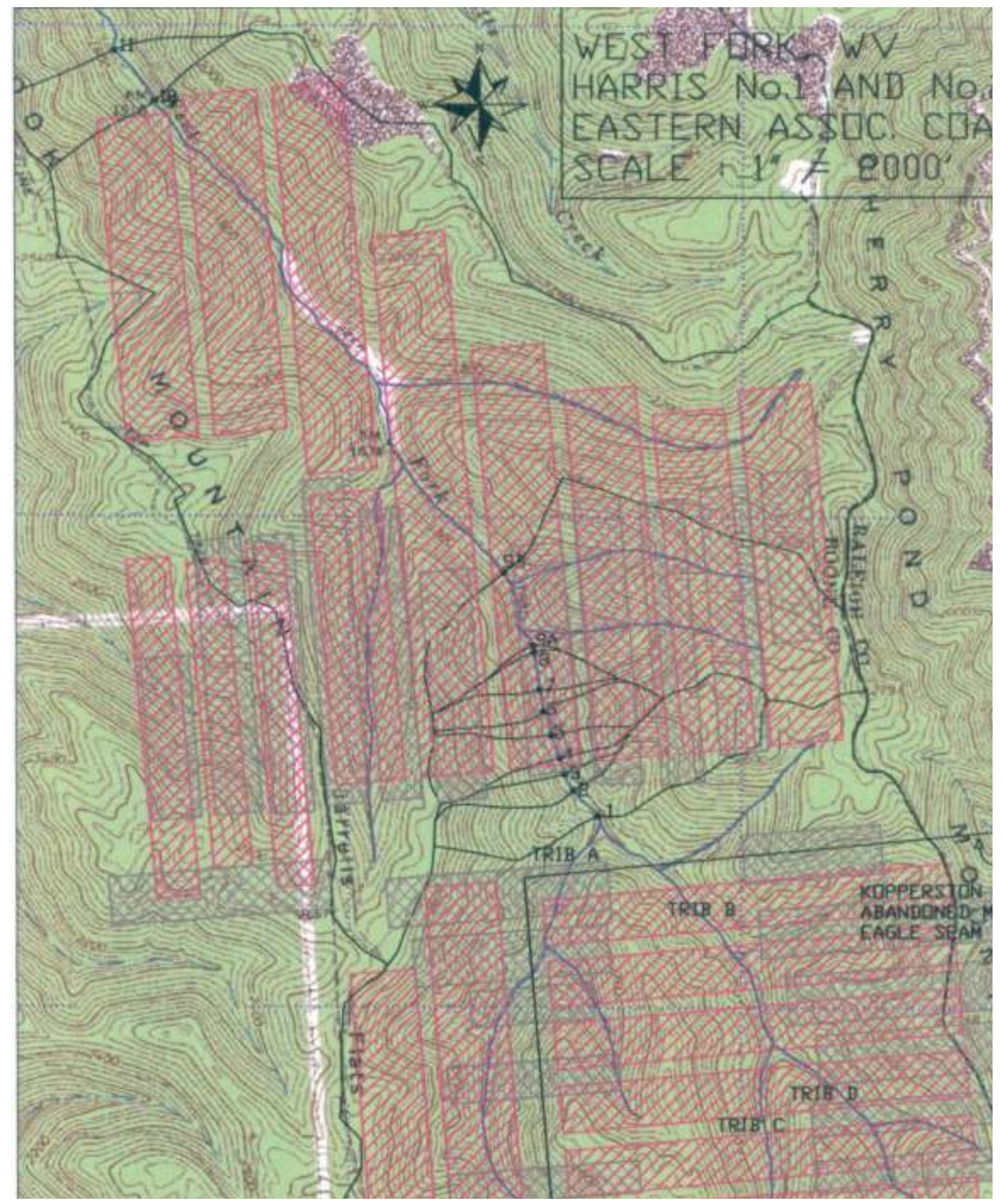

Figure 15. West Fork of Pond Fork, West Virginia, topographic map. Longwall panels of Eastern Associated Coal Company's Harris No. 1 and No. 2 mines are magenta (Eagle Seam) and grey (Campbell Creek/2 Gas Seam). Abandoned longwall mine Kopperston No. 1 are southeast of the Harris mines in magenta. West Fork and tributaries are blue. Drainage basins for measuring stations are black. The study reach of West Fork is located on the Pilot Knob WV, U.S.G.S. 7.5' Topographic Map. Scale: 1"'=2000'. 
beneath the stream (Appendix VI, Figure 5). The Campbell Creek / No. 2 Gas Coal longwall panel beneath the stream was completed in 1990 (Appendix V, Table 2). This panel was approximately 15 years old when field surveys began.

The Harris No. 1 longwall mine was in the Eagle Coal seam. This mine lays 200 feet (60.9 m) beneath the Campbell Creek / No. 2 Gas Coal seam. It is the first minable coal seam and the only longwall mine below the Campbell Creek / No. 2 Gas Coal seam. The youngest completed longwall panel beneath West Fork is two months old. It is identified as panel No. 1 and is in the Eagle Coal seam. Neither the Campbell Creek / No. 2 Gas nor the Eagle Coal seam crop out within the study area; all of the mine workings are below drainage.

The Eagle Coal seam is 340 to 360 feet (103.6 to $109.7 \mathrm{~m}$ ) below the elevation of the valley bottom within the study reach. Longwall panels are wider and longer in the Eagle Coal seam than in the Campbell Creek / No. 2 Gas Coal. The Campbell Creek / No. 2 Gas Coal seam longwall panels measured 650 feet $(198.2 \mathrm{~m})$ wide, while the Eagle Coal seam longwall panels measured 850 feet $(259.1 \mathrm{~m})$ wide. The Eagle Coal seam longwall panels are also two to three times longer than the shallower Campbell Creek / No. 2 Gas Coal mine. Upstream and downstream of the primary study reach, mine workings in the Eagle Coal seam were much more abundant than in the Campbell Creek / No. 2 Gas Coal seam.

The bedrock structure parallels the stream gradient within the study area (Appendix VI, Graph 6). As a result, the coal seams maintain a constant depth below the valley bottom within the study area. Towards the headwaters, the amount of cover increases as the topography, and stream gradient, increase at a greater rate than the structure. The subparalleling stream to structure relationship suggests that lithology exposed at creek elevation 
does not significantly change over the reach. Furthermore, any strata that crops out, or subcrops, at the stream level, will do so for an extended length.

The lithology of the rock beneath the stream and above the mined Campbell Creek / No. 2 Gas Coal seam is a typical sequence of alternating clastic sandstone and shales and coals (Appendix VIII, Figure 4). The lithology by percentage, based on one drill hole, is sandstone at $46 \%$, shale at $49 \%$, limestone at $0 \%$, claystone at $4 \%$ and coal above the mined bed at 4\%. The lithology beneath the Campbell Creek / No. 2 Gas Coal has more clay size units, with shale at $58 \%$, sandstone at $38 \%$, claystone at $2 \%$ and coal at $2 \%$.

The almost exclusively forested hillside is steep and the stream floodplain is narrow. West Fork, within the study reach and beyond, maintains a linear valley bottom. The valley sides that constitute the drainage area have a persistent orientation suggesting that the West Fork valley in this area may be structurally controlled. Structural controls on stream location may include structural dip and bedrock fractures.

West Fork flows across superimposed mined longwall panels between Stations 3 and 4. Longwall panels in both the Campbell Creek / No. 2 Gas Coal seam and the Eagle Coal seam lie beneath West Fork for approximately 2500 feet $(762.1 \mathrm{~m})$, beginning at 820 feet $(250.0 \mathrm{~m})$ downstream and ending to 3300 feet $(1006.1 \mathrm{~m})$ downstream.

Measuring Stations 1 and 2 are upstream of both mined longwall panels of the Campbell Creek / No. 2 Gas Coal and the Eagle Coal seam mines. These control stations are over sub-mains of both mines. Flow measurements between these two stations had low variability. The intermittent tributary streams that contribute flow to these control stations are mined under by longwall panels in Eagle Coal seam, and to a lesser extent, in the Campbell Creek / No. 2 Gas Coal seam. The stream flow recorded in the control reach may 
be impacted by mine subsidence in the headwater reaches, but consistent flow between stations in the control reach suggests the stream has an established baseline.

In the headwater reaches, longwall panels of the Harris No. 2 mine the in Campbell Creek / No. 2 Gas Coal seam mined under sixty percent of the drainage area. Tributary B, the southeastern intermittent tributary of West Fork, has less mining in the watershed than Tributary A. Tributary A enters West Fork from the southwest immediately above Station 1, where the measured reach begins. Fifty percent of the drainage area in Tributary A (TRIB A on Figure 15) has been longwall mined in the Campbell Creek / No. 2 Gas Coal seam. Longwall panels mined under only $30 \%$ of Tributary B, C, and D's drainage basin, and only $10 \%$ of the intermittent streams contributing flow to Tributary B. Mining of the Harris No. 2 Mine longwall panels in the Campbell Creek / No. 2 Gas continued from the 1970's to early 1990's. The longwall panel in the Campbell Creek / No. 2 Gas located beneath West Fork, and identified as panel 1, was mined between February and July 1990.

Panel 2, in the Eagle Coal seam, was mined by the Harris No. 1 Mine around October 2005. The Harris No. 1 longwall panels are both wider, longer, and more numerous, covering more area than longwall panels of the Harris No. 2 Mine in the Campbell Creek / No. 2 Gas Coal seam. For this reason, they may have a larger hydrologic impact on intermittent Tributaries B, C and D than the longwall panels of the Campbell Creek / No. 2 Gas Coal seam.

The Harris No. 1 mine in the Eagle seam has the only longwall panels between Station 9B and Station 10; the Campbell Creek / No. 2 Gas seam remains unmined in this reach. The West Fork flows across longwall panels in the Eagle Coal seam, and then over 
main headings near the downstream end of the study area. Near this location, a resurgence of stream flow was observed on May 3, 2006 (Appendix I, Table 13).

Upstream of the study area is the Kopperston No. 1 longwall mine in the Eagle Coal seam. This mine, now closed, was still active in 1995. The abandoned Kopperston No. 1 mine is reported to have a flooded mine pool elevation of 1450 feet $(442.0 \mathrm{~m})$. The elevation of this mine pool is approximately 37 feet $(11.2 \mathrm{~m})$ above the Kopperston No. 1 mine floor at its lowest point at the northwest corner of the mine.

\section{Methods of Investigation}

\section{Collection of Field Data}

\section{$\underline{\text { Stream Preparation }}$}

All streams are measured and staked, proceeding in the downstream direction. Therefore, increasing values indicate distance farther downstream. Negative values of distance indicate distances upstream from the initial starting point. Wooden stakes, 12 to 18 inches $(0.30$ to $0.45 \mathrm{~m})$ in length are driven into the stream bank every 100 feet $(30.5 \mathrm{~m})$. Downstream distances, recorded on the wooden stakes, mark distances and locations for future reference and maintain consistency between surveys. Plastic ribbon placed along the stream banks every 20 feet $(6.1 \mathrm{~m})$ documents increments between stakes.

Study streams were chosen to allow for a control reach to be contiguous to the study reach. The $24^{\circ}$ angle of draw (Peng, 2006) and the maximum angle of dewatering influence of $42^{\circ}$ (Tieman and Rauch, 1987) were utilized in deciding the proper amount of control reach. Two measuring stations outside of the maximum angle of draw and dewatering 
influence provide a minimum control reach baseline. Several of the study sites are near the headwater reaches of the stream, minimizing the length of stream that could be measured for control. Control stations were not place within intermittent stream reaches.

Geophysical surveys were conducted along the measured stream reaches. Data from the geophysical surveys were analyzed for anomalies. Stream measuring stations were established to quantify flow changes that could be associated with geophysical anomalies.

Three streams flowed over solid coal prior to flowing across the studied longwall panel. This setting will provide the most reliable base line survey data. However, not all streams had un-mined coal areas upstream of the study reaches. Two study stream control reaches flowed across room and pillar mined mains and sub-mains prior to flowing across study panels. Pillars of coal left in mains and sub-mains are typically large and designed to maintain the integrity of the opening. An assumption that subsidence would be minimal above these entries was made to provide a foundation by which to establish a control reach. One stream was mined quicker than stream surveys could be conducted and the control reach was completely mined under.

The length of stream monitored was chosen to provide a complete cross section of a longwall panel; including a control reach, a mined longwall panel and a downstream gateentry reach. The stream-surveying scheme provides the opportunity to establish a baseline for all surveys, identify possible near surface fractures, identify any stream sediment changes and quantify any stream flow changes in the study reach. This study provides data and interpretation on a short reach of stream. The scope of this study intends to characterize stream flow response to a particular longwall section, and hopes to be useful in explaining larger trends in stream flow changes over longwall mines. 


\section{$\underline{\text { Stream Flow Measurement Methods }}$}

Flow Meter Method

Stream discharge measurements are conducted using a cross-sectional area and average flow velocity method, as explained by Fetter (2001). The method is modeled after the U.S.G.S. method that involves use of a current meter for measuring stream flow velocity (Rantz, 1982).

To conduct a stream discharge measurement, a cross-section is first subdivided into vertical subsections by use of a measuring tape stretched across the stream. The subsection width and midpoint depth are measured to later calculate cross-sectional area of flow (Figure 16). Then each subsections average flow velocity is estimated by use of the current meter. The current meter, using the Six-Tenths Depth Method, is positioned at 0.6 tenths of the stream depth; as measured from the streams surface. The Six-Tenths Depth Method produces reliable average velocities for streams that have a depth less than 2.5 feet $(0.76 \mathrm{~m})$. Product of subsection velocity and area yield subsection discharge. Summation of all subsection discharge values yield total stream discharge (Rantz, 1982)

Stream discharge measuring stations are selected to meet the procedures for conventional current meter measurements outlined by Rantz (1982). Some of the criteria for selecting a measurement location include: 1) cross-section lying within a straight reach, and streamlines are parallel to each other, 2) velocities are greater than $0.5 \mathrm{feet} / \mathrm{s}$ and depths are greater than 0.5 feet, 3) Streambed is relatively uniform and free of numerous boulders and aquatic growth, 4) flow is relatively uniform and free of eddies, slack-water and excessive turbulence, and 5) measurement section is relatively close to the gaging-station control to avoid the effect of tributary inflow between the measurement section and control and to 
avoid the effect of storage between the measurement section and control during periods of rapidly changing stage.

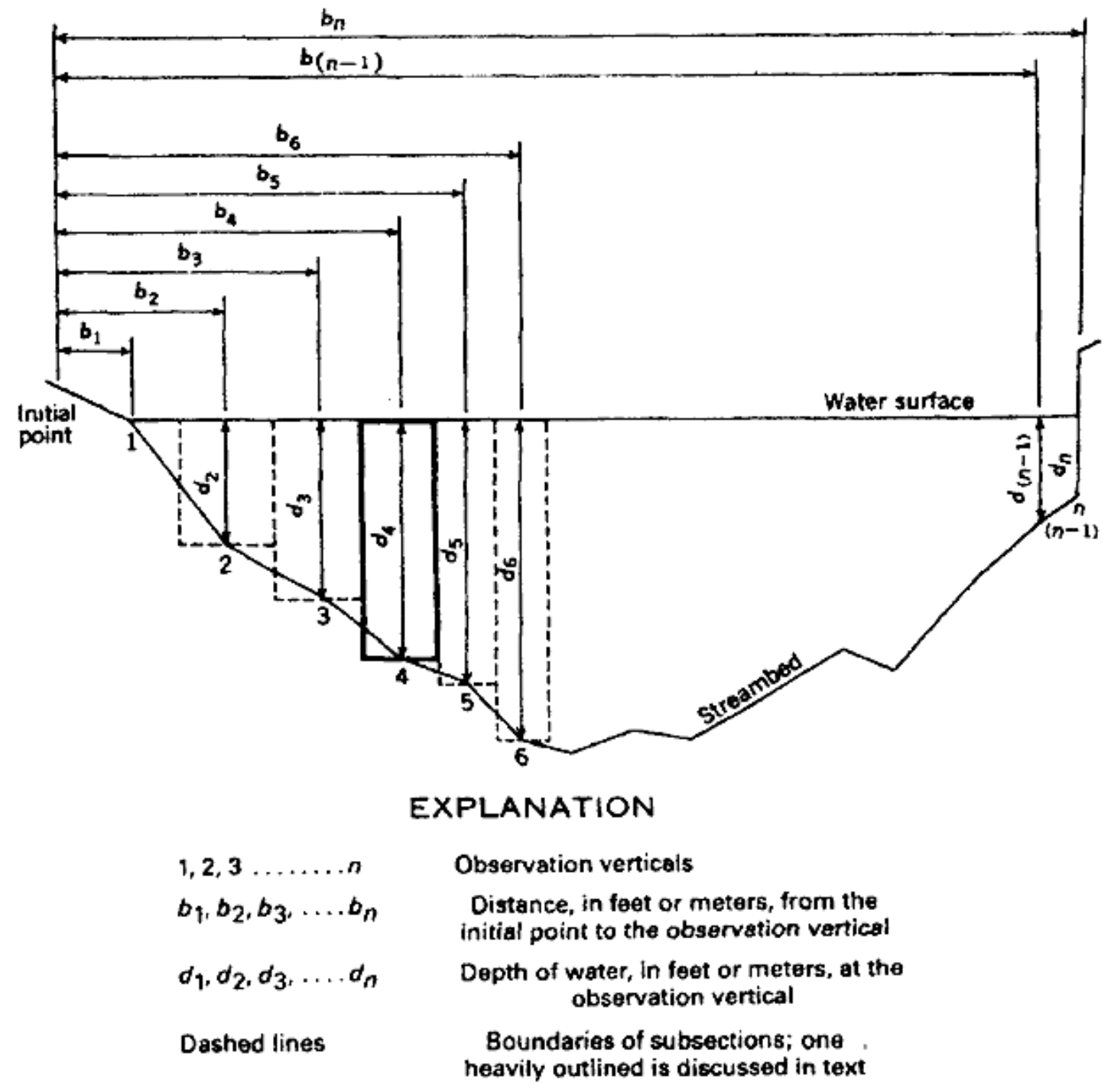

Figure 16. Stream flow cross-section methodology, taken from Rantz, 1982. 
The U.S.G.S. Guidance admits that it will often be impossible to meet all of these criteria and it is left to the hydrographer to exercise judgment in selecting the best sites for discharge measurements (Rantz, 1982). Some criteria, such as locating stream discharge stations near gaging-stations, is not an option. There were no U.S.G.S. stream gaging stations located on any of the creeks that are measured. Gaging-stations are located several miles downstream, or geographically closer but in different watersheds.

Early stream velocities are measured using a Marsh-McBirney Model \#201 analog meter, but most were collected using a Marsh-McBirney Model \#2000 digital meter that allowed for velocity averaging. The \#201 Model meter displayed velocities for at least 20 seconds prior to recording the displayed velocity. The velocity is recorded for the subsection of each stream cross section. The Marsh-McBirney Model \#201 meter was borrowed from Harold Miller of the Pennsylvania Department of Environmental Protection, Harrisburg, Pennsylvania. For the Marsh-McBirney Model \#2000, the velocity averaging standard was set for 10 seconds. This instrument was borrowed from Terry Ackman of the Department of Energy, National Energy Technology Laboratories in Pittsburgh, Pennsylvania.

Subsection depths for stream measurements are normally deeper than the criteria of $0.5 \mathrm{ft}(0.15 \mathrm{~m})$ deep, but occasionally stream measurements are taken at locations or at times when the stream depths were less than $0.5 \mathrm{ft}(0.15 \mathrm{~m})$ deep. This situation is minimized where possible, but the majority of the stream measurements have at least a few subsections that include these shallow stream measurements. Substantial sub-criteria depths are most often encountered during low baseflow conditions on a majority of the streams. The U.S.G.S. recommends that where streams have depths as shallow as 0.3 feet $(0.10 \mathrm{~m})$, the six-tenths method be used for measuring discharge (Rantz, 1982). Where the majority of the stream 
discharge is within subsections less than 0.5 feet $(0.15 \mathrm{~m})$ deep, the calculated discharge is considered only approximate, as there are no shallow-depth coefficients to rectify the calculated discharge for natural streams. Where the majority of the stream discharge is within subsections with less than 0.3 feet $(0.10 \mathrm{~m})$ deep, the surface velocity method is used to calculate the discharge. Low flow conditions are present within a wide channel where a Parshall Flume would be difficult to install.

The stream station total discharge, $\mathrm{Q}$, is the summation of the products of the stream subsection areas and their respective average velocities. The formula

$$
Q=\Sigma(a v) \quad(\text { Rantz, 1982) }
$$

represents the computation of $\mathrm{Q}$, where ' $a$ ' is the cross-sectional area of an individual subsection and ' $v$ ' is the average velocity for that subsection (Rantz, 1982). The flow meter measures the average velocity in the middle of the subsection, i.e. midsection. Each midsection is given a number for identification $1,2,3 \ldots . n$. The area of each subsection extends laterally from the midsection to half the distance to the preceding midsection, and then half the distance to the next midsection, and vertically from the water surface to the stream bottom, i.e. sounded depth. The sounding depth is the depth of water measured on the wading rod at the midsection. The subsection discharge is then computed for any subsection $x$ by use of the following equation.

$$
\begin{aligned}
& q_{x}=v_{x}\left\{\left(b_{x}-b_{(x-1)}\right) / 2+\left(b_{(x+1)}-b_{x}\right) / 2\right\} \\
& d_{x} \\
&=v_{x}\left\{b_{(x+1)}-b_{(x-1)} / 2\right\} d_{x} \quad(\text { Rantz, 1982) }
\end{aligned}
$$


Where as:

$$
\begin{aligned}
\mathrm{q}_{\mathrm{x}} & =\quad \text { discharge through subsection } \mathrm{x}, \\
\mathrm{v}_{\mathrm{x}} & =\text { mean velocity at vertical } \mathrm{x}, \\
\mathrm{b}_{\mathrm{x}} & =\text { distance from initial point to vertical } \mathrm{x}, \\
\mathrm{b}_{(\mathrm{x}-1)} & =\text { distance from initial point to preceeding vertical, } \\
\mathrm{b}_{(\mathrm{x}+1)} & =\text { distance from initial point to next vertical, and } \\
\mathrm{dx} & =\text { depth of water at vertical } \mathrm{x} .
\end{aligned}
$$

At the beginning of the cross section, where there are no preceding verticals, vertical 1 is considered the preceding vertical, instead of $b-1$, and the equation is as follows:

$$
q_{1}=v_{1}\left[b_{2}-b_{1} / 2\right] d_{1} \quad(\text { Rantz, 1982) }
$$

This equation is also applicable at the end of the cross section where $n$ and (n-1) would substitute for verticals 2 and 1 respectively (Rantz, 1982).

\section{$\underline{\text { Surface Velocity Method }}$}

The surface velocity method is employed to estimate stream discharge in instances where the majority of the station stream depth is less than 0.3 feet $(0.10 \mathrm{~m})$ deep. Using this method, a cross-sectional area of the stream is measured using a six-foot wooden ruler. The stream widths are divided into subsections across the measured cross-section. Floating objects are placed in the centers of these subsections and timed across the known distance several times to collect an average of the velocity within each cross-sectional subsection. 
The average velocity for each subsection is multiplied by the surface velocity coefficient of 0.85 to calculate the mean velocity. The corrected subsection velocities are then multiplied by the corresponding subsectional area to produce the discharge for each subsection. The summation of each subsection discharge provides an estimate of the discharge for the stream at the measuring station (Rantz, 1982). The same method and equation for calculating the cross-sectional area is used for the surface velocity method as was used for the six-tenths flow meter method.

The greatest distinction in this method is collecting the velocity. Similar to the

$$
Q=\Sigma\left(a v_{c}\right)
$$

where ' $a$ ' is the cross-sectional area of an individual subsection and ' $v_{c}$ ' is the average velocity for that subsection after being corrected by the surface velocity coefficient.

\section{Geophysical Survey Methods}

\section{Electromagnetic Geophysics Overview}

Terrain Conductivity (TC) and Very Low Frequency (VLF) are both Electromagnetic (EM) geophysical methods. These methods are sensitive to conductivity properties within the earth, including water filled fractures and metallic interference, i.e. buried metal. There are several factors that influence the response from an electromagnetic ground water survey over a stream reach without metallic interference. These factors are rock and soil porosity, moisture content, dissolved electrolyte content, temperature and phase state of pore water, and the amount and composition of colloids. 
Geophysical surveys are conducted down the middle of the stream, except where metallic objects, i.e. pipelines, metal junk, etc., were found on one side of the bank. If possible interference items were identified, the survey line would move towards the opposite side of the creek in order to decrease the interference impact on the readings. On occasion, it is necessary to conduct a portion of the geophysical survey on the stream bank, instead of within the stream channel. This is done when the depth of the stream becomes too great to safely walk the creeks with the geophysical equipment. The segments of geophysical surveys that are conducted on the stream bank record substantial lower conductivity values, for both the VD and HD components of the TC surveys. This change may be caused by an addition of unsaturated zone between the instrument and the saturated zone. In general, the saturated zone is closer to the instrument when the survey line is in the stream than when it is on the bank above the stream.

\section{Terrain Conductivity Survey Method}

$\mathrm{TC}$ is an induced electromagnetic survey that provides rapid estimates of apparent resistivity. Since a good conductor within a poorly conductive medium tends to be the focus of this investigation and has disproportionate effect on induction, the method of conductivity rather than resistivity is referenced. Conductivity is reported in millimhos per meter (mmhos $/ \mathrm{m})$, or Siemens per meter. Resistivity, the inverse of conductivity, is converted from mmhos/m into ohm-meters (ohm-m) by dividing the conductivity reading into 1000 (Milsom, 1996; EM-31 Instrument Manual, 1975). This study uses millimhos per meter for conductivity measurements. 


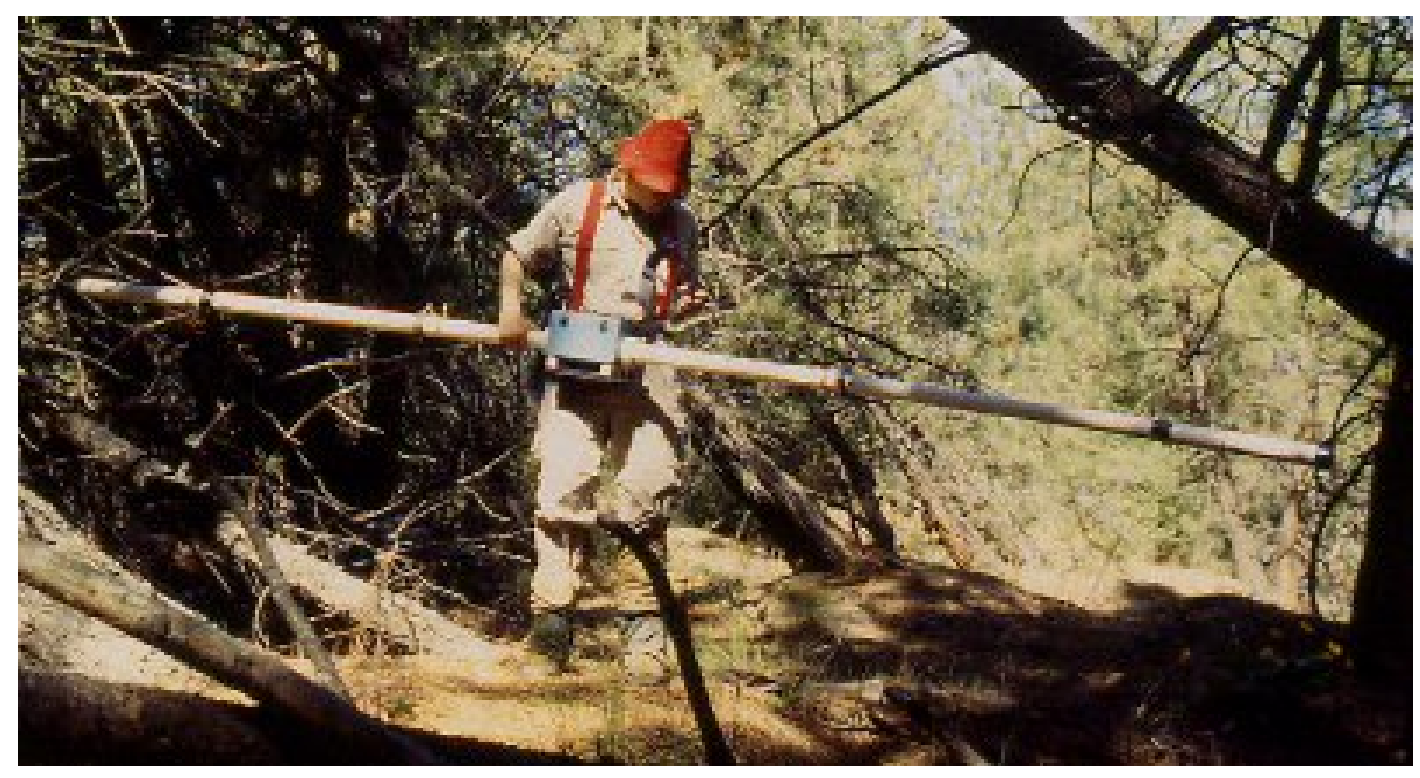

Figure 17. Example picture of Geonics EM-31 Terrain Conductivity meter.

TC measurements are conducted using the Geonics EM-31 instrument operating at $9.8 \mathrm{kHz}$ (Figure 17). This instrument was borrowed from Terry Ackman of the Department of Energy, National Energy Technology Laboratories in Pittsburgh, Pennsylvania. This unit has a 12 feet $(3.6 \mathrm{~m})$ inter-coil spacing, the length used to measure the depth of penetration, and a radius of investigation of about 10 feet $(3.0 \mathrm{~m})$. The EM-31 has a transmitter at one end of the instrument that induces circular eddy current loops in the earth. The premise is that the magnitude of any one of the current loops is directly proportional to the TC in the vicinity of that loop. Each current loop generates a magnetic field that is proportional to the value of the current flowing within that loop. The receiver coil intercepts a part of the magnetic field from each loop that results in an output voltage, which is linearly related to the apparent TC. (Geonics EM-31 Manual, 1975; Figure 18) 


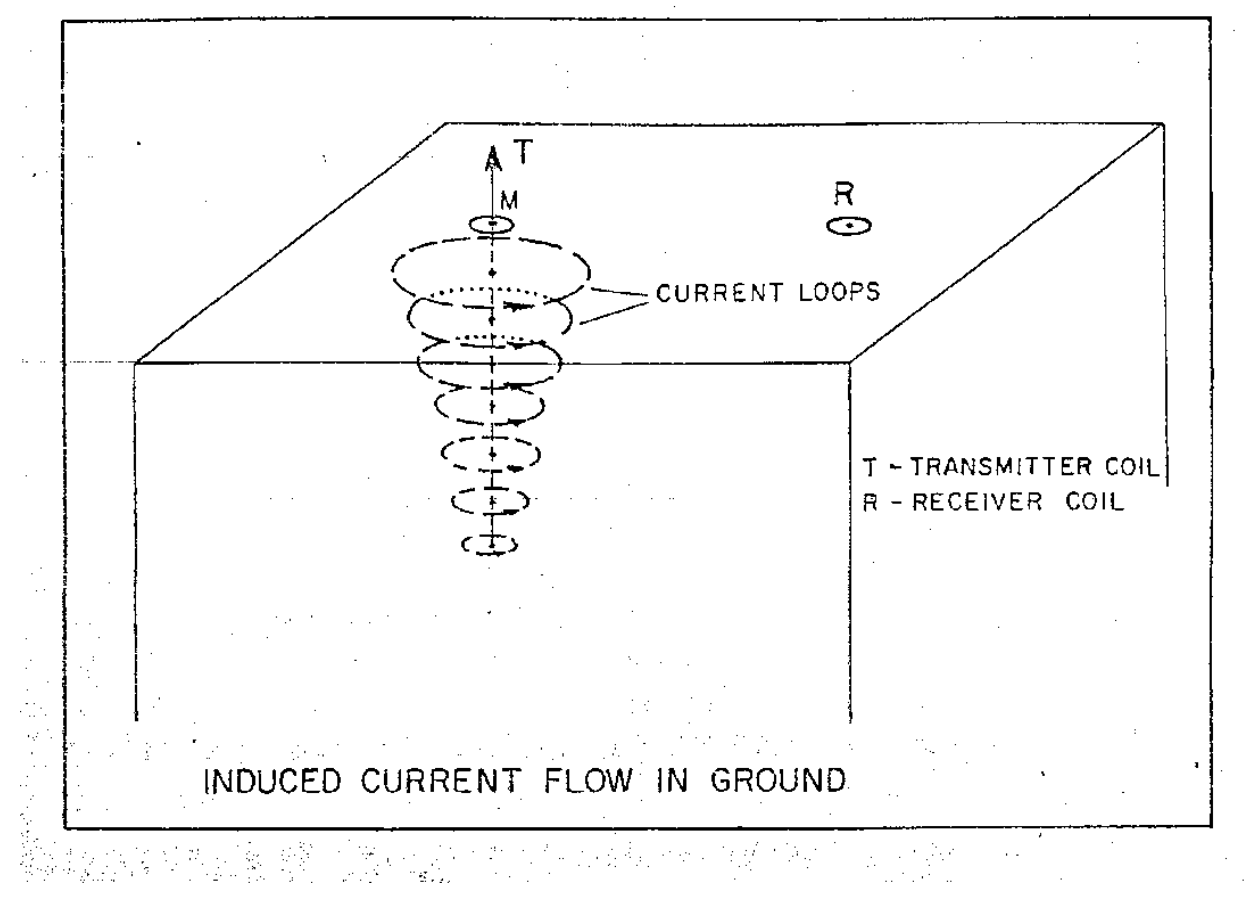

Figure 18. Schematic representing the principle used to collect apparent conductivity readings by the Geonics EM-31 Instrument (modified from Geonics EM-31 Manual, 1975).

The measuring depth of the EM-31 is controlled by inter-coil spacing, i.e. the distance between the transmitter and receiver. Although the EM-31 has a fixed inter-coil spacing, the penetration depth can be altered slightly by changing the dipole orientation. The dipole orientation refers to the axis of the coil within the instrument (Parasnis, 1986). When held upright, with the instrument panel facing upright, the instrument is in the vertical dipole (VD) position. In the vertical dipole position, the EM-31 penetrates to a depth of approximately 18 feet (5.5 meters), roughly 1.5 times the length of the inter-coil spacing. With the unit in the horizontal dipole (HD) position, where the instrument panel parallel to the horizontal plane, the instrument penetrates to a depth of approximately 9 feet (2.7 meters), roughly 0.75 times the length of the inter-coil spacing (Ackman and Barta, 2002). 
The VD and HD TC surveys consistently detected different values for each of the survey streams. The VD values were generally higher than their HD counterparts for a given sounding station. This difference is interpreted to be a function of the ionic strength of the ground water (Fetter, 2001). The TC survey, when sounding at these two different depths, will collect a higher apparent conductivity when encountering ground water with a higher ionic strength.

TC measurements were recorded at stations for each study stream, following the preparation of the stream by measuring and staking/flagging the station distances. The distance between consecutive geophysical stations was chosen to be 10 feet $(0.30 \mathrm{~m})$. This distance provides for a thorough representation of the streams subsurface, and will most likely detect any fracturing present beneath the stream. The diameter of investigation by the EM-31 is approximately 10 feet $(0.30 \mathrm{~m})$, providing complete coverage of the subsurface. The orientation of the TC unit does not affect the reading at any particular location, except when that location happens to be over a buried metal pipe (Geonics EM-31 Manual, 1975)

The TC survey is included in the study to supplement the VLF survey and provide data for the shallow subsurface. The TC instrument penetrates into the upper half of the 'soil zone', the uppermost subsidence zone delineated by mine subsidence theory (Peng, 2006). EM-31 Terrain Conductivity surveying has the potential to delineate fractures in strata between stream sediment and the VLF sounding depth.

\section{Very Low Frequency Survey Method}

VLF refers to the frequency band of radio waves that are used by this survey to conduct subsurface exploration. These radio waves are emitted from oscillating electric 
dipole transmitters scattered around the world that use the VLF bandwidth for purposes of military communications. The VLF bandwidth consists of the range of frequencies between 15 and $25 \mathrm{kHz}$ (Parasnis, 1986). This bandwidth allows the waves to be detected several hundred miles (kilometers) away from the source. The closest VLF transmitter to the study sites is in Cutler, Maine, station code NAA. This station is operating at a current frequency of $24.0 \mathrm{kHz}$ and 1 MW (mega-watt) of power (Milsom, 1996; Figure 19). This station has a range of $5600 \mathrm{~km}$ (ABEM Interpretation Guide, 1987).

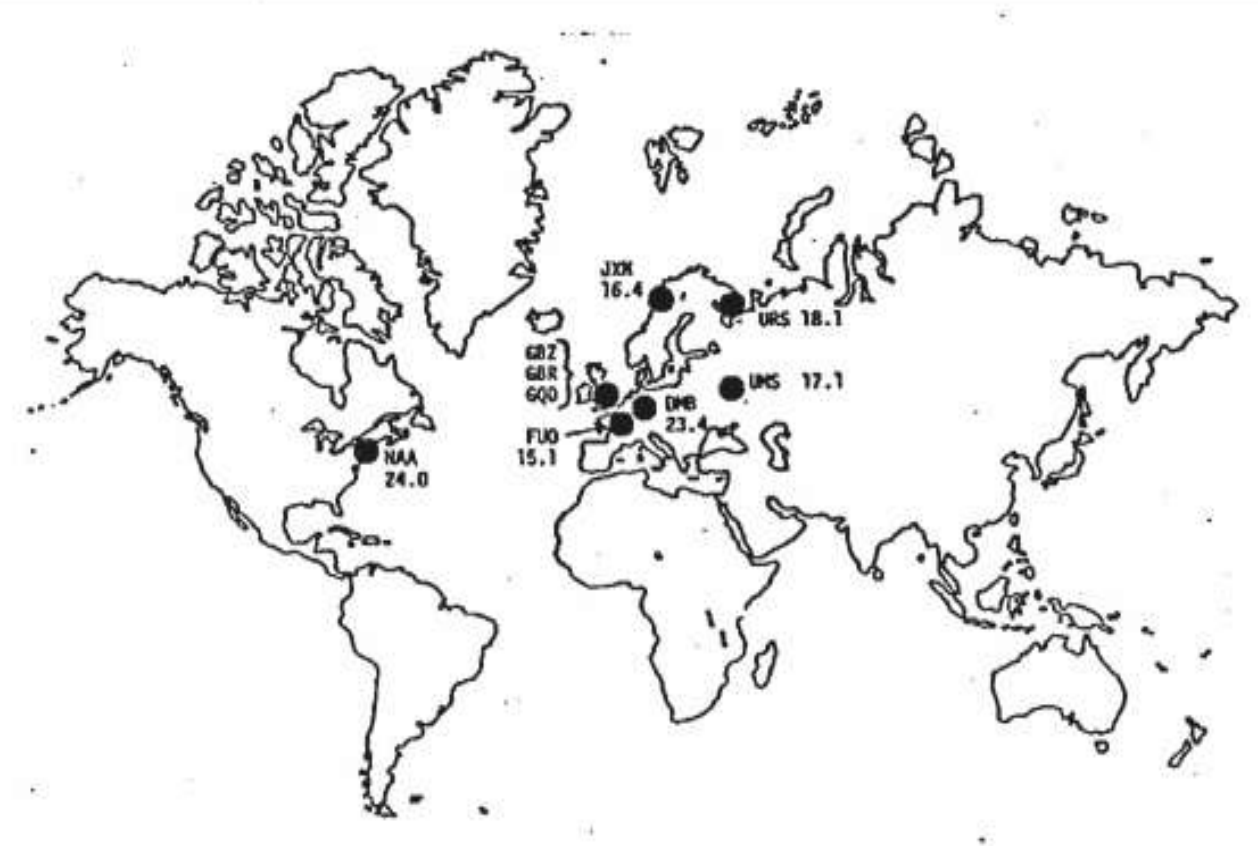

Figure 19. Sites of some of the most important Very Low Frequency (VLF) transmitters throughout the world. The station code and frequency are beside the indicator circle (ABEM Interpretation Guide, 1987)

The ABEM WADI VLF instrument is used in all of the VLF surveys over the study streams (Figure 20). This instrument was borrowed from Terry Ackman of the Department of Energy, National Energy Technology Laboratories in Pittsburgh, Pennsylvania. All of the 
surveys start at stream measurement point 000, and progress downstream. VLF readings are recorded every 10 feet $(3.0 \mathrm{~m})$, corresponding to the same frequency of readings taken using the Geonics EM-31 meter during the TC survey.

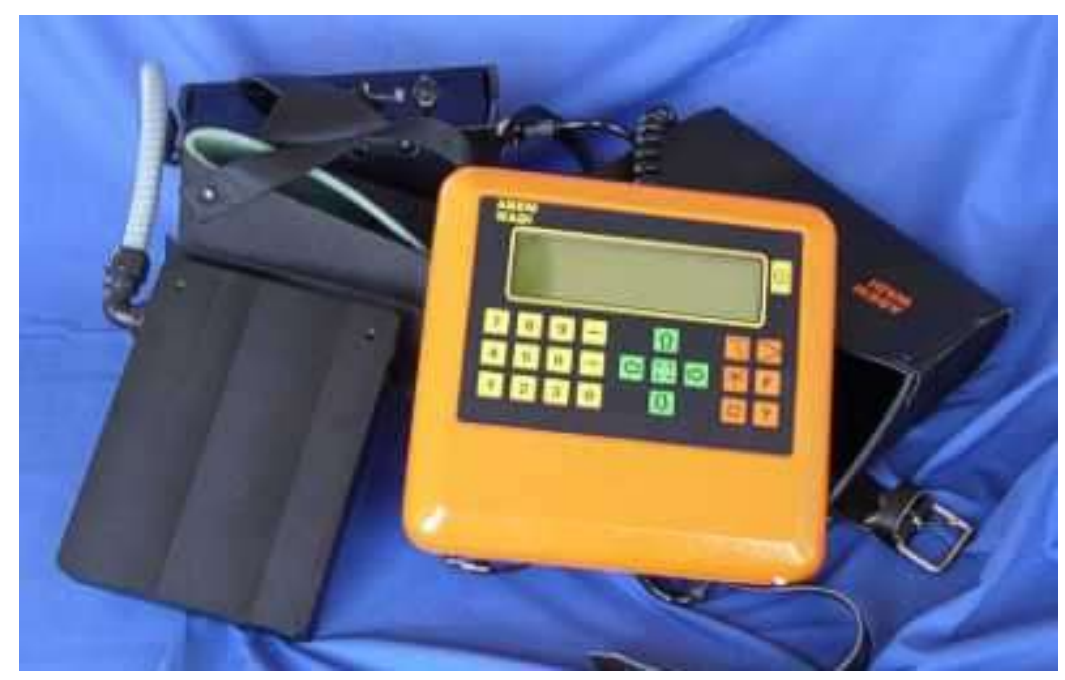

Figure 20. Picture of ABEM-Wadi VLF Instrument, similar to the one used to collect middepth electromagnetic anomalies along stream profiles.

For application purposes, the combination of dipole waves emitted from the VLF transmitter at large distances is considered to be uniform within a small area. The incident magnetic field from the transmitter has only the horizontal component with no vertical magnetic field (Parasnis, 1986). Conductive bodies induce eddy currents by the primary (horizontal) magnetic field producing a secondary magnetic field that opposes the primary magnetic field change. This creates a vertical component of the secondary primary field that has a relationship to the location and orientation of the conductive body. The VLF instrument records the ratio, or tangent, of the vertical secondary field to the primary horizontal field (Milsom, 1996; Figure 21). 


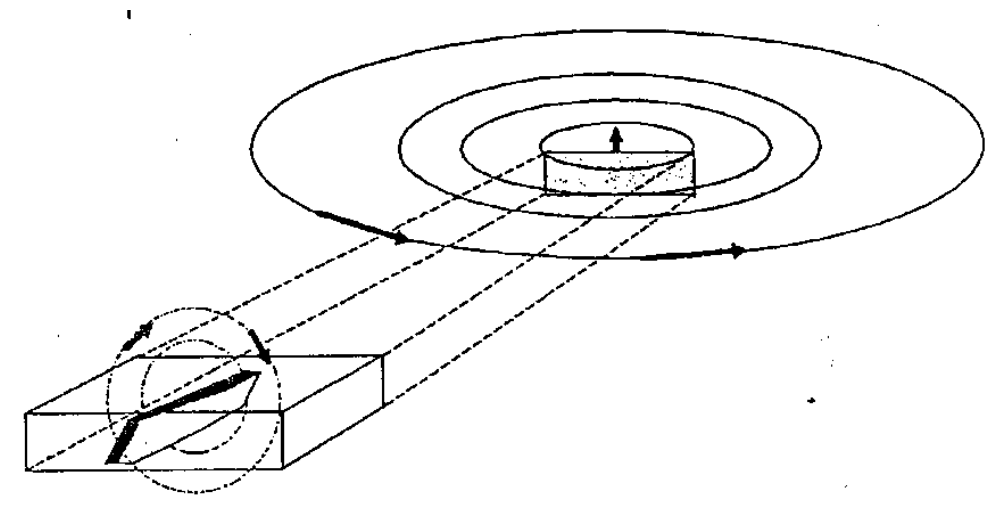

Figure 21. Schematic diagram of the VLF principle. Object in upper right is the transmitter (ex. NAA at Cutler, Maine). The circular rings around the transmitter represent the emitted primary horizontal magnetic field. The object in lower left is a thin near vertical sheet-like conductor located within a poorly conductive rectangular medium, striking in the general direction of the transmitter (dashed lines connecting the two objects). The secondary vertical magnetic field, induced from the primary, is shown around the thin conductive body with arrows showing direction of current flow (ABEM Interpretation Guide, 1987).

A graph plot of the ratio data will produce an asymmetrical wave across an anomaly (Figure 22). When raw data are graphed across an anomaly, the secondary magnetic field is at its greatest value, or near vertical when the graph plot peaks (Milsom, 1996). As the vertical to horizontal ratio decreases, the plotted data declines towards zero, because directly over the anomaly there will be no vertical component to the secondary magnetic field. This is caused by parallel horizontal secondary and primary magnetic field vectors, creating a net zero ratio. The wave plot continues as the negative part of the wave due to sign convention (Milsom, 1996).

In starting a VLF survey, the initial step is to find a VLF transmitter from your study area. This is achieved by scanning the available frequency strengths at different orientations. This prompts the instrument to recommend the strongest signal found. The signal strength 
must be between 10 and 50 units in order to conduct a reliable survey (ABEM Instrument Manual, 1987). Once a signal is chosen the operator slowly rotates 90 degrees, watching the signal strength, and stopping when the signal is the strongest. The orientation that the operator is facing, called the reference orientation, is recorded using a compass. In this study, the VLF surveys proceed along a line down the middle of the creek, unless obstructed, at the reference orientation with readings conducted every 10 feet.

The ABEM WADI is a unit worn around the waist, with the antenna unit on the right side of the belt. The antenna best detects a transmitter when facing its direction, and will reliably detect anomalies when the anomaly structure is oriented within 20 degrees of the maximum signal strength of the transmitter (ABEM Instrument Manual, 1987). This orientation causes the operator to stand and face an orientation of 90 degrees to the maximum signal strength. The lack of alternative transmitter sources strong enough for surveying has limited the investigative versatility of this method to identifying 'sheet like' anomalies oriented within $+/-20$ degrees of the maximum signal strength orientation of the Cutler, Maine transmitter. Conductive structures are best detected when the strike length of the conductor exceeds 164 feet $(50.0 \mathrm{~m})$ and is deeper than 33 feet $(10.0 \mathrm{~m})$; however, the conductor need only be 1.6 to 3 feet $(0.5$ to $1 \mathrm{~m})$ thick (ABEM Instrument Manual, 1987). Natural bedrock fractures and mine subsidence fractures have been identified using this method (Powers etal, 1999; Hutchinson and Barta, 2002) 


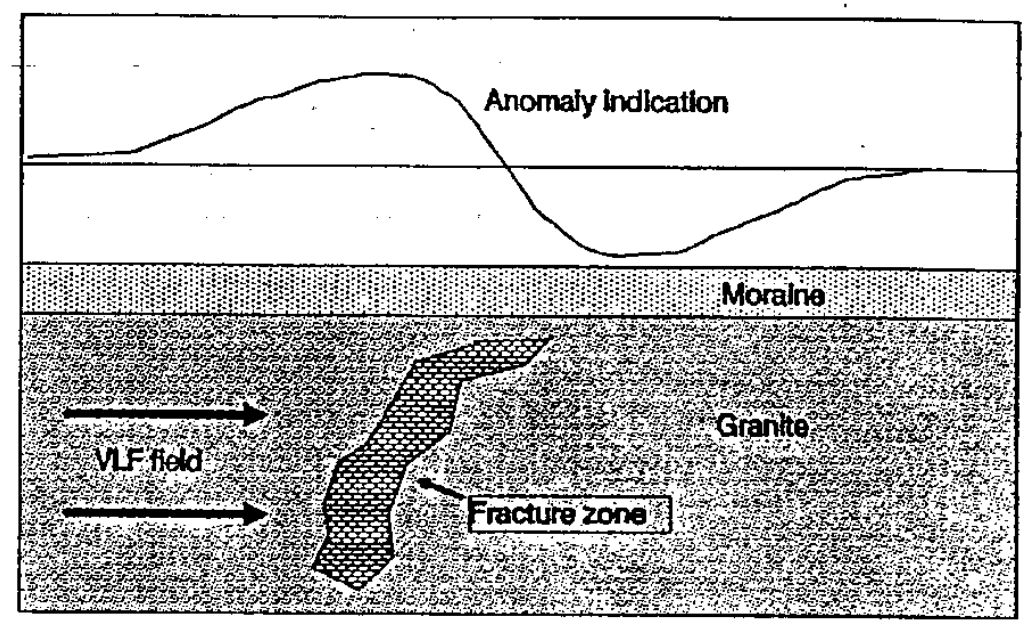

Figure 22. Anomaly indication of raw VLF data over a conductive fracture zone within a medium with high resistivity. Anomaly indication crosses zero (the horizontal line) over the location of the anomaly because the primary and secondary fields have the same horizontal orientation (ABEM Interpretation Guide, 1987).

Often the data from VLF surveys are noisy. The Karous-Hjelt (K-H) Filter is used in closely spaced VLF readings, and is applied to the raw data for each study stream in order to facilitate anomaly identification (Figure 23). The filtered data use equally spaced readings on either side of the filtered coordinate producing symmetrical plots with peaks over the center of the anomalies. The plotted filtered data is easier to compare against TC data, resulting in easier interpretations of subsurface anomalies. Filters can degrade the data, however, by destroying small but significant anomalies and distorting anomalies other than thin conductive sheets (Milsom, 1996). For graphical ease of comparison, the filtered data is used most often in presentation and interpretation. 
The K-H Filter equation is:

$$
D=0.102 A-0.059 B+0.561 C-0.561 E+0.059 F-0.102 G
$$

(Milsom, 1996)

where the recorded data is in alphabetical order, i.e. D follows $\mathrm{C}$ in order of being measured, which follows B and A.

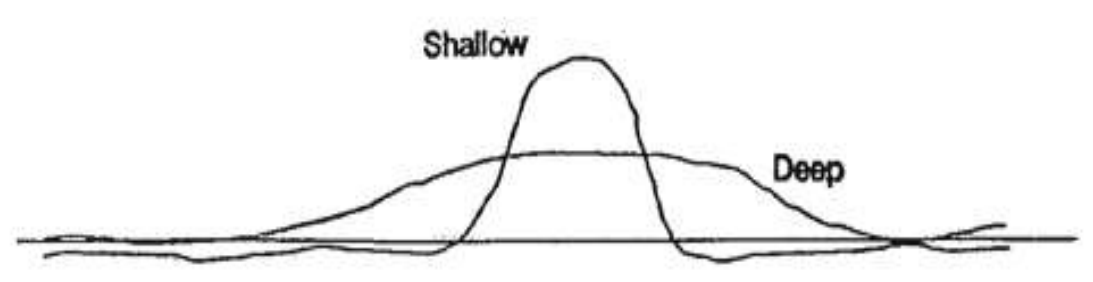

Figure 23. Anomaly indication of filtered VLF data over a conductive fracture zone. The filtered anomaly indication peaks over the location of the fracture zone. The steepness of the peak assists in determining the relative depth of the fracture zone. The steeper the peak, the shallower to the surface the fracture zone penetrates. ABEM-WADI Manual 1987.

The ground penetration depth of the VLF instrument, sometimes referred to as the skin depth, is the depth to which the VLF instrument can investigate. Below this depth, the electromagnetic wave from the transmitter has lost too much energy to create any induction. The penetration depth, calculated in meters, is defined as:

$$
\delta=503.3(\rho / f)^{1 / 2} \quad \text { (Parasnis, 1986) }
$$


where $\rho$ is the resistivity in Ohm-m and $\mathrm{f}$ is the frequency in $\mathrm{Hz}$ (ABEM Instrument Manual, 1987). The study areas do not have site specific resistivity studies to determine a good apparent resistivity value. However, the geology in the study area consists of alternating layers of rock typically falling between the resistivity ranges of $6 \times 10^{1}$ to $6 \times 10^{2} \mathrm{ohm}-\mathrm{m}$. With this assumption, the depth of penetration would range between 82 and 262 feet ( 25 and $80 \mathrm{~m})$ (Geonics EM-31 Manual, 1975). These depths are consistent with calculated depths using TC data and with findings in published reports of conducted studies using the VLF method (Hutchinson and Barta, 2002).

Conductive bodies that are not a part of the natural environment can create interference in a VLF electromagnetic survey. Interferences encountered were usually long conductive bodies oriented roughly toward the VLF transmitter. Common occurrences of interference include overhead electrical lines, buried pipes and metal culverts (Parasnis, 1986). Metallic debris, such as washers and dryers, interfere more with the TC surveying than the VLF surveying because of their local non-linear nature. Interference is identifiable on the survey with a great 'shadow' extending from the center of the body up to two hundred feet in both directions. This 'shadow' completely corrupts an accurate reading of the subsurface and makes data within the 'shadow' completely useless.

\section{$\underline{\text { Stream Alluvium Sampling Methods }}$}

\section{Alluvium Sediment Thickness}

The stream alluvial thickness survey method followed the practices of Reed (1998) in the study of Spruce Laurel Fork in Boone County, West Virginia. A three-quarter inch 
diameter metal rebar rod, 5 feet long with a chisel tip was driven into the stream alluvium to refusal, using a three-pound sledgehammer in an attempt to measure alluvium thickness. Three soundings were taken at each stream measuring station, and the average of the soundings was used for graphical presentations. This average is used to represent the alluvial thickness at the station at the time of the sounding.

This method is not without its limitations and errors. Errors occur when large particles restrict penetration depth; when sub-cropping clay units allow for easy penetration through alluvium and into the rock unit below; when depths greater than the rebar length are encountered; and when high baseflow conditions detract from the ability to use the full length of the rebar rod due to water height above the stream bed. Despite these drawbacks, this method of survey is conducted quickly and uses very little equipment. The data is easily processed and is reliable under favorable conditions.

The study streams are classified using Montgomery and Buffington's (1998) classification. They are classified at the valley segment level as alluvial valleys. They are characterized at the reach level as bedrock and free-formed alluvial reaches, with some streams having more than one classification within the study reach of each stream. The only bedrock reach stream encountered is classified as bedrock at the reach level and not at the valley segment level because of the presence of alluvium above and below the study reach. The bedrock reach study stream does not conform to the typical description presented by Montgomery and Buffington (1998) in which the stream is typically confined by valley walls and lacks floodplains. The bedrock reach stream does have a large floodplain and is not confined by valley walls. The stream fits a later exemption describing bedrock reaches in 
low-gradient portions of a watershed that reflect a high transport capacity relative to sediment supply.

The streams are also characterized by the historical method of stream ordering. The majority of the study streams are first or second order streams (Montgomery and Buffington, 1998). There is one stream that becomes third order immediately upstream of the survey reach.

\section{$\underline{\text { Alluvium Particle Size Distribution }}$}

The alluvium sampling and particle size distribution analysis procedures generally followed those outlined in Bunte and Abt (2001). Enough time was not available to conduct particle analysis on every stream measuring station included in this study; therefore, representative sample stations for stream reaches are analyzed in order to help identify potential factors affecting stream flow. Three sediment samples per stream was the goal for the study. One sample was typically in the stream control reach and two samples were located in the reach over the mined panel.

Eight different sizes of gravel were segregated and weighed; the larger gravel fractions were counted. The sieve sizes chosen to use in this survey are $64 \mathrm{~mm} 32 \mathrm{~mm}, 22$ $\mathrm{mm}, 16 \mathrm{~mm}, 8 \mathrm{~mm} 4 \mathrm{~mm}, 2 \mathrm{~mm}$ and $<2 \mathrm{~mm}$. A template split the particles larger than 22 mm. The particles smaller than $22 \mathrm{~mm}$ were sorted using a sieve stack. The study focuses on analyzing the gravel particle sizes and lumps every thing that is classified as sand and smaller into the $<2 \mathrm{~mm}$ sieve size.

A spade shovel, 'bottomless bucket' and 5 gallon bucket lined with a garbage bag were used to collect the samples. The 'bottomless' bucket is designed to allow for stream 
sediment sampling within a restricted flow environment, which allows the sampler to retain more of the finer particles instead of them being washed away, creating a bias in the sample. A plastic kitchen trashcan with an 8 inch $\times 12$ inch $(0.20 \times 0.30 \mathrm{~m})$ base is used as the 'bottomless' bucket. The bucket is pushed into the alluvium at the sampling station, and then the spade shovel digs out the alluvium and places it into the five gallon bucket with the plastic liner. The bucket is continually pushed down as the spade shovel excavates the subarmor sediment (Knighton, 1998). The typical depth of the excavated hole is about 12 inches $(0.30 \mathrm{~m})$, which is the length of the long axis of the bottomless bucket used for sampling. When the five gallon bucket is filled, it is then taken to an area where it could sampled. The plastic bags that the samples are collected into were opened and the sampled alluvium spread out to dry. The alluvium is placed on the plastic in order to prevent the finer particles from being lost.

Each sample is sifted through by hand to pick out the larger diameter particles. The particles that would not pass through the $64 \mathrm{~mm}$ template are gathered together, counted and weighed. This procedure repeats for the samples that did not pass the 32 and $22 \mathrm{~mm}$ templates as well. The remaining alluvial sample is sieved using the sieve stack. The sieves are stacked upon one another from largest diameter sieve $(16 \mathrm{~mm})$ to the smallest $(2 \mathrm{~mm})$. Then the pan is on the bottom to collect the sand, silt and clay size particles. Three or four spade shovel scoops of the alluvium is placed on the top sieve. The stack is then gently but briskly rocked back and forth on the bucket. The particles settl onto the appropriate sieve screen. The sieves are taken apart one by one and weighed on the scale. The weight is recorded for each sieve with particles on the screen. The particles collected on the $16 \mathrm{~mm}$ screen were also counted. Additional rocking is conducted as deemed necessary during the 
removal of the overlying sieves from the stack until the sample appeared to be accurately segregated. This procedure repeats for the entire sample.

The sediment collected on the screens is weighed. The recorded weight reflects the sieve weight plus the sample weight. Each recorded weight is corrected to true sediment weight by subtracting the weight of each sieve, which is measured before sampling begins.

Measuring stations are located in an attempt to meet the requirements of the flow survey, geophysical survey and sediment survey. Stream measuring stations are located after geophysical surveys are completed in order to place stations in locations that would best evaluate anomalies. These stations also have to be located in areas that provided accurate flow measurements, i.e. greater than six inches of water. These requirements restrict the location possibilities for measuring stations resulting in an inconsistency in pool/riffle conditions at stations. The inconsistency between pool and riffle measuring stations may induce error into calculated discharge measurements.

\section{$\underline{\text { Stream Flow Data Analysis }}$}

\section{Timing of Stream Flow Measurements}

Stream flow measurements are at baseflow conditions. Baseflow is the condition where stream flow is comprised of only ground water discharging to the stream (Fetter, 2001). Baseflow conditions are desirable to better characterize stream dynamic equilibrium conditions. Also, interpretations comparing high baseflow to low baseflow will be more accurate. 
The following formula is used to provide the time period after a storm event that must elapse before baseflow conditions are present. The area of the downstream measuring station was chosen to calculate the wait time.

$$
D=A^{0.2}
$$

where $\mathrm{D}$ is the number of days between storm peak and the end of overland flow, i.e. wait time, and $\mathrm{A}$ is the drainage basin in square miles.

Precipitation events were monitored using the internet to review rainfall amounts and times. The Advanced Flood Warning System web site, at www.afws.net, is system of stream gauges and rainfall gauges compiled as a cooperative effort and managed by the IFLOWS Program of the National Weather Service. This resource was routinely checked prior to scheduled fieldwork to determine the end of a storm event and predict the magnitude of stream flow response. The radar features at the National Oceanic and Atmospheric Administration website, www.noaa.nws.gov, were frequently reviewed to predict the intensity and duration of a storm event. The WaterWatch page of the United States Geological Survey website, www.water.usgs.gov/waterwatch/, was also reviewed on occasion to assist in predicting the stream level in the study regions. There are no stream gages, however, on the study streams in the study areas. Water levels in neighboring drainage basins are used to infer discharge levels in study streams.

High baseflow measurements were collected in the winter when the evapotranspiration rate is at its lowest and ground water recharge rates are high. These conditions result in surplus ground water that in turn causes higher water tables. Higher 
water tables then increase the ground water recharge rates to streams (Fetter, 2001). As ground water surpluses increase for a drainage basin, more ground water discharges into the streams increasing the discharge area ratio. Low baseflow measurements were collected in late spring and summer when ground water surplus levels are lower, resulting in lower discharge area ratios.

\section{Time Corrections for Stream Flow Measurements (aQ)}

Without recharge, streams constantly decrease in discharge as ground water, springs and tributary streams dewater the hillsides. The recession curve (Figure 24) demonstrates the stream level over time; before, during and after a storm event. The recession curve demonstrates a response to a storm event by a dramatic increase in stream discharge following a storm. The stream discharge then peaks and recedes rapidly to baseflow conditions. The basin factors influencing this recession are the topography, drainage pattern, soils and geology (Fetter, 2001).

Stream discharges decline during baseflow conditions at a certain rate. This decline increases discharge measurement error if the data is not corrected for time. For example, a stream measured over the course of a full day will have a lower stream flow measurement at a certain station in the evening than the station would have in the morning. The discharge decrease is quantified by measuring a single station at two separate times. The difference in discharge is distributed to all of the measuring stations, by weighted means, correcting the measured data and reducing data errors (Fetter, 2001). 

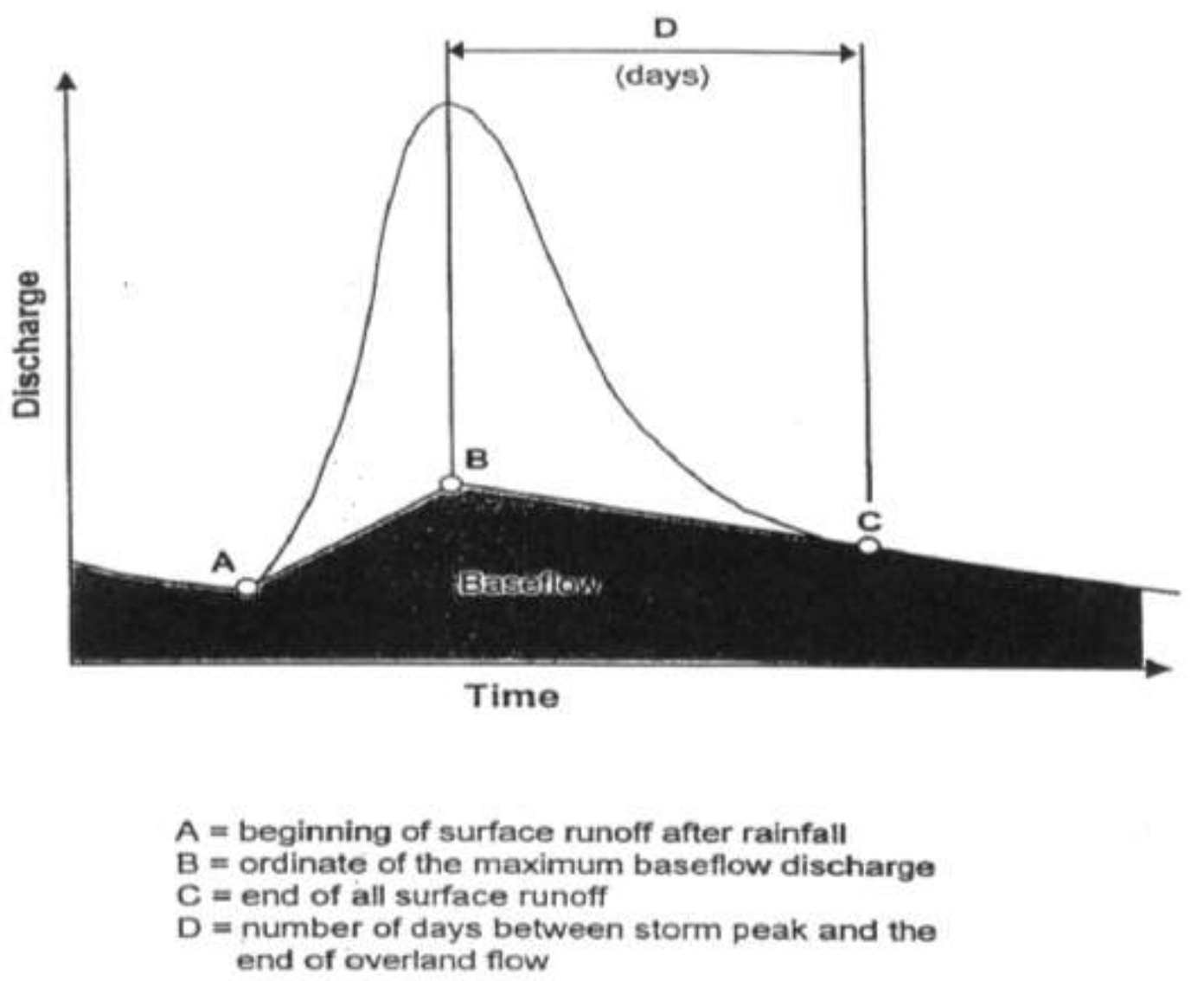

Figure 24. Recession curve hydrograph, taken from Fetter 2001.

The recession constant applies to stream flow measurements collected during a measurement event, adjusting each calculated discharge as if they were all collected at the same time. The equation for determining the baseflow recession constant is as follows:

$$
\mathrm{Q}_{\mathrm{t}}=\mathrm{Q}_{\mathrm{o}} \mathrm{e}^{-\mathrm{at}} \quad(\text { Fetter, 2001) }
$$

Whereas, $Q_{0}$ is the initial stream flow discharge, $t$ is some time after measurement of the initial stream flow, $\mathrm{Q}_{\mathrm{t}}$ is the discharge at time $\mathrm{t}$, and $\mathrm{a}$ is the recession constant for the basin. 
To acquire a recession constant for each measuring of each study stream, Formula 10 was rewritten as follows:

$$
\mathrm{a}=-\left(1 / \mathrm{t} \ln \mathrm{Q}_{\mathrm{t}} / \mathrm{Q}_{\mathrm{o}}\right) \quad(\text { Fetter, 2001) }
$$

Where, $\mathrm{Q}_{\mathrm{o}}$ was the flow for Station 1 recorded in the morning, and $\mathrm{Q}_{\mathrm{t}}$ was the flow for Station 1 in the evening, and $\mathrm{t}$ was the time, in minutes, between the two measurements.

Once a recession constant is calculated for each stream measuring event, the constant is applied in the original time corrected stream discharge formula (Equation 8), to provide for the time adjusted stream discharge data that is presented in tables and graphs. The data are typically adjusted to the morning flow time of Station 1, which provided for positive additions to subsequent stream flow data.

\section{Discharge to Area Ratio Calculation (aQdr)}

Time-adjusted discharge is divided by drainage area to create a stream discharge ratio, or normalized discharge, for each measured discharge. For reference, a stream discharge ratio in an undisrupted drainage basin with uniform geology and topography, should theoretically remain constant throughout the basin. Discharge area ratios are useful in reviewing inter-station stream flow impacts, as well as cumulative impacts.

$\mathrm{aQdr}(\mathrm{gpm} / \mathrm{ac})=\mathrm{Q} /$ cumulative drainage basin $\quad$ (Gill, 2000) 


\section{Net Discharge Ratio Change (Net aQdr)}

The net discharge ratio change is the comparison of contiguous basins in the downstream direction. For example: the discharge ratio of Station 2 is subtracted from the discharge ratio of Station 1 to better identify the basins with the greatest amount of change. Since stream flow measurements have an inherent $10 \%$ margin of error, this calculation helps identify basins that demonstrate a statistically significant change. The sign remains for easy identification of whether the net change is a net flow increase or a net flow loss.

\section{$\underline{\text { Stream Discharge Change per } 100 \text { Linear Feet of Stream }}$}

In order to quantify the change in stream discharge within a certain reach, the net stream discharge change-per-basin was divided by the length of stream between the same two stations. This value was then multiplied by 100 to produce a value of stream discharge change per 100 feet of stream. Net stream discharge should display slightly to moderately positive values as the stream gains drainage area and should increase in discharge going downstream. This column quantifies a stream reaches gain or loss between measuring stations. 


\section{$\underline{\text { Results and Discussion }}$}

Eastern Ohio Region

\section{Crabapple Creek, Ohio}

\section{Results and Discussion of Data}

\section{$\underline{\text { Stream Flow Measurements }}$}

High, low and extremely low baseflow stream measurements were conducted on Crabapple Creek, OH. Extremely low baseflow measurements were measured first, then high baseflow and then finally low baseflow (Appendix V, Table 1).

\section{Extremely Low Baseflow}

Extremely low baseflow conditions were present during the majority of the summer months of 2005. Earlier in the spring of 2005, geophysical surveys were conducted on Crabapple Creek, allowing the author to witness the gradual decline of the stream discharge over the first half of the year due to what appeared to be natural circumstances. By June, very little water was flowing in Crabapple Creek. On June 26, 2005, stream flow measurements were conducted because it appeared that the stream would go dry because of the drought conditions.

Since extremely low flows were so shallow that a flow meter could not produce accurate values and the channel was too wide to allow for the use of a Parshall Flume or weir, flows were obtained by the surface velocity method. The important data from this measuring event is the location of insurgent and resurgent points, as well as the relative insurgent discharge rate compared to the resurgent discharge rate. 


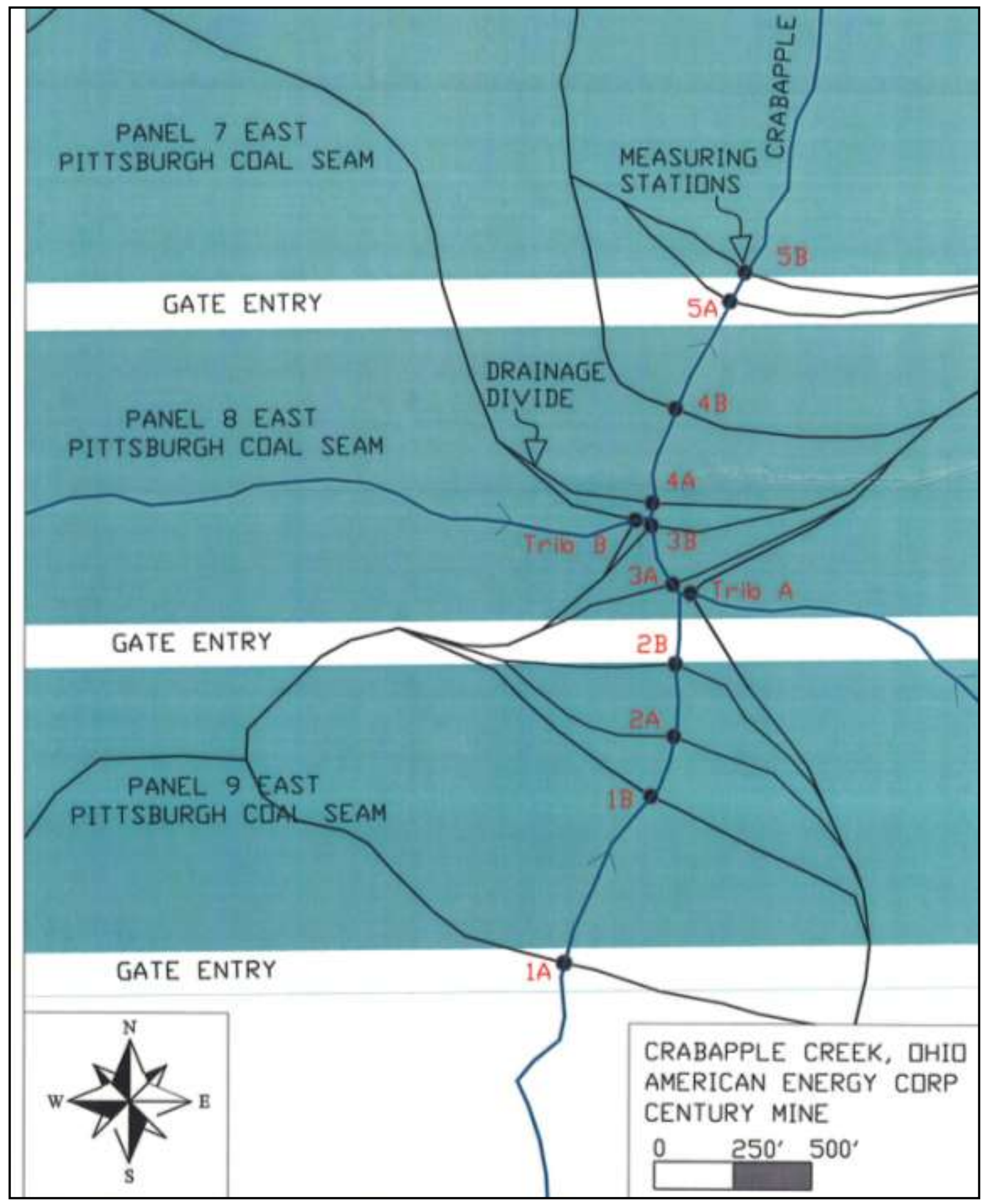

Figure 25. Station Location Map of Crabapple Creek, Ohio showing the stream, stream measuring stations, mined longwall panels and drainage divides for a portion of the American Energy Company's Century Mine in the Pittsburgh Coal seam, Belmont and Monroe Counties, Ohio. The location of longwall panel 9 East is shown. Panel 9 East was mined in August, 2005, after the extremely low baseflow measurements of June, 2005 were completed. Only longwall panels 6, 7 and 8 East were mined prior to the June, 2005 stream flow sampling. 
Stream discharge increases gradually between Station $1 \mathrm{~A}$ and $1 \mathrm{~B}$, then continued to flow from Station 1B to Station 2B over an unmined reach of stream (Figure 25). This reach will later be longwall mined by panel 9 East, but not until August, 2005 (Appendix V, Table 2). At Station $2 \mathrm{~B}$, approximately 150 feet $(45.7 \mathrm{~m})$ upstream of the upstream edge of the mined longwall panel 8 East, the stream stopped flowing and then went dry. The stream was dry from this point down to the intersection with Tributary B at 1070 feet (326.2 m) (Figure 26).

Shallow geophysical measurements conducted with the EM-31 meter demonstrate that a conductive zone was present at 590 feet $(179.8 \mathrm{~m})$ downstream prior to the extremely low flow measurements of June 26, 2005. Longwall panel 8 East mined under Crabapple Creek in February 2005, and original geophysical surveys were conducted in May 2005. The projected upstream extent of the 24 degrees angle of draw is approximately 130 feet $(39.6 \mathrm{~m})$. This projects the edge of the subsidence basin at around 600 feet $(182.9 \mathrm{~m})$ on the measured stream reach, nearly the same location as the insurgent point at high and extremely low flows. Crabapple Creek was dry from 590 feet $(179.8 \mathrm{~m})$ downstream to Tributary B, at 1070 feet $(326.2 \mathrm{~m})$. At that point in the watershed, Tributary B was the only stream flowing. Above Station 4A and below tributary B, a spring discharged from west bank directly out of a sandstone bedrock bed parting. This spring was discharging at an estimated 5-10 gpm (0.31 to $0.631 / \mathrm{sec}$ ) during the high and low flow measuring event. It was not noted during the very low flow event of Jun 26, 2005. The spring precipitated iron on the alluvium particles below the discharge point. 


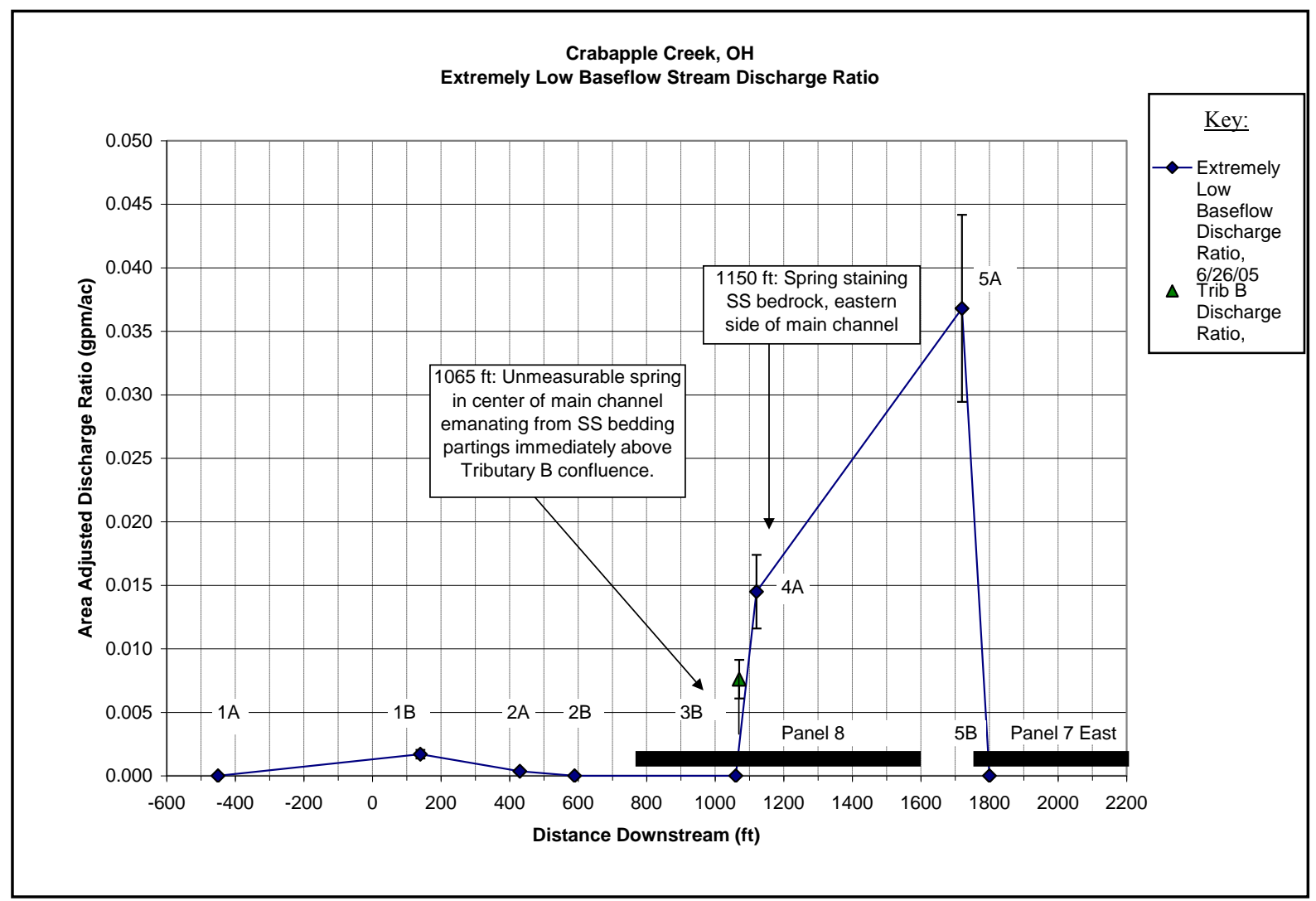

Figure 26. Crabapple Creek, Ohio extremely low flow stream discharge ratio of June 26, 2005, prior to longwall panel 9 East being mined. Note the flow beginning near Station $1 \mathrm{~A}$ and insurgence at Station 2A. A complete loss occurs at Station 2B, 590 feet $(179.8 \mathrm{~m})$ downstream. $10 \%$ error bars used. Mined longwall panel locations are depicted at the base of the graph.

The stream resurges at 1070 feet (326.2 m) downstream and was measured at Stations 4A and 5A. The average flow rate over a mined longwall panel, in this case panel 8 East, is 10 times as high as the flow measured over the un-mined control reach.

This data supports the theory of conservation of ground water by the reduction of evapotransporation rates due to subsidence fracturing (Hobba,1981; Carver and Rauch, 1994). The baseflow is maintained longer due to more recharge being preserved as ground water storage within subsidence fracturing. This extra storage capacity supplies baseflow to stream discharges for longer periods, even during drought conditions, whereas reaches without 
subsidence fracturing and secondary storage may have a smaller percentage of recharge contributing to baseflow. Mine subsidence fractures provide for a greater rate of infiltration, reducing evapotranspiration rates and sustaining baseflow rates by subsidence enhanced recharge.

\section{$\underline{\text { High Baseflow }}$}

High baseflow (HF) stream flow measurements were collected over a 2040-foot (621.9 m) reach of Crabapple Creek on February 2, 2006. Five flow measurement stations were established and stream flows were collected. These stations were selected based on the geophysical surveys and also by physical stream conditions.

Station 1B and Station 2B are located over longwall panel 9 East. Station 1B is located over the mid-panel position of the longwall and Station $2 \mathrm{~B}$ is located over the downstream quarter-panel. Station $2 \mathrm{~B}$ is 20 feet $(6.1 \mathrm{~m})$ upstream from the edge of longwall panel 9 East, at 610 feet $(185.9 \mathrm{~m})$. There is a decrease in normalized discharge across this reach of $25 \%$ (Figure 27 ).

The high baseflow measurements, which were collected 6 months after extremely low measurements, detected a $25 \%$ decrease in stream flow at Station $2 \mathrm{~B}$. This station was the insurgence point at extremely low baseflow conditions. Even though Station 2B is located over the downstream edge of panel 9 East, it was the point of insurgence before panel 9 East was mined out. This suggests that Station $2 \mathrm{~B}$ is located over a mine subsidence fracture from panel 8 East that intercepts the stream and impacts stream flow.

Station $3 \mathrm{~A}$ is located over the upstream quarter panel of panel $8 \mathrm{East}$, at 900 feet $(274.4 \mathrm{~m})$ downstream. This location is 20 feet $(6.1 \mathrm{~m})$ downstream of a major tributary to 
Crabapple Creek, identified as Tributary A. The same longwall panels that mined under Crabapple Creek also mined under this tributary, potentially affecting the tributary baseflow.

Tributary A's drainage area is similar in size and shape to Station 3A of Crabapple Creek. Tributary A has a contributing drainage area of 544 acres (220.2 hectares), doubling the recharge area of Crabapple Creek to 1175 acres (475.5 hectares) at their confluence. Upstream tension zone effects, similar to the dewatering effects detected at Station 2B, may impact Tributary A.

Station 4B is located over the mid-panel of longwall panel 8 East. It is 320 feet $(97.5$ $\mathrm{m})$ downstream of the previous monitoring point (3A) and 130 feet $(39.6 \mathrm{~m})$ downstream of the confluence of Tributary B. Tributary B enters the main stem at 1070 feet $(326.2 \mathrm{~m})$ downstream, increasing the overall drainage area by 510 acres ( 155.5 hectares), or $50 \%$. The normalized discharge of $0.67 \mathrm{gpm} / \mathrm{ac}$ remains constant through Station 4B only because Tributary B discharges at $1.04 \mathrm{gpm} / \mathrm{ac}$. If not for the high discharge ratio of Tributary $\mathrm{B}$, the discharge of the main stem of Crabapple Creek at Station 4B would be below the trend. Currently, Tributary B assists in maintaining the discharge downstream of its inflow, possibly mitigating any stream flow losses that might otherwise be present.

Station 4B marks the upstream extent of subsidence related pooling over longwall panel 8 East. The stream cross section still provides an acceptable flow measurement at this point, however between 1450 to 1650 feet $(442.0$ to $503.0 \mathrm{~m})$ downstream, the pooling is deeper and the velocity becomes imperceptible. The water depth in this reach is estimated to be approximately five feet $(1.5 \mathrm{~m})$ deep at the deepest point. Sediment in this deep slow moving water are soft and sticky silts and clays. The geophysical survey moved onto the 
stream bank, along the waters edge through this reach, and moved back into the stream as at 1650 feet $(503.0 \mathrm{~m})$ downstream.

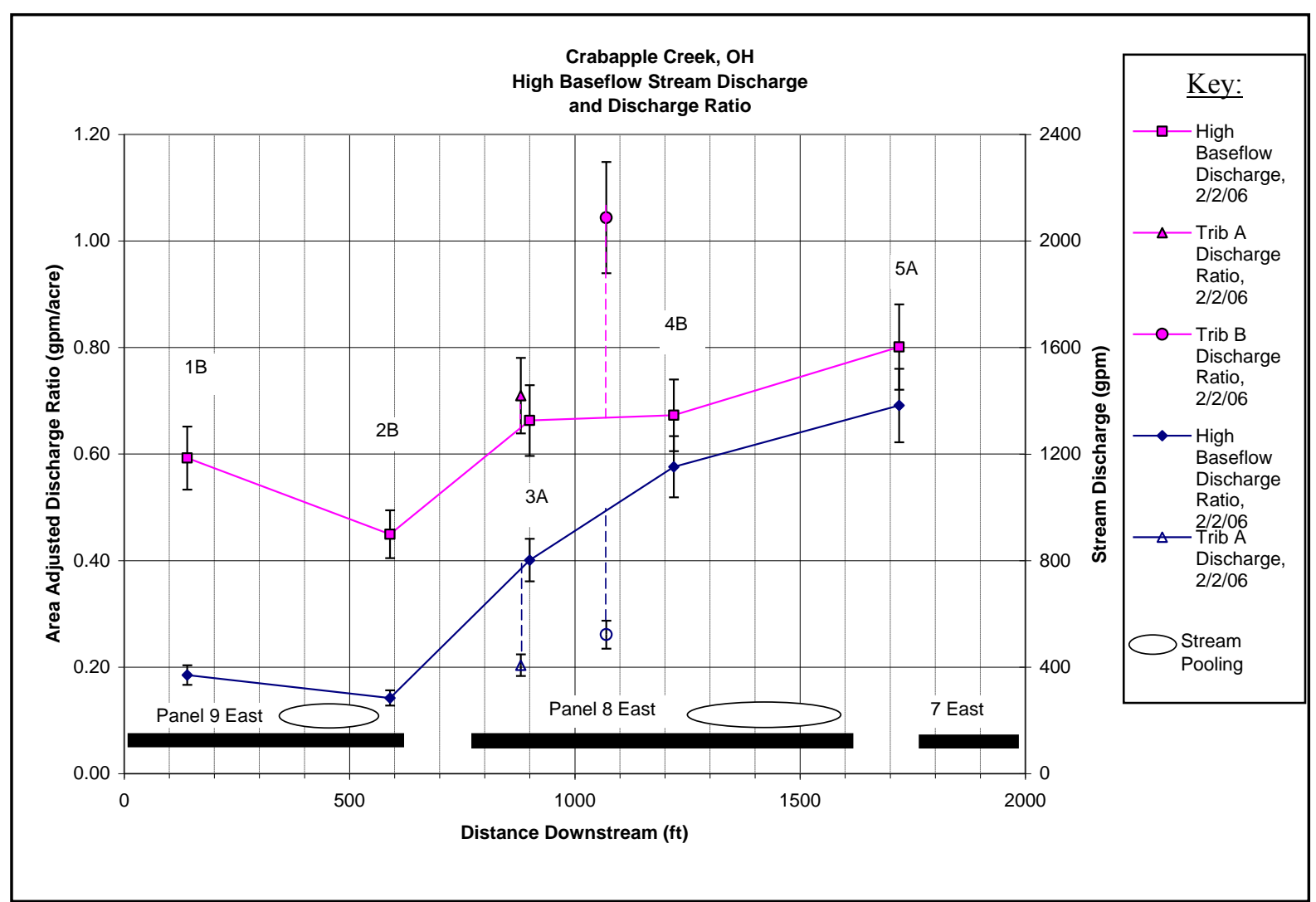

Figure 27. High baseflow stream discharge (gpm) and normalized discharge (gpm/ac) hydrograph, measured on February 2, 2006, for the measured reach of the main stem of Crabapple Creek, Ohio. Error bars represent 10\% of the time corrected flow measurement value. Mined longwall panel locations are depicted at the base of the graph. Tributary discharge (gpm) for Trib A and Trib B, and normalized discharge (gpm/ac), are plotted with respect to their confluence with the main stem of Crabapple Creek.

Air bubbles were observed migrated to the surface 1,400 feet (426.8 m) downstream, coming through the thin alluvium covering the bedrock fractures in the bottom of the creek bed. The bubbles surged, stopped, then surged again. Two or three fractures of six inches $(152.4 \mathrm{~mm})$ or less were observed on February 2, 2006 and only at this location during stream flow measurements. Longwall panel 8 East had already been mined, and longwall 
panel 9 East mined under Crabapple Creek in August 2005 (Appendix V, Table 2). The air bubbles observed were recorded 12 months after extraction of panel 8 East.

Station $5 \mathrm{~A}$ is located over the gate-entry that separates panel 8 East with panel 7 East, 500 feet $(152.4 \mathrm{~m})$ downstream of Station 4B. Similar to Station 2B, this station is on the downstream side of a pooled reach where the stream bed crests and begins to increase in downstream gradient. Station $5 \mathrm{~A}$ has a normalized discharge increase of $13 \%$ from Station 4B.

\section{Low Baseflow}

Low baseflow stream discharge measurements were collected on May 23, 2006; 4 months after high baseflow measurements and 11 months after extremely low baseflow measurements. Measured discharge at Station 1B is $16 \%$ lower at low baseflow than at high baseflow.

Low baseflow discharge measurements have less inter-station variability and resemble typical pre-mining conditions. Due to a significant flow change in the 'control reach' at high flow, Station 1A was added 600 feet $(182.9 \mathrm{~m})$ upstream of Station 1B (Figure 25). Normalized discharge is steady between Stations $1 \mathrm{~A}, 1 \mathrm{~B}$ and $2 \mathrm{~B}$ during low baseflow, a distance of 1090 feet $(332.3 \mathrm{~m})$. The normalized discharge from Station 1A to $2 \mathrm{~B}$ ranges from 0.52 to $0.50 \mathrm{gpm} / \mathrm{ac}$, demonstrating a more consistent discharge than the 0.61 to 0.45 gpm/ac discharge ratios at high baseflow. Pooling is still present between 350 feet $(106.7 \mathrm{~m})$ and 550 feet $(167.6 \mathrm{~m})$ downstream, and bedrock is still the primary stream substrate.

Tributary A continues to discharge below average, as it did at high baseflow. Station 3A, downstream of Tributary A confluence, records an $8 \%$ decrease in normalized discharge from Station 2B. This station receives drainage from both the main stem and Tributary A. 
The normalized discharge of Tributary A is $52 \%$ of that recorded at Station $2 \mathrm{~B}$. The lower normalized discharge ratio from Tributary A affects the main stream discharge by decreasing the discharge-area-ratio for Station 3A. Figure 28 illustrates how Station 3A and Tributary A plot below the trend line of the main stream, demonstrating their relationship.

Station 4B, downstream of Tributary B, regains all of the normalized discharge lost at Station 3A. Tributary B has a normalized discharge ratio 37\% higher than Station 3A, and $26 \%$ higher than Station 2B. Tributary B increases the discharge-area-ratio of the main stream by $22 \%$ at Station $4 \mathrm{~B}$ by discharging a higher than average ratio (Figure 28 ).

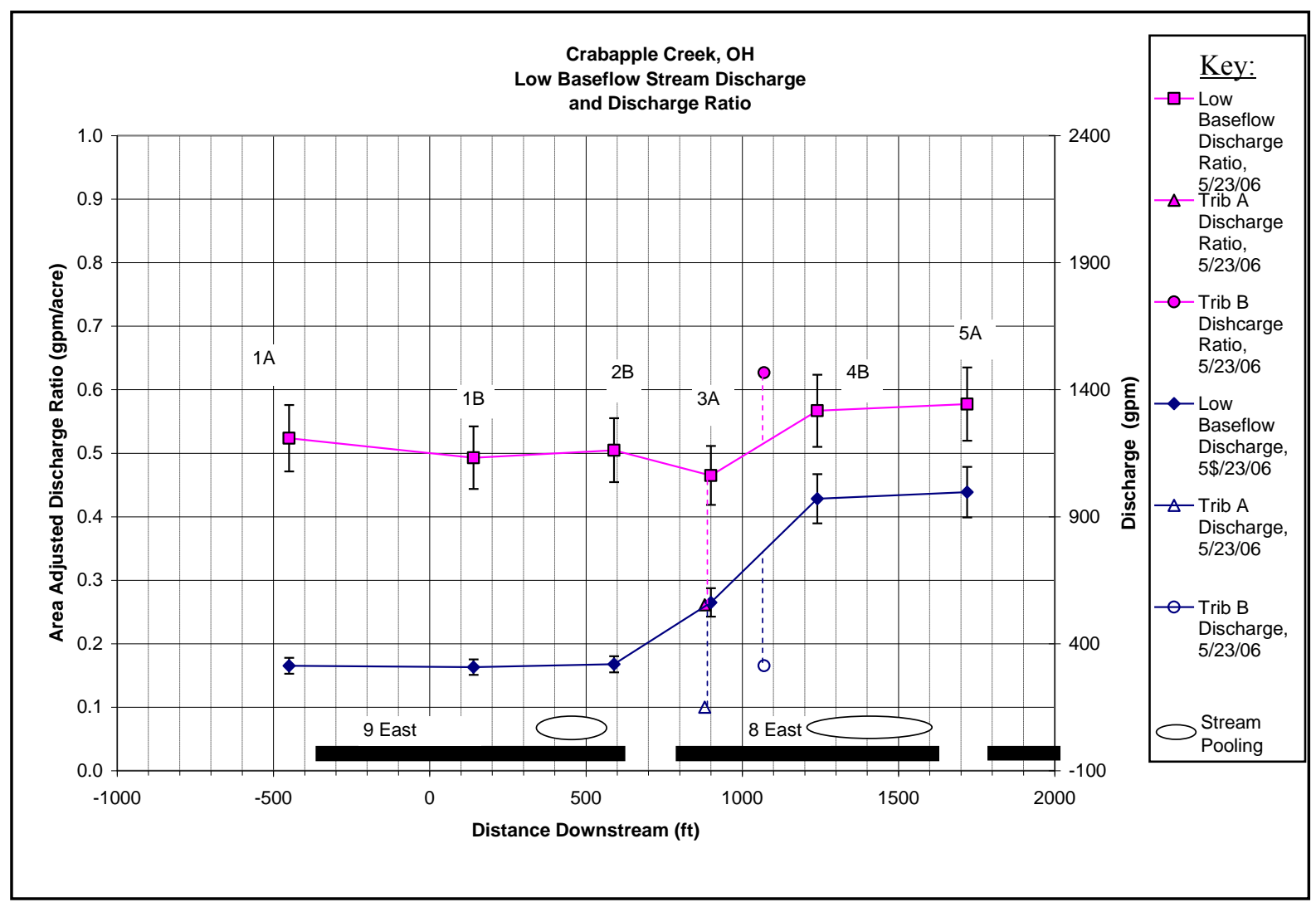

Figure 28. Crabapple Creek, Ohio hydrograph displaying low baseflow measurements taken on May 23, 2006. Error bars represent $10 \%$ of the time corrected flow measurement value. Mined longwall panel locations are depicted at the base of the graph. 
Station $5 \mathrm{~A}$ is located over the gate-entry between panels 8 East and 7 East. This station documented a significant resurgence of stream water during the earlier high flow measurement event. However, the low flow event records only a $2 \%$ change in the discharge ratio. The consistency in normalized discharge from Station $4 \mathrm{~B}$ to $5 \mathrm{~A}$ may indicate a reduction in subsidence related impacts and elimination of an anomalous recharge zone. One interpretation of the change is that fractures that were conveying ground water to the stream at the anomalous interval have been sealed by sedimentation in the pooled reach.

\section{Geophysical Measurements}

Several geophysical anomalies are identified across the 2000 foot $(609.7 \mathrm{~m})$ survey reach of Crabapple Creek. The TC data was compared to the K-H Filtered VLF data, and data that exceeded $80 \%$ of the remaining data in each survey was included in a Table of Geophysical Anomalies (Appendix III, Table 1). The table displays the survey type and the degree of significance, along with the particular reach of stream that the anomaly was significant. This data is also presented in the following section, and includes a description of the anomaly as defined by the degree of significance and potential orientation and location. Coordinated anomalies delineated as potential fractures have a greater potential for interaction between surface water and ground water (Ackman and Dilmore, 2002).

A substrate and lithologic change at stream level occurs between 600 and 870 feet (182.9 and $265.2 \mathrm{~m}$ ) downstream. This corresponds to a shift in the TC baseline. The median TC value from Station 0 to 690 feet $(210.3 \mathrm{~m})$ is $26.7 \mathrm{mmhos} / \mathrm{m}$ (Baseline A), but the median TC value from 700 to 2040 feet $(213.4$ to $621.9 \mathrm{~m})$ downstream is $17.7 \mathrm{mmhos} / \mathrm{m}$ (Baseline B), a decrease of $9.0 \mathrm{mmhos} / \mathrm{m}$ or $33 \%$. This baseline shift affects the statistical significance of peaks and anomalies. Therefore, the percentiles representing the TC 
anomalies are compared to the baseline for that reach of stream, and divided as discussed. This division, at 690 to 700 feet (210.3 to $213.4 \mathrm{~m})$ downstream, represents a lithologic change at stream level and the significant change in TC between these two points. The raw VLF data are also affected by this lithologic change. The filtered data, are not as affected, involving only a few data points at a time and ignoring the overall shift.

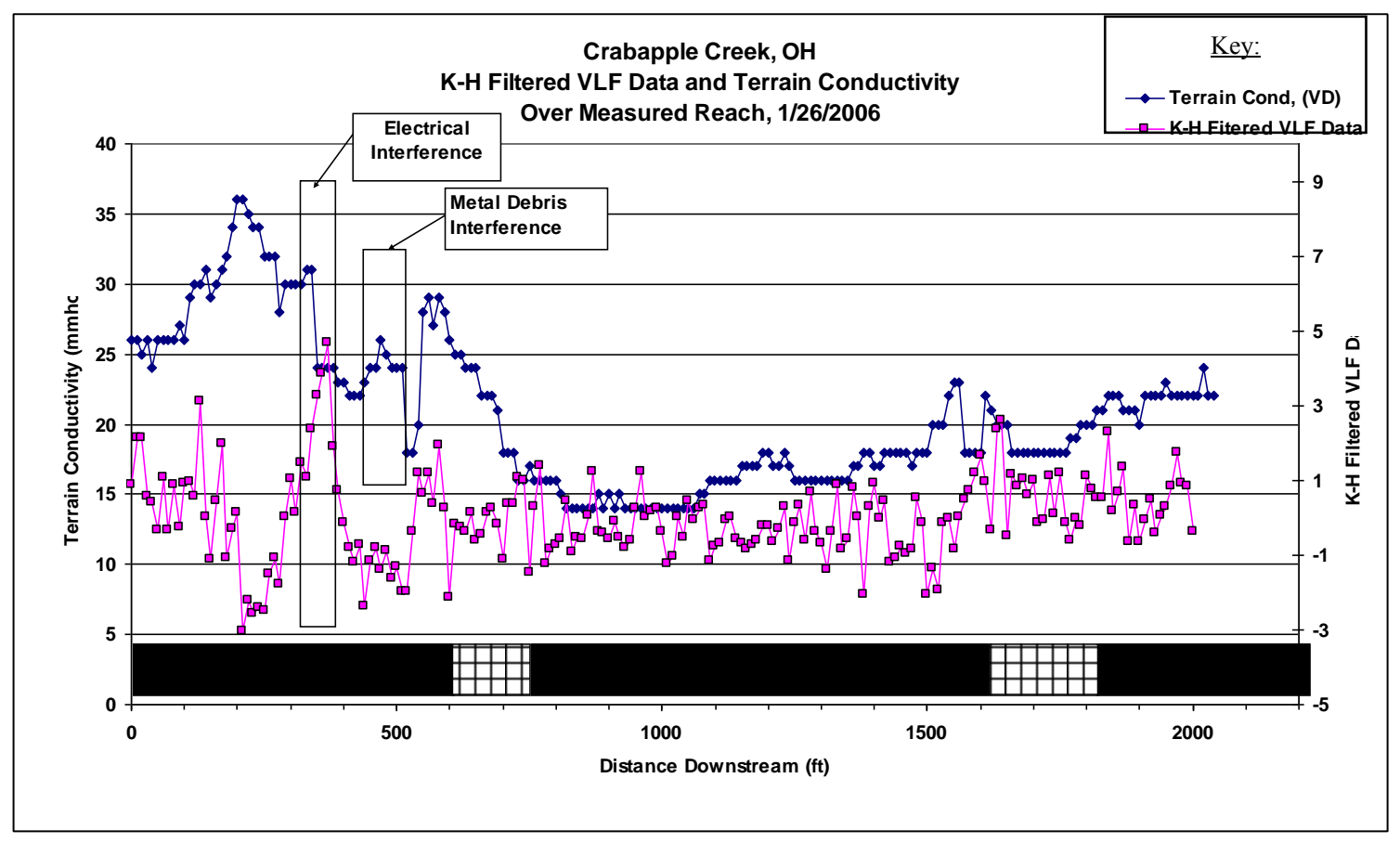

Figure 29. Crabapple Creek, OH. VLF and TC readings demonstrating the baseline shift in shallow conductivity readings by the Terrain Conductivity survey.

Anomaly CC1 (110 to $150 \mathrm{ft}) /(33.5$ to $45.7 \mathrm{~m})$

The first anomaly detected by the TC survey, above the $80^{\text {th }}$ percentile, is from 110 to 150 feet $(33.5$ to $45.7 \mathrm{~m})$ and peaks at 140 feet $(42.6 \mathrm{~m})$. This anomaly is in the $90-95^{\text {th }}$ percentile range. It is a short peak superimposed upon this already highly conductive reach of stream (30 mmhos $/ \mathrm{m})$. 
The VLF survey has a coordinated $95^{\text {th }}$ percentile peak at 130 feet $(39.6 \mathrm{~m})$, also superimposed on an already $80^{\text {th }}$ percentile stream reach (Figure 29). Reach 120 to 140 feet (36.5 to $42.6 \mathrm{~m}$ ), based on the geophysical surveys that show clear coordination, is expected to be connected to the stream hydrology and may influence the total discharge of the stream.

Anomaly CC2 (170 to $270 \mathrm{ft}) /(51.8$ to $82.3 \mathrm{~m})$

The second anomaly, above the $80^{\text {th }}$ percentile, detected by the TC and VLF survey, is from 170 to 270 feet $(51.8$ to $82.3 \mathrm{~m})\left(95-99^{\text {th }}\right.$ percentile). This TC graphed anomaly has a high broad peak suggesting that the anomalous item is shallow to mid-depth range. The anomaly is represented by VLF survey at 170 feet $(51.8 \mathrm{~m})$ with a $90^{\text {th }}$ percentile anomaly of 1.95 magnetic ratio. This coordinated anomaly suggests that although conductive near the surface for 100 feet, from 170 to 270 feet $(51.8$ to $82.3 \mathrm{~m})$, it is only narrowly conductive at mid-depth range. The VLF data is narrow with single high peak suggesting that the conductive anomaly does not reach the deeper strata, but is limited to the shallow to middepth range.

Anomaly CC3 (330 to $380 \mathrm{ft})$ / (100.6 to $115.8 \mathrm{~m})$

The next anomaly is unique. It is apparently caused by interference from an overhead electric line striking in a northeast/southwest direction and is not discussed in detail. The electric line is low voltage and is estimated to be 15 feet $(4.5 \mathrm{~m})$ overhead. The impact from this interference is limited in extent. 
Anomaly CC4 (440 to $510 \mathrm{ft})$ / (134.1 to $155.4 \mathrm{~m})$

The Terrain Conductivity survey detects an anomaly; however, the VLF survey does not detect any conductive feature at this location. The TC anomaly is identified from 440 to 510 feet $(134.1$ to $155.4 \mathrm{~m})$. This corresponds to an area that has undergone visually detectable surface subsidence and as a result, has experienced a pooling of the stream. The pooled stream reach stream begins to deepen at 310 feet $(94.5 \mathrm{~m})$ downstream, near limestone bedrock step-pools, and begins to shallow near 550 feet $(167.6 \mathrm{~m})$ downstream, just before the stream crosses a gate-entry. Due to this subsidence, the depth of the water became too deep to conduct geophysical measurements within the stream; therefore, geophysical measurements were conducted on the stream bank from 360 to 540 feet (109.7 to $164.6 \mathrm{~m})$. The data, especially for the TC survey, shows suppressed readings along this reach. The data therefore is not as accurate in identifying potential fractures beneath the stream subsurface. The anomaly within this reach detects metal junk that was identified in the stream prior to the pooling, during the ELF measuring event of June 26, 2006. This anomaly is interpreted to be caused by metallic interference and does not represent subsurface fracturing.

Anomaly CC5 (540 to $600 \mathrm{ft}) /(164.6$ to $182.9 \mathrm{~m})$

Terrain Conductivity values increase from the lower $80^{\text {th }}$ percentile, to the upper $80^{\text {th }}$ percentile with a corresponding VLF anomaly between 540 feet $(164.6 \mathrm{~m})$ and 600 feet (182.9 $\mathrm{m})$ downstream. The TC anomaly has two peaks, one at 560 feet $(170.7 \mathrm{~m})$ and one at 580 feet $(176.8 \mathrm{~m})$, suggesting a fracture zone 20 to 60 feet $(6.0$ to $18.2 \mathrm{~m})$ wide is located at the near-surface. 
The VLF anomaly reaches the $80^{\text {th }}$ percentile at 540 feet $(164.6 \mathrm{~m})$ and peaks at 580 feet $(176.8 \mathrm{~m})$, as a $90^{\text {th }}$ percentile anomaly. The VLF conductive zone is well coordinated with the TC survey, indicating a fracture zone with connectivity to the near surface and perhaps the stream water. This fracture zone has potential to influence stream discharge. This anomaly is located over the downstream quarter-panel of panel 9 East and the upstream angle of draw of panel 8 East. The rock units in this area are expected to have undergone substantial amount tensional strain.

Figure 30 depicts the VD Terrain Conductivity across the measured reach, both before and after panel 9 East was longwall mined. The Terrain Conductivity anomaly at CC5 is present before panel 9 East mined beneath the stream indicating that the this part of the anomaly is a fracture set associated with the upstream edge of panel 8 East's subsidence basin. The angle of draw is expected to intersect the surface within the range of this anomaly. Further review of this figure reveal reaches of Crabapple Creek that exhibit increases in TC over time ( 0 to 250 feet $(76.2 \mathrm{~m}), 580$ feet $(176.8 \mathrm{~m})$ ), and reaches that decrease over time i.e. 760 feet $(231.7 \mathrm{~m}), 1550$ to 1570 feet $(472.5$ to $478.6 \mathrm{~m}), 1850$ to 1900 feet $(564.0$ to $579.2 \mathrm{~m})$, and 2000 feet $(609.7 \mathrm{~m})$. The reaches with increasing conductivity are located over the most recently mined panel (panel 9 East), whereas the reaches that are decreasing over time are located over the older mined panels (panels 7 and 8). Tieman and Rauch (1987) found that streams exhibit less mining impacts over time and that by the time the stream reaches 3 years after mining, it has reached it maximum recovery status. This data supports that theory. 


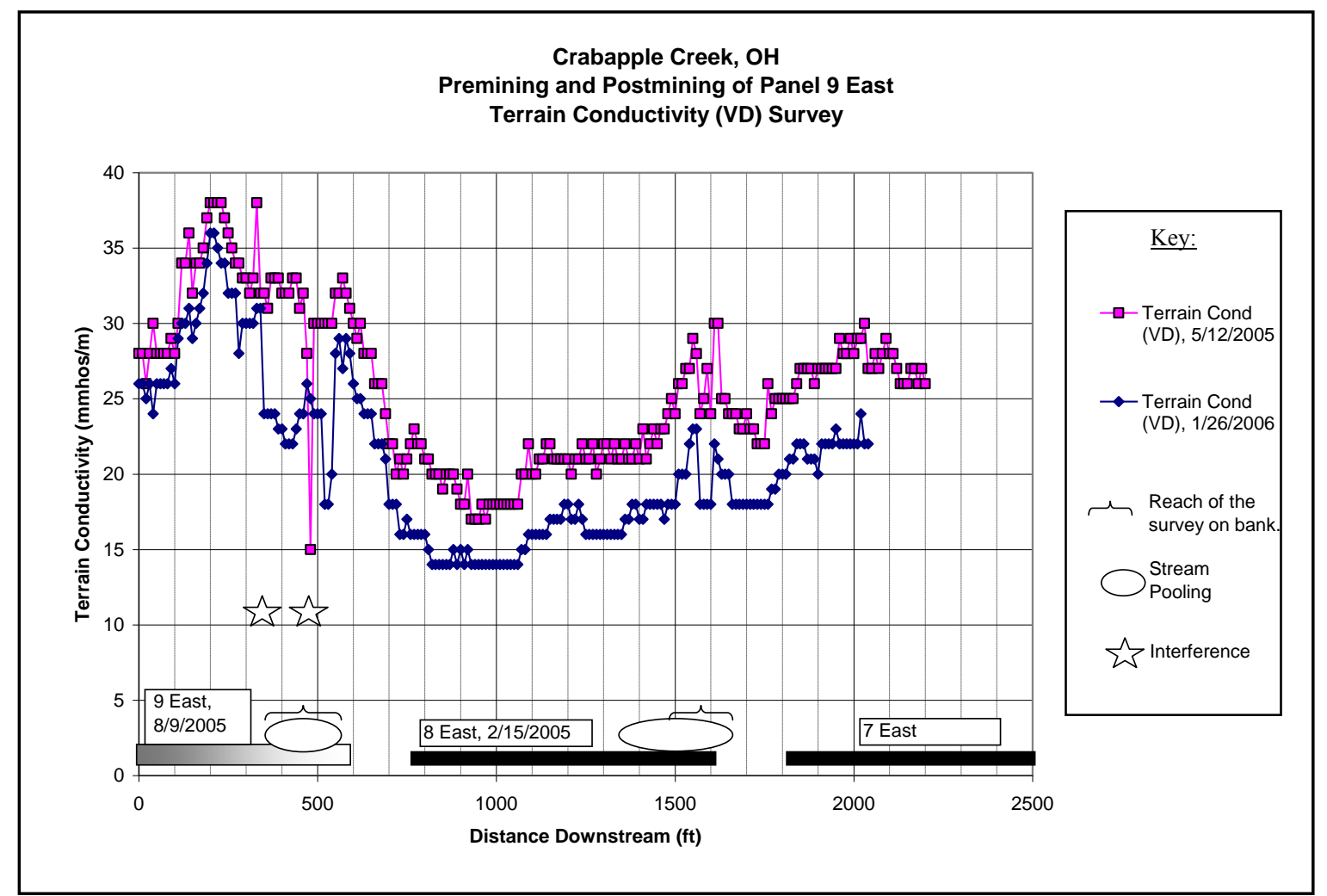

Figure 30. Comparative Terrain Conductivity (VD) data for surveys conducted before and after longwall panel 9 East was mined in August 2005. Data suggest that the Terrain Conductivity anomaly CC5 at 540 to 590 feet $(164.6$ to $179.8 \mathrm{~m})$ downstream, was present during pre-mining survey, is a result of longwall mine subsidence from panel 8 East.

The deeper VLF anomaly associated with CC5 was not present prior to mining of panel 9 East and is therefore interpreted to be a result of longwall subsidence from panel 9 East. This anomaly is located at the downstream edge of panel 9 East indicating that the subsidence fracture is near vertical and may intersect the shallow subsidence, delineated by the Terrain Conductivity survey, above it. Figure 31 demonstrates the presence of the VLF anomaly after panel 9 East was mined out. 


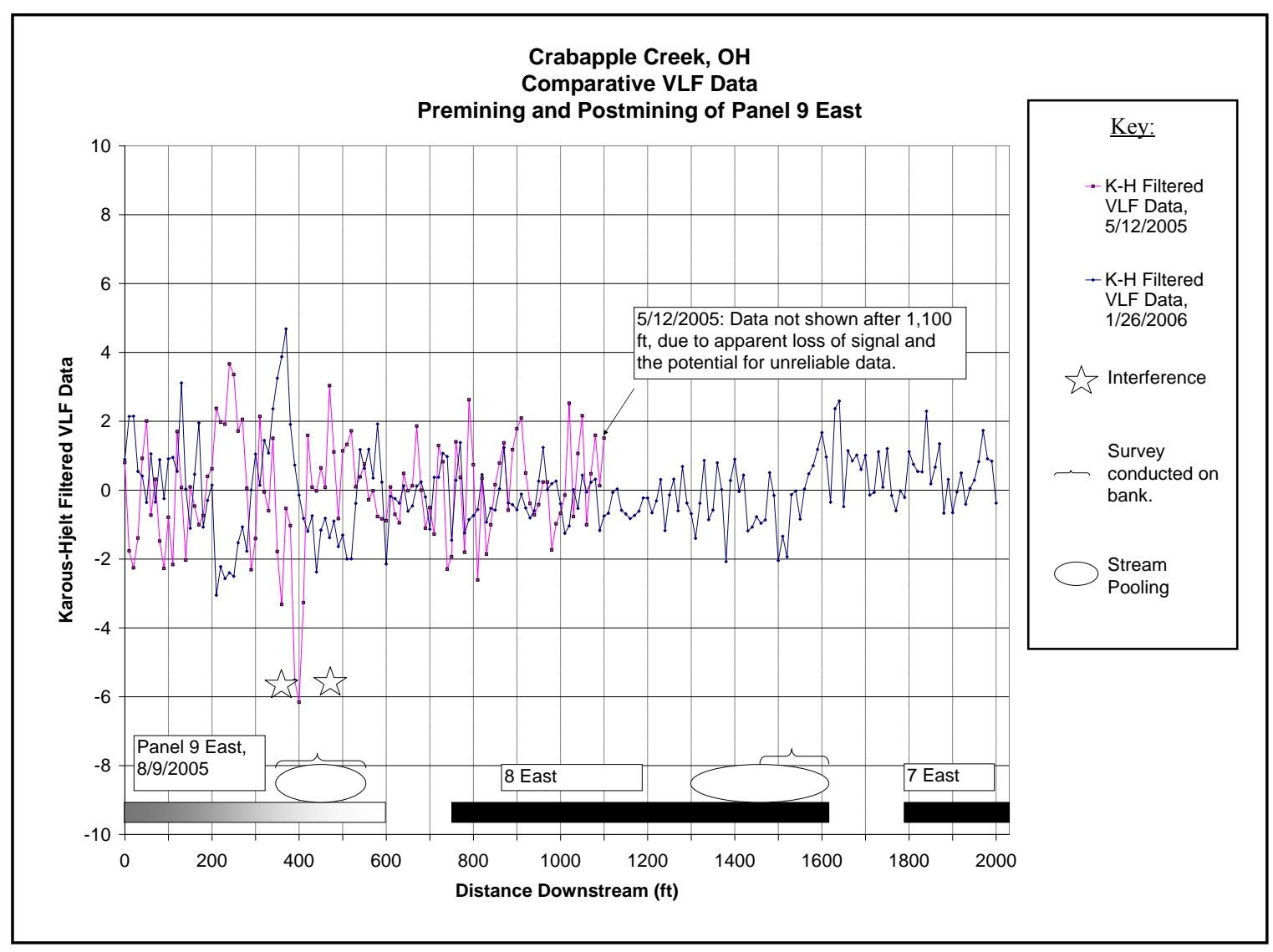

Figure 31. Comparative K-H Filtered VLF data for surveys conducted before and after longwall panel 9 East was mined in August 2005. Data suggest that the VLF anomaly CC5 at 540 to 590 feet (164.6 to $179.8 \mathrm{~m}$ ) was not present during the pre-mining survey and is a result of longwall mine subsidence from panel 9 East.

Anomaly CC6 (730 to $770 \mathrm{ft}) /(222.5$ to $234.7 \mathrm{~m})$

A series of four small VLF anomalies occur from 730 to 960 feet (222.5 to $292.6 \mathrm{~m}$ ). These anomalies are steep narrow peaks suggesting that they extend from shallow to middepth. The four anomalies are distinct peaks, with the latter three reaching the upper $80^{\text {th }}$ percentile (770, 870 and 960 feet). The first anomaly reaches only the lower $80^{\text {th }}$ percentile, but is supported by two data points indicating a slightly wider anomaly than the others (730 to 740 feet). The northern edge of the longwall panel crosses the stream at 770 feet $(234.7 \mathrm{~m})$ downstream. 
This group of anomalies, similar to anomaly CC5, corresponds to the tension zone expected over the edge of the panel. The following anomalies are only detected by VLF, there is no TC detection to assist in their delineation. The four anomalies are located over sandstone/siltstone bedrock exposed in the stream bottom, with little to no alluvium present. The VLF data suggest that the anomalies downstream of 160 feet $(48.7 \mathrm{~m})$ are shallow to mid-depth and, if present, should be detected by the TC survey.

The first anomaly occurs at 730 to 740 feet (222.5 to $225.6 \mathrm{~m})$. It is approximately 30 to 40 feet $(9.1$ to $12.1 \mathrm{~m})$ upstream of the edge of the panel, but within the upstream tension zone for panel 8 East. This VLF anomaly is located over the gate-entry between the panels, 10 to 20 feet $(3.0$ to $6.0 \mathrm{~m}$ ) from the edge of the coal removal area and extends from shallow to mid-depth. There is no TC anomaly to support the VLF anomaly in this same location. The TC survey is in the process of substantially changing its baseline due to a change in lithology, and the transition may be obscured any anomaly. The anomaly at 770 feet $(234.7$ m) appears to be a part of the 730 to 740 feet $(222.5$ to $225.6 \mathrm{~m})$ anomaly, and may be hydrologically connected at mid-depth.

Anomaly CC7 (870 ft) / (265.2 m)

Anomaly CC7 is limited to a width of one survey station at the intersection of a tributary stream, and is estimated to be at mid-depth. The location of the anomaly suggests that it is related to the tributary and not the main stream. However, the location of the anomaly within the upstream quarter-panel may increase the aperture of natural fractures within this zone, therefore enhancing subsurface conductivity. 
Anomaly CC8 (960 ft) / (292.6 m)

The anomaly CC8 at 960 feet $(292.6 \mathrm{~m})$ is also very small. This anomaly is also detected by VLF only and has a similar depth of location, however, this anomaly is not associated with a tributary stream. The anomaly is shallow to mid-depth.

Anomaly CC9 (1540 (469.5 m) to $1640 \mathrm{ft})$

Anomaly CC9 is the last major conductive zone over longwall panel 8 Eastg. There is a minor anomaly around the other tributary stream, near 1070 feet $(326.2 \mathrm{~m})$, and a few more minor anomalies around 1,400 feet (426.8 m). Mine subsidence has caused a decreased stream gradient over the second half of the longwall panel. The stream pools in this reach, causing silt and sand deposits between 1200 to 1620 feet (365.8 to $493.9 \mathrm{~m}$ ). The pooling corresponds to an area of increasing TC values.

A significant TC anomaly is detected around 1540 to 1620 feet (469.5 to $493.9 \mathrm{~m})$. This anomaly is broad, suggesting a wide area of increased conductivity. The VLF survey detected a substantial anomaly from 1590 to 1640 feet (484.7 to $500.0 \mathrm{~m}$ ). This coordinated anomaly is located within the downstream quarter-panel stream reach.

Within this pooled reach, the land to the east has impounded water in an otherwise well drained field. Furthermore, a small debris flow is located on the west side of the stream in this area. The abrupt change in topography at the edge of this panel is accompanied by a strong coordinated anomaly delineated by both geophysical surveys. This area is expected to be connected to the stream water, and affecting the quantity of water in the stream.

The anomaly CC9 is located over the downstream edge of panel 8. This subsidence fracture is associated with a stream flow increase, as measured by Station 5A. Station 5A, 
near the center of the gate-entry, is located over a lower conductivity reach. The conductivity is high over anomaly CC9 and high near the edge of longwall panel 7 East. The low conductivity of the subsurface over the middle of the gate entry indicates that water filled fractures are not present over the middle of the panel at a detectable depth.

\section{$\underline{\text { Alluvial Sediment Measurements }}$}

Alluvial thickness measurements and particle size analyses were conducted on May 23, 2006 (Appendix IV). This creek has the lowest average alluvial thickness of all the streams measured for this study. A significant portion consists of bedrock bedform. From 140 feet $(42.6 \mathrm{~m})$ to 330 feet $(100.6 \mathrm{~m})$ downstream, the bedrock is primarily thin coals and limestone. Below this bedrock exposure, the stream water pools due to mine subsidence. Mine subsidence is delineated as the cause because pre-mining conditions were observed. From Station 2 to 750 feet $(228.6 \mathrm{~m})$ downstream, there is thicker alluvium, and from 750 feet $(228.6 \mathrm{~m})$ to 1200 feet $(365.8 \mathrm{~m})$, sandstone bedrock is the dominant bedform. Pooling over panel 8 East exists from 1200 feet $(365.8 \mathrm{~m})$ downstream to 1650 feet $(503.0 \mathrm{~m})$. Through the slower velocity pools, sands and silts accumulate over the sandstone bedrock. Station 4 represents this depositional 'wedge'. The sediment thickness at this location averages only 0.2 feet $(0.06 \mathrm{~m})$ deep. Exposed sandstone bedrock becomes the dominant bedform for the remainder of the sampled reach after the end of the pool at 1650 feet $(503.0$ $\mathrm{m})$.

Particle size analyses is presented for two stations, Station 2B and Station 4B. Station 2B experienced a significant decrease in normalized discharge at high baseflow conditions, and Station $4 \mathrm{~B}$ is near the beginning of a pooled reach. Station $2 \mathrm{~B}$ has normal weight 
distribution of particle sizes with a mean particle size of $18.8 \mathrm{~mm}(-4.2 \mathrm{phi})$, slightly lower than the mean size for all six study streams, suggesting that the sediment consists of original pre-subsidence particles and is not a result of deposition due to pooling associated with longwall mine subsidence. The alluvium is poorly sorted with smaller grain sediment filling voids between larger grains.

Station 4B has a skewed distribution towards the finer particle sizes. The mean particle size for Station $4 \mathrm{~B}$ is $7.3 \mathrm{~mm}(-2.9 \mathrm{phi})$, significantly smaller than the overall mean of $32 \mathrm{~mm}$ (-5.0 phi) (Appendix IV). Pooling over the subsided longwall panel may be influencing the particle size distribution. Station 4 is located upstream of the pool that is located over the downstream quarter-panel of panel 8 East. The pool, based on visual observations, influences the velocity of the stream at Station 4B. The stream channel, before it enters the pooled reach, becomes wider and deeper with a lower discharge velocity at the measuring station than upstream of the station. The increase in stream cross-sectional area decreases the velocity and reduces the stream power forming a transition zone with downstream fining over a short length of stream. Station $4 \mathrm{~B}$, located partially into this transition zone, records the fining of the alluvium as it progresses towards the pool.

\section{Interpretation of Data}

The first stream flow measurement was conducted at extremely low baseflow conditions on June 26, 2005, prior to mining of longwall panel 9 East. Naturally occurring drought conditions persisted into late fall and early winter of 2005. High and low baseflow measurements were collected the following year, in February 2, and May 23, 2006. During this time interval, active mining continued upstream, mining longwall panel 9 East. 


\section{Longwall Panel 9 East}

Longwall panel 9 East is represented by Stations 1A (-450 (137.1 m) feet), 1B (140 feet), 2A (430 feet) and 2B (590 feet $(179.8 \mathrm{~m}))$. Low and extremely low baseflow measurements demonstrate a constant to gaining stream reach between Stations 1A to 1B. Stations 2A and 2B record the negative impacts that longwall subsidence can have on stream flow. Station 2A demonstrates a more significant impact from longwall subsidence on stream discharge during extremely low baseflow conditions. Partial losses appear to be more readily detectable at lower baseflows.

Stream losses are detected by Station 2A and 2B as a result of longwall panel 8 East. Station $2 \mathrm{~B}$ is located near the edge of the upstream tension zone of panel 8 East. The angle of draw intercepts the stream surface near the downstream edge of panel 9 East. The stream flow losses recorded during high baseflow are a result of subsidence from panel 8 East over the edge of panel 9 East.

Low baseflow discharge measurements on May 23, 2006 are consistent and demonstrate few significant stream discharge fluctuations. Stream flow fluctuations decrease over time, suggesting that subsidence impacts are healing as the mined panels become older. As the subsiding strata settles, the subsidence cracks previously detectable, are closing or are being clogged by fine grain sediments or strata with a clay matrix.

Three significant geophysical anomalies over panel 9 East are interpreted to be conductive subsurface fractures. These anomalies are CC1 (110 to 150 feet), $\mathrm{CC} 2$ (170 to 270 feet) and CC5 (540 to 590 feet). Anomalies CC1 and CC2 do not appear to have a stream flow impact, but CC5 does have an impact. CC5 is located immediately upstream of Station 2B. This anomaly is at the upstream edge of panel 8 East's subsidence basin, at the 
angle of draw. The Terrain Conductivity anomaly records the tension fracturing associated with panel 8 East, accounting for the temporary stream flow declines at high and extremely low baseflows. The VLF anomaly of CC5, which is not present prior to panel 9 East being mined, is superimposed on the Terrain Conductivity anomaly at this same location. The VLF anomaly of CC5 is associated with the subsidence from panel 9 East, possibly increasing the effect of previous fracturing on stream flow.

Station 2B records a normalized discharge decline over Anomaly CC5. Tributaries A and B also flow over the upstream tensional zone, and they display a different effect from mine subsidence. The differences between these measured locations are explained as the positive and negative effects of subsidence fracturing.

Subsidence fracturing increases the potential storativity and permeability of rock strata. Evapotranspiration rates in upland recharge areas decrease, inversely increasing groundwater volume. Tensional fractures allow migration of the groundwater down-slope through the fractured strata toward the discharge zones. At the valley bottoms, ground water discharges into streams at intersections with tensional fracture zones.

At this site, most of the upland recharge is divided among three drainage basins resulting in reduced recharge to the Crabapple Creek. As a result, the higher storativity of the tensional fracture zone causes a lowering of the water table in the valley bottom. This affects stream discharge by creating an influent stream, resulting in a temporary reach of decreases surface water discharge.

Alluvial sediment thickness over panel 9 East is variable. At Station 1A and 1B The ediment is thinner and bedrock exposures are common. The thickest sediment is present at Station 2B. This station characterizes the reach that realized stream flow losses during high 
and extremely low baseflows. The presence of 1.1 feet $(0.33 \mathrm{~m})$ of sediment, with an average particle size of $18.8 \mathrm{~mm}$, did not prevent stream flow losses initially. However, low baseflow measurements taken 15 months after panel 8 East was mined and 9 months after panel 9 East was mined, indicate that alluvial sediment may have sealed subsidence fractures that were known to be depleting stream discharge.

\section{Longwall Panel 8 East}

Stations 3A $(900 \mathrm{ft}), 3 \mathrm{~B}(1060 \mathrm{ft}), 4 \mathrm{~A}(1120 \mathrm{ft})$ and 4B $(1240 \mathrm{ft})$ represent the second panel in the study, Panel 8 East. These stations are located above and below two tributaries of the main stream that intersect with the main stream over this panel.

During extremely low baseflow, Crabapple Creek was dry across the upstream quarter-panel and half way across the mid-panel. Tributary A did not discharge and Tributary B supplied the only source of water to the stream. High and low baseflow are relatively consistent across this reach, despite influences from tributaries. The main stem holds a consistent discharge even as one tributary discharges less and one discharges more than the main stem. The main stem achieves a balance of normalized discharge, thought to be a result of unequal distribution of upland recharge caused by subsidence fracturing.

Station $4 \mathrm{~B}$ is a ground water discharge zone located over the downstream half of the mid-panel reach. During extremely low baseflow, springs discharge from bedrock within the main stem around near the confluence of Tributary B. Downstream of this discharge zone, the stream pools over the downstream quarter-panel of panel 8 East due to subsidence. The existence of a pooled reach and the identification of springs at a similar elevation, suggest that the water table is intersecting the surface in this area, and ground water that had been moving as underflow from upstream influent reaches is again recharging the stream. The 
waters-edge spring discharges at the water table is imperceptible at high and low baseflow due to a higher water level in the stream.

Two tributaries join the stream over panel 8 East. These tributaries are themselves impacted by mine subsidence of panel 8 East and panel 9 East. The impact to these tributaries substantially affects the discharge ratios of the main stem. In fact, these tributaries provide the greatest influence to normalized discharge over the upstream half of the panel.

During extremely low baseflow of June 2005, Tributary A was dry at its confluence with the main stem. The tributary is negatively impacted by traversing the fractured upstream tension of panel 8 East immediately upstream of the confluence. Tributary B crosses these same tensional factures, but it does so more perpendicular and further upstream from Crabapple Creek. Another difference of Tributary B is that it flows down the middle of longwall panel 8 East, where fracture aperture may be smaller due to being in a zone of compression

Tributary A and Tributary B have substantial differences in normalized discharges at all three measuring events. Both tributaries have similar sized and shaped drainage basins, the same longwall panels undermined both, and both drainage basins have similar terrain. One difference is the elevation of Tributary A, Tributary B and the main stem at the point where they cross the upstream tension zone of panel 8 East. This elevation difference relates to the amount of cover and the different lithologies present beneath the stream. Tributary A is estimated to have an elevation of 985 feet $(300.3 \mathrm{~m})$ where it crosses on panel 8 East, whereas Tributary B is estimated to have be 1045 feet $(318.5 \mathrm{~m})$. Station $2 \mathrm{~B}$, on the main stream, is similar to Tributary A in elevation at 975 feet $(297.2 \mathrm{~m})$. The extra 60 feet $(18.2 \mathrm{~m})$ 
of overburden beneath Tributary B may provide additional buffer to subdue the effects of mine subsidence fracturing on stream flow.

Station $5 \mathrm{~A}$ is measured on bare sandstone bedrock over the gate-entry between panel 8 East and panel 7 East. This station, at 1720 feet $(524.3 \mathrm{~m})$, records a 19 to $22 \%$ normalized discharge increase during the high and extremely low baseflows. However, three months after the high baseflow, the low baseflow measuring event records no change in normalized discharge from Station 4B.

Anomaly CC9, located 1540 to 1640 feet (469.5 to $500.0 \mathrm{~m})$ downstream, is the only significant anomaly in this area. The anomaly is located over the downstream edge of panel 8 East. It is also located at a physical change in channel slope, near the deepest point in the pooled reach. This anomaly is delineated as a subsidence fracture providing ground water discharge to the stream via subsidence fracturing from upland slopes.

The lack of impact by anomaly CC9 during low baseflow may be the age of the subsidence and/or the result of a thickening wedge of fine grain alluvial sediment over this fracture zone due to the pooling over the downstream quarter-panel zone.

\section{Stream Conclusion}

A stream survey of Crabapple Creek, in southern Belmont County Ohio, took place over an 11-month-old mined longwall panel. The depth of the mine in the Pittsburgh Coal seam is approximately 285 to 310 feet beneath the stream. Stream flow fluctuations were visually undetectable during this investigation, except during extremely low baseflow.

The upstream tension zone of the panel 8 East is the first subsidence zone that affects stream discharge. Increased conductivity recorded by geophysics across this zone indicates subsidence fractures are saturated. Orientation of this study stream's tension zone is 
perpendicular to the stream flow, projecting the fracture set into the adjacent upslope recharge areas. Stream discharge increases and decreases are detected at fracture and stream intersections. Topography and stream - panel orientation affect fracture zone traces and may affect ground water flow directions and rates. Stream discharge measurements indicate postmining stream flow stabilization and ground water baseflow restoration within fifteen months after mining of the longwall panel.

Erosion caused by an increased stream gradient across the upstream tension zone, removed the alluvial sediment within this zone, resulting in sandstone bedrock exposures. Pooling occurs across the downstream quarter-panel zone of the subsidence basin resulting in a downstream fining wedge of sediment deposition within the pooled reach. Sediment at the upstream edge of the subsidence basin assists in sealing delineated geophysical anomalies associated with subsidence cracks in the upstream tension zone.

The majority of this stream has a very thin or non-existent layer of sediment over the bedrock suggesting that stream sediment contributes only partially to stream flow stabilization and baseflow restoration. The age of mine subsidence and overburden thickness may be controlling factors at this study area.

\section{Williams Creek, Ohio}

\section{Results and Discussion of Data}

\section{$\underline{\text { Stream Discharge Measurements }}$}

High baseflow measurements were collected from Williams Creek in Ohio, on January 31, 2006 (Appendix I, Table 4). The measurements were collected approximately nine years after panel 21 East was completed. High baseflow measurements were conducted 


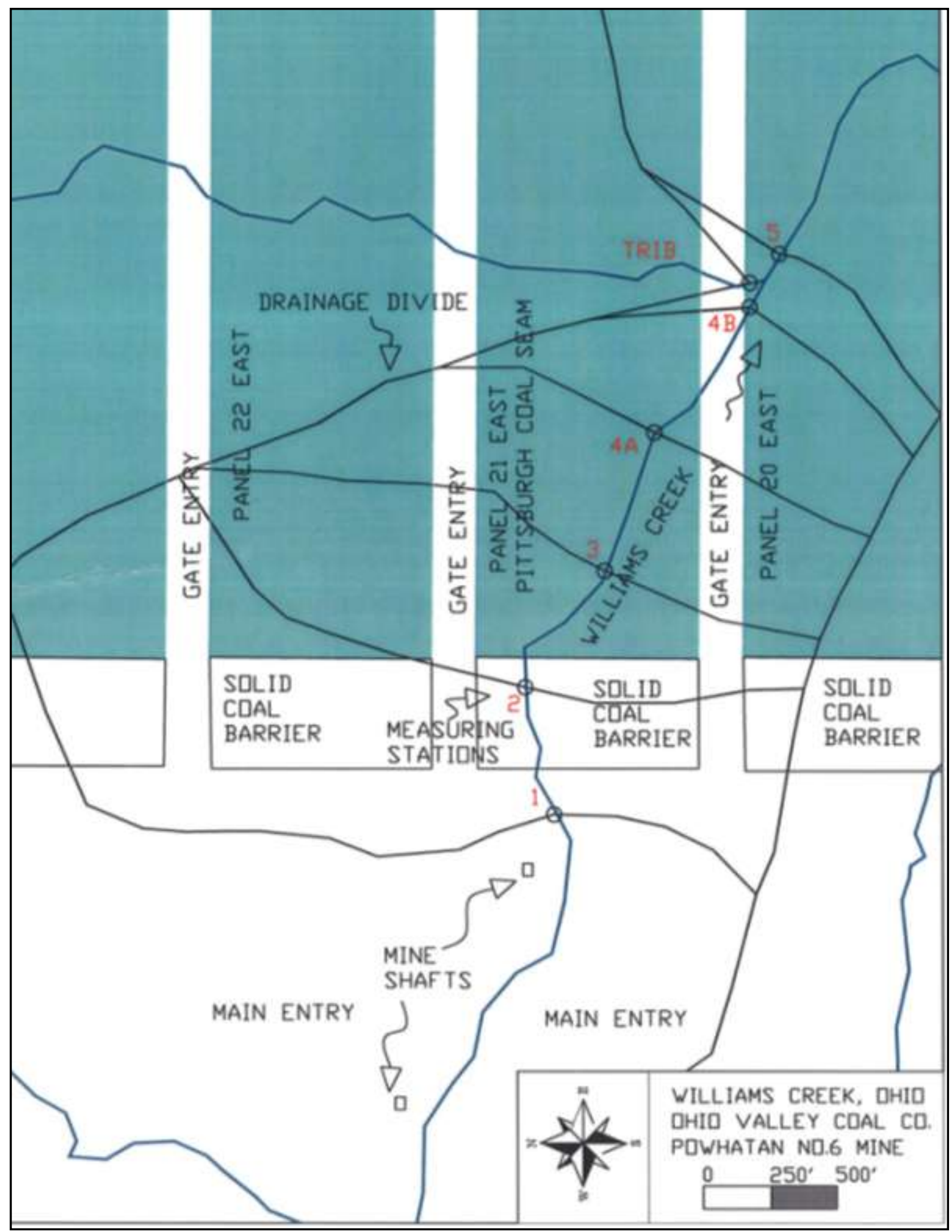

Figure 32. Station location map of Williams Creek, Ohio showing stream measuring stations, drainage divides, mine shafts near the stream and longwall panels for a portion of the Ohio Valley Coal Company's Powhatan No. 6 Mine in the Pittsburgh Coal seam, Belmont County, Ohio. 
first, followed by the low baseflow measurement three months later in April 2006. There are five measuring stations initially established within this reach; two within the control reach, two across panel 21 East and one over panel 20 East.

Station 1 is the furthest upstream station on this stream (Figure 32). It is located approximately 100 feet inside the edge of the room and pillar mining associated with the mine's main headings. It is also located immediately below a mine portal, but no mine discharges or ponds were observed.

Station 2 is located over the barrier coal, which is the solid coal that remains unmined to protect the main headings from the subsidence of the longwall panel. The normalized discharge remains steady across this reach, even though the alluvial sediment at Station 2 is thick and the Station 1 was on bedrock.

The normalized discharge remains steady from Station 2 to Station 4A. Station 3 is located over the mid-panel of 21-East. The mid-panel area is expected to be in zone of compression and generally have less of a water impact problem from longwall subsidence fracturing (Rauch, 1989). Between Station 2 and 3, Williams Creek crosses over the end of the panel, a reach associated with tension and subsidence fracturing. Then between Station 3 and 4A, the stream again crosses into the quarter-panel zone, a zone where the strata may be in tension.

Station 5 is located in the northern quarter panel zone over longwall panel 20 East. The stream passes over the gate-entry between the panels, from 1700 to 2140 feet $(518.2$ to $652.4 \mathrm{~m})$ downstream, where it then combines with a tributary stream at 2140 feet $(652.4 \mathrm{~m})$ downstream. It is within this reach that the normalized stream calculations detect a $12 \%$ increase in flow, the most significant inter-station change during high baseflow. As 
interpreted by this study, there are several areas within this reach that may impact the discharge observed at Station 5. These areas are the downstream edge of panel 21 East, the tributary stream or the upstream tension zone of panel 20 East. The downstream edges of panels can be zone of ground water recharge or underflow resurgence, tributary streams may have higher than average discharge, and upstream tension zones may be a zone of recharge (Dixon and Rauch, 1988).

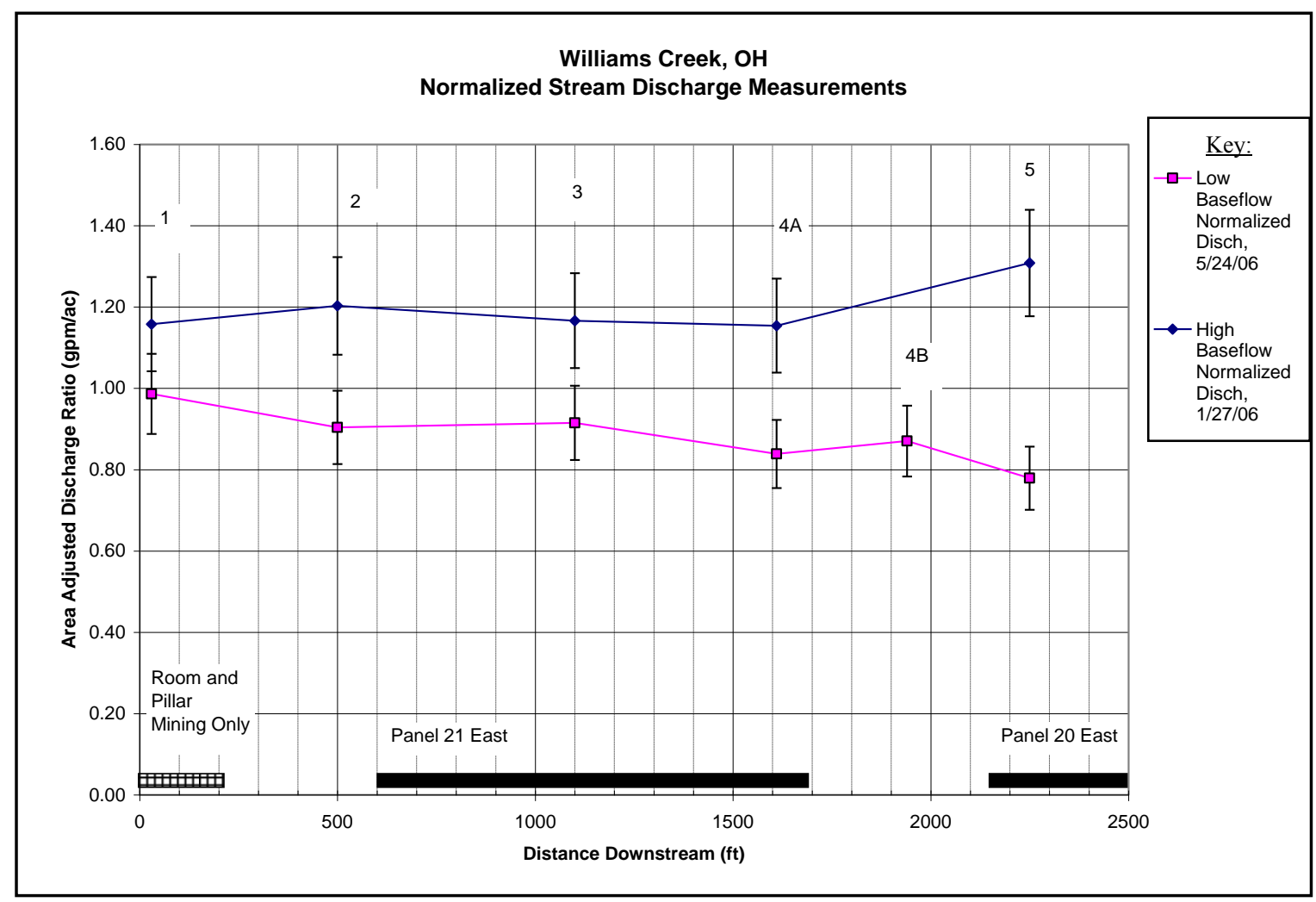

Figure 33. Measured high baseflow (HF) and low baseflow (LF) normalized discharges (aQdr) for Williams Creek, OH plotted over Powhattan No. 6 longwall panels and distance downstream. Discharges display $10 \%$ error bars.

Station 4B was added while conducting low baseflow measurements, midway between Station 4A and Station 5. This station was added to better define stream discharge the increase detected at high baseflow between Station 4A and 5. 
The stream demonstrates a decrease in normalized discharge throughout the measured reach during low baseflow. This trend is contrary to the trend produced by high baseflow data. The normalized stream discharge decreases $8 \%$ in the control reach, between Station 1 and 2. The edge of the mined longwall panel is 100 feet downstream of Station 2. Station 2 is beyond the limit of the subsidence basin but may be within the angle of dewatering influence(Appendix I, Table 5).

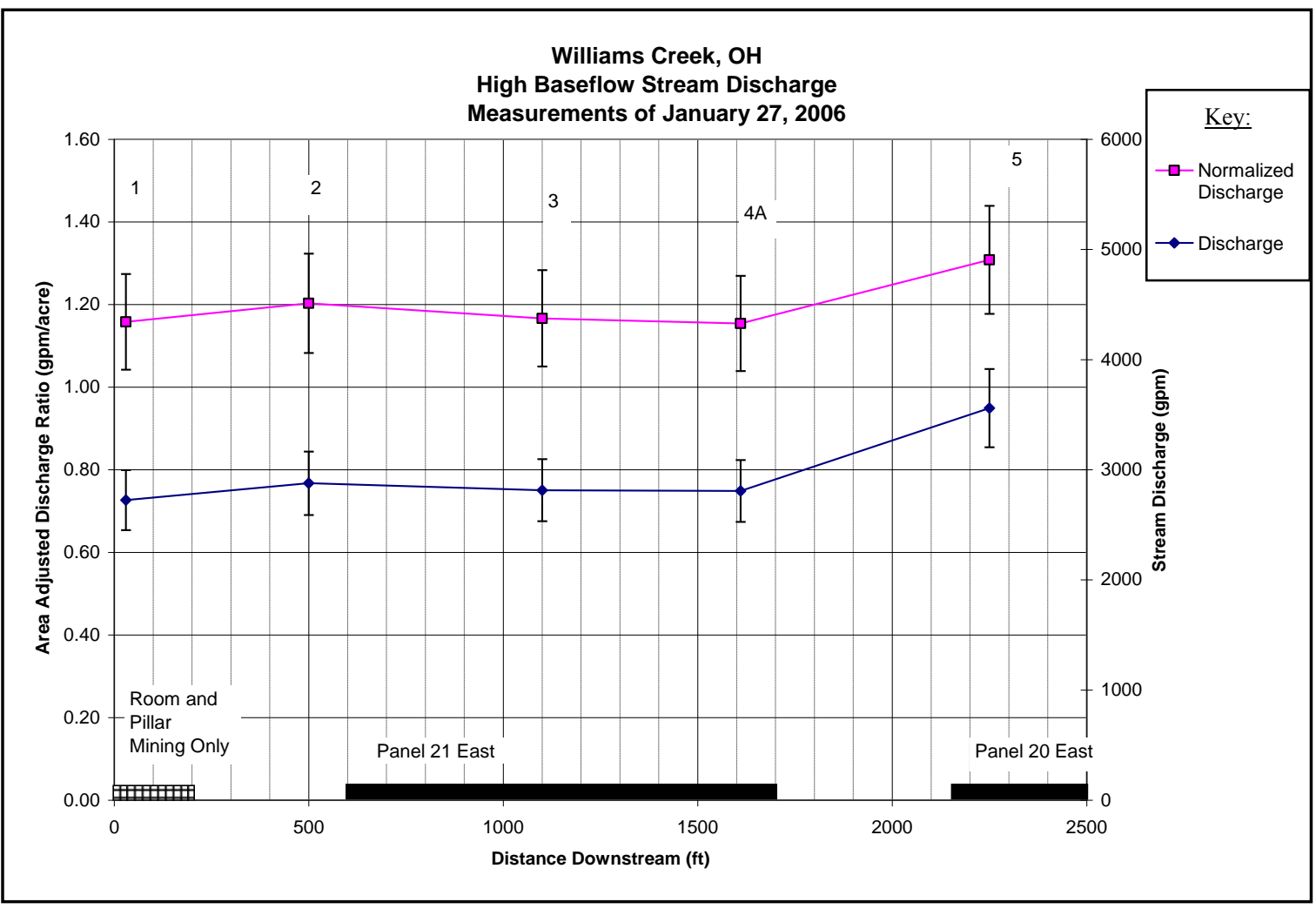

Figure 34. Measured high baseflow (HF) discharge (aQ) and normalized discharge (aQdr) for Williams Creek, OH. Discharges are plotted over Powhattan No. 6 longwall panels and measured distance downstream. Discharges display $+/-10 \%$ vertical error bars.

Station 1 has the highest discharge and highest normalized discharge of all the measuring stations for the low flow measuring event. Not only does the stream not receive 
enough baseflow over the mined area to keep the upstream ratio, the stream can be defined as a losing stream for three intervals of the measured reach (Fetter, 2001).

The stream decreases 15\% in normalized discharge between Station 1 and 4A, which is from the control reach to the downstream edge of panel 21 East. This relates to a stream flow loss of $280 \mathrm{gpm}(17.6 \mathrm{l} / \mathrm{sec})$. This calculated demonstrates the amount of water lost to underflow from the stream and does not include the baseflow that failed to reach the stream.

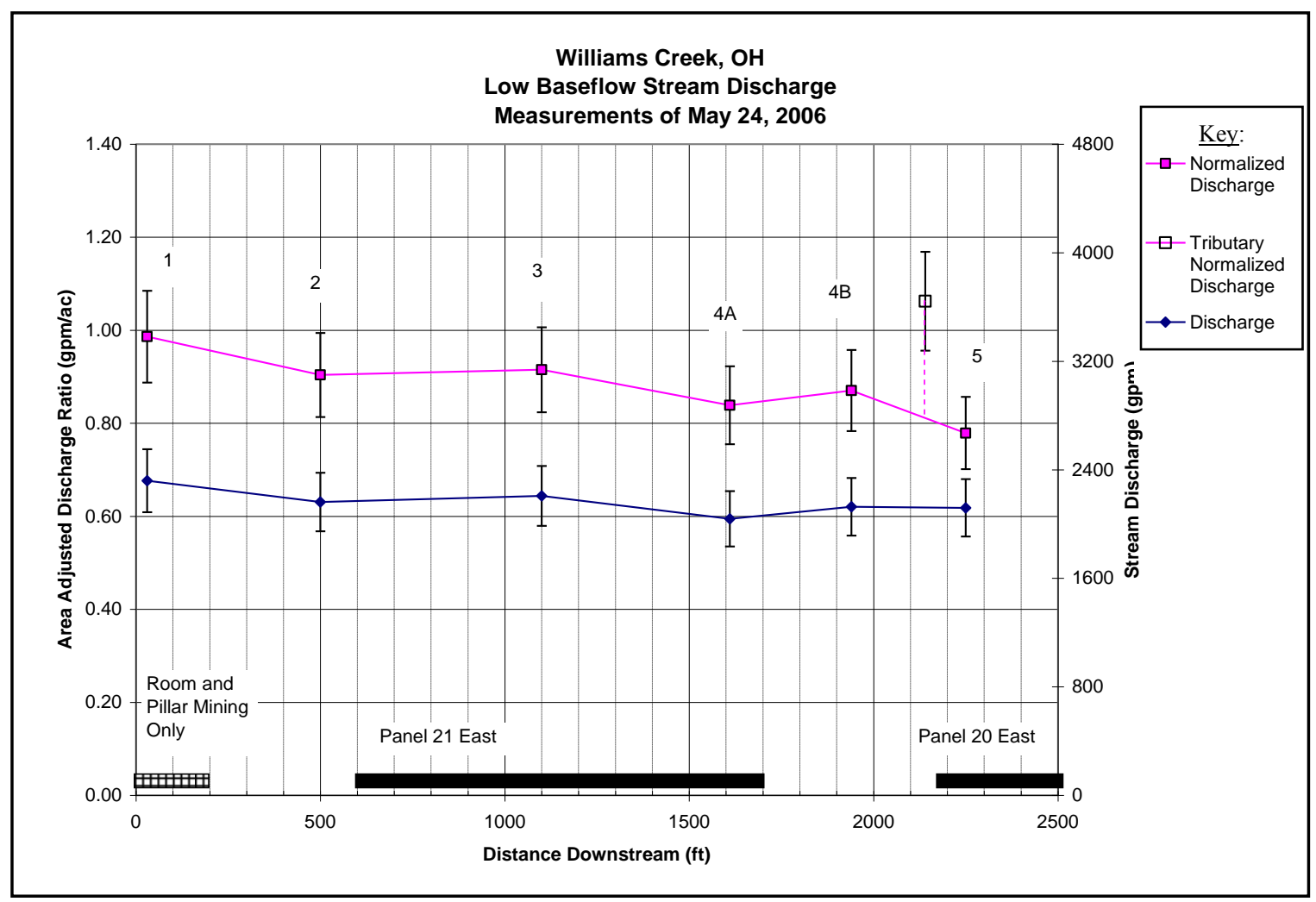

Figure 35. Measured low baseflow (HF) discharge (aQ) and normalized discharge (aQdr) for Williams Creek, OH. Discharges are plotted over Powhattan No. 6 longwall panels and measured distance downstream. Discharges display $+/-10 \%$ vertical error bars.

There is a minor 4\% increase in normalized discharge as Williams Creek flows over the downstream edge of panel 21 East, and onto the gate-entry separating panel 21 East from panel 20 East. An increase across this reach is consistent with other recorded discharges in 
Ohio and Pennsylvania where the stream will increase in discharge over the downstream edge of the panel.

Williams Creek joins a tributary 200 feet $(60.9 \mathrm{~m})$ downstream of Station 4B. The drainage basin of Williams Creek increases from 2304 acres (932.3 hectares) at Station 1, to 2380 acres (963.1 hectares) at Station 4A to 2652 acres (1073.0 hectares) at Station 5. Station 5 includes the drainage area of the tributary. This tributary appeared to be underdischarging during high baseflow, resulting in a normalized discharge decrease across this reach. However, low baseflow measurements of this tributary indicate that the stream is discharging higher than expected. The discharge area ratio was calculated to be $1.06 \mathrm{gpm} / \mathrm{ac}$, $7 \%$ higher than the ratio calculated at Station 1 within the control reach. It is inferred that the tributary was also discharging higher than expected at high baseflow

Overall, the measured reach of Williams Creek decreases $21 \%$ in normalized discharge from Station 1 to Station 5, a distance of 2220 feet $(676.8 \mathrm{~m})$. The resulting average rate of loss is $9 \mathrm{gpm}(0.5 \mathrm{1} / \mathrm{sec})$ per 100 feet $(30.5 \mathrm{~m})$ of stream, which is not dramatic, but for a stream that has had over nine years since mining to rehabilitate, is significant.

\section{Geophysical Measurements}

Very Low Frequency (VLF) and Terrain Conductivity (TC) geophysical surveys were completed over Williams Creek on August 2, 2005 (Appendix V, Table 1). The geophysical data show good correlation of anomalies. Good anomaly correlation suggests that the anomalies exist at both shallow and mid-depth, increasing the potential that they could influence stream flow (Appendix III, Table 2). There is very little metallic interference, 
allowing for a less cautious approach to interpreting the geophysical data. The data show some expected anomaly areas associated with mine subsidence, and some unexpected anomaly areas.

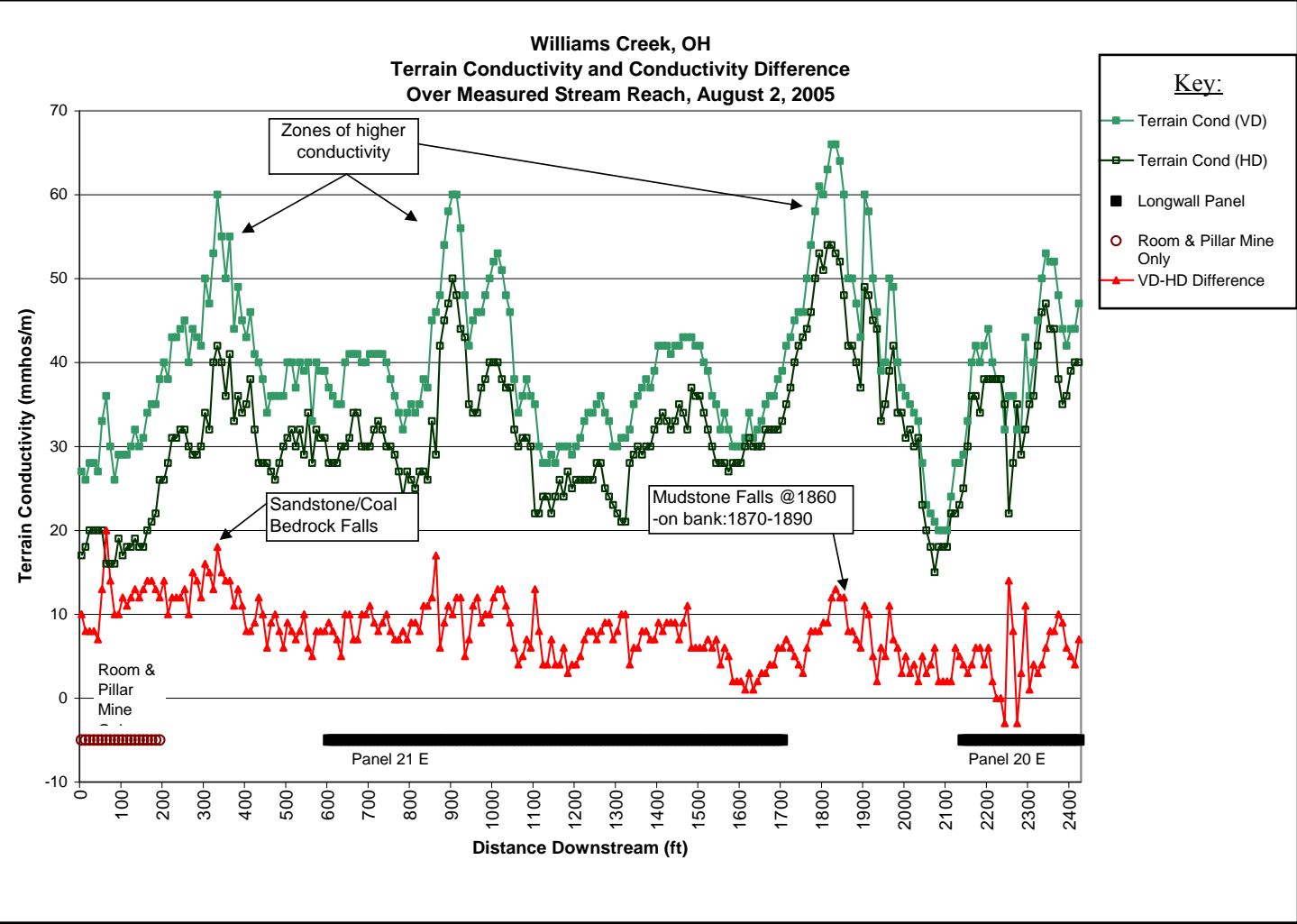

Figure 36. Terrain Conductivity (both vertical dipole (VD) and horizontal dipole (HD)), measurements along the study reach of Williams Creek, Ohio. Some higher conductivity zones are identified for the reader. Dipole value differences for each sounding location are also shown for relative difference changes across the study area. Data are shown with respect to longwall panel location located at the base of the graph, i.e. panel 21 E and panel 20 E. Room and pillar main headings are located at the bottom left of the graph. . 
Anomaly WC1 (330 feet) / (100.6 m)

Terrain Conductivity steadily increases from $27 \mathrm{mmhos} / \mathrm{m}$ at 0 feet, to $60 \mathrm{mmhos} / \mathrm{m}$ at 330 feet $(100.6 \mathrm{~m})$ (Figure 36). Since the TC survey average reading is $39.6 \mathrm{mmhos} / \mathrm{m}$, an increase of $33 \mathrm{mmhos} / \mathrm{m}$ over 300 feet $(91.4 \mathrm{~m})$ is a significant increase. The anomaly is also detected by VLF at 360 feet $(109.7 \mathrm{~m})$, and interpreted as a shallow subsurface anomaly due to its steep, narrow peak (Figure 37). The VLF anomaly is not interpreted as being very deep but more of a near surface limited zone of higher conductivity.

This anomaly is located over the barrier coal, which has not been mined. This anomaly is located in an unexpectedly fractured area. This anomaly may be a natural fracture enhanced by mine subsidence. This anomaly is related to the following three anomalies (WC2 to WC4).

\section{Anomaly WC2}

The VLF anomaly detected at 450 to 460 feet (137.7 to $140.2 \mathrm{~m}$ ) is not represented by the TC survey. The VLF anomaly indicates 20 feet $(6.0 \mathrm{~m})$ wide vertical anomaly seated mid-depth to deep. This anomaly is not represented near the surface and by itself is not expected to be a factor in stream flow changes. It too is located over the barrier coal, which is located from 200 to 600 feet $(60.9$ to $182.9 \mathrm{~m}$ ) downstream. The upstream edge of longwall panel 21 East is $450 \mathrm{ft}$ downstream but does not help explain the mid-depth to deep anomaly detected by the VLF since the edge of the panel is still 150 feet downstream. Furthermore, a shallow surface anomaly would be expected near the edge of the subsidence basin, not the deep anomaly that was detected. The strong VLF reading and deep vertical 
nature of the anomaly suggests that it is real and may again be caused by longwall mine subsidence.

The property owner noted during the initial field visit that the stream went dry immediately after longwall mining of panel 21 East. He pointed out a deep pooled reach of stream where the stream had stopped flowing at approximately 520 to 570 feet (158.5 to $173.7 \mathrm{~m})$ downstream. This location is approximately 30 to 80 feet $(9.1$ to $24.3 \mathrm{~m})$ upstream of the projected edge of longwall panel 21 East. There were no significant geophysical anomalies detected through this reach of known prior stream loss. The lack of an anomaly across this location may be due to the age of mining. The mining of panel 21 East was completed nine years prior to the time that the geophysical survey was conducted, possibly giving the strata time to seal fractures that may have opened immediately after mining.

\section{Anomaly WC3 and WC4}

A large VLF anomaly, identified as WC3, is present from 840 to 860 feet (256.0 to $262.1 \mathrm{~m}$ ) downstream. This anomaly has a steep peak, indicating its relative shallowness, but it is also very conductive and symmetrical as shown by the shape and large values of the K-H filtered VLF ratio (15.91). The full anomaly ranges from 810 to 890 feet (246.9 to $271.3 \mathrm{~m}$ ). The anomaly is detected over the mined longwall panel $21 \mathrm{E}$, approximately 210 feet $(64.0 \mathrm{~m})$ downstream from the edge of the unmined barrier coal. Due to the streams directions being at an acute angle to the long axis of the longwall panel, anomaly WC3 is only 145 feet (44.2 m) perpendicular from the barrier coal.

WC3 is a substantial anomaly and interpreted as a mine subsidence fracture. This anomaly is not located very near the edge of the limit of longwall mining, as would be 
expected. A deep seated VLF anomaly would be expected to have been detected west of the edge of mining, near 530 to 540 feet (161.5 to $164.6 \mathrm{~m})$ downstream, but no substantial anomalies were detected at that location.

Terrain Conductivity readings, for anomaly WC4, begin increasing around 840 (256.0 m) but do not peak until 900 to 910 (274.3 to $277.4 \mathrm{~m}$ ) feet with a value of $60 \mathrm{mmhos} / \mathrm{m}$. This peak is 50 to 60 feet $(15.2$ to $18.2 \mathrm{~m})$ removed from the VLF anomaly WC3. Since this shallow TC anomaly is not coincident at the surface with the deeper VLF anomaly, the anomaly set may reflect different parts of the same fracture. Dipping fractures would be detected at different distances on the creek at different sounding depths. Since the shallow anomaly (WC4) is detected further downstream (further east) from the deeper anomaly (WC3), the fracture is determined to be dipping west.

The perpendicular distance from the barrier coal, which happens to be the closest protuberance for the subsidence, is approximately 160 feet $(48.7 \mathrm{~m})$, only 15 feet $(4.5 \mathrm{~m})$ further downstream than the peak of anomaly WC3. While the graph data associated with anomaly WC3 and WC4 appears to have a substantial westerly dip, the stream profile between these two anomalies is sub-parallel to the edge of the barrier coal, placing them closer to each other with respect to the barrier coal.

Anomalies WC1, WC2, WC3 and WC4 are thought to represent mine subsidence fractures, or subsidence enhanced natural fractures, even though these anomalies were not detected at locations typical for longwall subsidence. The data recorded and presented in the graphs and tables by the geophysical surveys are very strong. There are no known human metal interferences and yet there are large deviations from baseline in the conductive and magnetic ratio databases, i.e. anomalies. The anomalies from both surveys correlate well 
with each other suggesting that they are real and represent conductive fractures in the subsurface of Williams Creek.

These two sets of fractures, WC1 and WC2 as set 1 and WC 3 and WC4 as set 2, are believed to be representing two fractures that have developed as a result of a cantilever beam being rotated across the eastern edge of the panel 21 East barrier coal. WC1 represents the surface expression of the fracture that is detected at depth by WC2. This fracture dips east, toward the eastern edge of the barrier coal. Anomaly WC1 is 240 feet $(73.1 \mathrm{~m})$ and WC2 is 150 feet $(45.7 \mathrm{~m})$ from this edge. WC4 represents the surface expression of the fracture that is detected at depth by anomaly WC3. This fracture is near vertical, but dips slightly west also towards the eastern edge of the barrier coal. Anomaly WC3 is 145 feet (44.2 m) and WC4 is 16 feet $(4.8 \mathrm{~m})$ from the eastern edge of the barrier coal. The cantilever beam appears to be weighted near equally between the supported and unsupported sides. The fulcrum of the beam is likely at or near the eastern edge of the barrier coal remaining at the western end of panel 21 East. The rotation of the cantilever would have increased the gradient of the stream through this reach, increasing the stream power. The increase in stream power would have increased erosion within this reach that may have been deposited downstream, possibly accounting for the excavation of stream sediment from 860 to 1120 feet ( 262.1 to $341.4 \mathrm{~m}$ ) downstream conducted by the operator approximately 1 year after mining panel 21 East. 


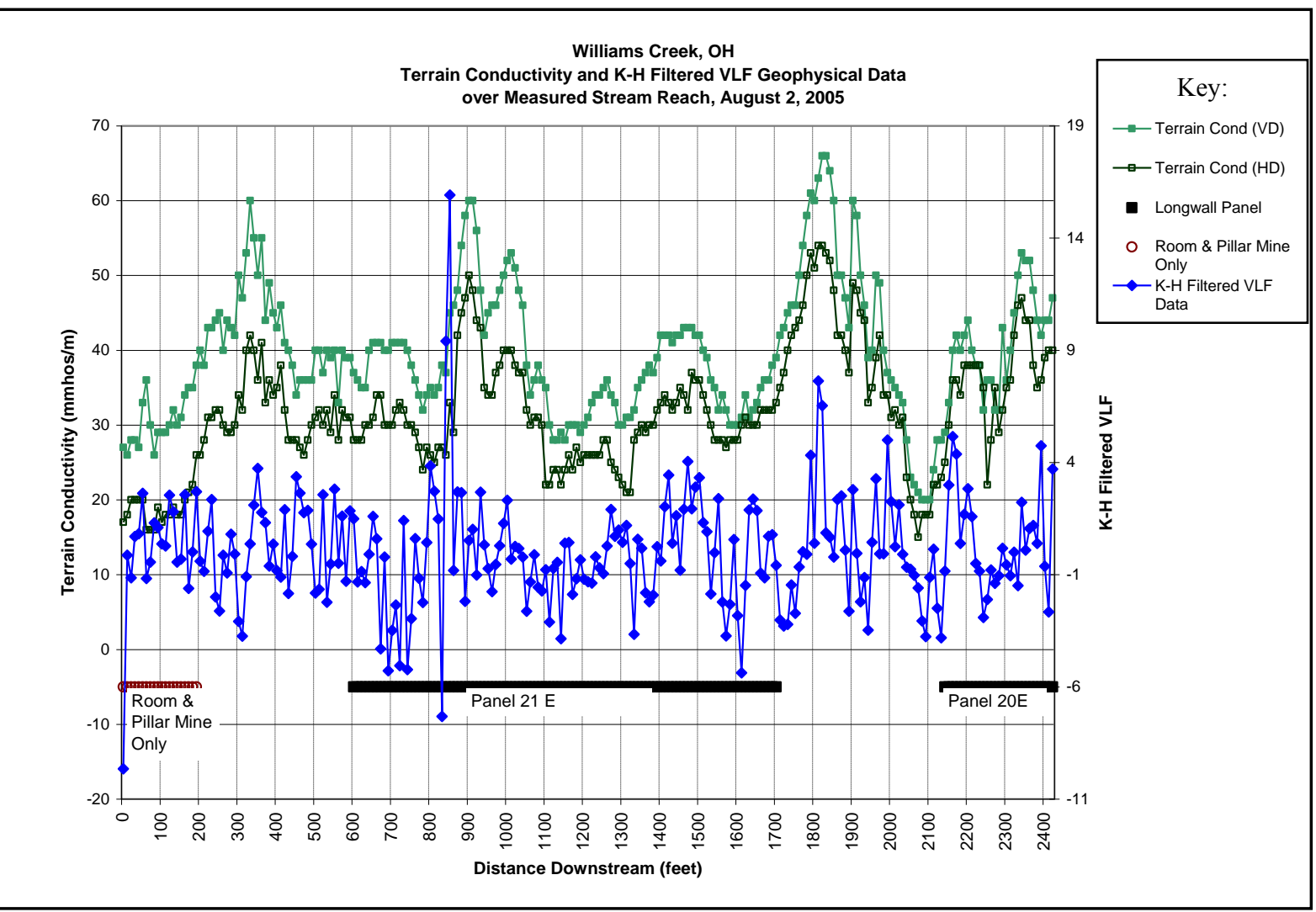

Figure 37. Terrain Conductivity measurements (both vertical dipole (VD) and horizontal dipole (HD)), and K-H Filtered VLF data recorded on August 2, 2005 over the study reach of Williams Creek, Ohio. Data are shown with respect to longwall panel locations, i.e. panel 21 E and panel $20 \mathrm{E}$ at the base of the graph. Room and pillar main headings are located at the bottom left of the graph.

Anomaly WC5

Terrain Conductivity and VLF surveys delineate an anomaly near 1470 feet (448.1 m) downstream. TC measurements (HD) peak around $43 \mathrm{mmhos} / \mathrm{m}$, a value only at the $80^{\text {th }}$ percentile. The VLF anomaly is broad and peaks within the $95^{\text {th }}$ percentile. The lateral distribution of the VLF anomaly and the low ranking of the TC values indicate a deep vertical anomaly without significant dip. The low ranking of the TC indicates that there should be poor, if any, connectivity of the anomaly to surface water.

This anomaly may represent a fracture zone, stemming from the lower fracture zone of mine subsidence, and penetrating further towards but not intersecting the surface. 


\section{Anomaly WC6}

As the stream nears the downstream edge of panel 21 East, the VLF survey detects significant shallow anomalies from 1630 to 1650 feet $(496.9$ to $503.0 \mathrm{~m})$ downstream. This anomaly is 20 feet $(6.0 \mathrm{~m})$ long and is relatively shallow, due to the steep peak. This anomaly is poorly detected by the TC survey by a peak at 1620 feet $(493.9 \mathrm{~m})$.

Shallow subsurface fracturing may be present at the edge of the longwall panel where a tension zone most likely exists near the surface, possibly causing the shallow anomalies. These shallow fractures would likely be oriented in an east- west orientation, parallel to the edge of the long axis of the longwall panel 21 East.

\section{Anomaly WC7}

Both geophysical surveys detect a significant anomaly over the gate-entry between panels $21-\mathrm{E}$ and 20-E. It is located 120 feet $(36.5 \mathrm{~m})$ from the downstream edge of panel 21 East and 320 feet $(97.5 \mathrm{~m})$ from the upstream edge of panel 20-E. The stream crosses over the gate-entry between the panels, from 1700 to 2140 feet $(518.2$ to $652.4 \mathrm{~m})$. The peak of the $\mathrm{TC}$ anomaly at 1820 to 1830 feet $(554.8$ to $557.9 \mathrm{~m})$ reaches the $99^{\text {th }}$ percentile. TC readings are within the $80^{\text {th }}$ percentile range from 1750 to 1880 feet (533.5 to 573.1 ), 50 to 80 feet $(15.2$ to $24.3 \mathrm{~m})$ on either side of the peak. VLF values go directly into the $99^{\text {th }}$ percentile from 1790 to 1820 feet $(545.7$ to $554.8 \mathrm{~m})$. This peak is steep and narrow indicating an anomaly that is at a high angle and comes near the surface.

Anomaly WC7 does have a high angle, but the shallower Terrain Conductivity survey detects the anomaly further downstream than the deeper sounding VLF survey, suggesting that the anomaly is dips slightly towards the southern edge of longwall panel 21 East. 
Anomaly WC7 is approximately 60 to 65 feet $(18.2$ to $19.8 \mathrm{~m})$ south of the mined longwall panel 21 East due the angle at which the stream crosses the panels. The anomaly peaks approximately 65 feet $(19.8 \mathrm{~m})$ within the 140 foot $(42.6 \mathrm{~m})$ wide gate-entry. It has such a steep inclination that it is interpreted to be either associated with the edge of the longwall panel subsidence fracture, or a subsidence enhanced natural fracture. The location of the fracture is not at the anticipated $24^{\circ}$ angle of draw but is near vertical fracture. Furthermore, geophysics detects this fracture at the near surface and at depth, suggesting that it will have an influence on the stream flow.

Bedrock exposed in the stream bottom across this anomaly correlates to the $30 \mathrm{ft}(9.1$ m) thick claystone unit present 170 to $200 \mathrm{ft}$ (51.8 to $61.0 \mathrm{~m})$ above the Pittsburgh main bed (Appendix XIII, Table 1). The claystone is exposed at in the streambed from 1730 to 1860 feet $(527.4$ to $567.0 \mathrm{~m})$ downstream, ending at a post-mining formed waterfall at 1860 feet (567.0 m).

The interpretation of anomaly WC7 is unclear, troubled by the fact that a thick conductive claystone unit is located at the surface. However, the VLF anomaly of WC7 is steep and narrow suggesting that a fracture is likely present beneath the conductive mudstone unit. Since the TC peak is well coordinated with the VLF peak, the presence of subsidence fractures within or beneath the claystone unit is expected.

The reason for the cautioned interpretation of anomaly WC7 stems from the properties of the rocks at the surface. Rock and sediment units high in clay content are denser and conduct electrical current better than other lithologic and sedimentary mediums. The clay mineral structure of the stratum offers low resistance to electrical current. The stratum may also be weathered, increasing the moisture content within the unit. Moisture in 
this unit will likely have a high dissolved ion concentration, further increasing the conductivity of the stratum. Claystone is expected to reduce surface water losses from the stream due to the low primary permeability that is typical of clay rich units and also for their ability to deform plastically into voids and crack (Fetter, 2001). The geophysical anomalies detected in this reach may be associated with a fracture set within the claystone unit itself, and the fractures that lie beneath.

\section{Anomaly WC8, WC9 and WC10}

A series of small distinct anomalies are recorded as the stream flows across the gateentry reach, and nears the upstream edge of the mined panel 20 East. These anomalies are all similar to each other in presentation. They are well detected by the TC survey but they are also represented by the VLF survey. The TC survey has two steep peaks at 1900 to 1910 feet (579.2 to $582.3 \mathrm{~m}$ ) and 1960 to 1970 feet (579.5 to $600.6 \mathrm{~m})$. Each peak has two data points at the peak, adding weight to the existence and shallowness of the anomalies, suggesting that the anomalies are only 20 -foot $(6.0 \mathrm{~m})$ zones of higher conductivity. These anomalies rank in the $95^{\text {th }}$ and $80^{\text {th }}$ percentiles, respectively. The VLF anomalies also peak at the same distances, 1900 and 1960 feet $(579.2$ to $597.5 \mathrm{~m})$. These are both only one data point anomalies, suggesting that there are shallow and less laterally extensive. Both VLF peaks are $90^{\text {th }}$ percentile anomalies.

Immediately following anomalies WC8 and WC9 is an anomaly detected only by VLF survey. At 1990 feet $(606.7 \mathrm{~m})$ downstream, the stream is still over the gate-entry between panels 20-East and 21-East. Anomaly WC10 is near vertical, appears to extend from mid-depth to deep, and shows possible connection to the TC anomaly WC9. 
The anomalies WC8, WC9 and WC10 are measured to be $60(18.2 \mathrm{~m}), 40(12.1 \mathrm{~m})$ and 30 feet $(9.1 \mathrm{~m})$ perpendicular from the edge of the mined panel 20-E. WC9 and WC10 appear to represent a high angle fracture with a southerly dip towards the edge of panel 20-E. These anomalies appear to be the near vertical expression of subsidence fracturing from panel 20-E.

\section{Anomaly WC11}

Terrain Conductivity values increase to $43 \mathrm{mmhos} / \mathrm{m}$, just less than the $80^{\text {th }}$ percentile, at a distance 2160 to 2200 feet ( 658.5 to $670.7 \mathrm{~m}$ ) downstream. The VLF survey detects a $95^{\text {th }}$ percentile mid-depth angular anomaly in this location. More specifically, this anomaly dips from shallow cover near 2160 feet $(658.5 \mathrm{~m})$ at the edge of the panel, southerly to middepth at 2200 feet $(670.7 \mathrm{~m})$, placing its detectable base 50 feet $(15.2 \mathrm{~m})$ inside the panel. Natural fractures typically occur with a strong vertical orientation. With an apparent dip of $30^{\circ}$ and an apparent strike of east west, the angle that the anomaly presents is more likely associated with subsidence induced fractures.

Anomaly WC12

A TC anomaly is detected from 2330 to 2360 feet ( 710.3 to $719.5 \mathrm{~m}$ ). The anomaly reaches the $90^{\text {th }}$ percentile range but may be a detection of shallow natural high conductivity ground water. Springs were noted coming from the southern stream bank near the stream water surface from 2330 to 2350 feet ( 710.3 to $716.4 \mathrm{~m}$ ). The TC survey likely detected these springs because they appeared to be precipitating metals as the water seeped down the bank to the creek. Since precipitates deposited at the surface and no significant VLF 
anomaly exists at this point, the TC anomaly represents the shallow subsurface; likely associated with this ground water.

\section{$\underline{\text { Alluvial Sediment Measurements }}$}

Alluvial thickness and particle size were measured on May 24, 2006. Low flow stream measurements were taken on the same day. Alluvial thickness measurements were collected at each stream monitoring station and the results are presented in Figure 38.

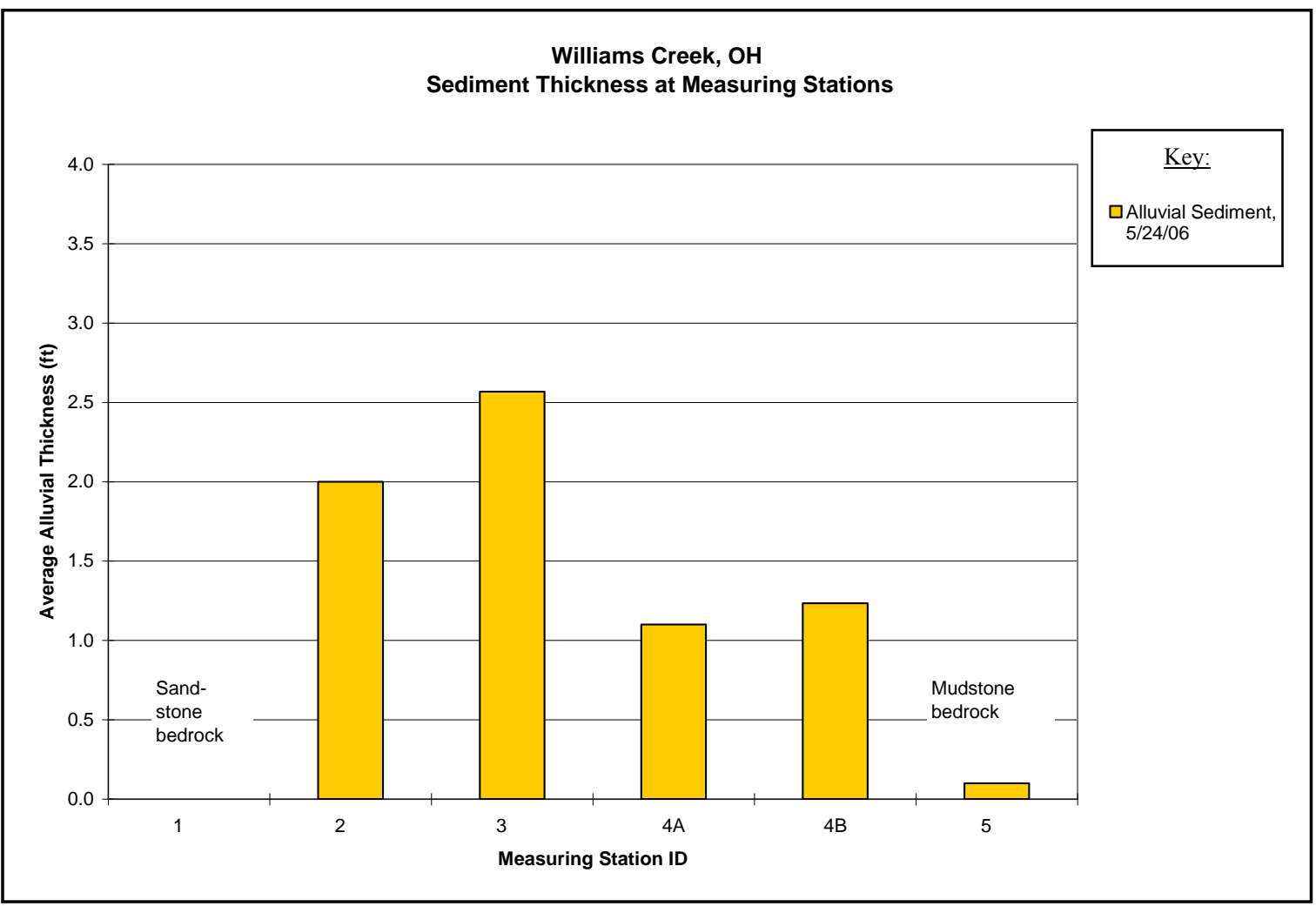

Figure 38. Average alluvial sediment thickness at stream measuring stations on the study reach of Williams Creek, Ohio.

During low flow, the stream decreases $20 \%$ in normalized discharge between the most upstream and downstream stations. During high flow, the stream gains $12 \%$ normalized discharge between these two same stations. 
The average sediment thickness for the entire measured stream reach is 1.2 feet $(0.36$ m). Sandstone bedrock is present at Station 1 and claystone bedrock is present at Station 5 . The thickest alluvium is at Stations 2 and 3, and the thinnest alluvium, aside from the bedrock noted at Stations 1 and 5, is found at Stations 4A and 4B. Samples 4A and 4B have a layer of sediment covering the same claystone bedrock as Station 5.

Alluvial sediment thickness decreases over the upstream tension zone due to a stream gradient increase towards the center of the subsidence basin. Eroded sediment from the tension zone reach is transported and deposited across the quarter-panel reach. The thickest sediment is within the upstream quarter-panel reaches.

The particle size distribution for Station $4 \mathrm{~A}$ is not normally distributed and does not have a linear cumulative frequency distribution. This distribution of the unstratified volumetric sampling of the armor and subarmor layers suggests that there has been some amount of change associated with the stream channel or stream discharge. The stream bedform, profile and pattern will adjust as conditions are imposed on the stream that may affect its discharge or profile, i.e. mine subsidence impacts.

\section{Interpretation of Data}

Stations 1 at 30 feet $(9.1 \mathrm{~m})$ and 2 at 500 feet $(152.4 \mathrm{~m})$ represents the control reach of Williams Creek. The high and low baseflow discharge ratio varies slightly, representing a good control reach. This consistency suggests that mine subsidence does not significantly impact this reach.

Geophysical surveys detect two significant anomalies within the control reach of Williams Creek. These anomalies are interpreted to be mine subsidence related fractures. The fractures are not at predicted locations or at the predicted angle of draw for subsidence. 
Instead, they are located further upstream away from the edge of panel 21 East. Anomaly WC1 (260 to 430 feet, 79.2 to $131.0 \mathrm{~m}$ ) is a shallow TC and VLF anomaly while anomaly WC2 (450 to 460 feet, 137.1 to $140.2 \mathrm{~m}$ ) is a deep VLF anomaly with no significant TC expression. These two anomalies represent the near surface and deeper locations of a high angle fracture. The detected fracturing does not have a significant impact on the stream flow of the control reach.

The alluvial sediment of the control reach is significantly varied. There is no alluvial sediment covering the sandstone bedrock substrate at Station 1 (30 feet, $9.1 \mathrm{~m})$. There is also no sediment covering the sandstone and coal bedrock exposures and resulting scours over part of anomaly WC1 (260 to 360 feet, 79.2 to $109.8 \mathrm{~m}$ ). There is, however, an average of two feet of alluvial sediment at Station 2, 500 feet $(152.4 \mathrm{~m})$ downstream. The lower normalized discharge recorded at Station 2 during low baseflow, although not significant, is attributed to this increase in alluvial sediment. The normally distributed coarse gravel sediment at Station 2, with a $\mathrm{D}_{50}$ of $21.6 \mathrm{~mm}$, is allowing a greater percentage of stream water to transmitting as shallow groundwater through the hyporheic zone, causing a reduction of the water present within the stream, and finally, accounting for the minor decrease in normalized discharge.

Geophysical surveys detect fracturing and alluvial thickness varies greatly within the control reach. Although mine subsidence may have previously impacted the control reach, the time and area adjusted discharges of Station 1 and 2 are within error limits concluding that no impact by longwall subsidence presently exists.

One hundred feet downstream of Station 2, the stream flows over the upstream edge of panel 21 East (600 feet, $182.9 \mathrm{~m})$. This reach of stream across panel 21 East is 
represented by Stations 3 (1100 feet, $335.3 \mathrm{~m}$ ) and 4A (1610 feet, $490.8 \mathrm{~m})$ The high and low baseflow measurements for these stations record a minor decrease in normalized discharge of $6 \%$ and $4 \%$, respectively, as calculated from Station 2 to Station $4 \mathrm{~A}$. Minor normalized discharge variations confirm a lack of mining impact over the upstream quarterpanel and mid-panel reaches of panel 21 East.

Geophysical surveys detect three significant anomalies within the panel 21 East reach of Williams Creek. These anomalies represent a high angle fracture. Anomaly WC3 (840 to 860 feet, 256.0 to $262.1 \mathrm{~m}$ ) is the VLF anomaly detecting the deeper portion of the fracture, and WC4 (900 to 910 feet, 274.3 to $277.4 \mathrm{~m}$ ) is the TC anomaly representing the near surface portion of the fracture. WC5 (1400 to 1500 feet, 426.8 to $457.3 \mathrm{~m}$ ) has both a VLF and a TC expression suggesting that this anomaly may represent a near vertical zone of fracturing. The detected fracturing, although well defined and coordinated, does not have a significant impact on the stream reach across panel 21 East.

Alluvial sediment across panel 21 East varies significantly. The thickest deposit of alluvial sediment is located at Station 3, over the upstream quarter-panel. Thickening at Station 3 is a result of an increased stream slope over the upstream tension zone of the subsidence basin. Sediment thicknesses further downstream decrease from Station 3 to Station $4 \mathrm{~A}$ by $58 \%$. Mean sediment particle size increases at Station $4 \mathrm{~A}$ from $21.6 \mathrm{~mm}$ at Station 2, to $34.0 \mathrm{~mm}$ (very course gravel). An increase of $100 \%$ in the weight distribution of the particles greater than $64 \mathrm{~mm}$ affected the mean. A coarsening of sediment particle size has increased the permeability of the alluvium and perhaps increasing the hyporheic zone discharge. 
Normalized stream discharge declines across the panel, at both high and low baseflow conditions. The high baseflow discharge ratio at Station $4 \mathrm{~A}$ is within $1 \%$ of the discharge ratio of Station 1. This ratio confirms that there are no detectable mine impacts to the high baseflow. During low baseflow conditions, however, a decline in normalized discharge is detected.

Differing degrees of baseflow contribution cause the differences in high and low normalized discharges. During high baseflow conditions, a higher volume of ground water surplus provides recharge to the stream, maintaining the high discharge ratio downstream. During low baseflow conditions, a lower volume of ground water surplus causes a discharge ratio decline downstream. Mine subsidence fracturing generally increases rock permeability and storativity values. When low baseflow conditions exist over subsided longwall panels, fractured strata may retain more ground water, reducing the ground water surplus available to sustain a stream.

Approximately 100 feet downstream from Station 4A (1610 feet, $490.8 \mathrm{~m}$ ), the stream flows over the downstream edge of longwall panel 21 East (+/- 1700 feet, $518.2 \mathrm{~m})$. The stream then flows across the gate-entry (1700 to 2140 feet, 518.2 to $652.4 \mathrm{~m}$ ) between panel 21 East and panel 20 East. This reach is represented by Station 4B (1940 feet,591.4 m). Station 4B was added during the low flow stream measuring event because of a significant increase in normalized discharge from Station 4A to Station 5 (2250 feet, $685.9 \mathrm{~m}$ ) during high base flow. High baseflow measurements from Station 4A to Station 5 record an increase of $12 \%$. Low baseflow stream discharge measurements fluctuate from losing, to gaining, back to losing between Station 4A to Station 4B to Station 5 . 
Geophysical surveys detect five significant anomalies between Station 4A and the upstream edge of panel 20 East. Three of these anomalies occur between Station 4A (1610 feet, $490.8 \mathrm{~m}$ ) and Station 4B (1940 feet, $591.4 \mathrm{~m}))$. These three anomalies are WC6 (1630 to 1650 feet, $490.8 \mathrm{~m}$ to $503.0 \mathrm{~m}$ ), WC7 (1750 to 1880 feet, $533.5 \mathrm{~m}$ to $573.1 \mathrm{~m}$ ) and WC8 (1900 to 1910 feet, 579.2 to $582.3 \mathrm{~m}$ ). These anomalies have no impact on low baseflow discharge, however, at high baseflow they may provide avenues of ground water resurgence . Anomalies WC9 (1960 to 1970 feet, 597.5 to 600.6), WC10 (1990 to 2000 feet, 606.7 $\mathrm{m}$ to $609.7 \mathrm{~m}$ ) and $\mathrm{WC} 11$ (2150 to 2200 feet, 655.4 to $670.2 \mathrm{~m})$ ), represent the upstream tension zone for panel 20 East. These anomalies have an impact on the stream discharge, even though a claystone bedrock is present from Station 4A to Station 5. Stream discharge decreases $10 \%$ during low baseflow from Station $4 \mathrm{~B}$ to Station 5, even though the tributary is discharging

Sediment thickness across the gate-entry between panel 21 East and panel 20 East is thin, or missing, over a thick claystone unit. The claystone unit does not completely inhibit stream flow loss, as identified from Station $4 \mathrm{~B}$ to Station 5 during low baseflow. Fractures may intersect this unit and induce underflow.

A first order tributary stream enters the main stem at anomaly WC11. This tributary stream may increase the normalized discharge downstream of its confluence during high baseflow. Tributary stream underflow may also be resurging at the main stem because the tributary underflow is forced to the surface as it reaches the regional drainage level of the main stem. This resurgence has caused the main stem normalized discharge to exceed the expected discharge-area ratio (Carver and Rauch, 1994). The tributary has a greater than expected impact to the flow at the regional drainage level because less evapotranspiration has 
occurred on the areas recharge water thereby allowing a greater quantity of water to be supplied to ground water and underflow (Tieman and Rauch, 1987). A situation consistent with the previous research appears to be recorded with Williams Creek and its tributary at high baseflow conditions on January 27, 2006. The tributary contributes more water than expected to the regional drainage level stream, i.e. Williams Creek, causing the monitoring station downstream of the tributary confluence to record a higher discharge ratio than previous stations on the main stem. Underflow may be moving through conductive zones beneath the streams, such as anomaly WC11 detected near the confluence of the tributary stream with the regional drainage level stream (Appendix III, Table 2).

However, this tributary may cause a reduction in the downstream discharge ratio during low baseflow. If the tributary discharges at a lower ratio than the main stem, it could depreciate the resulting ratio. Mine subsidence impacts may account for the lower discharge ratio of the tributary, but without a pre-mining comparison this assumption can not be conclusive.

\section{Stream Conclusion}

A stream survey of Williams Creek, in northern Belmont County Ohio, took place over an 8-year 3-month-old mined longwall panel, the oldest study stream in the group. The depth of the mine in the Pittsburgh Coal seam is approximately 260 to 280 feet beneath the stream. Stream flow fluctuations were visually undetectable during investigations.

The upstream tension zone is a subsidence fracture set with higher permeability and storativity values than that of the surrounding rock. Orientation of this study stream's tension zone is near parallel to the stream flow, projecting the panel-edge fracture sets down the valley sides within the study reach. Although some additional ground water recharge 
may affect stream flow, this fracture orientation will not encourage recharge from immediate hillsides within the study reach. Less measuring station variation is expected because edge of panel tension zones do not connect hilltop/hillside recharge areas with valley bottom discharge zones.

Substantial stream discharge changes are not detected, even though coordinated geophysical anomalies are present over the study reach. The anomalies that do not correspond to expected subsidence fracture areas are interpreted to be natural fractures that are conductively enhanced by mine subsidence.

Although not related directly to geophysical anomalies or sediment thickness and sizes, significant stream flow impacts persist at this study area. Dramatic fluctuations between measuring stations do not exist, however, effects from mine subsidence are detectable at low baseflow across the measured reach.

Sediment thickness changes across the measured reach. Erosion of the alluvial sediment is evident upstream of the measured panel and across the upstream tension zone. An increased stream gradient and alternating bedrock exposures and short deep pools represent this reach. Initial deposition of the eroded material occurs as sedimentary wedge deposited over the upstream quarter-panel reach. This sediment wedge is coarser than that measured in the remaining sediment stations and represents the deposition of lag, the heaviest material eroded from the upstream reach. A dramatic thinning and fining of alluvial material takes place over the downstream quarter-panel reach, representing a downstream fining of alluvial sediment across the study panel. Silt size particles may have deposited within the downstream quarter-panel reach if mine subsidence induced stream profile inversion and decreased stream velocity. 


\section{$\underline{\text { Southwestern Pennsylvania Streams }}$}

\section{Stream F}

\section{Results and Discussion of Data}

\section{Stream Flow Measurements}

\section{$\underline{\text { High Baseflow }}$}

High baseflow stream flow measurements were collected on January 28, 2006 (Appendix V, Table 1), approximately 18 months after panel 1 mined under the stream. This measuring event was conducted first, followed by the low baseflow measurement 3 months later. There were five measuring stations initially established within the study reach, two within the control reach, two across panel 1 and one over the gate-entry between panel 1 and panel 2. The recession constant for the high baseflow event, determined from Station 1 of the control reach, was calculated to be 5.69E-4 (Appendix I, Table 6).

Stations 1 and 2B represent the control reach (Appendix I, Table 6). Station 1 is approximately 670 feet $(204.2 \mathrm{~m})$ perpendicular from the edge of panel 1 over solid unmined coal (Figure 39). Station 2 is over the middle of the upstream gate-entry, separating the unmined coal from mined longwall panel 1. This station is approximately 120 feet $(36.5 \mathrm{~m})$ from the edge of the mined panel, and near the beginning of the cascade reach of the stream. Station 1 to Station 2 of the control reach records a normalized discharge increase of $10.4 \%$ (Figure 40).

Station 3B is located over the middle of the panel, between the steeper gradient over the upstream edge of panel 1 and the pooled reach over the downstream edge of panel 1. 


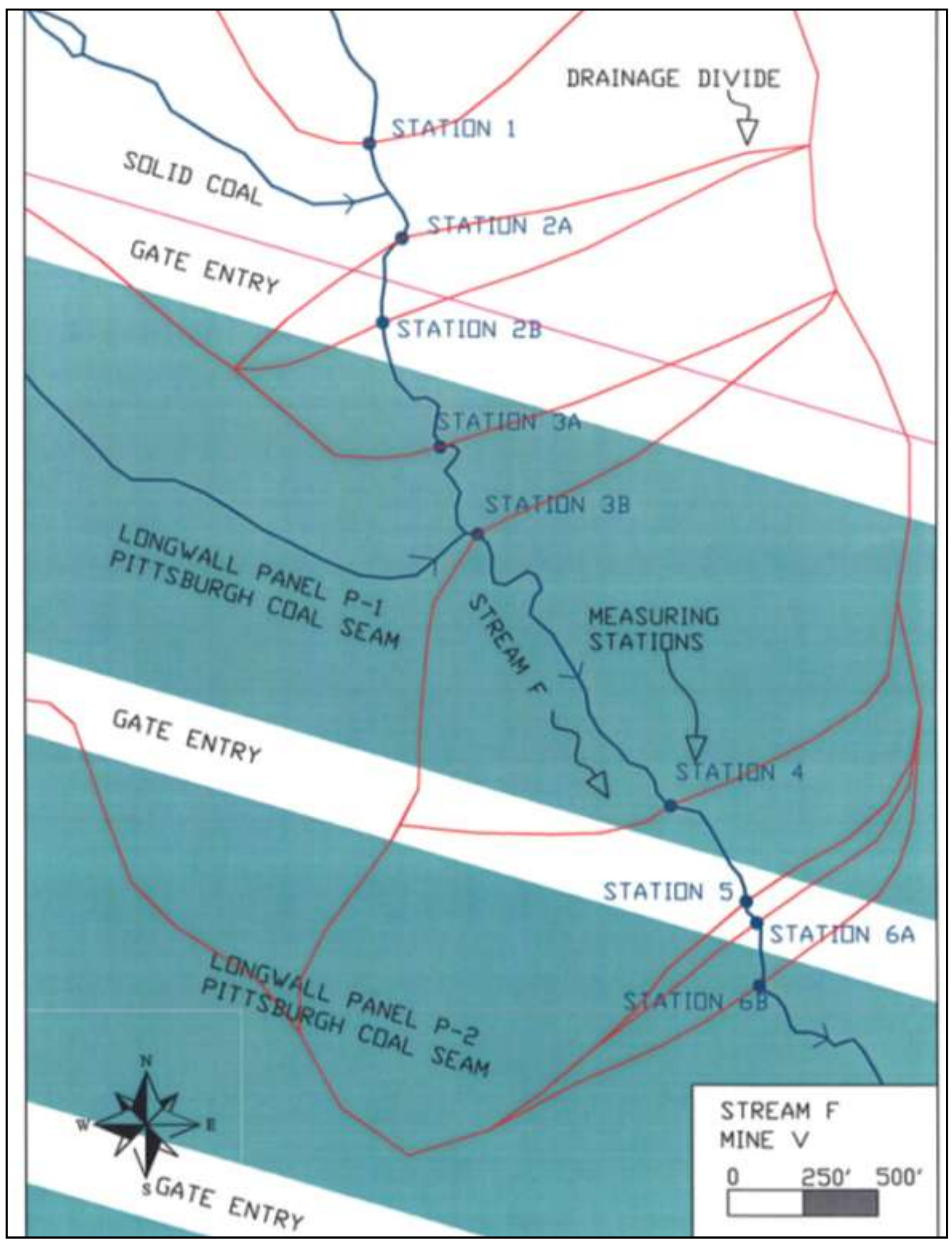

Figure 39. Station locator map for Stream F in Southwestern Pennsylvania. Panels P-1 and $P-2$ of Mine $V$ are shown in magenta. Stream $F$ and unnamed tributaries shown in blue. Drainage basins for measuring stations are shown in red. 
This station is immediately downstream of a tributary stream that joins the main channel from the west. This tributary joins the main channel over the mid-panel section of panel 1.

Normalized stream discharge decreases between Station $2 \mathrm{~B}$ and $3 \mathrm{~B}$ by $4 \%$ as the stream flows over the upstream edge of panel 1. The upstream edge of the panel has an increase in slope, followed by a plunge pool at the bottom. The tributary that joins Stream F from the west, between Station $2 \mathrm{~B}$ and $3 \mathrm{~B}$, receives drainage from a large area that has been longwall mined.

Downstream of Station 3B, the stream begins to pool and is pooled through Station 4 at 2610 feet $(795.7 \mathrm{~m})$ downstream. Station 4 is pooled but the channel width is restrictive enough to produce observable flow, which is not present elsewhere within the pool. Station 4 demonstrates a 12\% decrease in normalized discharge over 1090 feet $(332.3 \mathrm{~m})$. This measuring station records the lowest normalized discharge value for this measuring event. The value is $6 \%$ lower than Station 1 of the control reach. The pooling of the stream water and submerging of valley bottom soils in the vicinity of this station may induce lateral flow from the stream into the adjacent stream banks, possibly accounting for the minor reduction in stream discharge. Discharge of stream water into laterally and vertically accreted sands and silts may provide a ground water storage that was not present before subsidence.

Station 5 is located over the gate-entry, records the resurgence of the stream water after a mild decrease in Station 4. Normalized discharge increases $20 \%$ at Station 5, corresponding to a 101 gpm per 100 feet of stream rate of resurgence between these stations. Over the downstream gate-entry, Station 5 has a normalized discharge difference from Station 2B and 3B of 2\% and $6 \%$, respectively. The normalized discharge of Station 5 is similar to the higher rates of stream 
discharge of Station $2 \mathrm{~B}$ and $3 \mathrm{~B}$, but $12 \%$ greater than the normalized discharge recorded at Station 1.

Station 6B, located over the upstream quarter-panel of panel 2 , records a $7 \%$ decline in normalized discharge from Station 5. This station brings the discharge ratio back down to near control levels.

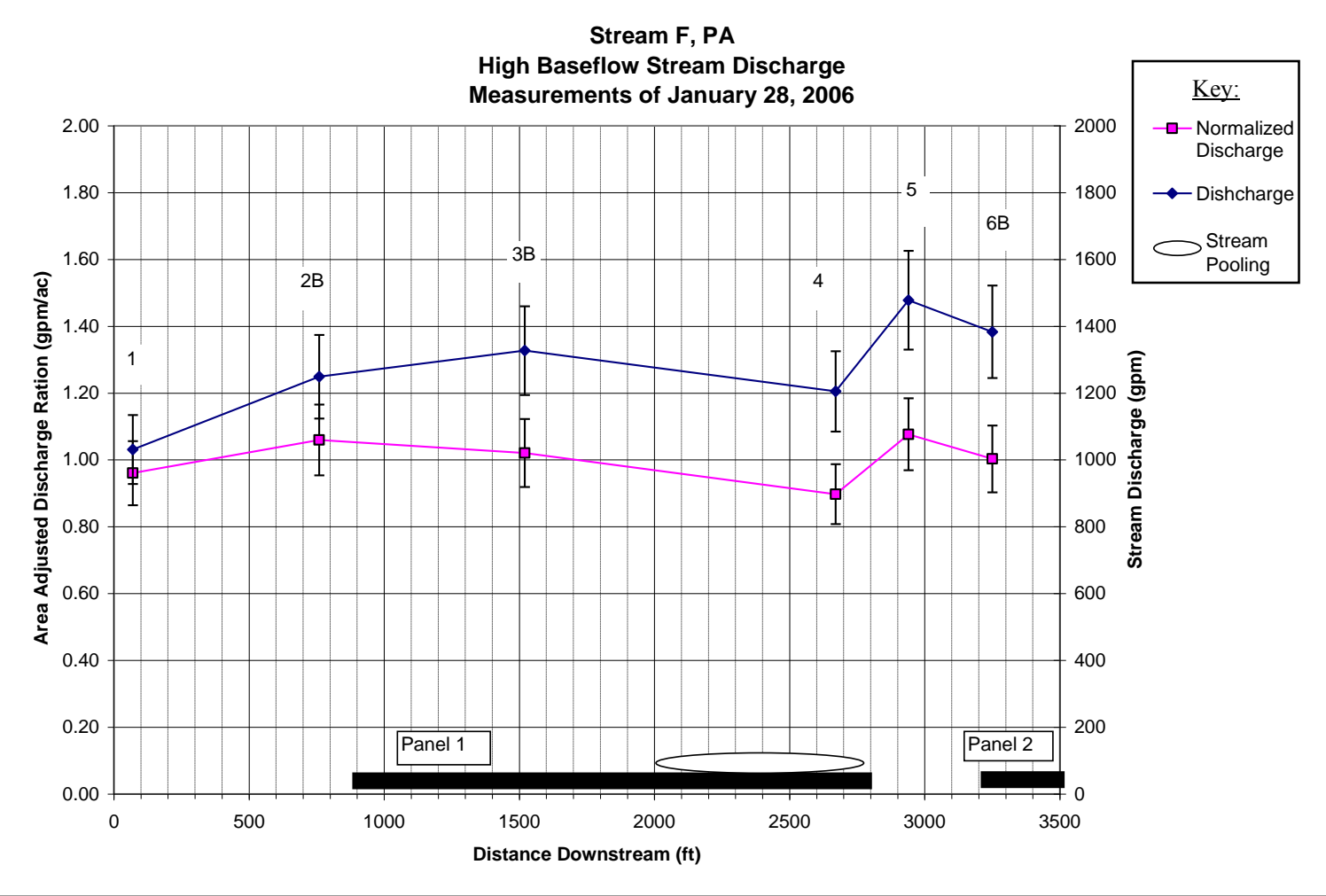

Figure 40. Measured high baseflow (HF) discharge (aQ) and normalized discharge (aQdr) for Stream F, PA. Discharges are plotted over Mine V longwall panels and measured distance downstream. Discharges display +/-10\% vertical error bars.

Over the measured stream reach, from Station 1 to Station $6 \mathrm{~B}$, there is a $5 \%$ increase in normalized stream discharge at high baseflow. This indicates that although there may be fluctuations in discharge and changes in the discharge ratio, Stream F shows no significant impact from long wall mining 18 months post-mining. This hydrograph also suggests that 
stream water may be temporarily stored in shallow aquifers over the panels, and then released over the downstream gate-entry. The stream resurgence over the downstream gateentry reach suggests no water is lost to the mine.

\section{Low Baseflow}

Three measuring stations were added during the low baseflow measuring event (Appendix I, Table 7). Station 2A was added as another control station. Station 3A was added over the upstream quarter-panel reach. Station 6A was added over the downstream gate-entry reach.

Stations 1 and 2A, the new control reach, show very good control at low baseflow (Figure 41). Station 2B, which showed an increase at high baseflow, now indicates a stream loss of $12 \%$ at low baseflow. Unlike the high flow values that only dropped below the baseline once, this station is one of several low baseflow measurements for this stream that have discharge ratio values below that of the control reach.

Station $3 \mathrm{~A}$ records a stream resurgence immediately downstream of the cascade reach that is present over the upstream tension zone. Normalized discharge increases $19 \%$ from Station 2B. Station 3B, which had a high baseflow discharge ratio higher than Station 1, has the lowest normalized discharge rate at low baseflow. This is a decrease of $16 \%$ from Station $3 \mathrm{~A}$. Station 4 has a $14 \%$ decrease in normalized discharge from Station $3 \mathrm{~B}$. The station documents a continued decrease in stream discharge and area normalized discharge.

High flow measurements at Station 5 delineated a reach of stream that experienced a resurgence of stream flow. This station at low flow indicates that the stream may now be losing water instead of gaining across this same reach. This reach represents the tension zone over the downstream edge of the mined panel and is an area that may experience a higher 
frequency of fracturing due to longwall mine subsidence. There is a $44 \%$ decrease in normalized discharge from Station 4 to Station 5, and is 53\% lower than the control reach.

Station $6 \mathrm{~A}$ is located 100 feet $(30.5 \mathrm{~m})$ downstream of Station 5 to check the low discharge recorded at Station 5. A normalized discharge increase of $79 \%$ is recorded from Station 5 to Station 6A; however, only a 6\% normalized discharge increase is detected from Station 4 to Station 6 A.

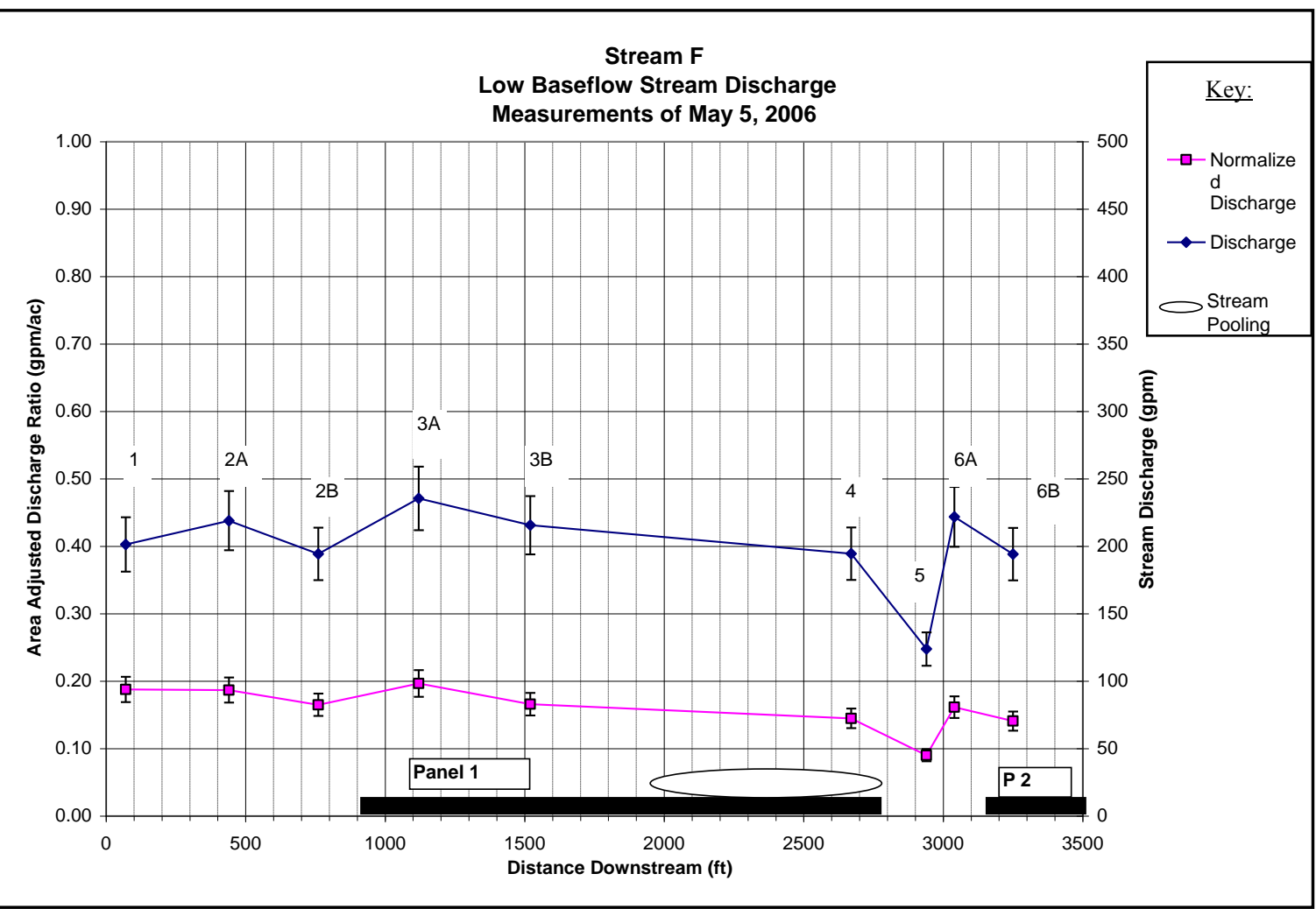

Figure 41. Measured low baseflow (LF) discharge (aQ) and normalized discharge (aQdr) for Stream F, PA. Discharges are plotted over Mine V longwall panels and measured distance downstream. Discharges display $+1-10 \%$ vertical error bars.

Station $6 \mathrm{~B}$ is located over the upstream quarter-panel of panel 2. The stream flow effects are not similar to those observed at Station 3A, which is also over the upstream quarter-panel. Station $3 \mathrm{~A}$ demonstrates a $12 \%$ increase in normalized discharge as the 
stream crosses the upstream edge of panel 1, whereas, Station 6B documents a decrease in normalized discharge of $12 \%$ as the stream crosses the upstream edge of panel 2 .

\section{$\underline{\text { Geophysical Survey Measurements }}$}

Stream $\mathrm{F}$ is a very good location to conduct a stream flow survey. There is an upstream reach with little development and plenty of distance before the headwaters are to be mined under, allowing for good control. Unfortunately, Stream $\mathrm{F}$ is also a terrible place to conduct geophysical surveys. There were interferences that caused problems collecting and interpreting the results.

Stream F winds its way through hay fields and overgrown fields filled. The banks of the creek in these fields are overgrown with small trees, shrubs and briars. This forced the TC survey, which uses a fixed 12 foot-long boom to be conducted entirely on the bank of the creek. This decision resulted in very low sensitivity to possible subsidence fractures beneath the stream because there was up to 5 feet $(1.5 \mathrm{~m})$ of difference between the creek level and the top of the bank.

Further complicating the survey, the pooling associated with the mine subsidence along the downstream edge of panel 1 resulted in overbank flooding forcing portions of the survey to be conducted even further from the stream (Figure 42).

In addition, there are seven major interferences within the surveyed. This caused both TC and VLF data to become anomalous over buried pipelines and metal bridges. Each object of interference has a range of influence. Interference over a buried pipeline will affected VLF data for 200 foot $(60.9 \mathrm{~m})$ both upstream and downstream of the source (Figure 43). 
Interference affected the TC data for approximately 25 feet both upstream and downstream of the source.

Nonetheless, some real data can be interpreted from the geophysical surveys.

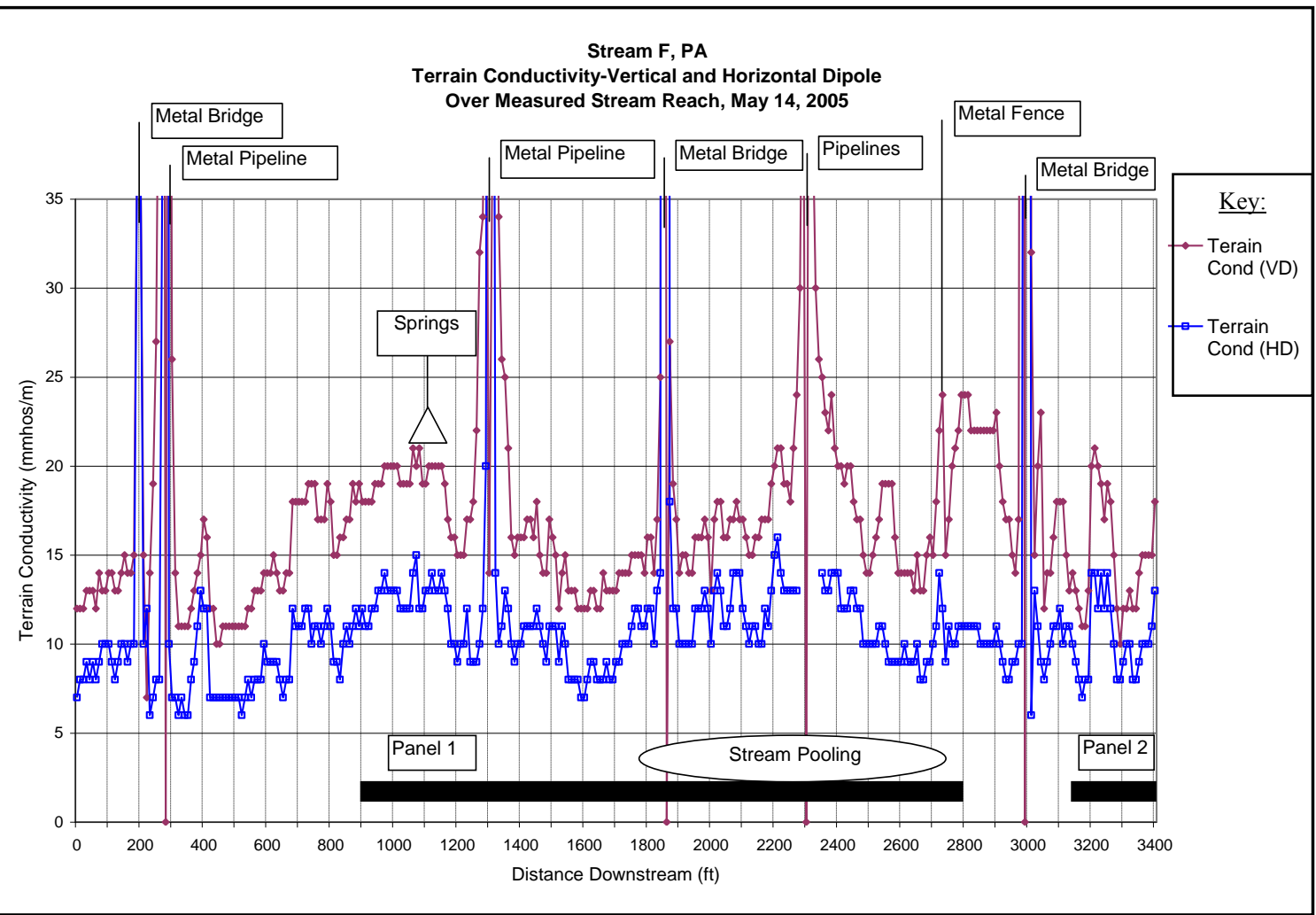

Figure 4. Terrain Conductivity with both vertical dipole (VD) and horizontal dipole (HD) along study reach of Stream F, PA. Data are shown with respect to longwall panel location located at the base of the graph.

Anomaly F1 (640 to 800 feet / 195.1 to $243.9 \mathrm{~m}$ ) and F2 (870 to $1160 \mathrm{feet} / 265.2$ to $353.6 \mathrm{~m}$ )

An increase in TC, from $10 \mathrm{mmhos} / \mathrm{m}$ to $20 \mathrm{mmhos} / \mathrm{m}$ (VD), is detected from 640 to 1160 feet (195.1 to $353.6 \mathrm{~m}$ ) downstream. This shift coincides with the upcoming upstream edge of panel 1, located at 900 feet $(274.3 \mathrm{~m})$ downstream. Anomaly F-1 and F-2, are coordinated anomalies located beneath Station 2B. A broad TC increase is observed in both 
the Vertical Dipole and the shallower, Horizontal Dipole (Figure 42). The increase of both of these surveys indicate that the anomaly is detected near surface and may influence the surface water discharge (Ackman and Barta, 2002). The VLF anomaly is located under the earlier portion of the TC anomaly from 680 to 730 feet $(207.3$ to $222.6 \mathrm{~m})$, upstream of Station 2B (760 feet / $231.7 \mathrm{~m})$. Station 2B records a flow increase at high baseflow and flow decrease at low baseflow indicating that shallow fracturing may influence the stream flow at this point.

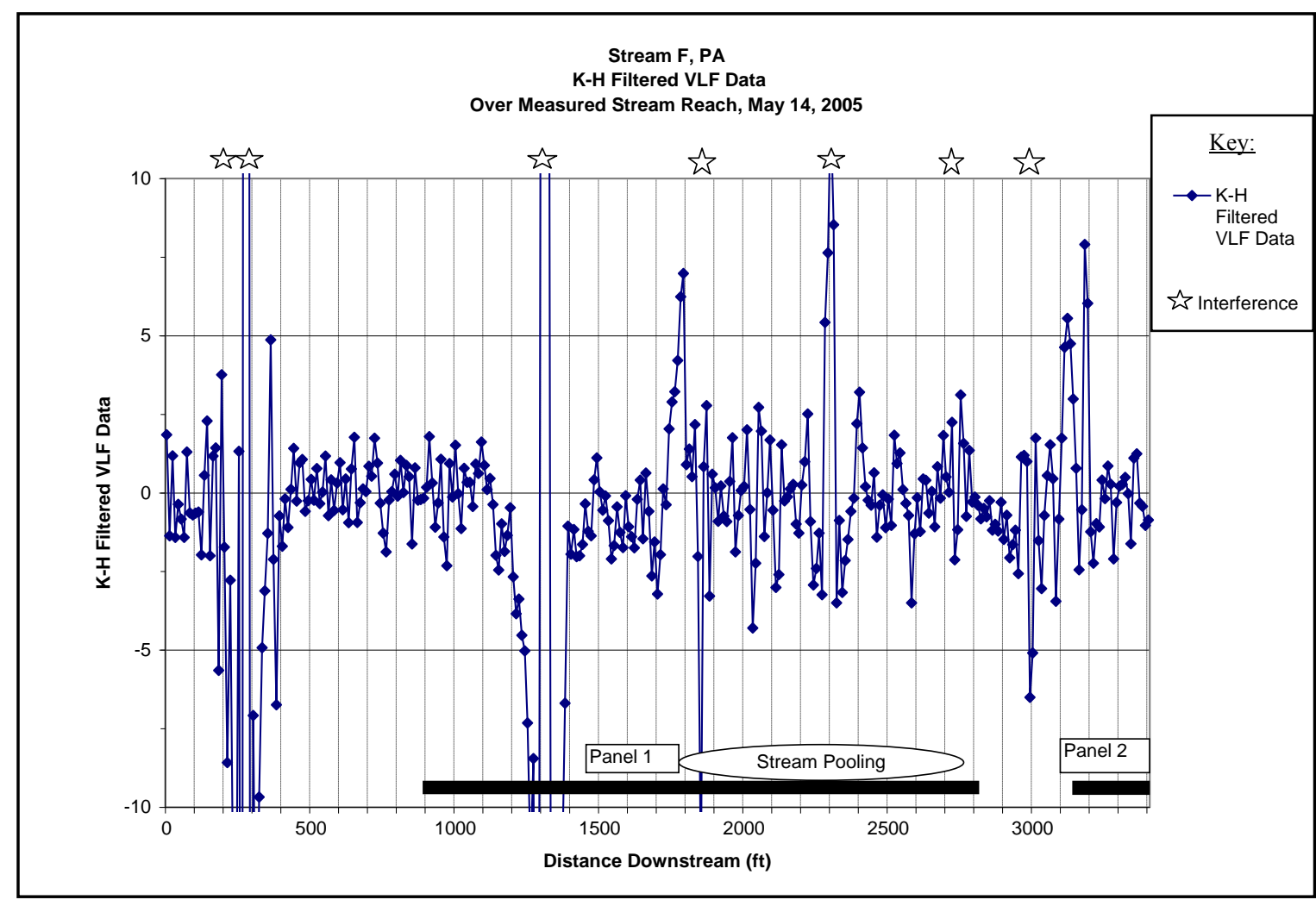

Figure 43. K-H Filtered VLF Data along study reach of Stream F, PA. Data are shown with respect to longwall panel location, at the base of the graph. Interferences from conductive man-made features are shown by stars.

The stream between 1010 and 1080 feet (307.9 to $329.2 \mathrm{~m}$ ) downstream increases in gradient over the upstream tension zone. Bedrock is exposed and dislodged large boulders 
show signs of scouring. Springs discharge at the top of the bank, on the other side of the creek from the TC survey, at 1080 feet (329.2 m) downstream. From 1080 to 1090 feet (329.2 to $332.3 \mathrm{~m}$ ) downstream, beginning at the bottom of the scouring riffle, is a 'pot hole' eroded out of the bedrock in the bottom of the stream bed. The 'pot hole' is approximately ten feet $(3.0 \mathrm{~m})$ in diameter and is deep enough that the bottom could not be observed. The large circular hole in the stream bottom appears to be derived from the erosive potential created by the steep gradient of the immediate upstream reach. The rock that was removed from the pot hole is strewn 60 feet $(18.2 \mathrm{~m})$ downstream. The gradient of the stream is significantly lower from the pot hole downstream.

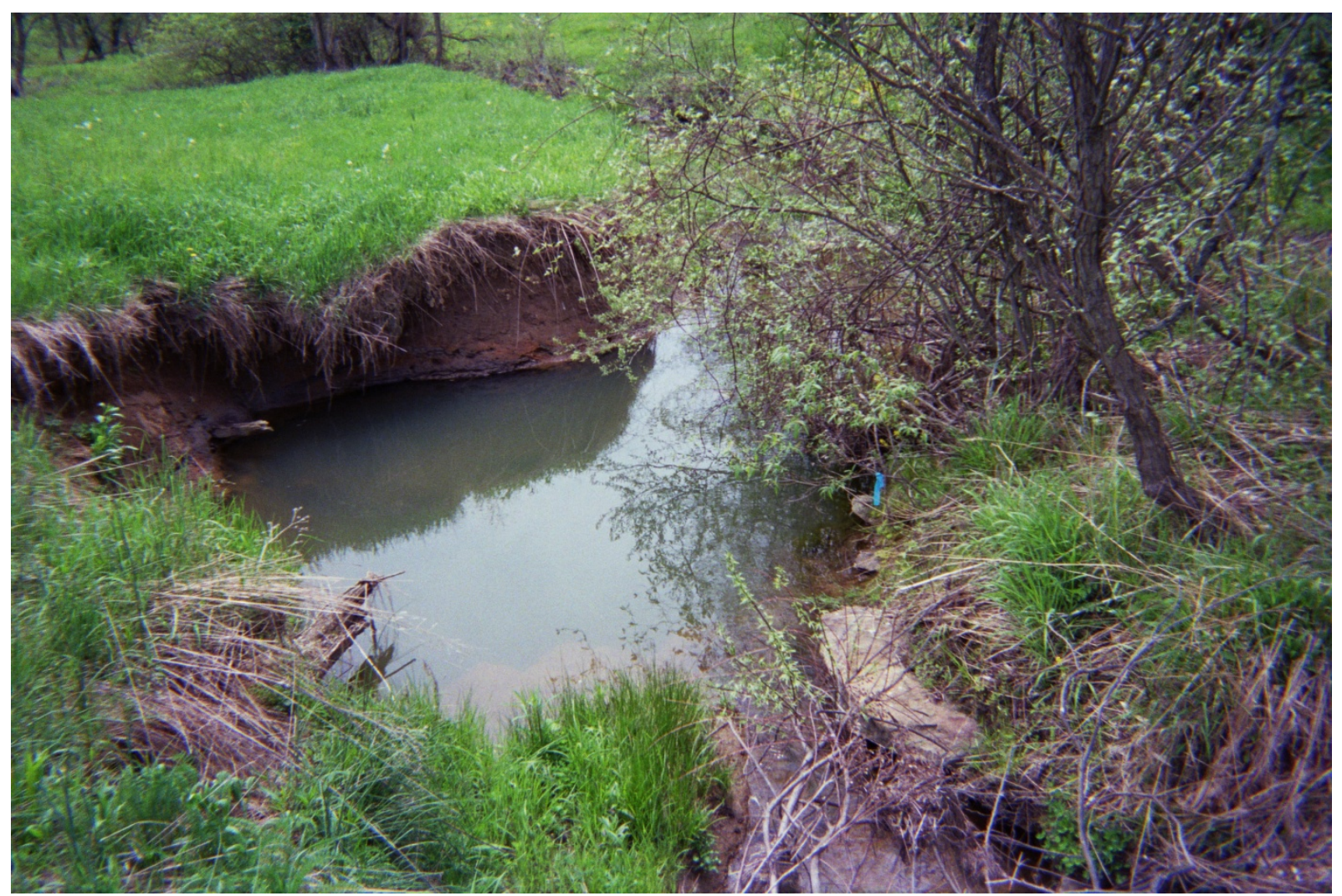

Figure 44. Stream F, PA. Pothole located between 1080 (329.2 m) and 1090 feet (332.3 m) downstream, over the upstream quarter-panel of longwall panel 1. This 'pot-hole' has formed at the base of the higher gradient cascade reach observed entering the pot-hole at lower right corner of the photo. Stream erosion has widened and deepened the channel at this location due to effects from longwall subsidence. 
Anomaly F3 (2020 to 2080 feet / 615.8 to $634.1 \mathrm{~m}$ )

This $5 \mathrm{mmhos} / \mathrm{m}$ increase gradually declines after the stream crosses the quarterpanel zone, just downstream of the this 'pot hole'. The conductivity decreases to a low of 13 mmhos $/ \mathrm{m} \mathrm{VD}$, at a distance of 1600 feet $(487.8 \mathrm{~m})$ downstream. The baseline gradually increases moving downstream from this point. A small peak is observed in the TC survey from 2020 to 2030 feet (615.8 to $618.9 \mathrm{~m})$ and then again at 2080 feet $(634.1 \mathrm{~m})$. This range corresponds to a VLF anomaly at 2050 to 2060 feet (625.0 to $628.0 \mathrm{~m}$ ). This coordinated anomaly is located in the middle of the panel, but is near the upstream extent of the pooling associated with mine subsidence.

Anomaly F4 (2520 to 2570 feet / 768.2 to $783.5 \mathrm{~m})$ )

A small anomaly was detected by TC from 2540 to 2570 feet ( 774.3 to $768.2 \mathrm{~m}$ ). This anomaly is coordinated with a shallow VLF anomaly from 2520 to 2540 feet (768.2 to $774.3 \mathrm{~m}$ ). It is detected only by the VD of the TC survey, the HD shows no substantial conductivity change at this point. The detection of the anomaly by VD and VLF suggest that it is not located near the surface or at depth and therefore should not influence surface water discharges.

Anomaly F5 (2790 to 2900 feet / 850.6 to $884.1 \mathrm{~m}$ )

The highest conductivity reading not associated with interference is located from 2790 to 2900 feet ( 850.6 to $884.1 \mathrm{~m}$ ), and reaches a conductivity reading of $24 \mathrm{mmhos} / \mathrm{m}$. The HD TC survey does not support a shallow anomaly at this location. The shallower HD survey suggests that any fracture in this location does not penetrate to the surface, or is at 
least not conductive all the way to the surface. The deeper sounding VLF survey also does not support an anomaly at this location. The anomaly, detected only by the VD TC, is significantly conductive and located over the downstream edge of panel 1 , but is not expected to influence surface water discharge.

Anomaly F6 (3090 to 3260 feet / 942.0 to 993,9 m)

Perhaps the most identifiable anomaly, best coordinated and with the most VLF significance, is the anomaly present between 3090 and 3260 feet (942.0 to $993,9 \mathrm{~m}$ ) downstream (Figure 45). This anomaly has good VD/HD correlation as well which suggests that the anomaly is connected with the shallow subsurface and possibly to the stream flow (Ackman and Barta, 2002). This anomaly corresponds to the upstream edge of longwall panel 2 and can be expected to have an influence on the stream flow.

This anomaly is very similar to upstream tension zone of panel 1. In fact, the VLF anomaly at 640 to 730 feet (195.1 to $222.5 \mathrm{~m}$ ) downstream (F-1) has similar profile shape with anomaly F-6. This similarity implies that the bedrock beneath Stream F breaks consistently over the upstream edges of the two panels studied. However, based on the geophysical surveys, it appears that the rock over the head gate-entry and tail gate-entry panels may break differently. This may have different impacts to stream flow.

The TC and VLF coordinated anomaly peaks do not match exactly. The VLF peaks are located closer together indicating that the anomaly is a $\mathrm{V}$ shaped fracture that gets narrower at depth. The interpretation of the angle of the fractures is based on the sounding depths of the geophysical surveys. The EM-31 TC surveys reads at a depth that is approximately $1.5 \mathrm{x}(\mathrm{VD})$ and $0.75 \mathrm{x}(\mathrm{HD})$ its boom length of 12 feet $(3.66 \mathrm{~m})$. This 
corresponds to a relatively shallow depth of penetration. The VLF survey reads at a depth that is several times deeper than either of the TC survey methods. If two anomalies were detected by the shallow methods wider apart from each other than two anomalies detected by a deeper method, then the detected anomalies would be described as becoming closer together as they extend deeper.

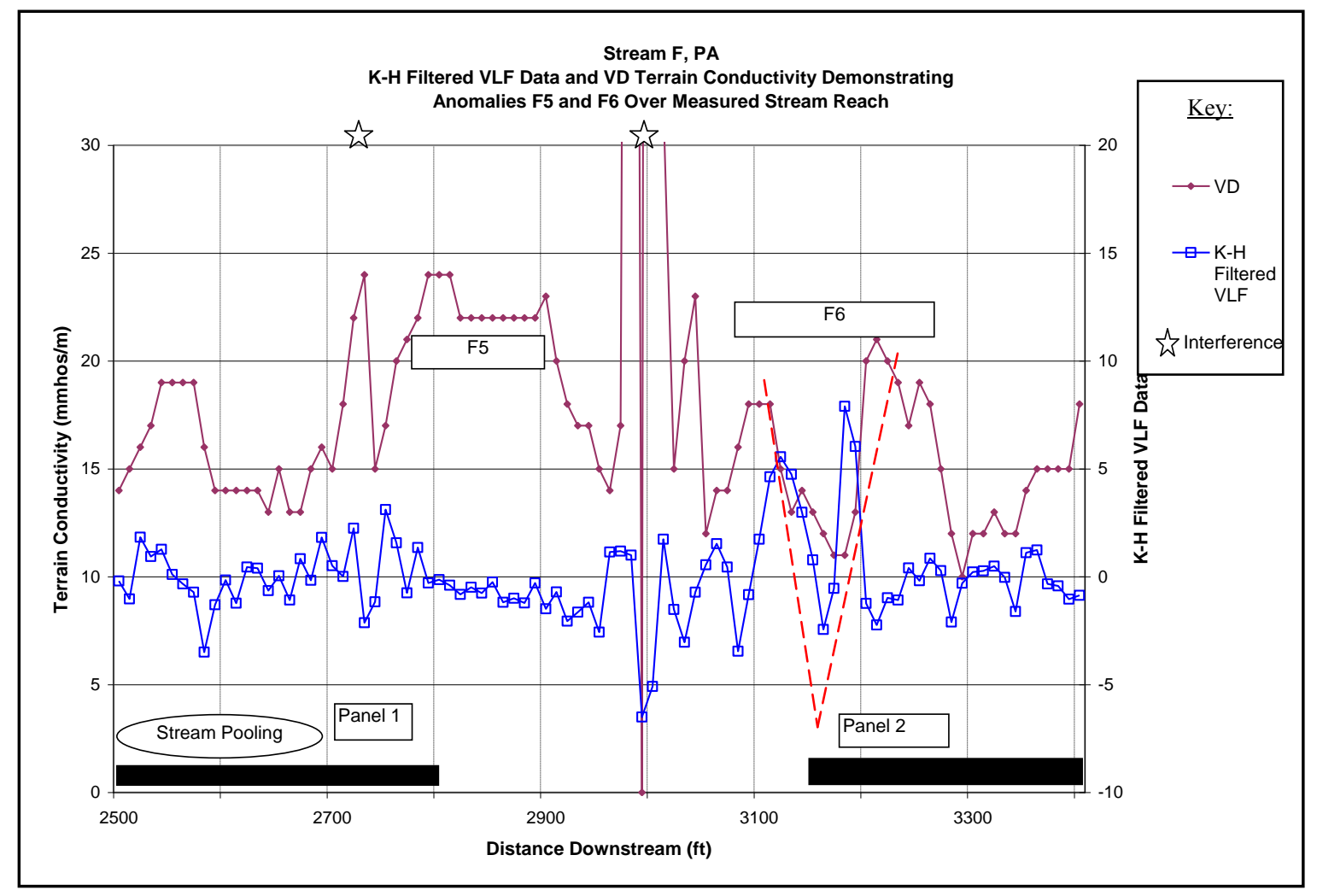

Figure 45. The vertical dipole (VD) of the TC survey plotted with the deeper sounding VLF readings for the downstream quarter-panel reach of stream over panel 1 to the upstream quarter-panel of panel 2. This graph highlights the TC peak over the downstream edge of panel 1 (F5) and the overlapping peaks (coordinated anomalies) of the surveys over panel 2 (F6). Red dashed lines beneath anomaly F6 interpret the possible orientation of mine subsidence fractures. 


\section{$\underline{\text { Alluvial Sediment Measurements }}$}

The average alluvial thickness for Stream F is 2.2 feet $(0.6 \mathrm{~m})$. This is one foot $(0.3$ m) thicker than the average for any of the other streams studied. The alluvium is occasionally gravelly, but the majority of the sediment sampled consists of sand size particles $(2 \mathrm{~mm})$ and smaller.

The distribution of the sediment thickness is consistent within the control reach, but inconsistent across the panel. The control section, which includes Stations 1,2A and 2B are located over solid coal, upstream of mined panel 1. The alluvial thickness at 1 and $2 \mathrm{~A}$ is 2.0 and 2.2 feet ( 0.61 to 0.67 ), respectively. These two measuring stations were determined to be, by the geophysical study earlier in the paper, upstream of the tension zone associated with the subsidence trough and angle of draw. Control Station 2B however is located over fracturing, possibly associated with this angle of draw. With an average of 0.8 feet $(0.2 \mathrm{~m})$, Station 2B has the thinnest amount of alluvium measured in the survey reach for this stream (Figure 46).

Station $3 \mathrm{~A}$ is at the bottom of the increased gradient reach, below the pot hole, and within the boulder strewn reach immediately downstream and a result of the pot hole. Sediment is thinner than average for this station, but the sediment particles are coarse as a result of the scouring.

The measuring Stations $2 \mathrm{~B}$ and $3 \mathrm{~A}$ are shown by the geophysics to within the tension zone because of the shallow subsurface fracturing delineated from $640(195.1 \mathrm{~m})$ to 800 (243.9 $\mathrm{m}$ ) feet downstream. This reach of stream over the edge of the subsidence trough has caused scouring to occur in the stream bottom and has eroded the alluvium, leaving less alluvium than average. The alluvium that was scoured from the upstream half of the panel is 
being deposited over the mid-panel and downstream quarter-panel reaches with a downstream fining distribution.

Beginning at Station 3B and continuing downstream, the alluvial thicknesses are average or above average for this stream. Just below Station $3 \mathrm{~B}$, the pooling over panel 1 begins. Any suspended sediment that passes Station 3B will deposit within the pooled reach. This pool extends for over 1500 feet $(457.3 \mathrm{~m})$ downstream with essentially no flow and plenty of woody debris along the banks to restrict any movement offered by gradient. The particle size for the alluvium in the pooled reach consists of sands and silts because of the low energy.

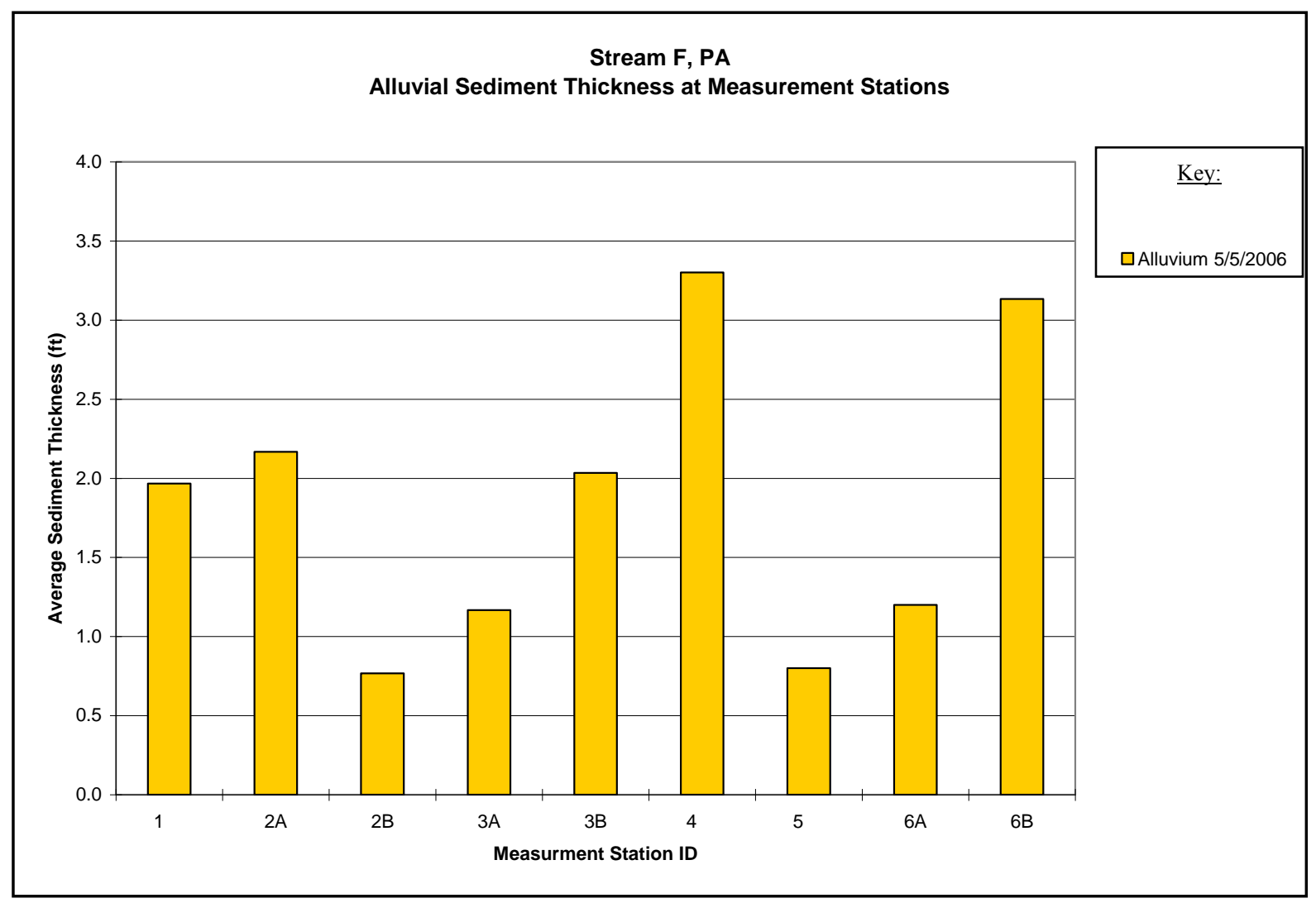

Figure 46. Average alluvial sediment thickness at stream measuring stations on the study reach of Stream F, PA. 
Particle size analysis was conducted for four measuring Stations; Station 1, Station 3B, Station 4 and Station 5. The mean of the particle size distribution for these sample sites is very representative of the relative conditions present within the measured reach.

Station 1 has a mean particle size of $2.3 \mathrm{~mm}$ (Appendix IV, Table 1). This is representative of the control reach, above any angle of draw delineated by geophysics. Station 3B, which represents the tension zone at the edge of the subsidence trough and an increase in stream gradient, has a mean particle size of $8.6 \mathrm{~mm}$. Further downstream, Station 4 and 5 are located over the downstream quarter-panel zone, an area that was flooded prior to being dredged. Now, both stations are below the beaver ponding but are still very low gradient, resulting in a majority of very fine gravels $(<4 \mathrm{~mm})$ and sands $(<2 \mathrm{~mm})$ (Bunte and Abt, 2001). The mean particle size of Station 4 is $1.4 \mathrm{~mm}$, and Station 5 is $1.5 \mathrm{~mm}$.

While collecting a sediment sample for Station 5 , in the reach where the stream was dredged, grey clay was encountered within 0.3 feet $(9.1 \mathrm{~cm})$ of the surface. This clay was soft and wet, and a portion of the weathered top of this clay was included in the particle sample.

\section{Interpretation of Data}

Station $1(70$ feet / $21.3 \mathrm{~m})$ and 2A (440 feet / $134.1 \mathrm{~m})$ represent the control reach of Stream F. Station 2B (760 ft / $231.7 \mathrm{~m})$, which was originally designed to be part of the control reach, has over $10 \%$ variation from Station 1 at both high and low baseflow events and within the angle of dewatering influence. Station $2 \mathrm{~A}$ was added during the low baseflow event to provide better control data. The consistent normalized discharge of Stations 1 and 2A delineates the extent to which panel 1 influences stream discharge to be found between Station 2A and Station 2B, and that Stream F upstream of Station $2 \mathrm{~A}$ is not impacted by mine subsidence.

There are no geophysically identifiable anomalous fractures within the control reach of Stream F, although there are several interference anomalies within this reach. These highly 
conductive environmental features leave a large interference shadow that obscures data beyond the location of the feature.

Sediment thickness and size within the control reach is very consistent. The alluvial thickness of this reach was measured at 2.0 and 2.2 feet $(0.61$ and $0.67 \mathrm{~m})$ thick. The alluvial sediment particles are evenly distributed between sand and small gravels. The small gravels, of particle diameter 2 to $16 \mathrm{~mm}$, are themselves evenly distributed. The mean particle size of the sediment analyzed at Station 1 is $2 . .3 \mathrm{~mm}$ (Appendix VIII, Table 5). The stream alluvium of the control reach is consistently thick and comprised of small gravel and sand/silt size sediment.

One hundred and forty feet downstream of Station 2B (760 feet / $231.7 \mathrm{~m})$, the stream flows over the upstream edge of panel 1. Station $2 \mathrm{~B}$ demonstrates a substantial fluctuation in discharge, from a $10 \%$ increase to a $12 \%$ decrease from the discharge ratios of the control reach. The influence of panel 1 includes Station 2B. Panel 1 is therefore represented by measuring Stations 2B, 3A (1120 ft), 3B (1520 ft) and 4 (2670 ft).

The subsidence of panel 1 increases the discharge ratio of Station $2 \mathrm{~B}$ during high baseflow and decreases its discharge ratio during low baseflow. This is a result of tension fractures from mine subsidence present near the surface. The upstream edge of the angle of draw intersects the valley bottom 150 feet $(45.7 \mathrm{~m})$ upstream of Station 2B. These fractures encourage ground water discharge from surrounding hillsides. Ground water flows from hilltop and hillside recharge zones to the stream during high baseflow. Lower rates of evapo-transpiration, as a result of higher rates of infiltration in upland recharge areas, is regarded as the source for this increase of high baseflow. Saturated subsidence induced or subsidence enhanced fractures at upstream edge of the subsidence basin intersect the creek and strike parallel to the long axis of the longwall panel. These fractures create a localized and concentrated ground water discharge zone whereby baseflow discharge increases between Station 2A and 2B. 
Tension fractures that intersect the stream encourage temporary stream flow losses during low baseflow due the strata's higher permeability and storativity values. Stream measuring Station $2 \mathrm{~B}$ records stream flow loss due to flowing across unsaturated shallow surface fracturing, inducing underflow through shallow fracturing. The shallow underflow zone is the cascade reach immediately downstream of Station 2B.

Geophysical anomalies F1 (640 to 800 feet / 195.1 to $243.9 \mathrm{~m}$ ) and F2 (870 to 1160 feet / 265.2 to $353.6 \mathrm{~m}$ ) are located between Station 2B and Station 3A. These anomalies are considered shallow to mid-depth subsidence fracturing. During low baseflow, when both of these stations were measured, a stream water insurgence and resurgence is recorded. The thickness of alluvial sediment of Station $2 \mathrm{~B}$ is 0.8 feet $(0.2 \mathrm{~m})$, substantially thinner than the control reach. The thin nature of alluvium, the identified fractures, and the discharge ratio of Statoin 2B suggest that between 640 to 1100 feet (195.1 to $335.3 \mathrm{~m}$ ), stream water is being lost to shallow subsidence fracturing, then returns to stream flow at the base of the cascade reach. This area is supported as being a discharge zone by the springs that are located on the stream bank near the pot-hole at 1100 feet $(335.3 \mathrm{~m})$.

The remainder of panel 1 is represented by Station 3B at 1520 feet (463.4 m) and Station 4 at 2670 feet $(814.0 \mathrm{~m})$. The discharge ratio at Station 3B was higher than the control reach during high baseflow and lower than the control reach during low baseflow. This fluctuation is possibly due to subsidence impacts to the first order tributary stream, with a 103 acre $(41.7$ hectares) drainage area, that joins the main channel just above Station 3B. There is a consistent time-adjusted discharge $(\mathrm{aQ})$ from Station $3 \mathrm{~A}$ to $3 \mathrm{~B}$, but the discharge-drainage area ratio (aQdr) indicates that the tributary is discharging less than expected, resulting in a decline in discharge area ratio for Station $3 \mathrm{~B}$.

Station 4 at 2670 feet $(814.0 \mathrm{~m})$ records a consistent decline in normalized discharge of $12 \%$ to $13 \%$ during both high and low baseflow events. This station is located in the reach of 
stream pooling. The pooled stream reach records a consistently lower discharge ratio indicating that some of the stream water is discharging laterally into the adjacent alluvial sediment. This infiltration reduces the total stream discharge but is not associated with stream water loss to the mine or to underflow.

Two minor geophysical anomalies are detected between Station 3B and Station 4. These anomalies may be subsidence related fracturing, but it does not appear that the anomalies have a connected by fractures to the surface. There is a significant amount of interference across panel 1 in this reach. This interference may be obscuring more significant subsidence fractures rendering them undetectable.

The alluvial sediment of panel 1 is variable. The coarsest sediment was detected at Station $3 \mathrm{~B}$, below the erosive cascade reach and the post-subsidence formed pot-hole. This sediment is partly comprised of eroded stream substrate from the upstream edge of the subsidence basin. The thickest sediment is measured at Station 4, within the pooled stream reach of the downstream quarter-panel. This station also has the smallest average particle diameter, confirming the fine grain depositional setting created by the surface subsidence. This thick finegrained sediment would restrict any stream flow losses into underflow beneath the stream, suggesting that the decline in stream discharge ratio at Station 4 is due to lateral discharge of stream water alluvial sediments of the flood plain.

Station 5 at 2940 feet $(896.3 \mathrm{~m})$ and Station $6 \mathrm{~A}$ at 3040 feet $(926.8 \mathrm{~m})$ downstream represent stream flow over the gate-entry between longwall panel 1 and 2. Stream F flows over the gate-entry from 2830 feet $(862.8 \mathrm{~m})$ to 3145 feet $(958.8 \mathrm{~m})$ downstream. The upstream edge of panel 2 was marked in the field with 2 wooden stakes, and correlated to a measured distance downstream of 3145 feet $(958.8 \mathrm{~m})$.

Station 5, located near the center of the gate-entry, recorded a $20 \%$ increase in normalized discharge from Station 4 during high baseflow. This increase corresponds to a $12.5 \%$ 
increase over the upstream control reach, represented by Station 1, but only a $2 \%$ increase from Station 2 at high baseflow. Station 5 at high baseflow suggests that the stream discharge increase that is measured at Station 2 resurges in the stream over the downstream gate-entry, after stream is influent across panel 1 .

Station 5 records a $38 \%$ decrease in discharge from Station 4 during low baseflow. Station 5 at 2940 feet $(896.3 \mathrm{~m})$ downstream appears to be impacted by the influent reach of stream between Station 3A and Station 4. While Station 5 is the resurgent station at high baseflow, it does not detect a resurgence at low baseflow. Station 6A at 3040 feet $(926.8 \mathrm{~m})$ is the resurgent station during low baseflow. The shift in resurgence location suggests that the shallow fracturing of the tension zone of the subsidence basin can impact the stream differently during different baseflow conditions.

Geophysical surveys detect two significant anomalies over the gate-entry between panel 1 and panel 2. These anomalies are interpreted as high angle fractures associated with longwall subsidence. Anomaly F5, from 2790 to 2900 feet ( 850.6 to $884.1 \mathrm{~m}$ ) downstream, is a shallow TC anomaly over the downstream edge of panel 1 . Anomaly F6 is a coordinated anomaly from 3090 to 3260 feet (942.0 to $993.9 \mathrm{~m}$ ) downstream, located over the upstream edge of panel 2. The shallow fracturing of anomaly F5 may explain the measured discharge difference between high and low baseflow at Station 5. The shallow fracturing of F5 behaves similarly to the shallow fracturing near Station 2B. In the shallow tension zone fractures, the storage and permeability of the shallow ground water system increases. This increases the discharge to the stream from this zone during high baseflow when recharge and baseflow is greater. The shallow fracture zone near the valley bottoms during low baseflow conditions has less recharge and is therefore less saturated than during high baseflow conditions. The stream may become influent across this fracture zone causing recharge to the shallow aquifer at the streams expense. 
Station 6A is further downstream and away from this zone of shallow fracturing associated with anomaly F5. This station is between anomalies F5, the shallow fracturing associated with panel 1 , and anomaly F6, the coordinated shallow and mid-depth fracturing associated with panel 2. Station $6 \mathrm{~A}$ records the stream resurgence from panel 1 before its insurgence over panel 2.

The alluvial sediment across the gate-entry is not fully representative of both the high and low baseflow settings. The gate-entry reach was excavated to create positive drainage and reduce the flooding experienced by the subsidence of panel 1 between the measurement of high baseflow, January 28, 2006, and low baseflow, May 5, 2006. The thickness measurements and particle analyses were conducted after the gate-entry reach was excavated. The recorded sediment thickness probably under-estimates the original sediment thickness.

The average one foot $(0.3 \mathrm{~m})$ of alluvial sediment measured across the gate-entry, even with a mean particle size of $1.5 \mathrm{~mm}$, does not prevent stream flow loss to shallow ground water systems where identified shallow fractures exist. There is no indication that the fine sediment over the gate-entry reduces the influence of the shallow 18 month old fracturing of anomaly F5.

Station 6B at 3250 feet $(990.8 \mathrm{~m})$ is located over panel 2, approximately 140 feet $(42.6 \mathrm{~m})$ perpendicular from the downstream edge of the gate-entry. This station records a normalized stream discharge decrease of $7 \%$ during high baseflow and $13 \%$ during low baseflow. This stream loss between from Station $6 \mathrm{~A}$ to Station $6 \mathrm{~B}$ is due to the coordinated anomaly F6, delineated from 3090 to 3260 feet $(942.0$ to $993.9 \mathrm{~m})$ downstream. Fracturing associated with anomaly F6 lowers the water table over the upstream edge of panel 2, inducing ground water recharge and reducing the measured stream discharge of both the high and low baseflow events. The thicker alluvial sediment at Station 6B does not appear to prevent subsidence fractures from impacting stream discharge either when the mined longwall panel is 1 month old, as during high baseflow measurements, or is 9 months old, as during low baseflow measurements. 
The subsidence fracturing associated with the upstream longwall panel edge of panel 2 causes a stream flow loss at both high and low baseflow; whereas a stream flow increase was recorded at high baseflow across panel 1.

More data is necessary to evaluate the causes for this difference. It is speculated however that the decline in measured stream flow at Station $6 \mathrm{~B}$ is similar to Station $3 \mathrm{~A}$ in the Station $3 \mathrm{~A}$ to 3B setting at the upstream edge of panel 1's subsidence basin. Cascade reaches are present at the upstream edge of both subsidence basins. This increased gradient over panel 2 may be inducing ground water recharge, similar to that observed over panel 1 during low baseflow. It is possible that subsidence fracturing has disrupted the ground water flow enough that the fracture zone of anomaly F6 does not behave exactly like the fracture zone of anomaly F1 and F2.

\section{Stream Conclusion}

A stream survey of Stream F, in Greene County Pennsylvania, took place over a 10month-old mined longwall panel. The depth of the mine in the Pittsburgh Coal seam is approximately 595 feet beneath the stream, the deepest in the study group. Measured stream discharges fluctuated modestly across the study reach, yet the author did not visibly detect these fluctuations.

The upstream tension zone of the primary study panel is the first subsidence impacted zone that affects stream discharge. Increased conductivity recorded by geophysics indicates subsidence fractures are saturated. Erosion of the alluvial sediment caused by an increased stream gradient within this zone caused its removal exposing the shallow fractured bedrock beneath. The fractured bedrock also experienced erosion resulting in a deep pool at the bottom of the steepest grade, and a boulder field downstream of the pool. 
The upstream tension zone is a subsidence fracture set with higher permeability and storativity values than that of the surrounding rock. Orientation of this study stream's tension zone is approximately at a $45^{\circ}$ angle to the stream flow, which projects the fracture across a large portion of the wide valley and into the adjacent hillsides. Detection of modest stream discharge increases and decreases are at the intersection of the fracture set and the stream.

Stream discharges increase across this fracture zone during high baseflow and decrease during low baseflow. While the increase at high baseflow is attributed to the concentration of hillside groundwater, the decrease at low baseflow is attributed to the increased storativity and the lowering of the water table in the fracture set. The compression zone of the subsidence basin, between the upstream and downstream tension zones, has a decrease in discharge-area ratio but an increase in measured discharge at each stream station for both high and low baseflow. A portion of the baseflow for this reach has captured by the higher permeable fracture sets at either end of the subsidence basin resulting in decreasing normalized discharge. Stream flow may also be going into underflow or through thickened and coarser alluvial sediment identified over the upstream half of the panel thereby accounting for some discharge-area-ratio decline across the panel. 


\section{Templeton Fork}

\section{Results and Discussion of Data}

\section{$\underline{\text { Stream Discharge Measurements }}$}

High baseflow

The control reach at high baseflow is represented by Stations 1B and 2 (Appendix I, Table 8). The control reach of the study is upstream in the direction of longwall panel advance. Station 2 is located 300 feet $(91.4 \mathrm{~m})$ upstream of the edge of study panel F10. Templeton Fork exhibits a small increase in discharge as it nears the upstream edge of the panel (Figure 47). This increase is a precursor to the dramatic increase observed in the following downstream stations.

Station 3 is 190 feet $(57.9 \mathrm{~m})$ upstream of longwall panel F10, and 115 feet $(35.0 \mathrm{~m})$ downstream of Station 2. Station 3 records a 37\% discharge ratio increase from Station 2, corresponding to a significant 620 gpm per 100 feet change in stream discharge (Figure 48).

The stream flow increase persists from Station 3 to Station 5. The normalized discharge remains $37 \%$ higher than the control reach for 275 feet $(83.8 \mathrm{~m})$, as the stream crosses over the edge of panel F10. Station 5 is located approximately 85 feet $(25.9 \mathrm{~m})$ from the edge of the panel, within the quarter-panel zone of the mined area.

Stations 6 and 7 display a constant discharge rate decrease that begins at Station 5. This change relates to a $16 \%$ decline in normalized discharge values over 510 feet $(155.4 \mathrm{~m})$ of stream resulting in an average water loss measurable stream flow of $58 \mathrm{gpm}$ per foot of stream.

Station 8 is located in the downstream quarter-panel zone of panel F10. This station documents a continued discharge rate decrease. The rate of normalized discharge decreases 


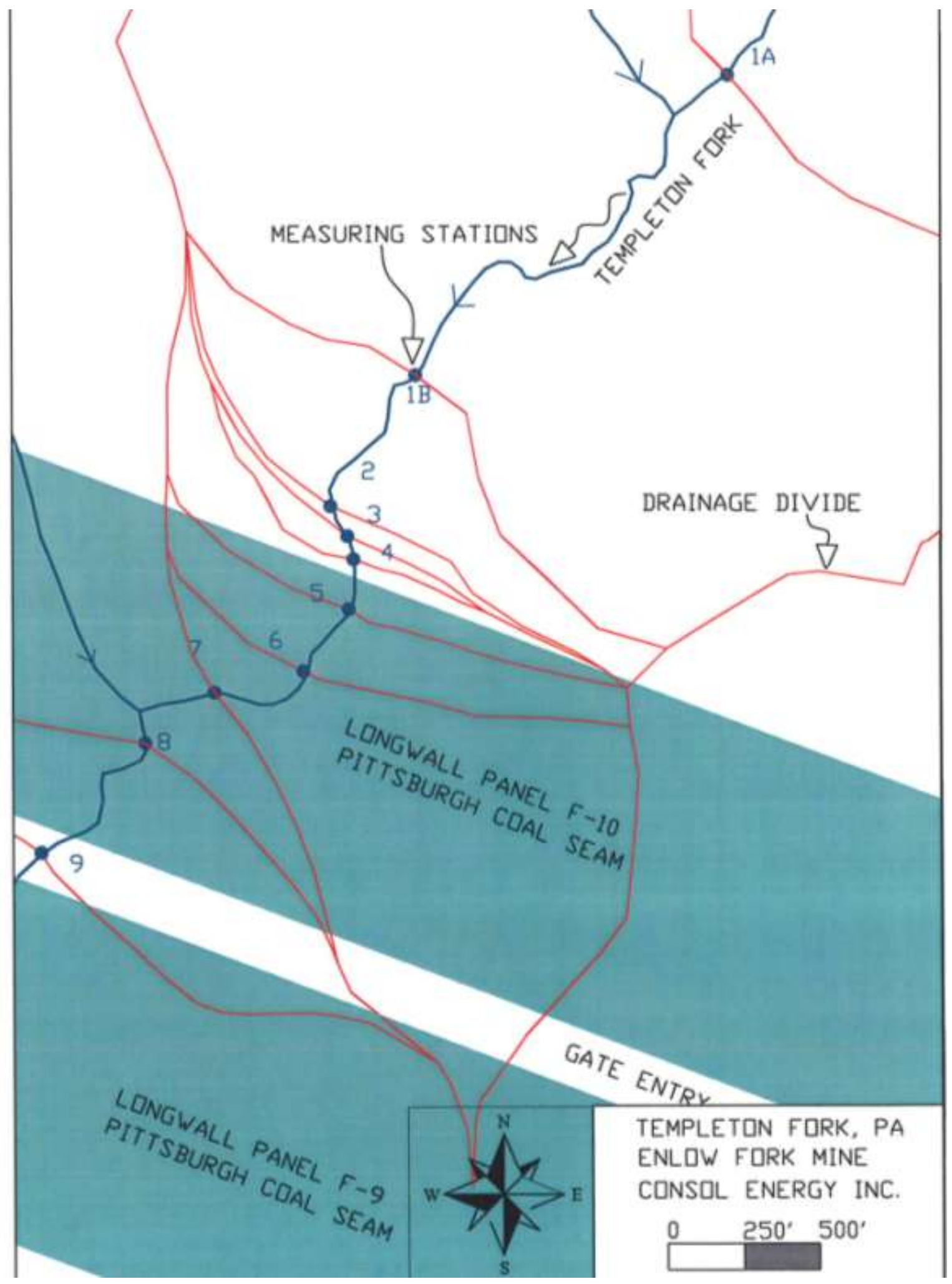

Figure 47. Station locator map for Templeton Fork in Washington County, Pennsylvania. Relevant longwall panels for Consol Energy's Enlow Fork Mine shown Templeton Fork and unnamed tributaries are in blue. Drainage basins for measuring stations are in red. 
by $30 \%$, resulting in a stream flow loss of $74 \mathrm{gpm}$ per foot for this reach. The reduction in normalized discharge from Station 3 or Station $5(0.57)$ to Station 8 is $42 \%$. The rate of water loss from Station 5 to Station 8, a distance of 1075 feet, is 59 gpm per 100 feet. This water loss rate is consistent with the loss rate experienced by Stations 6 and 7.

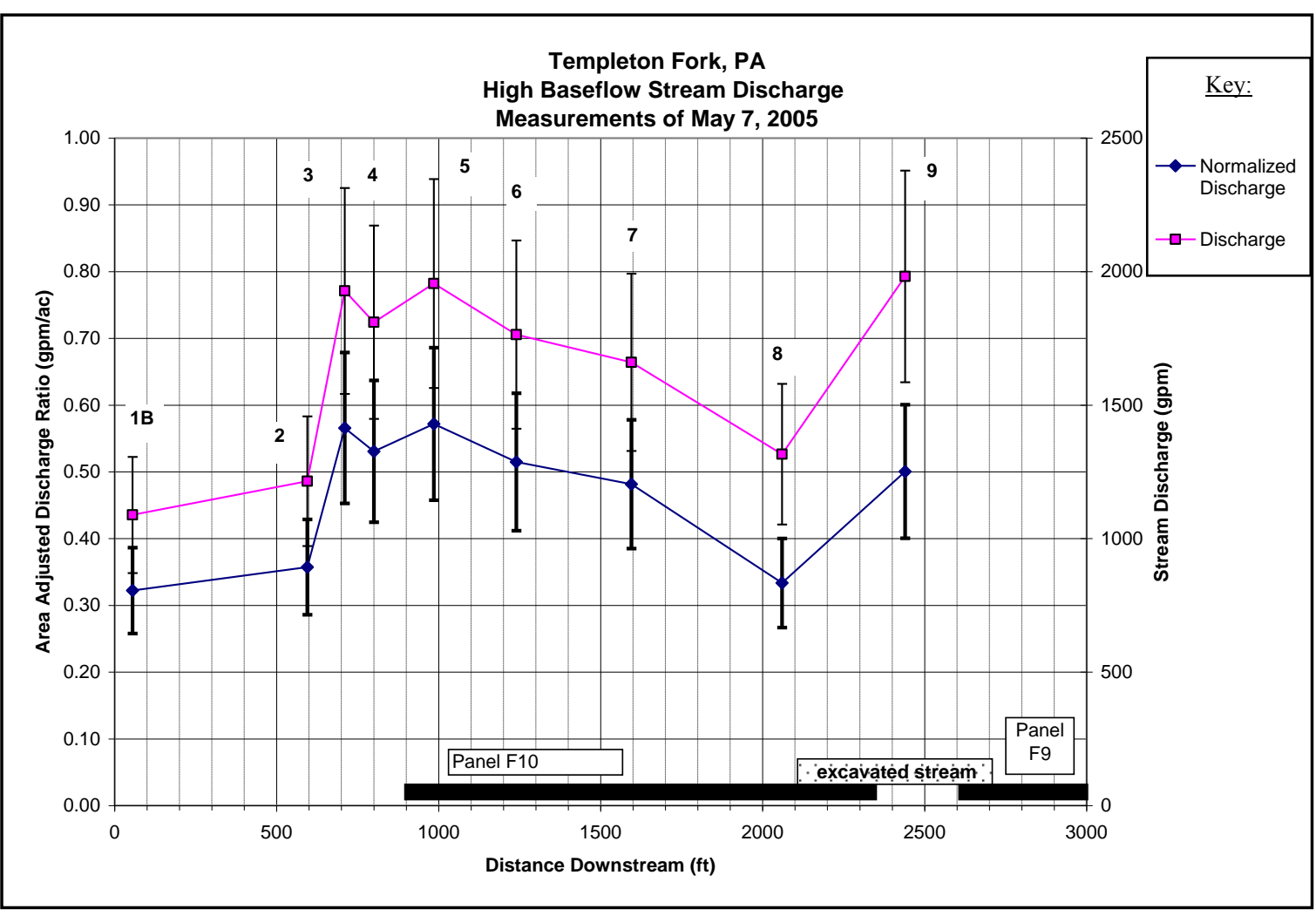

Figure 48. Measured high baseflow (HF) discharge (aQ) and normalized discharge (aQdr) for Templeton Fork, PA. Discharges are plotted over longwall panels and measured distance downstream. Discharges display +/-20\% vertical error bars, based on field measurements.

A second order tributary stream joins Templeton Fork between Station 7 and 8 . This unnamed tributary stream was flowing during both high and low baseflow measuring events. The flow was shallow and not easily obtained by flow meter cross-sectional velocity method, therefore, the calculation of drainage area was expected to incorporate this discharge. 
Station 9 is located over a gate-entry between longwall panel F10 and F9. This station records a 33\% increase in stream flow from Station 8 . The distance between Station 8 and 9 is 380 feet resulting in an average stream flow increase of 175 gpm per 100 feet of stream.

The stream demonstrates a total average normalized discharge increase of $36 \%$ from Station 1 to Station 9. The highest discharge ratio is recorded between Station 3 and $5(0.57)$. Once the stream flows over the longwall panel, the ratio is never this high again.

\section{$\underline{\text { Low Baseflow }}$}

One additional control station was added during the low flow measuring event of June 25, 2005. This new station is Station 1A and is located 1,500 feet (457.3 m) upstream of 1B. This station was located over a proposed gate-entry in anticipation of the control reach over longwall panel F11 being mined soon after measuring (Figure 49).

Station 1A and Station 1B show very good correlation with a consistent normalized discharge during low baseflow conditions (Appendix, I, Table 9). Station 2 recorded a modest $6 \%$ normalized discharge increase at high flow discharge, but demonstrates a much greater 24\% increase during low baseflow. This reach, between Station 1B and Station 2 no longer behaves like the control reach and is considered to be affected by mining of panel F10. Station 2 at 595 feet $(181.4 \mathrm{~m})$ is near the 24 degree angle of draw for longwall panel F10 but it is not beyond the angle of dewatering influence.

At high baseflow conditions, the positive flow change peaked and held steady between Station 3 and 5, now Station 3 demonstrates 22\% decrease in normalized discharge. This decrease in discharge returns the normalized discharge ratio of the stream to the same ratio observed in the control reach. Station 4 is only 90 feet $(27.4 \mathrm{~m})$ downstream, and 
confirms the decreasing discharge reach detected by Station 3. Station 4 also supported Station 3 during high flow conditions when this reach had higher than control normalized discharge ratio. At low flow, Station 4 is $8 \%$ lower in normalized discharge than the control reach. Station 4 also demonstrates a slightly lower discharge and normalized discharge, and although this change is only a few percent, it is persistent in both flow regimes.

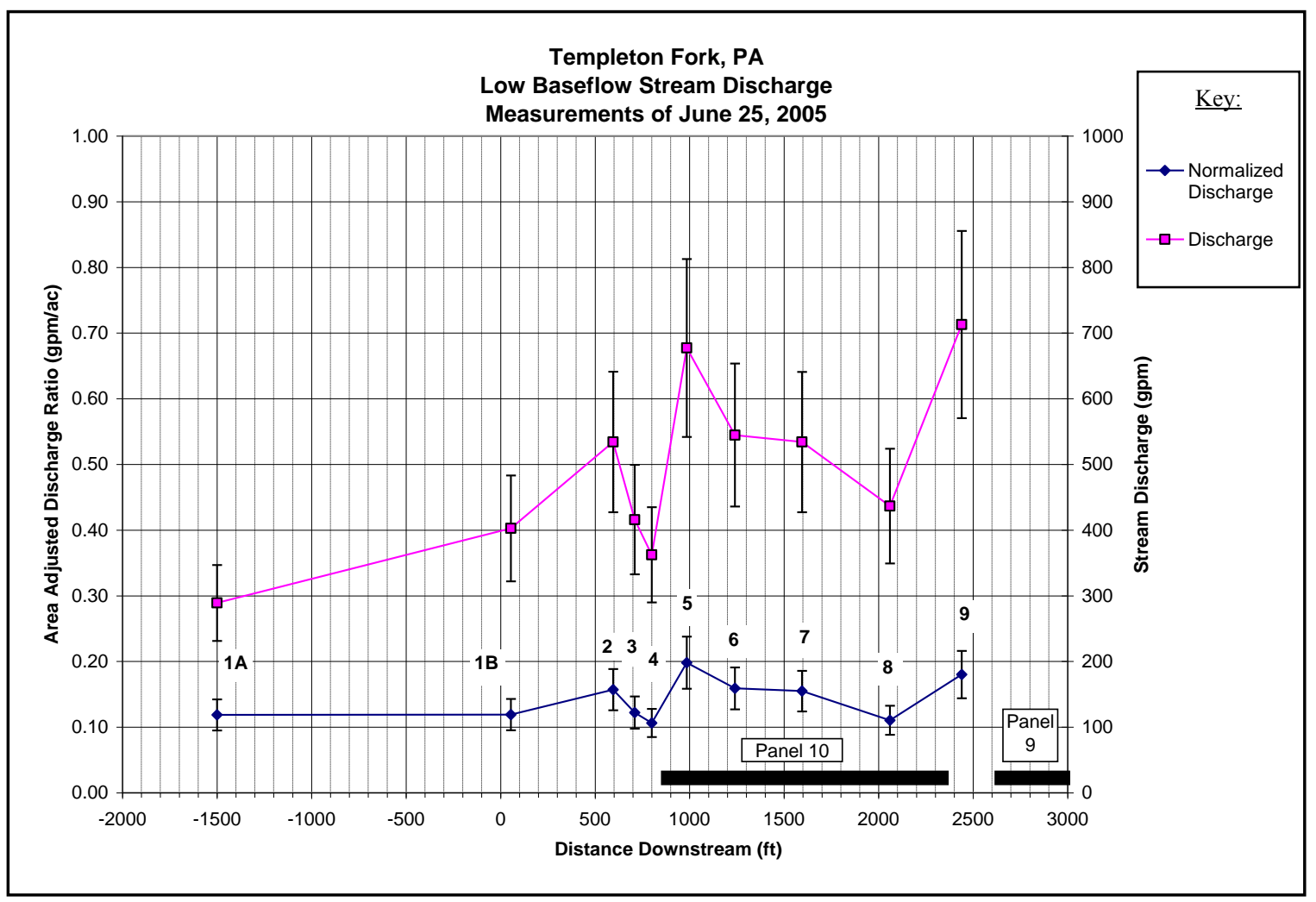

Figure 49. Measured low baseflow (LF) discharge (aQ) and normalized discharge (aQdr) for Templeton Fork, PA. Discharges are plotted over longwall panels and measured distance downstream. Discharges display +/-20\% vertical error bars, based on field measurements.

Station 5 shows an increase in normalized discharge of $86 \%$ from Station 4 . The high flow detected during this measuring event is similar to the flow rate detected during the high flow measuring event of May 7, 2005. This is the highest discharge ratio recorded for this 
measuring event, at $0.20 \mathrm{gpm} / \mathrm{ac}$. The normalized discharge is $66 \%$ greater than the control reach discharge.

The normalized discharge trend across the panel is similar to the high flow discharge measurements. From Station 5 to Station 8 there is a constant decrease in-stream discharge that terminates at Station 8 resulting in a $45 \%$ decrease in normalize discharge. This discharge rate decrease, or temporary loss, is 22 gpm per 100 feet, half of the decrease rate observed during the high flow rate (41 gpm per 100 feet) over the same reach. The lowest normalized discharge ratios measured during this event are Station 4 and Station 8. Similar to the discussion for Station 4, the calculated discharge of Station 8 does not drop very far below the control reach discharge.

Station 9, located over the gate-entry, shows a $63 \%$ normalized discharge increase from Station 8. High flow measurements show an increase of 33\%. The measured raw discharge for Station 9, for both high and low baseflow, is approximately the same as the raw discharge at Station 5. The average rate of resurgence from Station 8 to Station 9, a distance of 380 feet $(115.8 \mathrm{~m})$, is 73 gpm per 100 feet. The normalized discharge ratio for Station 9 is $50 \%$ higher than the control ratio.

\section{Geophysical Measurements}

Templeton Fork shows poor correlation between the TC and VLF surveys. The majority of observed stream bedrock is weathered mudstone, claystone or shale which has a low hydraulic conductivity, but is also relatively effective in conducting an electrical current. A good conductor located at the surface will reduce the overall penetration depth of conductivity surveys, based on the equation presented by Parasnis, discussed earlier in the 
'Methods of Geophysical Survey'. Based on only the TC survey, there is a baseline change around 700 feet $(213.4 \mathrm{~m})$, where the average shallow subsurface apparent conductivity value changes from 22.9 to $29.5 \mathrm{mmhos} / \mathrm{m}$. This baseline change could be a result of a lithologic change or an increase in conductivity related to mine subsidence fracturing. This is the approximate location of where significant stream flow changes occur in both high and low flow conditions (Figure 50).

The shallow subsurface conductivity values average $27.8 \mathrm{mmhos} / \mathrm{m}$ for the stream segment surveyed, and the average filtered VLF data is 0.0 . The first 600 feet of the survey $(182.9 \mathrm{~m})$ is over solid coal, 600 to 850 feet $(182.9$ to $259.1 \mathrm{~m})$ is over the upstream gateentry, 850 to 2350 feet ( 259.1 to $716.4 \mathrm{~m}$ ) is over the longwall panel F10, and 2350 to 2600 feet $(716.4$ to $792.6 \mathrm{~m})$ is over the downstream gate-entry. The starting point of the survey is approximately 75 feet $(22.8 \mathrm{~m})$ downstream of the stream crossing of Templeton Run Road. A reach of 2700 feet $(823.1 \mathrm{~m})$ was surveyed for this study. Longwall subsidence has created reaches in the stream where pools are too deep to be surveyed within the stream. It was necessary to continue the survey at the top of bank, until the stream became shallow enough to wade. These particular reaches are denoted by ovals on the attached graphs.

The stream flow varies significantly and frequently across the measured reach. There are 13 significant geophysical anomalies and 9 flow measuring stations. Anomalies that are not TC and VLF coordinated are not expected to have an influence on the stream discharge because they would have no surface expression and no conduit by which to transmit water to or from the stream flow. These anomalies are not considered unimportant, and some may be associated with mine subsidence and subsequent overburden fracturing, but if the fracturing 
is not detected to be near surface then any impact from fractures would be expected to be muted or substantially reduced.

Anomaly TF1 (60 to 90 feet / 18.2 to $27.4 \mathrm{~m})$

The first anomaly is from 60 to 90 feet (18.2 to $27.4 \mathrm{~m}$ ) downstream from the starting point of the survey (Appendix III, Table 4). The 80 to $95^{\text {th }}$ percentile anomaly is only detectable using the VLF survey. The graphed VLF data suggests that the anomaly is at middepth and may not be conductive near the surface. The anomaly is over solid, unmined coal.

Anomaly TF1a (140 to 150 feet / 42.6 to $45.7 \mathrm{~m}$ )

The second anomaly appears that it may a portion of the first anomaly. It is located at a distance of 140 to 150 feet from the starting point of the survey. This is an 80 to $90^{\text {th }}$ percentile anomaly. It is sharp peaked, suggesting a shallow subsurface detection. The anomaly is not, however, detected by TC survey and is therefore not considered an anomaly that has the potential to influence stream discharges. This fracture is within the control reach, an area that was not longwall mined. The anomaly is therefore considered to be naturally occurring. Natural fractures may be present and detectable at depth using the VLF but they could be plugged by weathered rock or alluvial sediments in the shallow subsurface rendering them undetectable using terrain conductivity methods .

Anomaly TF2 (360 to 400 feet / 109.7 to $121.9 \mathrm{~m})$

The next anomaly is located from 360 to 400 feet. It is a 90 to $95^{\text {th }}$ percentile anomaly that demonstrates a mid-depth to deep location depth, involving no shallow 
component. This anomaly may also be a natural fracture that is detectable at depth where is may not be filled with weathered rock and alluvial sediments.

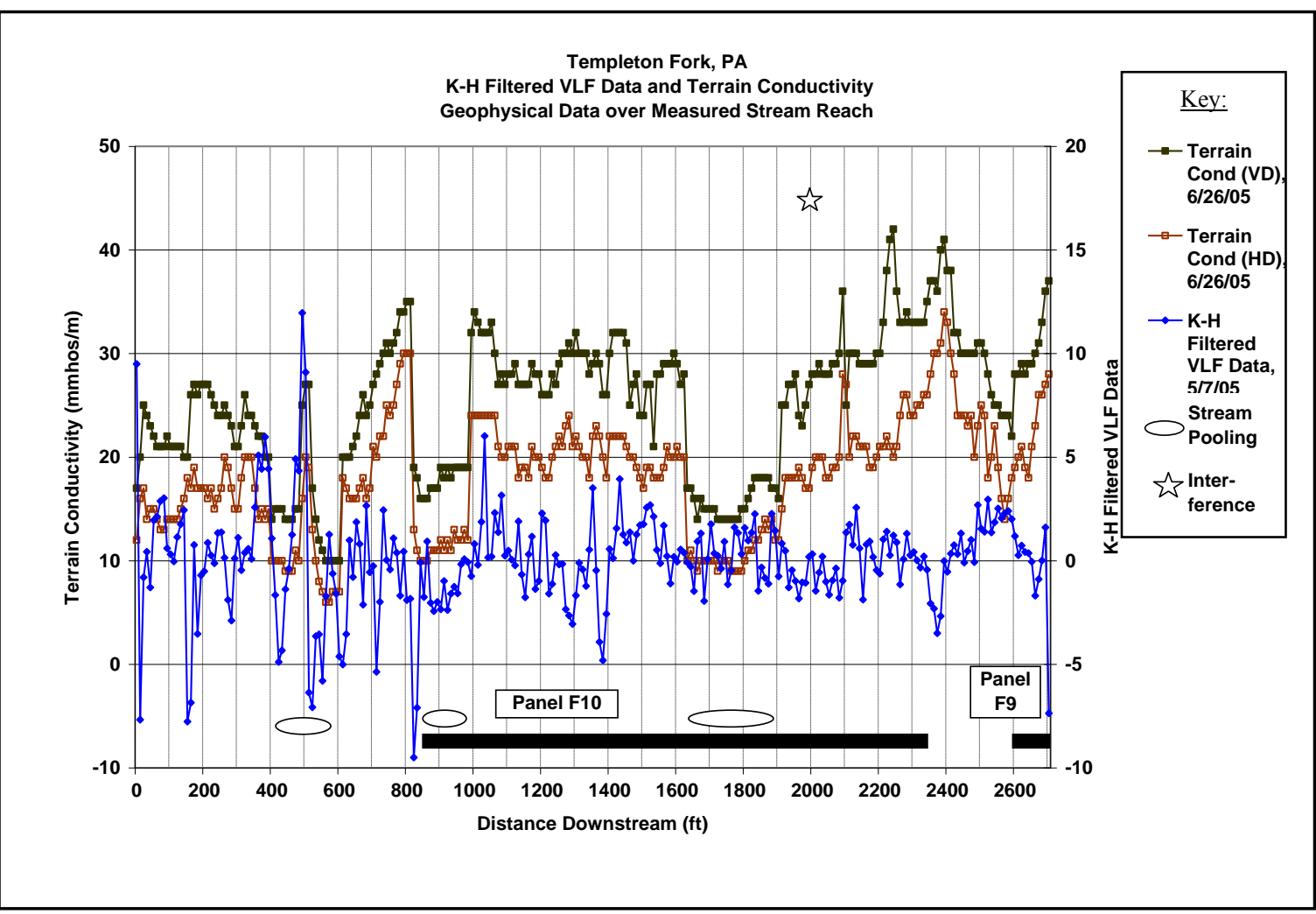

Figure 50. Terrain Conductivity data, both Vertical Dipole (VD) and Horizontal Dipole (HD) methods, and KH Filtered VLF Data displayed along study reach of Templeton Fork, PA. Data are shown with respect to longwall panel location, at the base of the graph. Interferences from conductive man-made features are shown by stars.

Anomaly TF3 (480 (146.3 m) to 510 feet / 143.6 to $155.4 \mathrm{~m})$

A large shallow to mid-depth anomaly is present around 500 feet $(152.4 \mathrm{~m})$. This anomaly is interpreted to be the surface expression of the angle of draw, at the edge of panel F10's subsidence basin, due to its steep shallow peak and near surface location. 
Anomaly TF4 (660 to 810 feet / 201.2 to $246.9 \mathrm{~m}$ )

A shallow subsurface increased conductivity zone was present between 600 to 800 $(243.9 \mathrm{~m})$ feet, with the geophysical surveys peaking at different locations within this distance. The VLF survey shows zones very shallow, to shallow mid-depth high conductivity zones between 640 and 740 feet (195.1 to $225.6 \mathrm{~m}$ ). This anomaly was very conductive and would inhibit delineation of deeper strata because of the high return at such a shallow depth. The VLF anomaly at this location was interpreted as a fracture zone. This conductive zone is located 100 to 200 feet (30.5 to $60.9 \mathrm{~m}$ ) north of the edge of the longwall panel F10, over the gate-entry. The coal further north of panel F10 was unmined at the time of the VLF survey. The TC survey records a steady increase in the shallow subsurface conductivity from 640 to 810 feet (195.1 to $246.9 \mathrm{~m}$ ). This area of conductivity is located over claystone bedrock that crops out immediately above Station 4 and forms a plunge pool at 810 feet $(246.9 \mathrm{~m})$ downstream. It is uncertain as to the full depth and cause of the anomaly, but if associated with mine subsidence; the depth to coal and the location of the longwall panel suggest that this area would be a shallow depth tension zone and the anomaly does not likely persist to the deeper fractured zones (Rauch, 1987). Most if not all of these anomalies are likely to terminate at the composite beam zone, below the surface fracturing zone.

The reach between 810 and 1000 feet (246.9 to $304.8 \mathrm{~m}$ ) is not well represented by geophysics due to its pooling and the inability of the survey to be conducted in the stream bed. This reach therefore does not rate as an anomaly zone, but based on field observation of the stream bed, it is appropriate to mention the stream conditions downstream of anomaly 4 . There is a substantial change in the stream bed beginning at 810 feet $(246.9 \mathrm{~m})$ and extending 
to 1000 feet $(304.8 \mathrm{~m})$, from being its shallow relatively uniform downstream gradient from 0 to $810(246.9 \mathrm{~m})$ feet, to having deep undulating pools. These pools appear to be recent erosion pools located at the beginning of the upstream edge of the panel, in a zone of compression. The surface compression zone, located just inside the quarter-panel, appears to have created strain on the surface rock, fracturing and weakening it, resulting in erosion. The VLF survey, which can detect anomalies at greater depths beneath the stream, does not detect an increase in conductivity, suggesting that the observed surface conditions of the stream from $810(246.9 \mathrm{~m})$ to 1000 feet are associated with the shallow subsurface. This anomaly is significant and somewhat coordinated and likely has connectivity with the surface water. The location of this anomaly with respect to the angle of draw of panel F10 suggests that the fracturing at anomaly TF-4 is associated with mine subsidence.

Anomaly TF5 (880 to 1090 feet / 268.2 to $332.3 \mathrm{~m}$ )

TF5 is a coordinated TC and VLF anomaly. The shallow subsurface survey of the TC returns to an $80^{\text {th }}$ percentile level of significance between the distances of 880 to 1050 feet (268.2 to $320.1 \mathrm{~m})$ The more significant VLF anomaly is depicted starting at 1030 feet $(314.0 \mathrm{~m})$ and ending around 1090 feet $(332.3 \mathrm{~m})$, with the most significant peak at 1040 feet $(317.0 \mathrm{~m})$. The graphed VLF data show a broad increase in conductivity starting at middepth and going deeper. This deep-seated anomaly also has a vertical component at 1040 feet $(317.0 \mathrm{~m})$, suggesting the presence of a near vertical fracture at this point. This vertical component extends from the deep anomaly towards the shallow subsurface. The TC survey has a broad higher level of conductivity in this area suggesting that the vertical VLF fracture 
of 1040 feet $(317.0 \mathrm{~m})$ may represent itself as a diffuse fracture zone at the surface. This anomaly is a significant fracture that may represent hydraulic connection to the surface water.

This anomaly set is better coordinated than TF-4 and is delineated to penetrate much deeper through the subsurface. This anomaly is located $+/-25$ feet $(7.6 \mathrm{~m})$ downstream of the longwall edge of panel F10. The location of the fracture with respect to the longwall panel, and the interpretation of the fracture as being deep seated and at the vertical limit of the WADI's capabilities, combine to suggest that this subsidence fracture penetrates from the surface to a depth of 180 to 246 feet (54.6 to $75.0 \mathrm{~m}$ ) (Hutchinson and Barta, 2002 and Powers etal, 1999). The Pittsburgh Coal seam lies approximately 530 feet (161.5 m) below the elevation of the stream, correlating to a fracture penetration depth of approximately $33 \%$ to $47 \%$ of the mine overburden.

Anomaly TF6 (1140 to 1300 feet / 347.5 to $396.3 \mathrm{~m}$ )

The VLF survey data show a convex curve from 930 to 1300 feet (283.5 to $396.3 \mathrm{~m}$ ), representing a deep high conductivity area. The following anomalies are a part of this overall deep anomaly (anomaly TF5), but are characteristically different and are discussed separately. These anomalies at 1140 feet $(347.5 \mathrm{~m})$ and 1210 to 1220 feet (368.9 to $371.9 \mathrm{~m})$ downstream are shallow and localized. They are $80^{\text {th }}$ percentile anomalies that do not have corresponding increased TC readings. These anomalies may be fractures at the shallow to mid-depth range, but should not have the potential to significantly influence the stream discharge.

The normalized discharge from Station 5 to Station 8 declines at a steady rate, suggesting that stream water is becoming ground water at a steady rate. There are several 
anomalies across the middle of the longwall panel, from TF6 to TF11. All but two of these anomalies are uncoordinated or poorly coordinated. The TC values recorded for this reach of stream suggests water is finding pathways into the shallow subsurface, possibly accounting for the shallow conductivity increase. Coordinated anomaly TF-8 may be one of the larger and more significant anomalies inducing shallow ground water flow.

Anomaly TF7 (1300 and 1360 feet / 396.3 and $414.6 \mathrm{~m}$ )

A shallow coordinated anomaly is present at 1360 feet $(414.6 \mathrm{~m})$. This is a single point peak, for both VLF and TC, suggesting that the anomaly is shallow and not extensive in length. The TC survey does not show the peak as being significant, i.e. $<80^{\text {th }}$ Percentile, but the VLF survey is significant. The VLF anomaly may be also associated with the TC anomaly at 1300 feet $(396.3 \mathrm{~m})$. This TC anomaly has a significance level of $80 \%$. It is delineated to have a downstream dip towards the VLF anomaly at 1360 feet $(414.6 \mathrm{~m})$. The downstream dip is determined by the plotted peaks of the HD and VD TC surveys. The shallower sounding HD peak plots further upstream than the deeper sounding VD peak, giving the connected peaks a downstream slant. This coordinated anomaly may have a hydrological connection with the surface water.

Anomaly TF8 (1410 to 1440 feet / 429.8 to $439.0 \mathrm{~m}$ )

A broad increase in conductivity is present from 1430 to 1570 feet (435.9 to $478.6 \mathrm{~m}$ ). This broad convex increase represents another deep anomaly, and the sharp increases in conductivity represent shallow reaching fractures that stem from this deeper anomaly. There 
are three specific shallow reaching fractures that are located above this deeper anomaly. The first is located at 1430 to 1440 feet ( 435.9 to $439.0 \mathrm{~m}$ ). This anomaly is steep and narrow representing its high conductivity and shallow subsurface location. The TC survey supports this interpretation by the location of significant data points from 1410 to 1440 feet (435.9 to $439.0 \mathrm{~m}$ ). This coordinated anomaly is connected from the near surface to a deeper highly conductive body, suggesting that this anomaly may be influence surface water discharge. Anomaly TF9: 1510 to 1540 feet ( 460.3 to $469.5 \mathrm{~m}$ )

The deeper anomaly, present between 1430 to 1570 feet ( 435.9 to $478.6 \mathrm{~m}$ ), has a vertical expression between 1510 to 1540 feet $(460.3 \mathrm{~m}$ to $469.5 \mathrm{~m})$. The graphed data for this anomaly has a broad arch indicating that the fracture is at mid-depth level. This anomaly does not have a shallow subsurface anomaly by the TC survey and is, therefore, not expected to influence the surface water.

Anomaly TF10: 1780 to 1900 feet (542.6 to $579.2 \mathrm{~m}$ )

Another mid-depth to deep VLF anomaly is present from 1780 to 1900 feet (542.6 to $579.2 \mathrm{~m}$ ). This anomaly has two major associated components. The first is the highly zone between 1780 to 1830 feet ( 542.6 to $557.9 \mathrm{~m}$ ). This anomaly suggests the presence of a relatively deep conductive zone. This deep conductive zone has a vertical expression towards the surface that is represented by TC increases of $4 \mathrm{mmhos} / \mathrm{m}(15 \%)$. The TC values do not exceed the $80^{\text {th }}$ percentile significance level, but do represent an increase in subsurface conductivity. The lack of anomaly significance suggests that the fracture is not a significant conduit for ground water and probably not able to impact surface water flow. 
The second component of this anomaly is a slightly lesser conductive vertical middepth VLF expression of the deeper anomaly located between 1890 to 1900 (576.2 to 579.2 m) feet. The TC survey does not correspondingly record significant data values in this area, but still displays a local high. The lack of significant shallow conductivity suggests that the anomaly is not hydraulically connected to the stream flow, and should not impact stream discharge.

Anomaly TF11 (2110 to 2140 feet / 643.2 to $652.4 \mathrm{~m}$ )

A coordinated anomaly is present between 2110 to 2140 feet (643.2 to $652.4 \mathrm{~m})$. This anomaly is represented by the TC survey with a moderate increase in conductivity from 2110 to 2130 feet $(643.2$ to $649.3 \mathrm{~m})$. This anomaly follows by a sharp positive peak and subsequent negative peak at 2090 feet $(637.1 \mathrm{~m})$ and 2100 feet $(640.2 \mathrm{~m})$ downstream, resulting from detection of a row of iron culverts in the creek forming a low water crossing. The iron culverts appear to have only a local interference impact to the survey and do not influence the coordinated anomaly detected from 2110 to 2140 feet (643.2 to $652.4 \mathrm{~m})$. The VLF survey detects an 80 to $90^{\text {th }}$ percentile anomaly from 2120 to 2140 feet (646.3 to 652.4 $\mathrm{m})$, but it is clear that the anomaly starts nearer to 2110 feet $(643.2 \mathrm{~m})$. This anomaly is located at a shallow to mid-depth level, but may extend to a deeper level further downstream as indicated by the elevated values from 2220 to 2290 feet (676.8 to $698.1 \mathrm{~m}$ ). This anomaly, from 2110 to 2140 feet $(643.2$ to $(652.4 \mathrm{~m})$ is not hydrologically connected to the stream due to low corresponding TC values. 
Anomaly TF12 (2210 to 2260 feet / 673.7 to $689.0 \mathrm{~m}$ )

The first part of this anomaly is from 2210 to 2260 feet (673.7 to $689.0 \mathrm{~m}$ ), and is located over the elevated values of the VLF survey, as anomaly TF11 extends downstream. The VLF for this area is significant at 2230 feet $(679.8 \mathrm{~m})$ indicating that this area is an anomaly with a very conductive shallow subsurface and a moderate significance of middepth conductivity. This coordinate anomaly might have some local influence on the total stream discharge because of its large exposure to stream surface area, 2210 to 2260 feet (673.7 to $689.0 \mathrm{~m}$ ), and because of its potential to be a high angle fracture that shows potential for mid-depth penetration.

A small amount of coordination between VLF and TC is detected around 2180 to 2190 feet (664.6 to $667.6 \mathrm{~m}$ ). A slight increase in shallow subsurface conductivity and a near $80^{\text {th }}$ percentile VLF detection suggest that the subsurface from 2210 to 2220 feet (673.7 to $676.8 \mathrm{~m}$ ) is a fracture zone and has potential to interact with the stream flow.

Interference from an overhead electric line crossing the stream at 2390 feet $(728.6 \mathrm{~m})$ obscures the data in this reach. The TC survey shows a significant increase in conductivity, as the VLF survey shows a significant decrease. This interference unfortunately falls over the edge of the longwall panel and may conceal any impact that subsidence may have had on the bedrock in this area.

Anomaly TF13 (2500 to 2600 feet / 762.1 to $792.6 \mathrm{~m}$ )

A deep-seated anomaly is present from 2500 to 2600 feet (762.1 to $792.6 \mathrm{~m})$. This anomaly is only detected at depth and does not have any vertical expression. It is over the 
gate-entry, between the mined longwall panels. This anomaly is likely deep fracturing over the panel edge.

\section{Alluvial Sediment Measurements}

Sediment thickness measurements for Templeton Fork were completed on June 25, 2005, while conducting low baseflow stream discharge measurements. The sediment is relatively thick throughout the reach that was studied, except for Stations 4, 5 and 9. Station 4 and 5 are over the upstream edge of panel F10 and Station 9 is over the downstream edge of panel F10. Station 4 and 5 are located in a reach that has undergone some erosion resulting from a channel grade increase over the upstream edge of the subsidence basin. Station 9 is located in a reach of stream that was excavated to lower the stream bottom over the mine gate-entry. The sediment was removed and the thickness most likely represents a portion of a weathered shale unit that was soft enough to penetrate with hammered rebar.

The particle size analyses samples were collected on August 19, 2006. The samples were dried, and later analyzed on November 11, 2006. Samples were collected at Station 1B and at Station 8. Station 1B was located over a solid unmined coal block when geophysical surveys and flow measurements were collected, however, due to the progression of the mine, the coal beneath Station 1 has since been longwall mined and the station has been subjected to subsidence. Furthermore, Station 1 is immediately below a stream crossing for Templeton Run Road. This culvert crossing was in place prior to initial surveys, i.e. geophysical and stream discharge, but the sample collected at Station 1 appeared to be comprised, perhaps as much as $50 \%$, by gravel that may have been used to construct the stream crossing. Although Station 1 may be comprised of the same alluvium that was present at the time of the initial 
surveys, its majority is no longer comprised of pre-crossing drainage basin geologic derivatives.

The location of the selected stations to sample was restricted due to the excavation of the upstream gate-entry of panel F10. This gate-entry reach was excavated before particle size analysis samples were collected. This excavation restricted the location of the samples to Stations 1 and 8, all other stations have been influenced by this regarding. This regrading also may introduce an over abundance of sediment into the stream and may result in inaccurate results of the particle size distribution as it were prior to the excavation.

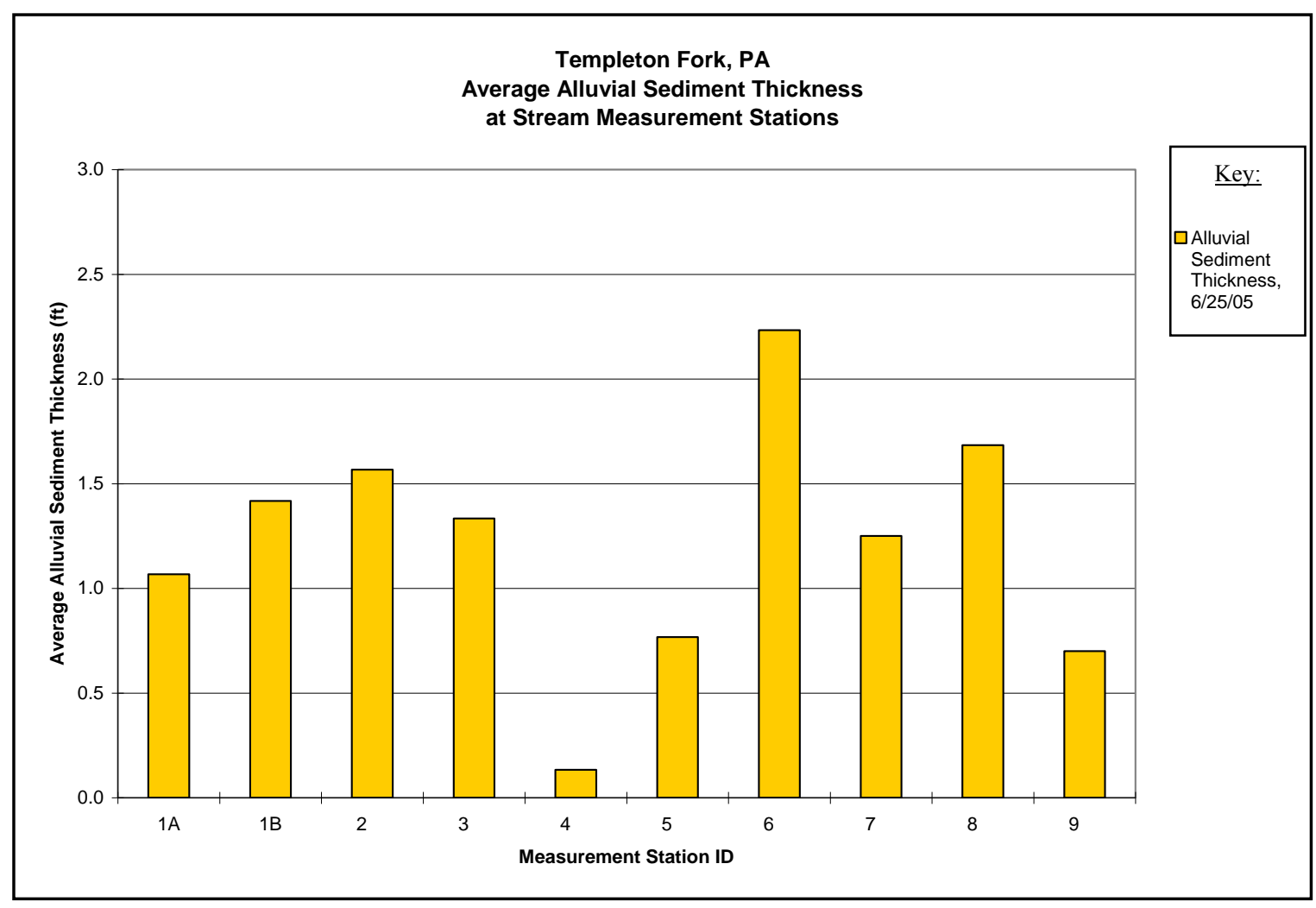

Figure 51. Average alluvial sediment thickness at stream measuring stations on the study reach of Templeton Fork, PA.

The results of the particle size distribution of Station 1 are presented in Appendix VIII, Tables 10 and 11. The alluvial particle weights are skewed right (Appendix XI, Graphs 
10 and 11). The mean particle size is $35.8 \mathrm{~mm}$. There is a large weight percent of particles that are retained by the $64 \mathrm{~mm}$ template. This cobble size dominant weight percent skews the mean towards the larger gravels.

The alluvial particle weights of Station 8 are skewed left. The mean particle size is $5.9 \mathrm{~mm}$. There is a large weight percent of particles that are retained only by the $<2 \mathrm{~mm}$ pan. This sand size dominant weight percent skews the mean towards the smaller gravels and reflects the low energy, previously pooled condition of this reach.

\section{Interpretation of Data}

The control reach of Templeton Fork is represented by Stations 1A at $-1,500$ feet $(-457.3 \mathrm{~m})$ and $1 \mathrm{~B}$ at 55 feet $(16.7 \mathrm{~m})$. The high baseflow discharge ratio of Station 1B is approximately three times as great as the discharge ratio for this station during the low baseflow measuring event. The control reach of Templeton Fork is delineated as being represented by Stations 1A and 1B because Station 2 at 595 feet $(181.4 \mathrm{~m})$ through Station 4 at 800 feet $(243.9 \mathrm{~m})$ demonstrate a substantial degree of variability. Even though the station may be over solid coal, the station may be within the angle of dewatering influence of longwall mine subsidence. The low baseflow measurement indicates the control reach of Station 1A and 1B is outside of any influence from longwall mine subsidence.

The geophysical survey began just above Station 1B, which was the initial upstream measuring station. There were no geophysical anomalies detected between upstream of Station 1B. Geophysical anomalies do likely exist in the control reach but based on the normalized discharge ratios, any possible natural fracturing does not affect the discharge ratio in this reach. 
The alluvial sediment thickness within the control reach is very stable, ranging from 1.1 feet $(0.33 \mathrm{~m})$ to 1.4 feet $(0.42 \mathrm{~m})$, further substantiating the lack of influence the that longwall subsidence may have on the reach.

Longwall panel F10 begins approximately $860(262.1 \mathrm{~m})$ feet downstream along the measured reach. The mine subsidence $24^{\circ}$ angle of draw places the beginning of the tension zone of the subsidence basin approximately 220 feet $(67.0 \mathrm{~m})$ upstream of the edge of panel F10, at 530 feet $(161.5 \mathrm{~m})$ downstream. Measuring Stations 2 at 595 feet $(181.4 \mathrm{~m}), 3$ at 710 feet $(216.4 \mathrm{~m})$ and 4 at 800 feet $(243.9 \mathrm{~m})$ are all within this reach and show discharge ratio changes from the control reach. Panel F10 is therefore represented by these three stations, as well as by the remaining stations over the panel, Stations 5 at 985 feet $(300.3 \mathrm{~m}), 6$ at 1240 feet $(378.0 \mathrm{~m}), 7$ at 1595 feet $(486.2 \mathrm{~m})$ and 8 at 2060 feet $(628.0 \mathrm{~m})$. Stations 3 and 4 demonstrate a dramatic change in discharge ratio, but the remainder of the stream measuring stations across panel F10 record a strong similarity in trend between high and low baseflow discharges.

Panel F10's upstream tension zone, represented by Stations 2, 3 and 4, demonstrates a significant impact from longwall mine subsidence. The impact at high baseflow is a $78 \%$ increase in normalized discharge. This same reach at low baseflow has a $30 \%$ increase, but then returns to the control reach discharge ratio.

There are two significant anomalies located within the upstream edge of the subsidence basin, TF3 from 480 to 510 feet (146.3 to $155.4 \mathrm{~m}$ ) downstream and TF4 from $660(201.2 \mathrm{~m})$ to $810(246.9 \mathrm{~m})$ feet downstream. The first anomaly, TF3, represents the upstream extent of the upstream tension zone of panel F10. TF4 depicts the shallow fracturing of the upstream tension zone at depth. Mine subsidence fractures associated with 
tension zones are parallel with the panel's edges (Peng, 2006). The stream discharge measurements do not indicate that the stream is being dewatered by these fractures, but rather that there is additional water being added to the base level discharge over the mining impacted reaches of stream. Therefore, the detected upstream tension zone fractures at depth (VLF of TF4) do not dewater the stream nor, based on the depth of the mine, does it take stream water into the mine. The only impact to stream discharge from mine subsidence is the increase of ground water recharge at high baseflow, and the temporary decline of stream discharge at low baseflow.

Tensional fractures increase storage and permeability of the shallow ground water aquifer in this reach. This change in aquifer characteristics increases the discharge from this aquifer during high baseflow; but also creates an influent reach during low baseflow as the fracture zone increases recharge to the shallow aquifer from the stream.

While there is very little variation in alluvial sediment thickness from the control reach through Stations 2 and 3, Station 4 exposes a claystone bedrock in bottom of the stream channel. The alluvial sediment is reduced to a thin cover over parts of this bedrock. The alluvial sediment thickness change between Station 3 and 4 does not create a significant difference in normalized discharge, which is 7 to $8 \%$, where there is a $92 \%$ decrease in sediment thickness. There is no hyporheic zone at Station 4, no loose alluvial gravels in which stream water may be moving downstream. The stream water at low baseflow must be passing into the shallow fractures beneath the stream at Stations 3 and 4, and flowing as underflow.

Immediately below this bedrock exposure at Station 4, a pot-hole formed in the stream bottom. This pot-hole is 4 feet deep and as wide as the channel itself. This pot-hole 
extends over 15 feet $(4.5 \mathrm{~m})$ downstream from the bedrock exposure. There are several potholes like the one, within the reach between Station 4 and Station 5. The breaking of the stream substrate in this reach expresses the surface tension that results from the subsidence of panel F10, supporting the shallow geophysical anomalies detected within this reach.

Station 2 records flow increases at both high and low baseflow. This station is located between geophysical anomalies TF3 and TF4 and is therefore not as impacted by shallow subsidence fracturing.

The remainder of the longwall panel is represented by Stations 5 through 8 . Station 5 continues the elevated high baseflow discharge ratio achieved by Stations 3 and 4 . This station is located near the end of the scoured bedrock reach that was discussed earlier, downstream of Station 4. The station also marks the end of the low baseflow influent reach and the beginning of an effluent reach resulting in the resurgence of ground water to the stream at $985(300.3 \mathrm{~m})$ feet downstream. Station 5 accounts for all of the flow detected at Station 2, plus ground water that is added further downstream of Station 2.

Station 5 is located over significant anomaly TF5. This fracture, located near the terminus of an increase in channel gradient, is likely the means by which the shallow underflow is able to return to the surface. The shallow alluvial sediment thickness reflects the erosive nature of this reach.

Just as there is a significant stream discharge increase over the upstream tension zone, there is just as much decrease between Station 5 and 8 . This is a discharge ratio decline during both high and low baseflow of $42 \%$ and $45 \%$, but at a much more gradual rate of change. This decline returns the normalized discharge ratio, as measured at Station 8 , to control reach levels. While this reach records a discharge and discharge ratio decrease, the 
water is not believed to be lost to the mine. It may be lost to shallow underflow or laterally redirected into alluvial deposits of the Templeton Fork floodplain. The gradual rate of stream flow loss from Station 5 to Station 8 suggests that there is no single set of fractures that have resulted in the water discharge decrease, but rather a near constant wicking of water from channel into the shallow aquifer of the alluvial floodplain.

There are five significant anomalies over the downstream two-thirds of panel F10. These anomalies consist of some highly significant VLF anomalies, with only two low significance TC anomalies. The anomalies are not well coordinated indicating these fractures do not have a hydrologic impact on the stream discharge.

The alluvial sediment thickens at Station $6(1240$ feet, $378.0 \mathrm{~m})$ to 2.2 feet $(0.67 \mathrm{~m})$. Alluvial thicknesses of Station 7 at 1595 feet (486.2 m) and Station 8 at 2000 feet $(609.7 \mathrm{~m})$ return to near control level thicknesses of 1.3 and 1.7 feet $(0.39$ and $0.51 \mathrm{~m})$. The thickening of sediment at Station 6 is a result of deposition from the eroded upstream tension zone

Station 9 at 2440 feet $(743.9 \mathrm{~m})$ represents the gate-entry reach between panel F10 and the older panel to the south, panel F9. The downstream edge of panel 10 is 2340 feet $(713.4 \mathrm{~m})$ downstream, 100 feet $(30.5 \mathrm{~m})$ upstream of Station 9. Station 9 records a normalized discharge increase from Station 8 of $33 \%$ and $63 \%$, at high and low baseflow. This normalized discharge increase across the edge of panel F10 elevates the discharge ratio over the gate-entry to within $11 \%$ to $14 \%$ of the highest discharge ratio for each event, measured at Station 5. This resurgence suggests that no additional water has been added to the stream since Station 5, but it also suggests that 85 to $89 \%$ of the water recorded at Station 5 resurges at Station 9, even though Stations 6, 7 and 8 record a stream flow loss. 
There are two significant anomalies detected between Station 8 and Station 9. Anomalies TF11 from 2120 to 2140 feet (646.3 to $652.4 \mathrm{~m}$ ) and TF12 from 2210 to 2260 feet $(673.7$ to $689.0 \mathrm{~m})$ are delineated as subsidence fractures. These fractures do not correspond with the edge of panel F10, but occur 80 to 220 (24.3 to $67.0 \mathrm{~m}$ ) feet inside the edge of the panel. Anomalies TF11 and TF12 likely represent two points on the same fracture. They are associated with the tension fracturing of longwall mine subsidence of panel F10. This fracture provides the avenue by which lost stream water re-enters the channel.

The floodplain between Station 8 and 9 is part of the East Finley Park. This area was inundated by stream pooling as a result of surface subsidence of longwall panel F10. The condition was present prior to stream surveys. The stream over the gate-entry between panel F10 and F9 was excavated prior to surveys to alleviate this flooding problem. Since then the park has installed a French drain that runs west to east on the western bank of the creek, at approximately 2120 feet $(646.3 \mathrm{~m})$ downstream, presumably to lower the shallow water table of the floodplain in this area. The need to install a shallow drain in this area demonstrates the presence of a shallow water table and saturated floodplain sediments. The presence of the drain at 2120 feet $(646.3 \mathrm{~m})$ downstream suggests that this area is a discharge zone for the shallow ground water.

The alluvial sediment thickness at Station 9 is significantly thinner than the baseline thickness because this station is located in a reach that was excavated to promote positive drainage. Large 4 to 5 inch limestone gravels lien the excavated reach with very little natural sediment in the inter-granular space. The lack of thicker alluvial sediment may assist in 
forcing the stream water lost to ground water across the middle of the panel, in returning to the stream channel where it can be measured.

\section{Stream Conclusion}

A stream survey of Templeton Fork, in Washington County Pennsylvania, took place over a 5-month-old mined longwall panel, the youngest mined panel in the study group. The depth of the mine in the Pittsburgh Coal seam is approximately 535 feet beneath the stream, the second deepest in the study group. Measured stream discharges fluctuated dramatically across the study reach, yet the author did not visibly detect these fluctuations.

The upstream tension zone of the primary study panel is the first subsidence impacted zone that affects stream discharge. Increased conductivity recorded by geophysics indicates subsidence fractures are saturated. Erosion of the alluvial sediment caused by an increased stream gradient within this zone caused its removal exposing the shallow fractured bedrock beneath. The fractured bedrock also experienced erosion resulting in deep pools separated by boulder produced drop bars.

The upstream tension zone is a subsidence fracture set with higher permeability and storativity values than that of the surrounding rock. Orientation of this study stream's tension zone is perpendicular to the stream flow, which projects the fracture set into the adjacent hillsides. Detection of dramatic stream discharge increases and decreases are at the intersection of the fracture set and the stream.

Stream discharges increase across this fracture zone during high baseflow and decrease during low baseflow. While the increase at high baseflow is attributed to the concentration of hillside groundwater, the decrease at low baseflow is attributed to the increased storativity and the lowering of the water table in the fracture set. Stream flow 
across the compression zone of the subsidence basin, between the upstream and downstream tension zones, has a decrease in discharge-area ratio but an increase in measured discharge at each stream station for both high and low baseflow. A portion of the baseflow for this reach was captured by the higher permeable fracture sets at either end of the subsidence basin resulting in decreasing normalized discharge. Discharge-area-ratio decline across the panel may be going into underflow, through thickened and coarser in-channel alluvial sediment over the upstream half of the panel, or into the flood plain over the downstream half of the mined panel.

Post-subsidence excavation of alluvial sediment and shallow bedrock over the downstream gate entry produced positive drainage and reduced the stream pooling effects of longwall subsidence. The excavation altered the sediment within the downstream quarterpanel and gate-entry reaches by this drainage correction. Sediment analysis was not conducted within the excavated reaches due to the presence of large replacement gravels and very little sediment. 


\section{$\underline{\text { Southern West Virginia Streams }}$}

\section{Island Creek, West Virginia}

\section{Results and Discussion of Data}

\section{$\underline{\text { Stream Discharge Measurements }}$}

\section{$\underline{\text { High Baseflow }}$}

Seven measuring stations were established during the high baseflow measuring event. Two were placed over the 15LT panel, and the remaining five were placed above, over and below the 16LT panel. The two measuring stations over the $15 \mathrm{LT}$ panel were placed without the assistance of geophysical surveying (Figure 52). They were placed in their present locations based on visual observations of water loss during the geophysical survey of August 5, 2005. Station 1B was located, during the high flow measuring event of January 30, 2006, upstream of any visual water losses that were observed on August 5, 2005, and Station 2 was placed at the site of final water loss observed on August 5, 2005. Their distance is approximately 320 feet $(97.5 \mathrm{~m})$ apart. They are located immediately above the panel and over the edge of the panel. VLF was conducted over this reach but electric line interference prevented any usable data from being obtained.

The data for the January 30, 2006 measuring event represents a losing stream. The decline in discharge/area ratio is gradual but persistent, from upstream to downstream. Although there is a significant decrease in stream discharge over the measured length of the stream, visual observations on the date of measurement could not detect significant cumulative changes down the length of the stream. Island Creeks normalized discharge 


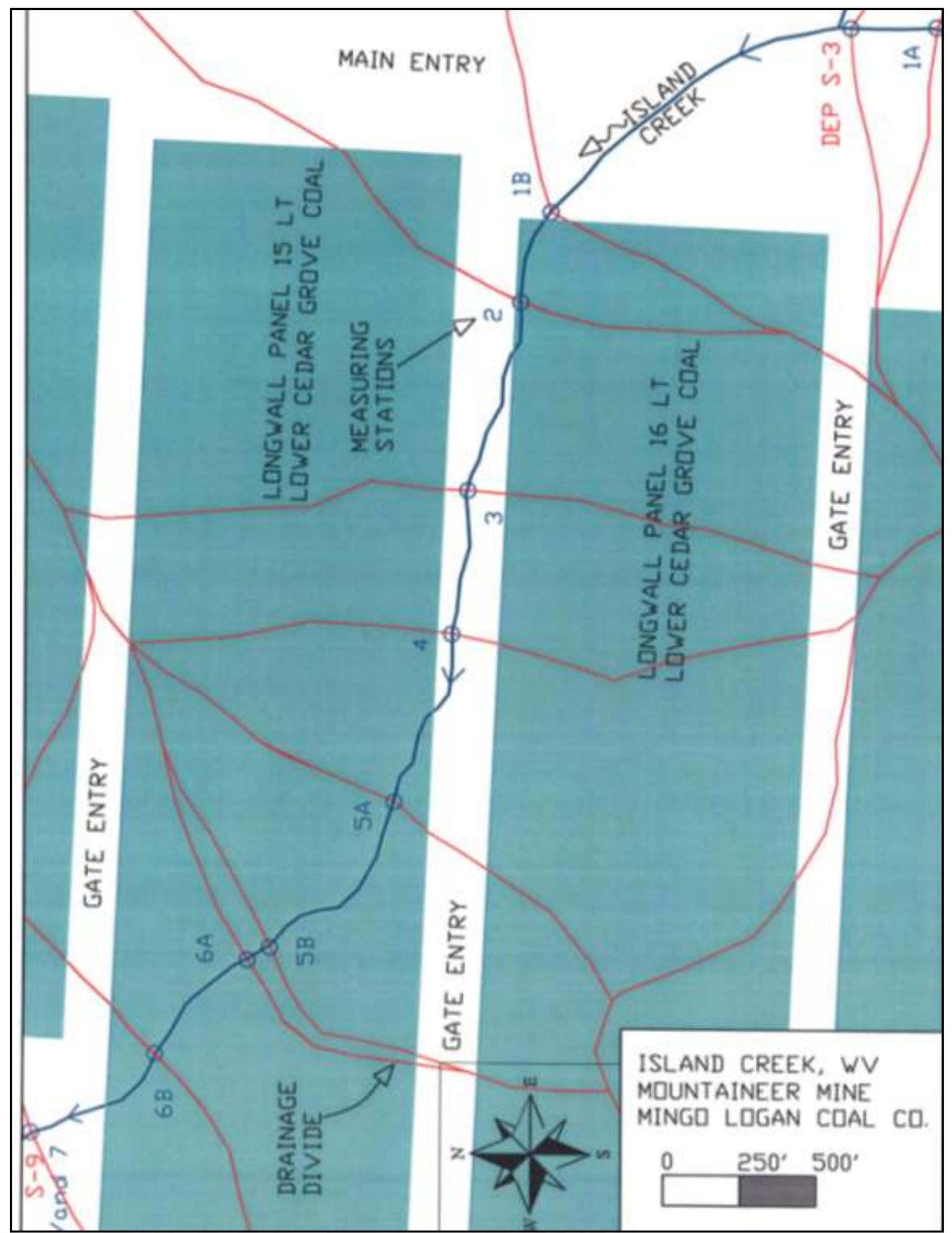

Figure 52. Station locator map for Island Creek showing stream measuring stations and longwall panels for a portion of the Mingo-Logan Coal Company's Mountaineer Mine in the Lower Cedar Grove Coal seam, Logan County, West Virginia. Island Creek and unnamed tributaries shown in blue. Drainage basins for measuring stations are shown in red. 
decreases from 0.88 to 0.28 , resulting in an overall decline of $68 \%$ (Appendix III, Table 10; Figure 53).

Measurement Stations 1B and 2, located over panel $15 \mathrm{LT}$, do not detect the water losses that were visually observed on August 5, 2005 between these measuring points. The measuring stations instead record an increase in measured discharge, resulting in an steady discharge ratio.

Measuring Stations 1B and 2 were placed in order to record 'water losses' that were thought to be associated with mine subsidence fracturing. This assumption was based upon the August 5, 2005 visual observations of the stream going dry between these two stations, and over panel 15LT. The data results however do not corroborate the assumption that any mine subsidence from panel $15 \mathrm{LT}$ is having a negative impact on the discharge of the stream in this reach. The measuring Stations $1 \mathrm{~B}$ and 2 show no impact from mine subsidence. The monitoring stations over panel $15 \mathrm{LT}$ are not properly spaced, nor are there enough upstream stations, to adequately characterize the complete influence that this panel has on the streams discharge. Due to their closeness, the two Stations 1B and 2, are likely within the angle of dewatering influence and too close to represent effects of dewatering.Downstream of Station 2 , the stream continues to flow parallel over panel 15LT for another 300 feet. The stream then flows down the center of the gate-entry, parallel to the long axis of the longwall panels for approximately $800(243.9 \mathrm{~m})$ feet before being measured at Station 3. Between Station 2 and 3, a normalized discharge decrease of $31 \%$ is recorded. The decrease could be a function of the stream flowing over a tension zone within panel $15 \mathrm{LT}$, or being over the gate-entry which has been documented to be a zone of water loss (Dixon and Rauch, 1988). The stream 
then flows across cross the upstream edge of longwall panel 15LT and into the quarter-panel zone without significant fluctuation.

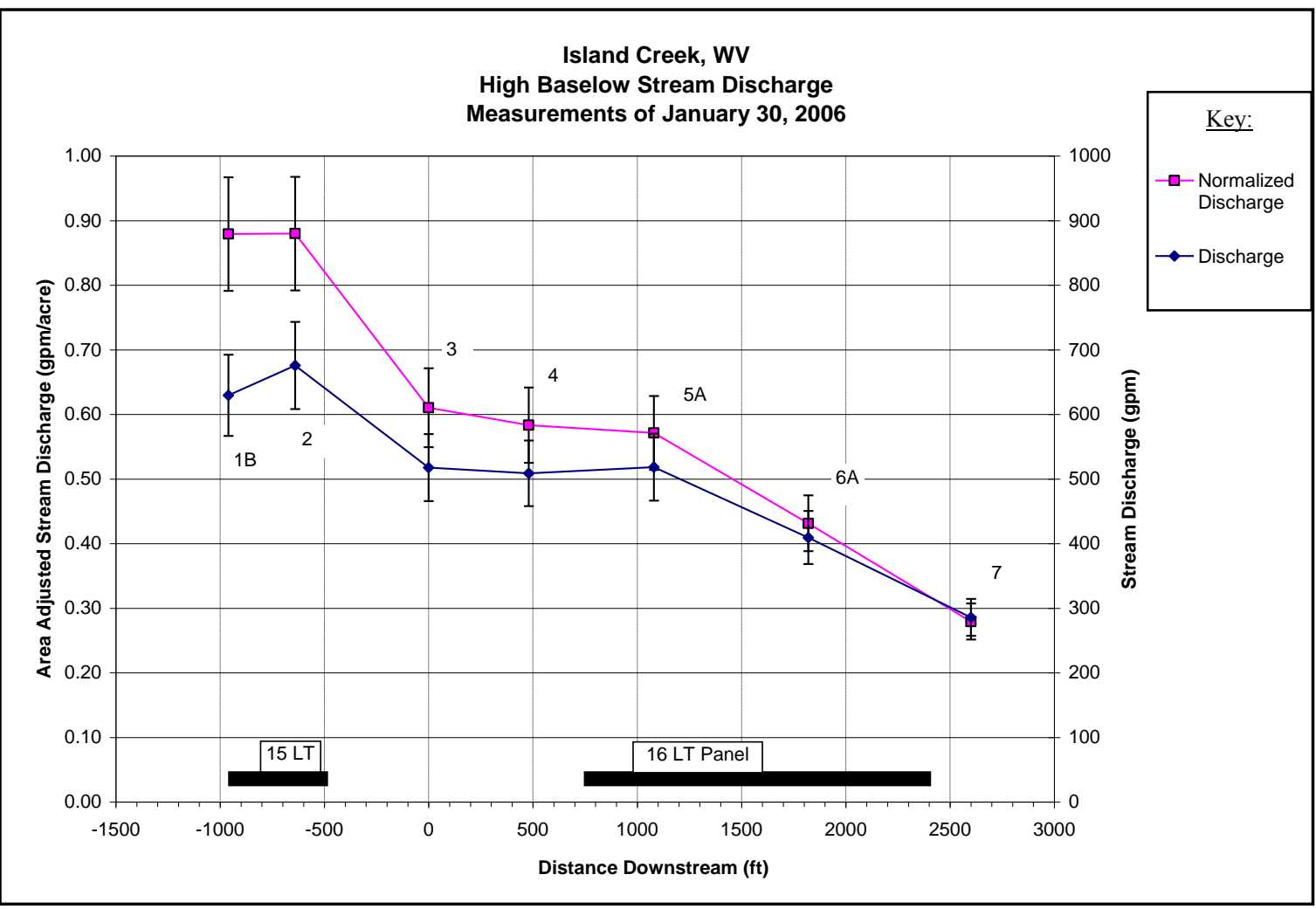

Figure 53. Measured high baseflow (HF) discharge (aQ) and normalized discharge (aQdr) for Island Creek, WV. Discharges are plotted over longwall panels and measured distance downstream. Discharges display +/-10\% vertical error bars.

Island Creek exhibits an average normalized discharge decline of $68 \%$ from Station 1B to Station 7. This decline does not show any sign of resurgence over the downstream tension zone, between Station 6A and Station 7. A resurgence has been observed in some other measured streams where the stream flows back over solid or low extraction mined coal.

An average rate of water loss can be calculated given the expected discharge difference and the measured distance downstream between the measuring stations. From Station 1B to Station 7, an average stream discharge loss of $9 \mathrm{gpm} / 100$ feet of stream length, was calculated. This stream water does not return within the measured stream reach. 
Discharge was not measured downstream of the study reach due to time constraints, but it is observed that the water did not visibly increase. The Lower Cedar Grove Coal seam is not deep mined downstream of Station 7, likely due to the shallowness of the seam beneath the stream.

$\underline{\text { Low Baseflow }}$

For the low flow measurement event, two stations were added to the program. Station 1A was added to better define the impact that panel 15LT had on Station 1B and Station 2. Station $6 \mathrm{~B}$ was added to clarify a significant change observed during this measurement event, identified between Station 6A and Station 7 (Figure 54).

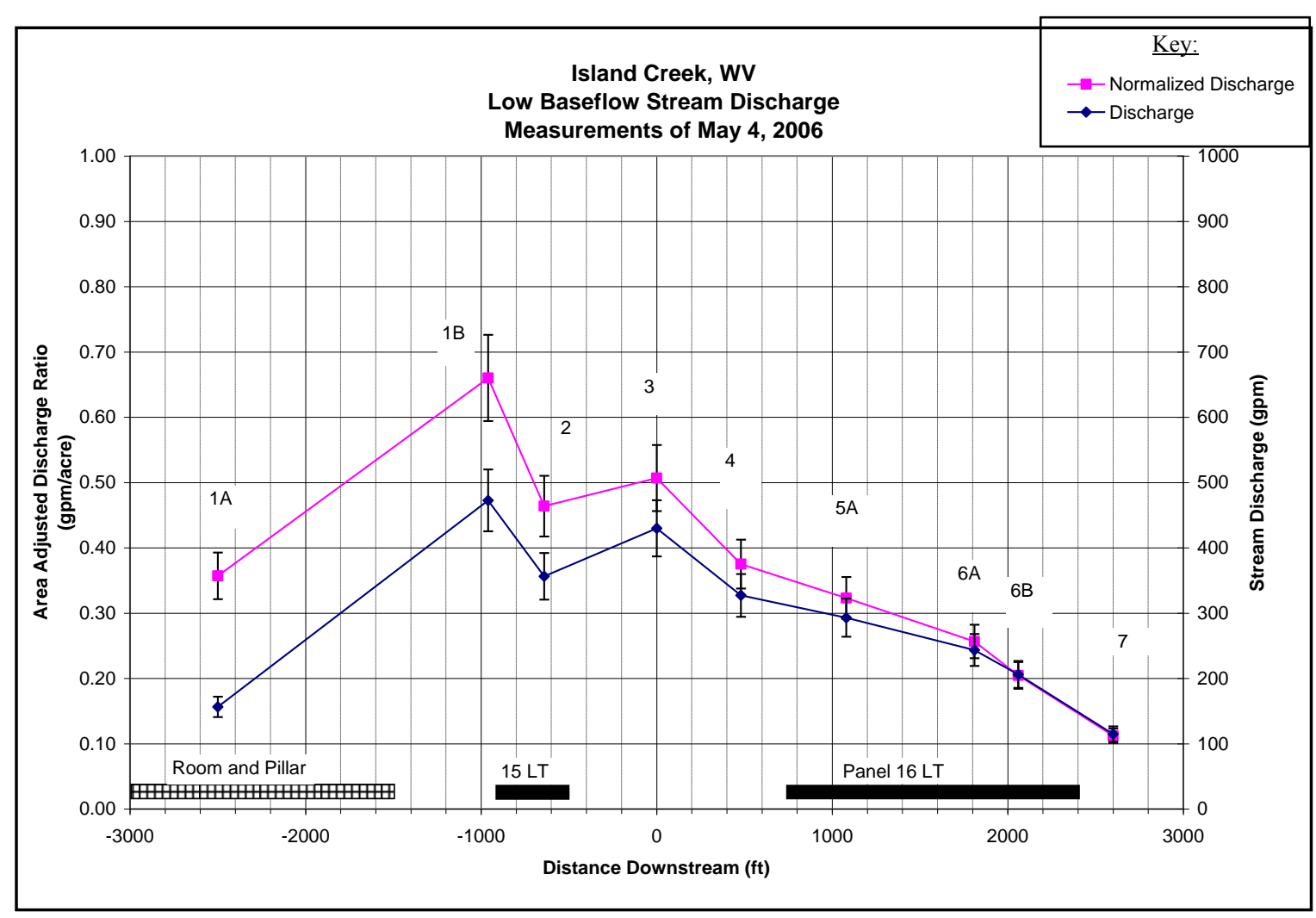

Figure 54. Measured low baseflow (LF) discharge (aQ) and normalized discharge (aQdr) for Island Creek, WV. Discharges are plotted over longwall panels and measured distance downstream. Discharges display +/-10\% vertical error bars. 
A normalized discharge increase of $85 \%$ is recorded from Station $1 \mathrm{~A}$ to $1 \mathrm{~B}$. This increase is likely a result of a tributary discharge that enters the stream between these stations. A decrease of $30 \%$ is recorded from Station $1 \mathrm{~B}$ to Station 2. This change occurs in only 320 feet $(97.5 \mathrm{~m})$ resulting in a $36 \mathrm{gpm}$ per 100 feet rate of decrease. This reach of stream flows across the upstream corner of panel 15LT, and this reach has been observed going dry on August 5, 2005 during really low flow conditions. The possibility of a stream impact by mine subsidence here is likely.

The lower half of the measured reach, starting at Station 3, is a losing stream that has an average rate of loss of $12 \mathrm{gpm}(0.75 \mathrm{l} / \mathrm{sec})$ per 100 feet $(30.5 \mathrm{~m})$ of stream (Appendix I, Table 11). The rate is very consistent throughout this reach, except for a small increase in rate loss from Station 3 to 4 , the stream loses water irrespective of the location of any of the mine features such as quarter-panels and gate-entry.

Stream discharges measured at Stations 3, 4 and 5A are demonstrate a more dramatic stream loss rate than during high baseflow. During the high flow measuring event, this 1080 foot $(329.2 \mathrm{~m})$ reach showed only a $6 \%$ decrease in area adjusted discharge ratio with a zero net loss of stream discharge. During low flow however, this reach no longer is able to maintain its discharge, and as a result, experiences a 37\% normalized discharge ratio decline and a 13 gpm $(0.8 \mathrm{l} / \mathrm{sec})$ per 100 feet $(30.5 \mathrm{~m})$ stream discharge loss rate. This loss, similar to the high flow measuring event, shows no sign of resurgence within the measured reach.

Station 6 A was added, downstream of Station 5, due to a calculated $34 \%$ decrease in discharge ratio calculated between Station 5 and 6B. Station 6A confirmed the declining trend of the discharge ratio within this reach. This reach has a $56 \%$ decline in area adjusted discharge ratio and loses water at $16 \mathrm{gpm}(1.0 \mathrm{l} / \mathrm{sec})$ per 100 feet $(30.5 \mathrm{~m})$ of stream. 
Extremely Low Baseflow

Another sampling event was conducted on Island Creek during extremely low baseflow conditions. This measuring event demonstrates the streams insurgent point being within the measured reach, and over mined longwall panels. An additional measurement point was added to show the terminus of the stream on this day and time.

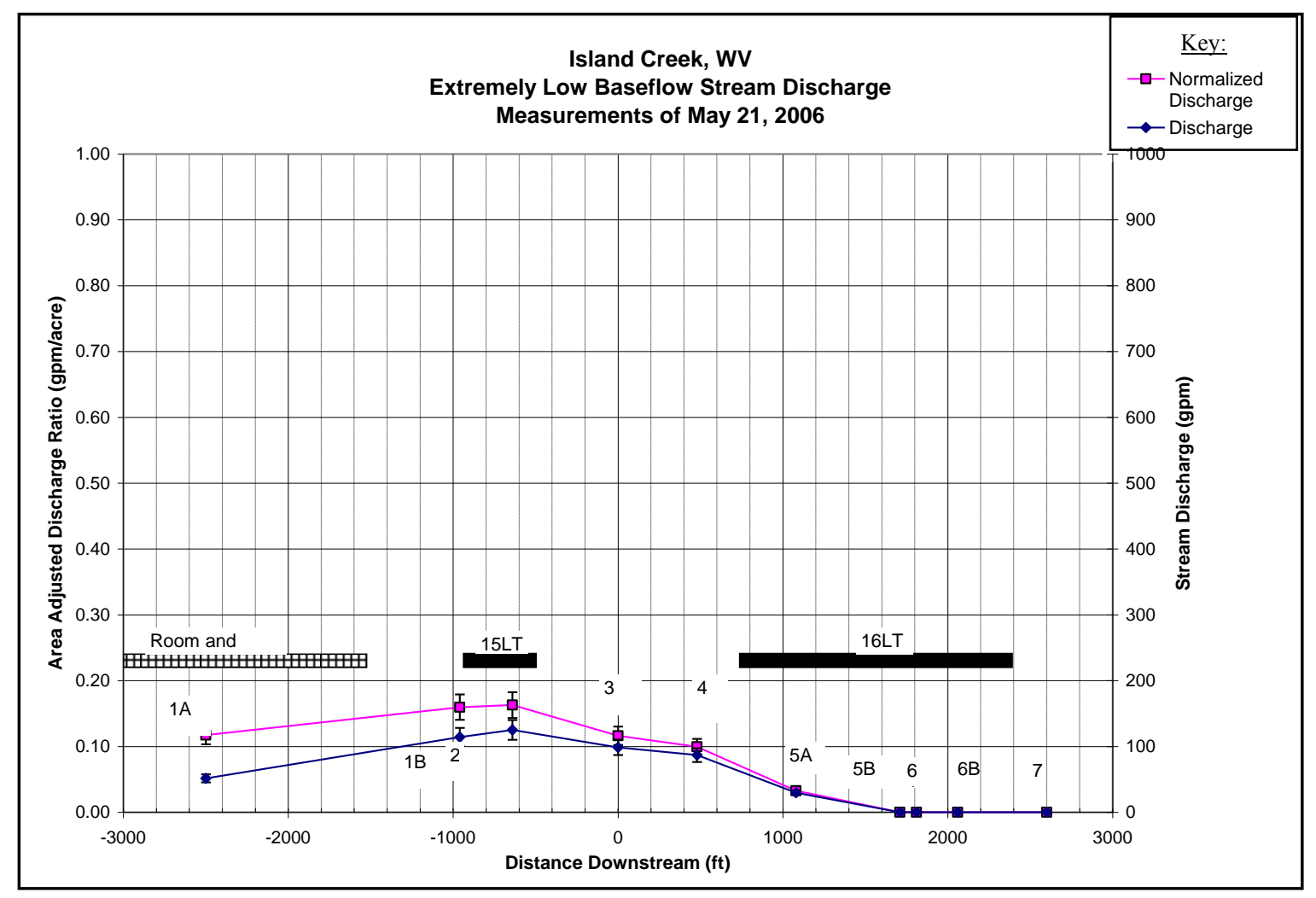

Figure 55. Measured low baseflow (LF) discharge (aQ) and normalized discharge (aQdr) for Island Creek, WV. Discharges are plotted over longwall panels and measured distance downstream. Discharges display $+1-10 \%$ vertical error bars.

The normalized stream flow increases from Station 1A to Station $1 \mathrm{~B}$ by $27 \%$. An increase is also observed in the data set of May 4, 2006; the low flow event. The stream flows over room and pillar mined 'mains' that are believed to have not been second mined, and then over the barrier coal left between the end of the panel and the main entries. 
Station $1 \mathrm{~B}$ and 2 demonstrate good control stream correlation of area adjusted discharge ratio. The two measuring stations were originally placed to detect loss at a previously observed water loss location. However, two of the three measuring events for Island Creek demonstrate normal stream behavior for Station $1 \mathrm{~B}$ and 2.

Stations 3 and 4 demonstrate a 16\% normalized discharge ratio decrease and a stream water loss rate of $2 \mathrm{gpm}(0.1 \mathrm{l} / \mathrm{sec})$ per 100 feet $(30.5 \mathrm{~m})$. The stream continues to lose water to the subsurface until it goes dry at Station 5A, 1710 feet $(521.3 \mathrm{~m})$ downstream. The stream shows no sign of resurgence within the measured reach, or for a significant distance downstream. Drift entries are shown on the U.S.G.S. topographic map further downstream on the sides of the creek, probably into the Lower Cedar Grove Coal seam. The stream water does not return until much further downstream.

\section{Mine Permit Flow Data}

Stream flow data collected by the mine operator prior to permit approval and mine activation was submitted to West Virginia DEP. Some of that data is presented in this thesis because of its relevancy. This flow data from the West Virginia DEP is not the optimal comparison to the author's data because the collection methods are unknown.

Six months of pre-mining stream flow measurements were obtained for this reach of Island Creek from the mining application submitted by the mine operator to the West Virginia DEP. The data is not directly comparable to study data because flow measurement times were not recorded, and the flows were not collected on the same day as each other. Since it would have been useless to compare upstream and downstream flows from different dates, the flows for each stream station were averaged. This supplied an average flow for each measuring station. A drainage area was calculated for each station and the normalized 
stream discharge was calculated by dividing the average discharge for each station by its contributing drainage area. This data is presented as DEP Station S-3, S-9 and S-11A on Figure 56.

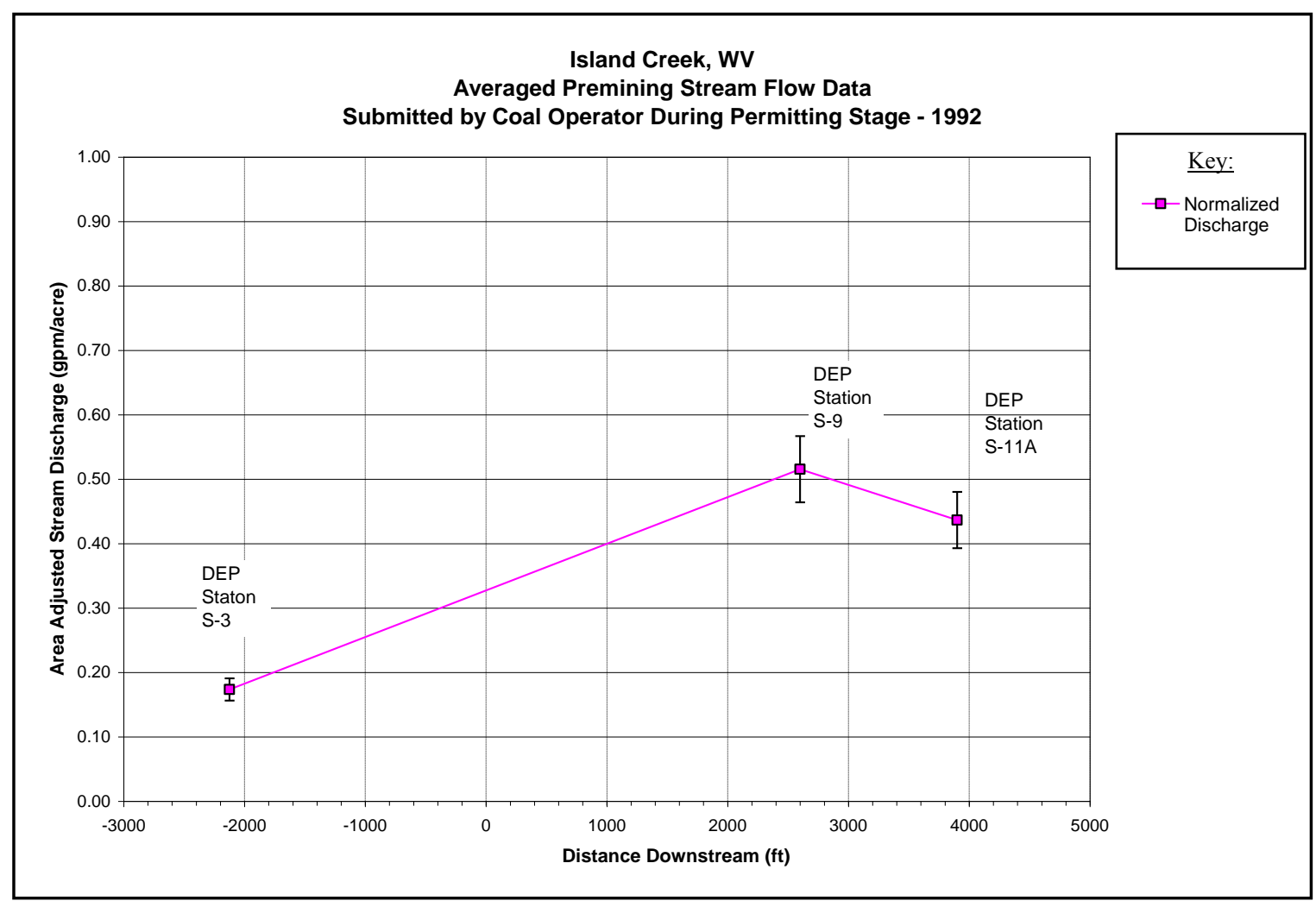

Figure 56. Pre-mining normalized stream discharge measurements over the study reach of Island Creek, WV. Discharges were averaged from all available measurements to acquire a representative graph due to the lack of measurements from all three stations on a single day. A $10 \%$ error is assumed.

The normalized discharge increases downstream from DEP Station S-3 to DEP Stations S-9 and S-11A. These data document the average stream flow for Island Creek increasing across the study area, prior to longwall mining. The comparison of pre-mining data to post-mining data collected by the author qualitatively demonstrates the dramatic changes in conditions of the stream. 
However, the increase in reported pre-mining stream flow data is not as expected. The normalized stream discharge should remain at approximately the same value for the entire watershed. As the stream gains in drainage area downstream, the stream discharge should increase and the division of the increasing drainage area into the increasing discharge should yield a relatively constant value for the measurement date, after correcting for time. Therefore, the data suggest that there is an increase in average normalized discharge, similar to the increase observed from Station 1A to Station 1B for the low baseflow measurement (LF) collected on May 4, 2006. DEP Station S-3 is immediately upstream of the confluence of Island Creek with Deadman Branch. The DEP data suggests there is some recharge influence into Island Creek that enters below DEP Station S-3 at -2125 feet (647.8 m) and above Station 1B at -960 feet $(292.6 \mathrm{~m})$.

\section{Geophysical Measurements}

The TC and VLF surveys for Island Creek, are very poor data sets for interpreting subsurface fracturing. There is a significant amount of interference within the surveyed reach. Interference from metallic objects in the creek bed has corrupted the data for the TC for 25 feet $(7.6 \mathrm{~m})$ in either direction. Conductive interference can obscure data as far as 200 feet $(60.9 \mathrm{~m})$ in either direction for the VLF survey. These estimates are based upon the collected data from this and other surveys included in this study. There are 12 major interferences within the 2600-foot (792.6 m) geophysical survey of Island Creek (Appendix III, Table 5).

The geophysical surveys were conducted in August, 2005. At this time, Island Creek was going dry between -640 and -960 feet (195.1 and $292.6 \mathrm{~m})$ downstream. The reach of 
stream selected originally for the survey, from 000 to 2600 feet $(792.6 \mathrm{~m})$ was completely dry and had been for some time. The ground in the stream was very dry, to the point that the stones had become 'set' in the stream bottom. The alluvium became like mortar, holding the creek bed together. The dry conditions at the site during the survey proved to influence the data recorded. The apparent vertical dipole TC baseline values ranged between 4 and 6 $\mathrm{mmhos} / \mathrm{m}$, the apparent horizontal dipole TC baseline ranged between 2 and $5 \mathrm{mmhos} / \mathrm{m}$.

The low conductivity baseline for Island Creek indicates the dry conditions of the shallow subsurface. Fractures that may be present may not be detected because they are likely dry as well. Generally, the electromagnetic surveys identify fractures on the basis of their higher conductivity than background non-fractured strata (Ackman and Barta, 2002). However, if there is no difference in conductivity values between fractures and background readings, then identification of fractures is not likely (Figure 57).

There are no geophysical anomalies within the data sets that can be differentiated from interference. Therefore, the data sets were not used to interpret sub-stream conditions and are not helpful in interpreting stream discharge changes.

\section{$\underline{\text { Alluvial Sediment Measurements }}$}

Sediment thickness was measured at each stream flow measuring station (Figure 58). The average alluvial thickness for the stream is 1.2 feet $(0.3 \mathrm{~m})$. Sandstone bedrock is present at Station 1B only.

Station 1B consistently had a high normalized discharge compared to the rest of the stream reach surveyed. This is the only station that has bedrock comprising the stream substrate, the remaining streams are composed of sands, gravels and boulders. 
This stream does not exhibit a significant change in stream gradient. This stream has the highest stream gradient of any of the study sites, based on U.S.G.S. topography. The stations located over the zone of tension are 4 and 5A. Station 5 suggests a $50 \%$ reduction in alluvial thickness compared to the control reach from Stations 3 to 4 . This is similar to other stream reaches at the upstream edge of longwall panels that have undergone scouring due to an increase in gradient as the stream crosses the angle of draw of longwall panels.

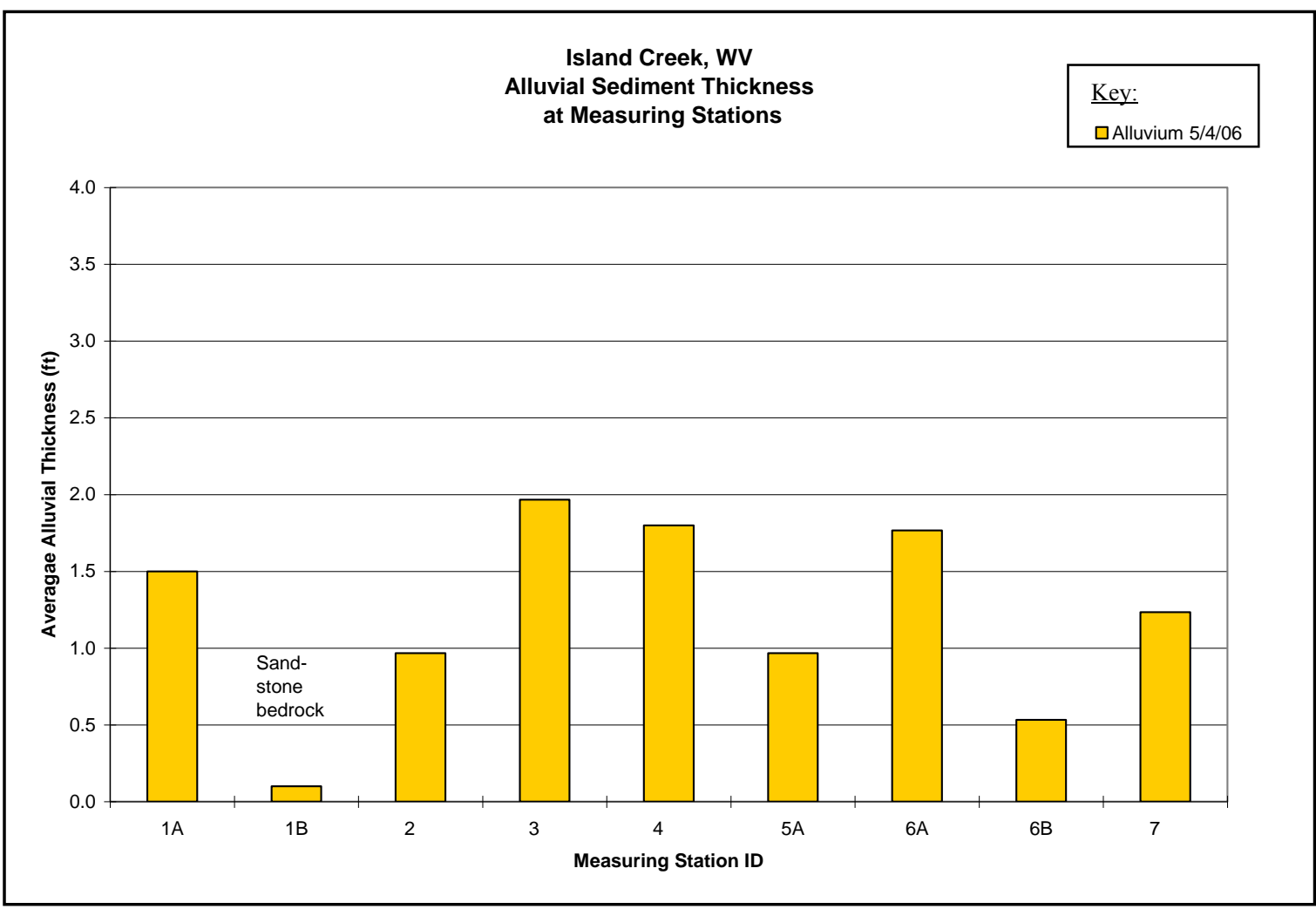

Figure 57. Average alluvial sediment thickness at stream measuring stations on the study reach of Island Creek, $W V$..

The median particle size for Station 2 is $52.6 \mathrm{~mm}$, for Station 4 it is also $50.6 \mathrm{~mm}$, and for Station 6A, the median particle size decreases to $32.7 \mathrm{~mm}$. The particle sizes for this creek are poorly distributed and skewed right toward cobbles, $>64 \mathrm{~mm}$ (Bunte and Abt, 2001). The largest mean particle sizes are found at Station 2 and 4 and decrease in particle 
size downstream (Station 6A), due to the decreasing gradient and downstream fining across the subsidence basin. Based on field observations, the stream reach from Station 1 to Station $5 \mathrm{~A}$ is the reach with the highest gradient. After the stream flows beneath the bridge around 1200 feet $(365.8 \mathrm{~m})$ downstream the gradient significantly lessens for the remainder of the surveyed reach.

\section{Interpretation of Data}

The control reach of Island Creek is represented by Stations 1A at -2500 feet $(-762.1$ $\mathrm{m}), 1 \mathrm{~B}$ at -960 feet $(292.6 \mathrm{~m}), 2$ at -640 feet $(195.1 \mathrm{~m}), 3$ at 0 feet and 4 at 480 feet $(146.3 \mathrm{~m})$. The flow measurements vary greatly within this control reach between the high, low and extremely low baseflow events. The discrepancies are believed to be a result of the location of the stations with respect to fracturing associated with subsidence basins of panels $15 \mathrm{LT}$ and 16 LT. Geophysical surveys encountered abundant interferences. This prevented data from being useful in evaluating the condition of the subsurface. Interpretations regarding fractures are inferred based on knowledge from this and other studies reviewed this research.

Station $1 \mathrm{~B}$ and 2 are near the edge of the panel $15 \mathrm{LT}$, within the tension zone of the subsidence basin. The subsidence basin is expected to consist of the 70 feet $(21.3 \mathrm{~m})$ surrounding the planimetric location of the panel. This tension zone is expected to be fractured near the surface increasing the shallow aquifer storage and permeability within this zone. The shallow fracture zone may increase discharge or decrease discharge depending on the baseflow level and the measuring station's location to the fractured zone.

The consistent increase from Station $1 \mathrm{~A}$ to Station $1 \mathrm{~B}$ of 26 to $85 \%$ indicates that the tensional fracture zone at the upstream edge of the subsidence basin increases the normalized discharge of the stream at both low baseflow and extremely low baseflow. The increase over 
this upstream edge is significant due to the fact that the stream is dewatered over the next panel, panel $16 \mathrm{LT}$. The increase is derived from upland recharge areas that have undergone mine subsidence that has increased the infiltration rate, reducing the infiltration rate, resulting in greater recharge rates. This subsidence enhanced recharge enters the stream through the higher storage and permeability zones that the stream crosses at the upstream edge of the subsidence basin.

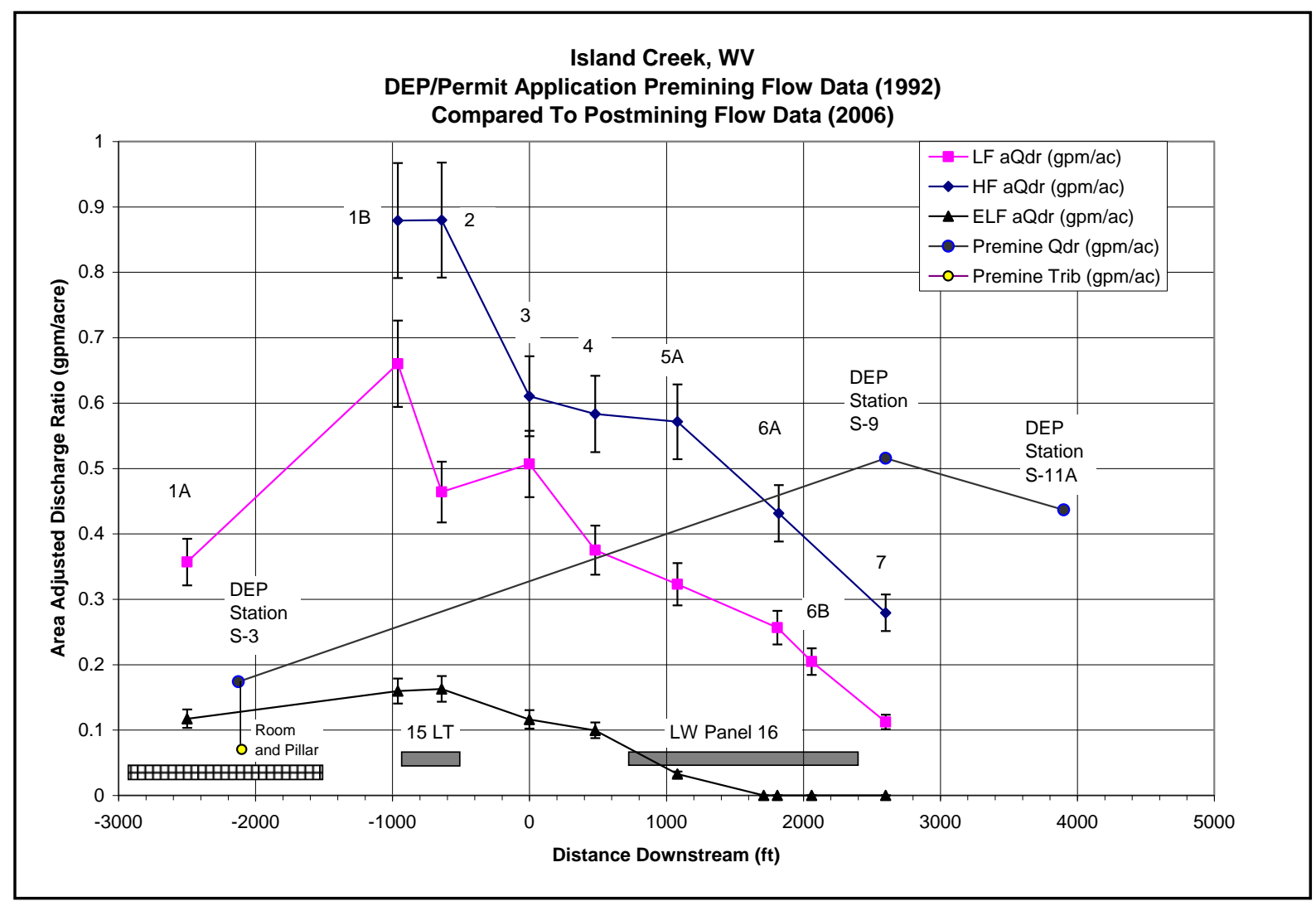

Figure 58. High flow $(H F)$, low flow $(L F)$ and extremely low flow (ELF) post-mining stream discharge measurements compared to pre-mining stream flow measurements across the study reach of Island Creek, West Virginia. DEP station discharge measurement methodologies are undefined, therefore error bars are not provided. 
The increase at Station 1B may be enhanced because of its location at a sandstone bedrock exposure. The lack of alluvial sediment will result in a greater amount of channel flow being measurable as in-stream discharge.

The low baseflow decline between Stations 1B and 2 is a result of the lowered water table over the fracture zone. The water table is lower because the baseflow is lower resulting in less recharge. Less recharge results in an unsaturated fracture zone with a high storativity. Stream water at low baseflow is pirated by the shallow fractures reducing the amount of water measured in the channel. Station 1B records an elevated discharge ratio at the upstream portion of the shallow fracture zone. The elevated ratio is due to the increased recharge as a result of faster rates of infiltration. Station 2 records a decline once the stream is well over the fracture zone. As the stream flows away from the subsidence basin of panel $15 \mathrm{LT}$ and its tensional fracture zone, the normalize discharge increases at low baseflow because of fracture zone discharges

The extremely low baseflow records a $26 \%$ increase from Station $1 \mathrm{~A}$ to $1 \mathrm{~B}$, then no detectable change in normalized discharge from Station 1B to Station 2. The discharge ratio at Station 1B decreases 76\% from low baseflow to extremely low baseflow. A substantial portion of this ratio is a part of the subsidence-enhanced recharge realized by lower evapotranspiration rates. This condition is present at both high and low baseflow. The significantly lower discharge ratio of Station 1B at extremely low baseflow reflects the reduction of the subsidence-enhanced recharge rates to the stream. As these recharge rates decrease, the detectable stream flow increase from Station 1A to Station 1B decreases from $85 \%$ to $26 \%$. At extremely low baseflow, the subsidence-enhanced recharge may eventually move directly to the tension fractures without being recorded as in-stream discharge. 
As baseflow declines, and the subsidence-enhanced recharge rate declines; Station 2 records no normalized discharge change from Station 1B at extremely low baseflow. The amount of subsidence-enhanced recharge has declined to the point where the water table across the fracture zone has stabilized, reducing the variability detected in the channel. During high baseflow, the water table is already high due to a very low rate of evapotranspiration during the winter. This large recharge rate has saturated the fracture zone and causes no effect to the measurable in-stream discharge because both Station $1 \mathrm{~B}$ and Station 2 are within the fracture zone.

High and extremely low baseflows record a normalized discharge decline between Station 2 and Station 3. This decline is a result of a lowering of the water table due to mine subsidence of panel $15 \mathrm{LT}$ and $16 \mathrm{LT}$. There is only 300 feet $(91.4 \mathrm{~m})$ of perpendicular distance between these two panels, and approximately 130 feet $(39.6 \mathrm{~m})$ of mine cover. The dewatering influence from these panels is far greater than the angle of draw influence. Impacts are expected even while the stream is over the gate-entry and outside of the predictable angle of draw. Dewatering impacts are expected, and are detected during all three measuring events from Station 3 to Station 7.

Consistent stream declines are recorded across panel 16 LT. This reach is characterized by measuring Stations $5 \mathrm{~A}$ at 1080 feet $(329.2 \mathrm{~m}), 5 \mathrm{~B}$ at 1710 feet $(521.3 \mathrm{~m})$, $6 \mathrm{~A}$ at 1810 feet $(551.8 \mathrm{~m})$ and $6 \mathrm{~B}$ at 2060 feet $(628.0 \mathrm{~m})$. These stations record a discharge ratio decrease across the panel, similar to other streams in the study. The rates of loss range from $4.6 \mathrm{gpm}(0.3 \mathrm{l} / \mathrm{sec})$ per 100 feet $(30.5 \mathrm{~m})$ at extremely low baseflow, to $14.7 \mathrm{gpm}(0.9$ 1/sec) per 100 feet $(30.5 \mathrm{~m})$ at high baseflow. 
There is no resurgence of stream discharge over the downstream edge of panel 16 LT. This lack of resurgence suggests that the surface water has been lost to the mine, approximately 100 feet $(30.5 \mathrm{~m})$ beneath the stream. The shallow cover likely induced the stream water deeper into the underlying sandstone rock, then into the mine pool of the Lower Cedar Grove mine workings. Since the shallowest cover is located near the most downstream point of mining, and is also at the at the most down-dip section of the mined coal, the reach of stream between Station $6 \mathrm{~A}$ and Station 7 may exhibit a resurgence in stream flow in the future. This may be realized only after the mine is abandoned and flooded.

The alluvial thickness does not appear to share any relationship to the normalized stream flow over the lower half of the study area. Island Creek is generally a losing stream in this reach and there are no instances where the alluvial sediment thickness appears to assist in keeping the surface water in the stream.

Even though the particle size decreases downstream, the data does not demonstrate an ability to retain the stream water on the surface. The mean particle size decreases from 52.6 $\mathrm{mm}$ near the upstream edge of panel $15 \mathrm{LT}$ to $32.7 \mathrm{~mm}$ at the downstream edge, which is still classified as a very course gravel (Bunte and Abt, 2001). The flow continues to be lost to the subsurface, whether it is through the courser upstream sediment or finer downstream sediment

\section{Stream Conclusion}

A stream survey of Island Creek, in Logan County West Virginia, took place over a 7-year 8-month-old mined longwall panel. The depth of the mine in the Lower Cedar Grove Coal seam is approximately 100 to 170 feet beneath the stream, the shallowest in the study group. Measured stream discharges fluctuated dramatically across the study reach. The 
author visibly detected these fluctuations only after the stream had begun losing half of its original flow.

Water is lost from the stream through the streambed at a constant rate. The streambed does not regain the lost discharge at the limit of mining.

Alluvial sediment is unevenly distributed across the study reach. Erosion across the upstream tension zone created a thickened and coarser deposit over the mined panel. The thick, large particle size alluvial deposit has not restricted the lost of stream water to the subsidence fractures.

\section{West Fork, West Virginia}

\section{Results and Discussion of Data}

\section{$\underline{\text { Stream Discharge Measurements }}$}

Ten stream measuring stations were placed across the flowing 3350-foot $(1021.3 \mathrm{~m})$ reach of West Fork in an attempt to characterize the losing nature of this stream. Two additional stations were placed further downstream, where the stream water resurges and the stream resumes flowing on the surface (Figure 60). These stations were placed after interpreting geophysical data and visual inspection of stream flow change.

Station 1,2, and 3 are control stations. All of the mines in this the study area were completed prior to initial field work. The control stations are located above longwall panels and provide for good control over the measured reach.

Mined longwall panels exist within the headwaters of West Fork, above the control reach, in both the Campbell Creek / No. 2 Gas Coal and the Eagle Coal seam. The extent of the longwall mining in the Campbell Creek / No. 2 Gas Coal seam is extensive beneath the 


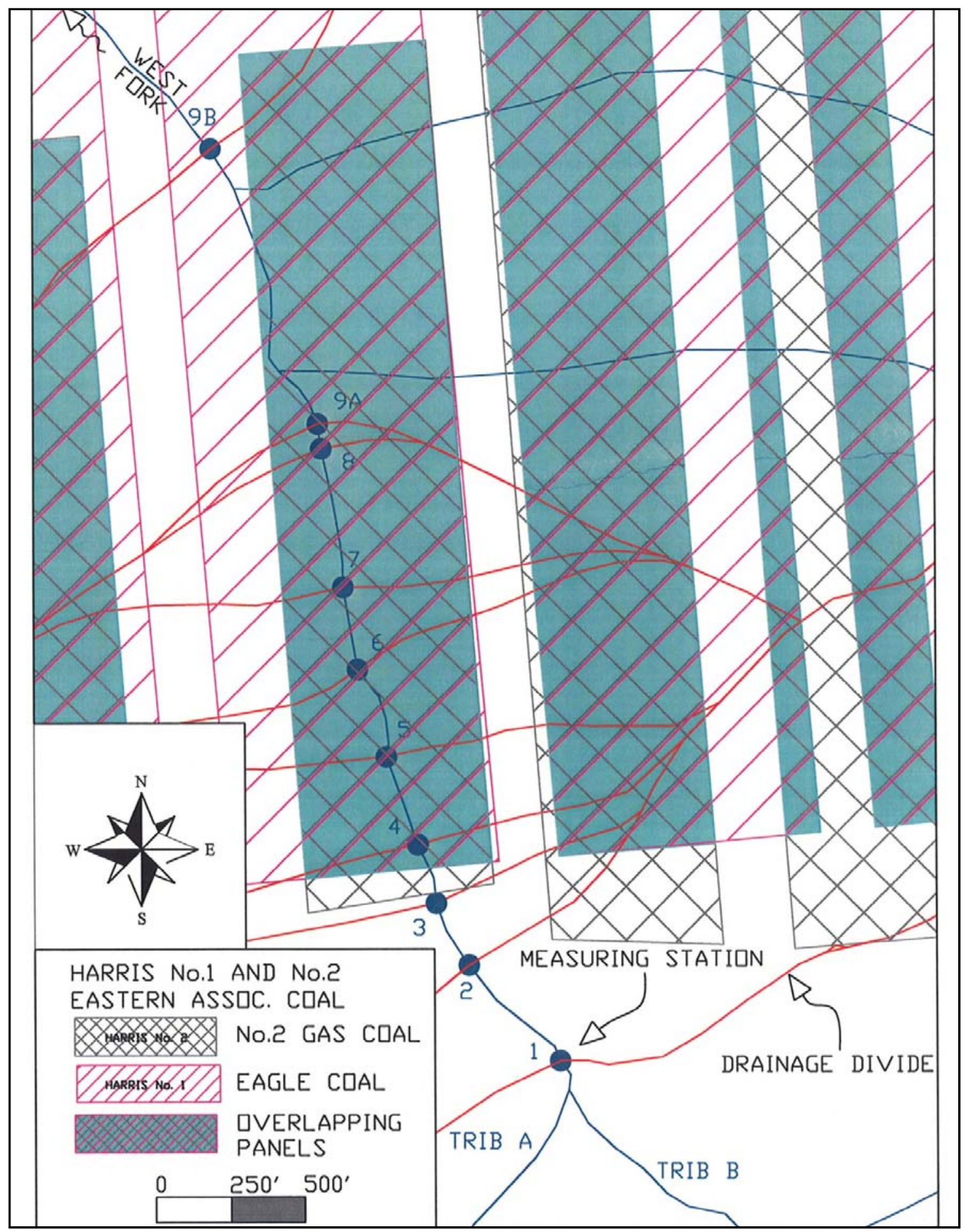

Figure 59. Station locator map of West Fork of Pond Fork showing stream measuring stations and longwall panel for portions of the Eastern Associated Coal Company's Harris No. 1 and Harris No. 2 Mines in the Eagle Coal seam and the Campbell Creek / No. 2 Gas Coal seam, Boone County, West Virginia. West Fork and unnamed tributaries shown in blue. Drainage basins for measuring stations are shown in red. 
southwestern tributary (Tributary A), upstream of Station 1, but the longwall mining beneath the southeastern tributary (Tributary B) is not as extensive. Stream loss due to longwall mine subsidence is expected.

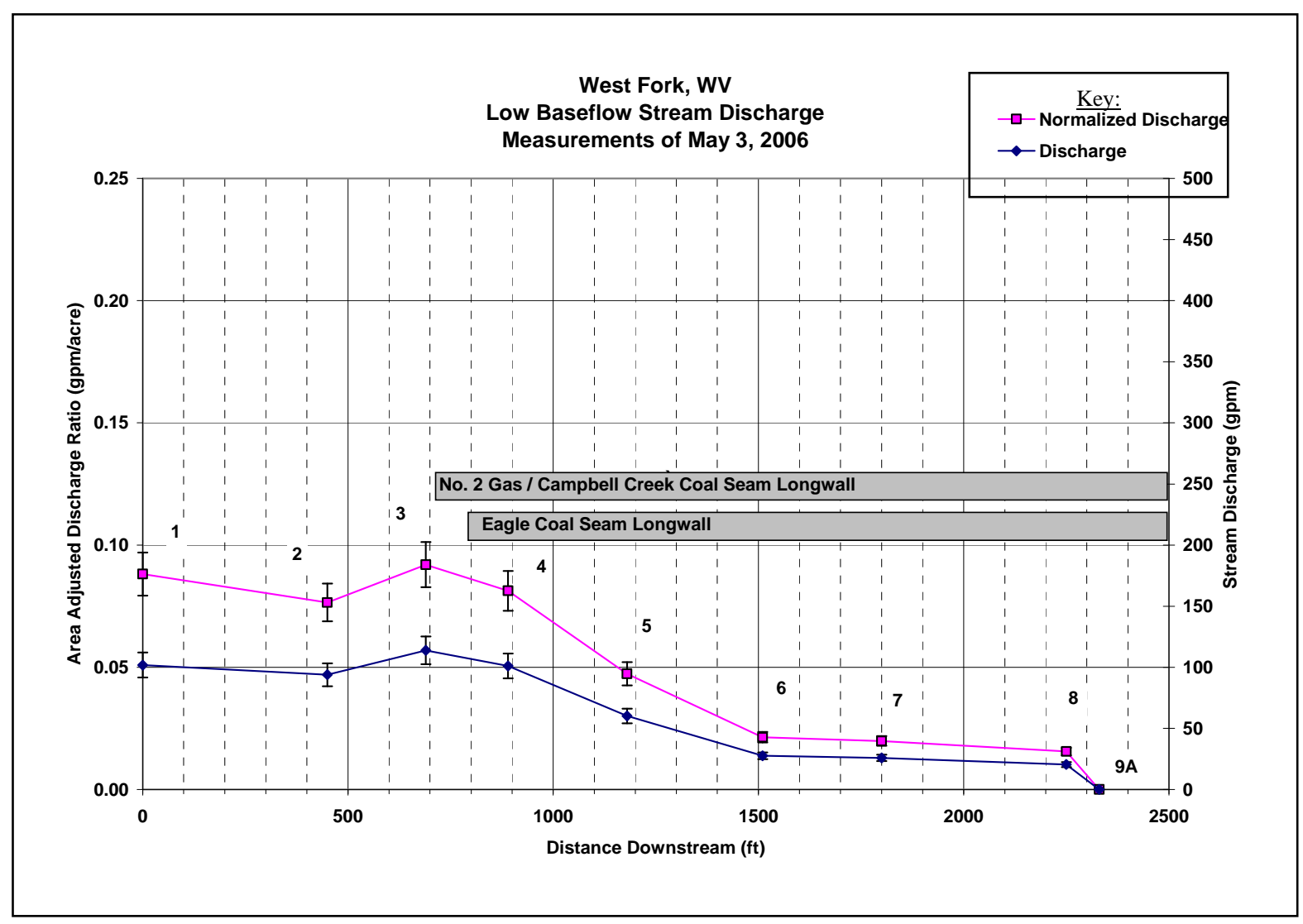

Figure 60. Measured low baseflow (LF) discharge (aQ) and normalized discharge (aQdr) for West Fork, WV. Discharges are plotted over longwall panels and measured distance downstream. Discharges display $+/-10 \%$ vertical error bars.

However, there is stream water present in the southeastern fork (Tributary B) and it was noted flowing as far upstream as the 1920 elevation (585.3 m) on May 3, 2006. Only Tributary C (southern fork) at this point was flowing on this day, Tributary D (southeastern fork) was dry suggesting that the longwall mining that is located under Tributary D stream, and not under the Tributary $\mathrm{C}$, has negatively impacted this intermittent stream reach. 


\section{$\underline{\text { Low Baseflow }}$}

The control reach, between Stations 1 and 2, is approximately 450 feet (137.1 m) long and located over main entries and barrier coal. The baseflow to these control stations are likely affected by previous longwall mines in the headwater reaches. The stations demonstrate some inter-station normalized discharge variability. The measured discharge differences are believed to be caused by differing alluvial thicknesses and not associated with mine subsidence.

Station 1 is 400 feet (121.9) from the closest longwall panel and Station 2 is 300 feet (91.4 m) from the closest longwall panel. The flow within the control reach between Station 1 and 2 has a 13\% decrease, accounting for a 0.01 gpm per ac, or an 8 gpm (0.5 l/sec) change (Figure 61).

The flow measurement at Station 3 records a 20\% increase from Station 2. The stream observes a significant increase 100 feet upstream of the longwall panel edge. This increase is unexpected since the station should be near the angle of draw and within the angle of dewatering influence. A stream flow decrease was anticipated since the stream goes dry over the mine workings farther downstream. The sandstone bedrock at Station 3 did not appear fractured or broken and there were no indications at the station that there had been any movement of the bedrock beneath the stream.

Between Station 3 and Station 6, 79 percent of the stream water disappears (Appendix I, Table 13). This is a water loss rate of $1.11 \mathrm{gpm}(0.06 \mathrm{l} / \mathrm{sec})$ per 100 feet $(30.5 \mathrm{~m})$ of stream. The panel width, as measured from the mine map, is approximately 890 feet (271.3 m) wide. The stream flows for 700 feet (213.4 m) over the mined panel, or a distance equal to $79 \%$ of the panel width of 890 feet $(271.3 \mathrm{~m})$, until its water loss rate abruptly changes at Station 6. 
The evidence of a compression zone with respect to the subsequent closing of fractures is not evident as the stream loses water at a constant rate while it flows down the middle of the panel.

The water loss rate is dramatically linear until it reaches Station 6, upon where it abruptly stops losing water and is sustained at a discharge rate of $0.02 \mathrm{gpm} / \mathrm{acre}$. The stream water maintains this discharge rate from Station 6 to Station 8, a distance of 740 feet (225.6 m). After Station 8, the stream begins losing water again and is dry by Station 9, 80 feet (24.3 m) downstream of Station 8.

The stream begins to recover at Station 10, at a measured distance of 10,500 feet (3201.2 m) downstream, 8170 feet (2490.8 m) downstream of its insurgence point at Station 9B. Station 10 is approximately one foot $(0.3 \mathrm{~m})$ upstream of where the first sign of resurgence appears. The flow of the resurgence was collected at Station 11, where it was measured to be discharging 249 gpm (15.6 l/sec). The drainage area adjusted discharge of Station 11 is $0.10 \mathrm{gpm}$ per acre, a $10 \%$ increase over Station 1. The resurgence point corresponds to the approximate location where longwall panels end and room and pillar mined main headings begin. West Fork demonstrates that as the water was lost within panel 5LT, it returns along with the baseflow that the stream would have received over this reach.

\section{High Baseflow}

High baseflow discharge measurements were obtained on West Fork on May 4, 2007. The stream had flowing water for the entire length of the surveyed reach, from Station 1 to Station 11. All of the tributaries above Station 1 were flowing. There were no noticeable changes in stream flow except between Station 9A and 9B. It was noticeable that there was a 
decline in discharge between these two stations while conducting the stream flow measurements.

The flow measured for recession was collected on May 3, 2007, with only a few snow flurries overnight. There were some snow flurries on May 4, 2007 as well, but the temperature stayed below 30 degrees all day. The light precipitation does not appear to have any recharge influence in the measurements.

The recession flow measurement was taken at Station 1 of the control reach. On the evening of May 3, 2007 at 6:35 pm, the flow was measured to be $2781 \mathrm{gpm}$ (175.2 l/sec). Then on May 4, 2007 at 7:45 am, the flow was measured to be 1990 gpm (125.3 l/sec), a decrease of $791 \mathrm{gpm}(49.8 \mathrm{l} / \mathrm{sec})$. The change in flow from May 3 to May 4, 2006 is a 28\% decline in normalized stream discharge over 13 hours and 10 minutes (Appendix I, Table 14)

The control reach, from Station 1 to Station 2, has good discharge correlation with a 2\% difference in normalized discharge. Station 3 records a normalized stream discharge increase, similar to the low baseflow data. The increase is $12.6 \%$ of the normalized discharge, which is $260 \mathrm{gpm}(16.3 \mathrm{l} / \mathrm{sec})$. This discharge is the greatest measured discharge for the upper reach of West Fork, as it was for the low baseflow event. The normalized discharge at Station 4 decreases from Station 3, to a value similar to that of Station 2 of the control reach. The difference in normalized discharge at high baseflow between Station 2 and Station 4 is 2\% and at low baseflow it was $7 \%$. This is the last station within the upper measured reach that resembles the low baseflow hydrograph. Starting with Station 5, the stream measurements portray a stream that does not appear to be significantly impacted by mine subsidence (Figure $62)$. 


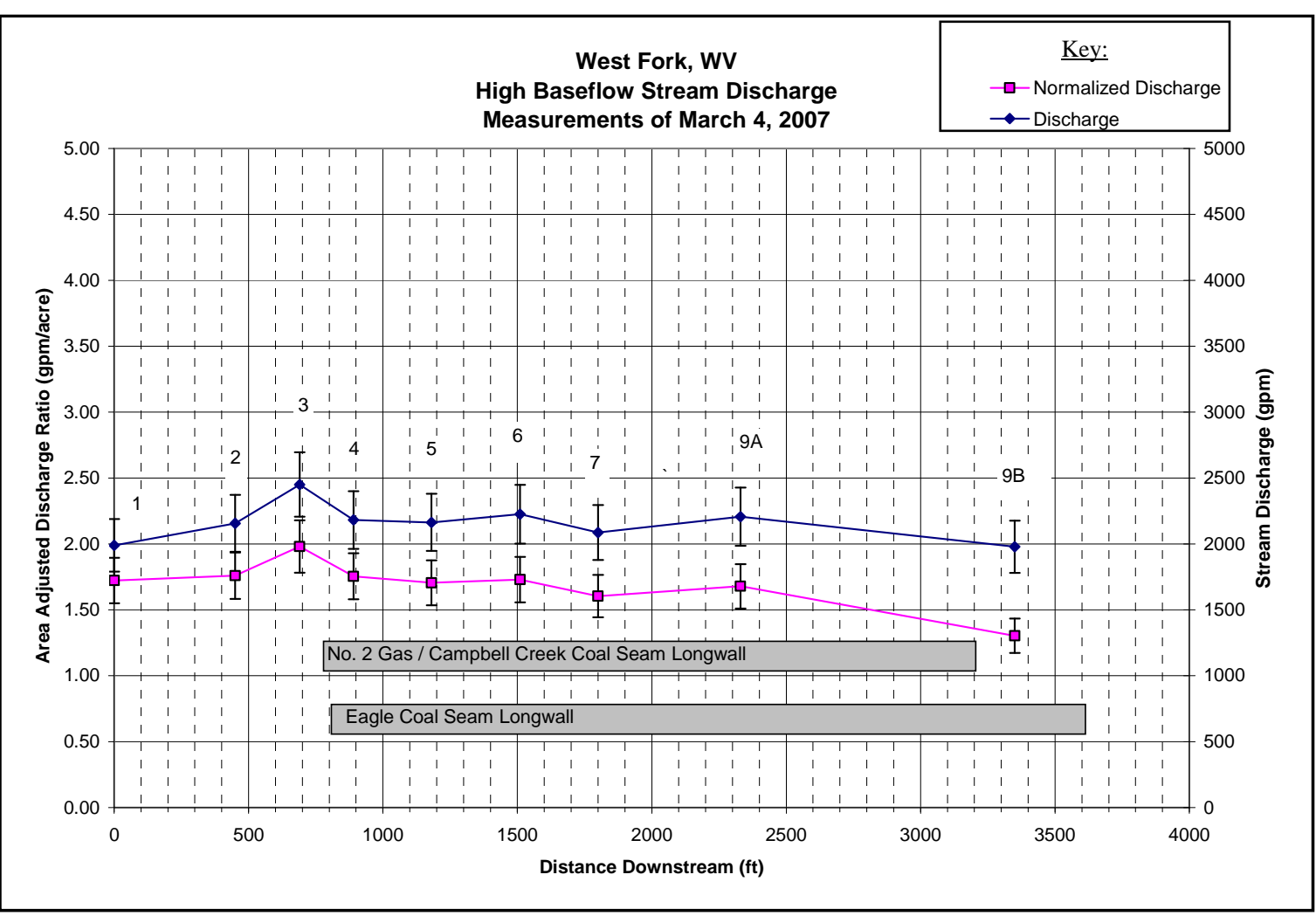

Figure 61. Measured high baseflow (HF) discharge (aQ) and normalized discharge (aQdr) for West Fork, PA. Discharges are plotted over longwall panels and measured distance downstream. Discharges display $+/-10 \%$ vertical error bars.

There are mild declines in normalized discharge from Stations 4 to 5 and from Station 6 to 7 . There are mild increases in normalized discharge from Station 5 to 6 and from 7 to 9A. Station 8 was not measured because of time constraints and the proximity of the station to Station 9A, which was 80 feet $(24.3 \mathrm{~m})$.

During low baseflow conditions, the clay seam found during the excavation for particle sampling did not encourage lost stream water to return to the surface. The stream measurements obtained during high baseflow record an increase of $1.4 \%$ from Station 5 to Station 6, suggesting that this clay unit may assist in returning some lost stream water to the surface. Although the normalized discharge at Station 5, which is upstream of this possible 
influence, is less than $1 \%$ different from Station 1, Station 5 is $13 \%$ lower than the normalized discharge of Station 3.

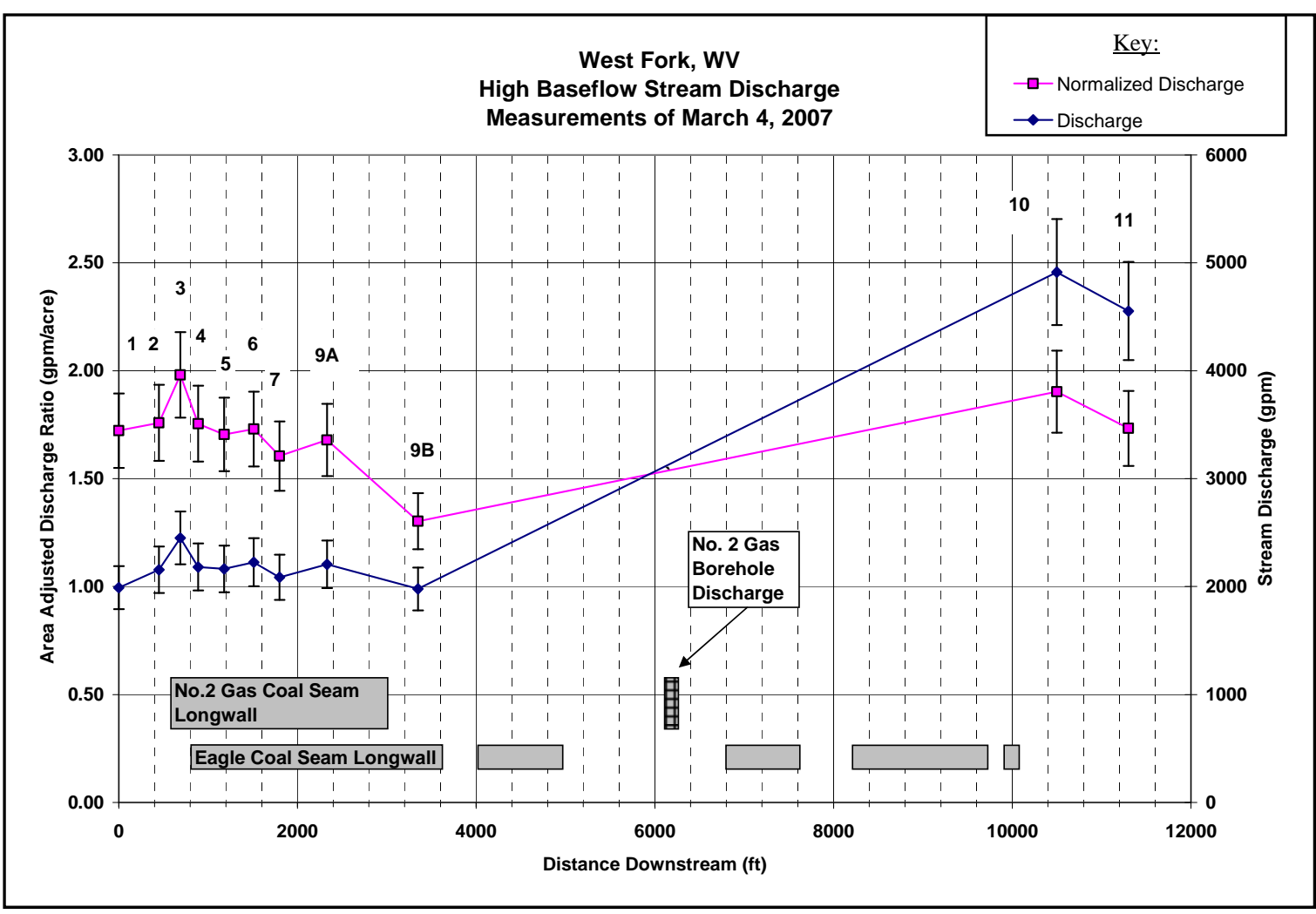

Figure 62. Measured high baseflow (HF) discharge (aQ) and normalized discharge (aQdr) for West Fork, WV. Discharges are plotted over longwall panels and measured distance downstream. Discharges display $+/-10 \%$ vertical error bars.

Station 9B records a significant decrease in normalized stream discharge from Station 9A and the control reach. Station 9B is the location of the final insurgent point of the stream as observed on January 31, 2006 while conducting geophysical measurements. Station 9B was the furthest downstream point, prior to March 4, 2007, that the sturdy reach of West Fork was observed having continuous flowing water within its channel. This station is located approximately 350 feet $(106.7 \mathrm{~m})$ downstream from the downstream edge of the longwall panel in the shallow Campbell Creek / No. 2 Gas Coal seam. The stream flows 
over this downstream edge, but sub-parallel with the edge for some distance; resulting in Station 9B being only 70 feet $(21.3 \mathrm{~m})$ from the edge of the panel. The edge of the subsidence basin for the shallow mine at approximately 150 feet (45.7 m) of cover is 67 feet (20.4 m). The greatest loss of stream water within the study reach occurs between Stations 9A and 9B. This reach lies within the downstream angle of draw of longwall panel 1 of the shallow Harris No. 2 Mine in the Campbell Creek / No. 2 Gas Coal seam.

Stations 10 and 11 recorded the resurgence of West Fork during the low baseflow discharge-measuring event. During high baseflow, these stations also record flow. Stations 10 records a $46 \%$ increase in normalized stream discharge from Station 9B. This increase brings the normalized stream discharge back up to within the range of values for Station 1 of the control reach and Station 3, the highest recorded normalized discharge within the measured reach.

Station 10 demonstrates a complete recovery of the lost stream flow across the Campbell Creek / No. 2 Gas Coal mine. Station 11 also demonstrates the streams recovery from the longwall impacts further upstream. The normalized discharge at Station 11 is less than $1 \%$ different from Station 1 . The stream has recovered its lost surface discharge along with its lost baseflow, similar to its recovery at low flow.

\section{Geophysical Survey Measurements}

Geophysical surveys were first conducted over August 10, 2005 and August 11, 2005. Data collected by the VLF unit would not download later when interfaced with a computer. The VLF survey was then conducted again on January 31, 2006, and a was able to be retrieved and is presented in the following graphs (Figure 64) 
Other difficulties also affect the data quality. Even though this stream is very isolated, the valley bottom turned out to be the easiest route for pipe-layers to get gas from their gas wells back down the creek. Unfortunately, this metal pipeline crosses the stream once and is close enough to the creek on several occasions to interfere with the geophysical surveys.

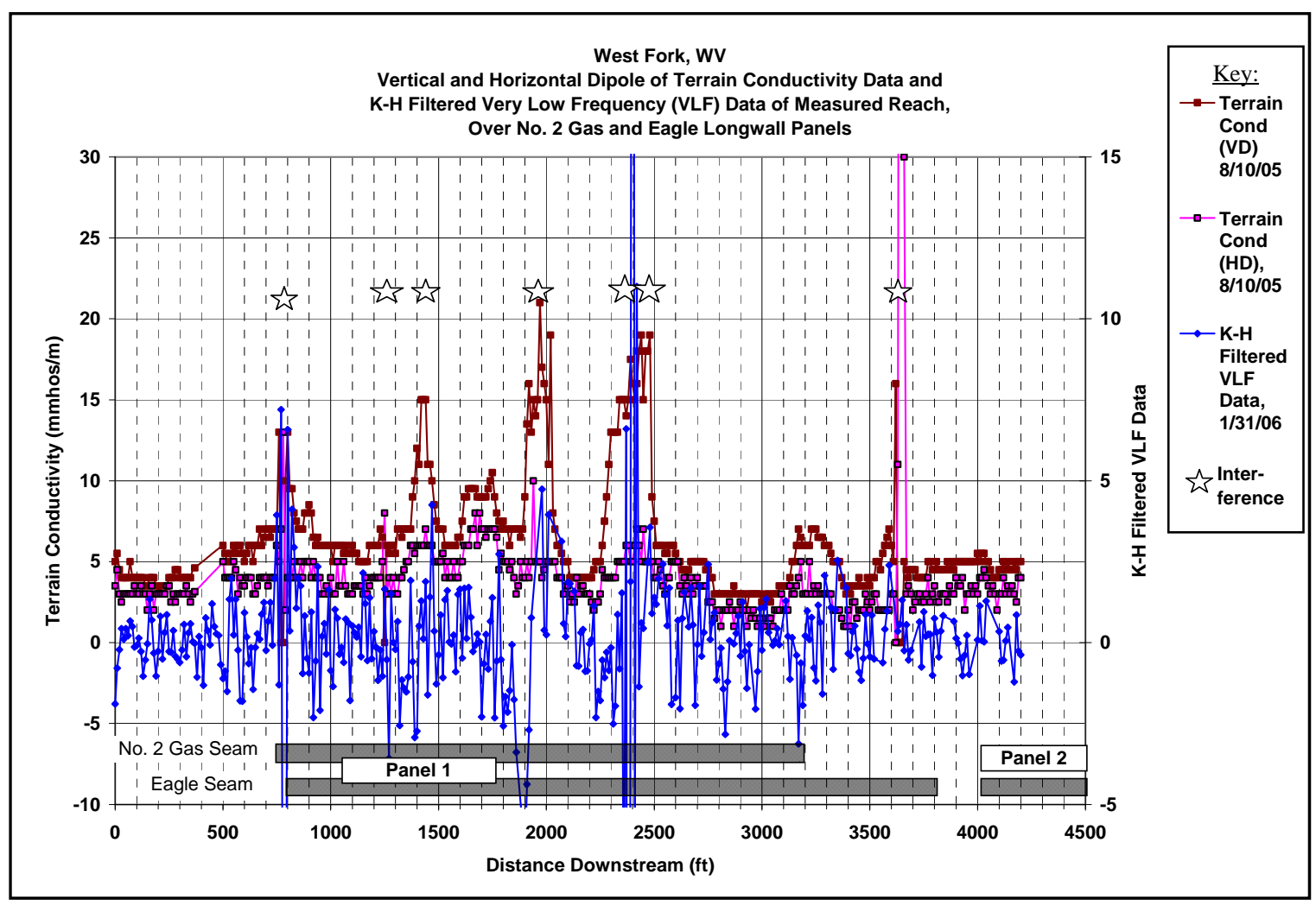

Figure 63. Vertical (VD) and horizontal dipole (HD) Terrain Conductivity Data and K-H Filtered VLF Data of West Fork, WV measured reach, with respect to longwall panel locations at the bottom of the graph. Interferences from man-made conductive features are shown by stars.

The conditions of the stream on August 10, 2005 were dry. The stream bottom was dry over the entire reach surveyed. This is likely the reason why the data values are so low for the TC survey. The low conductivity baseline suggests that the substrate, not only the stream, is dry. The pore space within the dominant sandstone lithologies beneath the stream 
are also probably dry, and any fractures that might have been detected due to their higher conductivity nature are likely blended in with the non-conductive background. There are a few exceptions, and these exceptions will be discussed below.

After the re-run of the VLF survey on January 31, 2006, it was noted that there was a substantial amount of water in the stream, and that it went dry within the surveyed reach. The stream was measured at the beginning of the geophysical survey, at Station 1, to be 206 gpm (12.9 l/sec), and at the point where the stream completely infiltrated into the substrate, at 3350 feet (1021.3 m) downstream (later to be labeled as Station 9B).

An anomaly table was prepared for West Fork. This data was compiled based on statistically significant values collected and analyzed for the TC Vertical Dipole (VD) and the Very Low Frequency (VLF) Karous-Hjelt (K-H) filtered data values (Appendix III, Table 6). Some 21 anomalies were identified, included are 7 interference anomalies. The following non-interference anomalies are described in detail.

Anomaly WF3: 530 to 560 feet (161.5 to $170.7 \mathrm{~m})$,

Anomaly WF4: 670 to 860 (204.3 to 262.2) and

WF6: 940 feet (286.5 m)

Anomaly WF-3 is located within the control reach, along with the smaller anomalies WF-1 and WF-2. WF-3 is located between measuring Station 2 and 3. Station 3 recorded a 20\% increase in normalized discharge from Station 2 between 450 (137.1 m) and 690 feet (210.3 m) downstream. This VLF anomaly is associated with gradual baseline increase in VD conductivity beginning around 500 feet $(152.4 \mathrm{~m})$ downstream and peaking over the edge of the panel, around 850 to 900 feet downstream. From 670 feet (204.3 m) to 860 feet 
(262.2 $\mathrm{m}$ ) the TC values increase. This anomaly includes the interference from the metal gas line around 800 feet $(243.9 \mathrm{~m})$, but also represents a peak beyond the influence of the interference. This increase in TC overlaps onto the next VLF anomaly WF-6. WF-6 is located approximately 150 within the panel and immediately downstream of Station 4.

The Horizontal Dipole (HD) over the edge of the panel from 500 (152.4 m) to 1000 feet (304.8 m) does not greatly increase. This survey detects no increase in conductivity over this reach during the dry conditions present in the stream, which may extend down to the sounding depth of the Horizontal Dipole (HD) survey (Ackman and Barta, 2002). This anomaly series includes several deeper VLF anomalies as well as an increase in the VD survey. The HD survey shows only a small increase. The data suggest that there is are fractures within this reach giving the reach a series of high conductivity anomalies, and that during flowing conditions, may influence the surface water quantity.

There is a significant amount of interference between 1150 and 1550 feet (350.6 and $472.5 \mathrm{~m}$ ) downstream. No identifiable anomalies are detectable from the data within this reach.

Anomaly WF11: 1610 to 1820 feet (490.8 to $554.8 \mathrm{~m}$ )

Anomaly WF-11 is a coordinated anomaly that is downstream of the interference referenced above, and is present from 1620 to 1820 feet (490.8 to $554.8 \mathrm{~m}$ ) downstream. This anomaly comprises nearly the entire reach between Station 6 at 1510 feet (460.3 m) and Station 7 at 1800 feet $(548.7 \mathrm{~m})$. The anomaly is downstream of the clayey shale bedrock present beneath Station 6 at 1510 feet (460.3 m) downstream. The anomaly is interpreted as being a fracture within a shale unit causing a higher than background conductivity reading. 
This may be the result of a clayey shale fracture retaining moisture due to the electromagnetic properties of the clay mineral structure. If the fracture is still wetted in shale, the residual water would likely have a higher dissolved solids concentration because of its contact with shale minerals. A shale fracture may therefore retain higher conductive moisture over a longer dry period, allowing detection by electromagnetic methods during a dry period when a fracture in a sandstone unit may not. The hydraulic conductivity of this fracture, if in fact it is a fracture, is not high.

The normalized discharge between Station 6 and 7 does changes little, only 2 gpm (0.12 l/sec). This anomaly is not expected to influence the surface water discharge.

Anomaly WF18: 3170 to 3390 feet (966.4 to 1033.5 m)

Anomaly WF-18, between 3170 and 3390 feet (966.4 to $1033.5 \mathrm{~m}$ ), is a coordinated anomaly that is located in the lower half of the stream survey. Water was not flowing to this point during the low flow measuring event of May 3, 2006, but it was flowing to and sinking within this reach during the VLF survey of January 31, 2006. The anomaly is coordinated indicating that even though the streambed was dry during the TC survey of August 5, 2005, it was still detected. Both the VD and HD TC surveys detect an anomaly in within this reach suggesting that a fracture zone extends from the surface to mid-depth. This fracture is documented influencing the surface flow of West Fork. Within this anomaly, the stream slows, pools and goes dry during a time of the year when ground water is typically at high surplus levels and baseflow recharge rates are near their highest. 


\section{$\underline{\text { Alluvial Sediment Measurements }}$}

Alluvial thickness was conducted the same day that the low flow measurement was taken (Figure 65). The average overall alluvial depth for the stream is 1.2 feet $(0.3 \mathrm{~m})$, which is also the average for the alluvial thickness for all the streams. Sandstone bedrock is present in Station 1 and 3, which correspond to the two highest flow measurements. Station 9 is located near a steep sandstone bedrock bank. This bedrock was measured to project out under the stream from the bank, getting deeper as it went away from the bedrock bank. Station 7 is located over a clayey shale unit that was discovered on May 21, 2006 during the particle analysis survey. This weathered clayey shale may have influenced the alluvial thickness measurements. The shale was noted to have been encountered at a depth of 0.78 feet $(0.2 \mathrm{~m})$. The weathered shale is considered to be bedrock, therefore reducing the actual alluvial thickness to 0.78 feet $(0.2 \mathrm{~m})$, similar to the surrounding alluvial thickness measurements.

Alluvium particle size was measured at Station 5, 7 and 9; all of which are over the mined longwall panel. The control area consists primarily of sandstone bedrock, or a thin cover of alluvium over sandstone bedrock. The control area is then being assumed to have little to no alluvium distributed throughout this reach. Station 2 has a thin layer of alluvium over bedrock, but the unimpacted bedrock is considered to have a much lower vertical hydraulic conductivity than the alluvial particles (Fetter, 2001) and is considered to be the controlling factor in this reach.

The particle sizes at Station 5 and Station 9 are very similar to each other. These two stations mean particle size is 53.8 and $64.4 \mathrm{~mm}$. The alluvium is poorly distributed for both of the samples, with half of the particles being greater than $64 \mathrm{~mm}$ (Appendix IV, Table 1). 


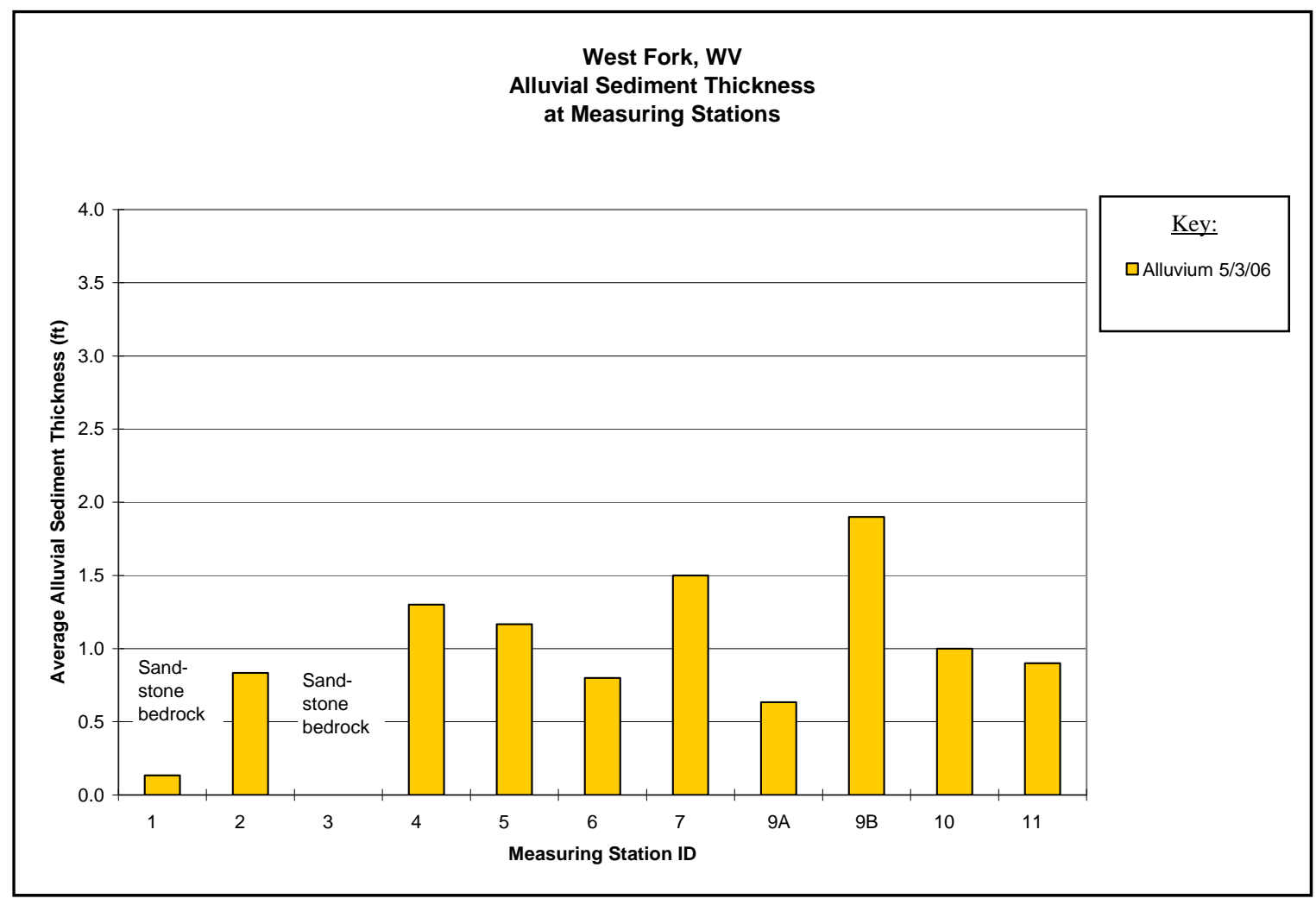

Figure 64. Average alluvial sediment thickness at stream measuring stations on the study reach of West Fork, WV.

Station 7 is similar, but with a significant difference in the distribution; it has $100 \%$ more particles less than $2 \mathrm{~mm}$. This disproportionate distribution is likely the result sampling of the weathered clayey shale unit that subcrops below the alluvium.

\section{Interpretation of Data}

The control reach of West Fork is represented by Station 1 (000 feet) and Station 2 at 450 feet $(137.1 \mathrm{~m})$. These stations demonstrate low normalized discharge variability, ranging from $2 \%$ to $13 \%$ at high and low baseflow. The control stations are located over the superimposed room-and-pillar mining of both the Campbell Creek / No.2 Gas and Eagle Coal seams. 
There are two significant geophysical anomalies detected in the control reach. They both are VLF anomalies with no Terrain Conductivity counterpart, indicating that they may be natural bedrock fractures detected at depth.

The alluvial sediment in this reach is variable, but sandstone bedrock dominates this reach. Alluvial sediment is present at Station 2 because it is located on a lower gradient reach beneath a higher gradient bedrock slide.

Longwall panel 1, of both the Harris No. 2 Mine in the Campbell Creek / No.2 Gas Coal and the Harris No. 1 Mine in the Eagle Coal, is represented by Stations 3 through 9B. The station distances are Station 3 at 690 feet $(210.3 \mathrm{~m})$, Station 4 at 890 feet $(271.3 \mathrm{~m})$, Station 5 at 1180 feet $(359.7 \mathrm{~m})$, Station 6 at 1510 feet $(460.3 \mathrm{~m})$, Station 7 at 1800 feet (548.7 m), Station 8 at 2250 feet (685.9 m), Station 9A at 2330 feet (710.3 m) and Station 9B at 3350 feet $(1021.3 \mathrm{~m})$.

Station 3 is approximately 70 feet $(21.3 \mathrm{~m})$ upstream of the upstream edge of longwall panel 1 of the Harris No. 2 Mine, and 110 feet (33.5 m) upstream of the edge of the longwall panel 1 of the Harris No. 1 Mine. This station records a $12 \%$ to 20\% discharge ratio increase at high and low baseflow and is apparently impacted by the subsidence associated with these panels, and therefore included with their discussion.

Unfortunately, a metal pipeline crosses the stream at 800 (243.9 m) feet downstream, significantly impacting the ability to detect any subsidence fracture anomalies. It is likely, however, that the Terrain Conductivity survey has detected a portion of the shallow subsidence fracturing before being impacted by interference from the pipeline. Anomaly WF4, from 670 to 860 feet (204.2 to $262.1 \mathrm{~m}$ ) partly represents the interference of the metal pipeline as it crosses West Fork. This anomaly also represents part of a statistically 
significant TC anomaly 100 feet $(30.5 \mathrm{~m})$ upstream of the interference shadow from the pipeline. This location, 670 feet (204.2 m), is also the expected edge of the subsidence basin for the Eagle seam longwall panel. This geophysical anomaly is the shallow tensional fracture zone of the upstream edge of the subsidence basin, and it has caused increase in the discharge ratio of Station 3 at 690 feet (210.3 m) at both high and low baseflow.

The alluvial sediment between the control reach and Station 3 is thin to non-existent. Most often bare sandstone bedrock is exposed throughout this reach. The sandstone bedrock does not exacerbate the longwall subsidence impacts within the stream reach upstream of the edge of panel 1.

The remainder of panel 1 exhibits a consistently influent stream reach during both high and low baseflow. At low baseflow, the stream is completely lost at Station 9A (2330 feet / $710.3 \mathrm{~m}$ ). During a visit on January 31, 2006, the stream was going dry at Station 9B (3350 feet / $1021.3 \mathrm{~m}$ ). During high baseflow, the stream does not go dry, but has a normalized discharge decline of 34\% from Station 3 to Station 9B. A flow loss of 472 gpm (29.7 l/sec) is detected between these two stations. This loss corresponds to $17.7 \mathrm{gpm} / 100$ feet of stream; the greatest panel-length loss rate recorded from all the streams in the study.

The alluvial thickness from Station 3 to 9B ranges from 0.8 to 1.5 feet $(0.2$ to $0.4 \mathrm{~m})$. The most significant influence to stream flow appears to be associated with Station 7, which detected a bedrock claystone unit immediately beneath the alluvial sediment at a depth of 0.8 feet $(0.2 \mathrm{~m})$. This claystone assists in reducing the stream loss rates during low baseflow, but no discernable influences are observed at high baseflow. Stations 5 and 9A have the largest recorded mean particle sizes of all the streams in the study. 
The largest normalized discharge decline over panel 1 is between Station 9A at 2330 feet $(710.3 \mathrm{~m})$ and Station 9B at 3350 feet $(1021.3 \mathrm{~m})$ during the high baseflow event. This is a $22.4 \%$ decline, and Station $9 \mathrm{~B}$ is the location where the stream was noted to have went dry on January 31, 2006.

Anomalies WF15, from 2640 to 2780 feet (804.8 to 847.5 m), WF16 at 2910 feet (887.1m), WF17 from 2990 to 3110 feet and WF18 from 3170 to 3390 feet (966.4 to 1033.5 m) are located between measuring Stations 9A and 9B. This reach crosses the downstream edge of the Campbell Harris No. 2 longwall panel 1 at 3200 feet $(975.6 \mathrm{~m})$. The anomalies in this reach are more likely associated with the mine subsidence of the shallower Harris No. 2 Mine longwall, not the deeper Harris No. 1 longwall. Anomaly WF18, located across the downstream edge of No. 2 Gas longwall panel 1, has a shallow TC anomaly associated with it, whereas the remaining anomalies mentioned have only a significant VLF anomaly. West Fork went completely dry within anomaly WF18 January 31, 2006. The fracturing associated with the Harris No. 2 longwall panel is likely the cause for this catastrophic loss. It is inferred that anomaly WF18 is also the cause for the $22.4 \%$ decline of normalized discharge at high baseflow.

Station 9B is located at the downstream edge of the TC portion of anomaly WF18. This station does not depict an effluent fracture zone over the downstream edge of the panel at high baseflow, as other streams have depicted. When the fracture zone WF-18 intersects the stream, it increases the rate of stream infiltration (Figure 66). The stream water lost across panel 1 in the No. 2 Gas seam does not have a resurgence at the downstream edge. The downstream edge actually increases the stream flow loss. This is partly attributed to the shallowness of the 150 -foot $(45.7 \mathrm{~m})$ deep mine and also to the underlying longwall $\mathrm{f}$ the 
Eagle Coal seam which lies 150 feet $(45.7 \mathrm{~m})$ beneath the Campbell Creek / No. 2 Gas Coal in this area.

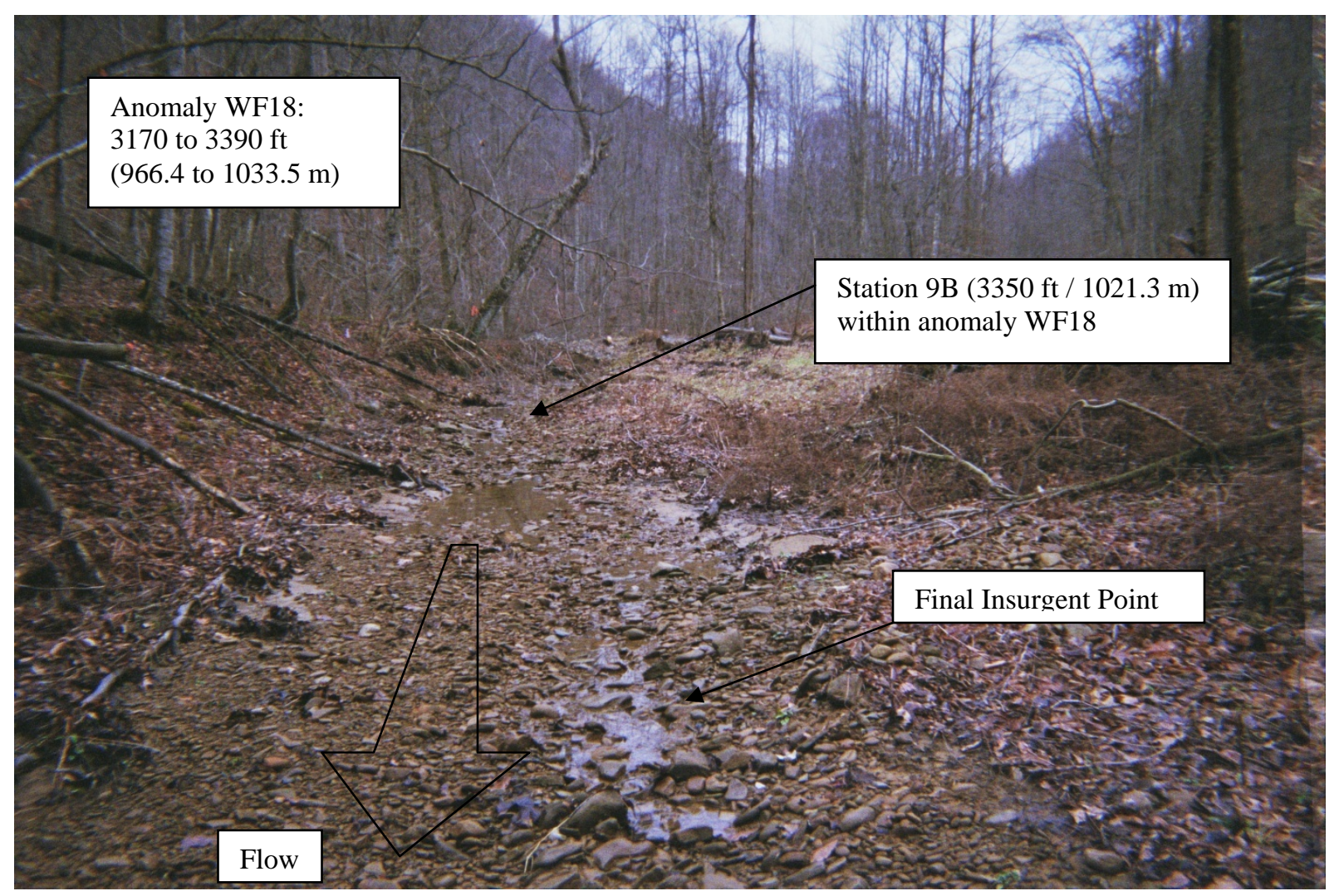

Figure 65. West Fork, WV at Station 9B within anomaly WF18. Photo taken looking upstream on January 31, 2006 when stream flow sunk at this location.

The stream flow loss across the longwall panel of the Harris No. 2 Mine most likely makes it to the mine since there is an increase in insurgence, not a resurgence, at the downstream edge of the panel. The Harris No. 2 longwall panel beneath the stream, panel 1, was the last panel to be mined in the down-dip portion of the mine. This suggests that the panel was expected to sink the stream once it was mined. There is an entry at the down-dip end of the mine that stops beneath West Fork at a distance downstream of 6250 feet (1905.4 m). A borehole from the surface penetrates the No. 2 Gas entry at its location near West Fork. It is believed that this borehole was intended to alleviate any mine pool that may have 
accumulated in the Harris No. 2 Mine. A substantial mine pool is not believed to exist in the Harris No. 2 Mine based on the significant stream flow losses detected at high base flow. The high baseflow measurements recorded steam loss over the entire length of the mine, with a significant loss over the down-dip edge of longwall panel 1. The stream water lost to the mine is believed to move through fractures beneath the stream, as a result of mine subsidence from the Harris No. 1 longwall mine.

There was no discharge from the vicinity of the borehole during the low baseflow event. At low baseflow, the stream over the longwall panel loses water to the Harris No. 2 Mine at $100 \mathrm{gpm}$, compared to control reach discharge. Mine subsidence fracturing over the Harris No. 1 Eagle Coal seam longwall mine may have created enough secondary permeability to transmit 100 gpm. During high baseflow, it was indiscernible if there was any discharge from the borehole during the high baseflow measuring event because the stream did not go dry where the borehole is located.

Stations 10 and 11 are located 7000 and 7800 feet (2134.1 and $2378.0 \mathrm{~m}$ ) downstream of Station 9B, and 4000 and 4800 feet (1219.5 and $1463.4 \mathrm{~m}$ ) downstream of the Campbell Creek / No. 2 Gas borehole. Station 10 was upstream of any resurgence detected during the low baseflow event. Station 11 is located downstream of the edge of a series of longwall panels, over a wide main heading. Station 11 records the resurgence of stream water from the upstream measured reach, at both high and low baseflow. The resurgences recorded at Station 11 are at the same normalized discharge rate as that measured within the control reach of the stream. This resurgence rate at Station 11 suggests that all of the water that was lost from the stream during both high and low baseflow is recovered by the stream. 
The water lost over the upstream reach of West Fork eventually returns to the stream over one mile downstream of where it was lost. Since this water returns, it does not appear to be lost to the deeper Harris No. 1 longwall mine. It may be transmitted through horizontal bedding fractures that have opened due to compressional forces of the composite beam zone. If so, the ground water could be transmitted to near Station 10 and 11 where main entries terminate the series of longwall panels and vertical subsidence fractures may provide conduits for stream flow resurgence. During high baseflow, it is possible that the borehole into the Harris No. 2 Mine will be discharging mine water to the stream that is not detectable with the location of the sampling stations.

\section{Stream Conclusion}

A stream survey of West Fork (of Pond Fork), in Boone County West Virginia, took place over a 15-year old mined longwall panel in the Campbell Creek/No. 2 Gas Coal seam and a 10 month-old mined longwall panel in the Eagle Coal seam. The depth of the mine in the No. 2 Gas Coal seam is approximately 150 feet beneath the stream and the depth of the mine in the Eagle Coal seam is approximately 350 feet. This is the only study area that took measurements over two mined longwall panels in different coal seams. Measured stream discharges fluctuated modestly across the study reach except at one identified subsidence fracture zone. At this point, the author detected a decrease at Station 9B during high baseflow measurements, and could sense a general declining discharge over the panel during low baseflow measurements

Water is lost from the stream through the streambed at a constant rate at low baseflow. The streambed does not regain the lost discharge at the limit of mining of the upper seam, but 
it does regain the lost discharge approximately 7000 feet downstream, at the limit of longwall mining of the lower seam.

The upstream tension zone of the primary study panel is the first subsidence impacted zone that affects stream discharge. Increased conductivity recorded by geophysics indicates subsidence fractures are saturated. Erosion of the alluvial sediment caused by an increased stream gradient within this zone caused its removal exposing sandstone bedrock beneath.

The upstream tension zone is a subsidence fracture set with higher permeability and storativity values than that of the surrounding rock. Orientation of this study stream's tension zone is perpendicular to the stream flow, which projects the fracture set into the adjacent hillsides. Detection of dramatic stream discharge increases are at the intersection of the fracture set and the stream.

Stream discharges increase across this fracture zone during high and low baseflow. The increase at the fracture zone at high and low baseflow is attributed to the concentration of hillside groundwater. The compression zone of the subsidence basin, between the upstream and downstream tension zones, has a decrease in discharge-area ratio and a decrease in measured discharge at each stream station for both high and low baseflow. The loss of measured discharge across the panel suggests that the stream water is being lost to the mine. Lost water not regained at the downstream limit of mining of the upper seam supports the interpretation that the stream water is lost to the No. 2 Gas Coal mine. 


\section{Conclusions}

The purpose of this study was to identify and interpret stream flow changes across a single longwall panel, characterize both high and low baseflow conditions, the stream alluvium and any underlying fractures.

Included in this study were six streams in three regions. For each of these six streams there were six different surveys conducted. Each stream had a high and low baseflow discharge measurements conducted, two different geophysical surveys and two stream sediment surveys. The following are conclusions derived from the data collected.

1) All six streams over mined longwall panels have a $20 \%$ discharge-ratio change between measuring stations during either high or low baseflow conditions. This includes streams with thick overburden, ranging between $500(152.4 \mathrm{~m})$ and 600 feet $(182.9 \mathrm{~m})$ above the mined longwall panel.

2) West Virginia streams are the only streams in the study to have had visibly detectable flow losses for both high and low baseflow conditions. Streams in Pennsylvania and Ohio did not have visible stream flow changes. The southern West Virginia study sites have the shallowest mined longwall panels in the study group; ranging from 100 to 150 feet beneath the streams. Southern West Virginia streams also have the highest occurrences of sandstone and the lowest occurrences of claystone in the overburden. 
3) The following are conclusions of data collected for this research on stream flow trends across subsidence basins;

a. Discharge-area ratios increase across the upstream tension zone during high baseflow and decrease during low baseflow,

i. These changes are interpreted to be caused by a substantial increase in permeability and storativity of the shallow rock ( $<50$ feet) that is in tensile strain between the surface expression of the angle of draw and edge of the mined longwall panel.

b. Discharge-area ratios decrease over the mined longwall panel,

i. This decrease is interpreted to be caused by a smaller increase in the permeability and storativity of the shallow rock ( $<50$ feet) beneath the stream. Stream water is being lost to shallow fractures and transmitted as underflow.

ii. Some stream water may be stored temporarily in flood plain sediments when pooling over the downstream quarter-panel zones occurs

c. Discharge-area ratios increase over the downstream tension zone of the subsidence basin (except where the overburden depth is shallow, i.e. $<150$ feet, and the stream water has been interpreted to have been lost to the mine).

i. This increase is interpreted to be caused by the higher permeability and storativity zones of either the downstream tension zone of the primary study panel or the overlapping upstream tension zone of the next downstream panel 
4) 'Subsidence-enhanced recharge and discharge' is described as follows, and is considered the primary factor contributing to increases of normalized discharge detected across the tension zones of longwall subsidence basins. Subsidenceenhanced recharge is a product of lower rates of evapotranspiration on hillside and hilltop recharge zones resulting in quicker rates of infiltration thorough the soil horizons. Recharge infiltration is accelerated by an increase in secondary permeability and storage capacity of the shallow rock zone that can be caused by mine subsidence fracturing and dilation of existing fractures throughout the subsidence basin. The higher permeable tension zones present at the perimeter of longwall subsidence basins may serve as conduits for groundwater to travel from recharge to discharge zones thereby significantly increasing stream discharge at distinct and predictable locations.

a. Streams flowing over mine subsidence basins less than 2 years old can experience a significant amount of groundwater recharge over a short reach of stream due to subsidence-enhanced recharge and discharge.

b. Older mine subsidence basins do not exhibit the same significant groundwater recharge properties as younger mine subsidence basins, although the effect is still detectable in properly spaced stream discharge measurements.

c. The same effect is somewhat detectable over shallow mines even though stream water may be lost to the mine across the mined longwall panel.

d. High baseflow stream discharges increase more substantially across tension zones that have the long axis of the longwall panel perpendicular to stream flow. 
5) During periods of low baseflow conditions, the water table is generally lower and less groundwater contributes to stream discharge. The fractures of the tension zones surrounding mine subsidence basins may have a lower water table than the stream elevation and thereby have a temporary negative impact on stream flow. During these periods, stream discharge may decrease significantly across the higher permeable and greater storage capacity tension zones of the mine subsidence basin as surface water enters shallow mine subsidence fractures.

a. Streams flowing over mine subsidence tension zones less than 2 years old can experience a significant stream flow decrease during low baseflow conditions.

b. Older mine subsidence tension zones exhibit a lesser effect on low baseflow stream discharge.

6) Normalized discharge in streams less than 300 feet above mined longwall panels appear to recover from mine induced subsidence at high baseflow but may continue to exhibit impacts at low baseflow as long as 8 years after mining.

7) Normalized discharge in streams greater than 300 feet above mined longwall panels appear to recover from mine subsidence impacts even at low baseflow, perhaps as soon as 15 months after longwall mining beneath stream. 
8) Alluvial sediment values vary significantly across the study reaches.

a. Alluvial sediment thickness is generally least variable over control reaches.

b. Alluvial sediment thickness is generally thinnest over the upstream tension zone of the subsidence basin where an increased channel slope causes erosion of the sediment and fractured shallow bedrock. The increased channel slope is a response to the stream flowing into the subsidence basin from the unsubsided control reach

c. Alluvial sediment thickness is generally thickest in the upstream quarter-panel zone, between the base of the increased channel slope and the middle of the subsidence basin.

d. The largest particle sizes of alluvial sediment and fractured bedrock from the eroded upstream tension zone reach deposits first; the silts deposit throughout the remaining subsidence basin. The alluvial sediment's mean particle size is typically largest within the upstream quarter-panel zone. The mean particle size decreases across the lower half of the subsidence basin due to decreasing stream gradient and decreased velocity and/or pooling.

e. Streams with older subsidence basins exhibit little to no signs of streambed slope inversion over the downstream quarter-panel reach, unlike streams flowing through younger subsidence basins. Stream water transports the eroded sediment throughout the subsidence basin, and over time create positive drainage in a previously inverted stream reach. Downstream quarterpanel reaches have the smallest mean particle sizes within the study reaches. 


\section{$\underline{\text { Recommendations }}$}

1. Sediment surveys are recommended to be conducted across longwall panels to determine the rate of transport, rate of recovery, thickness and particle size distribution changes that may occur as a result of mine subsidence.

2. Pre-mining geophysical surveys are recommended to be conducted in an effort to locate natural fractures that may prolong post-mining subsidence stream flow impacts. 


\section{$\underline{\text { References }}$}

ABEM Wadi Instructional Manual, 1987. Unpublished document.

ABEM Wadi Instrument Manual, 1987. Unpublished document.

Ackman, T., and Dilmore, R., 2002. Identifying and Sealing Water Loss Zones in the Anthracite Coal Region: in Proceedings of the $23^{\text {rd }}$ West Virginai Surface Mine Drainage Task Force Symposium; National Energy Technology Laboratory.

Allan, J.D., 1995. The River Continuum Concept; in Allan, J.D., ed. Stream Ecology Structure and Function of Running Waters. London, Chapman and Hall, p. 276-281.

Booth, Colin J., 1986. Strata-Movement Concepts and the Hydrogeological Impact of Underground Coal Mining. GROUND WATER, Vol. 24, NO. 4, pp. 507-515.

Bunte, K., and Abt, S.R., 2001. Sampling Surface and Subsurface Particle-Size Distributions in Wadable Gravel- and Cobble-Bed Streams for Analyses in Sediment Transport, Hydraulics and Streambed Monitoring. U.S. Department of Agriculture, Forest Service, General Technical Report RMRS-GTR-74.

Carver, L., and Rauch, H.W., 1994. Hydrogeologic Effects of Subsidence at a Longwall Mine in the Pittsburgh Coal Seam; in Proceedings of the $13^{\text {th }}$ International Conference on Ground Control in Mining, COMER, West Virginia University, Morgantown, West Virginia, pp. 298-307.

Cifelli, R.C., and Rauch, H.W., 1986. Dewatering Effects from Selected Underground Coal Mines in North-Central West Virginia; in Proceedings of the $2^{\text {nd }}$ Workshop on Surface Subsidence Due to Underground Mining, COMER, West Virginia University, Morgantown, West Virginia, pp. 249-263. 
Coe, C.J., and Stowe, S.M., 1984. Evaluating the Impact of Longwall Coal Mining on the Hydrologic Balance; Proceedings of the Conference on the Impact of Mining on Ground Water, National Water Well Association, Dublin, Ohio, 348-359 p.

Dixon, D.Y., and Rauch, H.W., 1990. The Impact of Three Longwall Coal Mines on Stream flow in the Appalachian Coalfield; in Proceedings of the $9^{\text {th }}$ International Confernce on Ground Control in Mining, COMER, West Virginia University, Morgantown, West Virginia, pp. 169-182.

Dodge, Clifford H., and Glover, Albert, D, 1984. Coal Resources of Greene County, Pennsylvania. Pennsylvania Geological Survey, Mineral Resource Report 86, Part 1.

Earth Sciences Consultants, 2001. Study of the Effects of Longwall Mining on Streams, Wetlands, and Riparian Areas, Robinson Fork, south Washington County, Pennsylvania. PADEP Project \#5904.

Fetter, C.W., 2001. Applied Hydrogeology, fourth edition. Prentice Hall, Inc., Upper Saddle River, NJ, 598 p.

Geonics EM-31 Instrument Manual, 1975. Unpublished document.

Geophysique GPR International Inc., The VLF Principle. September 2006. [On-line] Retrieved from http://www.geophysicsgpr.com/abem/wadi/wadi_vlf.htm

Gill, R., 2000. Hydrogeologic Analysis of Stream flow in Relation to Underground Mining in Northern West Virginia. Unpublished M.S. Thesis, Department of Geology and Geography, West Virginia University, Morgantown, West Virginia, 140 p.

Herz, A., 1986. Airborne EM instruments operating at VLF and higher frequencies in Airborne Resistivity Mapping. ed. G.J. Palacky; Geologic Survey of Canada, Paper 86-22, p. 5561. 
Hill, J.G., and Price, D.R., 1983. The Impact of Deep Mining on an Overlying Aquifer in Western Pennsylvania. Ground water Monitoring Review, Vol. 3, No. 1, pp. 138-143.

Hobba, William A., Jr, 1981. Effects of Underground Mining and Mine Collapse On the Hydrology of Selected Basins in West Virginia. Report of Investigation RI-33; West Virginia Geological and Economic Survey.

Hutchinson, P.J. and Barta, L.S., 2002 . VLF Surveying to Delineate Longwall Mine-Induced Fractures. The Leading Edge, May, 2002.

Jacobson, R. B., and Coleman, D. J., 1986. Stratigraphy and recent floodplain evolution of Maryland Piedmont flood plains. American Journal of Science, v. 286, p. 617-637.

Jacobson, R. B., Femmer, S. F., and McKenney, R., 2001. Land-Use Changes and the Physical Habitat of Streams. U.S. Geological Survey Circular 1175, 63 p.

Kite, J. Steven, 2003. Fluvial geomorphology train is leaving the station; shouldn't we be on board? Stream Notes (Quarterly): USDA Forest Service Stream Systems Technology Center, Fort Collins, CO, October 2003 issue, p. 6-7.

Knighton, David, 1998. Fluvial forms and processes: A new perspective. Revised edition, Arnold Publishers; 400 p., ISBN: 0340663138.

Leavitt, B.R., and Gibbens, J.F., 1992. Effects of Longwall Coal Mining on Rural Water Supplies and Stress Relief Fracture Flow Systems; in Proceedings of the $3^{\text {rd }}$ Subsidence Workshop due to Underground Mining. COMER, West Virginia University, Morgantown, West Virginia, pp. 228-236.

Leuhrs, Max, 2003. Unpublished Report, A Review of Stream Impacts from Longwall Mining at American Energy Corporation's Century Mine, Permit D-0425. Prepared by Office of Surface Mining, Pittsburgh Field Division - Columbus Office. 
Miller, J. R., and Ritter, J. B., 1996. An examination of the Rosgen classification of natural rivers. Catena; 27: p. 295-299.

Milsom, J., 1996. Field Geophysics, Second Edition. John Wiley and Sons Ltd.

Montgomery, D. R., and Buffington, J. M., 1998. River Ecology and Management, Chapter 2: Channel Processes, Classification and Response. Springer-Verlag New York, Inc.

Montgomery, David R., 2004. Geology, geomorphology, and the restoration ecology of salmon. GSA Today: Vol. 14, NO. 11, pp. 4-12.

Owsiany, John A. and Waite, Burt A., 2001. The Response of a High Order Stream to Shallow Cover Longwall Mining in the Northern Appalachian Coalfield; Proceedings of the $20^{\text {th }}$ International Conference on Ground Control in Mining, Morgantown, WV.

Parasnis, D.S., 1986. Principles of Applied Geophysics, Fourth Edition. Chapman and Hall Ltd.

Perizek, Richard R., and Ramani, Raja V., 1995. Longwall Coal Mines Pre-Mine Monitoring and Water Supply Replacement Alternatives. The Pennsylvania State University, University Park, Pennsylvania 16802.

Peng, S.S., 1992. Surface Subsidence Engineering, Society for Mining, Metallurgy, and Exploration, Inc. 161 p.

Peng, S.S., 2006. Longwall Mining, Second Edition.

Powers, C.J, Singha, K., and Haeni, F.P., 1999. Integration of Surface Geophysical Methods for Fracture Detection in Bedrock at Mirror Lake, New Hampshire; in Proceedings of the U.S.G.S. Toxic Substances Hydrology Meeting, U.S.G.S., Office of Ground water, Branch of Geophysics.

Rantz, S. E. and others, 1982. Measurement and Computation of Streamflow; Volume 1 and Volume 2. U.S.G.S. Water Supply Paper 2175. 
Rauch, H.W., 1989. Ground water Impacts from Surface and Underground Coal Mining, West Virginia Ground water '87: Status and Future Directions. West Virginia University, Morgantown, West Virginia, 41 p.

Reed, C, 1998. Hydrogeologic Analysis of Stream flow flor Spruce Laurel Fork in Relation to Underground Mines in Boone County, West Virginia. Unpublished Geology M.S. Thesis Option II research, Department of Geology and Geography, West Virginia University, Morgantown, West Virginia.

Reed, C., and Rauch, H.W., 2001. Mining Induced Stream flow Loss for Spruce Laurel Fork in Boone County, West Virginia; Presented at the 2001 National Associaton of Abandoned Mine Land Programs Annual Conference. August 19-22, Athens, Ohio.

Rosgen, David L, 1994. A classification of natural rivers. Catena, v. 22, p. 169-199.

Shields, F. D., Copeland, R. R., Klingeman, P. C., Doyle, M. W., and Simon, A., 2003. Design for stream restoration. Journal of Hydraulic Engineering, v. 129, p. 575-584.

Sophocleous, Marios, 2002. Interactions between ground water and surface water: the state of the science. Hydrogeology Journal, 2002; Vol. 10:52-67.

Stoner, J.D., 1983. Probable Hydrologic Effects of Subsurface Mining. Ground water Monitoring Review, V3, \#1, p. 128-137.

Silvas, J.M., 2004. Shallow Ground water Responses to Mine Subsidence, Eastern Ohio. Unpublished M.S. Thesis Proposal, January, 2004, West Virginia University, Morgantown, West Virginia,

Singh, Madan M. and Kendorski, Francis S, 1979. Strata Disturbance Prediction f or Mining Beneath Surface Water and Waste Impoundments. Engineers International Inc. 
Stout, B.M., III, 2003. Impacts of Longwall Mining on Headwater Streams in Northern West Virginia, Final Report for the West Virginia Water Research Institute. Wheeling Jesuit University, Wheeling.

Tieman, G.E., and Rauch, H.W., 1987. Study of Dewatering Effects at an Underground Longwall Mine Site in the Pittsburgh Coal seam of the Northern Appalachian Coalfield; in Proceedings of the Bureau of Mines Technology Transfer Seminar. Information Circular 9137, U.S. Bureau of Mines, Pittsburgh, Pennsylvania, pp. 72-89.

West Virginia Department of Environmental Protection, September 2004. Siltation Monitoring Procedures. [On line] Retrieved from http://www.dep.state.wv.us/docs/7748

Wiens, John A., 2002. Riverine landscapes: taking landscape ecology into the water. Freshwater Biology v. 47, p. 501-515.

Wiley, J. B., Atkins, J. T., Jr., and Tasker, G. D., 2000. Estimating magnitude and frequency of peak discharges for rural, unregulated, streams in West Virginia. U.S. Geological Survey Water Resources Investigations Report 00-4080, 90 p.

Wyrick, G.G., and Borchers, J.W., 1981. Hydrologic Effects of Stress-Relief Fracturing In an Appalachian Valley. U.S. Geological Survey Water-Supply Paper 2177. 
Appendix I

Stream Flow Tables 
Table 1: High Baseflow Stream Discharge Data of February 2, 2006,

With Baseflow Recession Constant Calculation, for Crabapple Creek, Ohio.

\begin{tabular}{|c|c|c|c|c|c|c|c|c|c|c|c|c|c|}
\hline 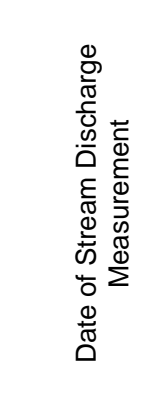 & 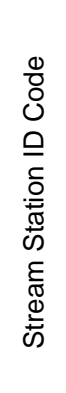 & 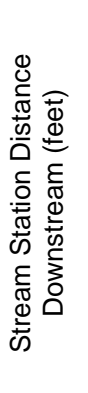 & 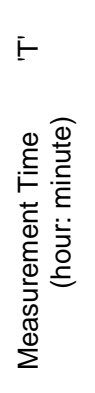 & 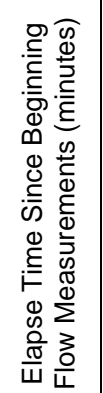 & 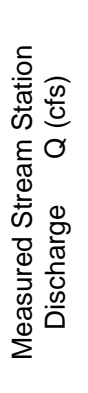 & 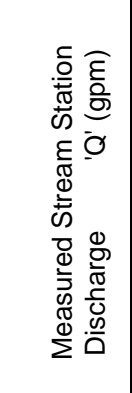 & 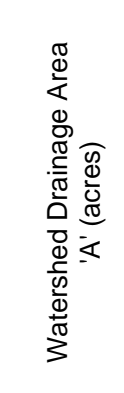 & 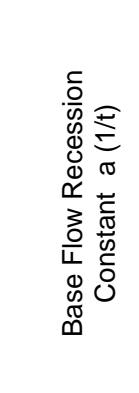 & 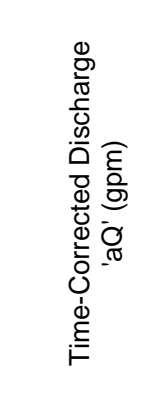 & 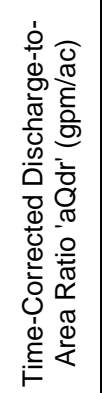 & 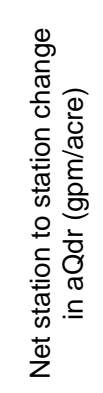 & 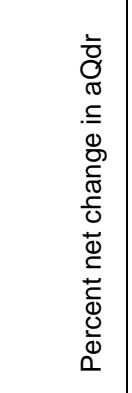 & 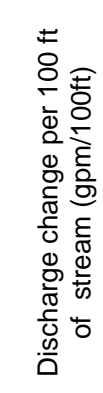 \\
\hline \multirow[t]{5}{*}{ 2/2/2006 } & $1 \mathrm{~B}$ & 140 & 8:20 & 0 & 0.82 & 369.77 & 624.23 & $9.28 \mathrm{E}-04$ & 369.77 & 0.59 & & & \\
\hline & $2 B$ & 590 & 9:30 & 70 & 0.59 & 266.19 & 632.27 & & 284.06 & 0.45 & -0.14 & -24.15 & -19.0 \\
\hline & $3 A$ & 900 & 10:08 & 108 & 1.62 & 725.26 & 1209.53 & & 801.72 & 0.66 & 0.21 & 47.53 & 167.0 \\
\hline & $4 \mathrm{~B}$ & 1220 & $11: 30$ & 190 & 2.15 & 965.82 & 1712.58 & & 1152.05 & 0.67 & 0.01 & 1.49 & 109.5 \\
\hline & $5 \mathrm{~A}$ & 1720 & $12: 10$ & 230 & 2.49 & 1116.50 & 1725.81 & & 1382.15 & 0.80 & 0.13 & 19.05 & 46.0 \\
\hline Trib A & TA & 880 & 10:45 & 145 & 0.79 & 355.85 & 573.63 & & 407.11 & 0.71 & & & \\
\hline Trib B & TB & 1070 & 11:00 & 160 & 1.00 & 449.65 & 499.75 & & 521.63 & 1.04 & & & \\
\hline
\end{tabular}

Values used to calculate the baseflow recession constant (a).

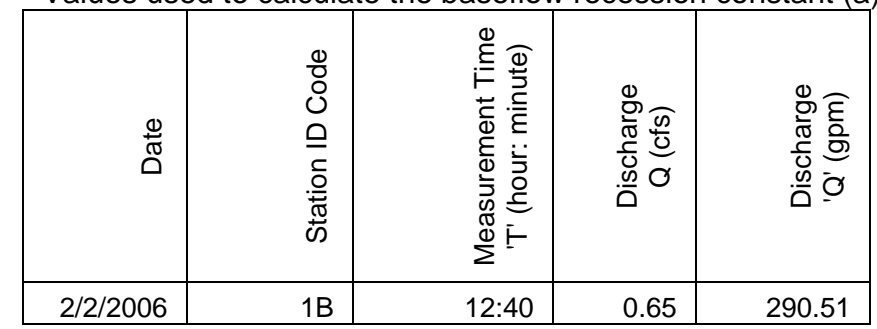

Base flow recession constant calculations.

\begin{tabular}{|l|r|l|l|}
\hline$Q_{t}=Q_{0} e^{- \text {at }}$ & & (after Fetter, 2001) & \\
\hline$Q_{t}$ & 290.51 & $\mathrm{gpm}$ & Discharge at some time $t$ after the recession curve started (L3/T) \\
\hline$Q_{0}$ & 369.77 & $\mathrm{gpm}$ & Discharge at the start of the recession curve (L3/T) \\
\hline $\mathrm{a}$ & $9.28 \mathrm{E}-04$ & $1 / \mathrm{min}$ & Recession constant calculated for the basin (1/T) \\
\hline $\mathrm{t}$ & 260.00 & minutes & Time since recession began when $\mathrm{Q}_{\mathrm{o}}$ was measured. $(\mathrm{T})$ \\
\hline
\end{tabular}


Table 2: Low Baseflow Stream Discharge Data of May 23, 2006,

With Baseflow Recession Constant Calculation, for Crabapple Creek, $\mathrm{OH}$.

\begin{tabular}{|c|c|c|c|c|c|c|c|c|c|c|c|c|c|}
\hline 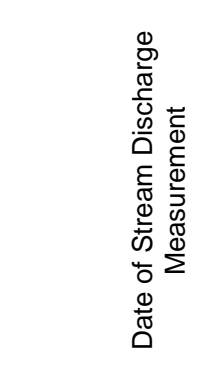 & 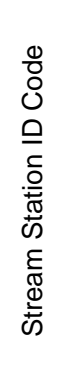 & 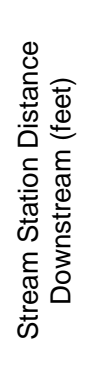 & 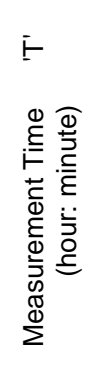 & 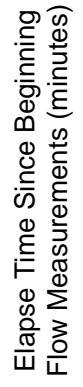 & 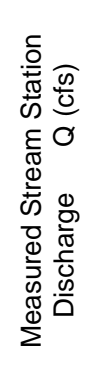 & 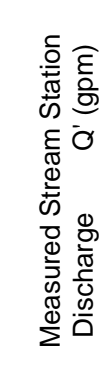 & 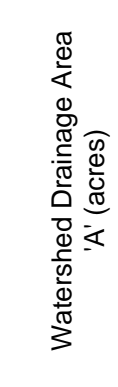 & 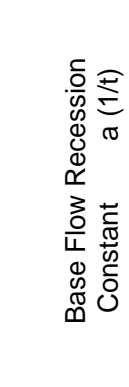 & 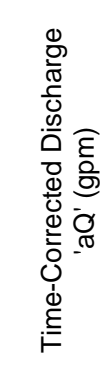 & 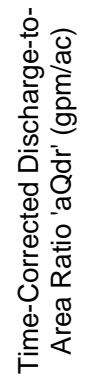 & 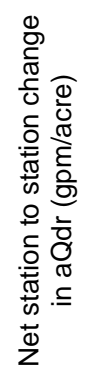 & 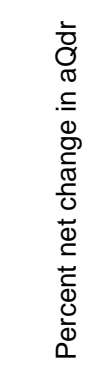 & 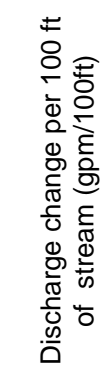 \\
\hline \multirow[t]{6}{*}{$5 / 23 / 2006$} & $1 \mathrm{~A}$ & -450 & $11: 50$ & 60 & 0.68 & 302.96 & 597.34 & & 312.60 & 0.52 & & & \\
\hline & $1 \mathrm{~B}$ & 140 & $10: 50$ & $0: 00$ & 0.69 & 307.56 & 624.23 & $5.22 \mathrm{E}-04$ & 307.56 & 0.49 & -0.03 & -5.85 & -0.85 \\
\hline & $2 \mathrm{~B}$ & 590 & $12: 25$ & 95 & 0.68 & 303.61 & 632.27 & & 319.05 & 0.50 & 0.01 & 2.42 & 2.55 \\
\hline & $3 \mathrm{~A}$ & 900 & $14: 20$ & 210 & 1.12 & 503.89 & 1209.53 & & 562.27 & 0.46 & -0.04 & -7.88 & 78.46 \\
\hline & $4 \mathrm{~B}$ & 1240 & $15: 15$ & 265 & 1.88 & 845.07 & 1712.58 & & 970.44 & 0.57 & 0.10 & 21.90 & 120.05 \\
\hline & $5 \mathrm{~A}$ & 1720 & $16: 00$ & 310 & 1.89 & 847.42 & 1725.81 & & 996.27 & 0.58 & 0.01 & 1.88 & 5.38 \\
\hline Trib A & TA & 880 & $14: 00$ & 190 & 0.30 & 135.60 & 573.63 & & 149.74 & 0.26 & & & \\
\hline Trib B & TB & 1070 & $14: 45$ & 235 & 0.62 & 276.95 & 499.75 & & 313.10 & 0.63 & & & \\
\hline
\end{tabular}

Values used to calculate the baseflow recession constant (a).

\begin{tabular}{|c|c|c|c|c|}
\hline$\frac{0}{\frac{0}{0}}$ & $\begin{array}{l}\frac{1}{0} \\
0 \\
0 \\
0 \\
\text {. } \\
\frac{0}{50} \\
\text { ஸे }\end{array}$ & 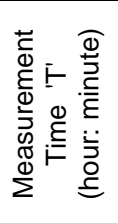 & 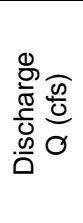 & 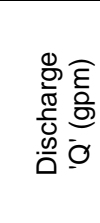 \\
\hline $5 / 23 / 2006$ & 140 & $16: 30$ & 0.57 & 257.57 \\
\hline
\end{tabular}

Base flow recession constant calculations.
\begin{tabular}{|l|r|l|l|}
\hline $\mathrm{Q}_{\mathrm{t}}=\mathrm{Q}_{0} \mathrm{e}^{- \text {at }}$ & & (after Fetter, 2001) & \\
\hline $\mathrm{Q}_{\mathrm{t}}$ & 257.57 & $\mathrm{gpm}$ & Discharge at some time t after the recession curve started (L3/T) \\
\hline $\mathrm{Q}_{0}$ & 307.56 & $\mathrm{gpm}$ & Discharge at the start of the recession curve (L3/T) \\
\hline $\mathrm{a}$ & $5.22 \mathrm{E}-04$ & $1 / \mathrm{min}$ & Recession constant calculated for the basin (1/T) \\
\hline $\mathrm{t}$ & 340.00 & minutes & Time since recession began when $\mathrm{Q}_{\mathrm{o}}$ was measured. $(\mathrm{T})$ \\
\hline
\end{tabular}


Table 3: Extremely Low Baseflow Stream Discharge Data of June 26, 2005,

With Baseflow Recession Constant Calculation, for Crabapple Creek, OH.

\begin{tabular}{|c|c|c|c|c|c|c|c|c|c|c|c|c|c|}
\hline 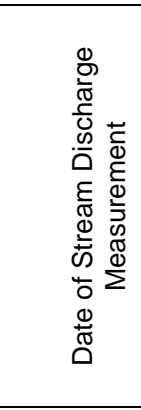 & 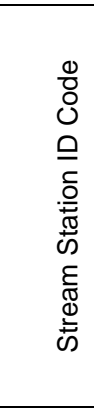 & 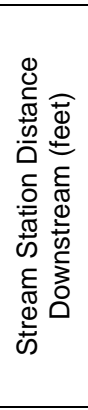 & 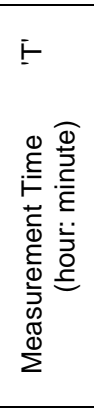 & 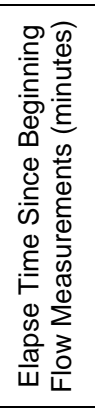 & 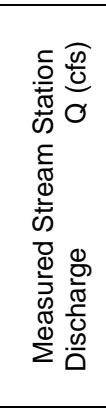 & 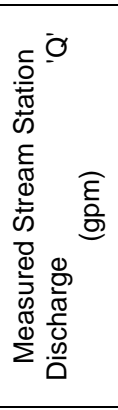 & 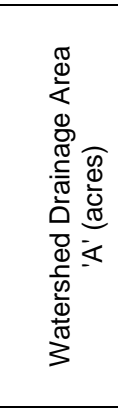 & 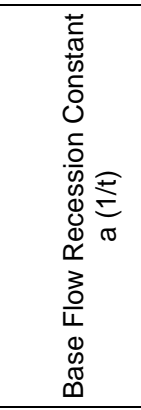 & 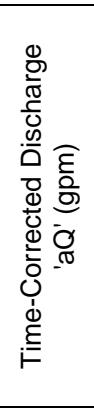 & 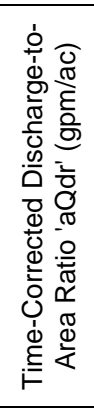 & 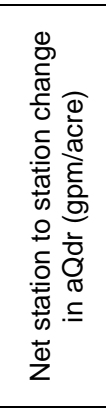 & 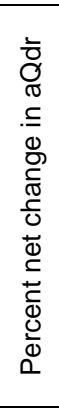 & 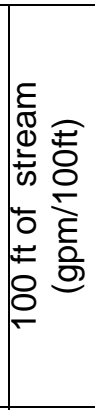 \\
\hline \multirow[t]{10}{*}{$6 / 26 / 2005$} & $1 \mathrm{~A}$ & -450 & $18: 20$ & -120 & 0.0000 & 0.00 & 597.34 & & 0.00 & 0.000 & & & \\
\hline & $1 \mathrm{~B}$ & 140 & $15: 30$ & $0: 00$ & 0.0040 & 1.80 & 624.23 & & 1.06 & 0.002 & 0.002 & - & - \\
\hline & $2 A$ & 430 & $16: 00$ & 100 & 0.0007 & 0.32 & 628.64 & & 0.23 & 0.000 & -0.001 & - & - \\
\hline & $2 \mathrm{~B}$ & 590 & $16: 10$ & 90 & 0.0000 & 0.00 & 632.27 & & 0.00 & 0.000 & 0.000 & - & - \\
\hline & $3 B$ & 1060 & $16: 15$ & 85 & 0.0000 & 0.00 & 1211.70 & & 0.00 & 0.000 & 0.000 & - & - \\
\hline & $4 \mathrm{~A}$ & 1120 & $17: 00$ & 0 & 0.0553 & 24.83 & 1712.54 & $1.65 \mathrm{E}-03$ & 24.83 & 0.014 & 0.014 & - & - \\
\hline & $5 \mathrm{~A}$ & 1720 & $17: 40$ & -40 & 0.1281 & 57.51 & 1770.37 & & 65.15 & 0.037 & 0.022 & - & - \\
\hline & $5 B$ & 1800 & $18: 00$ & -100 & 0.0000 & 0.00 & 1772.14 & & 0.00 & 0.000 & -0.037 & - & - \\
\hline & Trib A & 880 & $16: 15$ & 85 & 0.0000 & 0.00 & 574 & & 0.00 & 0.000 & & & \\
\hline & Trib B & 1070 & $16: 30$ & 70 & 0.0105 & 4.73 & 499.75 & & 3.8 & 0.008 & & & \\
\hline
\end{tabular}

Values used to calculate the baseflow recession constant (a).

\begin{tabular}{|c|c|c|c|c|}
\hline$\frac{0}{\stackrel{0}{\sigma}}$ & 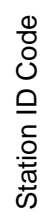 & 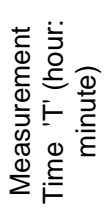 & 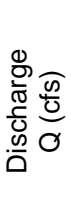 & 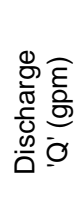 \\
\hline $6 / 26 / 2005$ & $4 \mathrm{~A}$ & 1830 & 0.04 & 20.05 \\
\hline
\end{tabular}

Base flow recession constant calculations.

\begin{tabular}{|l|r|l|l|}
\hline $\mathrm{Q}_{\mathrm{t}}=\mathrm{Q}_{\mathrm{o}} \mathrm{e}^{-\mathrm{at}}$ & & (after Fetter, 2001) & \\
\hline $\mathrm{Q}_{\mathrm{t}}$ & 0.0447 & $\mathrm{gpm}$ & Discharge at some time t after the recession curve started (L3/T) \\
\hline $\mathrm{Q}_{\mathrm{o}}$ & 0.0553 & $\mathrm{gpm}$ & Discharge at the start of the recession curve (L3/T) \\
\hline $\mathrm{a}$ & $1.65 \mathrm{E}-03$ & $1 / \mathrm{min}$ & Recession constant calculated for the basin $(1 / \mathrm{T})$ \\
\hline $\mathrm{t}$ & 130 & minutes & Time since recession began when $\mathrm{Q}_{\mathrm{o}}$ was measured. $(\mathrm{T})$ \\
\hline
\end{tabular}


Table 4: High Baseflow Stream Discharge Data of January 31, 2006,

With Baseflow Recession Constant Calculation, for Williams Creek, OH.

\begin{tabular}{|c|c|c|c|c|c|c|c|c|c|c|c|c|c|}
\hline 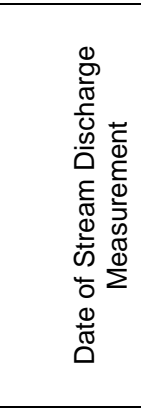 & 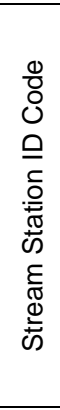 & 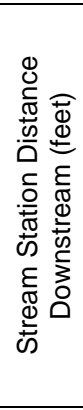 & 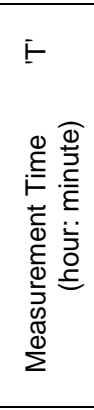 & 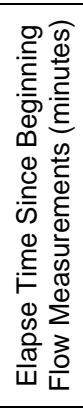 & 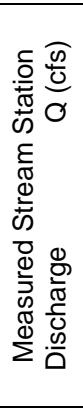 & 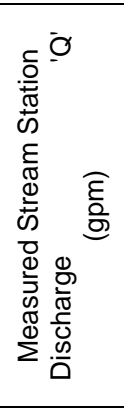 & 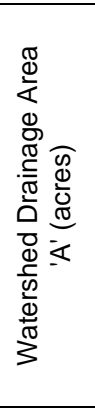 & 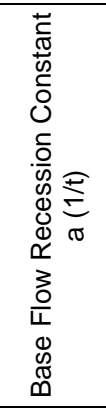 & 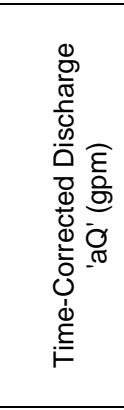 & 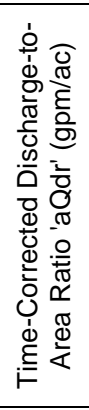 & 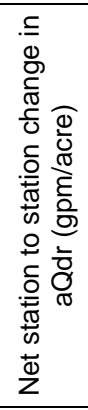 & 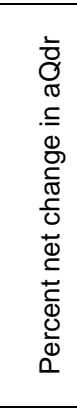 & 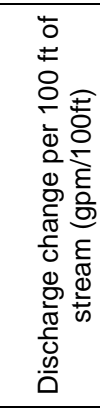 \\
\hline \multirow[t]{5}{*}{$1 / 31 / 2006$} & 1 & 30 & $10: 50$ & 0 & 6.07 & 2722.78 & 2351 & $\begin{array}{r}1.07 \mathrm{E}- \\
05 \\
\end{array}$ & 2722.78 & 1.16 & 0 & & \\
\hline & 2 & 500 & $11: 50$ & -60 & 6.41 & 2874.68 & 2392 & & 2876.51 & 1.20 & 0.04 & 3.9 & 32.71 \\
\hline & 3 & 1100 & $12: 30$ & -100 & 6.26 & 2810.34 & 2412 & & 2813.32 & 1.17 & -0.04 & -3.0 & -10.53 \\
\hline & $4 \mathrm{~A}$ & 1610 & 13:30 & -160 & 6.24 & 2801.21 & 2431 & & 2805.96 & 1.15 & -0.01 & -1.0 & -1.44 \\
\hline & 5 & 2250 & $14: 30$ & -220 & 7.68 & 3448.40 & 2721 & & 3559.09 & 1.31 & 0.15 & 13.3 & 117.68 \\
\hline
\end{tabular}

Values used to calculate the baseflow recession constant (a).

\begin{tabular}{|c|c|c|c|c|}
\hline 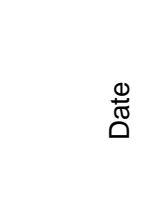 & $\begin{array}{l}\frac{0}{8} \\
0 \\
0 \\
0 \\
.0 \\
\frac{0}{0} \\
\text { ஸे }\end{array}$ & 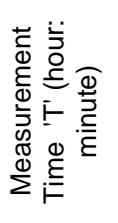 & 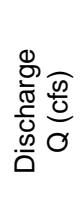 & 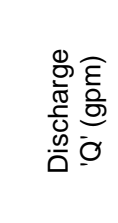 \\
\hline $1 / 31 / 2006$ & 30 & $15: 10$ & 6.05 & 2715.24 \\
\hline
\end{tabular}

Base flow recession constant calculations.
\begin{tabular}{|l|r|l|l|}
\hline$Q_{t}=Q_{0} e^{-a t}$ & & $($ after Fetter, 2001) & \\
\hline$Q_{t}$ & 2715.24 & $\mathrm{gpm}$ & Discharge at some time t after the recession curve started (L3/T) \\
\hline$Q_{0}$ & 2722.78 & $\mathrm{gpm}$ & Discharge at the start of the recession curve (L3/T) \\
\hline $\mathrm{a}$ & $1.07 \mathrm{E}-05$ & $1 / \mathrm{min}$ & Recession constant calculated for the basin (1/T) \\
\hline $\mathrm{t}$ & 260.00 & minutes & Time since recession began when $\mathrm{Q}_{0}$ was measured. (T) \\
\hline
\end{tabular}


Table 5: Low Baseflow Stream Discharge Data of May 24, 2006,

With Baseflow Recession Constant Calculation, for Williams Creek, $\mathrm{OH}$.

\begin{tabular}{|c|c|c|c|c|c|c|c|c|c|c|c|c|c|}
\hline 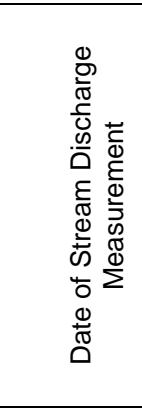 & 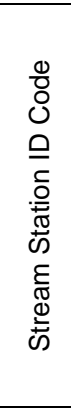 & 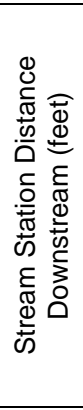 & 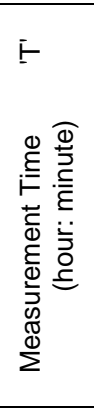 & 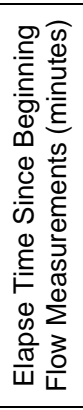 & 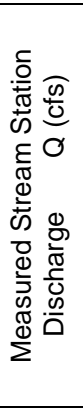 & 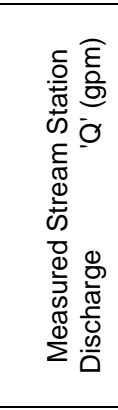 & 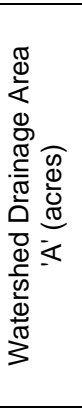 & 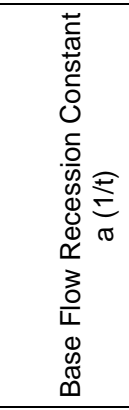 & 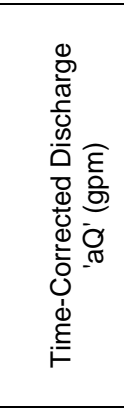 & 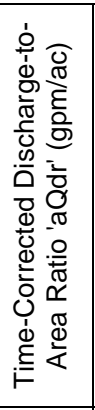 & 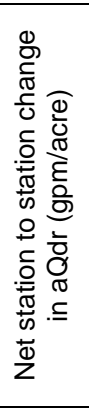 & 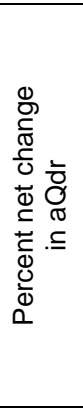 & 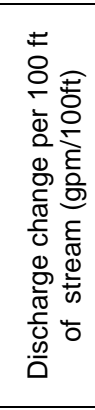 \\
\hline \multirow[t]{7}{*}{$5 / 24 / 2006$} & 1 & 30 & $8: 30$ & 0 & 5.17 & 2319.04 & 2351 & $1.85 \mathrm{E}-04$ & 2319.04 & 0.99 & 0 & & \\
\hline & 2 & 500 & $9: 45$ & 75 & 4.75 & 2132.09 & 2392 & & 2161.88 & 0.90 & -0.08 & -8.3 & -33.44 \\
\hline & 3 & 1100 & $10: 40$ & 130 & 4.80 & 2154.78 & 2412 & & 2207.23 & 0.91 & 0.01 & 1.2 & 7.56 \\
\hline & $4 \mathrm{~A}$ & 1610 & $11: 40$ & 190 & 4.39 & 1968.21 & 2431 & & 2038.63 & 0.84 & -0.08 & -8.4 & -33.06 \\
\hline & 4B & 1940 & $12: 50$ & 260 & 4.52 & 2026.69 & 2443 & & 2126.56 & 0.87 & 0.03 & 3.8 & 26.65 \\
\hline & 5 & 2250 & 13:35 & 305 & 4.46 & 2003.04 & 2721 & & 2119.31 & 0.78 & -0.09 & -10.5 & -2.34 \\
\hline & Trib & 2140 & $13: 15$ & 285 & 0.68 & 305.18 & 273 & & 289.51 & 1.06 & & & \\
\hline
\end{tabular}

\begin{tabular}{|c|c|c|c|c|}
\hline$\frac{\Phi}{\pi}$ & 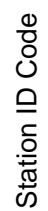 & 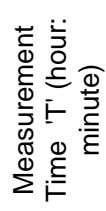 & 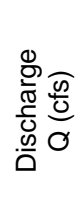 & $\begin{array}{l}0 \\
\frac{0}{0} \\
\frac{0}{0} \\
\frac{0}{0} \\
\frac{0}{0} \\
\frac{.0}{0}\end{array}$ \\
\hline $5 / 24 / 2006$ & 30 & $14: 25$ & 4.84 & 2171.38 \\
\hline
\end{tabular}

Base flow recession constant calculations.

\begin{tabular}{|c|c|c|c|}
\hline$Q_{t}=Q_{0} e^{-a t}$ & & (after Fetter, 2001) & \\
\hline$Q_{t}$ & 2171.38 & gpm & Discharge at some time $t$ after the recession curve started (L3/T) \\
\hline$Q_{0}$ & 2319.04 & gpm & Discharge at the start of the recession curve (L3/T) \\
\hline a & $1.85 \mathrm{E}-04$ & $1 / \min$ & Recession constant calculated for the basin $(1 / T)$ \\
\hline $\mathrm{t}$ & 355.00 & minutes & Time since recession began when $Q_{0}$ was measured. $(T)$ \\
\hline
\end{tabular}


Table 6: High Flow Stream Discharge Data of January 28, 2006,

With Baseflow Recession Constant Calculation, for Stream F, PA.

\begin{tabular}{|c|c|c|c|c|c|c|c|c|c|c|c|c|c|}
\hline 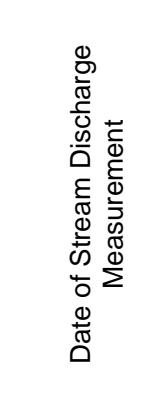 & 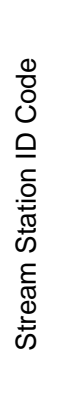 & 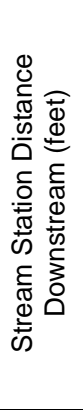 & 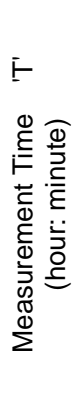 & 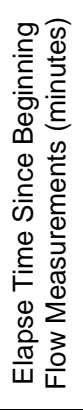 & 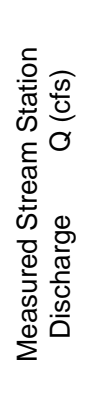 & 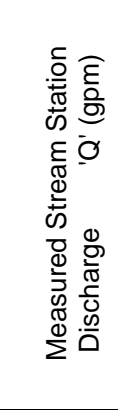 & 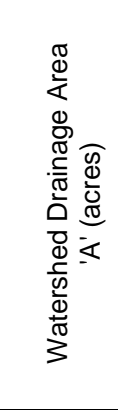 & 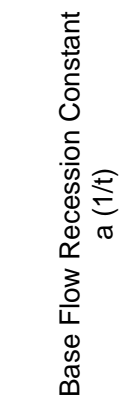 & 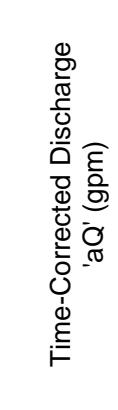 & 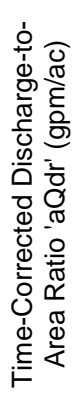 & 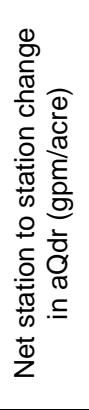 & 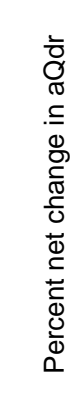 & 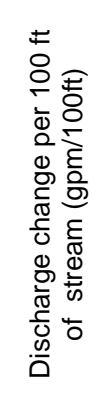 \\
\hline \multirow[t]{6}{*}{$1 / 28 / 2006$} & 1 & 70 & 9:00 & 0 & 2.297 & 1031.06 & 1073.59 & 5.66E-04 & 1031.06 & 0.96 & & & \\
\hline & $2 \mathrm{~B}$ & 760 & $9: 50$ & 50 & 2.705 & 1214.08 & 1178.36 & & 1248.93 & 1.06 & 0.10 & 10.4 & 31.58 \\
\hline & 3B & 1520 & $10: 50$ & 110 & 2.778 & 1246.97 & 1300.33 & & 1327.07 & 1.02 & -0.04 & -3.7 & 10.28 \\
\hline & 4 & 2670 & $11: 40$ & 160 & 2.452 & 1100.63 & 1342.70 & & 1204.95 & 0.90 & -0.12 & -12.1 & -10.62 \\
\hline & 5 & 2940 & 12:15 & 195 & 2.949 & 1323.51 & 1372.98 & & 1477.95 & 1.08 & 0.18 & 20.0 & 101.11 \\
\hline & $6 \mathrm{~B}$ & 3250 & 13:00 & 240 & 2.691 & 1207.63 & 1379.37 & & 1383.34 & 1.00 & -0.07 & -6.8 & -30.52 \\
\hline
\end{tabular}

Values used to calculate the baseflow recession constant (a).

\begin{tabular}{|c|c|c|c|c|}
\hline 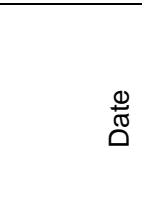 & $\begin{array}{l}0 \\
80 \\
0 \\
0 \\
0 \\
.0 \\
\frac{0}{0} \\
\text { ஸे }\end{array}$ & 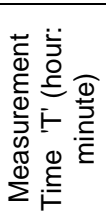 & 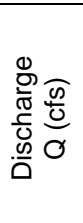 & 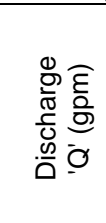 \\
\hline $1 / 28 / 2006$ & 70 & $14: 45$ & 1.89 & 848.23 \\
\hline
\end{tabular}

Base flow recession constant calculations.

\begin{tabular}{|l|r|l|l|}
\hline $\mathrm{Q}_{\mathrm{t}}=\mathrm{Q}_{0} \mathrm{e}^{-\mathrm{at}}$ & & $($ after Fetter, 2001) & \\
\hline $\mathrm{Q}_{\mathrm{t}}$ & 848.23 & $\mathrm{gpm}$ & Discharge at some time $\mathrm{t}$ after the recession curve started (L3/T) \\
\hline $\mathrm{Q}_{0}$ & 1031.06 & $\mathrm{gpm}$ & Discharge at the start of the recession curve $(\mathrm{L} 3 / \mathrm{T})$ \\
\hline $\mathrm{a}$ & $5.66 \mathrm{E}-04$ & $1 / \mathrm{min}$ & Recession constant calculated for the basin $(1 / \mathrm{T})$ \\
\hline $\mathrm{t}$ & 345.00 & minutes & Time since recession began when $\mathrm{Q}_{0}$ was measured. $(\mathrm{T})$ \\
\hline
\end{tabular}


Table 7: Low Flow Stream Discharge Data of May 5, 2006,

With Baseflow Recession Constant Calculation, for Stream F, PA.

\begin{tabular}{|c|c|c|c|c|c|c|c|c|c|c|c|c|c|}
\hline 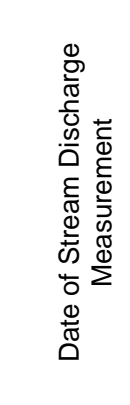 & 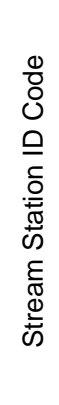 & 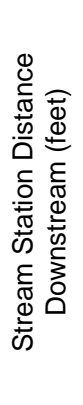 & 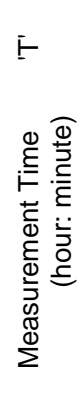 & 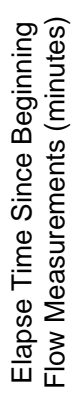 & 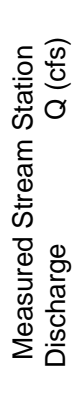 & 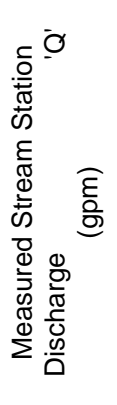 & 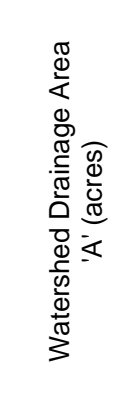 & 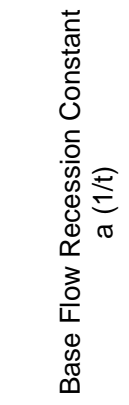 & 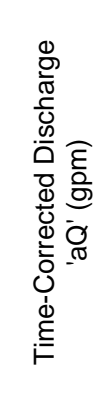 & 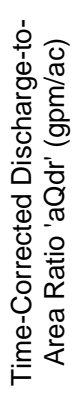 & 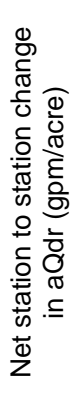 & 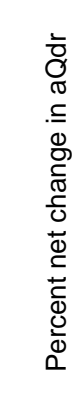 & 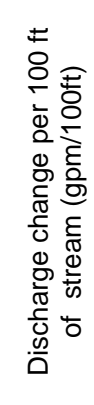 \\
\hline \multirow[t]{9}{*}{$5 / 5 / 2006$} & 1 & 70 & $10: 45$ & 0 & 0.45 & 201.42 & 1073.59 & $5.13 \mathrm{E}-04$ & 201.42 & 0.19 & & & \\
\hline & $2 A$ & 440 & $11: 45$ & 60 & 0.47 & 212.41 & 1172.10 & & 219.01 & 0.19 & 0.00 & -0.4 & 4.75 \\
\hline & $2 \mathrm{~B}$ & 760 & $12: 30$ & 105 & 0.41 & 184.21 & 1178.36 & & 194.41 & 0.16 & -0.02 & -11.7 & -7.69 \\
\hline & $3 \mathrm{~A}$ & 1120 & $17: 45$ & 420 & 0.42 & 189.91 & 1197.58 & & 235.45 & 0.20 & 0.03 & 19.2 & 11.40 \\
\hline & $3 B$ & 1520 & $13: 35$ & 170 & 0.44 & 197.65 & 1300.33 & & 215.66 & 0.17 & -0.03 & -15.6 & -4.95 \\
\hline & 4 & 2670 & $15: 20$ & 275 & 0.38 & 168.91 & 1342.70 & & 194.50 & 0.14 & -0.02 & -12.7 & -1.84 \\
\hline & 5 & 2940 & $15: 55$ & 310 & 0.24 & 105.60 & 1372.98 & & 123.81 & 0.09 & -0.05 & -37.7 & -26.18 \\
\hline & $6 \mathrm{~A}$ & 3040 & $17: 05$ & 380 & 0.41 & 182.55 & 1374.69 & & 221.84 & 0.16 & 0.07 & 79.0 & 98.03 \\
\hline & $6 \mathrm{~B}$ & 3250 & $16: 25$ & 340 & 0.36 & 163.12 & 1379.37 & & 194.20 & 0.14 & -0.02 & -12.8 & -13.16 \\
\hline
\end{tabular}

Values used to calculate the baseflow recession constant (a).

\begin{tabular}{|c|c|c|c|c|}
\hline$\frac{0}{\pi}$ & 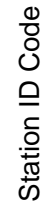 & 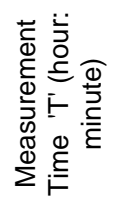 & 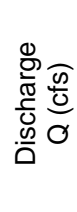 & 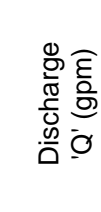 \\
\hline $5 / 5 / 2006$ & 70 & $18: 15$ & 0.36 & 159.92 \\
\hline
\end{tabular}

Base flow recession constant calculations.

\begin{tabular}{|l|r|l|l|}
\hline $\mathrm{Q}_{\mathrm{t}}=\mathrm{Q}_{0} \mathrm{e}^{-\mathrm{at}}$ & & $($ after Fetter, 2001) & \\
\hline $\mathrm{Q}_{\mathrm{t}}$ & 159.92 & $\mathrm{gpm}$ & Discharge at some time t after the recession curve started (L3/T) \\
\hline $\mathrm{Q}_{0}$ & 201.42 & $\mathrm{gpm}$ & Discharge at the start of the recession curve (L3/T) \\
\hline $\mathrm{a}$ & $5.13 \mathrm{E}-04$ & $1 / \mathrm{min}$ & Recession constant calculated for the basin $(1 / \mathrm{T})$ \\
\hline $\mathrm{t}$ & 450 & minutes & Time since recession began when $\mathrm{Q}_{\mathrm{o}}$ was measured. $(\mathrm{T})$ \\
\hline
\end{tabular}


Table 8: High Flow Stream Discharge Data of May 7, 2006,

With Baseflow Recession Constant Calculation, for Templeton Fork, PA.

\begin{tabular}{|c|c|c|c|c|c|c|c|c|c|c|c|c|c|}
\hline 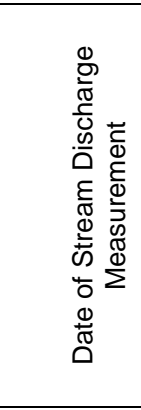 & 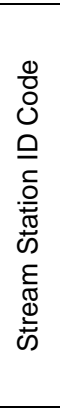 & 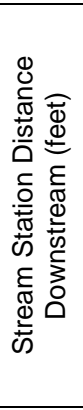 & 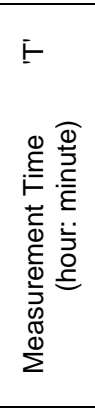 & 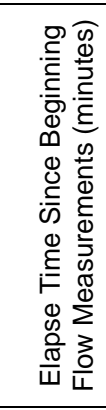 & 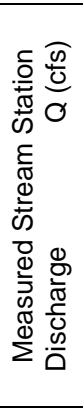 & 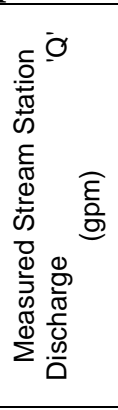 & 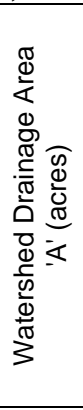 & 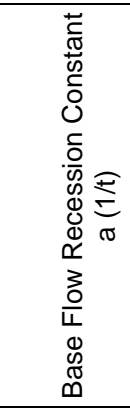 & 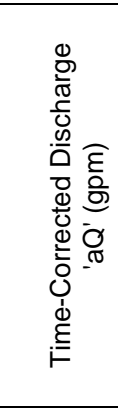 & 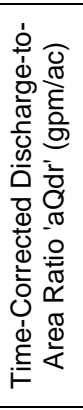 & 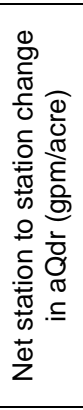 & 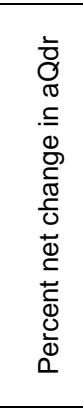 & 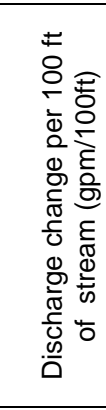 \\
\hline \multirow[t]{9}{*}{$5 / 72005$} & $1 \mathrm{~B}$ & 55 & $11: 30$ & 0.00 & 2.43 & 1088.34 & 3379 & 8.98E-04 & 1088.34 & 0.32 & & & \\
\hline & 2 & 595 & $12: 25$ & 55.00 & 2.58 & 1156.33 & 3400 & & 1214.88 & 0.36 & 0.04 & 10.9 & 23.43 \\
\hline & 3 & 710 & $16: 20$ & 290.00 & 3.31 & 1485.64 & 3408 & & 1927.58 & 0.57 & 0.21 & 58.3 & 619.74 \\
\hline & 4 & 800 & $15: 45$ & 255.00 & 3.21 & 1439.64 & 3411 & & 1810.10 & 0.53 & -0.03 & -6.2 & -130.53 \\
\hline & 5 & 985 & $15: 00$ & 210.00 & 3.61 & 1619.05 & 3420 & & 1955.05 & 0.57 & 0.04 & 7.7 & 78.35 \\
\hline & 6 & 1240 & 13:05 & 95.00 & 3.61 & 1619.72 & 3426 & & 1763.96 & 0.51 & -0.06 & 10.0 & -74.94 \\
\hline & 7 & 1595 & $16: 50$ & 320.00 & 2.78 & 1245.64 & 3449 & & 1660.32 & 0.48 & -0.03 & -6.5 & -29.19 \\
\hline & 8 & 2060 & 13:30 & 120.00 & 2.63 & 1181.69 & 3948 & & 1316.14 & 0.33 & -0.15 & 30.7 & -74.02 \\
\hline & 9 & 2440 & $14: 20$ & 170.00 & 3.79 & 1701.51 & 3961 & & 1982.14 & 0.50 & 0.17 & 50.1 & 175.26 \\
\hline
\end{tabular}

Values used to calculate the baseflow recession constant (a).

\begin{tabular}{|c|c|c|c|c|}
\hline$\frac{\mathbb{D}}{\pi}$ & \begin{tabular}{l}
0 \\
8 \\
0 \\
0 \\
0 \\
\multicolumn{1}{c}{} \\
.0 \\
$\frac{0}{0}$ \\
0
\end{tabular} & 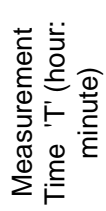 & $\begin{array}{l}\frac{0}{0} \\
\frac{0}{0} \\
\frac{D}{0} \\
\frac{D}{0} \\
\frac{.0}{0}\end{array}$ & 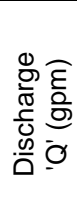 \\
\hline $5 / 72005$ & & & & \\
\hline
\end{tabular}

Base flow recession constant calculations.

\begin{tabular}{|c|c|c|}
\hline$Q_{t}=Q_{0} e^{-a t}$ & (after Fetter, 2001) & \\
\hline$Q_{t}$ & gpm & Discharge at some time $t$ after the recession curve started $(\mathrm{L} 3 / \mathrm{T})$ \\
\hline$Q_{0}$ & gpm & Discharge at the start of the recession curve $(\mathrm{L} 3 / \mathrm{T})$ \\
\hline a & $1 / \mathrm{min}$ & Recession constant calculated for the basin $(1 / T)$ \\
\hline $\mathrm{t}$ & minutes & Time since recession began when $Q_{0}$ was measured. $(T)$ \\
\hline
\end{tabular}


Table 9: Low Flow Stream Discharge Data of June 25, 2005,

With Baseflow Recession Constant Calculation, for Templeton Fork, PA.

\begin{tabular}{|c|c|c|c|c|c|c|c|c|c|c|c|c|c|}
\hline 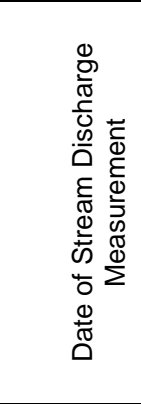 & 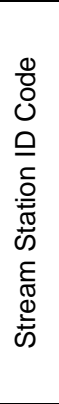 & 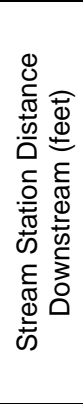 & 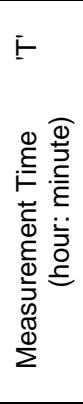 & 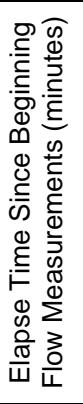 & 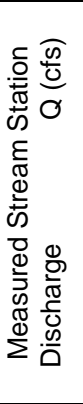 & 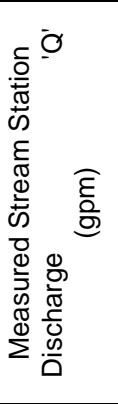 & 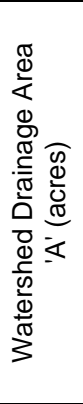 & 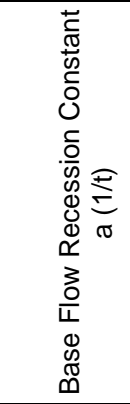 & 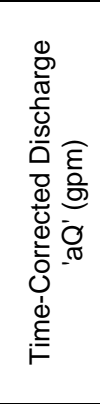 & 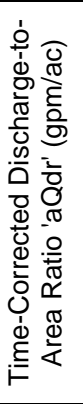 & 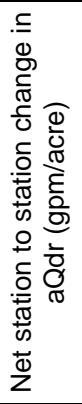 & 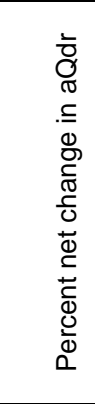 & 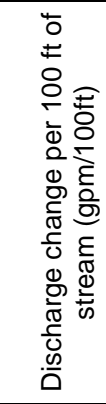 \\
\hline \multirow[t]{10}{*}{$6 / 25 / 2005$} & $1 \mathrm{~A}$ & -1500 & 19:00 & 300 & 0.49 & 220.81 & 2438 & & 289.08 & 0.12 & & & \\
\hline & 1B & 55 & $14: 00$ & 0 & 0.90 & 402.55 & 3379 & $8.98 \mathrm{E}-04$ & 402.55 & 0.12 & 0.00 & 0.48 & 7.30 \\
\hline & 2 & 595 & $14: 50$ & 50 & 1.14 & 510.73 & 3400 & & 534.19 & 0.16 & 0.04 & 31.89 & 24.38 \\
\hline & 3 & 710 & $15: 24$ & 84 & 0.86 & 385.74 & 3408 & & 415.97 & 0.12 & -0.04 & -22.30 & -102.80 \\
\hline & 4 & 800 & $15: 55$ & 115 & 0.73 & 326.84 & 3411 & & 362.40 & 0.11 & -0.02 & -12.96 & -59.52 \\
\hline & 5 & 985 & $16: 22$ & 142 & 1.33 & 596.12 & 3420 & & 677.19 & 0.20 & 0.09 & 86.38 & 170.16 \\
\hline & 6 & 1240 & $17: 02$ & 182 & 1.03 & 462.49 & 3426 & & 544.60 & 0.16 & -0.04 & -19.74 & -52.00 \\
\hline & 7 & 1595 & $17: 27$ & 207 & 0.99 & 443.41 & 3449 & & 534.00 & 0.15 & 0.00 & -2.58 & -2.99 \\
\hline & 8 & 2060 & $17: 50$ & 230 & 0.79 & 355.00 & 3948 & & 436.44 & 0.11 & -0.04 & -28.60 & -20.98 \\
\hline & 9 & 2440 & $18: 10$ & 250 & 1.27 & 569.53 & 3961 & & 712.88 & 0.18 & 0.07 & 62.80 & 72.75 \\
\hline
\end{tabular}

Values used to calculate the baseflow recession constant (a).

\begin{tabular}{|c|c|c|c|c|}
\hline$\frac{0}{\pi}$ & 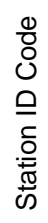 & 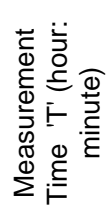 & $\begin{array}{l}0 \\
\frac{0}{0} \\
\frac{0}{0} \\
\frac{0}{0} \\
\frac{D}{0}\end{array}$ & 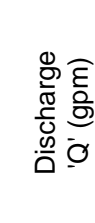 \\
\hline $6 / 25 / 2005$ & 55 & $19: 25$ & 0.67 & 300.70 \\
\hline
\end{tabular}

Base flow recession constant calculations.

Base flow recession constant calculations.
\begin{tabular}{|l|r|l|l|}
\hline$Q_{\mathrm{t}}=\mathrm{Q}_{\mathrm{o}} \mathrm{e}^{-\mathrm{at}}$ & & $\begin{array}{l}\text { (after Fetter, } \\
2001)\end{array}$ & \\
\hline $\mathrm{Q}_{\mathrm{t}}$ & 300.70 & $\mathrm{gpm}$ & Discharge at some time t after the recession curve started (L3/T) \\
\hline$Q_{0}$ & 402.55 & $\mathrm{gpm}$ & Discharge at the start of the recession curve (L3/T) \\
\hline $\mathrm{a}$ & $8.98 \mathrm{E}-04$ & $1 /$ min & Recession constant calculated for the basin $(1 / \mathrm{T})$ \\
\hline $\mathrm{t}$ & 325.00 & minutes & Time since recession began when $\mathrm{Q}_{\mathrm{o}}$ was measured. $(\mathrm{T})$ \\
\hline
\end{tabular}


Table 10: High Flow Stream Discharge Data of January 30, 2006,

With Baseflow Recession Constant Calculation, for Island Creek, WV.

\begin{tabular}{|c|c|c|c|c|c|c|c|c|c|c|c|c|c|}
\hline 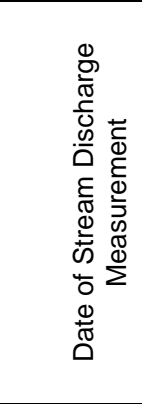 & 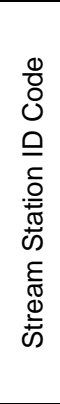 & 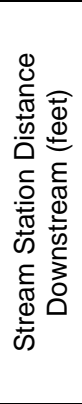 & 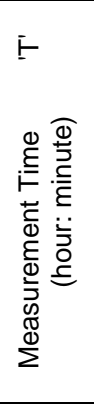 & 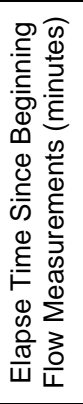 & 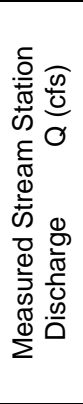 & 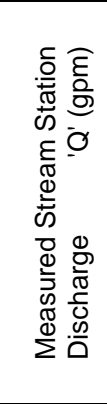 & 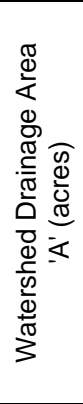 & 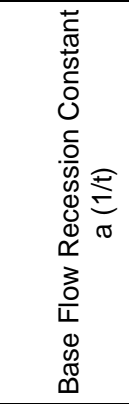 & 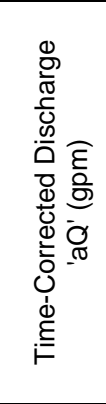 & 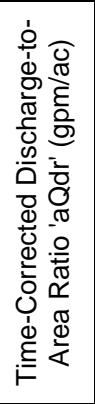 & 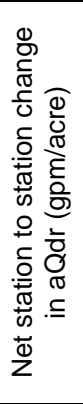 & 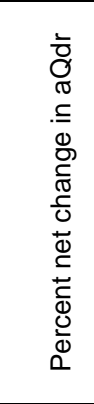 & 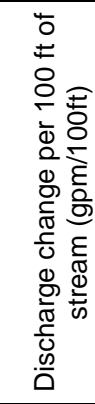 \\
\hline \multirow[t]{7}{*}{$1 / 30 / 2006$} & $1 \mathrm{~B}$ & -960 & $16: 45$ & 275 & 1.31 & 588.65 & 716 & & 629.50 & 0.88 & & & \\
\hline & 2 & -640 & $16: 15$ & 245 & 1.42 & 636.45 & 768 & & 675.66 & 0.88 & 0.00 & 0.1 & 14.43 \\
\hline & 3 & 0 & $12: 10$ & 0 & 1.15 & 517.58 & 848 & $2.44 \mathrm{E}-04$ & 517.58 & 0.61 & -0.27 & -30.6 & -24.70 \\
\hline & 4 & 480 & $12: 55$ & 45 & 1.12 & 503.08 & 872 & & 508.63 & 0.58 & -0.03 & -4.4 & -1.86 \\
\hline & $5 \mathrm{~A}$ & 1080 & $13: 35$ & 85 & 1.13 & 507.56 & 907 & & 518.20 & 0.57 & -0.01 & -2.1 & 1.59 \\
\hline & $6 \mathrm{~A}$ & 1820 & $14: 10$ & 120 & 0.89 & 397.52 & 949 & & 409.34 & 0.43 & -0.14 & -24.5 & -14.71 \\
\hline & 7 & 2600 & $14: 50$ & 160 & 0.61 & 274.76 & 1023 & & 285.69 & 0.28 & -0.15 & -35.3 & -15.85 \\
\hline
\end{tabular}

Values used to calculate the baseflow recession constant (a).

\begin{tabular}{|c|c|c|c|c|}
\hline 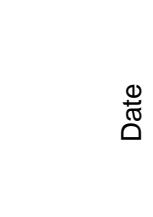 & 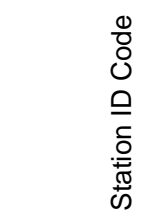 & 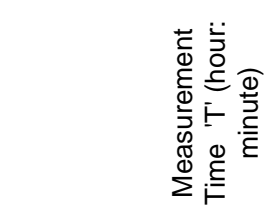 & 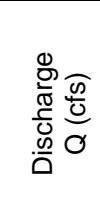 & 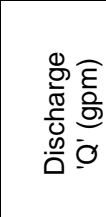 \\
\hline $1 / 30 / 2006$ & 0 & $15: 50$ & 1.09 & 490.52 \\
\hline
\end{tabular}

Base flow recession constant calculations.
\begin{tabular}{|l|r|l|l|}
\hline$Q_{t}=Q_{0} e^{-a t}$ & & $($ after Fetter, 2001) & \\
\hline$Q_{t}$ & 490.52 & $g p m$ & Discharge at some time t after the recession curve started (L3/T) \\
\hline$Q_{0}$ & 517.58 & $g p m$ & $\begin{array}{l}\text { Discharge at the start of the recession } \\
\text { curve }(\mathrm{L} 3 / \mathrm{T})\end{array}$ \\
\hline $\mathrm{a}$ & $2.44 \mathrm{E}-04$ & $1 / \mathrm{min}$ & $\begin{array}{l}\text { Recession constant calculated for the } \\
\text { basin }(1 / \mathrm{T})\end{array}$ \\
\hline $\mathrm{t}$ & 220.00 & minutes & $\begin{array}{l}\text { Time since recession began when } \mathrm{Q}_{\mathrm{o}} \text { was } \\
\text { measured. }(\mathrm{T})\end{array}$ \\
\hline
\end{tabular}


Table 11: Low Flow Stream Discharge Data of May 4, 2006,

With Baseflow Recession Constant Calculation, For Island Creek, WV.

\begin{tabular}{|c|c|c|c|c|c|c|c|c|c|c|c|c|c|}
\hline 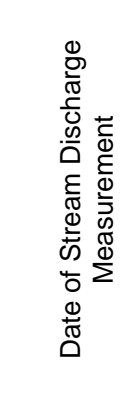 & 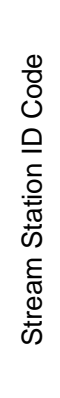 & 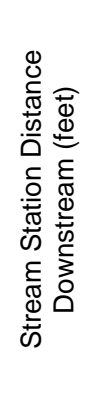 & 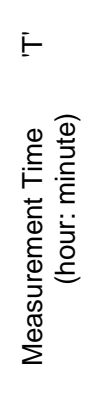 & 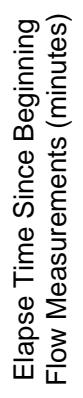 & 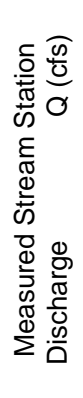 & 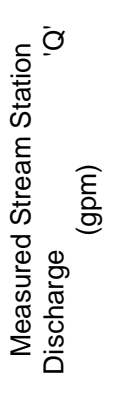 & 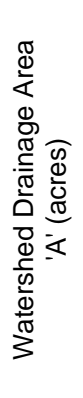 & 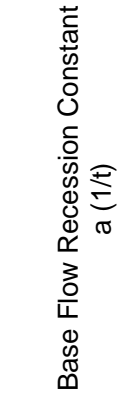 & 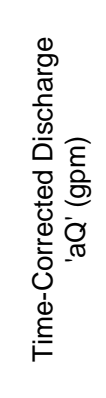 & 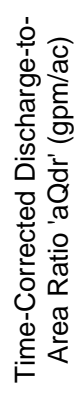 & 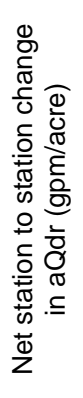 & 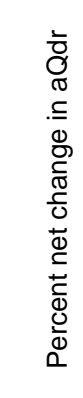 & 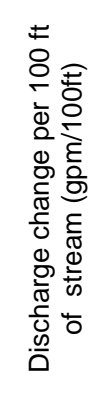 \\
\hline \multirow[t]{9}{*}{$5 / 4 / 2006$} & $1 \mathrm{~A}$ & -2500 & 7:00 & 45 & 0.35 & 157.55 & 438 & & 156.32 & 0.36 & & & \\
\hline & $1 \mathrm{~B}$ & -960 & $7: 45$ & 0 & 1.05 & 472.60 & 716 & $1.75 \mathrm{E}-04$ & 472.60 & 0.66 & 0.30 & 84.9 & 20.54 \\
\hline & 2 & -640 & 9:00 & 75 & 0.83 & 373.60 & 768 & & 356.26 & 0.46 & -0.20 & -29.7 & -36.36 \\
\hline & 3 & 0 & $9: 45$ & 120 & 0.94 & 420.84 & 848 & & 429.77 & 0.51 & 0.04 & 9.3 & 11.49 \\
\hline & 4 & 480 & $10: 30$ & 165 & 0.71 & 317.77 & 872 & & 327.08 & 0.38 & -0.13 & -26.0 & -21.39 \\
\hline & $5 \mathrm{~A}$ & 1080 & $11: 00$ & 195 & 0.63 & 283.13 & 907 & & 292.95 & 0.32 & -0.05 & -13.9 & -5.69 \\
\hline & $6 \mathrm{~A}$ & 1810 & $11: 50$ & 245 & 0.52 & 233.28 & 949 & & 243.49 & 0.26 & -0.07 & -20.6 & -6.78 \\
\hline & $6 B$ & 2060 & $13: 00$ & 315 & 0.43 & 194.98 & 1007 & & 206.03 & 0.20 & -0.05 & -20.3 & -14.99 \\
\hline & 7 & 2600 & $12: 30$ & 285 & 0.24 & 109.29 & 1023 & & 114.88 & 0.11 & -0.09 & -45.1 & -16.88 \\
\hline
\end{tabular}

\begin{tabular}{|c|c|c|c|c|}
\hline$\frac{0}{\pi}$ & 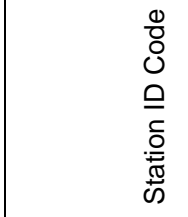 & 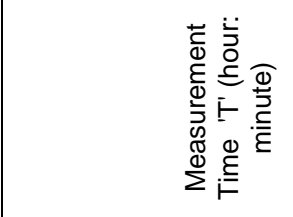 & 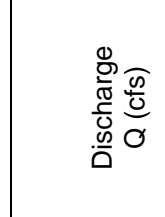 & 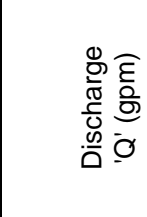 \\
\hline $5 / 4 / 2006$ & 0 & $15: 50$ & 1.09 & 490.52 \\
\hline
\end{tabular}

Base flow recession constant calculations.

\begin{tabular}{|l|r|l|l|}
\hline $\mathrm{Q}_{\mathrm{t}}=\mathrm{Q}_{0} \mathrm{e}^{-\mathrm{at}}$ & & $($ after Fetter, 2001) & \\
\hline $\mathrm{Q}_{\mathrm{t}}$ & 444.90 & $\mathrm{gpm}$ & Discharge at some time t after the recession curve started (L3/T) \\
\hline $\mathrm{Q}_{0}$ & 472.60 & $\mathrm{gpm}$ & Discharge at the start of the recession curve $(\mathrm{L} 3 / \mathrm{T})$ \\
\hline $\mathrm{a}$ & $1.75 \mathrm{E}-04$ & $1 / \mathrm{min}$ & Recession constant calculated for the basin $(1 / \mathrm{T})$ \\
\hline $\mathrm{t}$ & 345.00 & minutes & Time since recession began when $\mathrm{Q}_{\mathrm{o}}$ was measured. $(\mathrm{T})$ \\
\hline
\end{tabular}


Table 12: Extremely Low Flow Stream Discharge Data of May 21, 2006, With Baseflow Recession Constant Calculation, for Island Creek, WV.

\begin{tabular}{|c|c|c|c|c|c|c|c|c|c|c|c|c|c|}
\hline 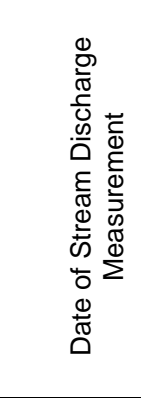 & 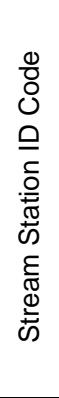 & 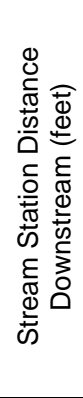 & 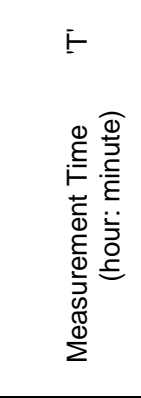 & 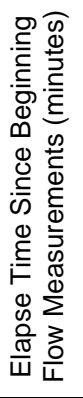 & 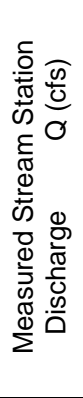 & 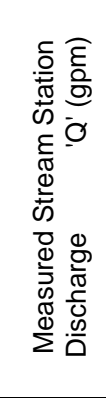 & 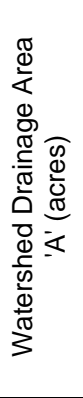 & 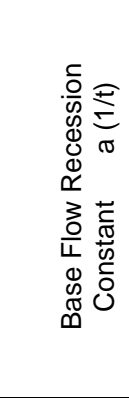 & 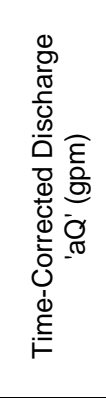 & 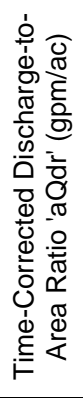 & 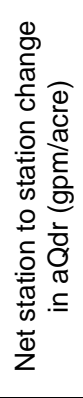 & 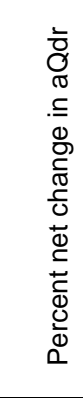 & 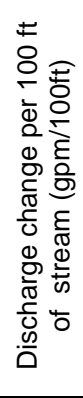 \\
\hline \multirow[t]{10}{*}{$5 / 21 / 2006$} & $1 \mathrm{~A}$ & -2500 & 9:45 & -25 & 0.16 & 70.02 & 438 & & 51.37 & 0.12 & 0 & & \\
\hline & $1 \mathrm{~B}$ & -960 & $10: 10$ & 0 & 0.25 & 114.31 & 716 & $4.75 \mathrm{E}-04$ & 114.31 & 0.16 & 0.04 & 26.5 & 4.09 \\
\hline & 2 & -640 & $11: 00$ & 50 & 0.29 & 129.21 & 768 & & 125.02 & 0.16 & 0.00 & 1.9 & 3.35 \\
\hline & 3 & 0 & $11: 15$ & 65 & 0.22 & 97.77 & 848 & & 98.59 & 0.12 & -0.05 & -28.6 & 4.13 \\
\hline & 4 & 480 & $11: 55$ & 105 & 0.19 & 85.65 & 872 & & 86.82 & 0.10 & -0.02 & $\begin{array}{l}-14.4 \\
\end{array}$ & 2.45 \\
\hline & $5 \mathrm{~A}$ & 1080 & $12: 25$ & 135 & 0.06 & 29.13 & 907 & & 29.64 & 0.03 & -0.07 & -67.2 & 9.53 \\
\hline & $5 B$ & 1710 & $12: 50$ & 160 & 0.00 & 0.00 & 929 & & 0.00 & 0.00 & -0.03 & -51.1 & 4.70 \\
\hline & $6 \mathrm{~A}$ & 1810 & $12: 55$ & 165 & 0.00 & 0.00 & 949 & & 0.00 & 0.00 & 0.00 & dry & 0.00 \\
\hline & $6 \mathrm{~B}$ & 2060 & $13: 00$ & 170 & 0.00 & 0.00 & 1007 & & 0.00 & 0.00 & 0.00 & dry & 0.00 \\
\hline & 7 & 2600 & 0.545139 & 175 & 0 & 0 & 1023 & & 0 & 0 & 0 & dry & 0 \\
\hline
\end{tabular}

\begin{tabular}{|c|c|c|c|c|}
\hline$\stackrel{\frac{0}{\pi}}{\stackrel{*}{0}}$ & 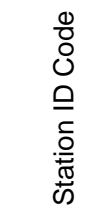 & 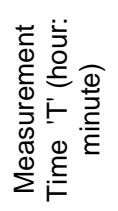 & 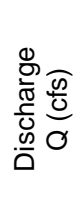 & 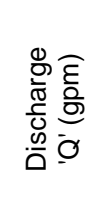 \\
\hline $5 / 21 / 2006$ & -1250 & $16: 10$ & 0.21 & 96.33 \\
\hline
\end{tabular}

Base flow recession constant calculations.
\begin{tabular}{|l|r|l|l|}
\hline $\mathrm{Q}_{\mathrm{t}}=\mathrm{Q}_{0} \mathrm{e}^{-\mathrm{at}}$ & & $($ after Fetter, 2001) & \\
\hline $\mathrm{Q}_{\mathrm{t}}$ & 96.33 & $\mathrm{gpm}$ & Discharge at some time $\mathrm{f}$ after the recession curve started (L3/T) \\
\hline $\mathrm{Q}_{0}$ & 114.31 & $\mathrm{gpm}$ & Discharge at the start of the recession curve (L3/T) \\
\hline $\mathrm{a}$ & $4.75 \mathrm{E}-04$ & $1 / \mathrm{min}$ & Recession constant calculated for the basin $(1 / \mathrm{T})$ \\
\hline $\mathrm{t}$ & 360 & minutes & Time since recession began when $\mathrm{Q}_{\mathrm{o}}$ was measured. $(\mathrm{T})$ \\
\hline
\end{tabular}


Table 13: Low Flow Stream Discharge Data of May 3, 2006,

With Baseflow Recession Constant Calculation, for West Fork, WV.

\begin{tabular}{|c|c|c|c|c|c|c|c|c|c|c|c|c|c|}
\hline 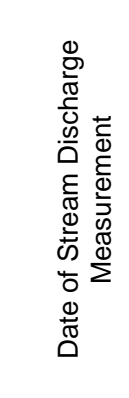 & 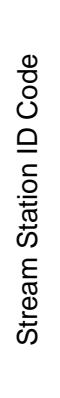 & 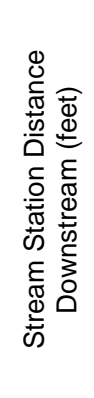 & 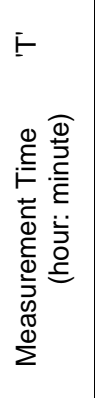 & 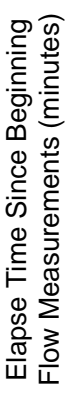 & 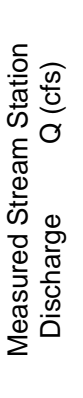 & 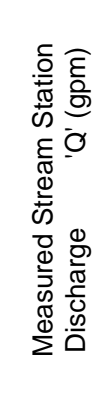 & 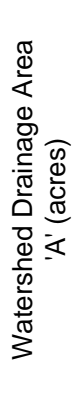 & 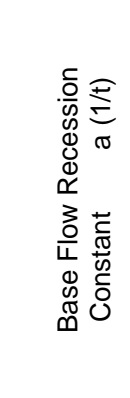 & 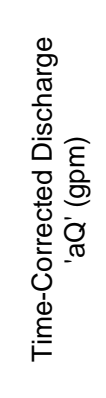 & 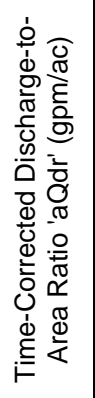 & 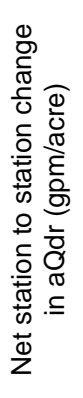 & 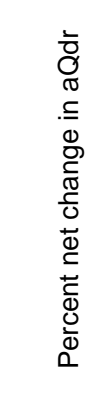 & 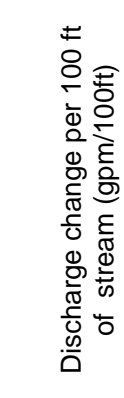 \\
\hline \multirow[t]{12}{*}{$5 / 3 / 2006$} & 1 & 0 & $11: 52$ & 0 & 0.23 & 101.81 & 1155 & $9.65 \mathrm{E}-05$ & 101.81 & 0.09 & & & \\
\hline & 2 & 450 & $12: 30$ & 38 & 0.21 & 93.49 & 1226 & & 93.83 & 0.08 & -0.01 & -13.2 & -1.77 \\
\hline & 3 & 690 & $18: 15$ & 383 & 0.24 & 109.69 & 1237 & & 113.82 & 0.09 & 0.02 & 20.2 & 8.33 \\
\hline & 4 & 890 & $13: 30$ & 98 & 0.22 & 100.10 & 1243 & & 101.05 & 0.08 & -0.01 & -11.7 & -6.39 \\
\hline & 5 & 1180 & $15: 30$ & 218 & 0.13 & 58.84 & 1269 & & 60.09 & 0.05 & -0.03 & -41.7 & -14.12 \\
\hline & 6 & 1510 & $15: 10$ & 198 & 0.06 & 27.00 & 1287 & & 27.52 & 0.02 & -0.03 & -54.8 & -9.87 \\
\hline & 7 & 1800 & $14: 45$ & 173 & 0.06 & 25.41 & 1300 & & 25.83 & 0.02 & 0.00 & -7.1 & -0.58 \\
\hline & 8 & 2250 & $14: 30$ & 158 & 0.04 & 20.07 & 1313 & & 20.38 & 0.02 & 0.00 & -21.9 & -1.21 \\
\hline & $9 \mathrm{~A}$ & 2330 & $14: 15$ & 143 & 0.00 & 0.00 & 1314 & & 0.00 & 0.00 & -0.02 & -100.0 & -25.48 \\
\hline & $9 \mathrm{~B}$ & 3350 & $16: 35$ & 283 & 0.00 & 0.00 & 1518 & & 0.00 & 0.00 & 0.00 & & 0.00 \\
\hline & 10 & 10500 & $17: 35$ & 343 & 0.00 & 0.00 & 2582 & & 0.00 & 0.00 & 0.00 & & 0.00 \\
\hline & 11 & 11300 & $17: 45$ & 353 & 0.47 & 211.32 & 2628 & & 218.64 & 0.08 & 0.08 & 100.0 & 27.33 \\
\hline
\end{tabular}

Values used to calculate the baseflow recession constant (a).

\begin{tabular}{|c|c|c|c|c|}
\hline 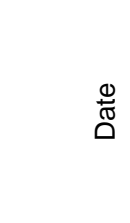 & $\begin{array}{l}0 \\
8 \\
0 \\
0 \\
\\
.0 \\
.00 \\
\text { ஸे }\end{array}$ & 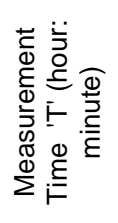 & 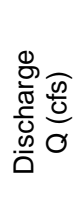 & 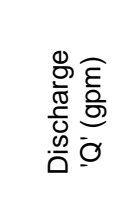 \\
\hline $5 / 3 / 2006$ & 0 & $18: 35$ & 0.22 & 97.93 \\
\hline
\end{tabular}

Base flow recession constant calculations.

\begin{tabular}{|c|c|c|c|}
\hline$Q_{t}=Q_{0} e^{-a t}$ & & (after Fetter, 2001) & \\
\hline$Q_{t}$ & 97.93 & gpm & Discharge at some time $t$ after the recession curve started (L3/T) \\
\hline$Q_{0}$ & 101.81 & gpm & Discharge at the start of the recession curve (L3/T) \\
\hline a & 9.65E-05 & $1 / \mathrm{min}$ & Recession constant calculated for the basin $(1 / \mathrm{T})$ \\
\hline $\mathrm{t}$ & 403 & minutes & Time since recession began when $Q_{0}$ was measured. $(T)$ \\
\hline
\end{tabular}


Table 14: High Flow Stream Discharge Data of March 4, 2007,

With Baseflow Recession Constant Calculation, for West Fork, WV.

\begin{tabular}{|c|c|c|c|c|c|c|c|c|c|c|c|c|c|}
\hline 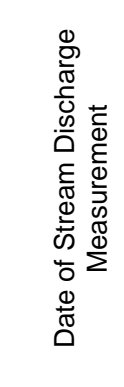 & 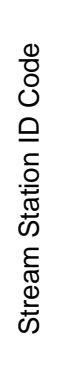 & 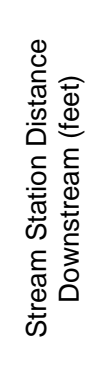 & 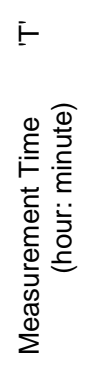 & 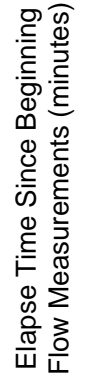 & 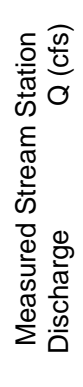 & 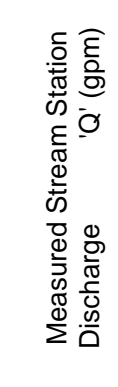 & 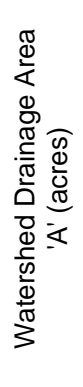 & 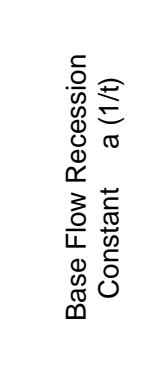 & 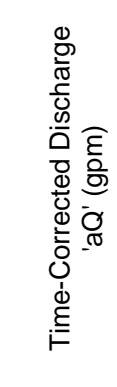 & 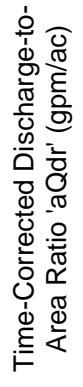 & 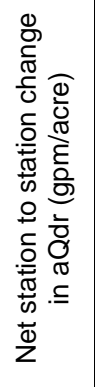 & 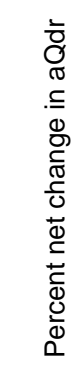 & 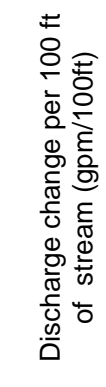 \\
\hline \multirow[t]{12}{*}{$3 / 4 / 2007$} & 1 & 0 & $7: 45$ & 0 & 4.43 & 1989.98 & 1155 & 4.01E-04 & 1989.98 & 1.72 & & & \\
\hline & 2 & 450 & $8: 30$ & 45 & 4.72 & 2118.07 & 1226 & & 2156.64 & 1.76 & 0.04 & 2.1 & 37.04 \\
\hline & 3 & 690 & 9:00 & 75 & 5.30 & 2378.37 & 1237 & & 2450.99 & 1.98 & 0.22 & 12.6 & 122.65 \\
\hline & 4 & 890 & $9: 45$ & 120 & 4.63 & 2079.51 & 1243 & & 2182.02 & 1.76 & -0.23 & -11.4 & -134.49 \\
\hline & 5 & 1180 & $14: 00$ & 375 & 4.15 & 1861.57 & 1269 & & 2163.65 & 1.71 & -0.05 & -2.8 & -6.33 \\
\hline & 6 & 1510 & $14: 45$ & 420 & 4.19 & 1880.67 & 1287 & & 2225.65 & 1.73 & 0.02 & 1.4 & 18.79 \\
\hline & 7 & 1800 & $15: 15$ & 450 & 3.88 & 1741.66 & 1300 & & 2086.08 & 1.60 & -0.12 & -7.2 & -48.13 \\
\hline & 8 & 2250 & & & & & 1313 & & & & & & \\
\hline & $9 \mathrm{~A}$ & 2330 & $15: 50$ & 485 & 4.05 & 1816.97 & 1314 & & 2207.05 & 1.68 & 1.68 & 4.6 & 22.82 \\
\hline & $9 \mathrm{~B}$ & 3350 & $16: 20$ & 515 & 3.59 & 1609.44 & 1518 & & 1978.62 & 1.30 & -0.38 & -22.4 & -22.40 \\
\hline & 10 & 10500 & $17: 45$ & 600 & 8.61 & 3863.49 & 2582 & & 4914.41 & 1.90 & 0.22 & 46.0 & 41.06 \\
\hline & 11 & 11300 & $17: 15$ & 570 & 8.07 & 3623.50 & 2628 & & 4554.02 & 1.73 & -0.17 & -8.9 & -45.05 \\
\hline
\end{tabular}

Values used to calculate the baseflow recession constant (a).

\begin{tabular}{|c|c|c|c|c|}
\hline$\frac{\Phi}{\tilde{N}}$ & 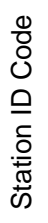 & 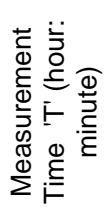 & 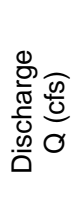 & 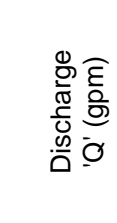 \\
\hline $3 / 3 / 2007$ & 0 & $18: 35$ & 6.20 & 2781.08 \\
\hline
\end{tabular}

Base flow recession constant calculations.

\begin{tabular}{|l|r|l|l|}
\hline$Q_{\mathrm{t}}=\mathrm{Q}_{0} \mathrm{e}^{-\mathrm{at}}$ & & (after Fetter, 2001) & \\
\hline $\mathrm{Q}_{\mathrm{t}}$ & 1989.98 & $\mathrm{gpm}$ & Discharge at some time t after the recession curve started (L3/T) \\
\hline $\mathrm{Q}_{0}$ & 2781.08 & $\mathrm{gpm}$ & Discharge at the start of the recession curve (L3/T) \\
\hline $\mathrm{a}$ & $4.01 \mathrm{E}-04$ & $1 / \mathrm{min}$ & Recession constant calculated for the basin (1/T) \\
\hline $\mathrm{t}$ & 835 & minutes & Time since recession began when $\mathrm{Q}_{\mathrm{o}}$ was measured. $(\mathrm{T})$ \\
\hline
\end{tabular}


Appendix II

Previously Reported

Stream Discharge Data 
Table 1: Mining Company Stream Discharge Data for October 29, 2003 Stream F, PA

\begin{tabular}{|c|c|c|c|c|c|c|c|}
\hline 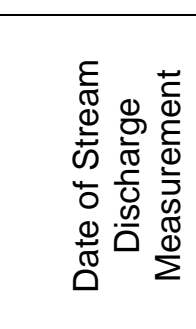 & 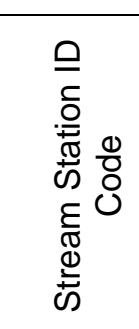 & 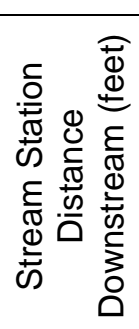 & 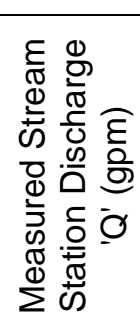 & 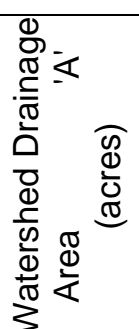 & 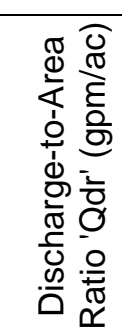 & 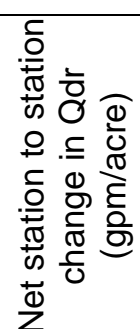 & 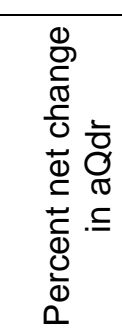 \\
\hline \multirow[t]{7}{*}{$10 / 29 / 2003$} & DR-5 & -4000 & 423.50 & 645 & 0.66 & & \\
\hline & DR-6 & -2500 & 557.00 & 799 & 0.70 & 0.04 & 6.3 \\
\hline & DR-7 & -1300 & 606.90 & 1023 & 0.59 & -0.10 & -14.9 \\
\hline & DR-8 & 650 & 623.60 & 1178 & 0.53 & -0.06 & -10.8 \\
\hline & DR-9 & 2000 & 709.30 & 1328 & 0.53 & 0.00 & 0.9 \\
\hline & DR-10 & 4600 & 956.20 & 1759 & 0.54 & 0.01 & 1.8 \\
\hline & DR-11 & 5700 & 1304.60 & 1848 & 0.71 & 0.16 & 29.8 \\
\hline
\end{tabular}

Panel P-1 mined July 2004.

Table 2: Mining Company Stream Discharge Data for January 20, 2006 Stream F, PA

\begin{tabular}{|c|c|c|c|c|c|c|c|}
\hline 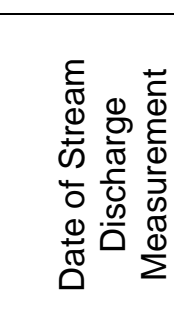 & 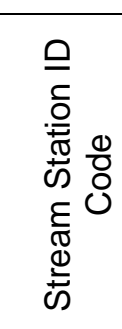 & 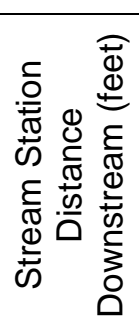 & 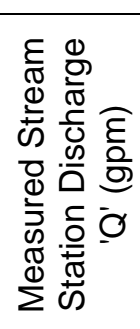 & 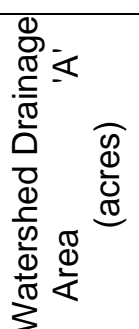 & 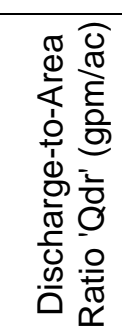 & 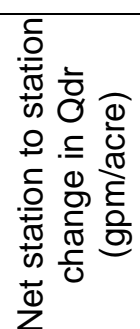 & 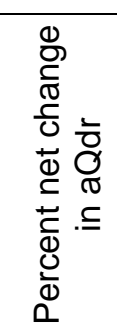 \\
\hline \multirow{7}{*}{$1 / 20 / 2006$} & DR-5 & -4000 & 677.20 & 645 & 1.05 & & \\
\hline & DR-6 & -2500 & 821.90 & 799 & 1.03 & -0.02 & -1.9 \\
\hline & DR-7 & -1300 & 1109.90 & 1023 & 1.09 & 0.06 & 5.5 \\
\hline & DR-8 & 650 & 1517.30 & 1178 & 1.29 & 0.20 & 18.6 \\
\hline & DR-9 & 2000 & 2025.50 & 1328 & 1.52 & 0.24 & 18.4 \\
\hline & DR-10 & 4600 & Flooded & 1759 & & & \\
\hline & DR-11 & 5700 & 1878.00 & 1848 & 1.02 & -0.51 & -33.4 \\
\hline
\end{tabular}

Panel P-1 mined July 2004. 
Table 3: Company Stream Discharge Data for May 9, 2006

Stream F, PA

\begin{tabular}{|c|c|c|c|c|c|c|c|}
\hline 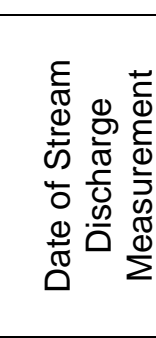 & 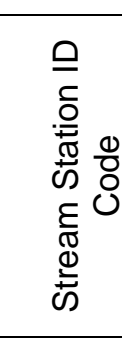 & 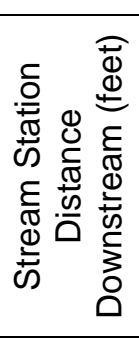 & 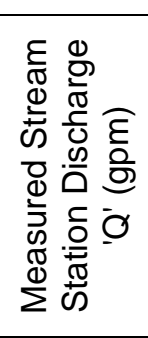 & 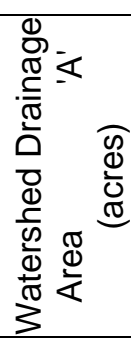 & 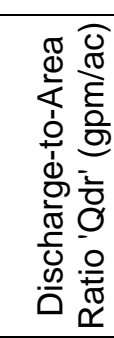 & 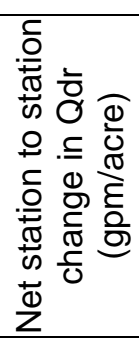 & 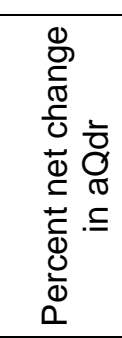 \\
\hline \multirow[t]{7}{*}{$5 / 9 / 2006$} & DR-5 & -4000 & 100.50 & 645 & 0.16 & & \\
\hline & $8-6$ & -2500 & 141. & 799 & 0.18 & 0.02 & 13.8 \\
\hline & DR-7 & -1300 & 32.80 & 1023 & 0.03 & -0.15 & -81.9 \\
\hline & DR-8 & 650 & 134.60 & 1178 & 0.11 & 0.08 & 256.1 \\
\hline & $1-9$ & 2000 & 00 & 1328 & & - & - \\
\hline & -10 & 4600 & Flooded & 1759 & & - & \\
\hline & DR-11 & 5700 & 48.00 & 1848 & 0.03 & -0.09 & -77.3 \\
\hline
\end{tabular}

Panel P-1 mined July 2004.

Table 4: Company Stream Discharge Data For February 12, 2007 Stream F, PA

\begin{tabular}{|c|c|c|c|c|c|c|c|}
\hline 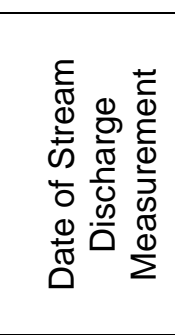 & 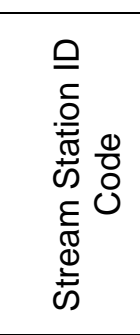 & 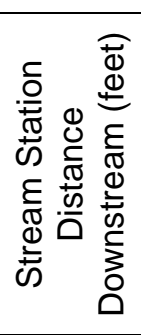 & 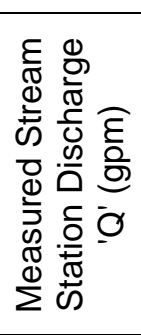 & 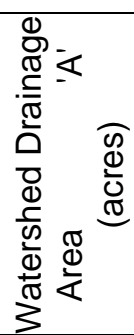 & 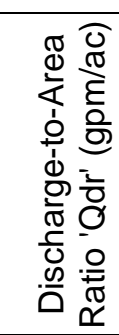 & 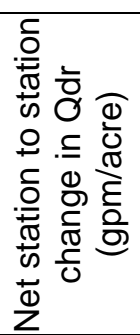 & 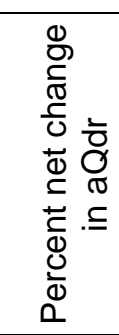 \\
\hline \multirow[t]{7}{*}{$2 / 12 / 2007$} & DR-5 & -4000 & 116.40 & 645 & 0.18 & & \\
\hline & DR-6 & -2500 & 126.80 & 799 & 0.16 & -0.02 & -12.0 \\
\hline & DR-7 & -1300 & 201.30 & 1023 & 0.20 & 0.04 & 24.0 \\
\hline & DR-8 & 650 & 99.50 & 1178 & 0.08 & -0.11 & -57.1 \\
\hline & DR-9 & 2000 & 165.20 & 1328 & 0.12 & 0.04 & 47.3 \\
\hline & DR-10 & 4600 & 171.40 & 1759 & 0.10 & -0.03 & -21.6 \\
\hline & DR-11 & 5700 & 280.00 & 1848 & 0.15 & 0.05 & 55.5 \\
\hline
\end{tabular}

Panel P-1 mined July 2004.

= data adjusted due show a straight line trend because flow measurements were unavailable for one reason or another. 
Appendix III

Geophysical Anomaly

Tables 
Table 1: Significant Geophysical Anomalies

For Crabapple Creek, OH

\begin{tabular}{|c|c|c|c|c|c|c|c|c|c|c|c|c|c|}
\hline \multirow{4}{*}{ Anomaly ID } & \multicolumn{4}{|c|}{ Date of Survey: } & \multicolumn{2}{|c|}{$1 / 26 / 2006$} & & & \multicolumn{2}{|c|}{$1 / 26 / 2006$} & & & \multirow{4}{*}{$\begin{array}{l}\text { Interference } \\
\text { Description }\end{array}$} \\
\hline & \multicolumn{4}{|c|}{ Anomaly Location } & \multirow{2}{*}{\multicolumn{2}{|c|}{$\begin{array}{l}\text { Terrain Conductivity } \\
\text { VD (mmhos/m) }\end{array}$}} & \multirow{2}{*}{\multicolumn{2}{|c|}{$\begin{array}{c}\text { TC Significance } \\
\text { (Percentile) }\end{array}$}} & \multirow{2}{*}{\multicolumn{2}{|c|}{$\begin{array}{c}\text { Very Low Frequency } \\
\text { K-H Filtered Data }\end{array}$}} & \multirow{2}{*}{\multicolumn{2}{|c|}{$\begin{array}{l}\text { VLF Significance } \\
\text { (Percentile) }\end{array}$}} & \\
\hline & \multicolumn{2}{|c|}{ From } & \multicolumn{2}{|c|}{ To } & & & & & & & & & \\
\hline & Feet & Meters & Feet & Meters & from & to & From & To & from & to & From & To & \\
\hline \multirow[t]{2}{*}{ CC-1 } & 110 & 360.8 & 150 & 492.0 & 29 & 31 & 89 & 99 & & & & & \\
\hline & 130 & 426.4 & 130 & 426.4 & & & & & 2.2 & 2.2 & 95 & 95 & \\
\hline \multirow[t]{2}{*}{ CC-2 } & 170 & 557.6 & 270 & 885.6 & 31 & 36 & 95 & 99 & & & & & \\
\hline & 170 & 557.6 & 170 & 557.6 & & & & & 2 & 2 & 90 & 90 & \\
\hline \multirow[t]{2}{*}{$\mathrm{CC}-3$} & 330 & 1082.4 & 380 & 1246.4 & 31 & 31 & 80 & 80 & & & & & Overhead Electric \\
\hline & 330 & 1082.4 & 380 & 1246.4 & & & & & 1.5 & 6.1 & 95 & 95 & Overhead Electric \\
\hline \multirow[t]{2}{*}{ CC-4 } & 440 & 1443.2 & 510 & 1672.8 & 30 & 33 & 80 & 90 & & & & & Metal Debris \\
\hline & - & - & - & - & & & & & - & - & - & - & \\
\hline \multirow[t]{2}{*}{ CC-5 } & 540 & 1771.2 & 590 & 1935.2 & 27 & 29 & 75 & 75 & & & & & \\
\hline & 540 & 1771.2 & 580 & 1902.4 & & & & & 1.2 & 1.9 & 80 & 90 & \\
\hline \multirow[t]{2}{*}{ CC- 6} & - & - & - & - & - & - & - & - & & & & & \\
\hline & 730 & 2394.4 & 760 & 2492.8 & & 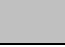 & & & 1 & 1.4 & 80 & 80 & \\
\hline \multirow[t]{2}{*}{ CC-7 } & - & - & - & - & - & - & - & - & & & & & \\
\hline & 870 & 2853.6 & 890 & 2919.2 & & & & & 1.2 & 1.2 & 80 & 80 & \\
\hline \multirow[t]{2}{*}{ CC-8 } & - & - & - & - & - & - & - & - & & & & & \\
\hline & 960 & 3148.8 & 960 & 3148.8 & & & & & 1.2 & 1.2 & 80 & 80 & \\
\hline \multirow[t]{2}{*}{ CC-9 } & 1540 & 5051.2 & 1620 & 5313.6 & 21 & 23 & 80 & 99 & & & & & \\
\hline & 1590 & 5215.2 & 1640 & 5379.2 & & & & & 1.2 & 2.6 & 80 & 95 & \\
\hline
\end{tabular}


Table 2: Significant Geophysical Anomalies

For Williams Creek, OH

\begin{tabular}{|c|c|c|c|c|c|c|c|c|c|c|c|c|c|}
\hline \multirow{4}{*}{ Anomaly ID } & \multicolumn{4}{|c|}{ Date of Survey: } & \multicolumn{2}{|c|}{$8 / 2 / 2005$} & & & \multicolumn{2}{|c|}{$8 / 2 / 2005$} & \multicolumn{2}{|c|}{ 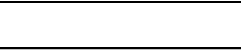 } & \multirow{4}{*}{$\begin{array}{r}\text { Interference } \\
\text { Description }\end{array}$} \\
\hline & \multicolumn{4}{|c|}{ Anomaly Location } & \multirow{2}{*}{\multicolumn{2}{|c|}{$\begin{array}{l}\text { Terrain Conductivity } \\
\text { VD (mmhos } / \mathrm{m})\end{array}$}} & \multirow{2}{*}{\multicolumn{2}{|c|}{$\begin{array}{l}\text { TC Significance } \\
\text { (Percentile) }\end{array}$}} & \multirow{2}{*}{\multicolumn{2}{|c|}{$\begin{array}{c}\text { Very Low Frequency } \\
\text { K-H Filtered Data }\end{array}$}} & \multirow{2}{*}{\multicolumn{2}{|c|}{$\begin{array}{c}\text { VLF Significance } \\
\text { (Percentile) }\end{array}$}} & \\
\hline & \multicolumn{2}{|c|}{ From } & \multicolumn{2}{|c|}{ To } & & & & & & & & & \\
\hline & Feet & Meters & Feet & Meters & from & to & From & To & from & to & From & To & \\
\hline \multirow[t]{2}{*}{ WC-1 } & 260 & 79.3 & 430 & 131.1 & 40 & 60 & 80 & 99 & & & & & \\
\hline & 330 & 100.6 & 360 & 109.8 & & & & & 1.7 & 3.7 & 80 & 90 & \\
\hline \multirow[t]{2}{*}{ WC-2 } & - & - & - & - & - & - & - & - & & & & & \\
\hline & 450 & 137.2 & 450 & 137.2 & & & & & 2.6 & 3.4 & 90 & 90 & \\
\hline \multirow[t]{2}{*}{ WC-3 } & - & - & - & - & - & - & - & - & & & & & \\
\hline & 840 & 256.1 & 860 & 262.2 & & & & & 15.9 & 15.9 & 99 & 99 & \\
\hline \multirow[t]{2}{*}{ WC-4 } & 900 & 274.4 & 1030 & 314.0 & 60 & 60 & 80 & 99 & & & & & \\
\hline & - & - & - & - & & & & & - & - & - & - & \\
\hline \multirow[t]{2}{*}{ WC-5 } & 1400 & 426.8 & 1500 & 457.3 & 42 & 43 & 70 & 80 & & & & & \\
\hline & 1420 & 432.9 & 1500 & 457.3 & & & & & 3.3 & 3.4 & 90 & 90 & \\
\hline \multirow[t]{2}{*}{ WC-6 } & - & - & - & - & - & - & - & - & & & & & \\
\hline & 1630 & 497.0 & 1650 & 503.0 & & & & & 1.9 & 2.4 & 80 & 80 & \\
\hline \multirow[t]{2}{*}{ WC-7 } & 1750 & 533.5 & 1880 & 573.2 & 46 & 66 & 80 & 90 & & & & & \\
\hline & 1790 & 545.7 & 1820 & 554.9 & & & & & 4.3 & 7.6 & 99 & 99 & \\
\hline \multirow[t]{2}{*}{ WC-8 } & 1900 & 579.3 & 1910 & 582.3 & 58 & 60 & 95 & 95 & & & & & \\
\hline & 1900 & 579.3 & 1900 & 579.3 & & & & & 2.8 & 2.8 & 90 & 90 & \\
\hline \multirow[t]{2}{*}{ WC-9 } & 1960 & 597.6 & 1970 & 600.6 & 49 & 50 & 80 & 80 & & & & & \\
\hline & 1960 & 597.6 & 1960 & 597.6 & & & & & 3.3 & 3.3 & 90 & 90 & \\
\hline \multirow[t]{2}{*}{ WC-10 } & - & - & - & - & - & - & - & - & & & & & \\
\hline & 1990 & 606.7 & 2000 & 609.8 & & & & & 2.3 & 5 & 80 & 95 & \\
\hline \multirow[t]{2}{*}{ WC-11 } & 2200 & 670.7 & 2200 & 670.7 & 44 & 44 & 80 & 80 & & & & & \\
\hline & 2150 & 655.5 & 2200 & 670.7 & & & & & 2.8 & 5.2 & 90 & 95 & \\
\hline \multirow[t]{2}{*}{ WC-12 } & 2330 & 710.4 & 2350 & 716.5 & 48 & 53 & 80 & 90 & & & & & \\
\hline & - & & - & - & & & & & - & - & - & - & \\
\hline
\end{tabular}


Table 3: Significant Geophysical Anomalies

For Stream F, PA

\begin{tabular}{|c|c|c|c|c|c|c|c|c|c|c|c|c|c|}
\hline \multirow{4}{*}{ Anomaly ID } & \multicolumn{4}{|c|}{ Date of Survey: } & \multirow{3}{*}{\multicolumn{2}{|c|}{$\begin{array}{c}5 / 14 / 2005 \\
\text { Terrain } \\
\text { Conductivity } \\
\text { VD }(\mathrm{mmhos} / \mathrm{m})\end{array}$}} & & & \multirow{3}{*}{\multicolumn{2}{|c|}{$\begin{array}{c}\text { 5/14/2005 } \\
\text { Very Low } \\
\text { Frequency } \\
\text { K-H Filtered Data }\end{array}$}} & & & \multirow{4}{*}{$\begin{array}{c}\text { Interference } \\
\text { Description } \\
*\end{array}$} \\
\hline & \multicolumn{4}{|c|}{ Anomaly Location } & & & \multirow{2}{*}{\multicolumn{2}{|c|}{$\begin{array}{c}\text { TC } \\
\text { Significance } \\
\text { (Percentile) }\end{array}$}} & & & \multirow{2}{*}{\multicolumn{2}{|c|}{$\begin{array}{c}\text { VLF } \\
\text { Significance } \\
\text { (Percentile) }\end{array}$}} & \\
\hline & \multicolumn{2}{|c|}{ From } & \multicolumn{2}{|c|}{ To } & & & & & & & & & \\
\hline & Feet & Meters & Feet & Meters & \multicolumn{2}{|c|}{ from to } & \multicolumn{2}{|c|}{ From To } & \multicolumn{2}{|c|}{ from to } & \multirow[t]{2}{*}{ From } & \multirow[t]{2}{*}{ To } & \\
\hline $\mathrm{F}-1$ & 690 & 210.4 & 800 & 243.9 & 18 & 19 & - & - & & & & & \\
\hline & 680 & 207.3 & 730 & 222.6 & & & & & 1.7 & 1.7 & - & - & \\
\hline \multirow[t]{2}{*}{$\mathrm{F}-2$} & 870 & 265.2 & 1160 & 353.7 & 18 & 21 & - & - & & & & & \\
\hline & 1070 & 326.2 & 1100 & 335.4 & & & & & 1.6 & 1.6 & - & - & \\
\hline \multirow[t]{2}{*}{$\mathrm{F}-3$} & 2020 & 615.9 & 2080 & 634.1 & 18 & 18 & - & - & & & & & \\
\hline & 2050 & 625.0 & 2060 & 628.0 & & & & & 1.9 & 2.7 & - & - & \\
\hline \multirow[t]{2}{*}{$\mathrm{F}-4$} & 2540 & 774.4 & 2570 & 783.5 & 19 & 19 & - & - & & & & & \\
\hline & 2520 & 768.3 & 2540 & 774.4 & & & & & 1.3 & 1.8 & & & \\
\hline \multirow[t]{2}{*}{$\mathrm{F}-5$} & 2790 & 850.6 & 2900 & 884.1 & 22 & 24 & - & - & & & & & \\
\hline & - & - & - & - & & & & & - & - & - & - & \\
\hline \multirow[t]{3}{*}{$\mathrm{F}-6$} & 3090 & 942.1 & 3260 & 993.9 & 18 & 21 & - & - & & & & & \\
\hline & 3110 & 948.2 & 3190 & 972.6 & & & & & 4.6 & 7.9 & - & - & \\
\hline & & & & & & & & & & & & & \\
\hline
\end{tabular}

* Interference anomalies are not delineated on this table due to the frequent nature of the interference. 
Table 4: Significant Geophysical Anomalies For Templeton Fork, PA

\begin{tabular}{|c|c|c|c|c|c|c|c|c|c|c|c|c|c|}
\hline \multirow{4}{*}{ Anomaly ID } & \multicolumn{4}{|c|}{ Date of Survey: } & \multicolumn{2}{|c|}{$6 / 26 / 2005$} & & & \multicolumn{2}{|c|}{$4 / 1 / 2005$} & \multicolumn{2}{|c|}{+2} & \multirow{4}{*}{$\begin{array}{l}\text { Interference } \\
\text { Description }\end{array}$} \\
\hline & \multicolumn{4}{|c|}{ Anomaly Location } & \multirow{2}{*}{\multicolumn{2}{|c|}{$\begin{array}{l}\text { Terrain Conductivity } \\
\text { VD }(\mathrm{mmhos} / \mathrm{m})\end{array}$}} & \multirow{2}{*}{\multicolumn{2}{|c|}{$\begin{array}{l}\text { TC Significance } \\
\text { (Percentile) }\end{array}$}} & \multirow{2}{*}{\multicolumn{2}{|c|}{$\begin{array}{l}\text { Very Low Frequency } \\
\text { K-H Filtered Data }\end{array}$}} & \multirow{2}{*}{\multicolumn{2}{|c|}{$\begin{array}{l}\text { VLF Significance } \\
\text { (Percentile) }\end{array}$}} & \\
\hline & \multicolumn{2}{|c|}{ From } & \multicolumn{2}{|c|}{ To } & & & & & & & & & \\
\hline & Feet & Meters & Feet & Meters & \multicolumn{2}{|c|}{ From $\quad$ To } & \multicolumn{2}{|c|}{ From To } & \multicolumn{2}{|c|}{ From $\quad$ To } & \multicolumn{2}{|c|}{ From To } & \\
\hline \multirow[t]{2}{*}{ TF-1 } & - & - & - & - & - & - & - & - & & & & & \\
\hline & 60 & 18.3 & 90 & 27.4 & & & & & 1.9 & 3 & 80 & 95 & \\
\hline \multirow[t]{2}{*}{ TF-1a } & - & - & - & - & - & - & - & - & & & & & \\
\hline & 140 & 42.7 & 150 & 45.7 & & & & & 1.7 & 2.4 & 80 & 90 & \\
\hline \multirow[t]{2}{*}{ TF-2 } & - & - & - & - & - & - & - & - & & & & & \\
\hline & 360 & 109.8 & 400 & 122.0 & & & & & 2.6 & 4.4 & 90 & 95 & \\
\hline \multirow[t]{2}{*}{ TF-3 } & 500 & 152.4 & 510 & 155.5 & 35 & 35 & 90 & 90 & & & & & \\
\hline & 480 & 146.3 & 510 & 155.5 & & & & & 4.9 & 12 & 95 & 99 & \\
\hline \multirow[t]{2}{*}{ TF-4 } & 770 & 234.8 & 810 & 247.0 & 32 & 35 & 80 & 90 & & & & & \\
\hline & 660 & 201.2 & 740 & 225.6 & & & & & 1.9 & 2.6 & 80 & 90 & \\
\hline \multirow[t]{2}{*}{ TF-5 } & 880 & 268.3 & 1050 & 320.1 & 32 & 34 & 80 & 90 & & & & & \\
\hline & 1030 & 314.0 & 1090 & 332.3 & & & & & 1.9 & 6 & 80 & 99 & \\
\hline \multirow[t]{2}{*}{ TF-6 } & 1300 & 396.3 & 1300 & 396.3 & 32 & 32 & 80 & 80 & & & & & \\
\hline & 1140 & 347.6 & 1220 & 372.0 & & & & & 1.9 & 2.3 & 80 & 80 & \\
\hline \multirow[t]{2}{*}{ TF-7 } & - & - & - & - & - & - & - & - & & & & & \\
\hline & 1360 & 414.6 & 1360 & 414.6 & & & & & 3.5 & 3.5 & 95 & 95 & \\
\hline \multirow[t]{2}{*}{ TF-8 } & 1410 & 429.9 & 1440 & 439.0 & 32 & 32 & 80 & 80 & & & & & \\
\hline & 1430 & 436.0 & 1440 & 439.0 & & & & & 1.6 & 3.9 & 80 & 95 & \\
\hline TF-9 & - & - & - & - & - & - & - & - & & & & & \\
\hline & 1510 & 460.4 & 1539 & 469.2 & & & & & 1.7 & 2.7 & 80 & 90 & \\
\hline TF-10 & - & - & - & - & & & & & & & & & Metal Backstop \\
\hline & 1780 & 542.7 & 1900 & 579.3 & & & & & 1.3 & 2.3 & 80 & 90 & Metal Backstop \\
\hline TF-11 & - & - & - & - & - & - & - & - & & & & & Metal Culverts \\
\hline & 2110 & 643.3 & 2140 & 652.4 & & & & & 1.7 & 2.6 & 80 & 90 & Metal Culverts \\
\hline TF-12 & 2210 & 673.8 & 2260 & 689.0 & 33 & 42 & 80 & 90 & & & & & Electric Wire \\
\hline & - & - & - & - & & & & & - & - & - & - & Electric Wire \\
\hline TF-13 & - & - & - & - & - & - & - & - & & & & & \\
\hline & 2500 & 762.2 & 2600 & 792.7 & & & & & 1.5 & 3 & 80 & 95 & \\
\hline
\end{tabular}


Table 5: Significant Geophysical Anomalies

For Island Creek, WV

\begin{tabular}{|c|c|c|c|c|c|c|c|c|c|c|c|c|c|}
\hline \multirow{4}{*}{ Anomaly ID } & \multicolumn{4}{|c|}{ Date of Survey: } & \multicolumn{2}{|c|}{$8 / 5 / 2005$} & & & \multicolumn{2}{|c|}{$8 / 5 / 2005$} & \multicolumn{2}{|c|}{$x^{2}+x^{2}$} & \multirow{4}{*}{$\begin{array}{l}\text { Interference } \\
\text { Description }\end{array}$} \\
\hline & \multirow{2}{*}{\multicolumn{4}{|c|}{\begin{tabular}{l|l}
\multicolumn{2}{|c|}{ Anomaly Location } \\
From & To \\
\end{tabular}}} & \multirow{2}{*}{\multicolumn{2}{|c|}{$\begin{array}{l}\text { Terrain Conductivity } \\
\text { VD }(\mathrm{mmhos} / \mathrm{m})\end{array}$}} & \multirow{2}{*}{\multicolumn{2}{|c|}{$\begin{array}{c}\text { TC Significance } \\
\text { (Percentile) }\end{array}$}} & \multirow{2}{*}{\multicolumn{2}{|c|}{$\begin{array}{l}\text { Very Low Frequency } \\
\text { K-H Filtered Data }\end{array}$}} & \multirow{2}{*}{\multicolumn{2}{|c|}{$\begin{array}{l}\text { VLF Significance } \\
\text { (Percentile) }\end{array}$}} & \\
\hline & & & & & & & & & & & & & \\
\hline & Feet & Meters & Feet & Meters & From & To & From & To & From & To & From & To & \\
\hline \multirow[t]{2}{*}{ IC-1 } & - & - & - & - & - & - & - & - & & & & & \\
\hline & 50 & 15.2 & 70 & 21.3 & & & & & 1 & 2.7 & 80 & 90 & \\
\hline \multirow[t]{2}{*}{ IC-2 } & - & - & - & - & - & - & - & - & & & & & \\
\hline & 180 & 54.9 & 190 & 57.9 & & & & & 2.3 & 3.1 & 90 & 95 & $\mathrm{OH}$ Electric \\
\hline \multirow[t]{2}{*}{ IC-3 } & 230 & 70.1 & 280 & 85.4 & 7 & 8 & 90 & 90 & & & & & Metal Debris \\
\hline & 270 & 82.3 & 340 & 103.7 & & & & & 0.9 & 7 & 80 & 99 & Metal Debris \\
\hline \multirow[t]{2}{*}{ IC-4 } & - & - & - & - & - & - & - & - & & & & & \\
\hline & 420 & 128.0 & 450 & 137.2 & & & & & 0.9 & 2.1 & 80 & 90 & \\
\hline \multirow[t]{2}{*}{ IC-5 } & 500 & 152.4 & 520 & 158.5 & 7 & 8 & 90 & 90 & & & & & Metal Debris \\
\hline & 550 & 167.7 & 570 & 173.8 & & & & & 1.2 & 1.2 & 80 & 80 & \\
\hline \multirow[t]{2}{*}{ IC-6 } & 880 & 268.3 & 880 & 268.3 & 6.5 & 6.5 & 80 & 80 & & & & & \\
\hline & 860 & 262.2 & 870 & 265.2 & & & & & 1 & 1.1 & 80 & 80 & \\
\hline \multirow[t]{2}{*}{ IC-7 } & 940 & 286.6 & 940 & 286.6 & 10 & 10 & 99 & 99 & & & & & Metal Debris \\
\hline & 920 & 280.5 & 920 & 280.5 & & & & & 1.8 & 1.8 & 95 & 95 & \\
\hline \multirow[t]{2}{*}{ IC-8 } & - & - & - & - & - & - & - & - & & & & & \\
\hline & 1020 & 311.0 & 1030 & 314.0 & & & & & 0.9 & 1.8 & 80 & 90 & \\
\hline \multirow[t]{2}{*}{ IC-9 } & 1060 & 323.2 & 1210 & 368.9 & 6.5 & 10 & 80 & 99 & & & & & Bridge/Metal Debris \\
\hline & 1150 & 350.6 & 1220 & 372.0 & & & & & 1.2 & 15 & & & Bridge/Metal Debris \\
\hline \multirow[t]{2}{*}{ IC-10 } & 1410 & 429.9 & 1450 & 442.1 & 6.5 & 9.5 & 80 & 99 & & & & & Metal Debris \\
\hline & - & - & - & - & & & & & - & - & - & - & \\
\hline \multirow[t]{2}{*}{ IC-11 } & 1490 & 454.3 & 1550 & 472.6 & 6.5 & 7 & 80 & 90 & & & & & Electric Lines \\
\hline & 1490 & 454.3 & 1490 & 454.3 & & & & & 1.4 & 1.4 & 80 & 80 & Electric Lines \\
\hline \multirow[t]{2}{*}{ IC-12 } & 1570 & 478.7 & 1590 & 484.8 & 6.5 & 7.5 & 80 & 90 & & & & & Metal Debris \\
\hline & 1570 & 478.7 & 1580 & 481.7 & & & & & 4.1 & 4.3 & & & Metal Debris \\
\hline \multirow[t]{2}{*}{ IC-13 } & 1760 & 536.6 & 1760 & 536.6 & 7 & 7 & 90 & 90 & & & & & \\
\hline & 1700 & 518.3 & 1700 & 518.3 & & & & & 0.9 & 0.9 & 80 & 80 & \\
\hline IC-14 & - & - & - & - & - & - & - & - & & & & & \\
\hline & 2060 & 628.0 & 2140 & 652.4 & & & & & 0.9 & 1 & 80 & 80 & Tributary/Fracture \\
\hline IC-15 & 2200 & 670.7 & 2220 & 676.8 & 8.5 & 8.5 & 95 & 95 & & & & & Metal Debris \\
\hline & - & - & - & - & & & & & - & - & - & - & \\
\hline IC-16 & - & - & - & - & - & - & - & - & & & & & \\
\hline & 2280 & 695.1 & 2480 & 756.1 & & & & & 95 & 6.3 & 80 & 95 & Electric Lines \\
\hline
\end{tabular}


Table 6: Significant Geophysical Anomalies

For West Fork, WV

\begin{tabular}{|c|c|c|c|c|c|c|c|c|c|c|c|c|c|}
\hline \multirow{4}{*}{ Anomaly ID } & \multicolumn{4}{|c|}{ Date of Survey: } & \multicolumn{2}{|c|}{$8 / 10 / 2005$} & & & \multicolumn{2}{|c|}{$1 / 31 / 2006$} & \multicolumn{2}{|c|}{$x^{2}+x^{2}$} & \multirow{4}{*}{$\begin{array}{c}\text { Interference } \\
\text { Description }\end{array}$} \\
\hline & \multirow{2}{*}{\multicolumn{4}{|c|}{\begin{tabular}{l|l}
\multicolumn{2}{c}{ Anomaly Location } \\
From
\end{tabular}}} & \multirow{2}{*}{\multicolumn{2}{|c|}{$\begin{array}{l}\text { Terrain Conductivity } \\
\text { VD (mmhos } / \mathrm{m})\end{array}$}} & \multirow{2}{*}{\multicolumn{2}{|c|}{$\begin{array}{c}\text { TC } \\
\text { (Percentile) }\end{array}$}} & \multirow{2}{*}{\multicolumn{2}{|c|}{$\begin{array}{l}\text { Very Low Frequency } \\
\text { K-H Filtered Data }\end{array}$}} & \multirow{2}{*}{\multicolumn{2}{|c|}{$\begin{array}{l}\text { VLF Significance } \\
\text { (Percentile) }\end{array}$}} & \\
\hline & & & & & & & & & & & & & \\
\hline & Feet & Meters & Feet & Meters & \multicolumn{2}{|l|}{ From } & \multicolumn{2}{|c|}{ From To } & \multicolumn{2}{|c|}{ From $\quad$ To } & \multicolumn{2}{|c|}{ From To } & \\
\hline \multirow[t]{2}{*}{ WF-1 } & - & - & - & - & - & - & - & - & & & & & \\
\hline & 160 & 48.8 & 160 & 48.8 & & & & & 1.3 & 1.3 & 80 & 80 & \\
\hline \multirow[t]{2}{*}{ WF-2 } & 370 & 112.8 & 490 & 149.4 & \multicolumn{2}{|c|}{ No Data Collected } & - & - & & & & & Dead Battery \\
\hline & 450 & 137.2 & 450 & 137.2 & & & & & 1.2 & 1.2 & 80 & 80 & \\
\hline \multirow[t]{2}{*}{ WF-3 } & - & - & - & - & - & - & - & - & & & & & \\
\hline & 530 & 161.6 & 560 & 170.7 & & & & & 1.3 & 2 & 80 & 90 & \\
\hline \multirow[t]{2}{*}{ WF-4 } & 670 & 204.3 & 860 & 262.2 & 7 & 13 & 80 & 90 & & & & & Metal Pipeline \\
\hline & 740 & 225.6 & 860 & 262.2 & & & & & 1.7 & 7.2 & 90 & 99 & Metal Pipeline \\
\hline \multirow[t]{2}{*}{ WF-5 } & 880 & 268.3 & 910 & 277.4 & 8 & 8.5 & 80 & 80 & & & & & \\
\hline & - & - & - & - & & & & & - & - & - & - & \\
\hline WF-6 & - & - & - & - & - & - & - & - & & & & & \\
\hline & 940 & 286.6 & 940 & 286.6 & & & & & 2.3 & 2.3 & 90 & 90 & \\
\hline WF-7 & - & - & - & - & & & & & & & & & \\
\hline & 990 & 301.8 & 990 & 301.8 & & & & & 1.6 & 1.6 & 80 & 80 & \\
\hline WF-8 & - & - & - & - & - & - & - & - & & & & & \\
\hline & 1150 & 350.6 & 1180 & 359.8 & & & & & 1.2 & 2.1 & 80 & 90 & \\
\hline WF-9 & 1230 & 375.0 & 1230 & 375.0 & 7 & 7 & 80 & 80 & & & & & \\
\hline & 1250 & 381.1 & 1280 & 390.2 & & & & & 1.5 & 1.7 & 80 & 90 & Metal Debris \\
\hline WF-10 & 1310 & 399.4 & 1520 & 463.4 & 7 & 15 & 80 & 95 & & & & & Metal Pipeline \\
\hline & 1370 & 417.7 & 1540 & 469.5 & & & & & 1.2 & 4.2 & 80 & 95 & Metal Pipeline \\
\hline WF-11 & 1610 & 490.9 & 1820 & 554.9 & 7 & 10.5 & 80 & 90 & & & & & \\
\hline & 1600 & 487.8 & 1780 & 542.7 & & & & & 1.6 & 2.7 & 80 & 95 & \\
\hline WF-12 & 1890 & 576.2 & 2040 & 622.0 & 7 & 21 & 80 & 99 & & & & & Metal Pipeline \\
\hline & 1980 & 603.7 & 2130 & 649.4 & & & & & 3.1 & 4.7 & 95 & 95 & Metal Pipeline \\
\hline WF-13 & - & - & - & - & - & - & - & - & & & & & \\
\hline & 2220 & 676.8 & 2220 & 676.8 & & & & & 1.1 & 1.1 & 80 & 80 & \\
\hline WF-14 & 2270 & 692.1 & 2500 & 762.2 & 7.5 & 19 & 80 & 99 & & & & & Metal Pipeline \\
\hline & 2330 & 710.4 & 2570 & 783.5 & & & & & 0.9 & 56.9 & 80 & 99 & Metal Pipeline \\
\hline WF-15 & - & - & - & - & - & - & - & - & & & & & \\
\hline & 2640 & 804.9 & 2780 & 847.6 & & & & & 0.9 & 2.4 & 80 & 95 & \\
\hline WF-16 & - & - & - & - & - & - & - & - & & & & & \\
\hline & 2910 & 887.2 & 2910 & 887.2 & & & & & 1.3 & 1.3 & 80 & 80 & \\
\hline WF-17 & - & - & - & - & - & - & - & - & & & & & \\
\hline & 2990 & 911.6 & 3110 & 948.2 & & & & & 1.0 & 1.3 & 80 & 80 & \\
\hline
\end{tabular}


Table 6 (continued): Significant Geophysical Anomalies for West Fork, WV

\begin{tabular}{|c|c|c|c|c|c|c|c|c|c|c|c|c|c|}
\hline \multirow{4}{*}{ Anomaly ID } & \multicolumn{4}{|c|}{ Date of Survey: } & \multicolumn{2}{|c|}{$8 / 10 / 2005$} & & & \multicolumn{2}{|c|}{$1 / 31 / 2006$} & \multicolumn{2}{|c|}{ 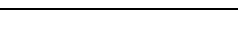 } & \multirow{3}{*}{$\begin{array}{c}\text { Interference } \\
\text { Description }\end{array}$} \\
\hline & \multirow{2}{*}{\multicolumn{4}{|c|}{\begin{tabular}{l|l}
\multicolumn{2}{c}{ Anomaly Location } \\
From
\end{tabular}}} & \multirow{2}{*}{\multicolumn{2}{|c|}{$\begin{array}{l}\text { Terrain Conductivity } \\
\text { VD (mmhos } / \mathrm{m})\end{array}$}} & \multirow{2}{*}{\multicolumn{2}{|c|}{$\begin{array}{c}\text { TC } \\
\text { (Percentile) }\end{array}$}} & \multirow{2}{*}{\multicolumn{2}{|c|}{$\begin{array}{l}\text { Very Low Frequency } \\
\text { K-H Filtered Data }\end{array}$}} & \multirow{2}{*}{\multicolumn{2}{|c|}{$\begin{array}{l}\text { VLF Significance } \\
\text { (Percentile) }\end{array}$}} & \\
\hline & & & & & & & & & & & & & \\
\hline & Feet & Meters & Feet & Meters & From & To & From & To & From & To & From & To & \\
\hline \multirow[t]{2}{*}{ WF-18 } & 3170 & 966.5 & 3250 & 990.9 & 7.0 & 7 & 80 & 80 & & & & & \\
\hline & 3210 & 978.7 & 3390 & 1033.5 & & & & & 0.9 & 2.5 & 80 & 95 & \\
\hline \multirow[t]{2}{*}{ WF-19 } & - & - & - & - & - & - & - & - & & & & & \\
\hline & 3480 & 1061.0 & 3510 & 1070.1 & & & & & 0.9 & 0.9 & 80 & 80 & \\
\hline \multirow[t]{2}{*}{ WF-20 } & 3590 & 1094.5 & 3620 & 1103.7 & 7 & 16 & 80 & 95 & & & & & Metal Culverts \\
\hline & 3580 & 1091.5 & 3650 & 1112.8 & & & & & 1.0 & 2.4 & 80 & 95 & \\
\hline \multirow[t]{2}{*}{ WF-21 } & - & - & - & - & - & - & - & - & & & & & \\
\hline & 4010 & 1222.6 & 4039 & 1231.4 & & & & & 1.1 & 1.3 & 80 & 80 & \\
\hline
\end{tabular}


Appendix IV

Stream Sediment Table 
Table 1: Stream Sediment Table

\begin{tabular}{|c|c|c|c|c|c|c|c|c|c|c|c|c|c|c|}
\hline \multirow[b]{2}{*}{ Stream } & & & & & \multicolumn{4}{|c|}{ Sediment Particle Size } & \multicolumn{3}{|c|}{ Alluvial Thickness } & \multirow[b]{2}{*}{ Alluvial } & \multirow[b]{2}{*}{ Reach } & \multirow[b]{2}{*}{ Control } \\
\hline & & Station & Station & Pool & & & & Date & Avg. Thick & Date & & & & \\
\hline Name & State & ID & Distance & Riffle & $D_{50}$ & $\Phi_{50}$ & $\Phi_{84}$ & Measured & $(\mathrm{ft})$ & Measured & Avg & Descripter & Descripter & Reach \\
\hline Crabapple & $\mathrm{OH}$ & $1 \mathrm{~A}$ & -500 & Riffle & \multicolumn{2}{|c|}{ Coal/LS } & & $5 / 23 / 2006$ & 0.1 & $5 / 23 / 2006$ & & Coal/LS BR & Gate & \\
\hline Crabapple & $\mathrm{OH}$ & $1 \mathrm{~B}$ & 140 & Riffle & \multicolumn{2}{|c|}{ Coal Bedrock } & & $5 / 23 / 2006$ & 0.2 & $5 / 23 / 2006$ & & Coal BR & Midpanel & \\
\hline Crabapple & $\mathrm{OH}$ & $2 \mathrm{~B}$ & 590 & Pool & 18.8 & -4.2 & & $5 / 23 / 2006$ & 1.1 & $5 / 23 / 2006$ & & Gravel/Cobble & Gate & \\
\hline Crabapple & $\mathrm{OH}$ & $3 A$ & 900 & Riffle & \multicolumn{2}{|c|}{$\begin{array}{l}\text { Sandstone } \\
\text { Bedrock }\end{array}$} & & $5 / 23 / 2006$ & 0.0 & $5 / 23 / 2006$ & & Sandstone BR & Quarterpanel & \\
\hline Crabapple & $\mathrm{OH}$ & $3 B$ & 1060 & Riffle & & & & - & 0.0 & - & & & & \\
\hline Crabapple & $\mathrm{OH}$ & $4 \mathrm{~A}$ & 1100 & Pool & & & & - & 0.1 & - & & & & \\
\hline Crabapple & $\mathrm{OH}$ & $4 \mathrm{~B}$ & 1230 & Pool & 7.3 & -2.9 & & $5 / 23 / 2006$ & 0.2 & $5 / 23 / 2006$ & & Sand/ssBrock & Midpanel & \\
\hline Crabapple & $\mathrm{OH}$ & $5 \mathrm{~A}$ & 1720 & Pool & \multicolumn{2}{|c|}{$\begin{array}{l}\text { Sandstone } \\
\text { Bedrock }\end{array}$} & & $5 / 23 / 2006$ & 0.0 & $5 / 23 / 2006$ & & SS Brock & Gate & \\
\hline Crabapple & $\mathrm{OH}$ & $5 \mathrm{~B}$ & 1800 & Riffle & \multicolumn{2}{|c|}{$\begin{array}{c}\text { Sandstone } \\
\text { Bedrock }\end{array}$} & & $5 / 24 / 2006$ & 0.0 & $5 / 24 / 2006$ & & SS Brock & Quarterpanel & \\
\hline avg & & & & & & & & & & & 0.2 & & & \\
\hline Williams & $\mathrm{OH}$ & 1 & 30 & Pool & \multicolumn{2}{|c|}{$\begin{array}{c}\text { Sandstone } \\
\text { Bedrock }\end{array}$} & & $5 / 24 / 2006$ & 0.0 & $5 / 24 / 2006$ & & SS Bedrock & Room/Pillar & $x$ \\
\hline Williams & $\mathrm{OH}$ & 2 & 500 & Riffle & 21.6 & -4.4 & & $5 / 24 / 2006$ & 2.0 & $5 / 24 / 2006$ & & Gravels/grey clay & Solid Coal & $x$ \\
\hline Williams & $\mathrm{OH}$ & 3 & 1100 & Riffle & & & & & 2.6 & $5 / 24 / 2006$ & & Gravel & Quarterpanel & \\
\hline Williams & $\mathrm{OH}$ & $4 \mathrm{~A}$ & 1610 & Riffle & 34.0 & -5.1 & & $5 / 24 / 2006$ & 1.1 & $5 / 24 / 2006$ & & Gravel/Cobble & Midpanel & \\
\hline Williams & $\mathrm{OH}$ & $4 \mathrm{~B}$ & 1940 & Pool & & & & & 1.2 & $5 / 24 / 2006$ & & Gravel over clay & Gate & \\
\hline Williams & $\mathrm{OH}$ & 5 & 2250 & Riffle & \multicolumn{2}{|c|}{$\begin{array}{c}\text { Claystone } \\
\text { Bedrock }\end{array}$} & & $5 / 24 / 2006$ & 0.1 & $5 / 24 / 2006$ & & Claystone BR & Quarterpanel & \\
\hline avg & & & & & & & & & & & 1.2 & & & \\
\hline Stream F & PA & 1 & 75 & Pool & 2.3 & -1.2 & & $8 / 19 / 2006$ & 2.0 & $5 / 5 / 2006$ & & Silt/Sand & Solid Coal & $x$ \\
\hline Stream F & PA & $2 A$ & 440 & Riffle & & & & & 2.2 & $5 / 5 / 2006$ & & Sand Gravel & Solid Coal & $x$ \\
\hline Stream F & PA & $2 \mathrm{~B}$ & 760 & Riffle & & & & & 0.8 & $5 / 5 / 2006$ & & Gravel/Clay & Solid Coal & $x$ \\
\hline Stream F & $\mathrm{PA}$ & $3 A$ & 1120 & Riffle & & & & & 1.2 & $5 / 5 / 2006$ & & Gravel/Cobble & Quarterpanel & \\
\hline Stream $\mathrm{F}$ & PA & $3 \mathrm{~B}$ & 1520 & Pool & 8.6 & -3.1 & & $8 / 19 / 2006$ & 2.0 & $5 / 5 / 2006$ & & Silt/Sand & Midpanel & \\
\hline Stream F & PA & 4 & 2610 & Pool & 1.4 & -0.5 & & $8 / 19 / 2006$ & 3.3 & $5 / 5 / 2006$ & & Silt/Sand & Quarterpanel & \\
\hline Stream F & PA & 5 & 2945 & Pool & 1.5 & -0.5 & & $8 / 19 / 2006$ & 0.8 & $5 / 5 / 2006$ & & Silt/Sand & Gate & \\
\hline Stream F & PA & $6 \mathrm{~A}$ & 3040 & Riffle & & & & & 1.2 & $5 / 5 / 2006$ & & Sand & Gate & \\
\hline Stream F & PA & $6 \mathrm{~B}$ & 3250 & Riffle & & & & & 3.1 & $5 / 5 / 2006$ & & Sand & Quarterpanel & \\
\hline avg & & & & & & & & & & & 1.8 & & & \\
\hline
\end{tabular}


Table 1 (continued): Stream Sediment Table

\begin{tabular}{|c|c|c|c|c|c|c|c|c|c|c|c|c|c|}
\hline Templeton & $\mathrm{PA}$ & $1 \mathrm{~A}$ & -1500 & Pool & & & & 1.1 & $6 / 25 / 2005$ & & Sand/Gravel & Solid Coal & $\mathrm{x}$ \\
\hline Templeton & $\mathrm{PA}$ & $1 \mathrm{~B}$ & 55 & Riffle & 35.8 & -5.2 & $8 / 19 / 06$ & 1.4 & $6 / 25 / 2005$ & & Gravel/Cobble & Solid Coal & $\mathrm{x}$ \\
\hline Templeton & $\mathrm{PA}$ & 2 & 595 & Pool & & & & 1.6 & $6 / 25 / 2005$ & & Sand/Gravel & Solid Coal & $x$ \\
\hline Templeton & PA & 3 & 710 & Riffle & & & & 1.3 & $6 / 25 / 2005$ & & Gravel & Solid Coal & $x$ \\
\hline Templeton & PA & 4 & 800 & Riffle & \multicolumn{2}{|c|}{$\begin{array}{c}\text { Claystone } \\
\text { Bedrock }\end{array}$} & $6 / 25 / 06$ & 0.1 & $6 / 25 / 2005$ & & Sand over Clay & Solid Coal & $\mathrm{x}$ \\
\hline Templeton & PA & 5 & 985 & Riffle & & & & 0.8 & $6 / 25 / 2005$ & & Gravel/Cobble & Quarterpanel & \\
\hline Templeton & $\mathrm{PA}$ & 6 & 1240 & Riffle & & & & 2.2 & $6 / 25 / 2005$ & & Sand/ Gravel over & Quarterpanel & \\
\hline Templeton & $\mathrm{PA}$ & 7 & 1595 & Pool & & & & 1.3 & $6 / 25 / 2005$ & & Sand /Gravel & Midpanel & \\
\hline Templeton & PA & 8 & 2000 & Pool & 5.9 & -2.6 & $8 / 19 / 06$ & 1.7 & $6 / 25 / 2005$ & & Sand/Gravl & Quarterpanel & \\
\hline Templeton & PA & 9 & 2440 & Riffle & & & & 0.7 & $6 / 25 / 2005$ & & Riprap/Grey Clay & Gate & \\
\hline avg & & & & & & & & & & 1.2 & & & \\
\hline Island Creek & WV & $1 \mathrm{~A}$ & -2500 & Riffle & & & & 1.5 & $5 / 4 / 2006$ & & Sand/Cobble & Room/Pillar & $x$ \\
\hline Island Creek & WV & 1B & -960 & Riffle & \multicolumn{2}{|c|}{$\begin{array}{c}\text { Sandstone } \\
\text { Bedrock }\end{array}$} & $5 / 21 / 2006$ & 0.1 & $5 / 4 / 2006$ & & Sandstone BR & Solid Coal & $\mathrm{x}$ \\
\hline Island Creek & WV & 2 & -640 & Riffle & 52.6 & -5.7 & $5 / 21 / 2006$ & 1.0 & $5 / 4 / 2006$ & & Sand/Gravel & Panel & \\
\hline Island Creek & WV & 3 & 0 & Riffle & & & & 2.0 & $5 / 4 / 2006$ & & Sand/Gravel & Gate & $x$ \\
\hline Island Creek & WV & 4 & 480 & Riffle & 50.6 & -5.7 & $5 / 21 / 2006$ & 1.8 & $5 / 4 / 2006$ & & Sand/Gravel & Gate & $x$ \\
\hline Island Creek & WV & $5 A$ & 1080 & Pool & & & & 1.0 & $5 / 4 / 2006$ & & Gravel/Cobbles & Quarterpanel & \\
\hline Island Creek & WV & $5 B$ & 1710 & Riffle & & & & 1.4 & $5 / 21 / 2006$ * & & Gravel/Cobbles & Midpanel & \\
\hline Island Creek & WV & $6 \mathrm{~A}$ & 1810 & Riffle & 32.7 & 1.0 & $5 / 21 / 2006$ & 1.8 & $5 / 4 / 2006$ & & Gravel/Cobbles & Midpanel & \\
\hline Island Creek & WV & $6 \mathrm{~B}$ & 2060 & Riffle & & & & 0.5 & $5 / 4 / 2006$ & & Sand/Gravel & Quarterpanel & \\
\hline Island Creek & WV & 7 & 2600 & Riffle & & & & 1.2 & $5 / 4 / 2006$ & & Gravel/Boulders & Solid Coal & \\
\hline avg & & & & & & & & & & 1.2 & & & \\
\hline West Fork & WV & 1 & b & Riffle & \multicolumn{2}{|c|}{$\begin{array}{c}\text { Sandstone } \\
\text { Bedrock }\end{array}$} & $5 / 20 / 2006$ & 0.1 & $5 / 3 / 2006$ & & Sandstone BR & Solid Coal & $\mathrm{x}$ \\
\hline West Fork & WV & 2 & 450 & Riffle & & & & 0.8 & $5 / 3 / 2006$ & & Gravel & Solid Coal & $x$ \\
\hline West Fork & WV & 3 & 690 & Riffle & \multicolumn{2}{|c|}{$\begin{array}{c}\text { Sandstone } \\
\text { Bedrock }\end{array}$} & $5 / 20 / 2006$ & 0.0 & $5 / 3 / 2006$ & & Sandstone BR & Solid Coal & $\mathrm{x}$ \\
\hline West Fork & WV & 4 & 890 & Riffle & & & & 1.3 & $5 / 3 / 2006$ & & Cobble & Quarterpanel & \\
\hline West Fork & WV & 5 & 1180 & Riffle & 53.8 & -5.8 & $5 / 20 / 2006$ & 1.2 & $5 / 3 / 2006$ & & Gravel & Quarterpanel & \\
\hline West Fork & WV & 6 & 1510 & Riffle & & & & 0.8 & $5 / 3 / 2006$ & & Boulder & Midpanel & \\
\hline West Fork & WV & 7 & 1800 & Riffle & 34.4 & -5.1 & $5 / 20 / 2006$ & 1.5 & $5 / 3 / 2006$ & & Cobble & Midpanel & \\
\hline West Fork & WV & 8 & 2250 & Riffle & & & & 0.8 & $5 / 3 / 2006$ & & Cobble & Midpanel & \\
\hline West Fork & WV & $9 A$ & 2330 & Riffle & 64.4 & -6.0 & $5 / 20 / 2006$ & 0.6 & $5 / 3 / 2006$ & & Gravel & Midpanel & \\
\hline West Fork & WV & $9 \mathrm{~B}$ & 3550 & Riffle & & & & 1.9 & $3 / 4 / 2007$ & & Gravel & Quarterpanel & \\
\hline West Fork & WV & 10 & 10500 & Riffle & & & & 1.0 & $5 / 3 / 2006$ & & Cobble & Quarterpanel & \\
\hline West Fork & WV & 11 & 11300 & Riffle & & & & 0.9 & $5 / 3 / 2006$ & & Cobble & Solid Coal & \\
\hline avg & & & & & & & & & & 0.8 & & & \\
\hline
\end{tabular}




\section{Appendix V}

\section{Stream Survey and}

Mining Sequence Tables 
Table 1: Survey Sequence Table

\begin{tabular}{|c|c|c|c|c|c|c|c|}
\hline \multicolumn{2}{|l|}{$\underline{\text { Stream ID }}$} & \multicolumn{2}{|c|}{$\underline{\text { Geophysical Measurements }}$} & \multicolumn{2}{|c|}{$\underline{\text { Stream Flow Measurements }}$} & \multicolumn{2}{|c|}{ Alluvial Measurements } \\
\hline Stream Name & State & Terrain Conduct. & VLF & High Flow & Low Flow & Thickness & Particle Analysis \\
\hline Crabapple Creek & $\mathrm{OH}$ & $5 / 12 / 2005$ & $5 / 12 / 2005$ & - & $6 / 26 / 2005$ & - & - \\
\hline (ELF) & & $1 / 26 / 2006$ & $1 / 26 / 2006$ & $2 / 2 / 2006$ & $5 / 23 / 2006$ & $5 / 23 / 2006$ & $5 / 23 / 2006$ \\
\hline Williams Creek & $\mathrm{OH}$ & $8 / 2 / 2005$ & $8 / 2 / 2005$ & $1 / 27 / 2006$ & $5 / 24 / 2006$ & $5 / 24 / 2006$ & $5 / 24 / 2006$ \\
\hline Stream F & $\mathrm{PA}$ & $5 / 14 / 2005$ & $5 / 14 / 2005$ & $1 / 28 / 2006$ & $5 / 5 / 2006$ & $5 / 5 / 2006$ & $8 / 18 / 2006$ \\
\hline Templeton Fork & PA & $6 / 26 / 2005$ & $4 / 1 / 2005^{\star}$ & $5 / 7 / 2005$ & $6 / 25 / 2005$ & $6 / 25 / 2005$ & $8 / 19 / 2006$ \\
\hline Island Creek & WV & $8 / 5 / 2005$ & $8 / 5 / 2005$ & $1 / 30 / 2006$ & $5 / 4 / 2006$ & $5 / 4 / 2006$ & $5 / 21 / 2006$ \\
\hline West Fork & WV & $8 / 10 / 2005$ & $1 / 31 / 2006$ & $3 / 4 / 2007$ & $5 / 3 / 2006$ & $5 / 3 / 2006$ & $5 / 20 / 2006$ \\
\hline
\end{tabular}

Table 2: Mining Sequence Table

\begin{tabular}{|c|c|c|c|c|}
\hline \multicolumn{2}{|c|}{$\underline{\text { Stream ID }}$} & \multirow{2}{*}{$\begin{array}{l}\text { Coal Seam } \\
\text { Mined }\end{array}$} & \multirow{2}{*}{$\begin{array}{l}\text { Panel } \\
\text { ID }\end{array}$} & \multirow{2}{*}{$\begin{array}{c}\text { Panel @ Creek } \\
\mathrm{Mo} / \mathrm{Yr}\end{array}$} \\
\hline Stream Name & State & & & \\
\hline \multirow[t]{3}{*}{ Crabapple Creek } & $\mathrm{OH}$ & Pittsburgh & 7-East & \\
\hline & & Pittsburgh & 8-East & Feb-05 \\
\hline & & Pittsburgh & 9-East & Aug-05 \\
\hline \multirow[t]{2}{*}{ Williams Creek } & $\mathrm{OH}$ & Pittsburgh & 20-East & Dec-96 \\
\hline & & Pittsburgh & 21-East & May-97 \\
\hline \multirow[t]{2}{*}{ Stream F } & PA & Pittsburgh & $\mathrm{P}-1$ & Jul-04 \\
\hline & & Pittsburgh & $\mathrm{P}-2$ & Apr-05 \\
\hline \multirow[t]{3}{*}{ Templeton Fork } & $\mathrm{PA}$ & Pittsburgh & $F-9$ & Mar-04 \\
\hline & & Pittsburgh & $F-10$ & Nov-04 \\
\hline & & Pittsburgh & $\mathrm{F}-11$ & Jun-05 \\
\hline \multirow[t]{2}{*}{ Island Creek } & WV & L. Cedar Grove & $15 \mathrm{LT}$ & Dec-97 \\
\hline & & L. Cedar Grove & $16 \mathrm{LT}$ & May-97 \\
\hline \multirow[t]{3}{*}{ West Fork } & WV & No. 2 Gas & 1 & Apr-90 \\
\hline & & Eagle & 1 & Oct-04 \\
\hline & & Eagle & 2 & Oct-03 \\
\hline
\end{tabular}


Appendix VI

Stream and Coal Mine

Elevation Figures 
Figure 1: Stream and Coal Mine Elevations

Crabapple Creek, $\mathrm{OH}$
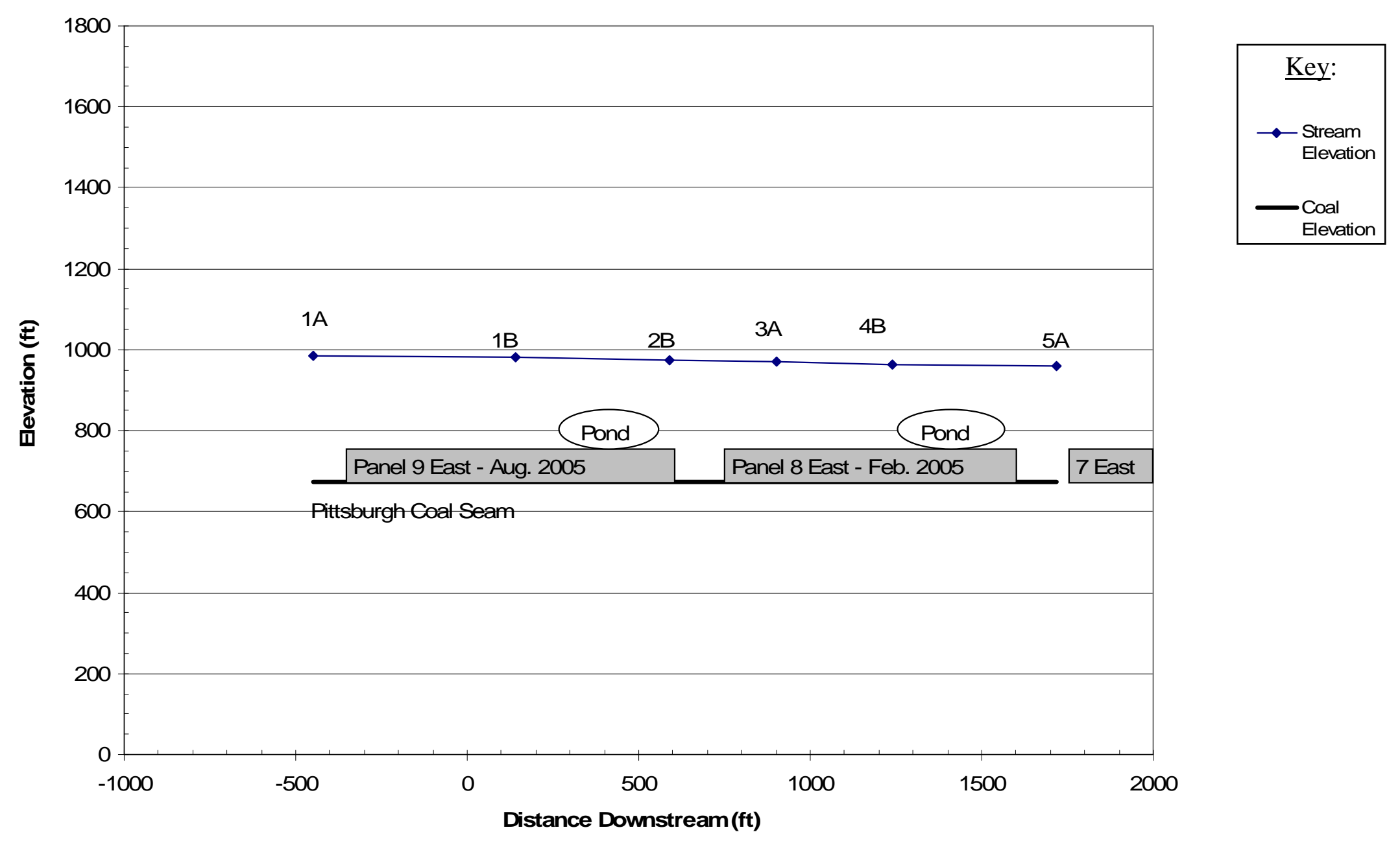
Figure 2: Stream and Coal Mine Flevation Willians Creek, $\mathrm{OH}$

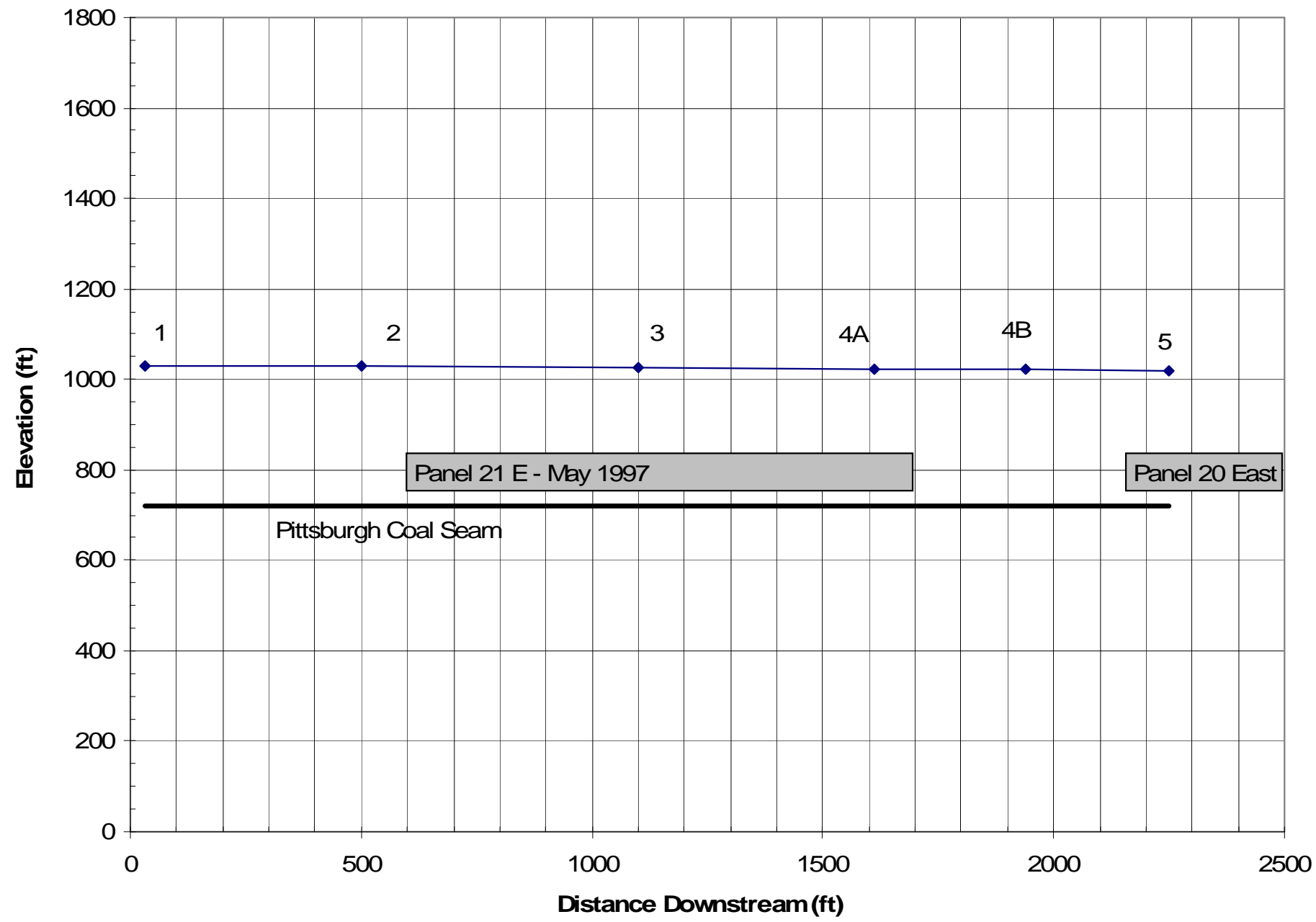


Figure 3: Stream and Coal Mine Elevation Stream F, PA

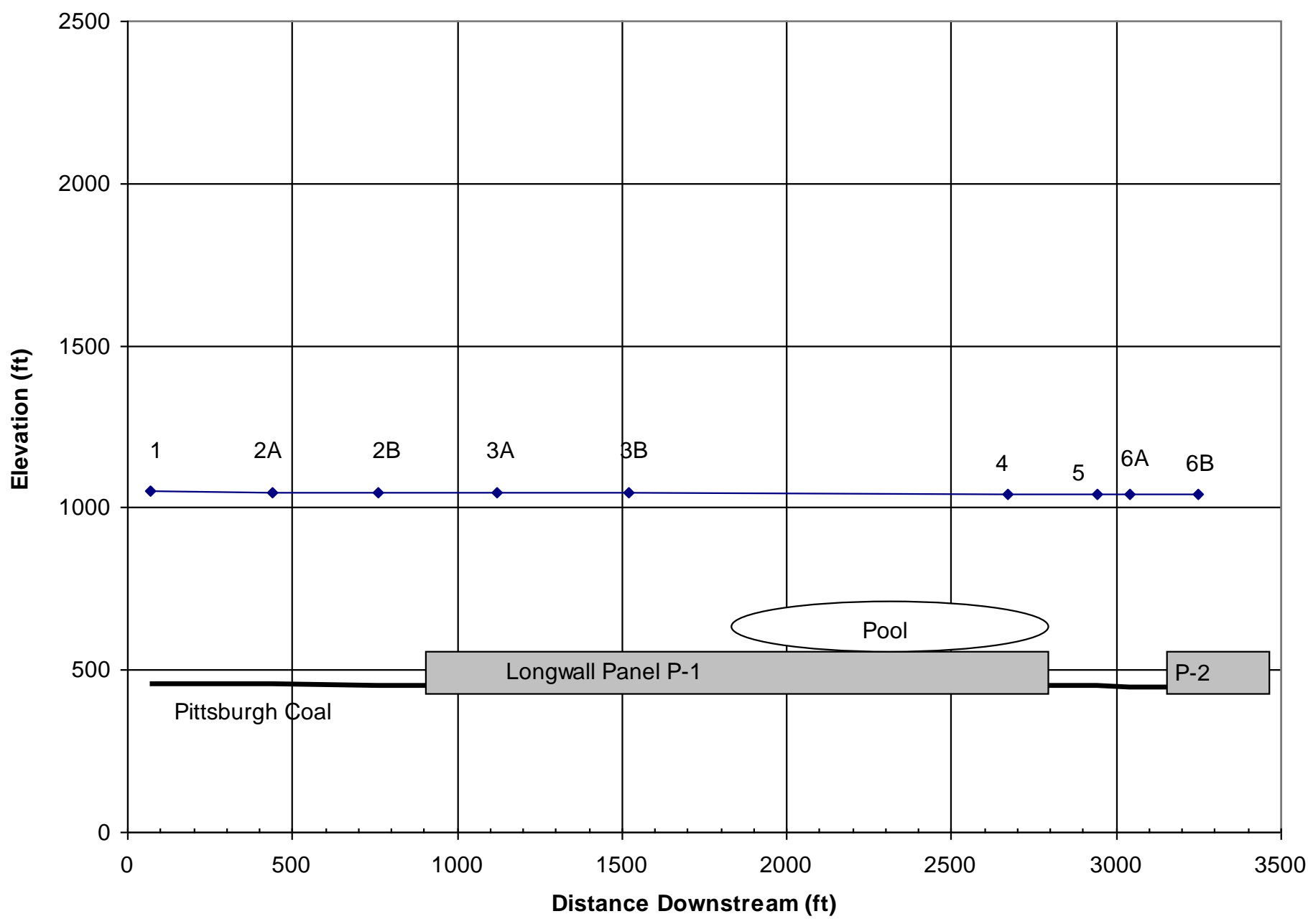


Figure 4: Stream and Coal Mine Elevation

Templeton Fork, PA

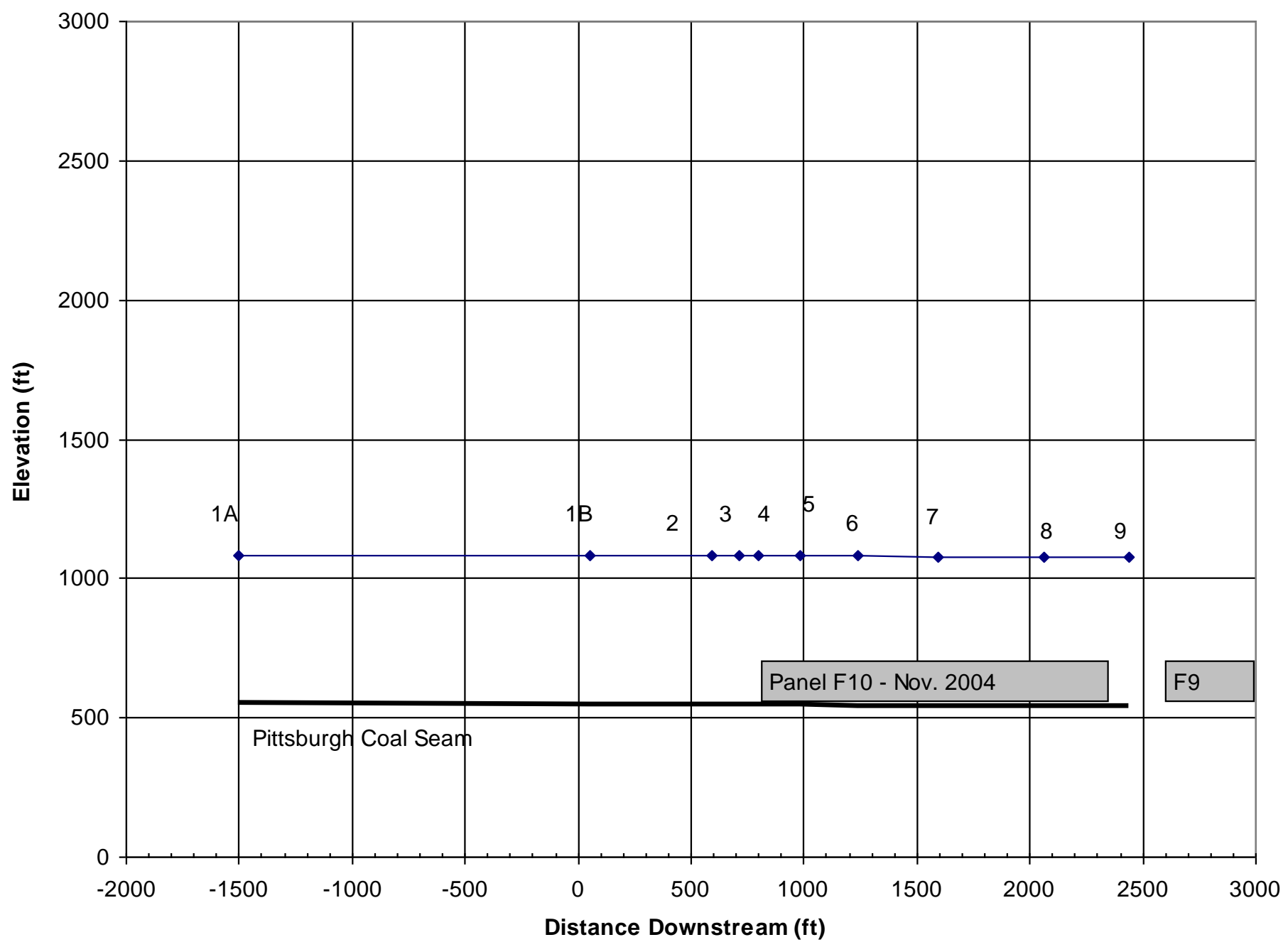

\begin{tabular}{c} 
Key: \\
$\rightarrow$ Stream \\
Elevation \\
Coal \\
Elevation \\
\hline
\end{tabular}


Figure 5: Stream and Coal Mine Elevation

Island Creek, WV

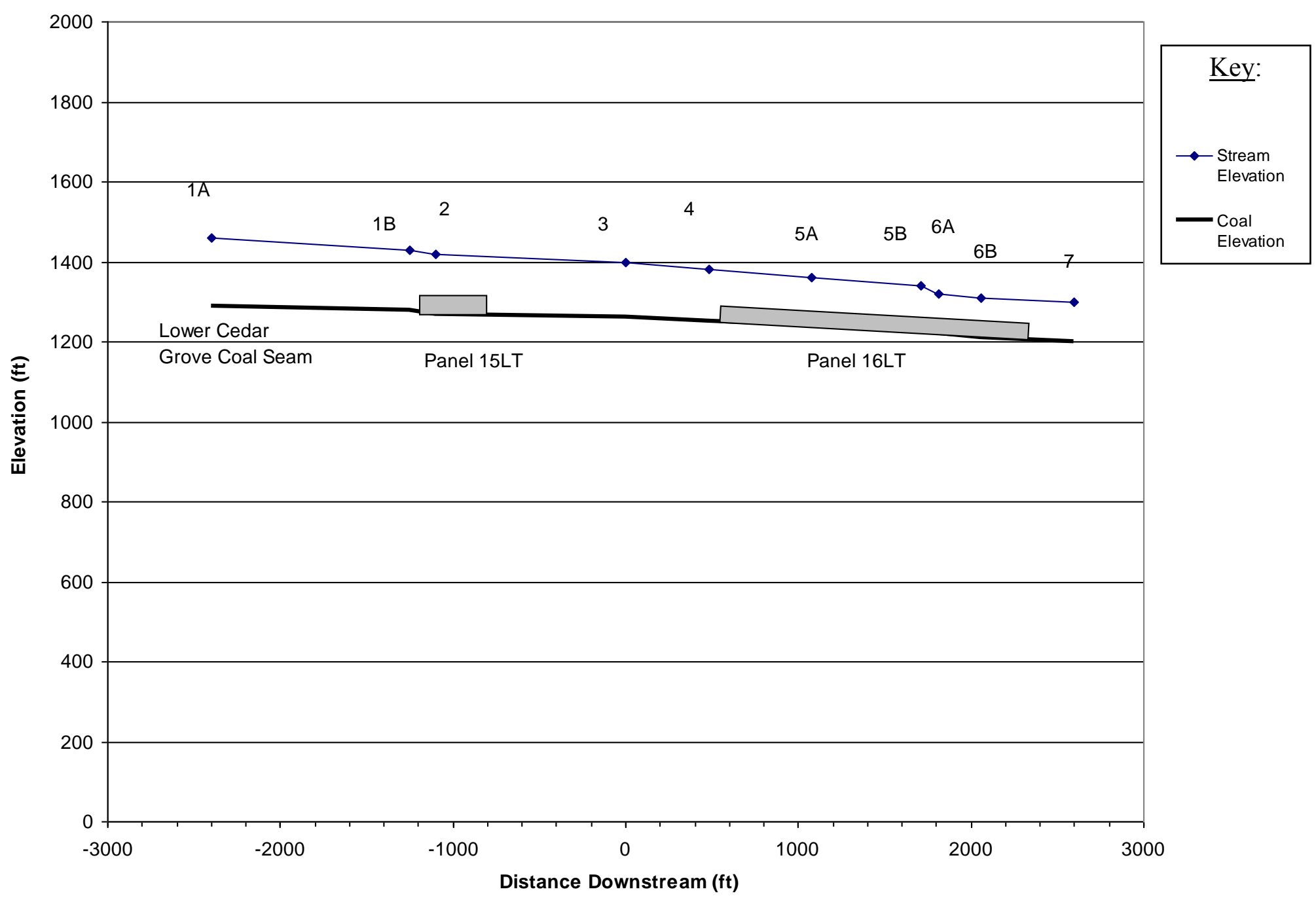


Figure 6: Stream and Coal Mine Elevation

West Fork, WV

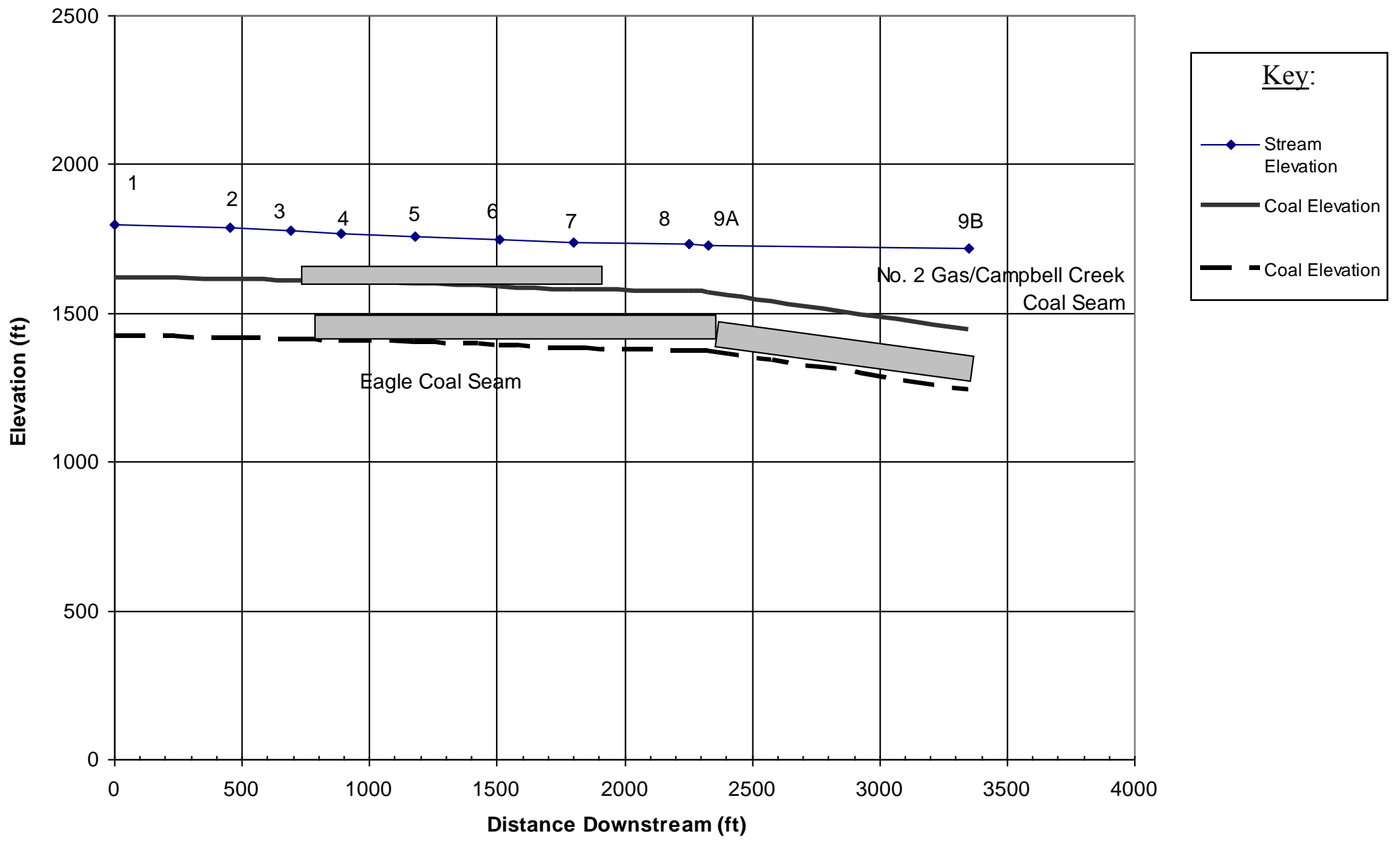


Appendix VII

Geomorphological Channel Classifications for Studied Stream Reaches 


\section{Ohio Stream Geomorphology}

Table 1: Crabapple Creek, $\mathrm{OH}$

Geomorphological Hierarchical Channel Classification

$\begin{gathered}\text { Distance Downstream } \\ \text { (feet) }\end{gathered}$
0 to 200
330 to 350
350 to 560
560 to 850
850 to 1150
1150 to 1620
1620 to 1800

Reach Type
Free-Formed Alluvial
Free-Formed Alluvial
Free-Formed Alluvial
Free-Formed Alluvial
Free-Formed Alluvial
Free-Formed Alluvial
Free-Formed Alluvial

Morphology

Step-Pool

Cascade

Step-Pool ${ }^{*}$

Plane-Bed

Cascade

Step-Pool ${ }^{*}$

Cascade

* $=$ large pool channel unit

\section{Table 2: Williams Creek, $\mathrm{OH}$}

\section{Geomorphological Hierarchical Channel Classification}

\begin{tabular}{|c|}
\hline $\begin{array}{c}\text { Distance Downstream } \\
\text { (feet) } \\
0 \text { to } 100\end{array}$ \\
\hline 100 to 300 \\
\hline $300-400$ \\
\hline $400-900$ \\
\hline 900 to 1700 \\
\hline 1700 to 1850 \\
\hline 1850 to 1950 \\
\hline 1948 to 2150 \\
\hline 2150 to 2300 \\
\hline
\end{tabular}

\author{
Reach Type \\ Free-Formed Alluvial \\ Free-Formed Alluvial \\ Free-Formed Alluvial \\ Free-Formed Alluvial \\ Free-Formed Alluvial \\ Free-Formed Alluvial \\ Free-Formed Alluvial \\ Free-Formed Alluvial \\ Free-Formed Alluvial
}
Morphology
Cascade
Pool-Riffle
Step-Pool
Pool-Riffle
Plane-Bed
Step-Pool
Step-Pool*
Plane-Bed
Plane-Bed

${ }^{*}=$ large pool channel unit 


\section{Pennsylvania Stream Geomorphology}

Table 3: Stream F, PA

Geomorphological Hierarchical Channel Classification

$\begin{gathered}\text { Distance Downstream } \\ \text { (feet) }\end{gathered}$
0 to 700
700 to 1100
1100 to 1800
1800 to 2800
2800 to 3200
3200 to 3300

Reach Type
Free-Formed Alluvial
Free-Formed Alluvial
Free-Formed Alluvial
Free-Formed Alluvial
Free-Formed Alluvial
Free-Formed Alluvial

Morphology

Pool-Riffle

Cascade

Pool-Riffle

Step-Pool*

Plane-Bed ${ }^{* *}$

Cascade

* = large pool channel unit

${ }^{* *}=$ gate cutting reach

\section{Table 4: Templeton Fork, PA}

Geomorphological Hierarchical Channel Classification

$\begin{gathered}\text { Distance Downstream } \\ \text { (feet) }\end{gathered}$
0 to 700
700 to 1000
1000 to 1600
1600 to 2150
2150 to 2700

Reach Type
Free-Formed Alluvial
Free-Formed Alluvial
Free-Formed Alluvial
Free-Formed Alluvial
Free-Formed Alluvial

Morphology

Pool-Riffle

Step-Pool

Pool-Riffle

Step-Pool ${ }^{*}$

Plane-Bed ${ }^{\star *}$ 


\section{West Virginia Stream Geomorphology}

Table 5: Island Creek, WV

Geomorphological Hierarchical Channel Classification

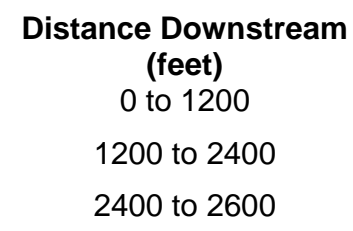

\author{
Reach Type \\ Free-Formed Alluvial \\ Free-Formed Alluvial \\ Free-Formed Alluvial
}

\author{
Morphology \\ Step-Pool \\ Pool-Riffle \\ Step-Pool \\ ${ }^{*}=$ large pool channel unit \\ ${ }^{* *}$ = gate cutting reach
}

Table 6: West Fork, WV

Geomorphological Hierarchical Channel Classification

\begin{tabular}{|c|}
\hline $\begin{array}{c}\text { Distance Downstream } \\
\text { (feet) } \\
0 \text { to } 300\end{array}$ \\
\hline 300 to 500 \\
\hline 500 to 800 \\
\hline 800 to 2200 \\
\hline 2200 to 2350 \\
\hline 2350 to 3200 \\
\hline 3200 to 3400 \\
\hline 3400 to 3800 \\
\hline 3800 to 4000 \\
\hline 4000 to 11300 \\
\hline
\end{tabular}

Reach Type
Free-Formed Alluvial
Free-Formed Alluvial
Free-Formed Alluvial
Free-Formed Alluvial
Free-Formed Alluvial
Free-Formed Alluvial
Free-Formed Alluvial
Free-Formed Alluvial
Free-Formed Alluvial
Free-Formed Alluvial

Morphology

Cascade
Step-Pool
Cascade
Step-Pool
Plane-Bed
Step-Pool
Plane-Bed
Pool-Riffle
Cascade
Step-Pool

* = large pool channel unit

${ }^{* *}=$ gate cutting reach 
Appendix VIII

Particle Size

Distribution Tables 
Table 1: Crabapple Creek, PA

Particle Size Distribution Table

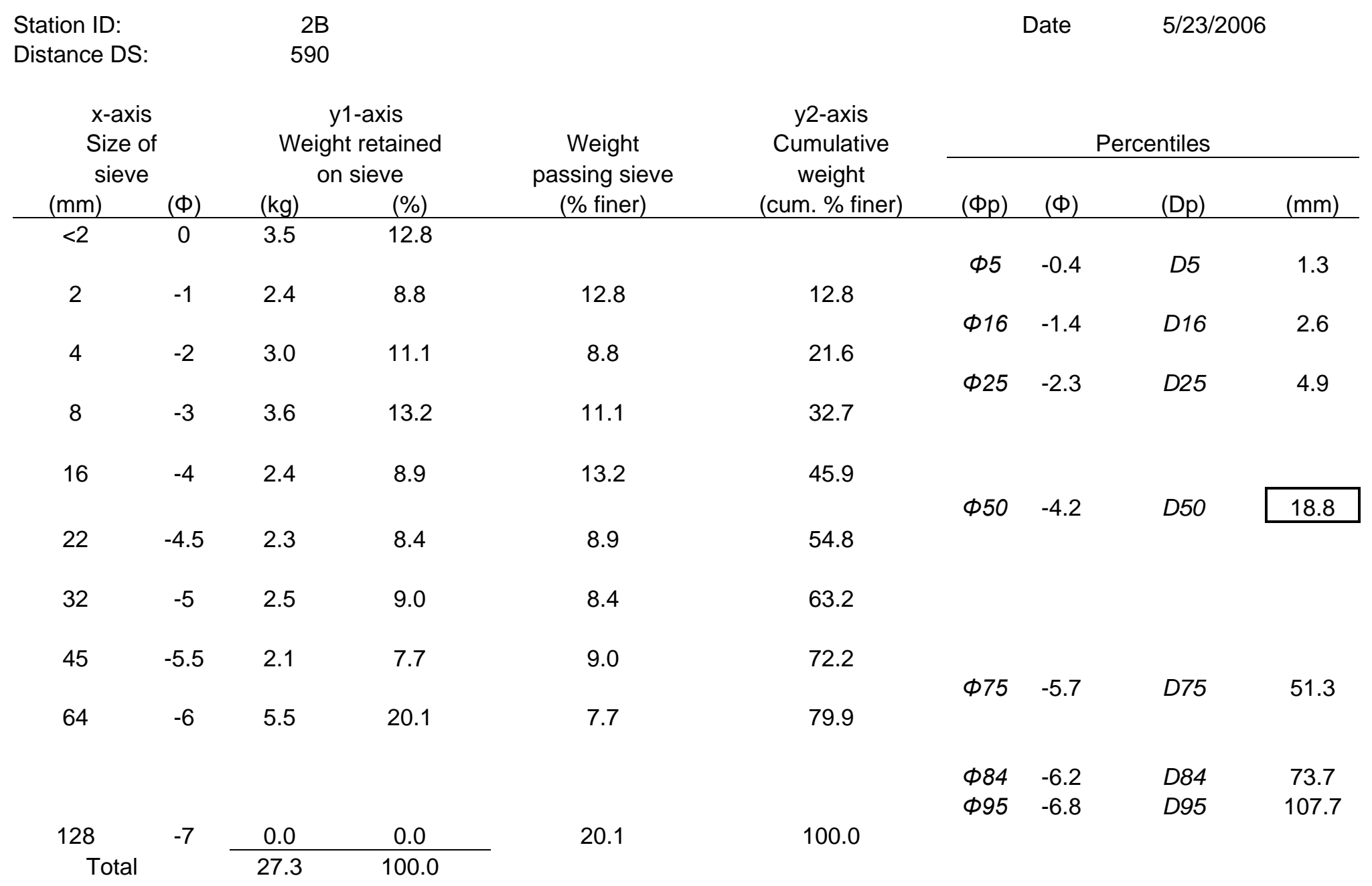

Dmax Surface Particle Intermediate Axis ( $\mathrm{mm})$ : 
Table 2: Crabapple Creek, PA

Particle Size Distribution Table

\begin{tabular}{|c|c|c|c|c|c|c|c|c|c|}
\hline \multirow{3}{*}{\multicolumn{2}{|c|}{$\begin{array}{l}\text { Station ID: } \\
\text { Distance DS: } \\
\\
\text { x-axis } \\
\text { Size of } \\
\text { sieve }\end{array}$}} & \multicolumn{2}{|c|}{$\begin{array}{r}4 \mathrm{~B} \\
1220\end{array}$} & & & \multicolumn{2}{|r|}{ Date } & \multicolumn{2}{|c|}{$5 / 23 / 2006$} \\
\hline & & \multirow{2}{*}{\multicolumn{2}{|c|}{$\begin{array}{c}y 1 \text {-axis } \\
\text { Weight retained } \\
\text { on sieve }\end{array}$}} & \multirow{3}{*}{$\begin{array}{c}\text { Weight } \\
\text { passing sieve } \\
\text { (\% finer) }\end{array}$} & \multirow{3}{*}{$\begin{array}{c}\text { y2-axis } \\
\text { Cumulative } \\
\text { weight } \\
\text { (cum. \% finer) }\end{array}$} & \multirow{2}{*}{\multicolumn{4}{|c|}{ Percentiles }} \\
\hline & & & & & & & & & \\
\hline & $(\Phi)$ & $(\mathrm{kg})$ & $(\%)$ & & & $(\Phi p)$ & $(\Phi)$ & (Dp) & $(\mathrm{mm})$ \\
\hline$<2$ & 0 & 4.0 & 17.4 & & & & & & \\
\hline & & & & & & $\begin{array}{c}\Phi 5 \\
\Phi 16\end{array}$ & $\begin{array}{l}-0.3 \\
-0.9\end{array}$ & $\begin{array}{c}D 5 \\
D 16\end{array}$ & $\begin{array}{l}1.2 \\
1.9\end{array}$ \\
\hline 2 & -1 & 3.6 & 15.5 & 17.4 & 17.4 & & & & \\
\hline 4 & -2 & 45 & 196 & 155 & 32.9 & $\Phi 25$ & -1.5 & $D 25$ & 2.8 \\
\hline 4 & -2 & 4.5 & & 10.5 & 02.5 & $\Phi 50$ & -2.9 & $D 50$ & 7.3 \\
\hline 8 & -3 & 5.7 & 24.8 & 19.6 & 52.5 & Ф75 & -30 & D75 & 150 \\
\hline 16 & -4 & 2.7 & 11.5 & 24.8 & 77.3 & & & & \\
\hline 22 & -4.5 & 1.7 & 7.2 & 11.5 & 88.9 & $\Phi 84$ & -4.3 & $D 84$ & 19.5 \\
\hline 32 & -5 & 0.9 & 3.9 & 7.2 & 96.1 & $\Phi 95$ & -4.9 & D95 & 30.4 \\
\hline 45 & -5.5 & 0.0 & 0.0 & 3.9 & 100.0 & & & & \\
\hline 64 & -6 & 0.0 & 0.0 & 0.0 & 100.0 & & & & \\
\hline 128 & -7 & 0.0 & 0.0 & 0.0 & 100.0 & & & & \\
\hline Tot & & 23.0 & 100.0 & & & & & & \\
\hline
\end{tabular}

Dmax Surface Particle Intermediate Axis (mm): 
Table 3: Williams Creek, $\mathrm{OH}$

Particle Size Distribution Table

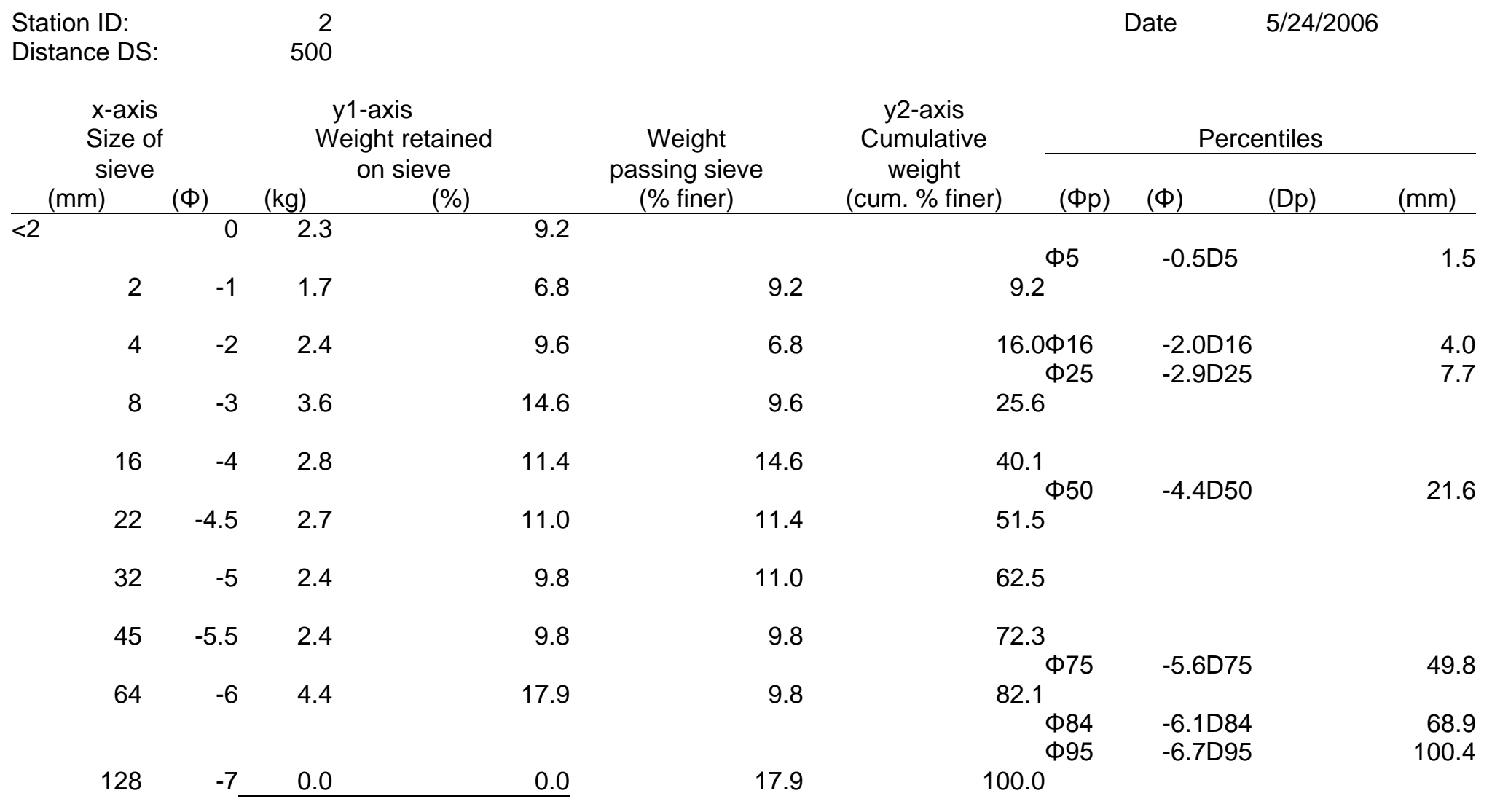

Total

$24.6 \quad 100.0$

Dmax Surface Particle Intermediate Axis (mm): 150 
Table 4: Williams Creek, $\mathrm{OH}$

Particle Size Distribution Table

\begin{tabular}{|c|c|c|c|c|c|c|c|c|c|}
\hline \multirow{4}{*}{$\begin{array}{l}\text { Station ID: } \\
\text { Distance DS: } \\
\\
\text { X-axis } \\
\text { Size of } \\
\text { sieve } \\
(\mathrm{mm})\end{array}$} & \multicolumn{3}{|c|}{$\begin{array}{r}4 \mathrm{~A} \\
1610\end{array}$} & & & \multicolumn{2}{|c|}{ Date } & \multicolumn{2}{|c|}{$5 / 24 / 2006$} \\
\hline & \multirow[b]{3}{*}{ (Ф) } & \multirow{2}{*}{\multicolumn{2}{|c|}{$\begin{array}{c}\text { y1-axis } \\
\text { Weight retained } \\
\text { on sieve }\end{array}$}} & \multirow{3}{*}{$\begin{array}{l}\text { Weight } \\
\text { passing sieve } \\
\text { (\% finer) }\end{array}$} & \multirow{3}{*}{$\begin{array}{c}\text { y2-axis } \\
\text { Cumulative } \\
\text { weight } \\
\text { (cum. \% finer) }\end{array}$} & \multirow{2}{*}{\multicolumn{4}{|c|}{ Percentiles }} \\
\hline & & & & & & & & & \\
\hline & & $(\mathrm{kg})$ & $(\%)$ & & & $(\Phi p)$ & $(\Phi)$ & (Dp) & $(\mathrm{mm})$ \\
\hline$<2$ & 0 & 3.2 & 9.9 & & & & & & \\
\hline 2 & -1 & 24 & 75 & 99 & 99 & Ф5 & -0.5 & D5 & 1 \\
\hline & & & & & & $\Phi 16$ & -1.8 & D16 & 3.5 \\
\hline 4 & -2 & 2.3 & 7.1 & 7.5 & 17.4 & & & & \\
\hline 8 & -3 & 3.3 & 10.2 & 7.1 & 24.5 & & & & \\
\hline & & & & & & $\Phi 25$ & -3.1 & D25 & 8.3 \\
\hline 16 & -4 & 2.4 & 7.4 & 10.2 & 34.7 & & & & \\
\hline 22 & -4.5 & 2.0 & 6.2 & 7.4 & 42.1 & & & & \\
\hline 32 & -5 & 3.2 & 9.8 & 6.2 & 48.3 & & & & \\
\hline & & & & & & Ф50 & -5.1 & D50 & 34.0 \\
\hline 45 & -5.5 & $1 . c$ & 5.9 & 9.8 & 58.1 & & & & \\
\hline 64 & -6 & 11.6 & 36.0 & 5.9 & 64.0 & & & & \\
\hline & & & & & & $\Phi 75$ & -6.3 & D75 & 79.1 \\
\hline & & & & & & Ф84 & -6.6 & D84 & 94.1 \\
\hline & & & & & & Ф95 & -6.9 & D95 & 116.3 \\
\hline 128 & -7 & 0.0 & 0.0 & 36.0 & 100.0 & & & & \\
\hline
\end{tabular}

Total

$32.2 \quad 100.0$

Dmax Surface Particle Intermediate Axis (mm): 220 
Table 5: Stream F, PA

\section{Particle Size Distribution Table}

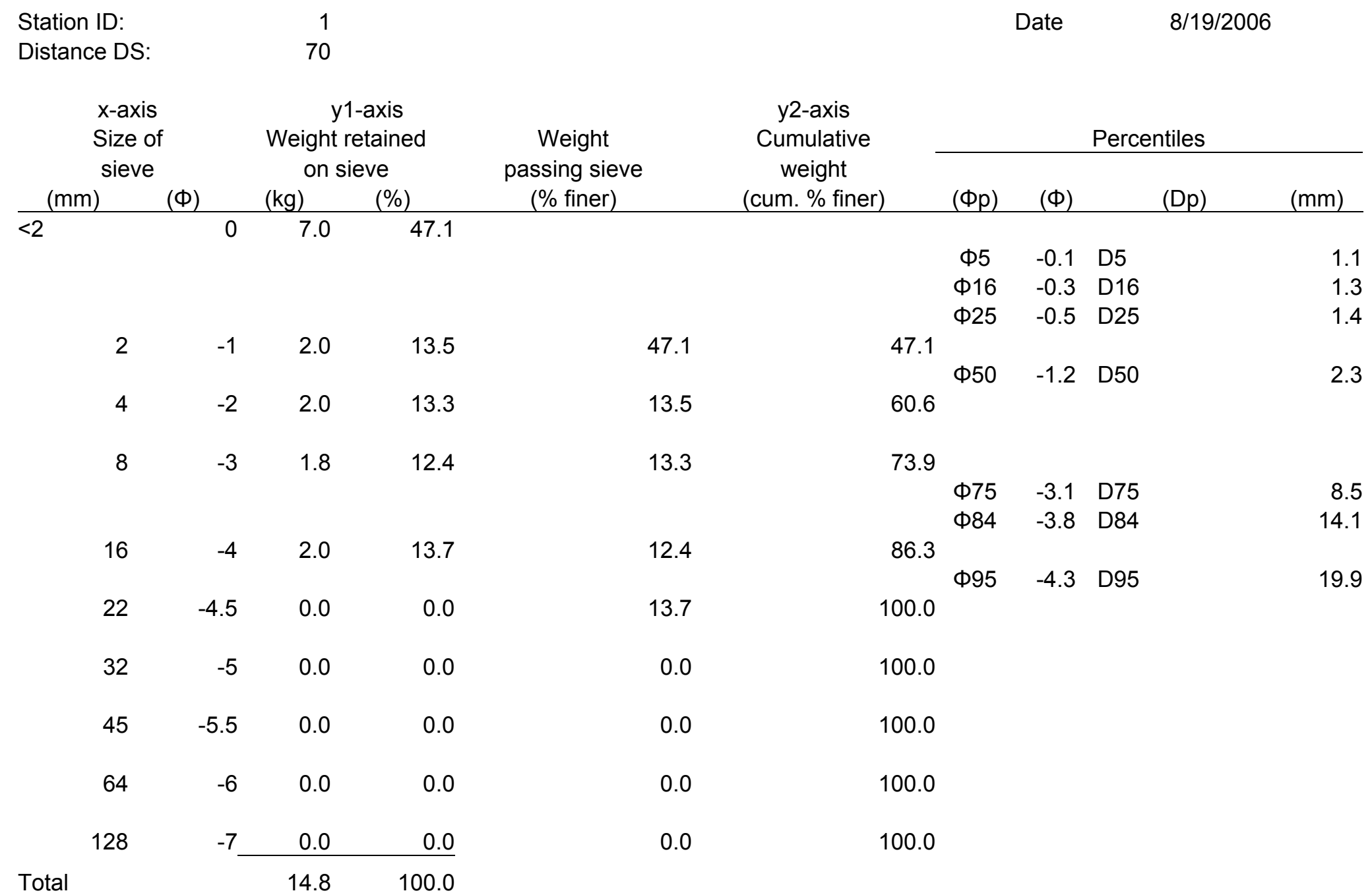


Table 6: Stream F, PA

Particle Size Distribution Table

Station ID:

Distance DS:

$x$-axis

Size of

$\frac{(\mathrm{mm})}{<2}$ sieve $(\Phi)$

$(\Phi)$
$3 \mathrm{~B}$

1520

\section{y1-axis}

Weight retained

on sieve

(\%)

(\%)

(kg)

$7.2 \quad 28.3$

2

$-1$

4

8

$-2$

1.9

7.5

2.5

9.6

11.0

43.2

0.9

3.5

43.2

3.5

3.9

2.0

2.0

0.0

128

$-7$
Date $\quad 8 / 19 / 2006$

Percentiles

Cumulative weight (cum. \% finer)

(Фp) (Ф)

(Dp) (mm)

Ф5

-0.2 D5

1.1

$\begin{array}{lll}\Phi 16 & -0.6 & \mathrm{D} 16\end{array}$

$\begin{array}{lll}\Phi 25 & -0.9 & \text { D25 }\end{array}$

1.5

28.3

35.8

45.4

$\begin{array}{lllr}\text { Ф50 } & -3.1 & \text { D50 } & 8.6 \\ \text { Ф75 } & -3.7 & \text { D75 } & 12.9 \\ \text { Ф84 } & -3.9 & \text { D84 } & 14.9\end{array}$

88.6

92.1

96.1

$\Phi 95$

$-4.9 \quad$ D95

29.1

Total

$\begin{array}{rr}0.0 & 0.0 \\ 25.5 & 100.0\end{array}$


Table 7: Stream F, PA

Particle Size Distribution Table

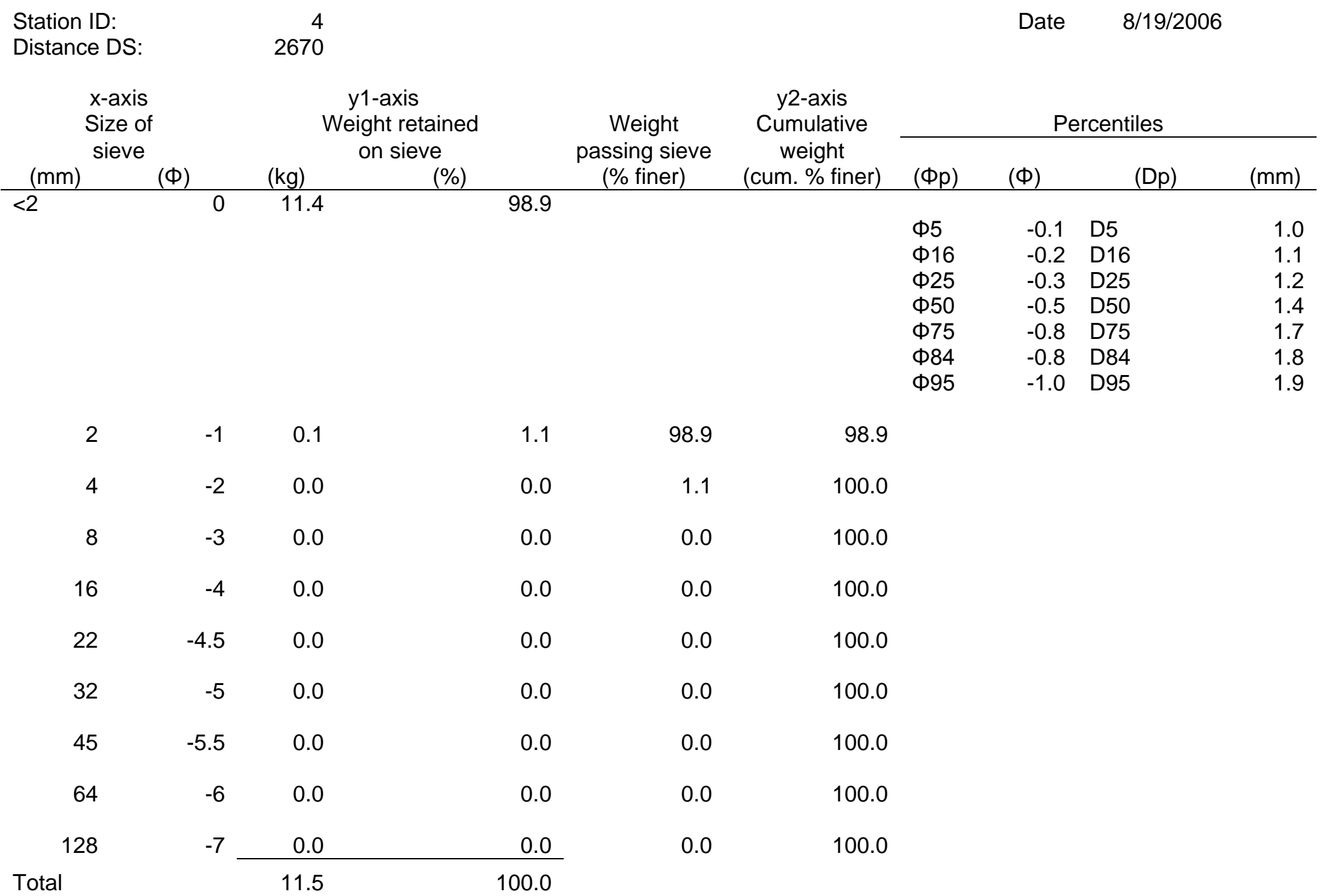


Table 8: Stream F, PA

Particle Size Distribution Table

\begin{tabular}{|c|c|c|c|c|c|c|c|c|c|}
\hline $\begin{array}{l}\text { Station II } \\
\text { Distance }\end{array}$ & & $\begin{array}{r}5 \\
2940\end{array}$ & & & & & Date & 8/19/2 & \\
\hline & & Weight & axis & & y2-axis & & & ercentiles & \\
\hline & & on & & passing sieve & weiaht & & & & \\
\hline$(\mathrm{mm})$ & $(\Phi)$ & $(\mathrm{kg})$ & (\%) & (\% finer) & (cum. \% finer) & $(\Phi p)$ & $(\Phi)$ & (Dp) & $(\mathrm{mm})$ \\
\hline$<2$ & 0 & 23.8 & 91.5 & & & & & & \\
\hline & & & & & & Ф5 & -0.1 & D5 & 1.0 \\
\hline & & & & & & $\Phi 16$ & -0.2 & D16 & 1.1 \\
\hline & & & & & & $\Phi 25$ & -0.3 & D25 & 1.2 \\
\hline & & & & & & $\Phi 50$ & -0.5 & D50 & 1.5 \\
\hline & & & & & & $\Phi 75$ & -0.8 & D75 & 1.8 \\
\hline & & & & & & Ф84 & -0.9 & D84 & 1.9 \\
\hline 2 & -1 & 0.0 & 0.0 & 91.5 & 91.5 & & & & \\
\hline 4 & -2 & 0.0 & 0.0 & 0.0 & 91.5 & & & & \\
\hline 8 & -3 & 0.6 & 2.3 & 0.0 & 91.5 & & & & \\
\hline 16 & -4 & 0.7 & 2.7 & 2.3 & 93.8 & & & & \\
\hline & & & & & & Ф95 & -4.2 & D95 & 18.7 \\
\hline 22 & -4.5 & 0.3 & 1.2 & 2.7 & 96.5 & & & & \\
\hline 32 & -5 & 0.2 & 0.8 & 1.2 & 97.6 & & & & \\
\hline 45 & -5.5 & 0.0 & 0.0 & 0.8 & 98.4 & & & & \\
\hline 64 & -6 & 0.4 & 1.6 & 0.0 & 98.4 & & & & \\
\hline 128 & -7 & 0.0 & 0.0 & 1.6 & 100.0 & & & & \\
\hline Total & & 26.0 & 100.0 & & & & & & \\
\hline
\end{tabular}


Table 9: Stream F, PA

Particle Size Distribution Table

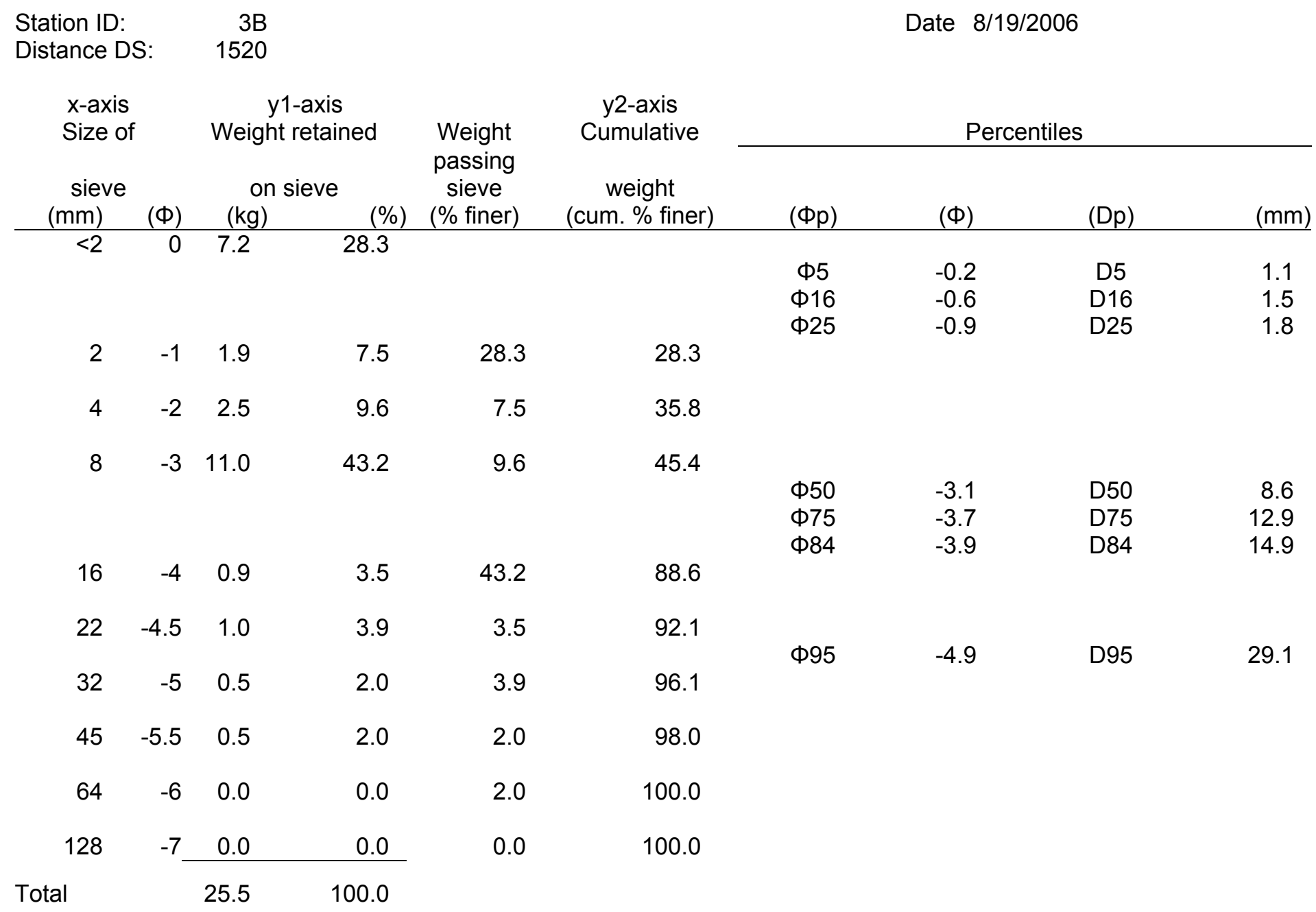


Table 10: Templeton Fork, PA

Particle Size Distribution Table

\begin{tabular}{|c|c|c|c|c|c|c|c|c|c|}
\hline \multirow{4}{*}{$\begin{array}{l}\text { Station ID: } \\
\text { Distance DS: } \\
\\
\text { x-axis } \\
\text { Size of } \\
\text { sieve } \\
(\mathrm{mm}) \\
\end{array}$} & \multicolumn{3}{|c|}{$\begin{array}{l}1 \mathrm{~B} \\
55\end{array}$} & & & \multicolumn{2}{|r|}{ Date } & \multicolumn{2}{|c|}{ 8/19/2006 } \\
\hline & \multirow[b]{3}{*}{$(\Phi)$} & \multirow{2}{*}{\multicolumn{2}{|c|}{$\begin{array}{c}y 1 \text {-axis } \\
\text { Weight retained } \\
\text { on sieve }\end{array}$}} & \multirow{3}{*}{$\begin{array}{c}\text { Weight } \\
\text { passing sieve } \\
\text { (\% finer) }\end{array}$} & \multirow{3}{*}{$\begin{array}{c}\text { y2-axis } \\
\text { Cumulative } \\
\text { weight } \\
\text { (cum. \% finer) }\end{array}$} & \multirow{2}{*}{\multicolumn{4}{|c|}{ Percentiles }} \\
\hline & & & & & & & & & \\
\hline & & $\begin{array}{r}\text { on } \\
(\mathrm{kg})\end{array}$ & $(\%)$ & & & $(\Phi p)$ & $(\Phi)$ & (Dp) & $(\mathrm{mm})$ \\
\hline$<2$ & 0 & 2.3 & 8.3 & & & & & & \\
\hline & & & & & & $\Phi 5$ & -0.6 & D5 & 1.5 \\
\hline 2 & -1 & 1.0 & 3.4 & 8.3 & 8.3 & & & & \\
\hline 4 & -2 & 1.7 & 5.8 & 3.4 & 11.7 & & & & \\
\hline & & & & & & $\Phi 16$ & -2.7 & D16 & 6.7 \\
\hline 8 & -3 & 3.2 & 11.2 & 5.8 & 17.5 & & & & \\
\hline & & & & & & $\Phi 25$ & -3.7 & D25 & 12.7 \\
\hline 16 & -4 & 2.2 & 7.8 & 11.2 & 28.7 & & & & \\
\hline 22 & -4.5 & 3.0 & 10.4 & 7.8 & 36.5 & & & & \\
\hline 32 & -5 & 2.8 & 9.7 & 10.4 & 46.9 & & & & \\
\hline & & & & & & Ф50 & -5.2 & D50 & 35.8 \\
\hline 45 & -5.5 & 1.0 & 3.4 & 9.7 & 56.6 & & & & \\
\hline 64 & -6 & 11.4 & 40.1 & 3.4 & 59.9 & & & & \\
\hline & & & & & & $\Phi 75$ & -5.8 & D75 & 53.9 \\
\hline & & & & & & Ф84 & -6.6 & D84 & 97.0 \\
\hline & & & & & & Ф95 & -6.7 & D95 & 100.4 \\
\hline 128 & -7 & 0.0 & 0.0 & 40.1 & 100.0 & & & & \\
\hline
\end{tabular}

$28.3 \quad 100.0$

Note: $\quad$ Sample was dried and was not redampened prior to sieving. Alluvium was sampled dry. 
Table 11: Templeton Fork, PA

Particle Size Distribution Table

\begin{tabular}{|c|c|c|c|c|c|c|c|c|c|}
\hline \multirow{4}{*}{$\begin{array}{l}\text { Station ID: } \\
\text { Distance DS: } \\
\text { x-axis } \\
\text { Size of } \\
\text { sieve } \\
(\mathrm{mm})\end{array}$} & \multirow[b]{4}{*}{$(\Phi)$} & \multicolumn{2}{|l|}{$\begin{array}{r}8 \\
2060\end{array}$} & \multirow{4}{*}{$\begin{array}{c}\text { Weight } \\
\text { passing sieve } \\
\text { (\% finer) }\end{array}$} & \multirow{4}{*}{$\begin{array}{c}\text { y2-axis } \\
\text { Cumulative } \\
\text { weight } \\
\text { (cum. \% finer) }\end{array}$} & \multicolumn{2}{|r|}{ Date } & \multicolumn{2}{|c|}{ 8/19/2006 } \\
\hline & & \multirow{2}{*}{\multicolumn{2}{|c|}{$\begin{array}{c}y 1 \text {-axis } \\
\text { Weight retained } \\
\text { on sieve }\end{array}$}} & & & \multirow{2}{*}{\multicolumn{4}{|c|}{ Percentiles }} \\
\hline & & & & & & & & & \\
\hline & & $(\mathrm{kg})$ & $(\%)$ & & & $(\Phi p)$ & $(\Phi)$ & $(\mathrm{Dp})$ & $(\mathrm{mm})$ \\
\hline$<2$ & 0 & 7.4 & 27.8 & & & $\Phi 5$ & -0.2 & D5 & 1.1 \\
\hline & & & & & & Ф16 & -0.6 & D16 & 1.5 \\
\hline & & & & & & $\Phi 25$ & -0.9 & D25 & 1.9 \\
\hline 2 & -1 & 3.5 & 13.3 & 27.8 & 27.8 & & & & \\
\hline 4 & -2 & 4.2 & 15.9 & 13.3 & 41.0 & & & & \\
\hline & & & & & & $\Phi 50$ & -2.6 & D50 & 5.9 \\
\hline 8 & -3 & 5.0 & 18.7 & 15.9 & 56.9 & & & & \\
\hline & & & & & & $\Phi 75$ & -2.6 & D75 & 6.2 \\
\hline 16 & -4 & 3.2 & 11.8 & 18.7 & 75.7 & & & & \\
\hline & & & & & & Ф84 & -4.4 & D84 & 20.4 \\
\hline 22 & -4.5 & 2.3 & 8.4 & 11.8 & 87.5 & & & & \\
\hline & & & & & & Ф95 & -4.9 & D95 & 30.9 \\
\hline 32 & -5 & 0.5 & 1.9 & 8.4 & 95.9 & & & & \\
\hline 45 & -5.5 & 0.6 & 2.2 & 1.9 & 97.8 & & & & \\
\hline 64 & -6 & 0.0 & 0.0 & 2.2 & 100.0 & & & & \\
\hline 128 & -7 & 0.0 & 0.0 & 0.0 & 100.0 & & & & \\
\hline
\end{tabular}

Total

100.0

Note: $\quad$ Sample was dried and was not redampened prior to sieving. Alluvium was sampled dry. 
Table 12: Island Creek, WV

Particle Size Distribution Table

\begin{tabular}{|c|c|c|c|c|c|c|c|c|c|}
\hline \multirow{3}{*}{$\begin{array}{l}\text { Station ID: } \\
\text { Distance DS: } \\
\\
\text { x-axis } \\
\text { Size of } \\
\text { sieve } \\
(\mathrm{mm})\end{array}$} & \multirow[b]{3}{*}{$(\Phi)$} & \multicolumn{2}{|c|}{$\begin{array}{r}2 \\
1100\end{array}$} & & & \multicolumn{2}{|r|}{ Date } & \multicolumn{2}{|c|}{$5 / 21 / 2006$} \\
\hline & & \multicolumn{2}{|c|}{$\begin{array}{c}\mathrm{y} 1 \text {-axis } \\
\text { Weight retained } \\
\text { on sieve }\end{array}$} & \multirow{2}{*}{$\begin{array}{l}\text { Weight } \\
\text { passing sieve } \\
\text { (\% finer) }\end{array}$} & \multirow{2}{*}{$\begin{array}{c}\text { y2-axis } \\
\text { Cumulative } \\
\text { weight } \\
\text { (cum. \% finer) }\end{array}$} & \multicolumn{4}{|c|}{ Percentiles } \\
\hline & & & (\%) & & & $(\Phi p)$ & $(\Phi)$ & (Dp) & $(\mathrm{mm})$ \\
\hline$<2$ & 0 & 4.9 & 13.5 & & & & & & \\
\hline & & & & & & Ф5 & -0.4 & D5 & 1.3 \\
\hline 2 & -1 & 1.2 & 3.3 & 13.5 & 13.5 & $\Phi 16$ & -1.8 & D16 & 3.4 \\
\hline 4 & -2 & 2.1 & 5.8 & 3.3 & 16.8 & & & & \\
\hline 8 & -3 & 2.6 & 7.2 & 5.8 & 22.6 & & & & \\
\hline & & & & & & Ф25 & -3.3 & D25 & 10.1 \\
\hline 16 & -4 & 1.9 & 5.3 & 7.2 & 29.8 & & & & \\
\hline 22 & -4.5 & 1.4 & 3.9 & 5.3 & 35.1 & & & & \\
\hline 32 & -5 & 2.2 & 6.1 & 3.9 & 39.0 & & & & \\
\hline 45 & -5.5 & 4.1 & 11.4 & 6.1 & 45.1 & & & & \\
\hline & & & & & & $\Phi 50$ & -5.7 & D50 & 52.6 \\
\hline 64 & -6 & 15.7 & 43.6 & 11.4 & 56.4 & & & & \\
\hline & & & & & & $\begin{array}{l}\text { Ф75 } \\
\text { Ф84 }\end{array}$ & $\begin{array}{l}-6.4 \\
-6.6\end{array}$ & $\begin{array}{l}\text { D75 } \\
\text { D84 }\end{array}$ & $\begin{array}{l}86.0 \\
99.2\end{array}$ \\
\hline & & & & & & Ф95 & -6.9 & D95 & 118.2 \\
\hline 128 & -7 & & 0.0 & 43.6 & 100.0 & & & & \\
\hline
\end{tabular}

Dmax Surface Particle Intermediate Axis ( $\mathrm{mm})$ : 
Table 13: Island Creek, WV

\section{Particle Size Distribution Table}

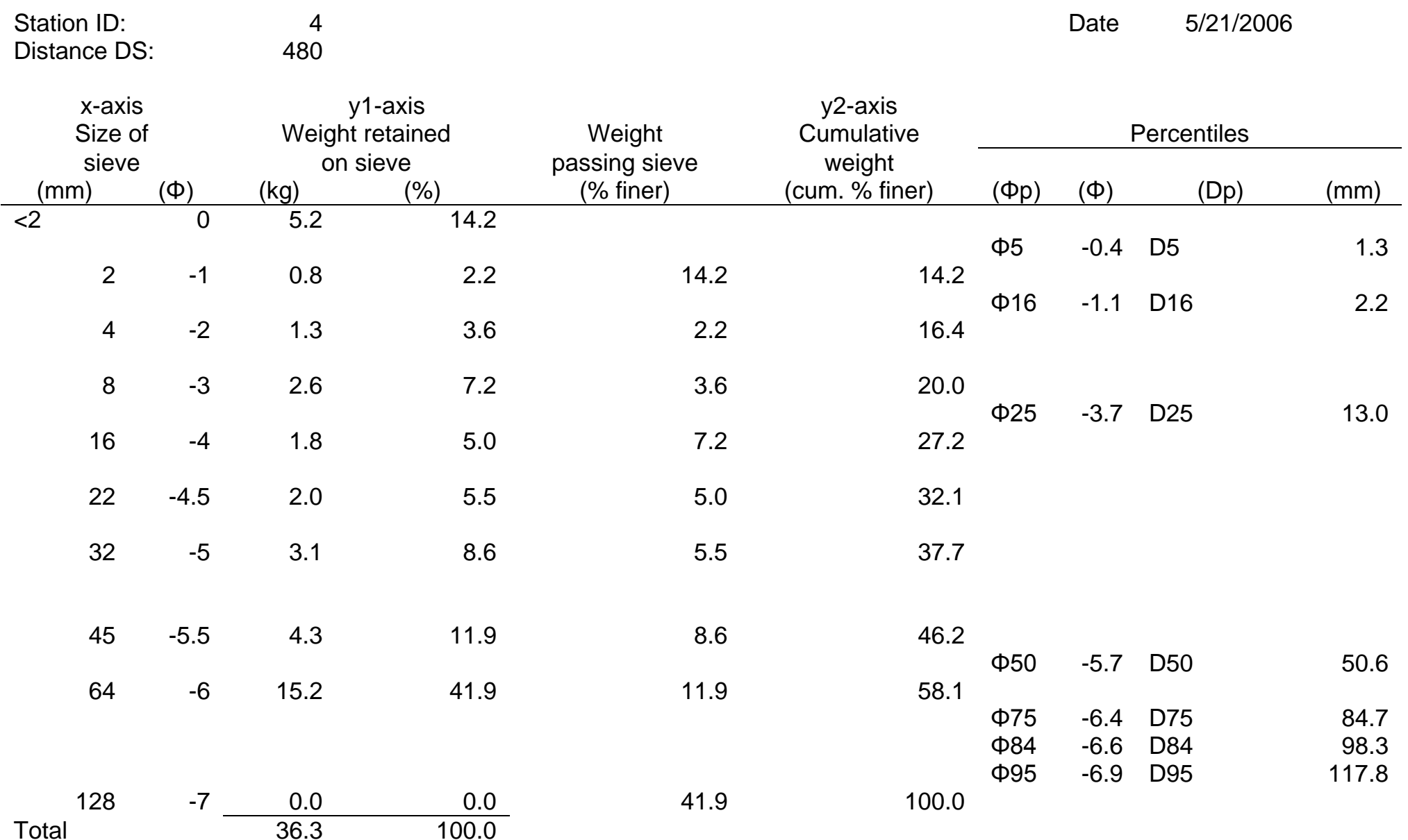

Dmax Surface Particle Intermediate Axis

$(\mathrm{mm})$ : 
Table 14: Island Creek, WV

Particle Size Distribution Table

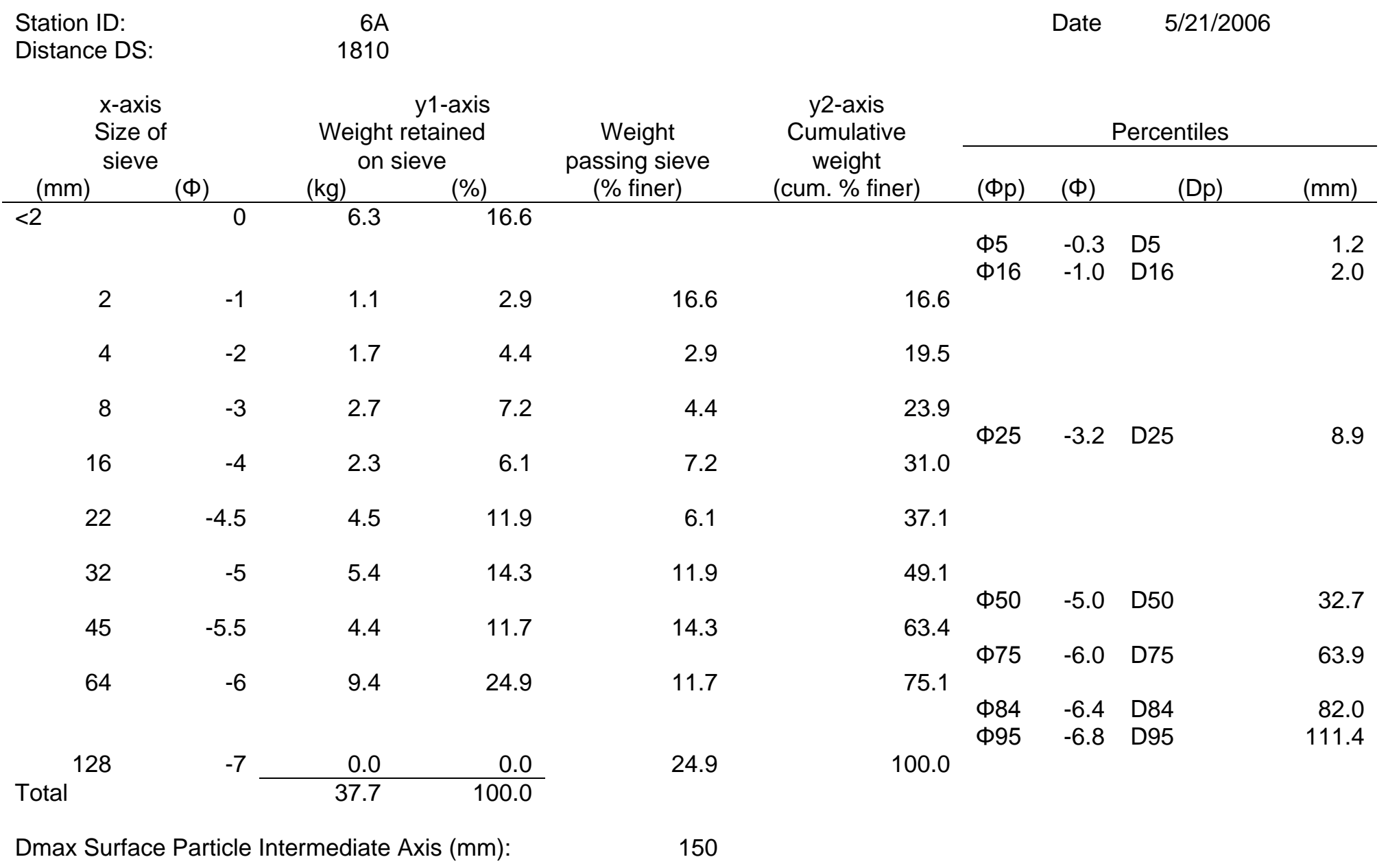


Table 15: West Fork, WV

Particle Size Distribution Table

\begin{tabular}{|c|c|c|c|c|c|c|c|c|c|}
\hline $\begin{array}{l}\text { Station ID: } \\
\text { Distance DS: }\end{array}$ & & $\begin{array}{r}5 \\
1180\end{array}$ & & & & & ate & $5 / 20 /$ & \\
\hline $\mathrm{x}$-axis & & & & & y2-axis & & & & \\
\hline Size of & & Weight & & Weight & Cumulative & & & centile & \\
\hline$(\mathrm{mm})$ & $(\Phi)$ & $(\mathrm{kg})$ & $(\%)$ & (\% finer) & (cum. \% finer) & $(\Phi p)$ & $(\Phi)$ & $(D p)$ & $(\mathrm{mm})$ \\
\hline$<2$ & 0 & 5.5 & 10.4 & & & & & & \\
\hline & & & & & & Ф5 & -0.5 & D5 & 1.4 \\
\hline 2 & -1 & 2.0 & 3.7 & 10.4 & 10.4 & & & & \\
\hline 4 & -2 & 2.4 & 4.6 & 3.7 & 14.1 & & & & \\
\hline & & & & & & $\Phi 16$ & -2.4 & D16 & 5.4 \\
\hline 8 & -3 & 4.1 & 7.8 & 4.6 & 18.6 & & & & \\
\hline & & & & & & $\Phi 25$ & -3.8 & D25 & 14.1 \\
\hline 16 & -4 & 2.6 & 4.8 & 7.8 & 26.4 & & & & \\
\hline 22 & -4.5 & 3.7 & 7.0 & 4.8 & 31.3 & & & & \\
\hline 32 & -5 & 3.3 & 6.3 & 7.0 & 38.3 & & & & \\
\hline 45 & -5.5 & 5.7 & 10.8 & 6.3 & 44.6 & & & & \\
\hline & & & & & & Ф50 & -5.8 & D50 & 53.8 \\
\hline 64 & -6 & 23.5 & 44.6 & 10.8 & 55.4 & & & & \\
\hline & & & & & & $\Phi 75$ & -6.4 & D75 & 86.8 \\
\hline & & & & & & Ф84 & -6.6 & D84 & 99.8 \\
\hline & & & & & & Ф95 & -6.9 & D95 & 118.4 \\
\hline 128 & -7 & 0.0 & 0.0 & 44.6 & 100.0 & & & & \\
\hline
\end{tabular}


Table 16: West Fork, WV

Particle Size Distribution Table

\begin{tabular}{|c|c|c|c|c|c|c|c|c|c|}
\hline \multicolumn{2}{|c|}{$\begin{array}{l}\text { Station ID: } \\
\text { Distance DS: }\end{array}$} & \multicolumn{2}{|l|}{$\begin{array}{r}7 \\
1800\end{array}$} & & & \multicolumn{2}{|c|}{ Date } & \multicolumn{2}{|c|}{$5 / 20 / 2006$} \\
\hline \multirow{2}{*}{$\begin{array}{l}\text { X-axis } \\
\text { Size of } \\
\text { sieve } \\
(\mathrm{mm})\end{array}$} & \multirow[b]{2}{*}{$(\Phi)$} & Weig & $\begin{array}{l}\text { xis } \\
\text { ined }\end{array}$ & \multirow{2}{*}{$\begin{array}{l}\text { Weight } \\
\text { passing sieve } \\
\text { (\% finer) }\end{array}$} & \multirow{2}{*}{$\begin{array}{c}\text { y2-axis } \\
\text { Cumulative } \\
\text { weight } \\
\text { (cum. \% finer) }\end{array}$} & \multicolumn{4}{|c|}{ Percentiles } \\
\hline & & $(\mathrm{kg})^{0}$ & $(\%)$ & & & $(\Phi p)$ & $(\Phi)$ & (Dp) & $(\mathrm{mm})$ \\
\hline$<2$ & 0 & 15.4 & 20.7 & & & & & & \\
\hline & & & & & & $\begin{array}{l}\text { Ф5 } \\
\Phi 16\end{array}$ & $\begin{array}{l}-0.2 \\
-0.8\end{array}$ & $\begin{array}{l}\text { D5 } \\
\text { D16 }\end{array}$ & $\begin{array}{l}1.2 \\
17\end{array}$ \\
\hline 2 & -1 & 2.6 & 3.4 & 20.7 & 20.7 & & & & \\
\hline 4 & -2 & 4.9 & 6.5 & 3.4 & 24.1 & & & & \\
\hline 8 & -3 & 4.8 & 6.4 & 6.5 & 30.7 & Ф25 & -2.1 & D25 & 4.4 \\
\hline 16 & -4 & 4.2 & 5.6 & 6.4 & 37.1 & & & & \\
\hline 22 & -4.5 & 3.5 & 4.7 & 5.6 & 42.7 & & & & \\
\hline 32 & -5 & 9.3 & 12.5 & 4.7 & 47.4 & & & & \\
\hline & & & & & & Ф50 & -5.1 & D50 & 34.4 \\
\hline 45 & -5.5 & 3.8 & 5.1 & 12.5 & 59.9 & & & & \\
\hline 64 & -6 & 26.0 & 35.0 & 5.1 & 65.0 & & & & \\
\hline & & & & & & $\Phi 75$ & -6.3 & D75 & 78.0 \\
\hline & & & & & & Ф84 & -6.5 & D84 & 93.2 \\
\hline & & & & & & Ф95 & -6.9 & D95 & 115.9 \\
\hline 128 & -7 & 0.0 & 0.0 & 35.0 & 100.0 & & & & \\
\hline Total & & 74.4 & 100.0 & & & & & & \\
\hline
\end{tabular}

Dmax Surface Particle Intermediate Axis (mm): 180 
Table 17: West Fork, WV

\section{Particle Size Distribution Table}

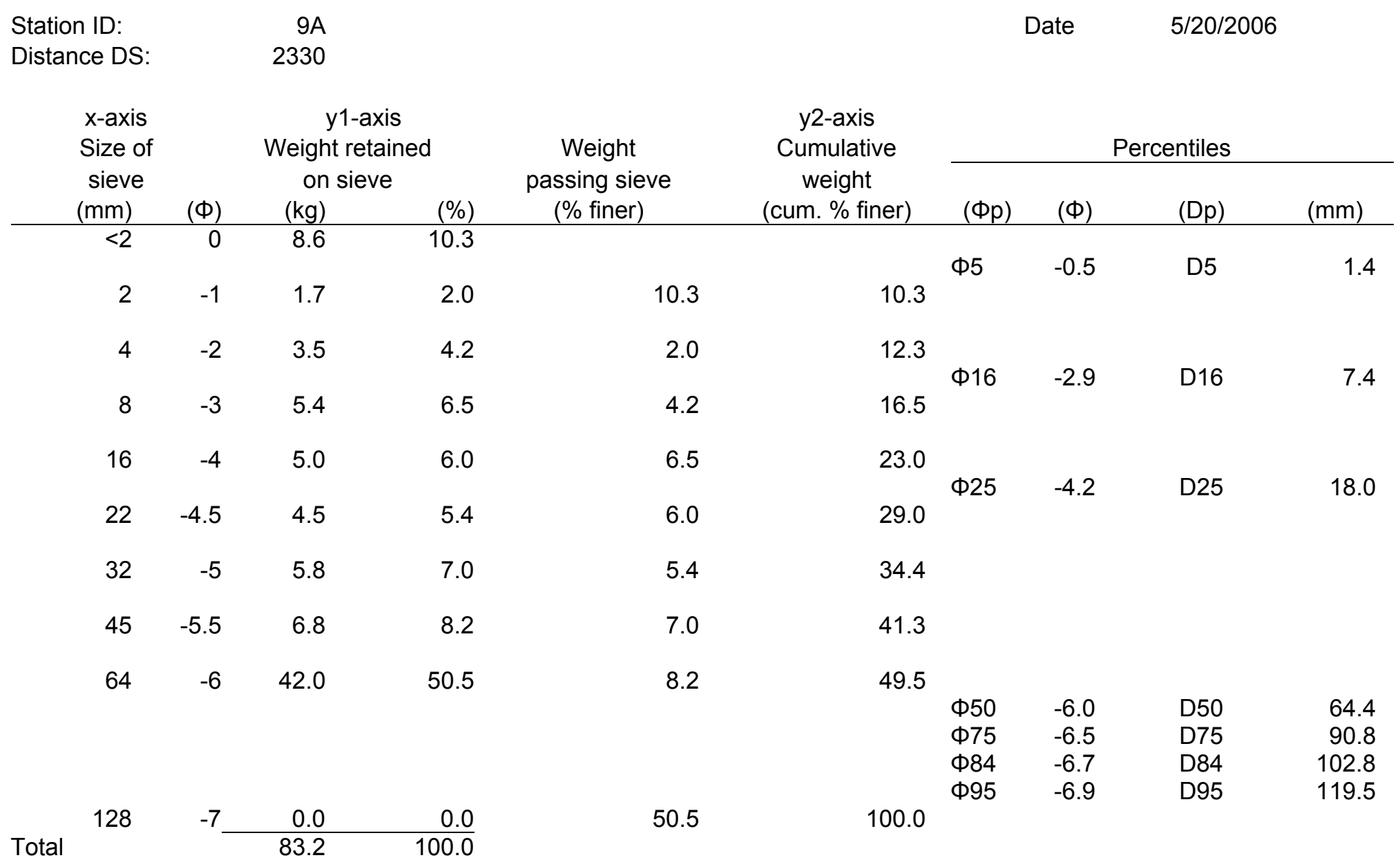

Dmax Surface Particle Intermediate Axis (mm): 256 
Appendix IX

Particle Size

Distribution Figures 
Figure 1: Particle Size Distribution

Crabapple Creek, OH - Station 2B

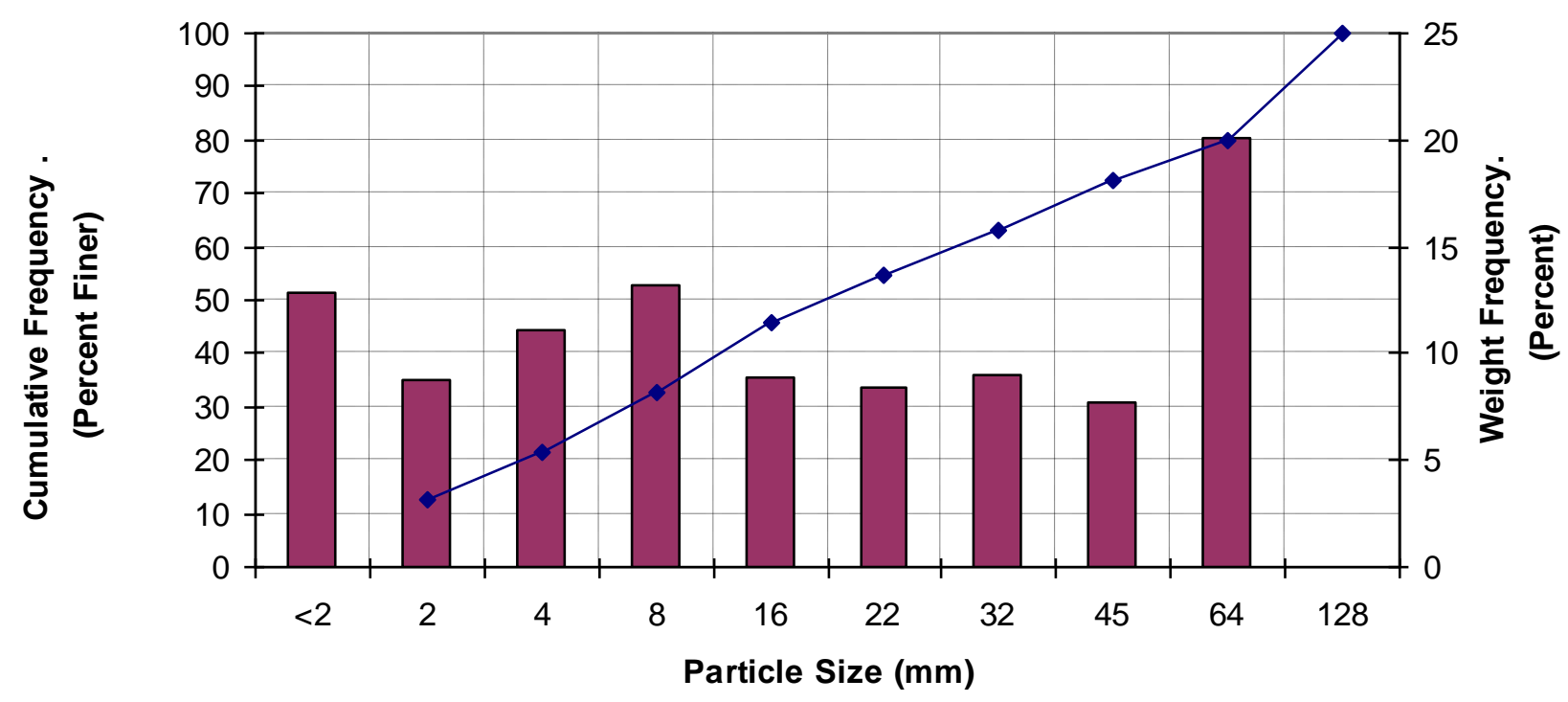


Figure 2: Particle Size Distribution

Crabapple Creek, OH - Station 4B

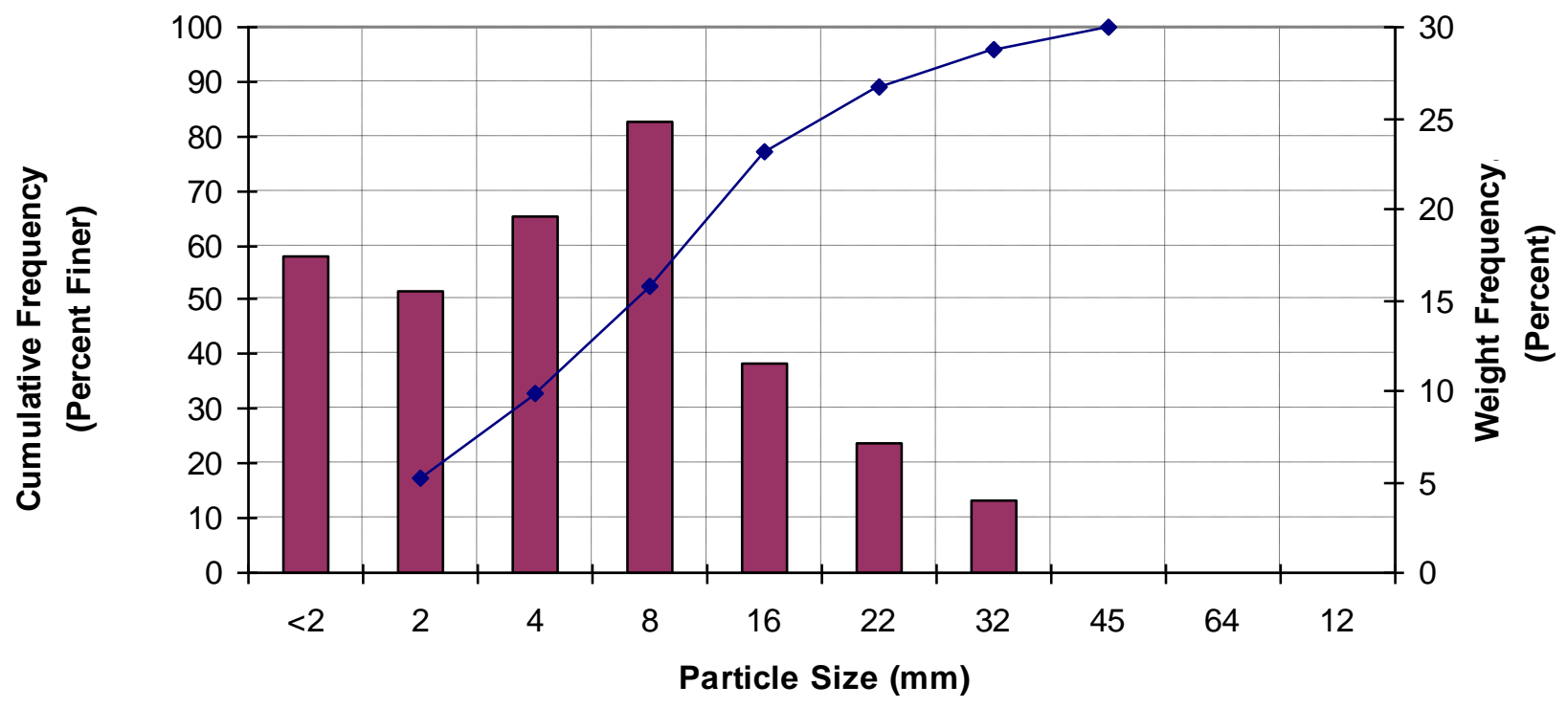


Figure 3: Particle Size Distribution

Williams Creek, OH - Station 2

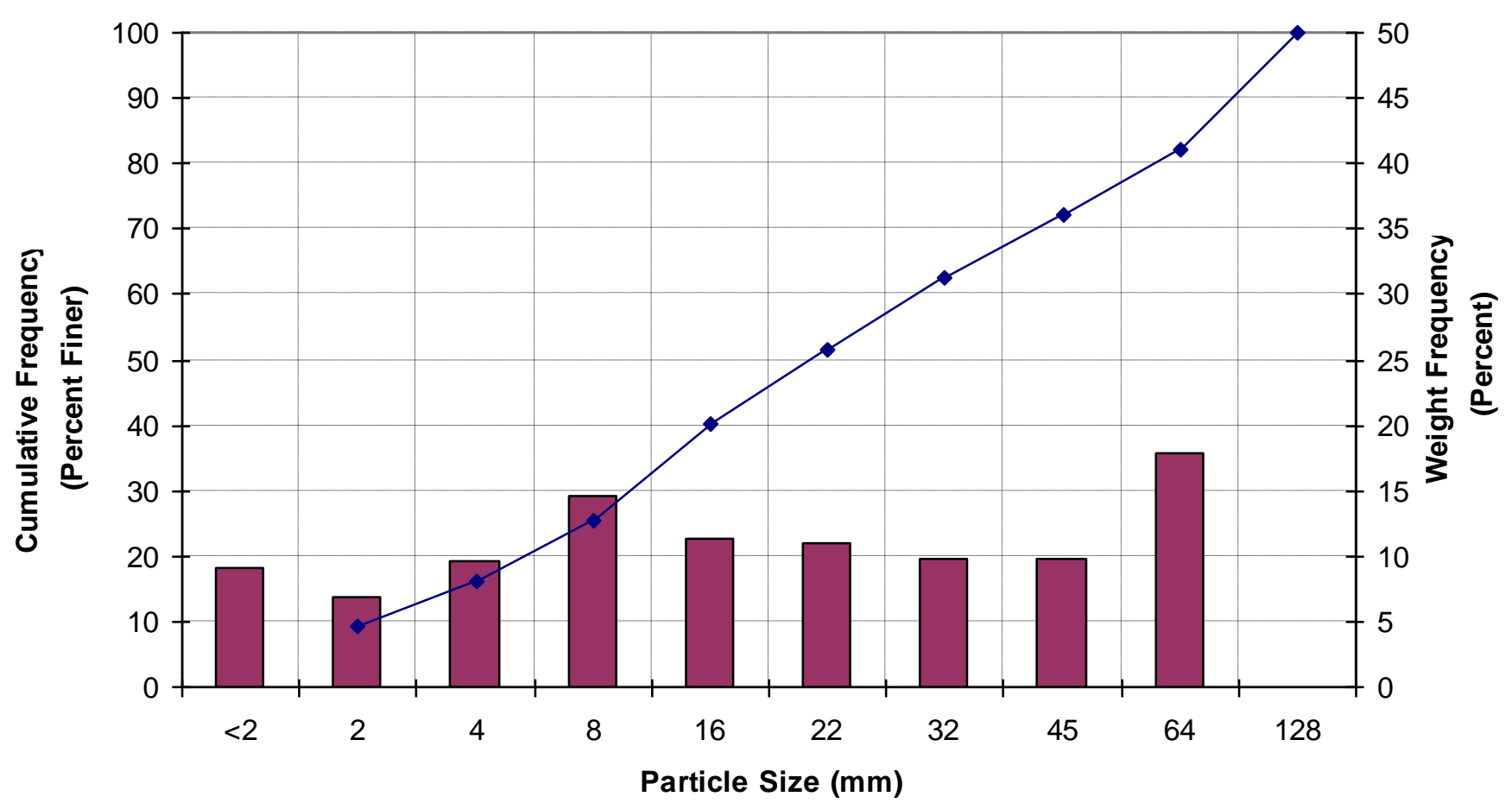


Figure 4: Particle Size Distribution

Williams Creek, OH - Station 4A

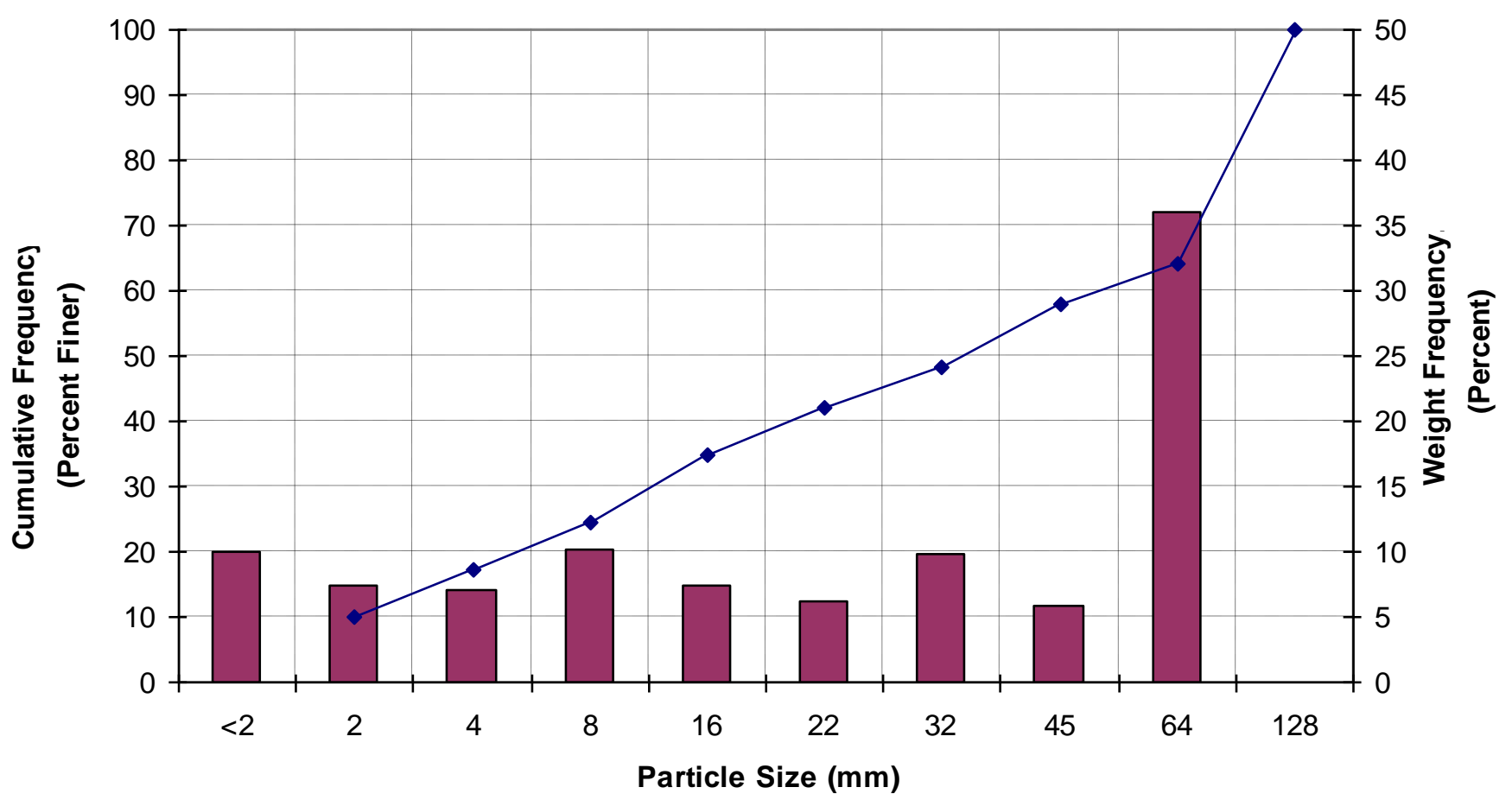


Figure 5: Particle Size Distribution

Stream F, PA - Station 1

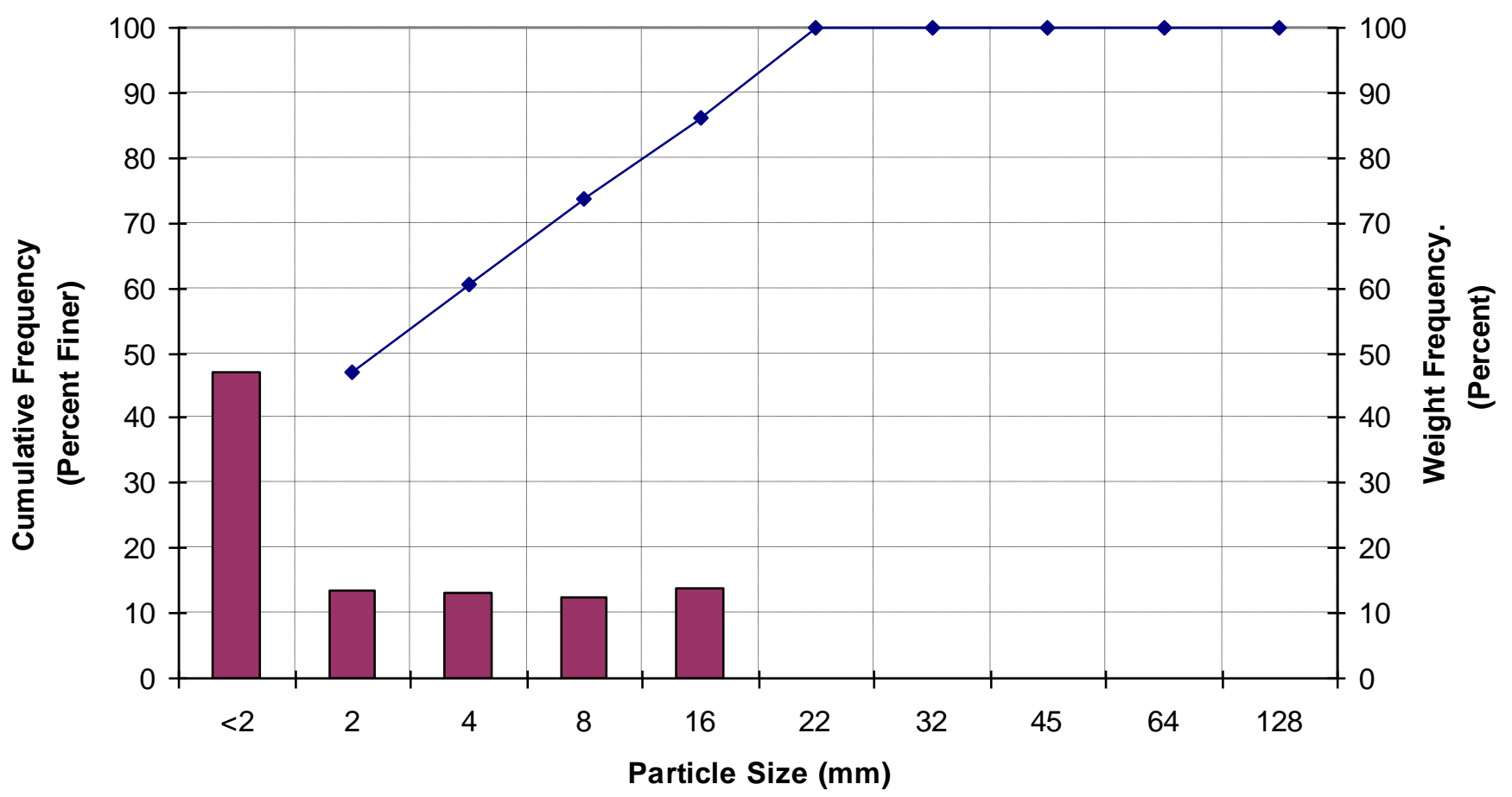


Figure 6: Particle Size Distribution

Stream F, PA - Station 3B

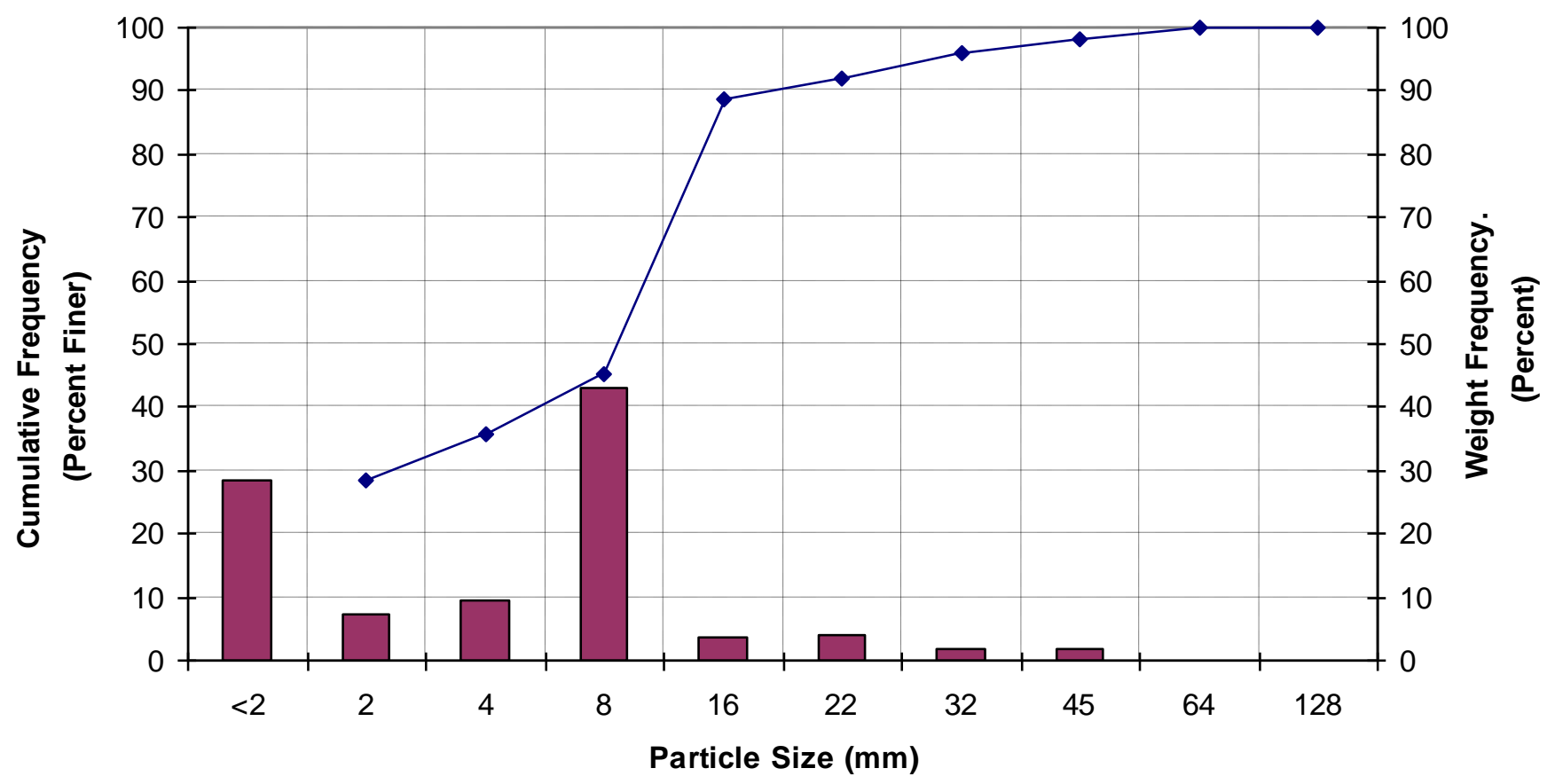


Figure 7: Particle Size Distribution

Stream F, PA - Station 4

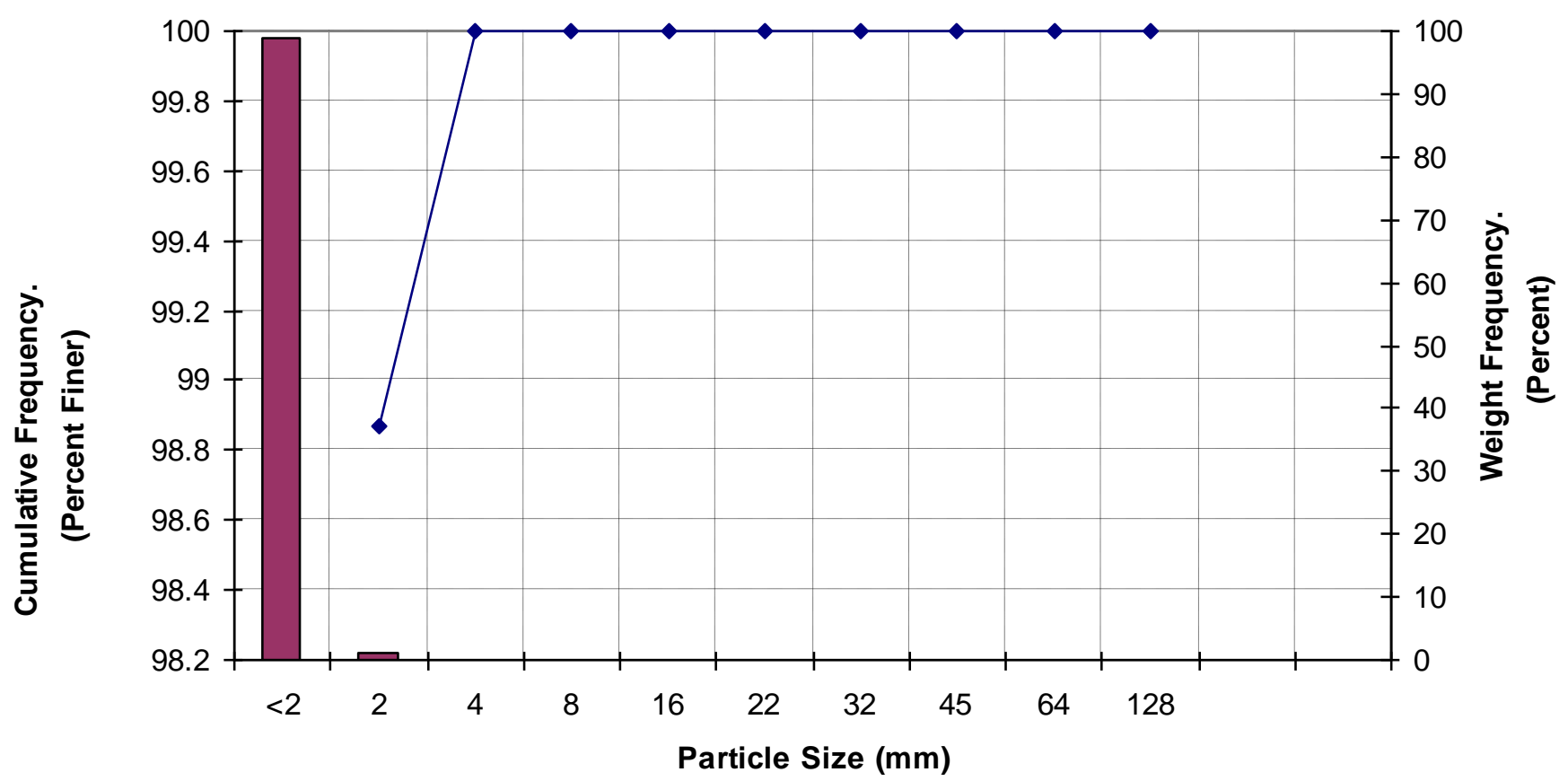


Figure 8: Particle Size Distribution Stream F, PA - Station 5

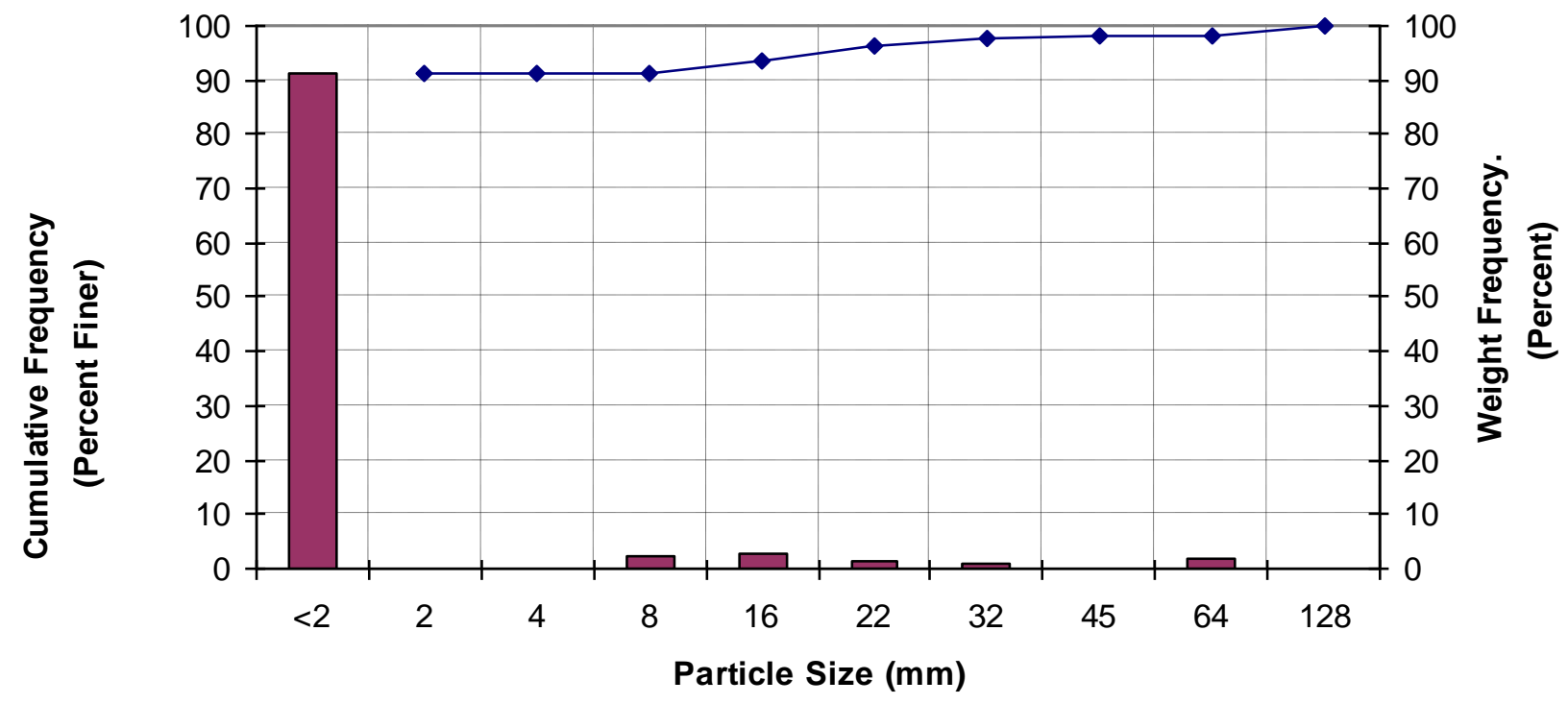


Figure 9: Particle Size Distribution

Templeton Fork, PA - Station 1B

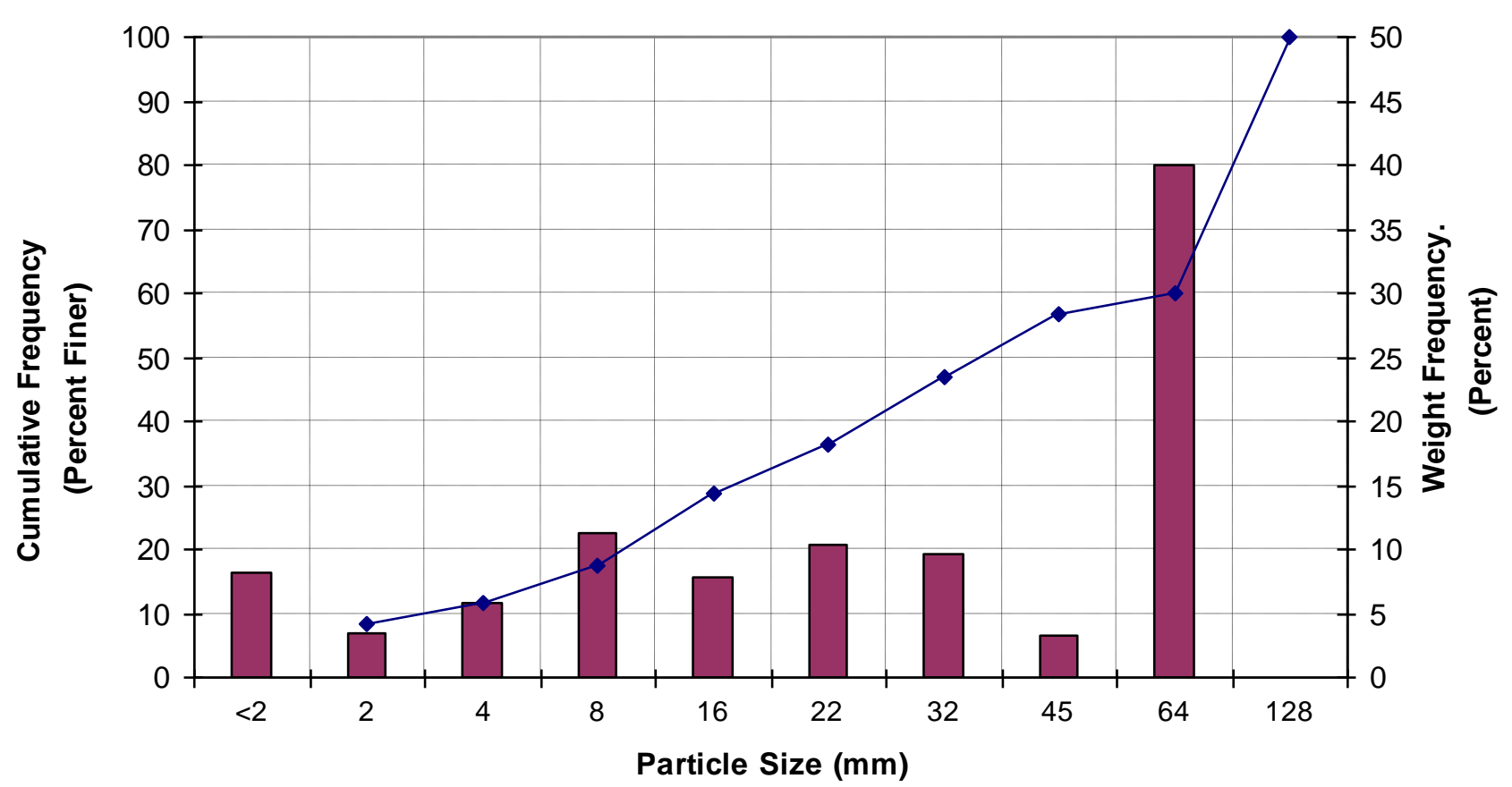


Figure 10: Particle Size Distribution

Templeton Fork, PA - Station 8

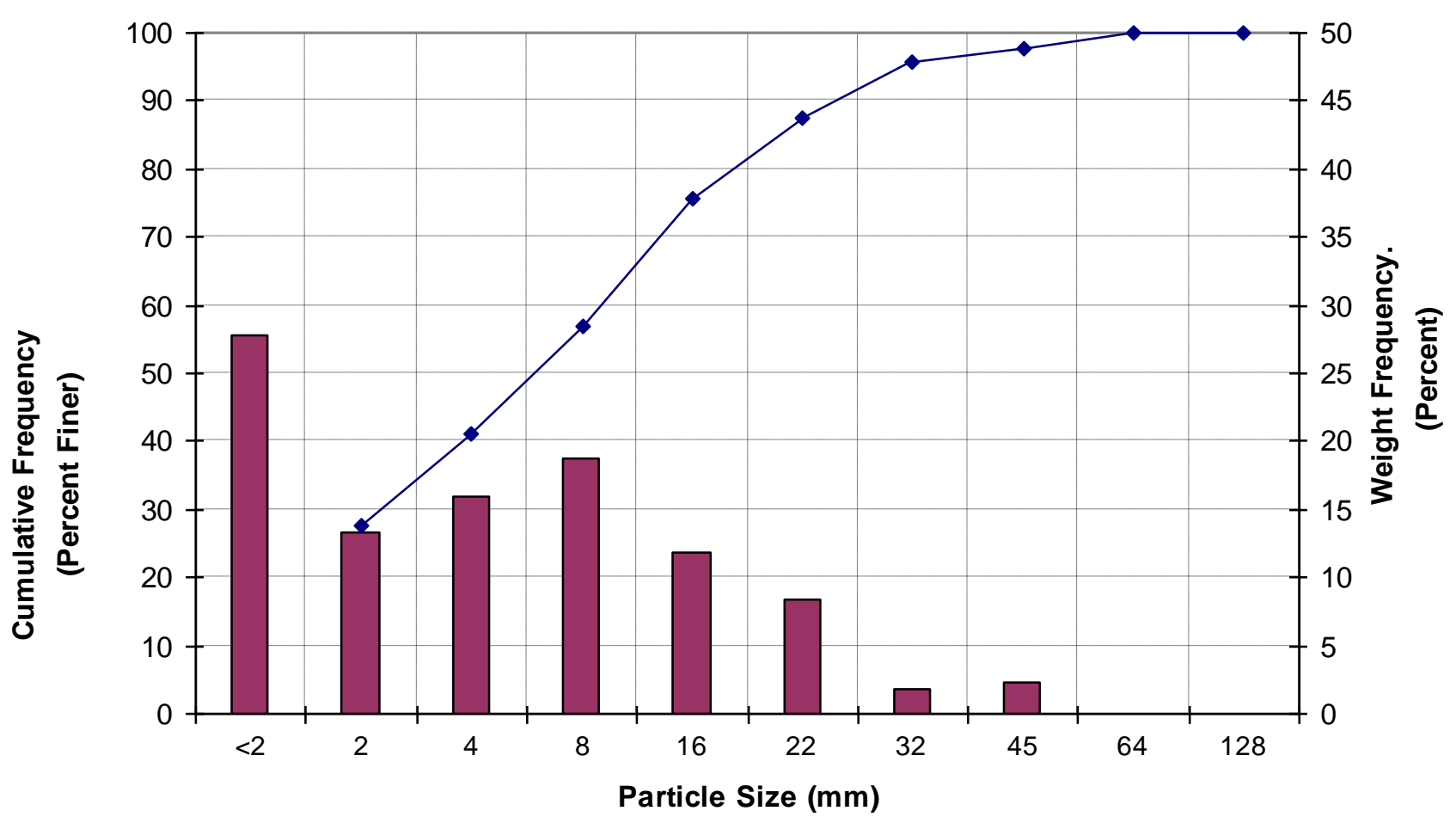


Figure 11: Particle Size Distribution

Island Creek, WV- Station 2

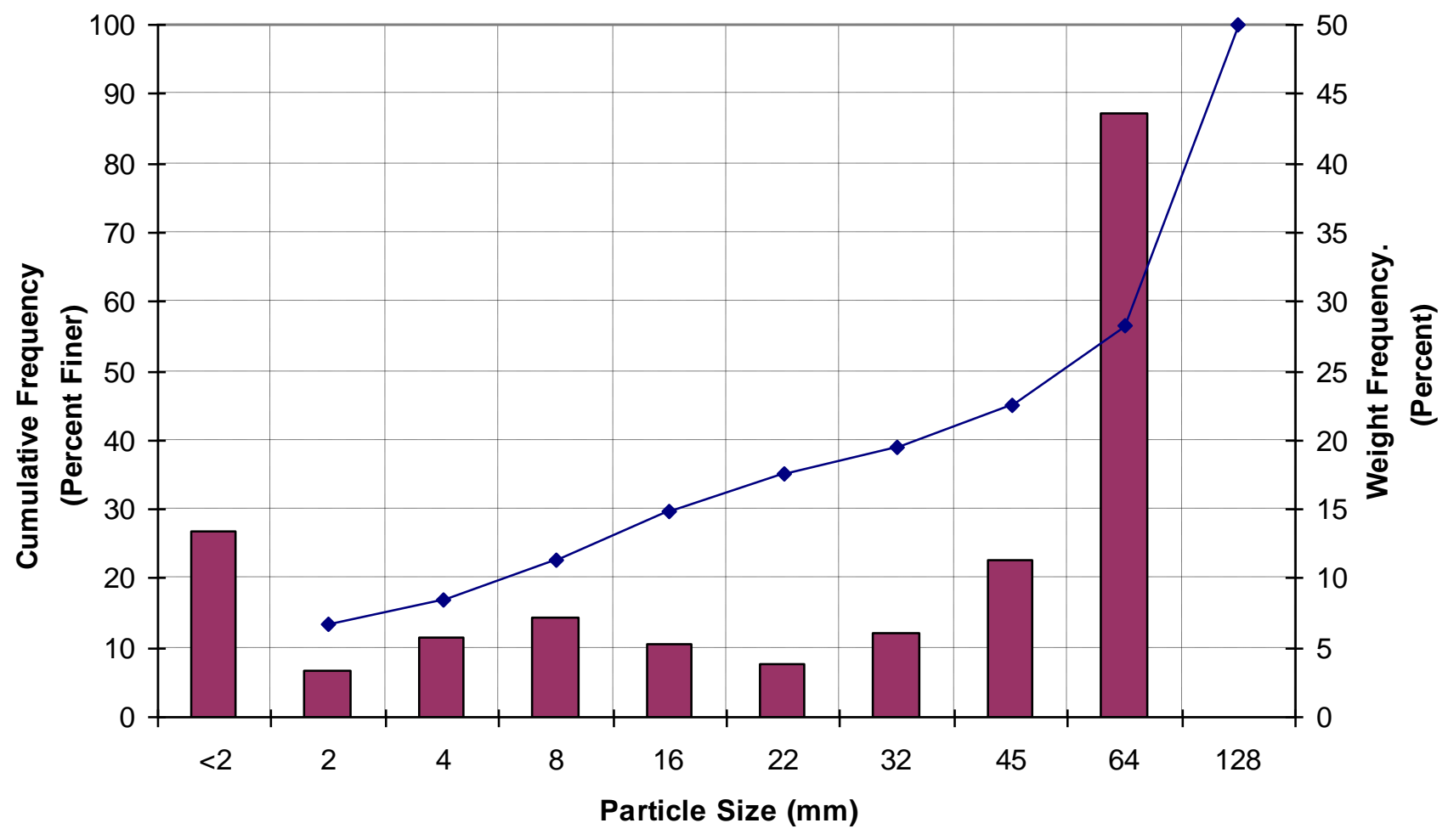


Figure 12: Particle Size Distribution

Island Creek, WV - Station 4

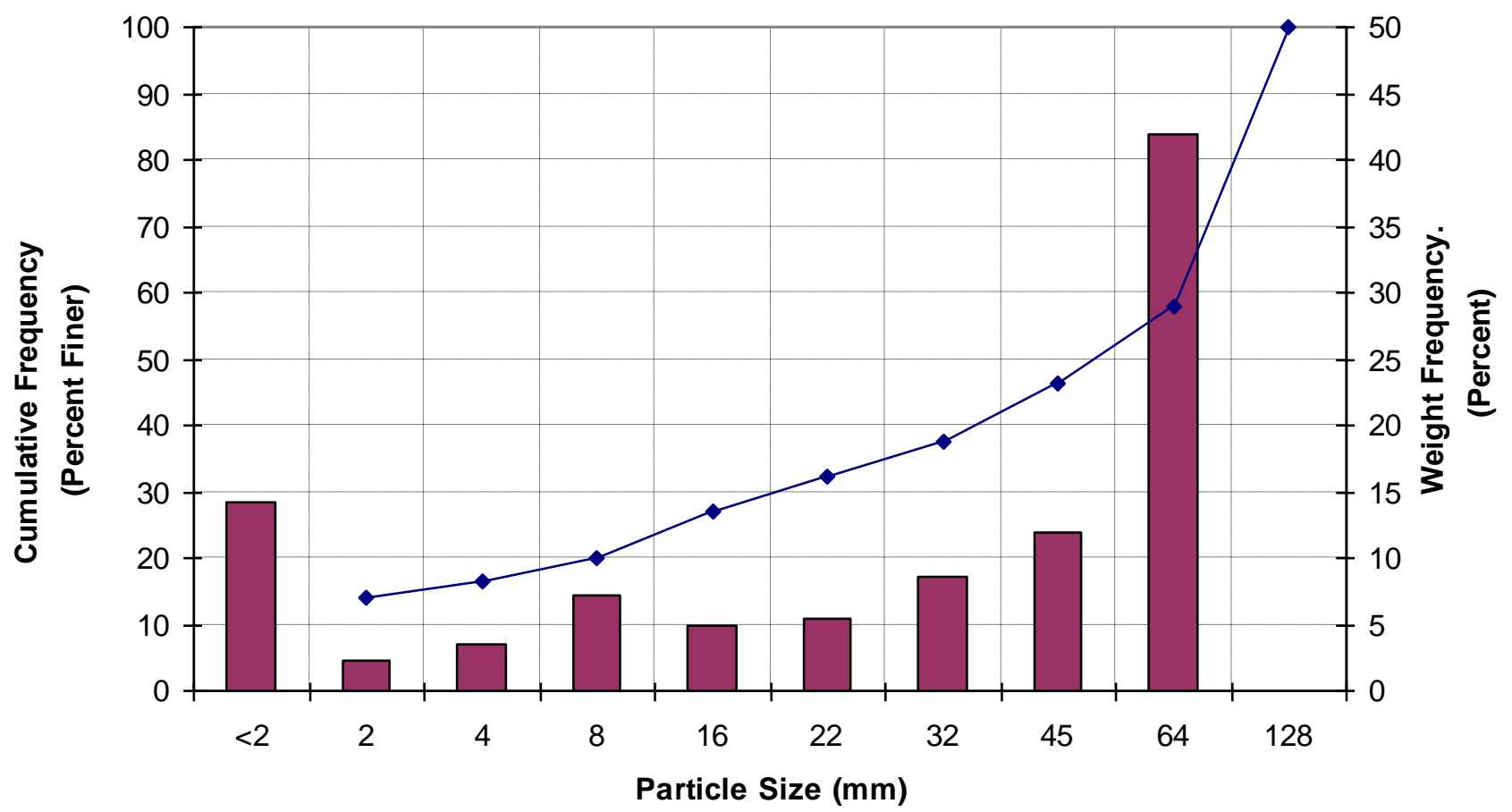


Figure 13: Particle Size Distribution

Island Creek, WV - Station 6A

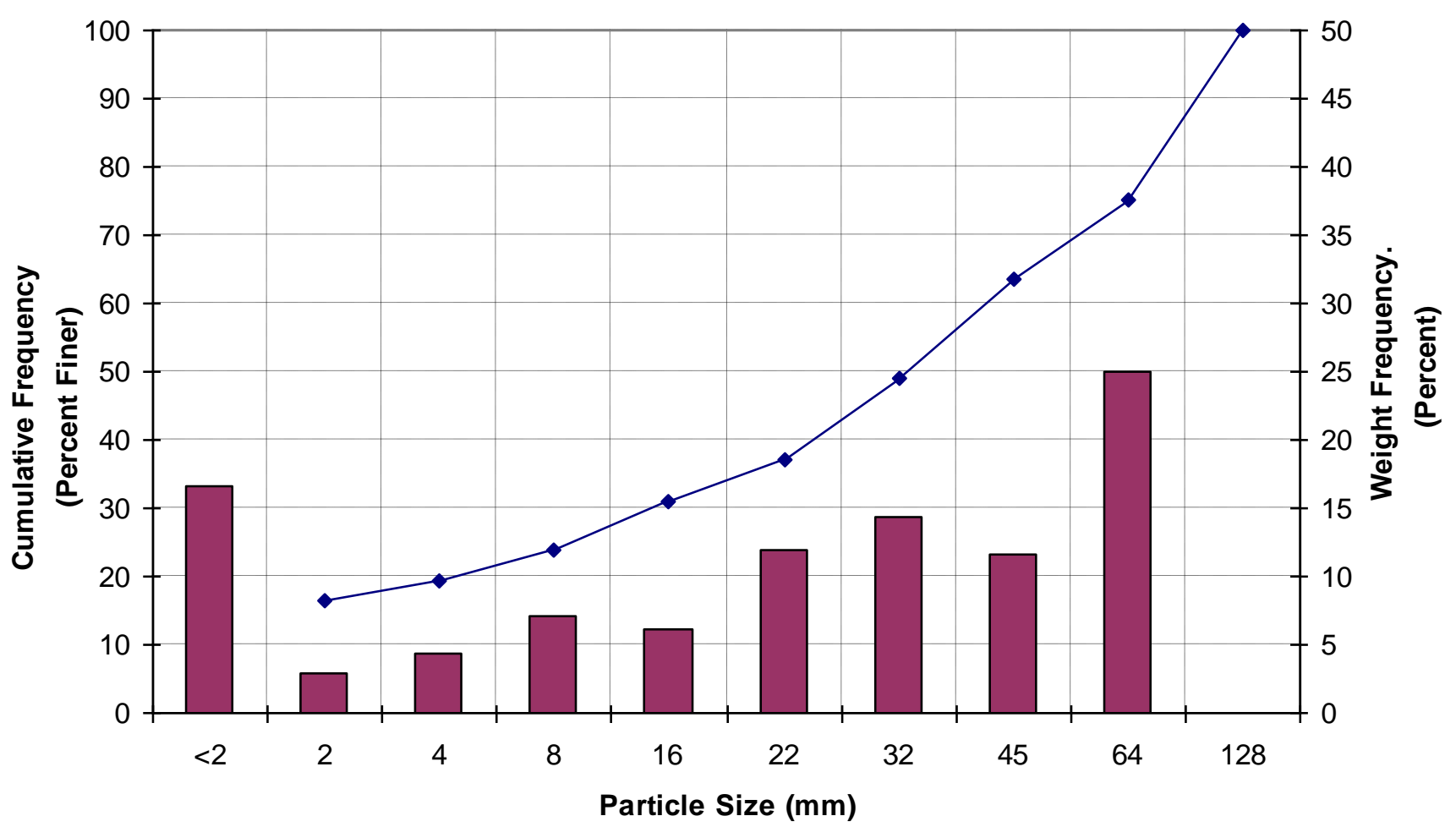




\section{Figure 14: Particle Size Distribution}

\section{West Fork, WV - Station 5}

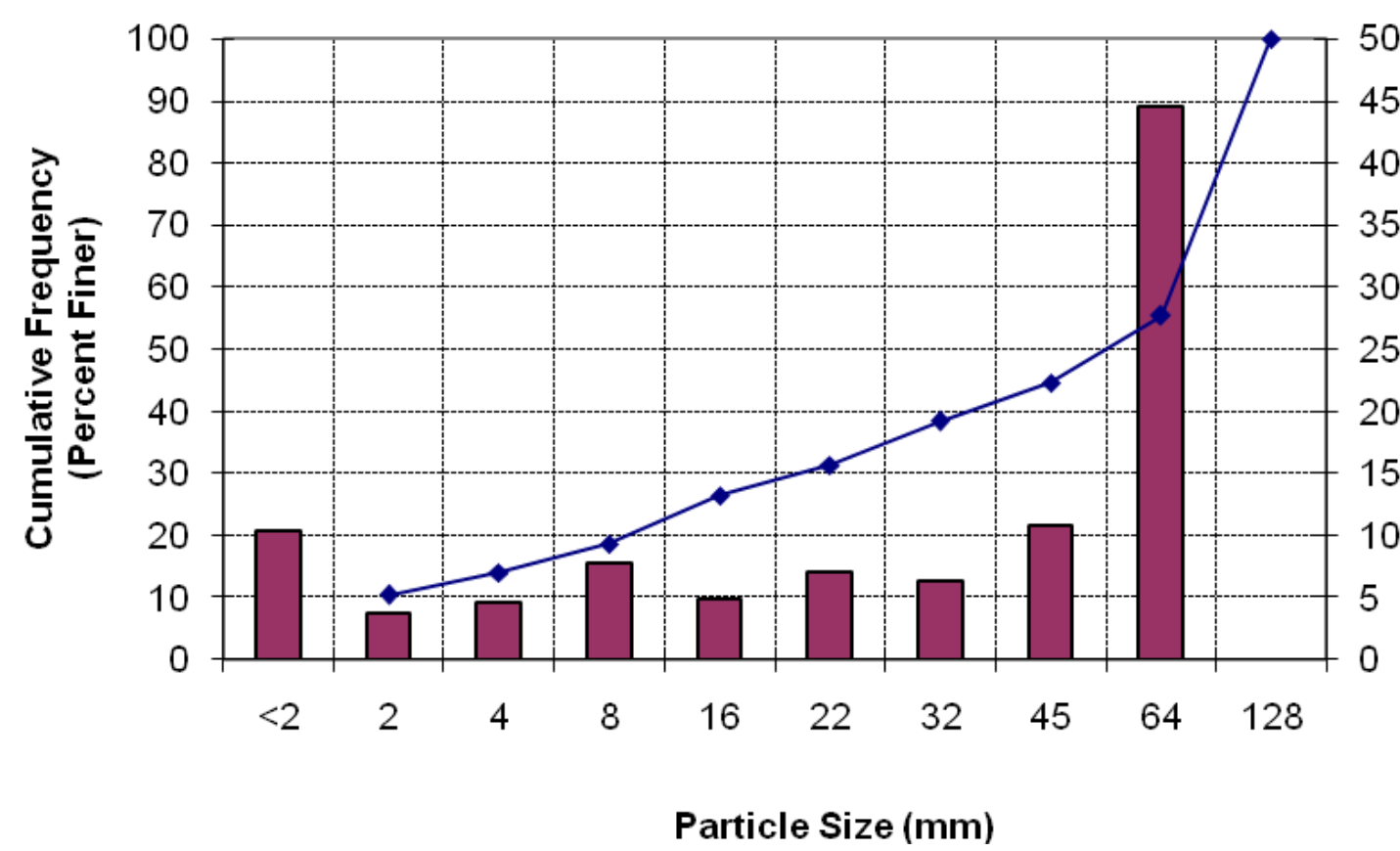


Figure 15: Particle Size Distribution

West Fork, WV - Station 7

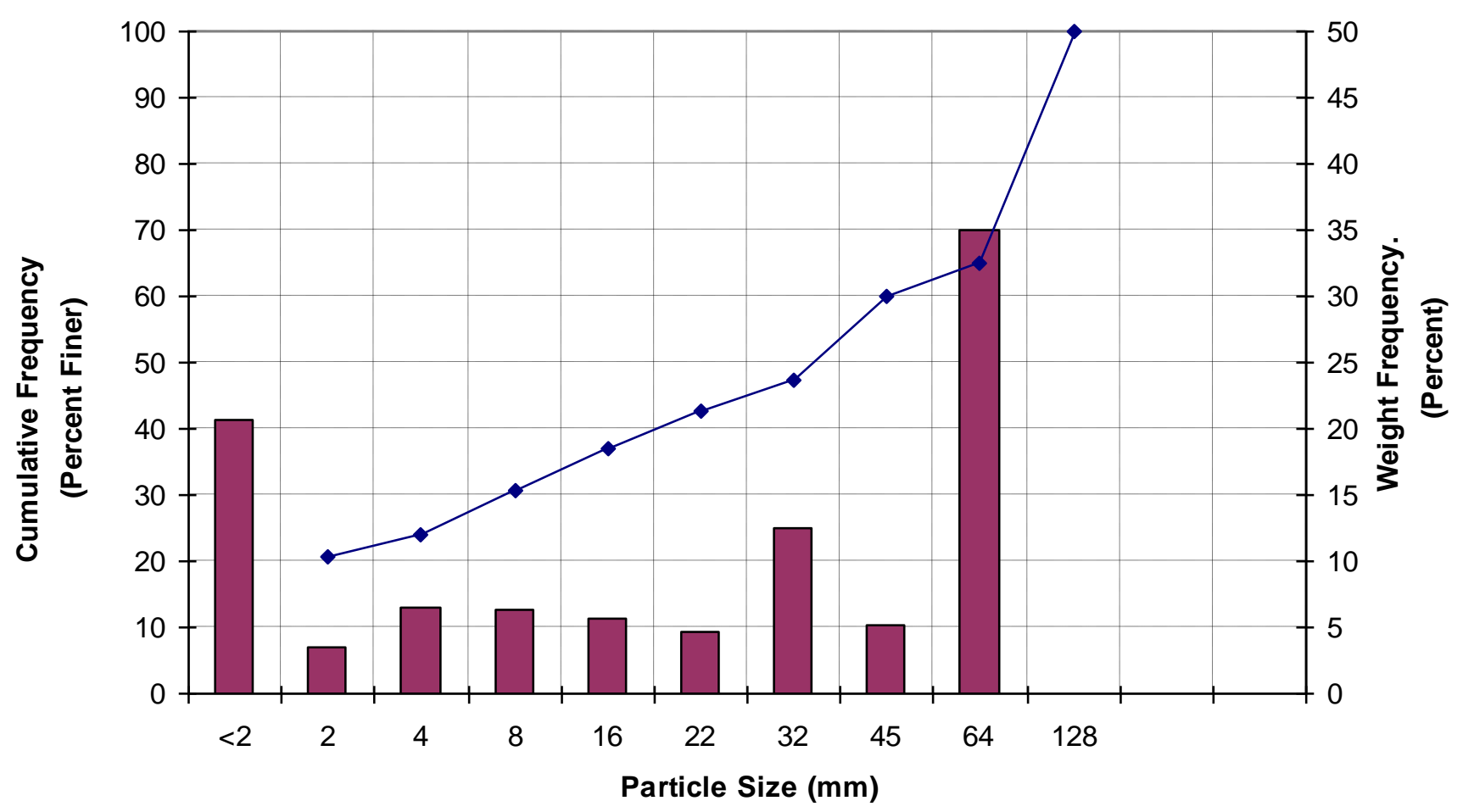


Figure 16: Particle Size Distribution

West Fork, WV - Station 9

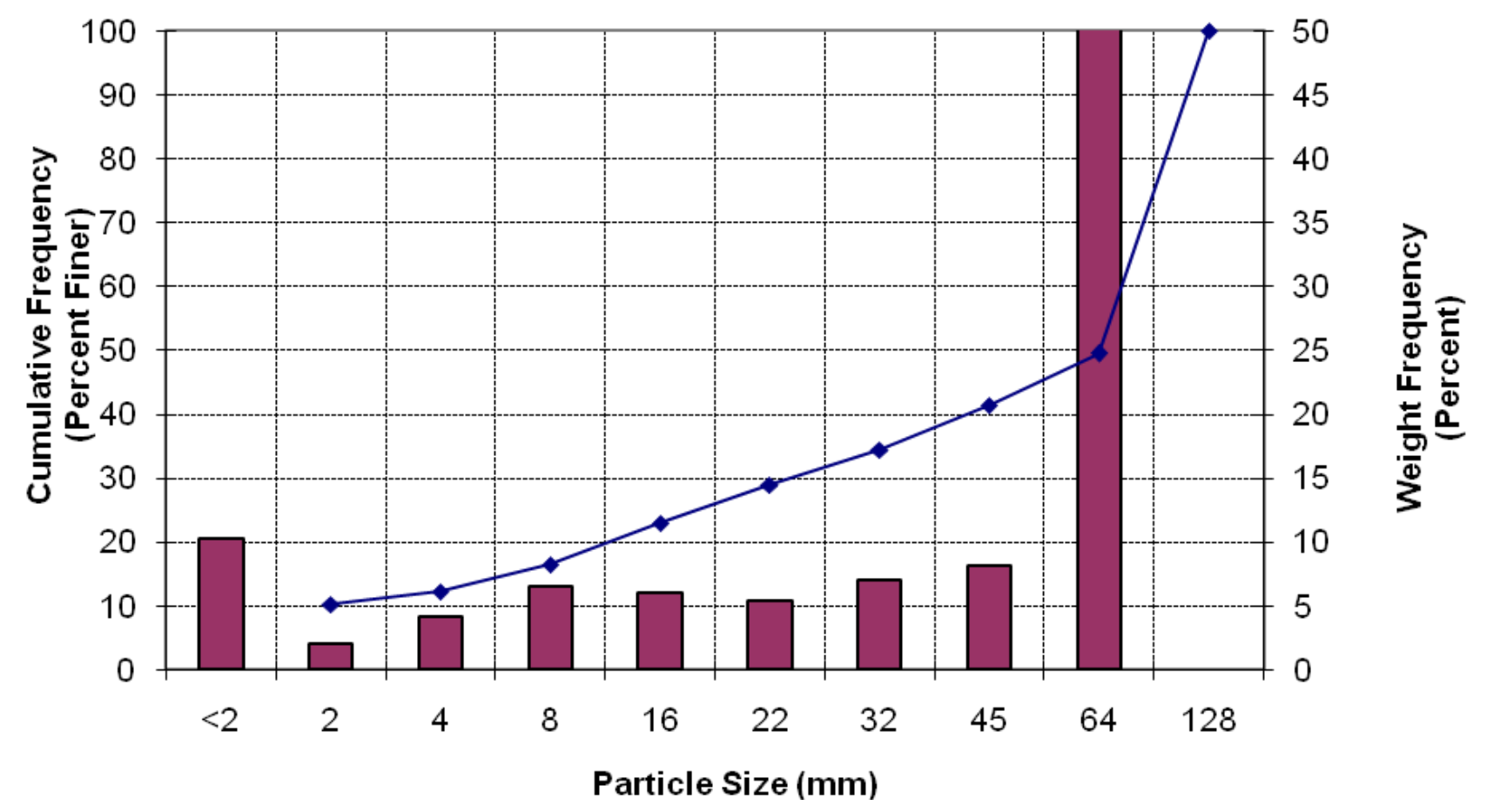


Appendix X

Stream Discharge

Summary Figures 
Figure 1: Crabapple Creek, $\mathrm{OH}$

Normalized Discharge Summary

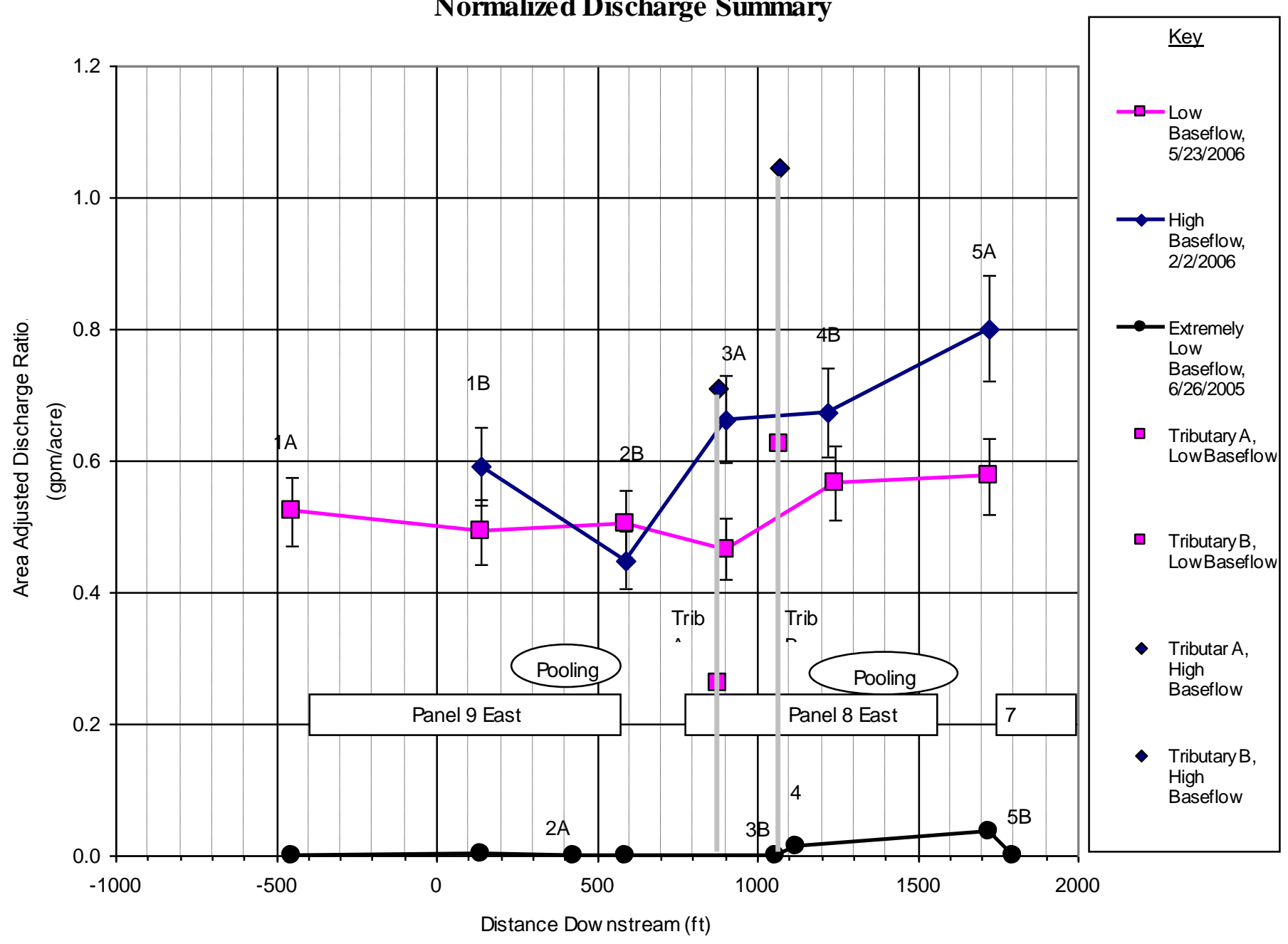


Figure 2: Williams Creek, Ohio

Normalized Discharge Summary

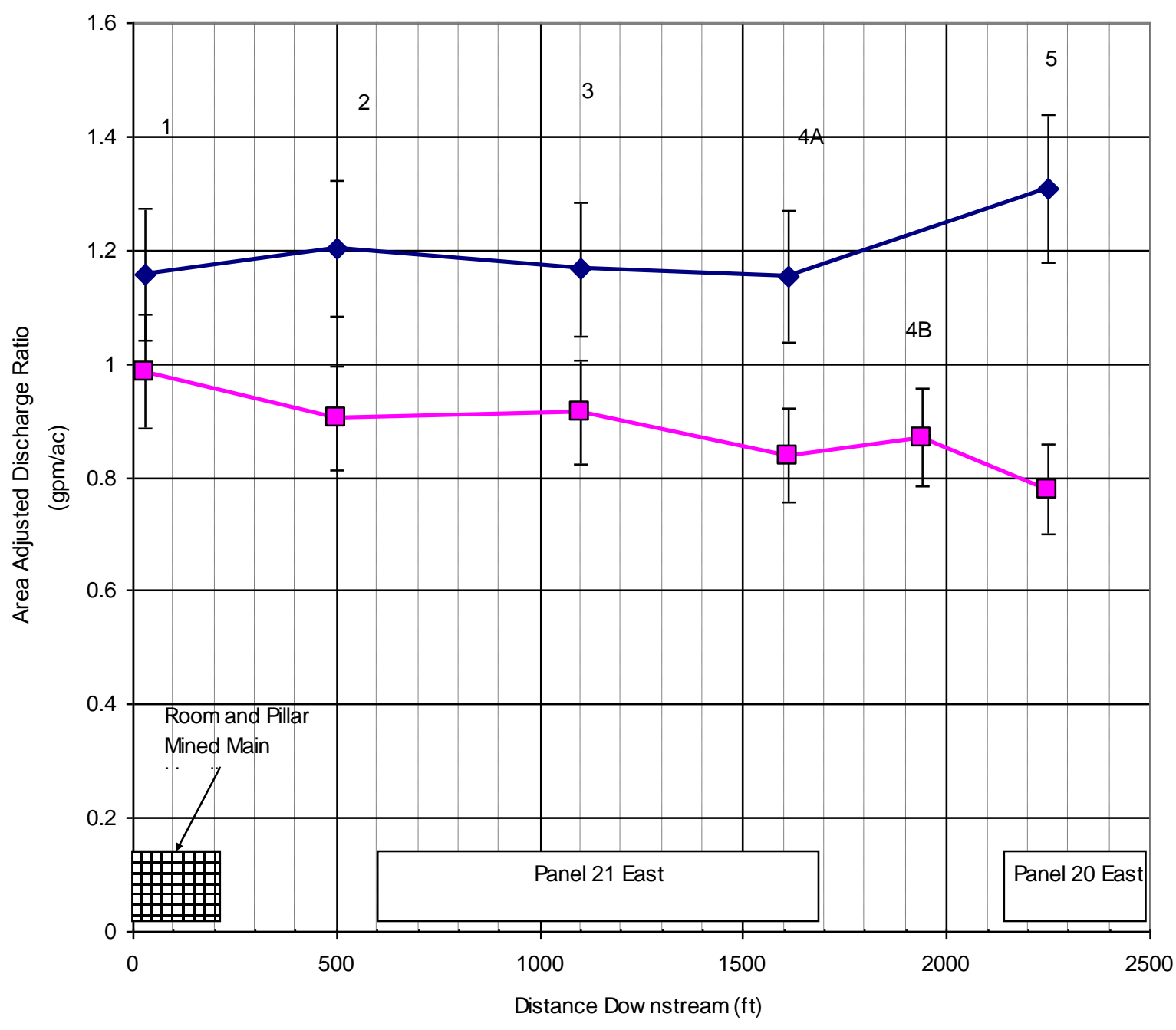

\begin{tabular}{|c|}
\hline Key \\
$\rightarrow$ LowBaseflow \\
Normalized \\
Disch, 5/24/06 \\
\\
\\
\\
$\rightarrow$ High Baseflow \\
Normalized \\
Disch, V27/06
\end{tabular}




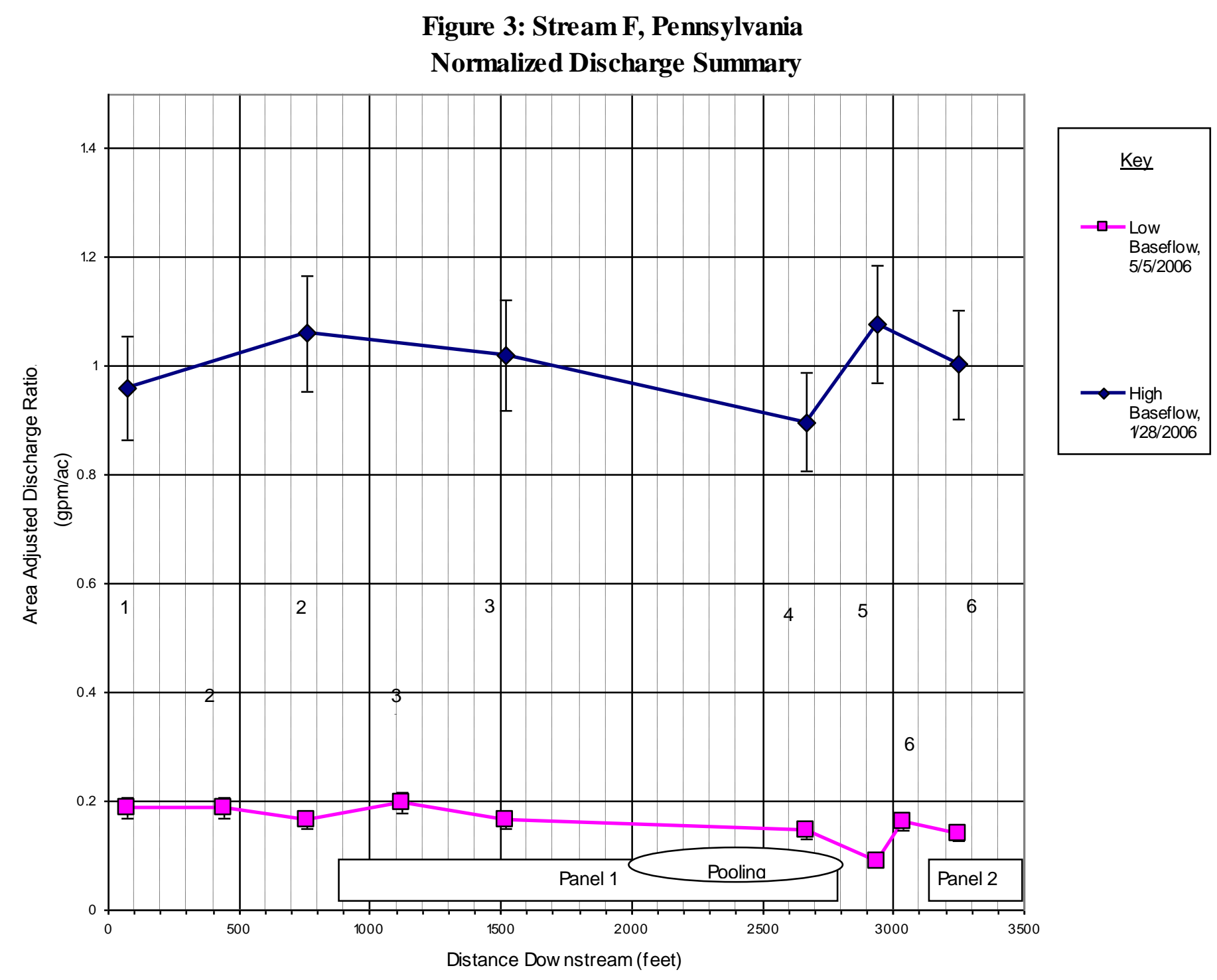




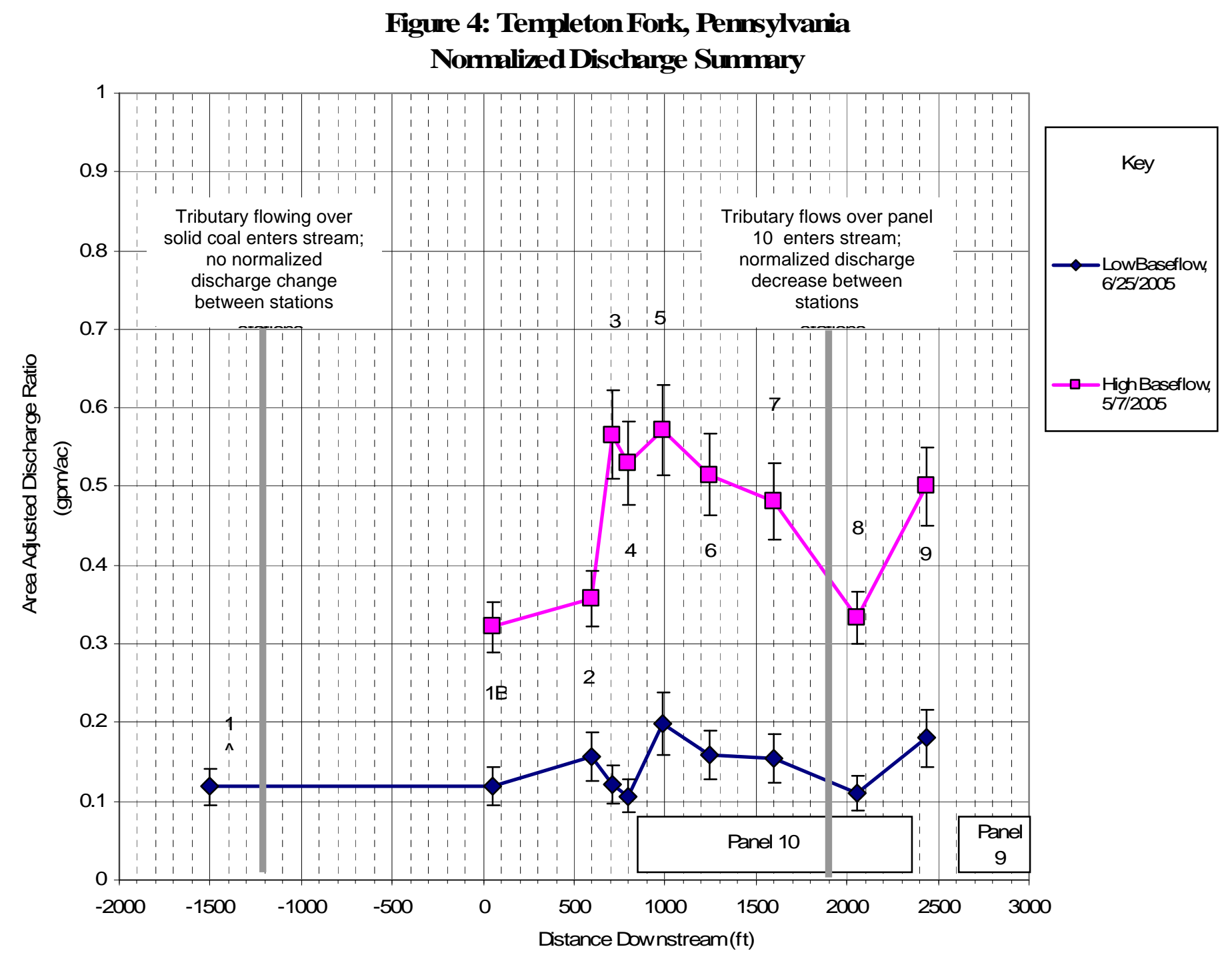


Figure 5: Island Creek, West Virginia Normalized Discharge Summary

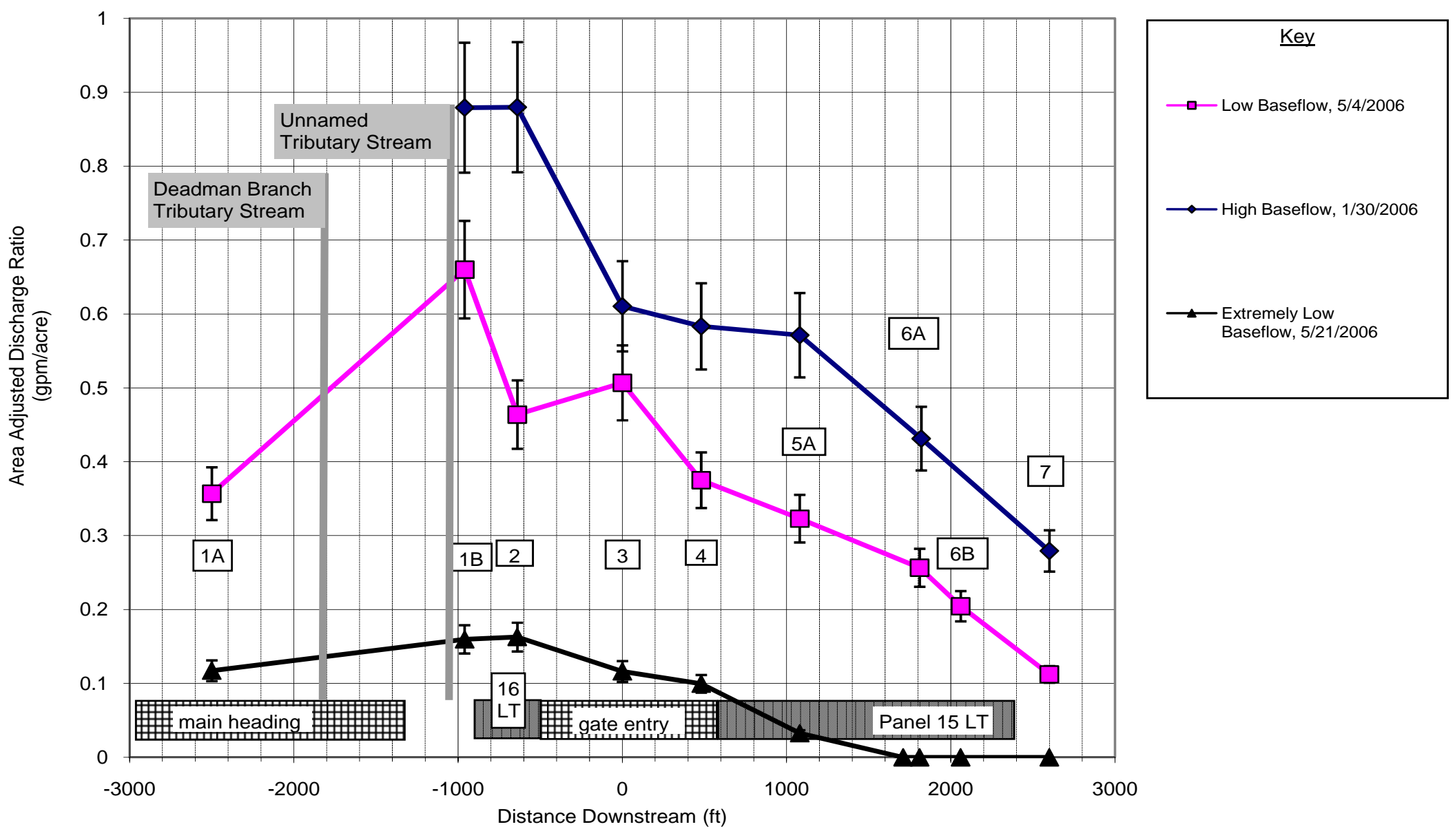




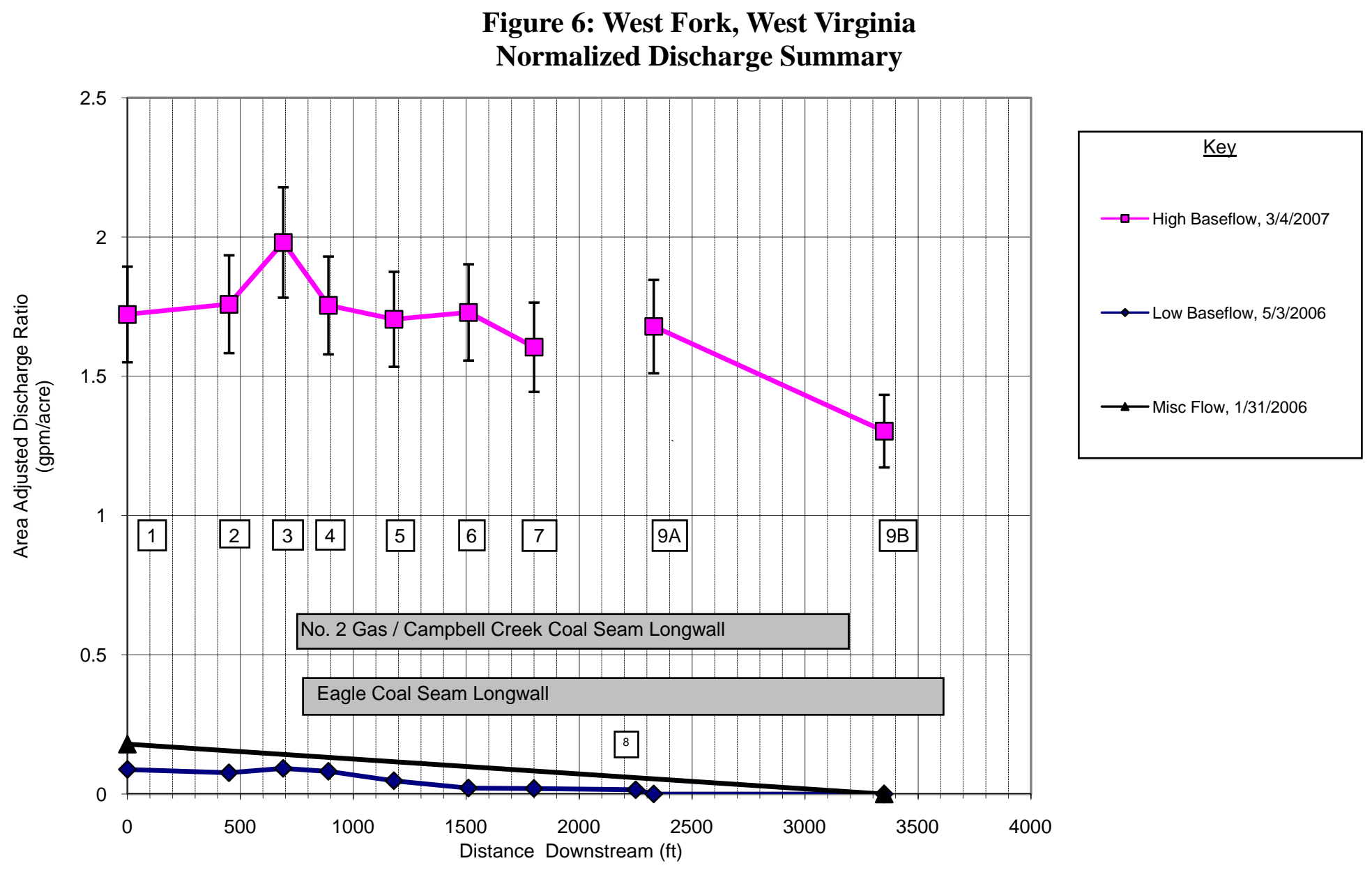




\section{Appendix XI}

\section{Stream Discharge}

\section{Terrain Conductivity Figures}


Figure 1: Crabapple Creek, Ohio

High and Low Baseflow Normalized Discharge

Compared to Terrain Conductivity and Delineated Anomalies

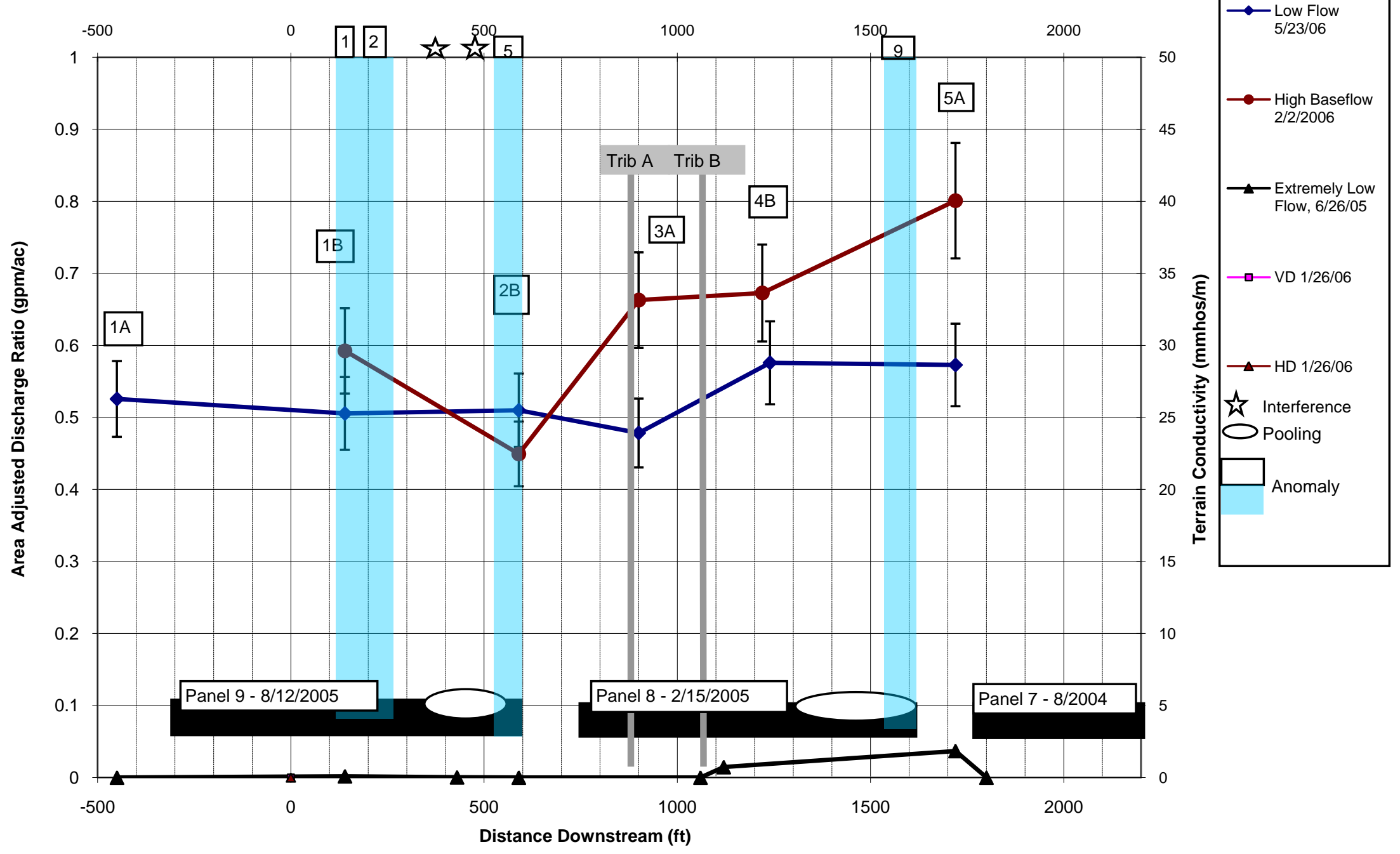


Figure 2: Williams Creek, Ohio

High and Low Baseflow Normalized Discharge Ratio

Compared to Terrain Conductivity and Delineated Anomalies

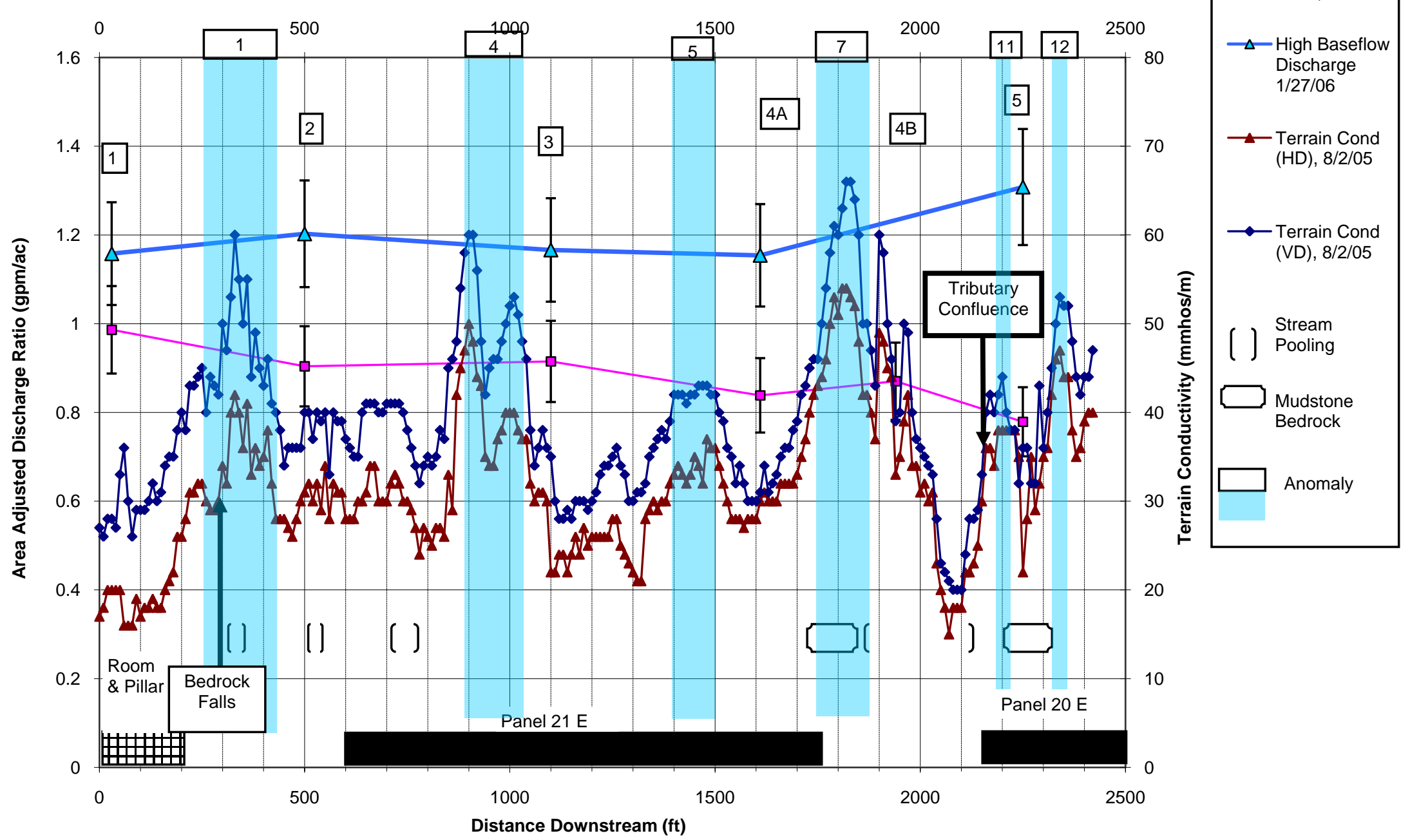


Figure 3: Stream F, Pennsylvania

High and Low Baseflow Normalized Discharge

Compared to Terrain Conductivity and Delineated Anomalies
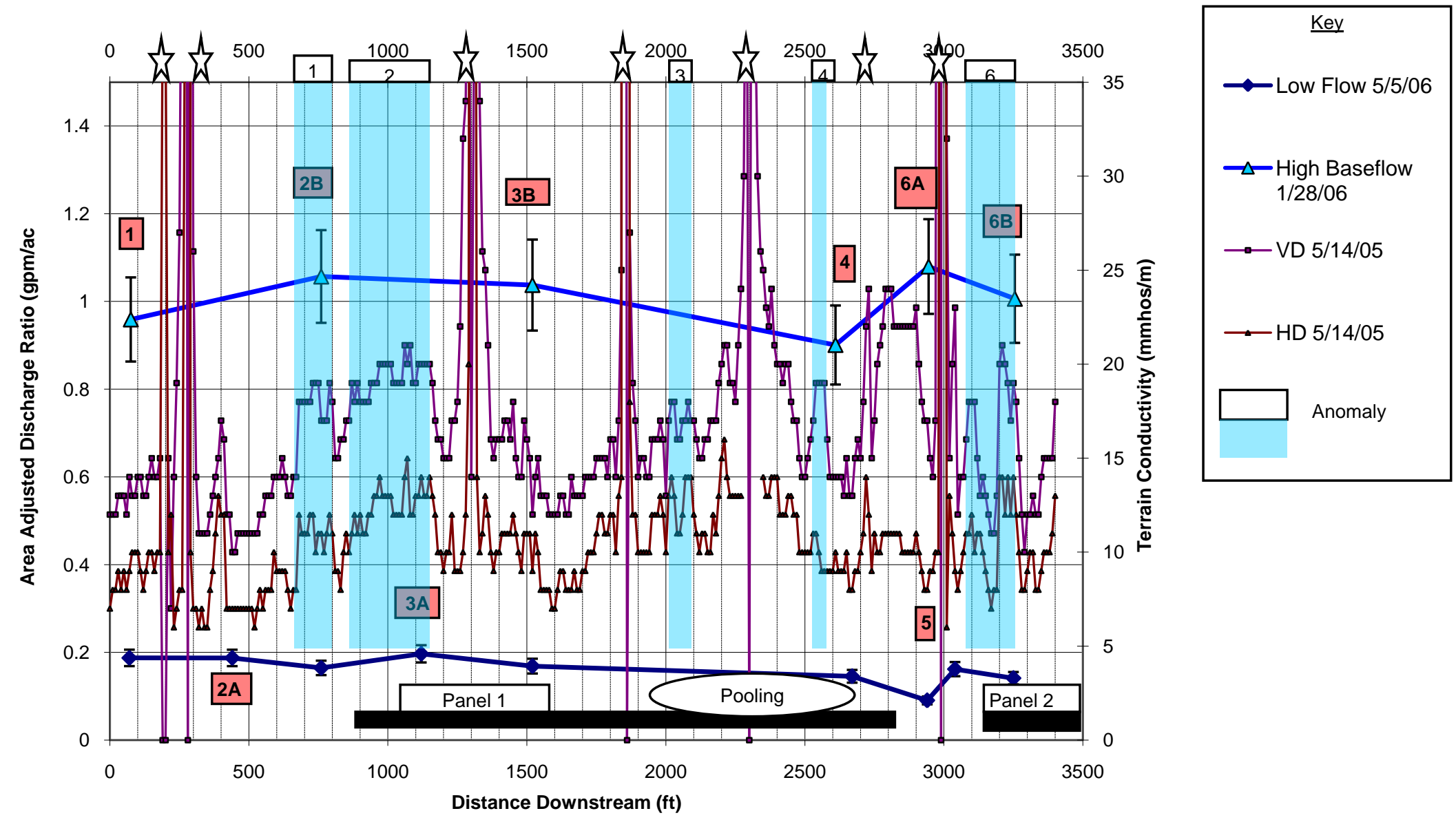
Figure 4: Templeton Fork, Pennsylvania

High and Low Baseflow Normalized Discharge

Compared to Terrain Conductivity Data and Delineated Anomalies

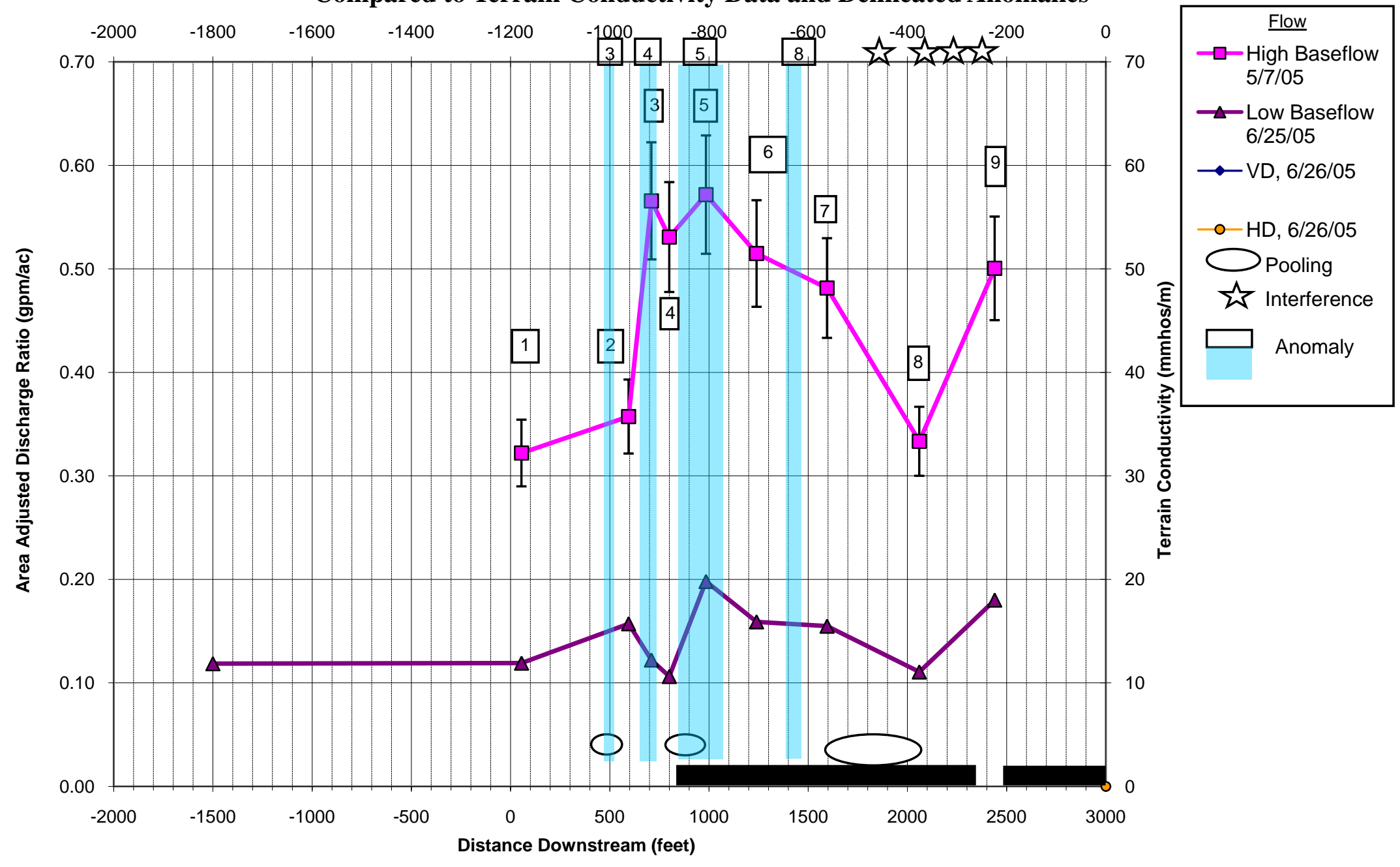


Figure 5: Island Creek, West Virginia

High, Low and Extremely Low Baseflow Normalized Discharge Compared to Terrain Conductivity and Delineated Anomaly

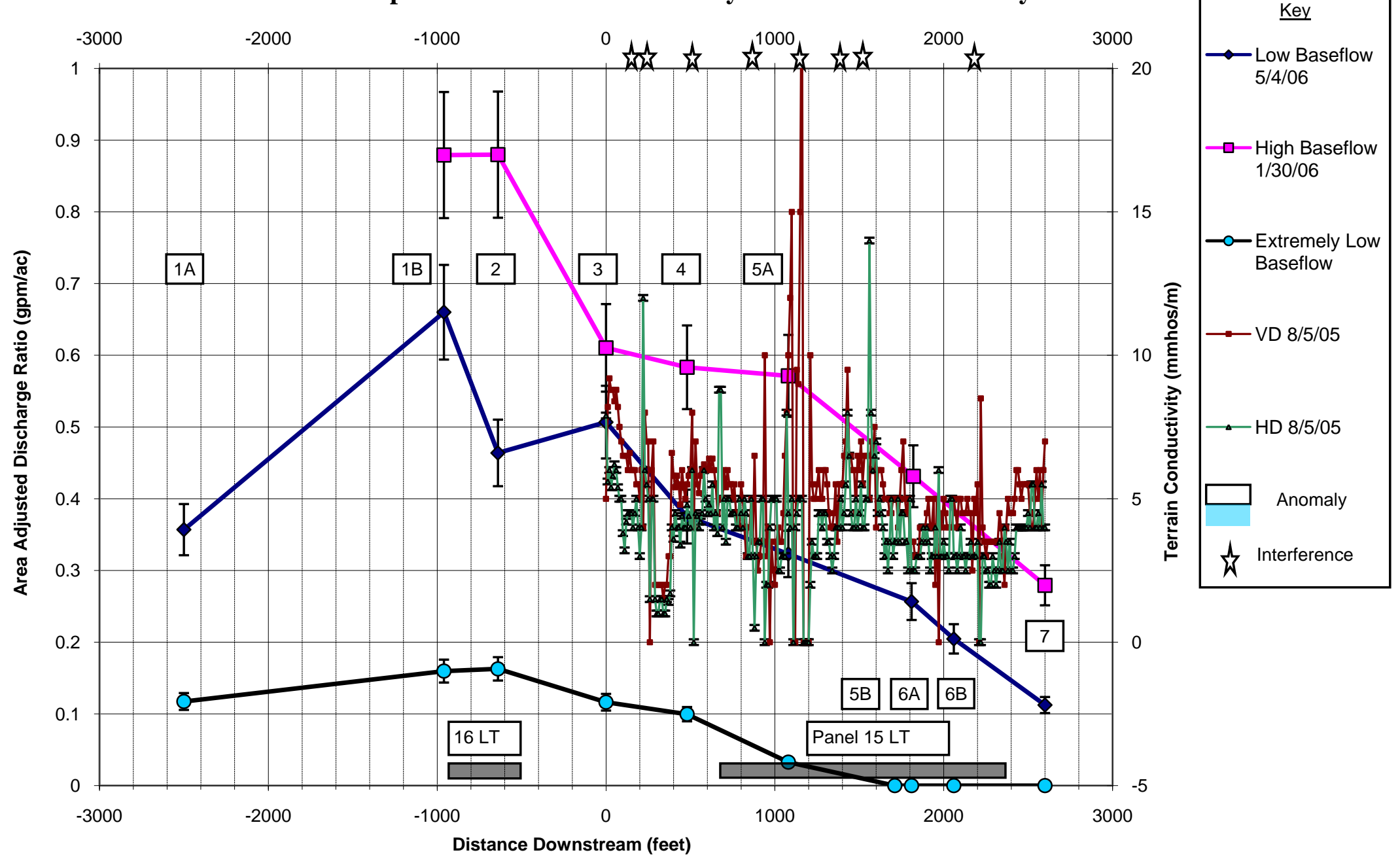


Figure 6: West Fork, West Virginia

High and Low Normalized Baseflow Discharge

Compared to Terrain Conductivity and Delineated Anomalies

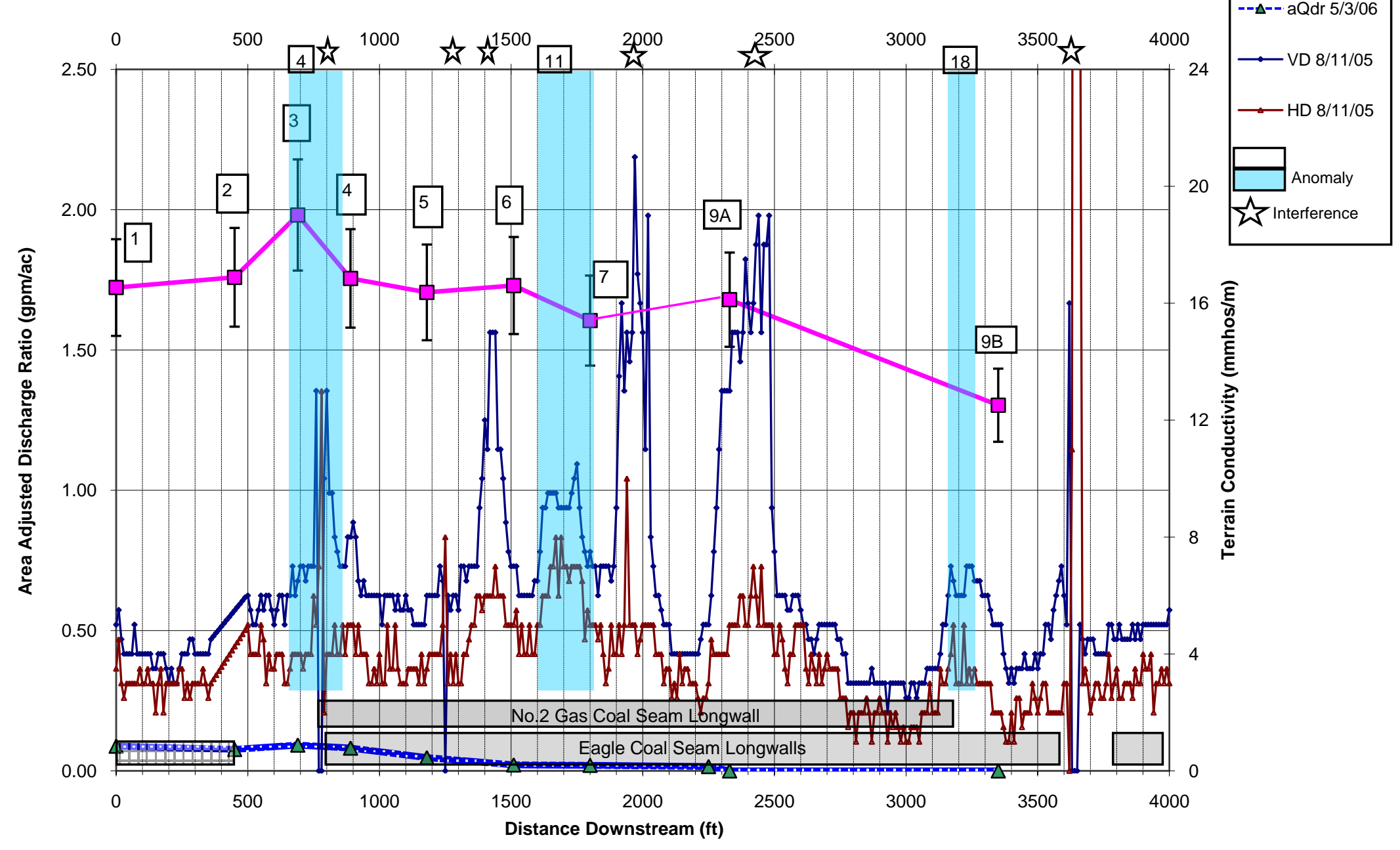


Appendix XII

Stream Discharge

Very Low Frequency Figures 
Figure 1: Crabapple Creek, Ohio

High and Low Baseflow Normalized Discharge

Compared to K-H Filtered VLF Data and Delineated Anomalies

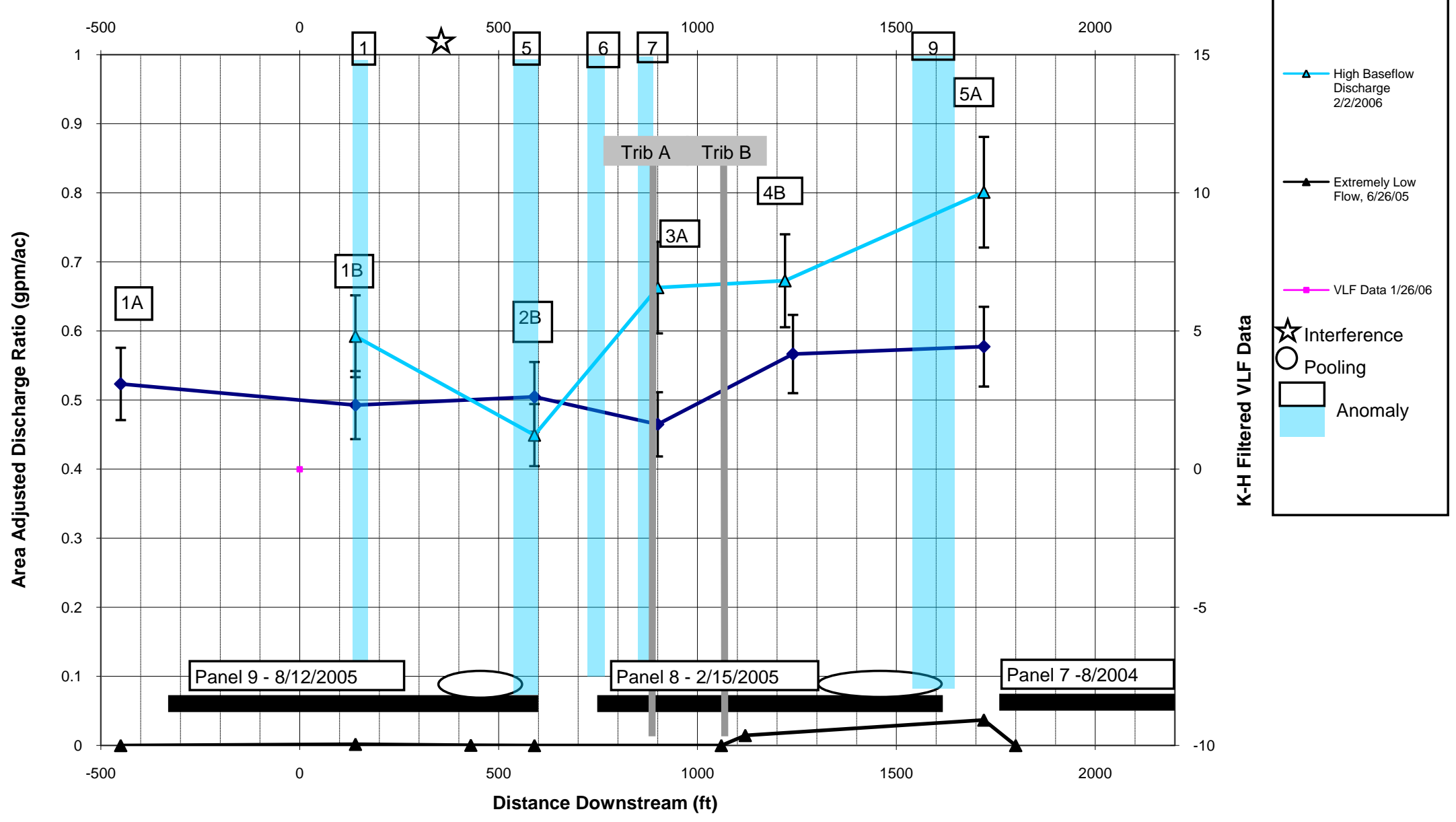


Figure 2: Williams Creek, Ohio

High and Low Baseflow Normalized Discharge Ratio Compared to K-H Filtered VLF Data and Delineated Anomalies

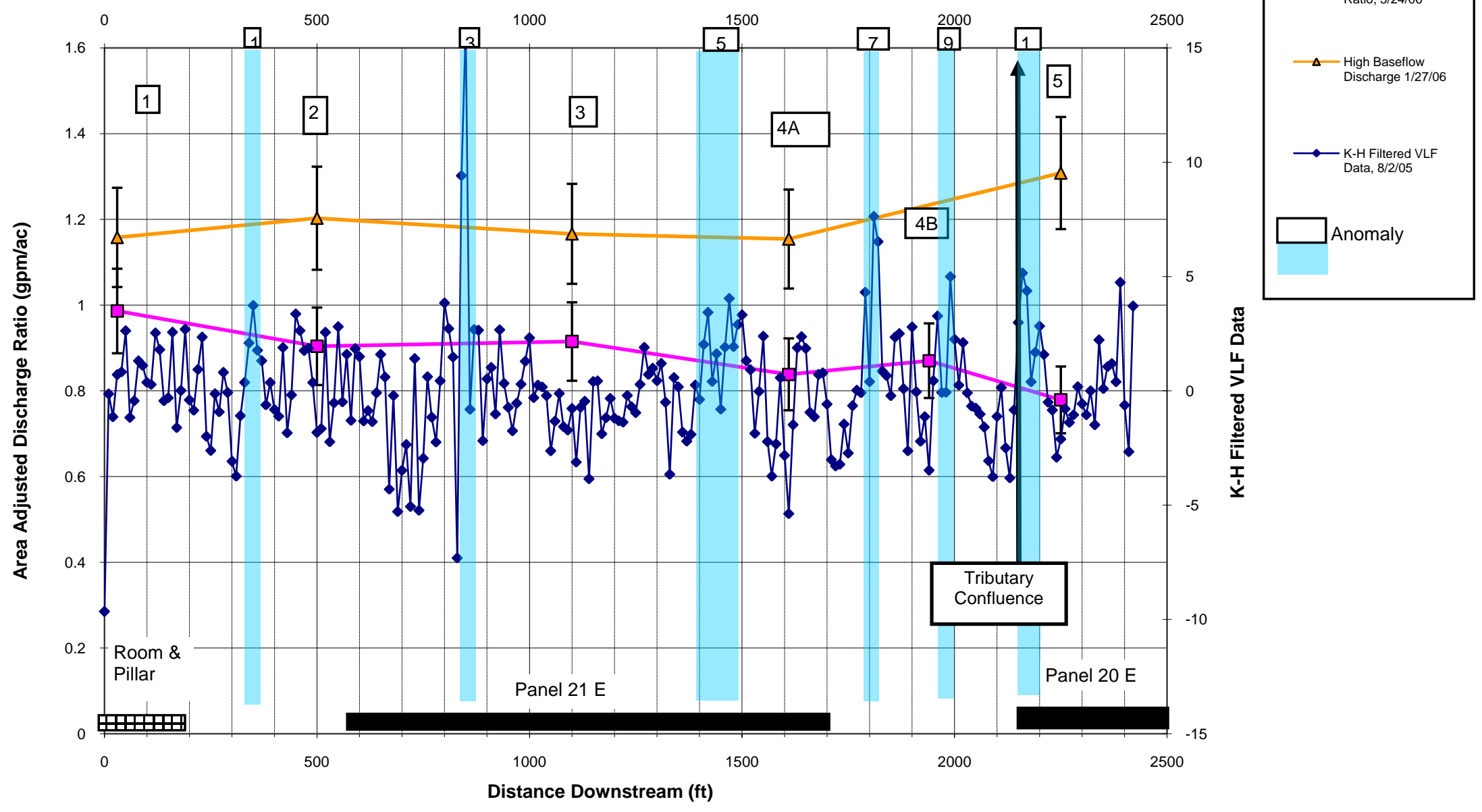


Figure 3: Stream F, Pennsylvania

High and Low Flow Normalized Discharge

Compared to K-H Filtered VLF Data and Delineated Anomalies

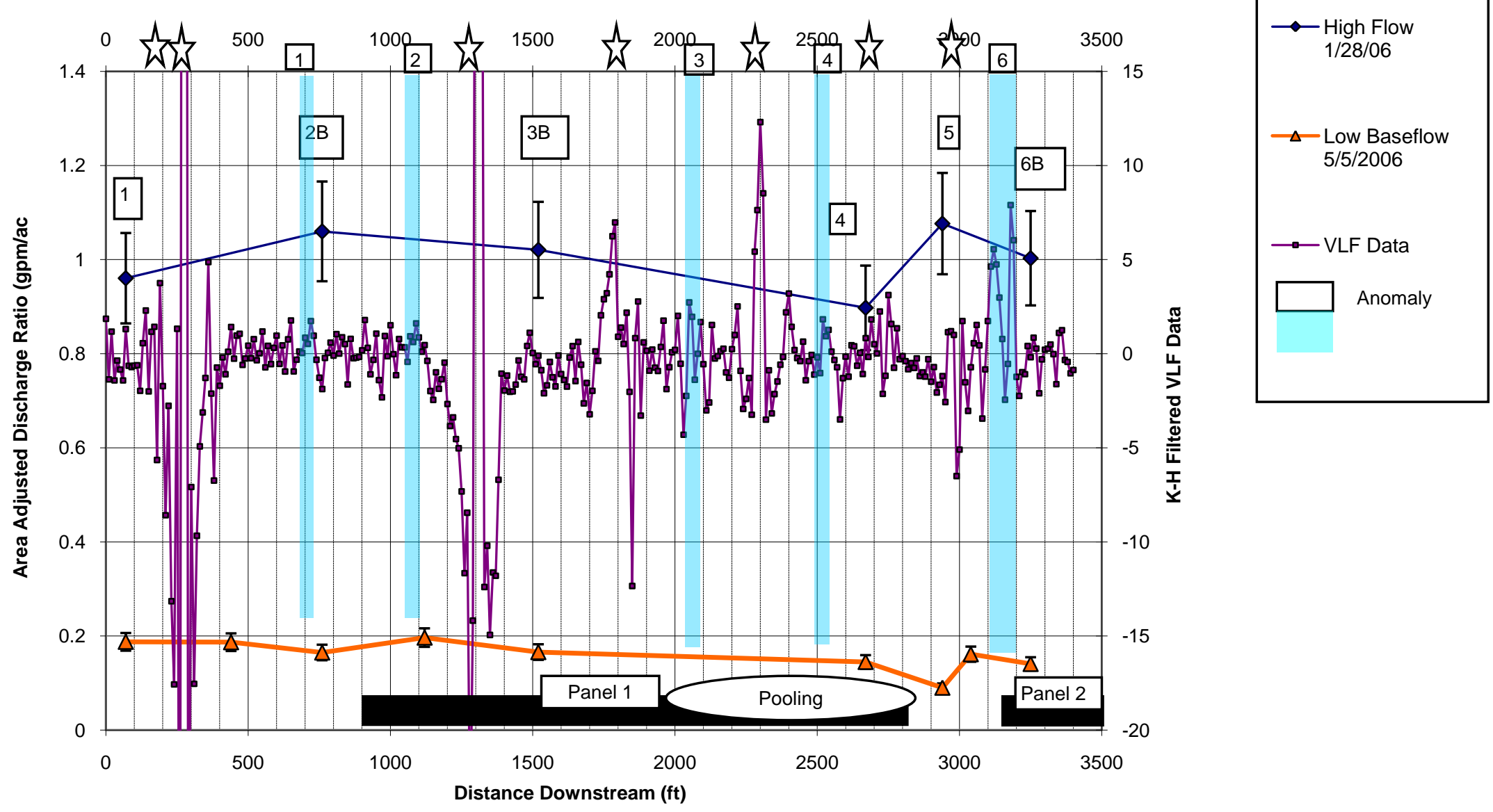


Figure 4: Templeton Fork, Pennsylvania

High and Low Baseflow Normalized Discharge

Compared to Karous-Hjelt Filtered VLF Data and Delineated Anomalies

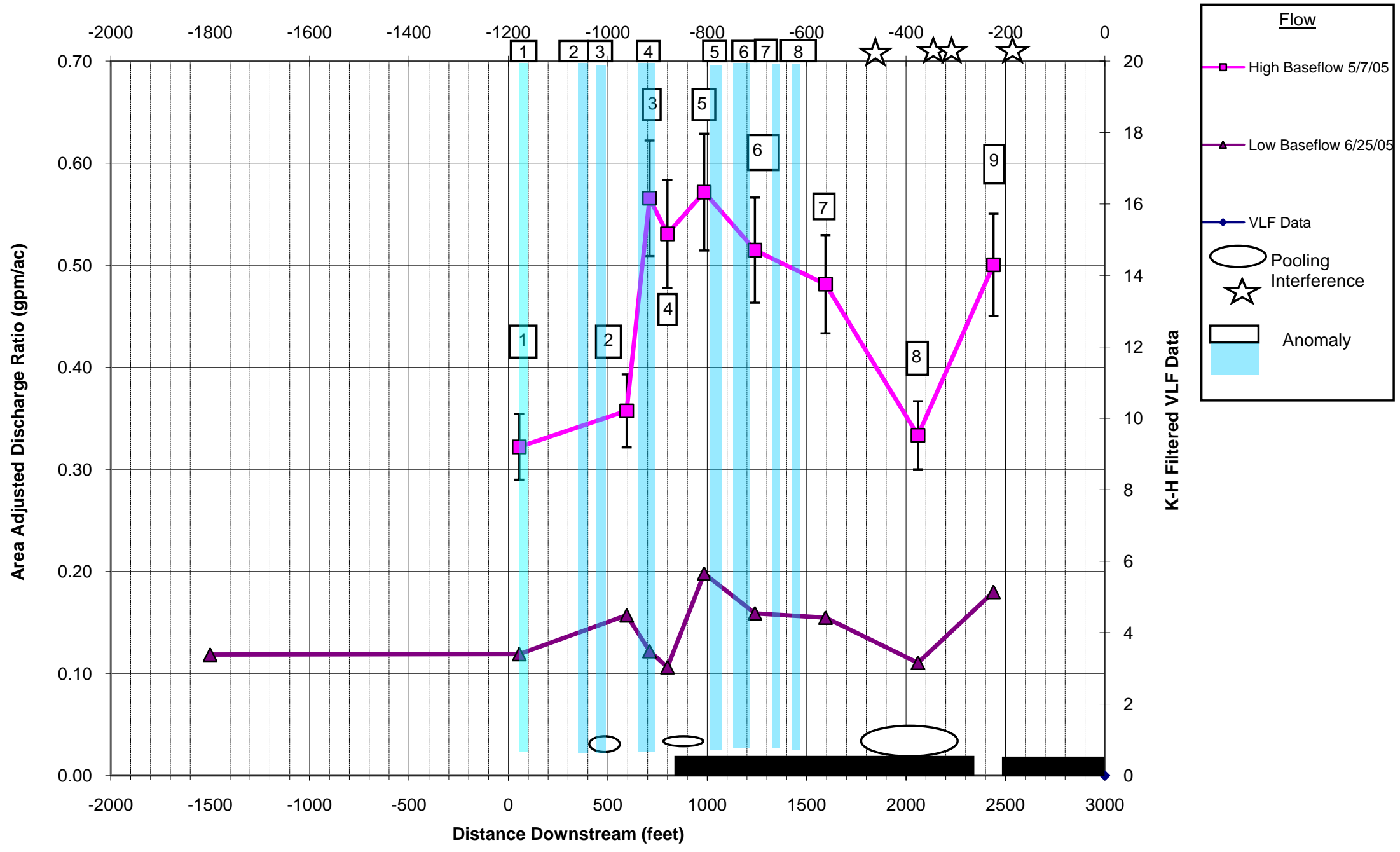


Figure 5: Island Creek, West Virginia

High, Low and Extremely Low Baseflow Normalized Discharge

Compared to K-H Filtered VLF Data and Delineated Anomalies

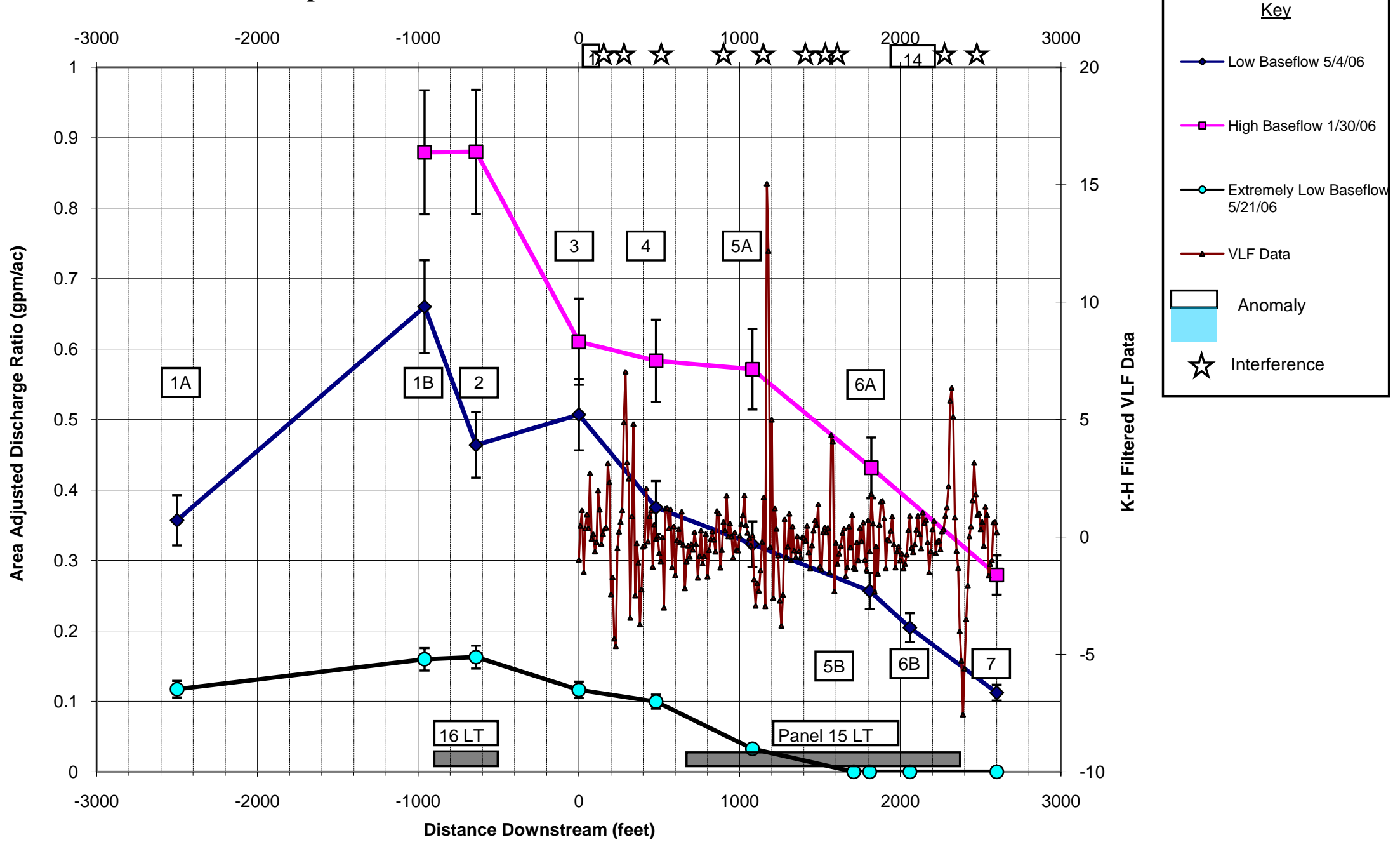


Figure 6: West Fork, West Virginia

High and Low Normalized Baseflow Discharge

Compared to K-H Filtered VLF Data and Delineated Anomalies
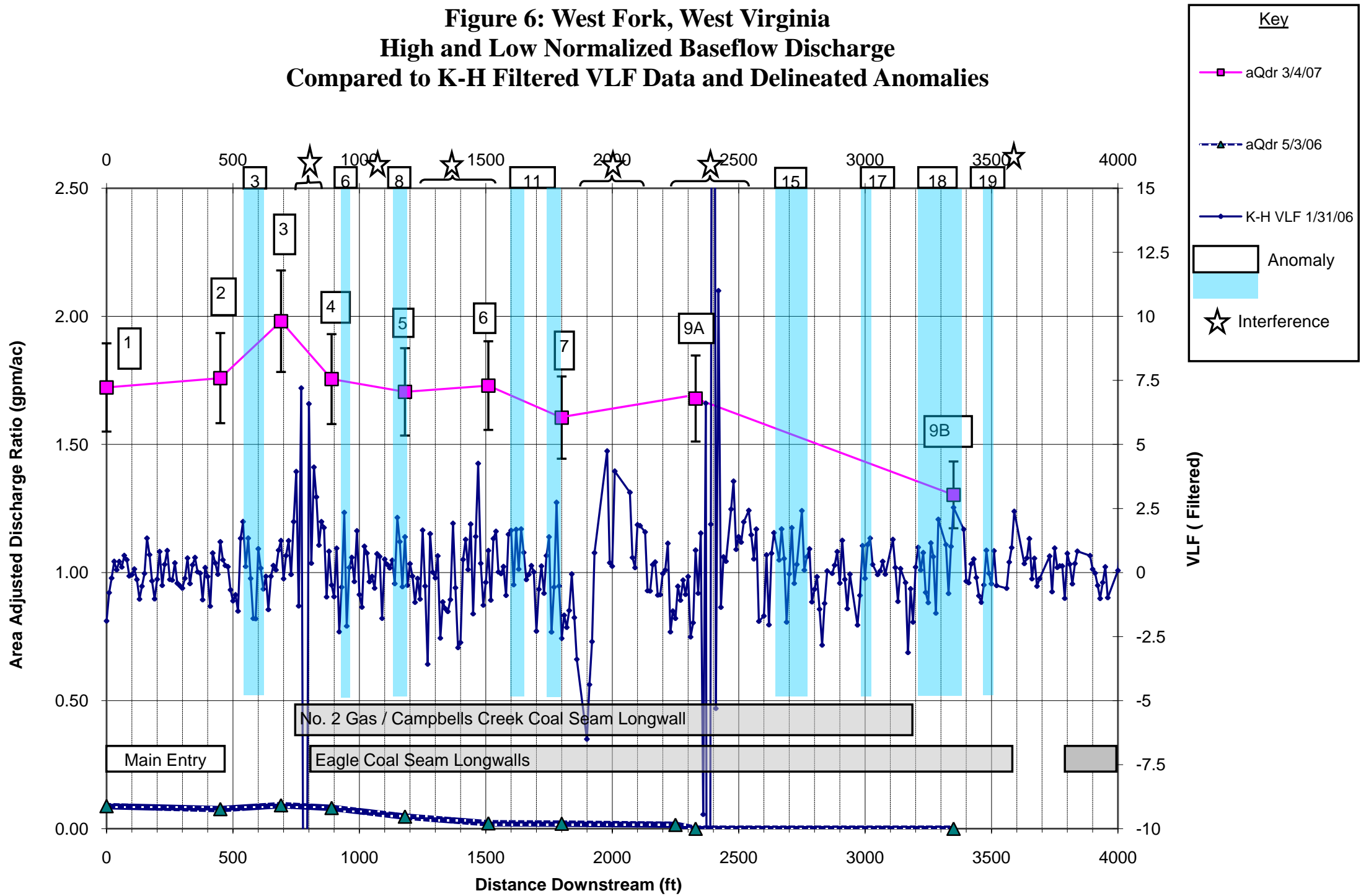

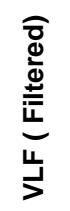




\section{Appendix XIII}

Geologic Logs for Study Area 


\section{TABLE 1}

OHIO STUDY AREA

Data reproduced from drillers log

Drill Hole: N-86-19

Date Drilled: December 1, 1986

Drilling Company: L.J. Hughes

Surface Elevation: Approx 1060'

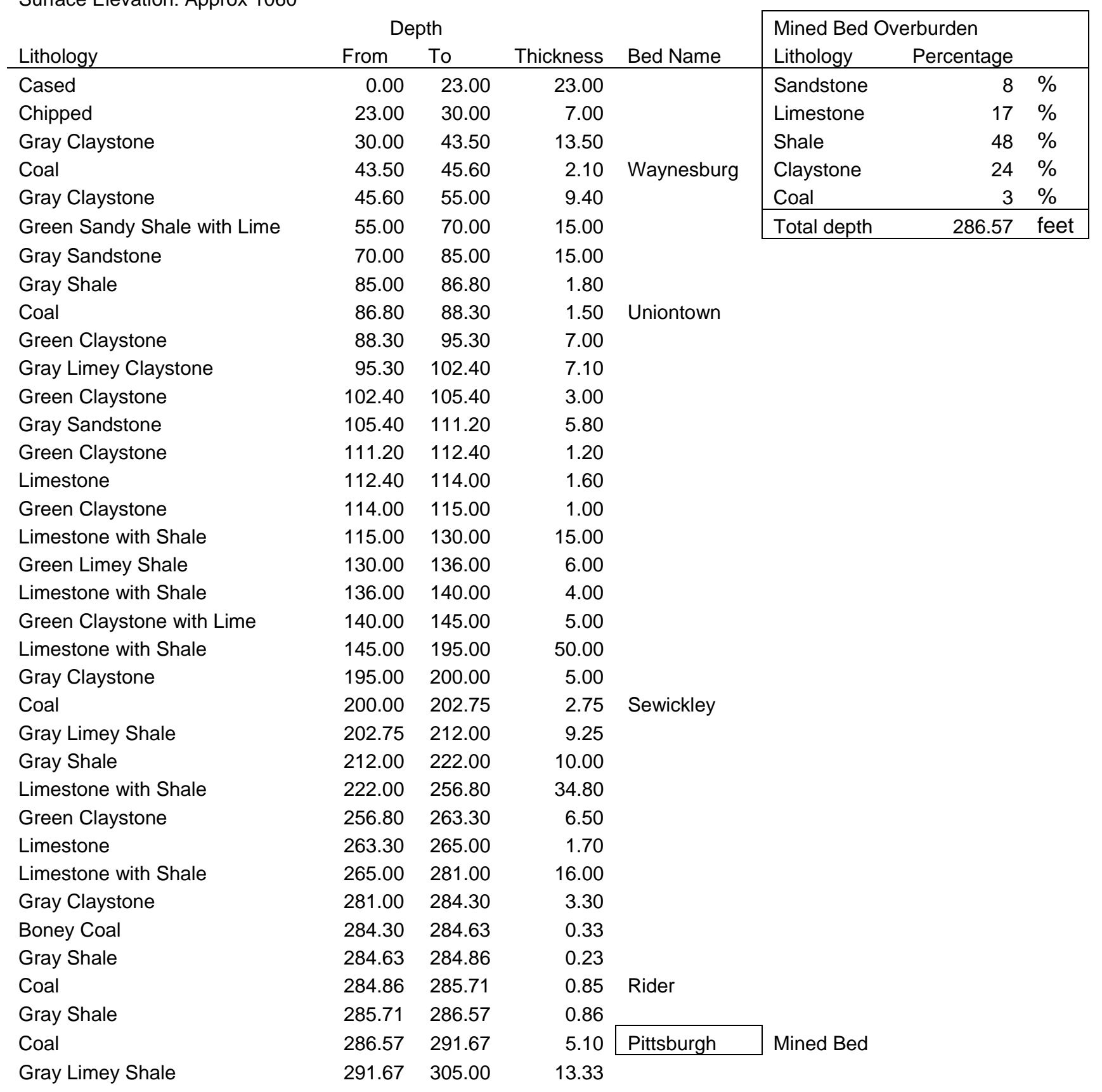




\section{TABLE 2}

\section{PENNSYLVANIA STUDY AREA}

Data reproduced from Mine Operator's records.

Drill Hole: $\mathrm{XXX}$

Date Drilled: Unk

Drilling Company: Unk

Surface Elevation: 1085.36'

\begin{tabular}{|c|c|c|c|c|c|c|}
\hline \multirow[b]{3}{*}{ Lithology } & \multirow{2}{*}{\multicolumn{2}{|c|}{ Depth }} & \multirow[b]{3}{*}{ Thickness } & \multirow[b]{3}{*}{ Bed Name } & \\
\hline & & & & & \multicolumn{2}{|c|}{$\begin{array}{l}\text { Mined Bed Overburden } \\
\text { Lithology } \quad \text { Percentage }\end{array}$} \\
\hline & From & To & & & Sandstone & $25 \%$ \\
\hline Rotary Methods & 0.00 & 21.00 & 21.00 & & Limestone & $23 \%$ \\
\hline Sandstone & 21.00 & 22.00 & 1.00 & & Shale & $40 \%$ \\
\hline Gray Clay Shale & 22.00 & 49.40 & 27.40 & & Claystone & $10 \%$ \\
\hline Gray Sandy Silt Shale & 49.40 & 60.00 & 10.60 & & Coal & $2 \%$ \\
\hline Gray Clay Shale & 60.00 & 62.00 & 2.00 & & Total depth & 628.40 feet \\
\hline Gray Sandy Silt Shale & 62.00 & 69.80 & 7.80 & & & \\
\hline Sandstone & 69.80 & 76.10 & 6.30 & & & \\
\hline Shale & 76.10 & 97.00 & 20.90 & & & \\
\hline Carbonaceous Clay Shale & 97.00 & 98.40 & 1.40 & & & \\
\hline Limestone & 98.40 & 103.60 & 5.20 & & & \\
\hline Shale & 103.60 & 107.20 & 3.60 & & & \\
\hline Carbonaceous Clay Shale & 107.20 & 110.00 & 2.80 & & & \\
\hline Dark Shale & 110.00 & 111.80 & 1.80 & & & \\
\hline Gray Sandy Silt Shale & 111.80 & 119.50 & 7.70 & & & \\
\hline Dark Shale & 119.50 & 123.70 & 4.20 & & & \\
\hline Dark Shale & 123.70 & 125.80 & 2.10 & & & \\
\hline Shale & 125.80 & 127.20 & 1.40 & & & \\
\hline Sandstone & 127.20 & 128.50 & 1.30 & & & \\
\hline Shale & 128.50 & 137.00 & 8.50 & & & \\
\hline Gray Sandy Silt Shale & 137.00 & 142.50 & 5.50 & & & \\
\hline Sandstone & 142.50 & 150.00 & 7.50 & & & \\
\hline Dark Shale & 150.00 & 152.80 & 2.80 & & & \\
\hline Coal & 152.80 & 154.00 & 1.20 & Little Washington & & \\
\hline Shale & 154.00 & 165.60 & 11.60 & & & \\
\hline Gray Sandy Silt Shale & 165.60 & 173.60 & 8.00 & & & \\
\hline Shale & 173.60 & 181.60 & 8.00 & & & \\
\hline Sandstone & 181.60 & 188.30 & 6.70 & & & \\
\hline Shale & 188.30 & 208.30 & 20.00 & & & \\
\hline Coal & 208.30 & 209.60 & 1.30 & Waynesburg "A" & & \\
\hline Shale & 209.60 & 222.60 & 13.00 & & & \\
\hline Sandstone & 222.60 & 281.30 & 58.70 & & & \\
\hline Dark Shale & 281.30 & 287.60 & 6.30 & & & \\
\hline Coal & 287.60 & 289.20 & 1.60 & Waynesburg UB & & \\
\hline Dark Shale & 289.20 & 290.20 & 1.00 & & & \\
\hline Coal & 290.20 & 293.70 & 3.50 & Waynesburg LB & & \\
\hline Shale & 293.70 & 298.80 & 5.10 & & & \\
\hline Gray Sandy Silt Shale & 298.80 & 312.80 & 14.00 & & & \\
\hline Limestone & 312.80 & 314.80 & 2.00 & & & \\
\hline
\end{tabular}


PENNSYLVANIA STUDY AREA (cont.)

\begin{tabular}{|c|c|c|c|c|}
\hline Lithology & $\begin{array}{l}\text { Depth } \\
\text { From }\end{array}$ & To & Thickness & Bed Name \\
\hline Shale & 314.80 & 318.80 & 4.00 & \\
\hline Sandstone & 318.80 & 355.00 & 36.20 & \\
\hline Gray Clay Shale & 355.00 & 357.00 & 2.00 & \\
\hline Sandstone & 357.00 & 360.00 & 3.00 & \\
\hline Gray Clay Shale & 360.00 & 375.30 & 15.30 & \\
\hline Limestone & 375.30 & 387.00 & 11.70 & \\
\hline Gray Clay Shale & 387.00 & 403.00 & 16.00 & \\
\hline Limestone & 403.00 & 486.00 & 83.00 & \\
\hline Gray Sandy Silt Shale & 486.00 & 490.10 & 4.10 & \\
\hline Sandstone & 490.10 & 500.00 & 9.90 & \\
\hline Sandstone & 500.00 & 520.30 & 20.30 & \\
\hline Dark Gray Clay Shale & 520.30 & 520.40 & 0.10 & \\
\hline Coal & 520.40 & 523.50 & 3.10 & Sewickley UB \\
\hline Gray Clay Shale & 523.50 & 531.30 & 7.80 & \\
\hline Sandstone & 531.30 & 548.70 & 17.40 & \\
\hline Dark Gray Clay Shale & 548.70 & 549.70 & 1.00 & \\
\hline Coal & 549.70 & 550.60 & 0.90 & Sewickley LB \\
\hline Carbonaceous Clay Shale & 550.60 & 552.00 & 1.40 & \\
\hline Gray Clay Shale & 552.00 & 554.80 & 2.80 & \\
\hline Limestone & 554.80 & 580.00 & 25.20 & \\
\hline Limestone & 580.00 & 584.10 & 4.10 & \\
\hline Green Claystone & 584.10 & 584.15 & 0.05 & \\
\hline Limestone & 584.15 & 584.35 & 0.20 & \\
\hline Calcareous Clay Shale & 584.35 & 584.70 & 0.35 & \\
\hline Green Sandy Silt Shale & 584.70 & 585.05 & 0.35 & \\
\hline Gray Clay Shale & 585.05 & 585.15 & 0.10 & \\
\hline Limestone & 585.15 & 592.35 & 7.20 & \\
\hline Claystone & 592.35 & 594.80 & 2.45 & \\
\hline Carbonaceous Clay Shale & 594.80 & 594.95 & 0.15 & \\
\hline Bone Coal & 594.95 & 595.00 & 0.05 & Redstone \\
\hline Carbonaceous Clay Shale & 595.00 & 595.25 & 0.25 & \\
\hline Gray Clay Shale & 595.25 & 595.90 & 0.65 & \\
\hline Calcareous Clay Shale & 595.90 & 598.65 & 2.75 & \\
\hline Limestone & 598.65 & 600.00 & 1.35 & \\
\hline Limestone & 600.00 & 606.95 & 6.95 & \\
\hline Green Claystone & 606.95 & 608.00 & 1.05 & \\
\hline Limestone & 608.00 & 608.80 & 0.80 & \\
\hline Green Claystone & 608.80 & 611.50 & 2.70 & \\
\hline Gray Clay Shale & 611.50 & 620.00 & 8.50 & \\
\hline Gray Clay Shale & 620.00 & 621.35 & 1.35 & \\
\hline Dark Gray Clay Shale & 621.35 & 621.55 & 0.20 & \\
\hline Carbonaceous Clay Shale & 621.55 & 622.65 & 1.10 & \\
\hline Sandstone & 622.65 & 622.70 & 0.05 & \\
\hline Coal & 622.70 & 623.90 & 1.20 & Rider \\
\hline Carbonaceous Clay Shale & 623.90 & 624.55 & 0.65 & \\
\hline Coal & 624.55 & 624.60 & 0.05 & Rider \\
\hline Carbonaceous Clay Shale & 624.60 & 625.15 & 0.55 & \\
\hline
\end{tabular}




\begin{tabular}{lcccl}
\multicolumn{1}{l}{$\begin{array}{l}\text { PENNSYVANIA STUDY AREA (cont.) } \\
\text { Depth }\end{array}$} & & & & \\
Lithology & From & To & Thickness & Bed Name \\
\hline Coal & 625.15 & 625.55 & 0.40 & Rider \\
Carbonaceous Clay Shale & 625.55 & 625.65 & 0.10 & \\
Coal & 625.65 & 625.80 & 0.15 & Rider \\
Carbonaceous Clay Shale & 625.80 & 626.20 & 0.40 & \\
Coal & 626.20 & 626.30 & 0.10 & Rider \\
Carbonaceous Clay Shale & 626.30 & 626.90 & 0.60 & \\
Coal & 626.90 & 627.75 & 0.85 & Rider \\
Gray Clay Shale & 627.75 & 628.15 & 0.40 & \\
Limestone & 628.15 & 628.40 & 0.25 & \\
\cline { 5 - 6 } Coal & 628.40 & 635.60 & 7.20 & Pittsburgh \\
Claystone & 635.60 & 635.75 & 0.15 & \\
Limestone & 635.75 & 635.90 & 0.15 & Mined Bed
\end{tabular}




\section{TABLE 3}

ISLAND CREEK, WEST VIRGINIA STUDY AREA

Data reproduced from permit geologic cross section.

Drill Hole: LS-008

Date Drilled: Unk

Drilling Company: Unk

Surface Elevation: $1455^{\prime}$

\begin{tabular}{|c|c|c|c|c|c|c|}
\hline \multirow[b]{3}{*}{ Lithology } & \multirow{2}{*}{\multicolumn{2}{|c|}{ Depth }} & \multirow[b]{3}{*}{ Thickness } & \multirow[b]{3}{*}{ Bed Name } & \multicolumn{2}{|c|}{ Mined Bed Overburden } \\
\hline & & & & & Lithology & Percentage \\
\hline & From & To & & & \multirow{3}{*}{$\begin{array}{l}\text { Sandstone } \\
\text { Shale } \\
\text { Coal }\end{array}$} & \multirow{2}{*}{$\begin{array}{r}\text { rercentage } \\
38 \% \\
60 \%\end{array}$} \\
\hline Casing & 0.00 & 23.00 & 23.00 & & & \\
\hline Shale & 23.00 & 42.00 & 19.00 & & & $2 \%$ \\
\hline Sandstone & 42.00 & 44.00 & 2.00 & & Total & 192.00 feet \\
\hline Shale & 44.00 & 91.00 & 47.00 & & & \\
\hline Sandstone & 91.00 & 100.00 & 9.00 & & & \\
\hline Shale & 100.00 & 108.00 & 8.00 & & & \\
\hline Sandstone & 108.00 & 132.00 & 24.00 & & & \\
\hline Shale & 132.00 & 135.00 & 3.00 & & & \\
\hline Coal & 135.00 & 138.00 & 3.00 & Upper Cedar Grove & & \\
\hline Shale & 138.00 & 144.00 & 6.00 & & & \\
\hline Sandstone & 144.00 & 160.00 & 16.00 & & & \\
\hline Shale & 160.00 & 180.00 & 20.00 & & & \\
\hline Sandstone & 180.00 & 190.00 & 10.00 & & & \\
\hline Shale & 190.00 & 192.00 & 2.00 & & & \\
\hline Coal & 192.00 & 198.00 & 6.00 & Lower Cedar Grove & Mined Bed & \\
\hline
\end{tabular}


TABLE 4

WEST FORK, WEST VIRGINIA STUDY AREA

Data reproduced from stream flow study.

Drill Hole: V-88C

Date Drilled: Unk

Drilling Company: Unk

Surface Elevation: Approx 1738'

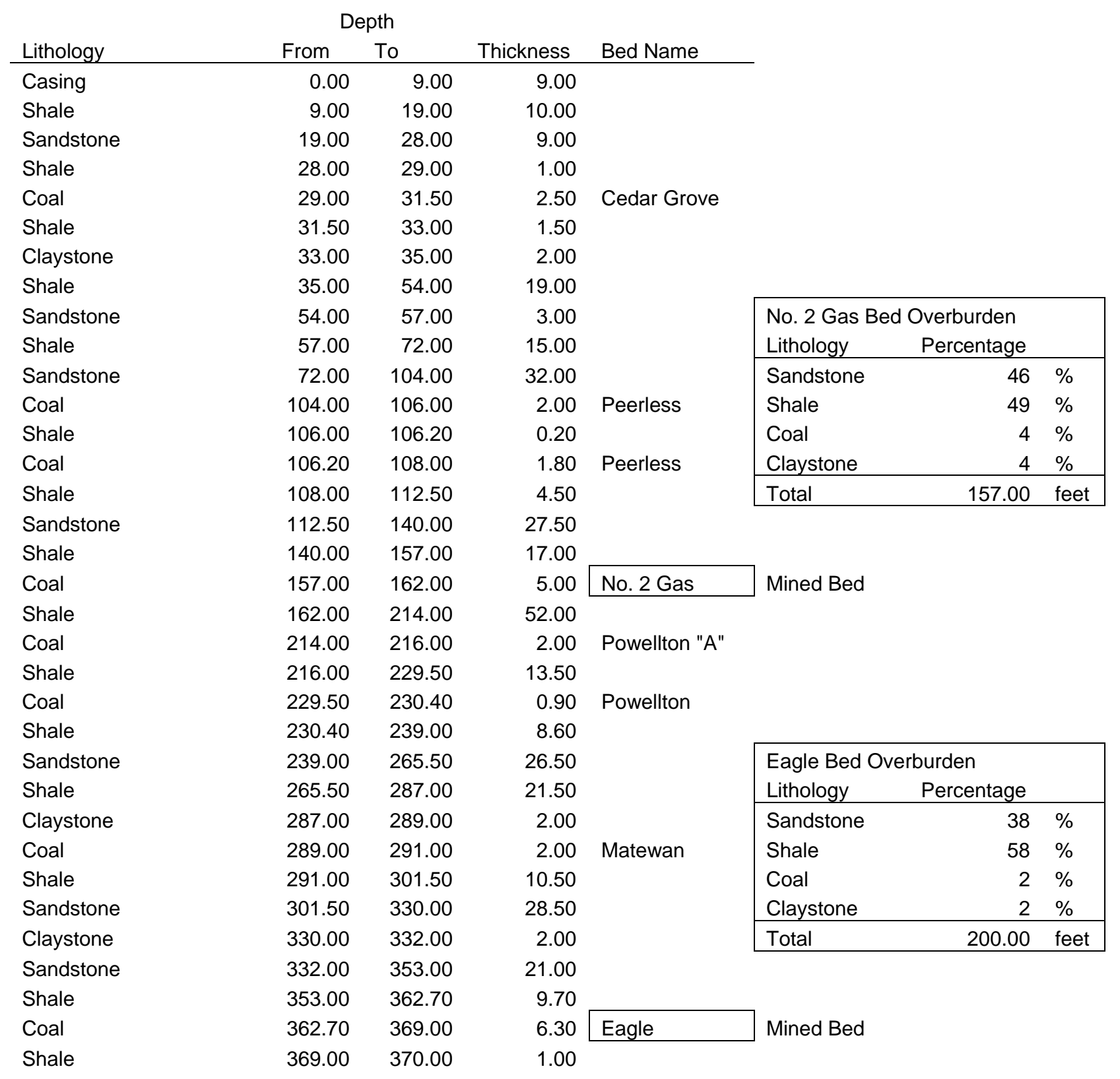

Digitally signed by John $\mathrm{H}$. Hagen

$\mathrm{DN}$ : $\mathrm{cn}=$ John $\mathrm{H}$. Hagen, o=West Virginia

University Libraries, ou=Acquisitions

Department, email=John.Hagen@mail. wvu.edu, c=US

Reason: I am approving this document

Date: 2008.05.02 17:44:06 -04'00' 